\title{
DOCTORATE SCHOOL
}

DOCTORATE IN ENGINEERING AND INDUSTRIAL PRODUCTION

CLOUD COMPUTING, SUPPLY CHAIN INTEGRATION, SUPPLY CHAIN FLEXIBILITY AND MASS PERSONALIZATION: INTERRELATIONSHIPS WITH LEAN PRODUCTION AND PERFORMANCE

DOCTORAL THESIS

AUTHOR:

LUCIANO ROMUALDO NOVAIS

DIRECTORS:

DR. ÁNGEL ORTIZ BÁS

DR. JUAN MANUEL MAQUEIRA MARÍN 
This doctoral thesis has been developed thanks to the support of the Conselho Nacional de Desenvolvimento Científico e Tecnológico (CNPq) of Brazil and the Spanish Ministry of Economy and Competitiveness Research Project ECO2015-65874-P. 


\section{ACKNOWLEDGEMENTS}

These four years dedicated to this research have been a journey of learning, challenges, building and maturing. Since the beginning of my doctorate, I have had the confidence and support of countless people and institutions, without whom this work would not have been possible. For this reason, I sincerely and deeply thank all those who have encouraged and helped me on this journey.

First, I thank God for His voice that did not allow me to give up and, especially, for having placed such special people along this journey. I have not yet discovered what I have done to deserve so much.

I thank my mother, Ivone, for all the teachings of love, dedication, understanding and forgiveness she gives me each new day. To my father, José, for the profound lessons of overcoming, perseverance and hope. To my sister, Josi, for believing in me, for sharing many of my anguish and achievements, and for being my safe haven. To my niece, Ana, for nourishing my dream of a better world for all people. To my uncles, cousins and brother-in-law, for being by my side in such a loving way.

I also thank my friends for being responsible for the colourful moments of my days, for sharing with me so much affection and joy, and for being part of my family's heart. In particular, I would like to thank Sebastián, to whom I have difficulties in finding the right words to express all the feeling of admiration, recognition and gratitude for all that he has done and does for me. To Sabrina, for show me that "home" is where our heart is. To Taty, for teaching me that distance and time are just numbers.

I am sure I would not have reached the end of this doctoral thesis without the support of my directors. To Professor Dr. Ángel Ortiz Bás, I thank for the learning transmitted and for the confidence in the accomplishment of this research, which helped me a lot and stimulated me to move forward. Thank you very much for your support and availability. To Professor Dr. Juan Manuel Maqueira Marín, I am deeply grateful for having assumed the direction of this thesis, having given me with his dedication, competence and professionalism. Thank you for your generosity in sharing with me your knowledge, ethics and humbleness. I will not forget your eternal teachings, your precious advice and your invaluable trust. Thank you very much!

I would like to express my gratitude to all the professors, employees and co-workers of the Polytechnic University of Valencia, University of Jaén and University of Porto. Especially to Professor Dr. José Moyano Fuentes for his support, sharing of knowledge and precious contributions to this work. To Professor Dr. Américo Azevedo, for the rich exchange of experiences that we made possible during my stay in Porto. I would also like to thank the indispensable support of CNPq (Conselho Nacional de Desenvolvimento Científico e Tecnológico) who, through the Ciência sem Fronteiras program, gave me the opportunity to be here today, concluding this doctoral thesis. I would also like to thank the Spanish Ministry of Economy and Competitiveness and the Erasmus Programme for supporting the development of this research.

My respectful thanks to the Professors Dr. Jesús García Arca, Dr. Marco Trégua and Dra. Anna D'Auria who were so kindly willing to participate as external reviewers of this doctoral thesis, offering valuable consideration to the present work and generous suggestions for improvement.

Finally, to all those who contributed, directly or indirectly, to the accomplishment of this work, my sincere thanks! 


\section{RESUMEN}

La Gestión de la Cadena de Suministro se define como un conjunto de acciones que permiten a las empresas gestionar, planificar y controlar sus operaciones como una forma de facilitar la colaboración entre los miembros de la Cadena de Suministro. Para ser más eficaces y eficientes, las empresas están cada vez más dispuestas a rediseñar sus estrategias de Gestión de la Cadena de Suministro y a adoptar prácticas de gestión. Esta tesis doctoral analiza cómo se interrelacionan algunas variables relacionadas con la eficacia y la eficiencia en la Gestión de la Cadena de Suministro, y el posible impacto de estas interrelaciones en los resultados empresariales. Específicamente, profundizamos en las relaciones entre Cloud Computing, Integración de la Cadena de Suministro, Flexibilidad de la Cadena de Suministro, Personalización en Masa y Lean Production (que son variables asociadas con la eficacia y eficiencia de la Cadena de Suministro) y su papel en los resultados empresariales.

En esta tesis, inicialmente consideramos dos factores importantes para conseguir eficacia y eficiencia en la Cadena de Suministro. Así, un primero factor estaría formado por la interrelación entre el uso de Cloud Computing, un nuevo paradigma en la interpretación de las Tecnologías de la información, y la Integración de la Cadena de Suministro. Bajos niveles en este factor permitirán a las empresas conseguir sus objetivos (ser eficaces) pero empleando muchos más recursos (menos eficientes) que altos valores en este factor. Un segundo factor recoge la interrelación de la Flexibilidad de la Cadena de Suministro y la Personalización en Masa. De forma similar al factor anterior, bajos niveles en este factor estarían asociados a una menor eficiencia (aun siendo eficaces), mientras que altos niveles, estaría asociados a una alta eficiencia. Ambos factores son consideradas en esta tesis, en primer lugar, de forma aislada, mediante revisiones sistemáticas de la literatura que permiten identificar qué se sabe en la literatura sobre la relación existente entre las variables que conforman cada factor. En segundo lugar, en esta tesis, se realiza un análisis explicativo en que se considera el efecto de Lean Production, y su relación con cada uno de los factores, lo que estaría asociado a unos altos niveles de eficiencia en la Cadena de Suministro, y se analiza cómo el efecto conjunto de Lean Production y cada uno de los factores (variables) consideradas afecta a los resultados de la empresa. Finalmente, en esta tesis se consideran todas las variables de forma conjunta (ambos factores y el efecto de Lean Production, actuando sobre los resultados empresariales), en un modelo holístico que utiliza la simulación para analizar el comportamiento del modelo.

El valor de esta tesis es que académicos y gerentes de negocios pueden tener evidencia de apoyo sobre el papel que juegan Cloud Computing, Integración de la Cadena de Suministro, Flexibilidad de la Cadena de Suministro, Personalización en Masa y Lean Production, vinculadas operativa y estratégicamente, y cómo esta combinación podría transformarse en un mejor desempeño empresarial. El mejor conocimiento de estas relaciones puede afectar la manera en que investigadores y directivos abordan estos recursos de gestión, siendo más conscientes del importante papel de la Cadena de Suministro en la competitividad. Este trabajo se diferencia de los aportes anteriores por proporcionar enfoques teóricos y empíricos de las posibles interrelaciones entre las variables antes mencionadas. Los resultados de este estudio, por lo tanto, podrían ser muy útiles en el diseño de futuros esfuerzos de investigación en esta área. 


\begin{abstract}
Supply Chain Management is defined as a set of actions that allow companies to manage, plan and control their operations as a way to facilitate collaboration between Supply Chain members. To be more effective and efficient, companies are increasingly willing to redesign their Supply Chain Management strategies and adopt management practices. This doctoral thesis analyses how some variables related to effectiveness and efficiency in Supply Chain Management are interrelated, and the possible impact of these interrelations on business performance. Specifically, we delve into the relationships between Cloud Computing, Supply Chain Integration, Supply Chain Flexibility, Mass Personalization and Lean Production (which are variables associated with the effectiveness and efficiency in the Supply Chain) and their role in business performance.

In this doctoral thesis, we initially considered two important factors to achieve effectiveness and efficiency in the Supply Chain. A first factor would be the interrelation between the use of Cloud Computing, a new paradigm in the interpretation of Information Technologies, and Supply Chain Integration. Low levels in this factor will allow companies to achieve their goals (be effective) but using many more resources (less efficient) than high values in this factor. A second factor is the interrelationship of Supply Chain Flexibility and Mass Personalization. Similar to the previous factor, low levels of this factor would be associated with lower efficiency (even if effective), while high levels would be associated with high efficiency. Both factors are considered in this thesis, in the first place, in an isolated way, by means of systematic literature reviews that allow identifying what is known in the literature about the existing relation between the variables that conform each factor. Secondly, an explanatory analysis is made in which the effect of Lean Production is considered, and its relation with each one of the factors, which would be associated with high levels of efficiency in the Supply Chain, and it is analysed how the joint effect of Lean Production and each one of the factors (variables) considered affects business performance. Finally, this thesis considers all variables together (both factors and the effect of Lean Production, acting on business performance), in a holistic model that uses simulation to analyse the model's behaviour.

The value of this doctoral thesis is that academics and business managers can have supporting evidence on the role played by Cloud Computing, Supply Chain Integration, Supply Chain Flexibility, Mass Personalization and Lean Production, operationally and strategically linked, and how this combination could be transformed into better business performance. The better knowledge of these relationships can affect the way researchers and managers approach these management resources, being more aware of the important role of the Supply Chain in competitiveness. This work differs from previous contributions in that it provides theoretical and empirical approaches to the possible interrelations between the variables mentioned above. The results of this study, therefore, could be very useful in the design of future research efforts in this area.
\end{abstract}




\section{RESUM}

La Gestió de la Cadena de Subministrament es defineix com un conjunt d'accions que permeten a les empreses gestionar, planificar i controlar les seues operacions com una manera de facilitar la col-laboració entre els membres de la Cadena de Subministrament. Per a ser més eficaços i eficients, les empreses estan cada vegada més disposades a redissenyar les seues estratègies de Gestió de la Cadena de Subministrament i a adoptar pràctiques de gestió. Aquesta tesi doctoral analitza com s'interrelacionen algunes variables relacionades amb l'eficàcia i l'eficiència en la Gestió de la Cadena de Subministrament, i el possible impacte d'aquestes interrelacions en els resultats empresarials. Específicament, aprofundim en les relacions entre Cloud Computing, Integració de la Cadena de Subministrament, Flexibilitat de la Cadena de Subministrament, Personalització en massa i Lean Production (que són variables associades amb l'eficàcia i eficiència de la Cadena de Subministrament) i el seu paper en els resultats empresarials.

En aquesta tesi, inicialment considerem dos factors importants per a aconseguir eficàcia i eficiència en la Cadena de Subministrament. Així, un primer factor estaria format per la interrelació entre l'ús de Cloud Computing, un nou paradigma en la interpretació de les Tecnologies de la informació, i la Integració de la Cadena de Subministrament. Baixos nivells en aquest factor permetran a les empreses aconseguir els seus objectius (ser eficaços) però emprant molts més recursos (menys eficients) que alts valors en aquest factor. Un segon factor recull la interrelació de la Flexibilitat de la Cadena de Subministrament i la Personalització en massa. De forma similar al factor anterior, baixos nivells en aquest factor estarien associats a una menor eficiència (fins $i$ tot sent eficaces), mentre que alts nivells, estaria associats a una alta eficiència. Tots dos factors són considerades en aquesta tesi, en primer lloc, de forma aïllada, mitjançant revisions sistemàtiques de la literatura que permeten identificar què se sap en la literatura sobre la relació existent entre les variables que conformen cada factor. En segon lloc, en aquesta tesi, es realitza una anàlisi explicativa en què es considera l'efecte de Lean Production, i la seua relació amb cadascun dels factors, la qual cosa estaria associat a uns alts nivells d'eficiència en la Cadena de Subministrament, i s'analitza com l'efecte conjunt de Lean Production i cadascun dels factors (variables) considerades afecta als resultats de l'empresa. Finalment, en aquesta tesi es consideren totes les variables de forma conjunta (tots dos factors i l'efecte de Lean Production, actuant sobre els resultats empresarials), en un model holístic que utilitza la simulació per a analitzar el comportament del model.

El valor d'aquesta tesi és que acadèmics i gerents de negocis poden tindre evidència de suport sobre el paper que juguen Cloud Computing, Integració de la Cadena de Subministrament, Flexibilitat de la Cadena de Subministrament, Personalització en massa i Lean Production, vinculades operativa i estratègicament, i com aquesta combinació podria transformar-se en un millor acompliment empresarial. El millor coneixement d'aquestes relacions pot afectar la manera en què investigadors i directius aborden aquests recursos de gestió, sent més conscients de l'important paper de la Cadena de Subministrament en la competitivitat. Aquest treball es diferencia de les aportacions anteriors per proporcionar enfocaments teòrics i empírics de les possibles interrelacions entre les variables abans esmentades. Els resultats d'aquest estudi, per tant, podrien ser molt útils en el disseny de futurs esforços d'investigació en aquesta àrea. 


\section{CONTENTS}

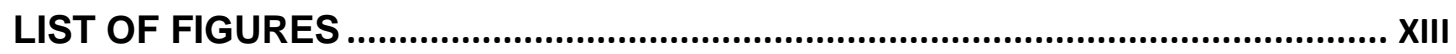

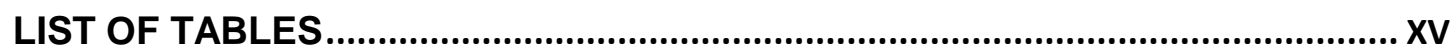

GENERAL INTRODUCTION........................................................................

I. PRESENTATION

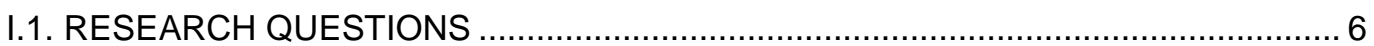

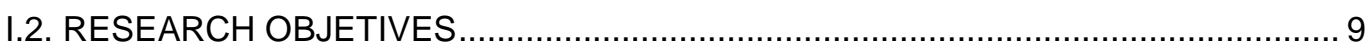

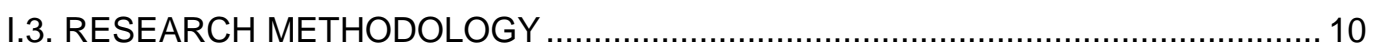

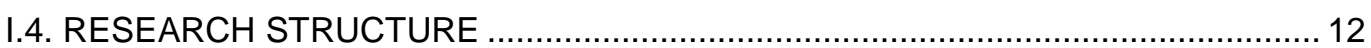

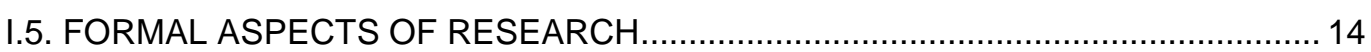

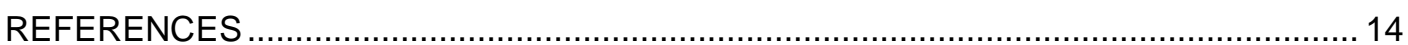

BLOCK I: SYSTEMATIC LITERATURE REVIEWS...................................17

CHAPTER 1: A Systematic Literature Review of Cloud Computing Use in Supply

Chain Integration ......................................................................................................19

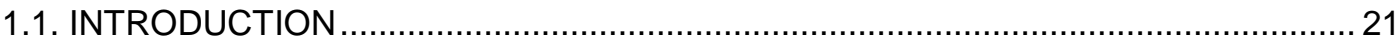

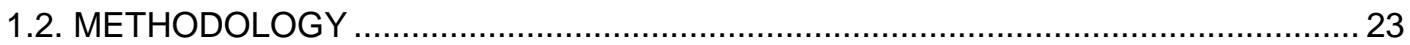

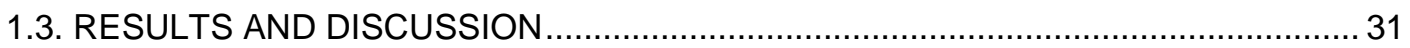

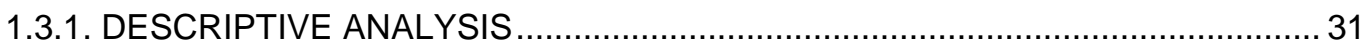

1.3.2. LITERATURE CLASSIFICATION AND ANALYSIS: MAIN TOPICS AND

RESEARCH LINES/SUBLINES ……........................................................... 35

1.3.3. IDENTIFIED GAPS AND PATHS FOR FURTHER INVESTIGATION ................ 50

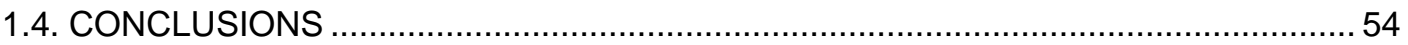

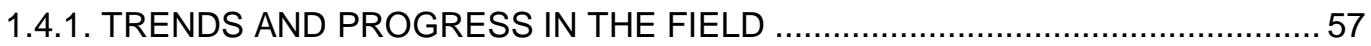

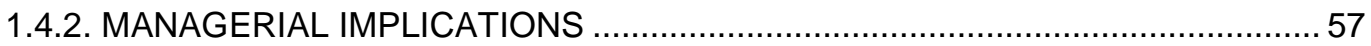

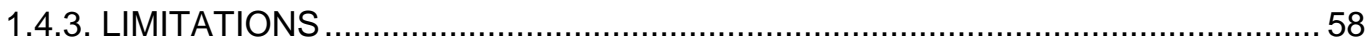

1.5. SUMMARY

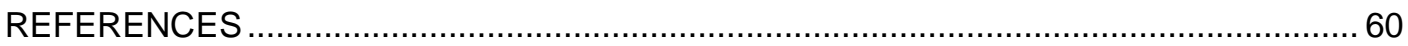

CHAPTER 2: A Systematic Literature Review of Supply Chain Flexibility and Customer Microsegmentation/ Mass Personalization adoption .........................67

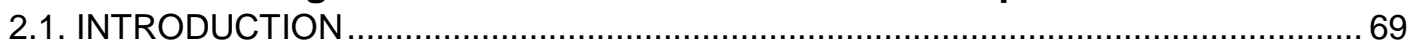

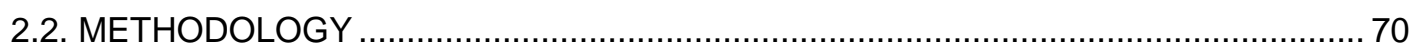

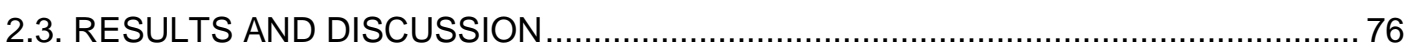

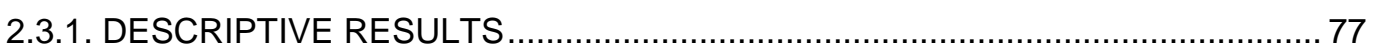

2.3.2. LITERATURE CLASSIFICATION AND ANALYSIS: MAIN TOPICS, RESEARCH

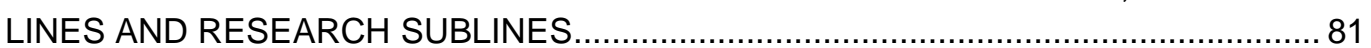

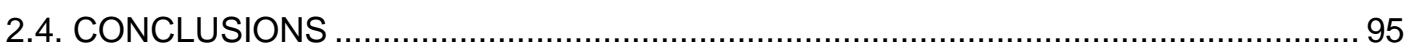

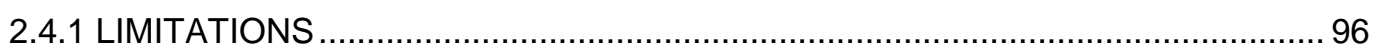

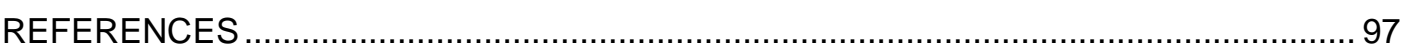

BLOCK II: EXPLICATIVE ANALYSES ...................................................103

CHAPTER 3: Lean Production implementation, Cloud-supported Logistics and Supply Chain Integration: Interrelationships and effects on Business Performance 105 


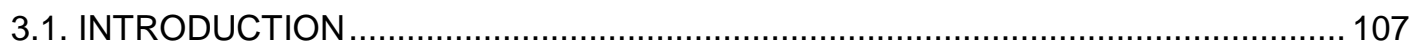

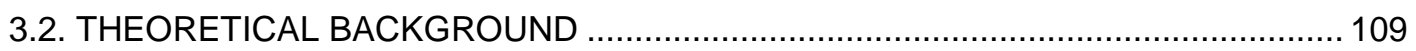

3.2.1. LEAN PRODUCTION, IT AND BUSINESS PERFORMANCE .......................... 109

3.2.2. CLOUD COMPUTING, SUPPLY CHAIN INTEGRATION AND BUSINESS

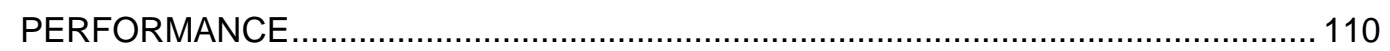

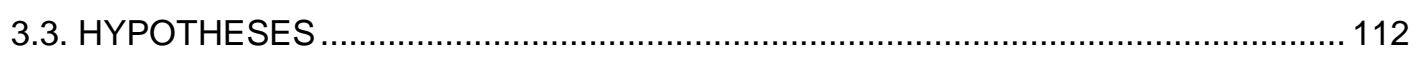

3.3.1. LEAN PRODUCTION IMPLEMENTATION AND BUSINESS PERFORMANCE 112

3.3.2. LEAN PRODUCTION IMPLEMENTATION AND CLOUD-SUPPORTED

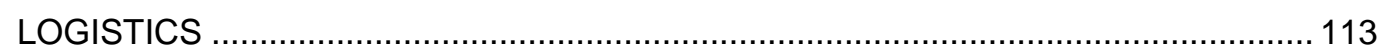

3.3.3. CLOUD-SUPPORTED LOGISTICS AND BUSINESS PERFORMANCE ........... 115

3.3.4. CLOUD-SUPPORTED LOGISTICS AND SUPPLY CHAIN INTEGRATION ...... 116

3.3.5. SUPPLY CHAIN INTEGRATION AND BUSINESS PERFORMANCE ...............117

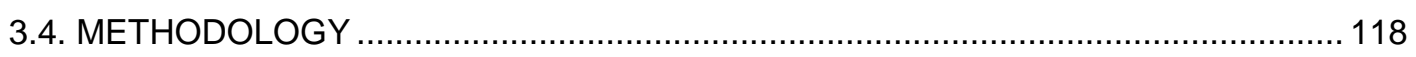

3.4.1. POPULATION, QUESTIONNAIRE AND DATA GATHERING ....................... 118

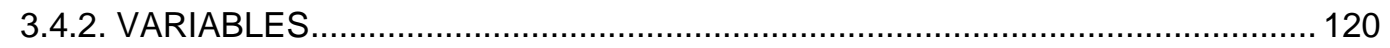

3.4.3. DATA ANALYSIS: FACTOR ANALYSIS AND STRUCTURAL EQUATION MODEL

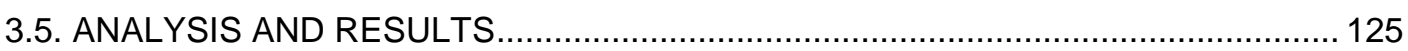

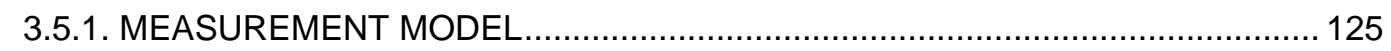

3.5.2. STRUCTURAL MODEL AND DISCUSSION OF RESULTS ............................. 129

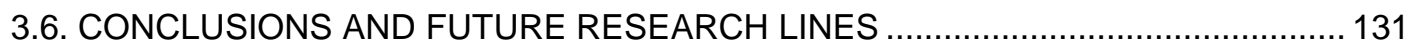

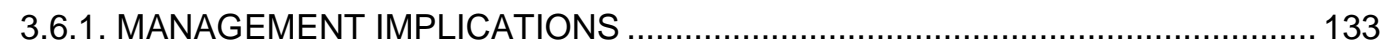

3.6.2. LIMITATIONS AND FUTURE RESEARCH LINES ....................................... 133

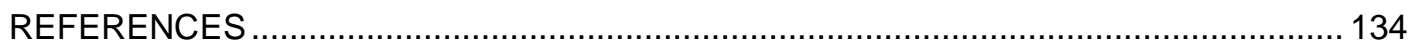

CHAPTER 4: Lean Production Implementation, Mass Personalization and Business Performance: How does Supply Chain Flexibility affect their

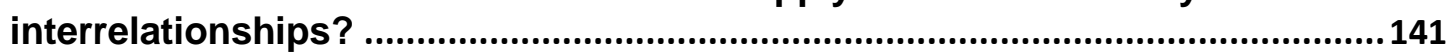

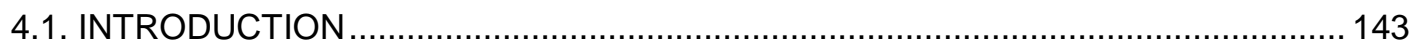

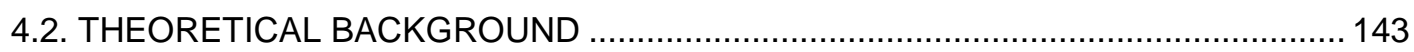

4.2.1. LEAN PRODUCTION, SUPPLY CHAIN FLEXIBILITY AND BUSINESS

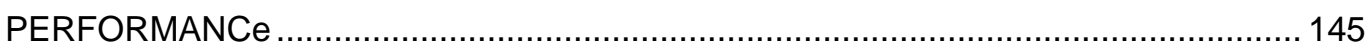

4.2.2. LEAN PRODUCTION, MASS PERSONALIZATION AND BUSINESS

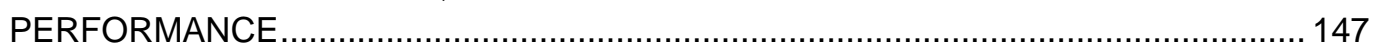

4.2.3. SUPPLY CHAIN FLEXIBILITY, MASS PERSONALIZATION AND BUSINESS

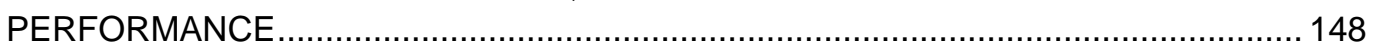

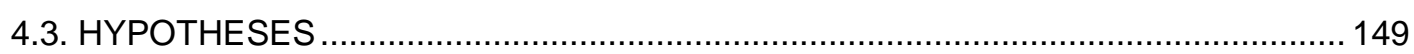

4.3.1. LEAN PRODUCTION IMPLEMENTATION AND BUSINESS PERFORMANCE 149

4.3.2. LEAN PRODUCTION IMPLEMENTATION AND SUPPLY CHAIN FLEXIBILITY

4.3.3. LEAN PRODUCTION IMPLEMENTATION AND MASS PERSONALIZATION.. 151

4.3.4. SUPPLY CHAIN FLEXIBILITY AND BUSINESS PERFORMANCE ................... 152

4.3.5. SUPPLY CHAIN FLEXIBILITY AND MASS PERSONALIZATION ....................... 153

4.3.6. MASS PERSONALIZATION AND BUSINESS PERFORMANCE ...................... 154

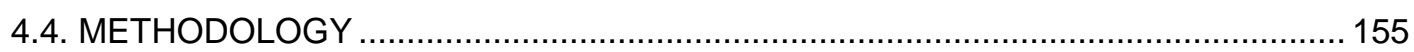

4.4.1. POPULATION, QUESTIONNAIRE AND DATA GATHERING .......................... 155

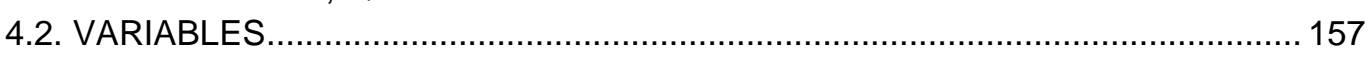

4.4.3. DATA ANALYSIS: FACTORIAL ANALYSIS AND STRUCTURAL EQUATION

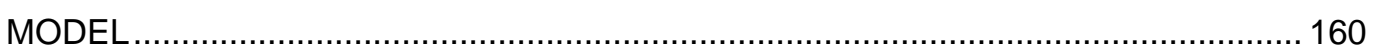

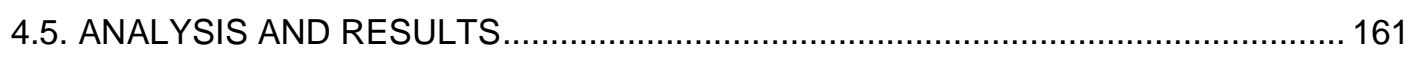

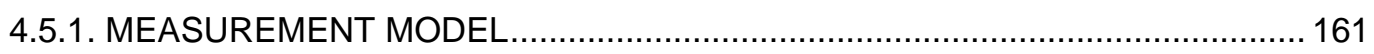

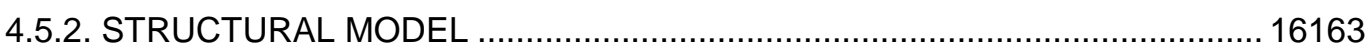


4.6. DISCUSSION, CONCLUSIONS AND FUTURE RESEARCH LINES........................ 167

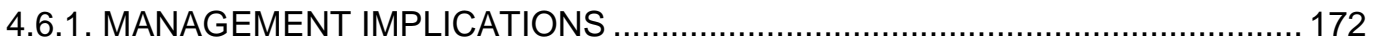

4.6.2. LIMITATIONS AND FUTURE RESEARCH LINES ...................................... 173

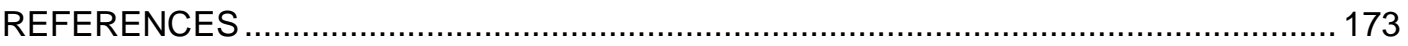

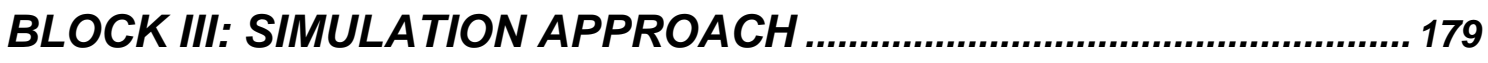

CHAPTER 5: Strategic simulation models as a new methodological approach: A decision support tool based on Structural Equations Models and System Dynamics Models........................................................................................................ 181

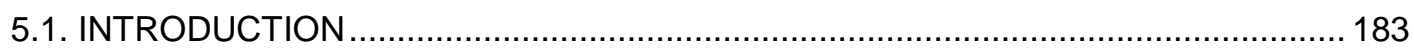

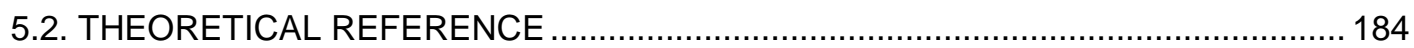

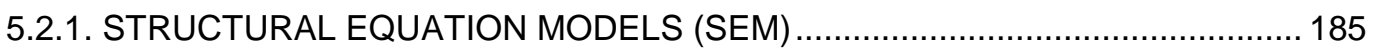

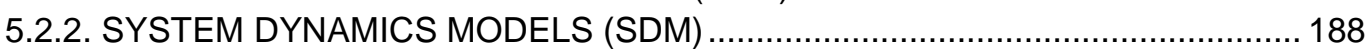

5.3. SEM/SDM METHODOLOGICAL PROPOSAL AT A STRATEGIC LEVEL.................. 191

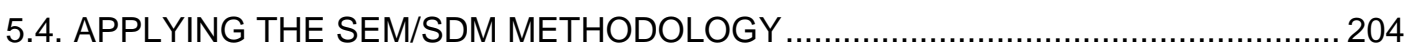

5.4.1 APPLICATION ONE: COMMUNITY CLOUD, SUPPLY CHAIN INTEGRATION

AND OPERATIONAL PERFORMANCE ……........................................................ 204

5.4.2. APPLICATION TWO: INFORMATION TECHNOLOGIES INTEGRATION, LEAN

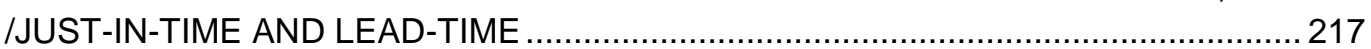

5.4. CONCLUSIONS, LIMITATIONS AND FUTURE RESEARCH LINES ....................... 230

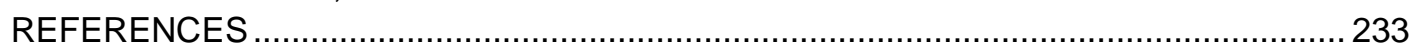

CHAPTER 6: A strategic-simulation model for Business Performance: Analysis of factors affecting Supply Chain effectiveness and efficiency .........................2235

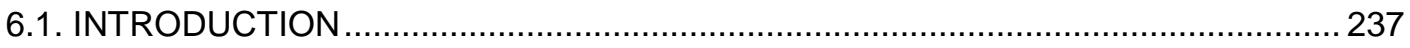

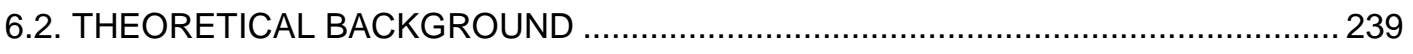

6.2.1. SUPPLY CHAIN EFFECTIVENESS FACTORS AND BUSINESS

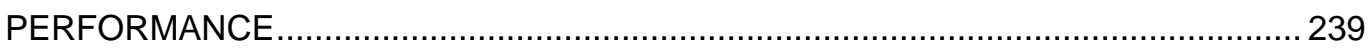

6.2.2. SUPPLY CHAIN EFFICIENCY FACTORS AND BUSINESS PERFORMANCE 240

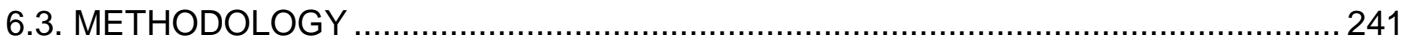

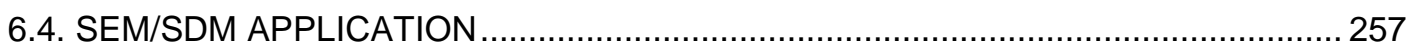

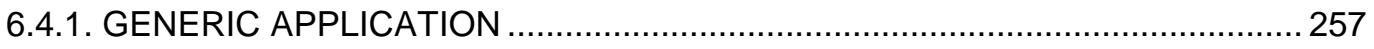

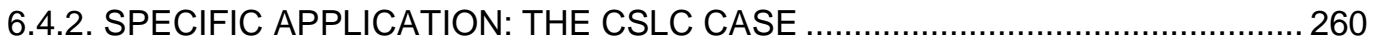

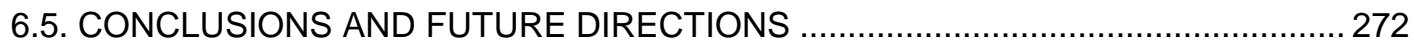

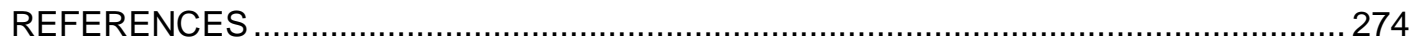

CHAPTER 7: GENERAL CONCLUSIONS.............................................279

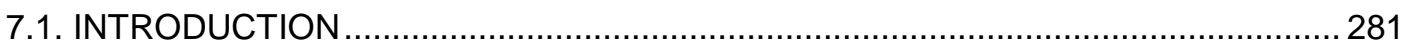

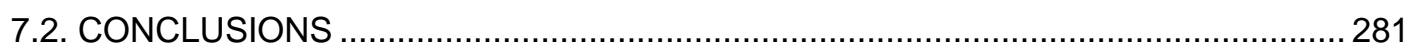

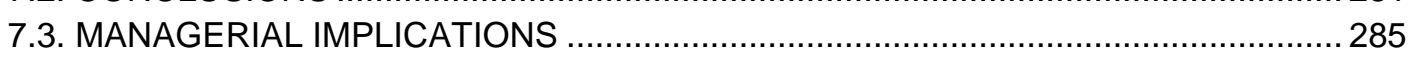

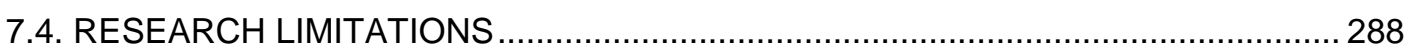

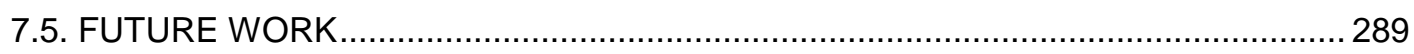

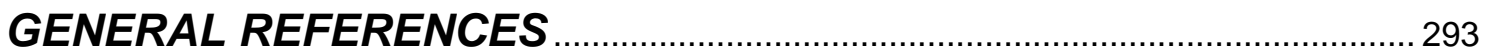

APPENDIX 


\section{LIST OF FIGURES}

\section{INTRODUCTION}

Figure I.1. Relationship between Supply Chain effectiveness, Supply Chain efficiency and Business Performance

Figure I.2. Graphical representation of the Research Questions ............................... 9

Figure I.3. Graphical representation of the research specifics objectives and the

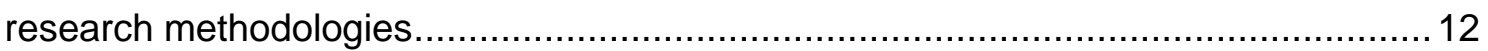

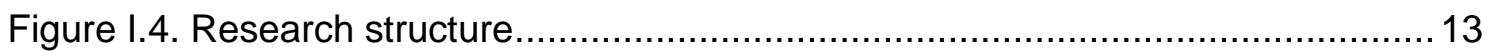

\section{CHAPTER 1}

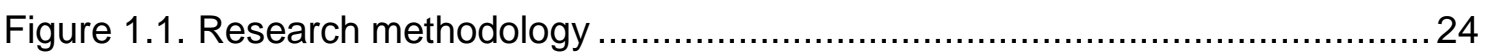

Figure 1.2. Proposed framework for the literature classification ................................29

Figure 1.3. Summary of the research methodology................................................. 30

\section{CHAPTER 2}

Figure 2.1. Simultaneous relationship between SCF and CMS/MP as research

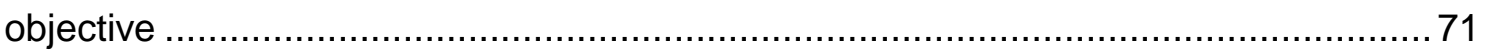

Figure 2.2. Identification and selection of the papers ........................................... 73

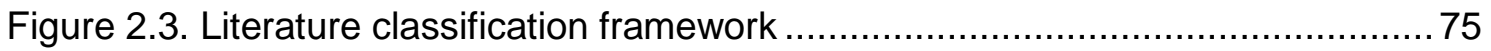

Figure 2.4. Summary of the research methodology .............................................. 76

Figure 2.5. Time evolution of research on SCF and CMS/MP .................................77

\section{CHAPTER 3}

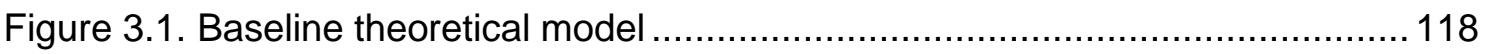

Figure 3.2. Measurement model and theoretical structural model ............................ 129

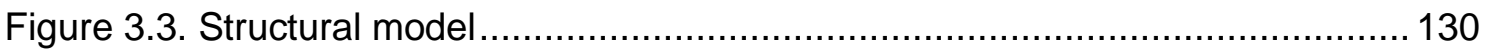

\section{CHAPTER 4}

Figure 4.1. Theoretical baseline model .............................................................. 155

Figure 4.2. Measurement model and theoretical structural model ............................ 166

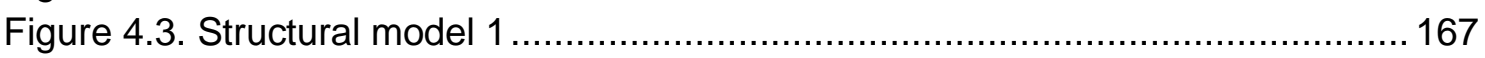

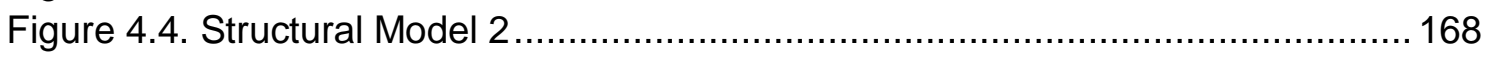

\section{CHAPTER 5}

Figure 5.1. Example of measurement and structural models in SEM ......................187

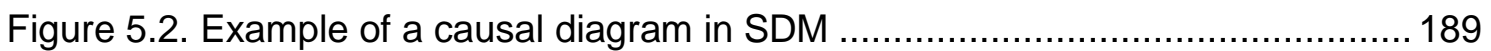

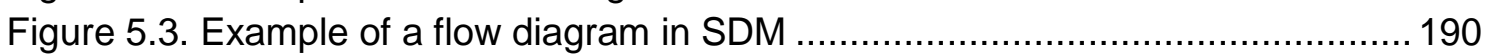

Figure 5.4. SEM structural model convert to SDM causal diagram............................193

Figure 5.5. Identification of the SEM quantitative data to be used in SDM ................ 194

Figure 5.6. Generic SEM/SDM flow diagram....................................................... 195 


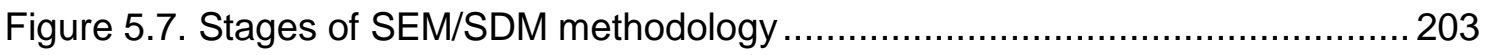

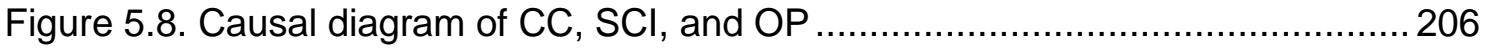

Figure 5.9. Selected SEM data for the SDM …................................................ 207

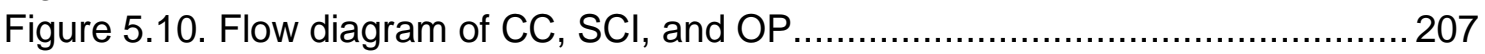

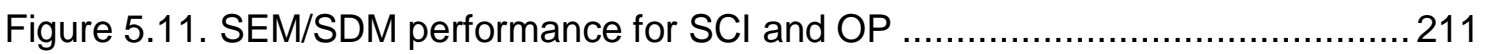

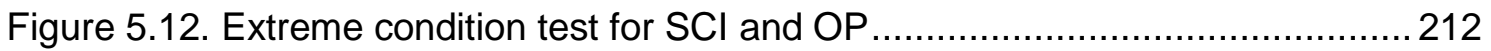

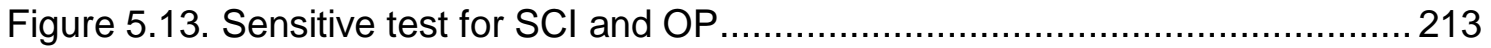

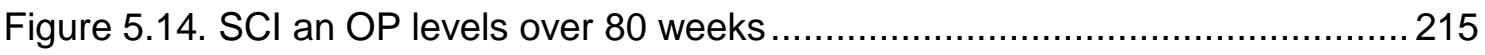

Figure 5.15. Causal diagram of internal and external IT, Lean/JIT, and Lead-time.... 220

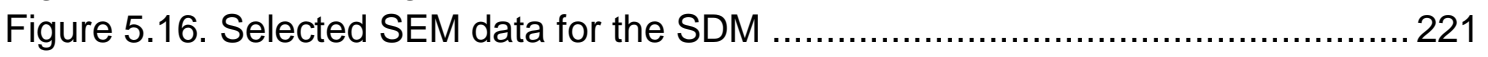

Figure 5.17. Flow diagram of INTERNAL, EXTERNAL, JIT and LEAD ......................221

Figure 5.18. Performance of INTERNAL, EXTERNAL, JIT and LEAD .....................225

Figure 5.19. Robustness analysis for INTERNAL, EXTERNAL, JIT and LEAD .........226

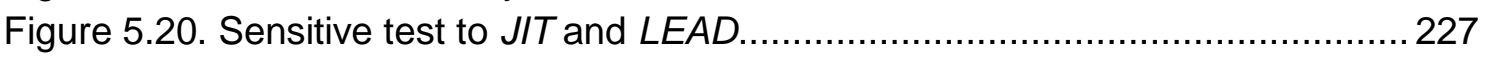

Figure 5.21. JIT and LEAD simulation results over 80 weeks................................229

\section{CHAPTER 6}

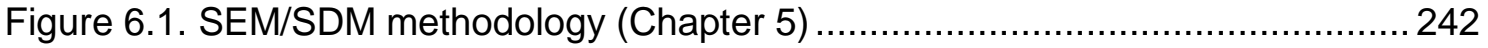

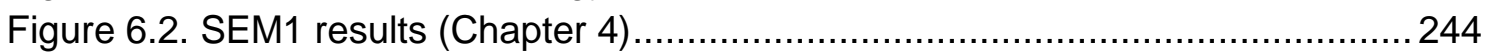

Figure 6.3. SEM2 results (Chapter 5) ......................................................... 244

Figure 6.4. Causal diagram to Supply Chain effectiveness and efficiency, and their

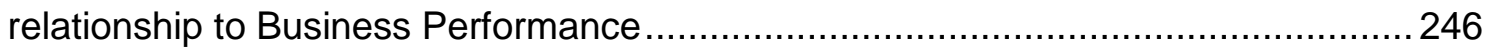

Figure 6.5. Flow diagram of Supply Chain effectiveness and efficiency and their relationship to Business Performance............................................................. 248

Figure 6.6. SEM/SDM run for the level variables interrelationships .......................... 254

Figure 6.7. Extreme condition test for the SEM/SDM variables .................................255

Figure 6.8. Sensitive test for the SEM/SDM variables ............................................256

Figure 6.9. Impact of LPI dimensios on LPI over 24 months ...................................258

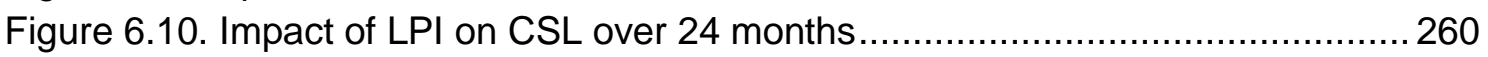

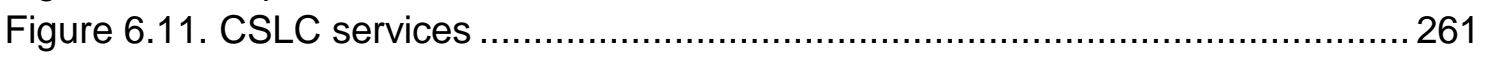

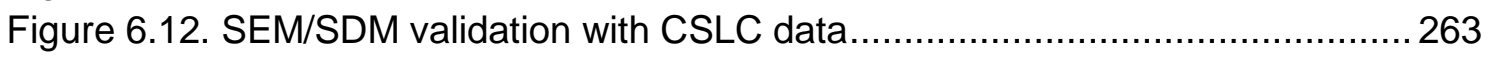

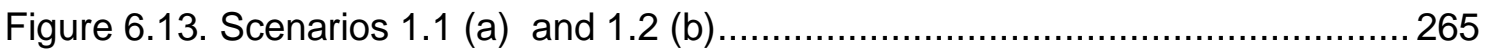

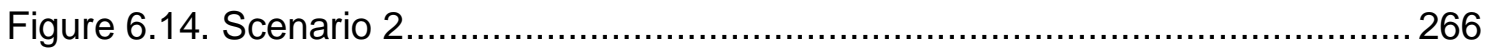

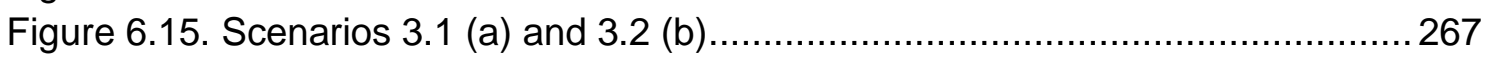

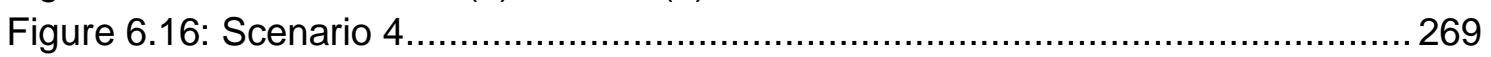

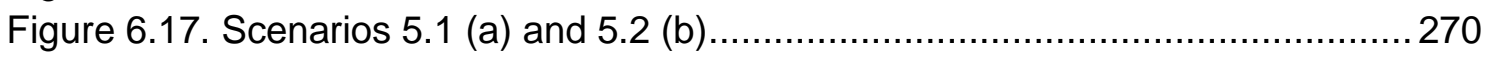

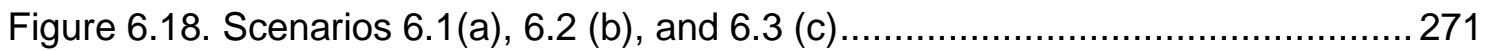




\section{LIST OF TABLES}

\section{CHAPTER 1}

Table 1.1. Journals in which the papers were published .......................................... 32

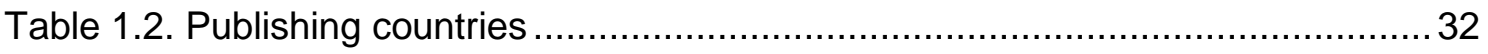

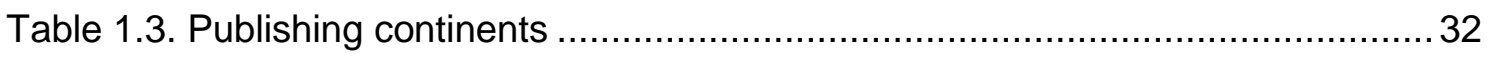

Table 1.4. Methodologies used in the papers analyzed.......................................... 33

Table 1.5. Literature classification according to main research topics .......................... 34

Table 1.6. Papers related to manufacturing integration research line and its sublines. 36

Table 1.7. Papers related to logistics integration research line and its sublines ...........38

Table 1.8. Papers related to design/process development integration research/sublines

Table 1.9. Papers related to financial processes integration research line and its sublines

Table 1.10. Papers related to marketing/commercial integration research line and its sublines

Table 1.11. Papers related to intra-organizational technology/system integration research line and its sublines.

Table 1.12. Papers related to inter-organizational technology/system integration

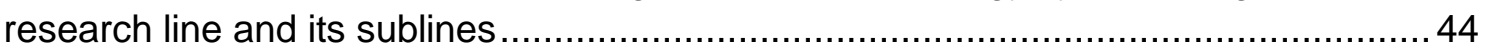

Table 1.13. Papers related to supplier integration research line and its sublines.........46 46

Table 1.14. Papers related to internal integration research line and its sublines .........47

Table 1.15. Papers related to customer integration research line and its sublines ......47

\section{CHAPTER 2}

Table 2.1. Journals in which the papers analysed were published ............................78

Table 2.2. Countries of origin of the main authors ............................................... 79

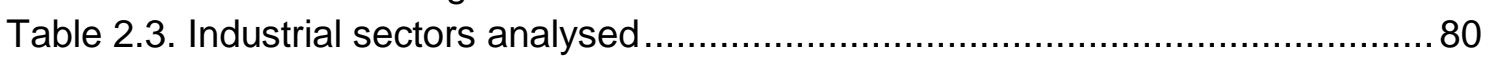

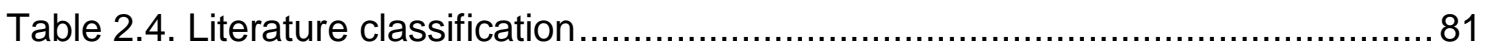

Table 2.5. Papers related to personalization levels and flexible processes in Supply

Chain .....

Table 2.6. Papers related to Supply Chain collaborative processes for SCF-CMS/MP 87

Table 2.7. Papers related to SCF and CMS/MP enabling technologies....................... 88

Table 2.8. Identified gaps and paths for further investigation ...................................92

\section{CHAPTER 3}

Table 3.1. Sample, population distribution and response rate by industry ................ 120

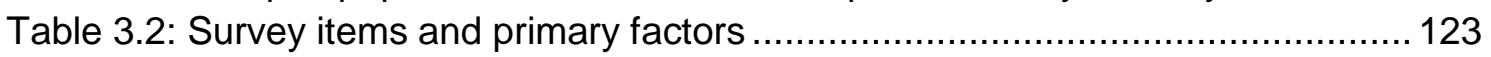

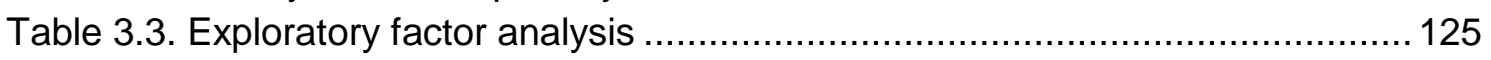

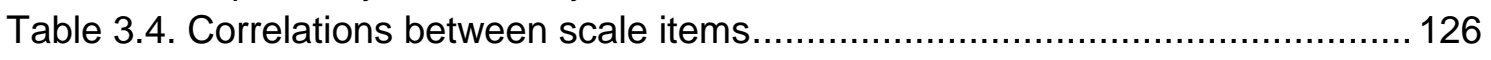

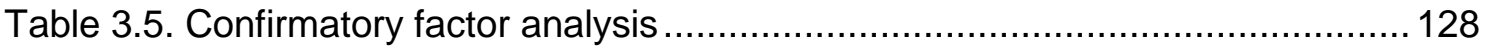

\section{CHAPTER 4}

Table 4.1. Sample, population distribution and response rate by industry 157 


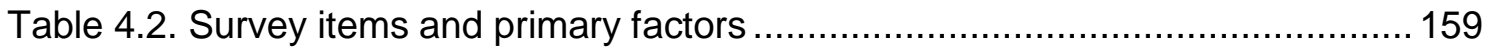

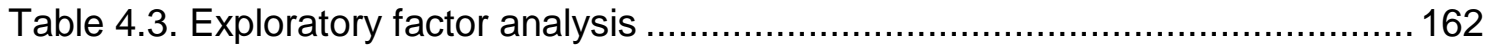

Table 4.4. Correlations between scale items..................................................... 163

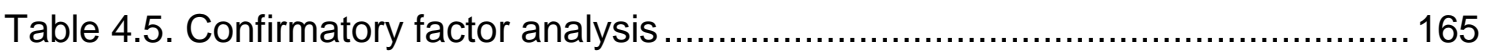

Table 4.6. Comparison of Baseline structural model and Structural model 1........... 1655

\section{CHAPTER 5}

Table 5.1. Mathematical equations of SEM/SDM variables ................................... 197

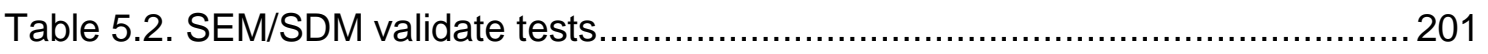

Table 5.3. The SEM qualitative relationships (Bruque et al., 2016) ...........................205

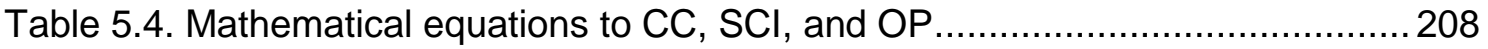

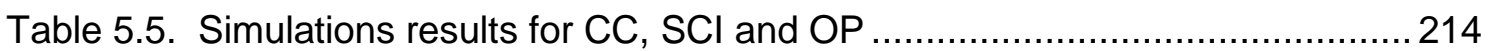

Table 5.6. Check list of SCI and OP measurement model ...................................... 216

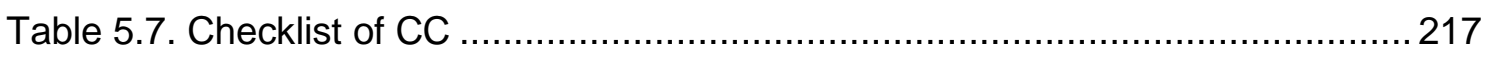

Table 5.8. The SEM qualitative relationships (Ward and Zhou, 2006) .......................220

Table 5.9. Mathematical equations to INTERNAL, EXTERNAL, JIT and LEAD .........222

Table 5.10. Simulations results for INTERNAL, EXTERNAL, JIT and LEAD .............228

Table 5.11. Checklist of JIT measurement model .................................................. 230

Table 5.12. Checklist of INTERNAL and EXTERNAL items average .......................230

\section{CHAPTER 6}

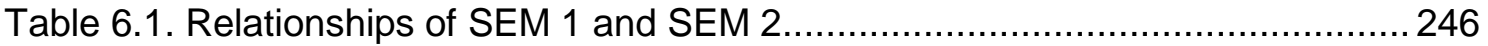

Table 6.2. Mathematical equations to the SEM/SDM variables ................................250

Table 6.3. Checklist of LPI measurement model .................................................... 259

Table 6.4: SEM/SDM scenarios and starting data ............................................... 264

Table 6.5. Checklist of Cloud Computing (based on Mell and Grance definition) ......267

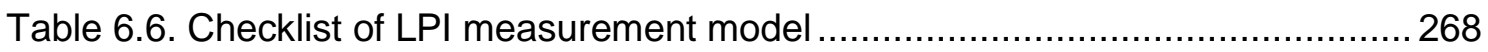

Table 6.7. Checklist of SCF measurement model ................................................269

\section{APPENDIX}

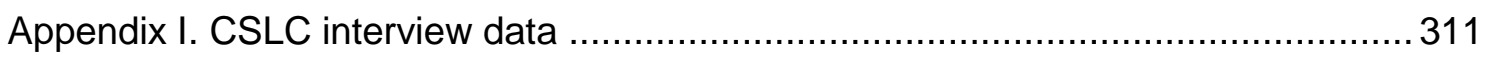


General Introduction 


\section{GENERAL INTRODUCTION}

\section{PRESENTATION}

This doctoral thesis, carried out by Luciano Romualdo Novais, under the direction of Dr. Ángel Ortiz Bás and Dr. Juan Manuel Maqueira Marín, analyses how some variables related to the effectiveness and efficiency in Supply Chain Management are interrelated, and the possible impact of these interrelations on Business Performance. Specifically, we will delve into the relationships between Cloud Computing, Supply Chain Integration, Supply Chain Flexibility, Mass Personalization and Lean Production (which are variables associated with Supply Chain effectiveness and efficiency) and their role in Business Performance.

Supply Chain Management is defined as a set of actions that allows companies to manage, plan and control their operations as a way to facilitate collaboration between Supply Chain members (suppliers, producers, distributors and customers) (Frazelle, 2001; Gunasekarana et al., 2008). Supply Chain Management has been recognised as an extremely important aspect of business strategy to improve competitiveness (McCormack, et al., 2008; Oh et al., 2013). In fact, Supply Chain Management enables companies to manage their processes as a way to respond the very high competitiveness observed in current economic environment (Romano, 2003; MoyanoFuentes et al., 2012). To improve effectiveness and efficiency in Supply Chain, companies are increasingly willing to implement new mechanisms in their management practices and Supply Chain strategies (Flynn et al., 2010; Moyano-Fuentes, SacristánDíaz and Martínez-Jurado, 2012). Cloud Computing, Supply Chain Integration, Supply Chain Flexibility, Mass Personalization and Lean Production play an important role in the quest to improve Supply Chain effective and efficient, and, ultimately, improve Business Performance (Molina et al., 2005; Bruque et al., 2015; Purohit et al., 2016).

Cloud Computing is defined as a model for enabling ubiquitous, convenient, on-demand network access to a shared pool of configurable computing resources (e.g. networks, servers, storage, applications and services) that can be rapidly provisioned and released with minimal management effort or service provider interaction (Mell and Grance, 2011). More specifically, Cloud-supported Logistics is the application of cloud systems to the area of logistics. In Cloud-supported Logistics, the information that supports the logistics process is no longer located on local systems, but located and run on distributed networks accessible through a web browser (Wang et al., 2012; Nowicka, 2014). 
Supply Chain Integration is conceptualized as the degree to which a company collaborates with its supply chain partners and collaboratively manages intraorganizational and inter-organizational processes, in order to achieve effective and efficient integration of physical, information and financial flows (Rai et al., 2006; Flynn et al., 2010).

Supply Chain Flexibility is the ability of a Supply Chain to change its processes, resources, structure and governance mechanisms within a given scope, responding in terms of production volume and product variability to changes in demand (Molina et al., 2005, Rojo et al., 2016).

Customer Microsegmentation is defined as a set of plans that serve as a reference for business decision-making, in order to meet the individual customer requirements (Squire et al. 2006; Tien 2011). A strategy closely related to Customer Microsegmentation is the Mass Personalization, which refers to a company's ability to provide personalized products and services at a price and speed comparable to standard offers for a mass market (Purohit et al., 2016).

Lean Production is a is a socio-technical management system oriented to efficiency, which is used for the identification and elimination of waste-low or nil value-added activities through continuous improvement (Womack et al., 1990; Shah and Ward, 2003).

In this thesis, we initially considered two important drivers to achieve effectiveness and efficiency in the supply chain. The first driver would be formed by the interrelationship between the use of Cloud Computing, a new paradigm in the interpretation of Information Technologies, and Supply Chain Integration. Low levels in this driver will allow companies to achieve their objectives (to be effective) but using many more resources (less efficient) than high values in this driver. The second driver relates to the interrelationship of Supply Chain Flexibility and Mass Personalization. Similar to the previous driver, low levels in this driver would be associated with lower efficiency (still being effective), while high levels would be associated with high efficiency. Both drivers are considered in this thesis, in the first place, in an isolated way, through a Systematic Literature Review that allows us to identify what is known in the literature about the relationship between the variables that make up each driver. Secondly, this thesis considers the effect of Lean Production, and its relationship with each of the drivers, which would be associated with high levels of efficiency in the Supply Chain, and analyses how the joint effect of Lean Production and each of the drivers (variables) considered affects Business Performance. Finally, this thesis considers all variables together (both drivers and the effect of Lean Production, acting on Business 
Performance), in a holistic approach that uses simulation to analyse the model's behaviour. The logic of this study is shown in Figure I.1.

In this sense, Figure I.1 shows the relationship between Supply Chain effectiveness, Supply Chain efficiency and Business Performance that we seek to analyse in this doctoral thesis. In order to achieve their goals, companies are adopt management recourses as a way to improve Supply Chain effectiveness and responding quickly to changes in demand (Flynn et al., 2010). Supply Chain Integration, Supply Chain Flexibility, Mass Personalization and Lean Production are resources that play an important role in the quest to improve Supply Chain effectiveness and, ultimately, improve Business Performance (Molina et al., 2005; Bruque et al., 2015; Purohit et al., 2016). Once their Supply Chain effectiveness goals are achieved, companies need to reduce the management resources used to achieve higher Business Performance levels. To do so, companies use Supply Chain efficiency as a way to produce with quality, lower costs and in the shortest possible time (Flynn et al., 2010). In the search for improved Business Performance, it has been found that Cloud Computing plays an important role in Supply Chain efficiency (Bruque et al., 2015, 2016). Likewise, Lean Production, Supply Chain Integration, Supply Chain Flexibility and Mass Personalization also pursue this goal (Flynn et al., 2010; Moyano-Fuentes et al., 2012; Purohit et al., 2016).

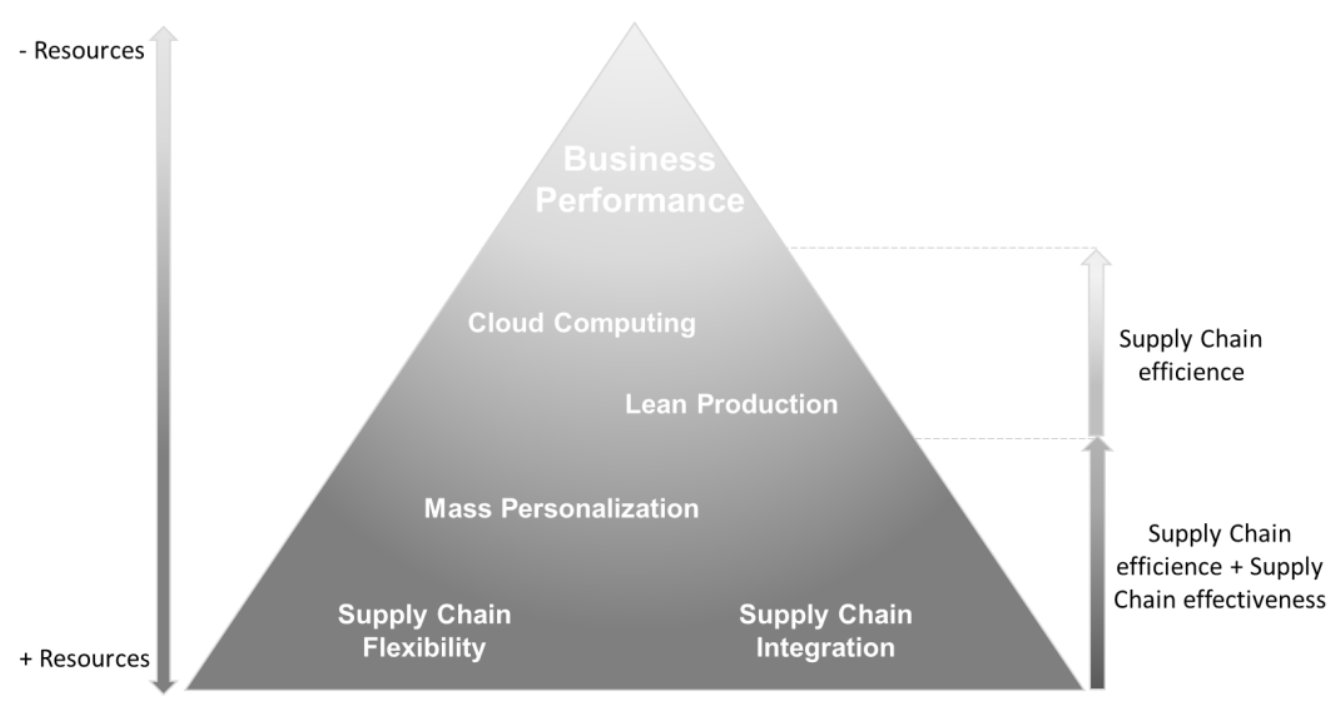

Figure I.1. Relationship between Supply Chain effectiveness, Supply Chain efficiency and Business Performance

The previous literature has dealt separately with the relationship between Lean Production implementation-IT (Bruun and Mefford, 2004; Ward and Zhou, 2006; Riezebos et al., 2009), IT-Supply Chain Integration (Gunasekaran and Ngai, 2004; Li et 
al., 2009; Prajogo and Olhager, 2012), Cloud Computing-Supply Chain Integration (Mehrsai, et al., 2013; Bruque et al., 2015, 2016), and Supply Chain Flexibility-Mass Personalization (Moon et al. 2012; Oh et al. 2013; Stojanov and Ding 2015). After a meticulous search in the previous literature, it has been observed that the interrelationship between these variables related to Supply Chain effectiveness and efficiency, and their impacts on Business Performance remains largely unexplored. This joint analysis could be relevant, since these organisational and technological resources could have multiplier effects on Business Performance.

The value of this study is that academics and practitioners may have supporting evidence on the role played by such management strategies, operationally and strategically linked, and how this combination could be transformed into better Business Performance. The better knowledge of these relationships can affect the way researchers and business managers approach these management resources, becoming more aware of the important role of Supply Chain in competitiveness. This work differs from previous contributions by providing theoretical and empirical approaches of the possible interrelationships between the aforementioned variables. The findings of this study, therefore, could be very useful in the design of future research efforts in this area.

\section{I.1. RESEARCH QUESTIONS}

Literature shows that recent research addresses the effects of applying Cloud Computing technologies in the Supply Chain Integration (Bruque et al., 2015, Bruque et al., 2016). On the one hand, Cloud Computing, and in particular Cloud-supported Logistics, may be positively related to higher Supply Chain Integration, facilitating Supply Chain development through the effective integration of information, physical, and financial flows (Rai et al., 2006; Bruque et al., 2016). On the other hand, Supply Chain Integration may be compromised by certain factors closely linked to Cloud Computing adoption, such as the need for a high quality and highly available Cloud Computing service, which is not always the case; the great complexity involved in systems integration; the lack of standardization; and the loss of control over data (Oliveira et al., 2014, Vermula and Zsifkovits, 2016). However, results to date regarding Cloud Computing-Supply Chain Integration relationship are diffuse, not fully understood, and with many mechanisms and effects that have only been addressed in part or not at all. Based on the above, the first Research Question (RQ1) have been determined for the purpose of this study:

RQ1: What are the findings to date, the areas of study developed and the research gaps related to Cloud Computing use in the firm and its effect on Supply Chain Integration? 
Lean Production is a management system that seeks efficiency and so has a positive impact on Business Performance (van der Vaart et al., 2012; Stump and Badurdeen, 2012). Cloud Computing is an IT that achieves greater efficiency than previous technologies, and its direct effect on logistics activities and on Supply Chain Integration has also been confirmed (Bruque et al., 2015; Trappey et al., 2016). Thus, companies that use Lean Production may be induced to use Cloud-supported Logistics in order to continue gaining in efficiency. Previous literature has also dealt separately with the Lean Production -IT Implementation (Ward and Zhou, 2006), and IT implementation-Supply Chain Integration (Li et al., 2009; Prajogo and Olhager, 2012). However, no papers have been identified that address these variables together and the relationship/s between them and Business Performance. This joint analysis could be relevant, since organisational factors such as Lean Production implementation, and technological factors such as Cloud Computing, could have multiplier effects on Supply Chain Integration and Business Performance. Considering the aforementioned, the second Research Question (RQ2) have been determined for the purpose of this study:

RQ2: What role do Lean Production Implementation, Cloud-supported Logistics, and Supply Chain Integration approaches play in Business Performance?

The relationship between Supply Chain Flexibility as a productive response to Customer Microsegmentation/Mass Personalization environments has resulted in an emerging research line (Moon et al., 2012; Stojanov and Ding, 2015). Supply Chain Flexibility allows companies to be able to provide individually designed products and services to each customer as a way of responding to unanticipated changes in customer needs and market dynamism (Lummus et al., 2003; Huo et al., 2017). Although there are some indications of a positive relationship between Supply Chain Flexibility and Customer Microsegmentation/Mass Personalization (Da Silveira et al., 2001; Urgo et al., 2016), greater and more complete attention is required to understand the causes and consequences of this relationship. To delve deeper into this issue, the third Research Question (RQ3) have been determined for the purpose of this study:

RQ3. What are the findings to date, the areas of study developed and the research gaps related to Supply Chain Flexibility-Customer Microsegmentation/Mass Personalization relationship?

Previous literature has dealt separately with the relationship between Lean ProductionBusiness Performance, and Supply Chain Flexibility-Mass Personalization. On the one hand, the underlying principles of Lean Production and its effects on Business Performance have been extensively studied in recent decades and there is growing 
interest among researchers in this area (Shah and Ward, 2003, Cagliano et al., 2006). Such studies show that Lean Production implementation could increase production efficiency, reducing the production waiting times, and eliminating everything that is not strictly necessary to produce added value for the organization (van der Vaart et al., 2012). On the other hand, there are also a considerable number of studies investigating the relationship between Supply Chain Flexibility and Mass Personalization (Moon et al., 2012; Stojanov and Ding, 2015). These studies indicate that Supply Chain Flexibility could be a way to respond to unforeseen changes in customer needs, market dynamism and competitors' actions in a Mass Personalization context (Da Silveira et al., 2001; Urgo et al., 2016). However, the interrelationship between Lean Production implementation, Supply Chain Flexibility, Mass Personalization, and their impacts on Business Performance remains largely unexplored. Based on the above, the fourth Research Question (RQ4) have been determined for the purpose of this study:

RQ4: What role do Lean Production Implementation, Supply chain Flexibility, and Mass Personalization approaches play in Business Performance?

Finally, to understand the possible relationships between the aforementioned variables related to the Supply Chain effectiveness and efficiency, and how these variables could be related to Business Performance it is to delve deeper into this issue. To do so, it is necessary to make a joint analysis of the above-mentioned variables, and how this mutual relationship could be related to Business Performance. Thus, the fifth Research Question (RQ5) have been determined for the purpose of this study:

RQ5: What role do the combined action of Lean Production Implementation, Cloudsupported Logistics, Supply Chain Integration, Supply chain Flexibility, and Mass Personalization play in Business Performance?

Figure I.2 shows the graphical representation of the Research Questions (RQ). RQ1 and RQ3 are first level, and their answers will serve to construct a theoretical basis for this research (descriptive analyses). RQ1 and RQ3 do not consider the relationship between Lean Production and Business Performance, but describe, using a theoretical approach, the trade-off of Business Performance from the Cloud Computing-Supply Chain Integration (RQ1) and Supply Chain Flexibility-Mass Personalization (RQ3) relationships. RQ2 and RQ4 are second level, and their answers will serve as reference for development and contrasting of the research hypotheses (explicative analyses). Although RQ2 and RQ4 are supported by the theoretical base obtained from the RQ1 and RQ3 answers, the relationship that Lean Production could exert on the Business Performance is also analysed. Finally, RQ5 is third level, and its answer will serve as a 
reference for the dynamic analysis involving all the variables studied in this thesis (simulation approach). It is supported by the relationships between variables analysed empirically from RQ2 and RQ4.

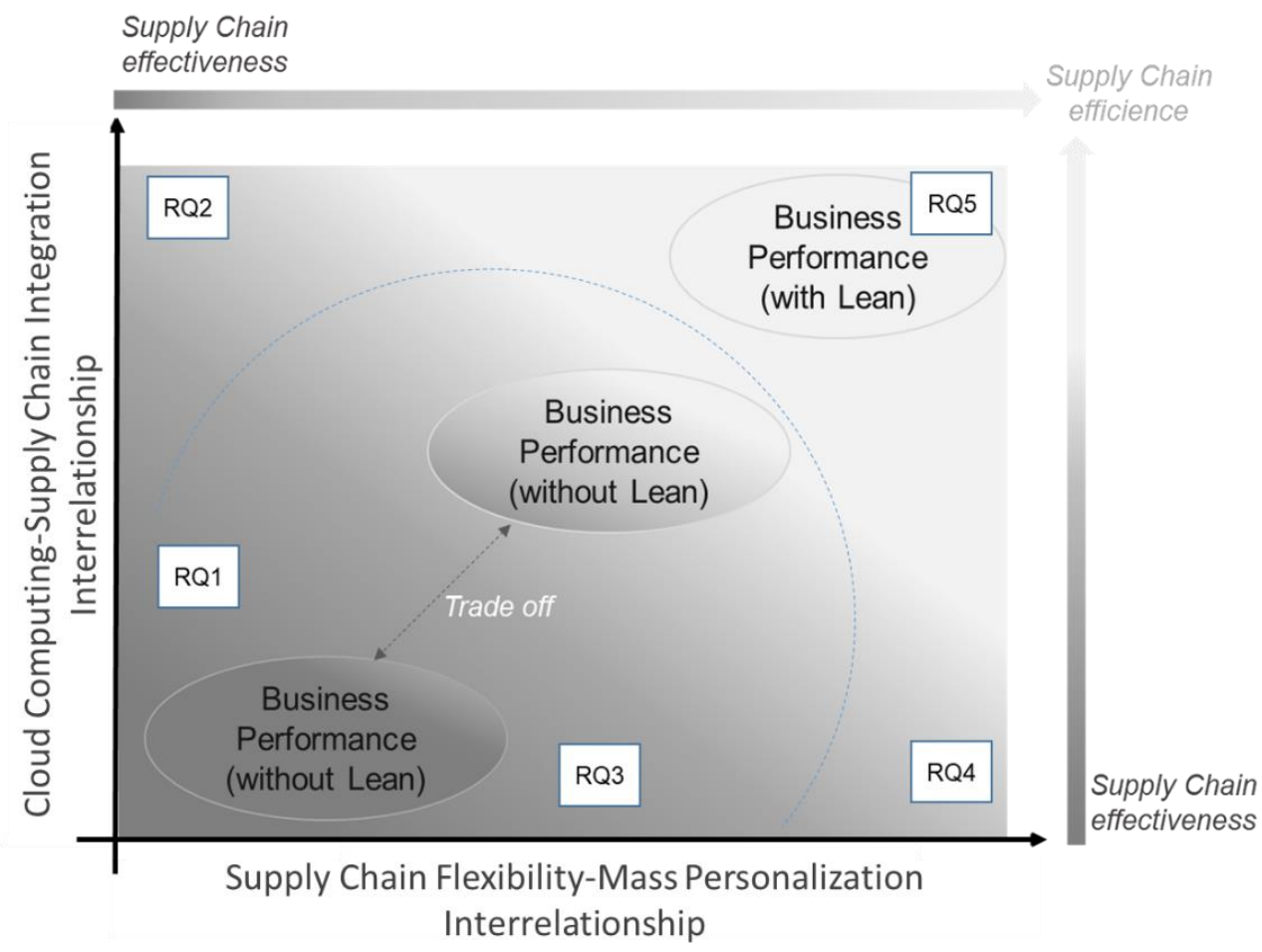

Figure I.2. Graphical representation of the Research Questions

Research Questions have guided the formulation of the general and specific research objectives, as shown in the following section.

\section{RESEARCH OBJETIVES}

This research pursues the following general objective: analyse how some factors related to Supply Chain effectiveness and efficiency (Cloud Computing, Supply Chain Integration, Supply Chain Flexibility, Customer Microsegmentation/Mass Personalization and Lean Production) are interrelated and how they affect Business Performance. Specific objectives (SO) derived from the general objective are as follows:

SO1: Scrutinize previous research that examines the Cloud Computing-Supply Chain Integration relationship to identify the findings to date, lines of study developed and gaps to advance research in the area. 
SO2: Scrutinize previous research that simultaneously examines the Supply Chain Flexibility-Customer Microsegmentation/Mass Personalization relationship to identify the findings to date, topics, lines and sublines of study developed and gaps to advance research in the area.

SO3: Develop an explicative analysis of existing interrelationships between Lean Production Implementation, Cloud-supported Logistics use, Supply Chain Integration, and the effects on Business Performance.

SO4: Develop an explicative analysis of existing the interrelationships between Lean Production Implementation, Supply Chain Flexibility, Mass Personalization and their effects on Business Performance.

SO5: Generate a new methodology, named Strategic Simulation, which encompasses the importance of the Time variable in the relationships between Lean Production, Cloudsupported Logistics, Supply Chain Integration, Supply Chain Flexibility and Mass Personalization. For this purpose, Structural Equations Models are combined with System Dynamics Models.

SO6: Apply the previously generated methodology to develop a new model that analyse, over time, the relationships between Lean Production, Cloud-supported Logistics, Supply Chain Integration, Supply Chain Flexibility and Mass Personalization.

SO7: By using the model previously developed, carry out a Case Study in a specific company with Cloud-based Logistics, whose Strategic Simulation is applied to consider all the variables involved in this study.

\section{I.3. RESEARCH METHODOLOGY}

In order to achieve the general and specific objectives aforementioned, the following methodologies will be used:

(i) Systematic Literature Review (SLR) will be used to examine the bibliographic sources for specifics topics with the aim of arriving at an organized outcome based on current accumulated knowledge of the topic in question (Denyer and Tranfield, 2009). A SLR seeks to classify and analyse contributions to the literature in a specific research area. SLR is considered to be an aid to researchers, as it enables the synthesis of available studies on a particular subject and provides scientific knowledge to underpin practice (Denyer and Tranfield, 2009). SLR will be used to achieve the specific objectives 1 and 2. 
(ii) Establishment and contrast of hypotheses will be used to analyse the interrelationship between factors. Two hypothetical models will be created which, through Structural Equation Modelling, will analyse the cause-effect relationships. Structural Equation Modelling (SEM) is a statistical approach to test hypotheses on relationships between observable and non-observable variables (Satorra, 1993) and has been used quite extensively in the Supply Chain Management field. The objective of SEM is to confirm the relationships proposed in the explanatory model, confronting hypotheses with empirical data (Kaplan, 2000). A SEM is divided into two basic parts: the measurement model and the structural model. The first determines how the unobservable construct is measured by means of these indicators, while the second estimates the effects and relations between variables (Hair et al., 2009). SEM will be used to achieve the specific objectives 3 and 4 .

(iii) System Dynamics Models (SDM) will be used to simulate complex systems over time and to understand the structural causes that lead the represented system behaviour (Forrester, 1961). The objective of SDM is to examine the interaction that exists between various functions within a system over time, which makes it possible to understand and improve the components interaction of that system (Campuzano and Mula, 2010).

(iv) Strategic Simulation is a new methodologic approach proposed in this study, which uses the complementarity between Structural Equation Models (Satorra, 1993) and System Dynamics Models (Forester, 1961). Strategic Simulation provide both a fixed picture of the relationships between variables at a given moment in time and the perspective view of these relationships, considering time. Therefore, Strategic Simulation allows the strategic analyse of variables of the company, its relationships and its evolution over time. Strategic Simulation will be used to achieve the specific objective (v) A Case Study will be conducted to analyse the cause-effect relationships of variables in a Cloud-based logistics company. Through an interview with the company's Operations Manager, strategic data will be obtained for the years 2016 and 2018, as well as projections for the year 2020. These data will be used in the Strategic Simulation.

Figure I.3 shows the graphical representation of the research specifics objectives (SO) and the research methodologies. SO1 and SO2 present a more qualitative character, while SO3, SO4, SO5, SO6 and SO7 have both a qualitative and a quantitative character. The interrelations between the variables analysed in SO1, SO2, SO3 and SO4 are dimensions that, when they are low levels, achieving Supply Chain effectiveness and, when they are high levels, achieving Supply Chain efficiency. Furthermore, SO5, 
SO6 and SO7 are based on the interrelations analysed in SO3 and SO4, when they are high levels (achieving supply chain efficiency).

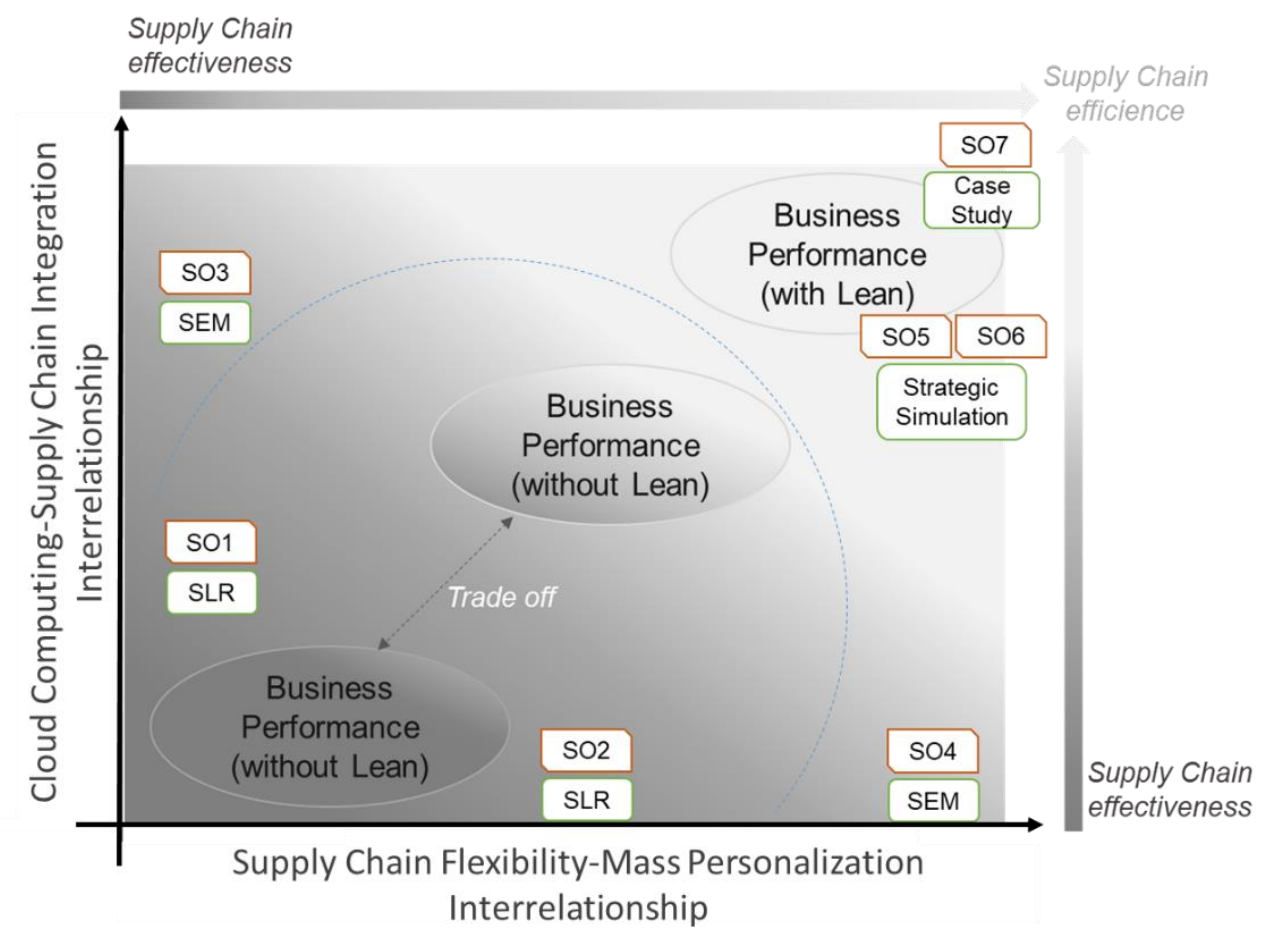

Figure I.3. Graphical representation of the research specifics objectives and the research methodologies

\section{I.4. RESEARCH STRUCTURE}

To achieve the general and specific objectives aforementioned, this doctoral thesis has been organized into seven chapters, preceded by this introduction. The seven chapters have been structured in three blocks: the first block is eminently descriptive, the second block is especially explicative, and the third block is based on a simulation approach. The first block (chapters 1 and 2) will be used as the theoretical basis for the second block (chapters 3 and 4), which in turn will be used in the simulations carried out in chapter 6 . Chapters 5 and 6 make up the third block, with chapter 5 being the methodological basis of chapter 6 . Figure I.4 shows the research structure, including the chapters in which it is organised, the research questions posed, the specific objectives pursued, and the methodologies used in each chapter. 


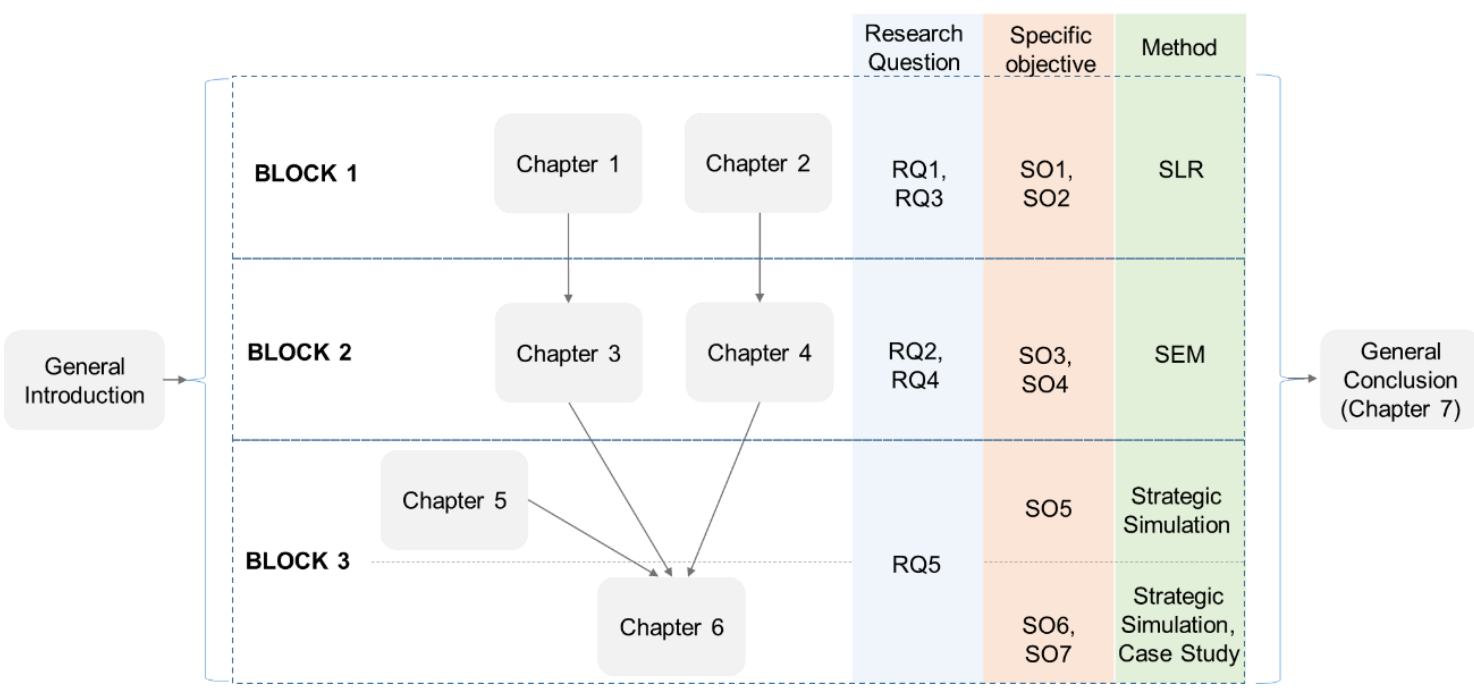

Figure I.4. Research structure

In chapter 1, the current state of research into Cloud Computing and Supply Chain Integration is analysed, while chapter 2 delves into the current state of research into Supply Chain Flexibility and Customer Microsegmentation/Mass Personalization. RQ1 and RQ3, SO1 and SO2, and the use of SLR methodology are covered at the end of chapters 1 and 2 . In chapter 3 , the interrelationships between Lean Production implementation, cloud-supported Logistics use, Supply Chain Integration, and their effects on Business Performance are analysed. Furthermore, chapter 4 deals with the mediating role of Supply Chain Flexibility in the interrelationships between Lean Production implementation, Mass Personalization and Business Performance. RQ2 and $\mathrm{RQ} 4, \mathrm{SO} 3$ and SO4, and the use of SEM methodology are covered at the end of chapters 3 and 4 . In chapter 5 , a methodological proposal to carry out simulations at a strategic level, using the complementarity between Structural Equation Models and System Dynamics Models is presented. From a dynamic and strategic point of view, chapter 6 delves into some factors related to the effectiveness and efficiency in Supply Chain are interrelated and how they affect Business Performance are analysed. RQ5, SO5, SO6 and SO7, and the use of Strategic Simulation and Case Study methodologies are covered at the end of chapters 5 and 6 . Finally, in chapter 7 the main conclusions of this research are shown. 


\section{I.5. FORMAL ASPECTS OF RESEARCH}

Some formal questions regarding the form of presenting this doctoral thesis are shown below.

- The bibliography consulted is included at the end of each chapter.

- At the end of the work, there is a section that includes all the references of the different chapters;

- Each chapter has a section of conclusions, although there is also a final chapter of general conclusions (Chapter 7);

- At the end of the manuscript, a series of research annexes are incorporated;

- At the end of the manuscript, the doctoral candidate's curriculum vitae is incorporated.

\section{REFERENCES}

Brunn, P., and Mefford, R.N. (2004). Lean production and the Internet. International Journal of Production Economics, 89 (3), 247-260.

Bruque, S., Moyano, J., and Maqueira, J. M. (2015). Use of Cloud technology, Web 2.0 and operational performance: the mediating role of supply chain integration. International Journal of Logistics Management, 26 (3), 426-458.

Bruque, S., Moyano, J., and Maqueira, J. M. (2016). Supply chain integration through community Cloud: Effects on operational performance. Journal of Purchasing and Supply Management, 22 (2), 141-153.

Cagliano, R., Caniato, F., and Spina, G. (2006). The linkage between Supply Chain Integration and manufacturing improvement programmes. International Journal of Operations \& Production Management, 26 (3), 282-99.

Da Silveira, G., D. Borenstein, and Fogliatto F. S. (2001). Mass customization: Literature review and research directions. International journal of production economics, 72(1), 1-13.

Denyer, D., and Tranfield, D. (2009). Producing a systematic review. The SAGE handbook of organizational research methods. London: Sage Publications, 671-689.

Devaraj, S., Krajewski, L., and Wei, J. C. (2007). Impact of e-business technologies on operational performance: the role of production information in the supply chain. Journal of Operations Management, 25 (6), 1199-1216.

Flynn, B.B., Huo, B., and Zhao, X. (2010). The impact of Supply Chain Integration on performance: a contingency and configuration approach. Journal of Operations Management, 28 (1-2), 58-71.

Frazelle, E. (2001) Supply Chain Strategy: The Logistics of Supply Chain Management (2nd Ed.). McGrawHill Professional, New York.

Griffiths, J., and Margetts, D. (2000). Variation in production schedules - implications for both the company and its supplier. Journal of Materials Processing Technology, 103 (1), 155-159.

Gunasekarana A., Laib K., and Chenge T. (2008). Responsive supply chain: A competitive strategy in a networked economy. Omega, 36(1), 549-564.

Hair, J.F., Black, W.C., Babin, B.J., and Anderson, R.E. (2009). Multivariate Data Analysis. New Jersey: Prentice Hall.

Huo, B., M., Gu, and Z. Wang. (2017). Supply chain flexibility concepts, dimensions and outcomes: an organisational capability perspective. International Journal of Production Research, 56 (17), 5883-5903.

Kaplan, D. (2000). Structural equation modelling: Foundations and extensions. Newbury Park: Sage. 
Li, G., Yang, H., Sun, L., and Sohal, A. S. (2009). The impact of IT implementation on Supply Chain Integration and performance. International Journal of Production Economics, 120 (1), 125-138.

Lummus, R. R., Duclos, L. K., and Vokurka, R. J. (2003). Supply Chain Flexibility: Building a New Model. Global Journal of Flexible Systems Management, 4 (4), 1-13.

McCormack, K., Ladeira, M.B., and Oliveira, M.P.V. (2008). Supply chain maturity and performance in Brazil. Supply Chain Management: An International Journal, 13 (4), 272-282.

Mell, P., and Grance, T. (2011). The NIST definition of Cloud Computing. Recommendations of the National Institute of Standards and Technology. National Institute of Standards and Technology, Gaithersburg, MD.

Molina, A., Rodriguez, C.A., Ahuett, H., Cortés, J.A., Ramírez, M., Jiménez, G. and Martinez, S. (2005). Next-generation manufacturing systems: Key research issues in developing and integrating reconfigurable and intelligent machines. International Journal of Computer Integrated Manufacturing, 18 (7), 525-536.

Moon, K., C. Yi, and Ngai, E. (2012). An instrument for measuring Supply Chain flexibility for the textile and clothing companies. European Journal of Operational Research, 222 (2), 191-203.

Moyano-Fuentes, J., and Sacristán-Díaz, M. (2012). Learning on Lean: a review of thinking and research. International Journal of Operations \& Production Management, 32 (5), 551-582.

Moyano-Fuentes, J., Sacristán-Díaz, M., and Martínez-Jurado, P. J. (2012). Cooperation in the supply chain and Lean Production adoption: Evidence from the Spanish automotive industry. International Journal of Operations \& Production Management, 32 (9), 1075-1096.

Nowicka, K. (2014). Smart city Logistics on cloud computing model. Procedia - Social and Behavioral Sciences, 151, 266-281.

Oh, S., Ryu K., and Jung, M. (2013). Reconfiguration framework of a supply network based on flexibility strategies. Computers and Industrial Engineering, 65 (1), 156-165.

Oliveira, T., Thomas, M., and Espadanal, M. (2014). Assessing the determinants of Cloud Computing adoption: an analysis of the manufacturing and services sectors. Information and Management, 51 (5), 497-510.

Prajogo, P., and Olhager, J. (2012). Supply chain integration and performance. The effects of long-term relationships, information technology and sharing, and Logistics integration. International Journal of Production Economics, 135, 514-522.

Purohit, J.K., Mittal, M.L., Mittal, S. et al. (2016). Interpretive structural modelling-based framework for mass customisation enablers: an Indian footwear case. Production Planning and Control, 27 (9), 774-786.

Rai, A., Patnayakuni, R., and Seth, N. (2006). Firm performance impacts of digitally enabled supply chain integration capabilities. MIS Quarterly, 30 (2), 225-246.

Rojo, A., Llorens-Montes, F. J., and Perez-Arostegui, M. N. (2016). The impact of ambidexterity on supply chain flexibility fit. Supply Chain Management: An International Journal, 21 (4), 433-452.

Romano, P., 2003. Coordination and integration mechanisms to manage Logistics processes across supply networks. Journal of Purchasing \& Supply Management, 9 (3), 119-34.

Satorra, A. (1993). Multi-sample analysis of moment-structures: asymptotic validity of inferences based on second order moments. In: Haagen, K., Bartholomeusz, A., Deistler, M. (Eds.), Statistical modelling and latent variables. Elsevier, North Holland, Amsterdam.

Shah, R., and Ward, P.T. (2003). Lean manufacturing: context, practice bundles and performance. Journal of Operations Management, 21 (2), 129-49.

Squire, B., Cousins, P.D., and Brown, S. (2006). Collaborating for customisation: an extended resourcebased view of the firm. International Journal of Productivity and Quality Management, 1 (1), 8-25.

Stojanov, T., and Ding, X. (2015). Supplier selection for mixed-model production: A case study from the apparel industry. Fibres and Textiles in Eastern Europe, 23 (1), 8-12.

Stump, B., and Badurdeen, F. (2012). Integrating Lean and other strategies for mass customization manufacturing: A case study. Journal of Intelligent Manufacturing, 23 (1), 109-124.

Tien, J. M. (2011). Manufacturing and services: From mass production to mass customization. Journal of Systems Science and Systems Engineering, 20 (2), 129-154.

Trappey, A. J. C., Trappey, C. V., Chang, S. W. C., and Tun Nien Hsu, W. T. L. (2016). A one-stop logistic services framework supporting global supply chain collaboration. Journal of Systems Science and Systems Engineering, 25(2), 229-253. 
Urgo, M., W. Terkaj, C. Cenati, F. Giannini, M. Monti, and S. Pellegrinelli. (2016). Zero-point fixture systems as a reconfiguration enabler in flexible manufacturing systems. Computer-Aided Design and Applications, 13 (5), 684-692.

Van der Vaart, T., Van Donk, P., Giménez, C., and Sierra, V. (2012). Modelling the integration-performance relationship. Collaborative practices, enablers and contextual factors. International Journal of Operations and Production Management, 32 (9), 1043-1074.

Vermula, R., and Zsifkovits, H. (2016). Cloud Computing for Supply Chain Management. BHM, 161 (5), 229_ 232.

Wang, X., Li, W.F., Zhong, Y. and Zhao, W. (2012). Research on cloud Logistics-based one-stop service platform for Logistics center. IEEE 16th International Conference on Computer Supported Cooperative Work in Design, 558-563, May 23-25, 2012, Wuhan, China.

Ward, P., and Zhou, H. (2006). Impact of information technology integration and Lean/ just-in-time practices on lead-time performance. Decision Sciences, 37 (2), 177-203.

Womack, J.P., Jones, D.T., and Ross, D. (1990). The Machine That Changed the World, MacMillan, New York, NY. 


\section{BLOCK I}

Systematic Literature Reviews 


\title{
Chapter 1
}

\section{A Systematic Literature Review of Cloud Computing Use in Supply Chain Integration}

\begin{abstract}
This chapter analyses the current state of research into Cloud Computing and Supply Chain Integration with the objective to identify the findings to date, the areas of study developed and research gaps to provide guidance for future research. For this, a Systematic Literature Review was conducted, with 77 papers addressing the Cloud Computing-Supply Chain Integration relationship identified for analysis. These papers provide evidence of a positive relationship between the adoption of Cloud Computing use in process/activity integration, technology/system integration, and supply chain partner integration. The reviewed literature also indicates that Cloud Computing use in supply chain can also have an impact on the integration of the supply chain's information, physical and/or financial flows.
\end{abstract}

Keywords: Cloud Computing; Supply Chain Integration; Systematic Literature Review. 


\section{A Systematic Literature Review of Cloud Computing Use in Supply Chain Integration}

\subsection{INTRODUCTION}

There is currently a broad consensus among the scientific community as to Information Technology's (IT) role as a source of competitive advantage. In this regard, IT is not a tool that has a direct impact on results, but does so through other company resources and capabilities; and Supply Chain Integration (SCl) is one of these capabilities (Bruque et al., 2015). Likewise, a technological trend, named Cloud Computing (CC), emerged to modify the use of IT in a more effective way. In CC (Buyya et al., 2009, Buyya et al., 2011), resources are located in virtualized and distributed environments geographically disperse. They can be accessed on an on-demand basis through web-based technologies, combining internet connectivity and pay-per-use systems (Winans and Brown, 2009) in a new business model for IT provisioning (Son et al., 2014; Maqueira et al., 2017). The National Institute of Standards and Technology, US department of commerce defines Cloud Computing as a model for enabling ubiquitous, convenient, ondemand network access to a shared pool of configurable computing resources (e.g. networks, servers, storage, applications and services) that can be rapidly provisioned and released with minimal management effort or service provider interaction (Mell and Grance, 2011).

CC is composed of five essential characteristics, including on-demand self-service, broad network access, resource pooling, rapid elasticity and measured service (Mell and Grance, 2011). Three different types of service models can be distinguished in Cloud Computing: Infrastructure as a Service (laaS), Platform as a Service (PaaS) and Software as a Service (SaaS) (Ryan and Loeffler, 2010). laaS involves sharing data or IT infrastructure that can be used as a service; PaaS entails providing a complete platform for application development and deployment; and SaaS involves delivering software online as an on-demand service. These service models can be organized into four deployment models: Private Cloud, internally in a single organization; Community Cloud, enabling a group of business partners to share key resources; Public Cloud, deployed by providers who offer their services to the business community; and Hybrid Cloud, which combines public and private models (Ryan and Loeffler, 2010; Mell and Grance, 2011). CC offers a number of advantages over traditional IT models, including faster data transactions, elasticity, resource-sharing, pay-per-use, flexibility, ease of configuration, low IT deployment cost, the need for data centres, and increased IT 
performance (Marston et al., 2011, Wu et al., 2013, Jede and Teuteberg, 2015, Bruque et al., 2015, Liu et al., 2016). However, CC is not without its barriers, including concerns about data security and privacy, uneven service availability, limited compatibility with existing applications and systems, and a weak regulatory framework (Oliveira et al. 2014, Doherty et al., 2015, Vermula and Zsifkovits, 2016).

Supply Chain Integration ( $\mathrm{SCl}$ ) is conceptualized as the degree to which a company collaborates with its supply chain partners and collaboratively manages intraorganizational and inter-organizational processes, in order to achieve effective and efficient integration of physical, information and financial flows (Flynn et al., 2010). SCI emerges as an important field of interest and involves the strategic alignment of functions and processes within an organization and between supply chain members (Chen et al., 2009; Kumar et al., 2017). In fact, a highly integrated supply chain involves interaction and collaboration between company, customers and suppliers, and depends on a high degree of information exchange, mutual dependence and joint actions between supply chain members (Harland et al., 2004; Huang and Huang, 2018). The cross-functional border integration of processes and activities, involving suppliers and customers in supply chains, is considered a key to achieving competitive advantage (Littler et al., 1995; Frohlich and Westbrook, 2001; Bruque et al., 2015; Diaz-Madroñero et al., 2017). For the full potential of $\mathrm{SCl}$ to be exploited, it is necessary to integrate flows, processes, activities, technologies and partners in the chain (Troyer and Cooper, 1995; FabbeCostes and Jahre, 2008). Integration is achieved by integrating information, physical, and financial flows (Rai et al., 2006).

Companies are rapidly adopting CC in their business processes and in all their functional areas, and the potential for the application of these technologies in the supply chain is very high (Bruque et al., 2015). This has resulted in an emerging line of research that focuses on the effects that derive from the application of CC technologies in the supply chain (Schramm et al., 2011, Casey et al., 2012, Azevedo et al., 2013; Jede and Teuteberg, 2015, Li et al., 2015a, Vermula and Zsifkovits, 2016). So, recent research addresses the CC-SCI relationship (Bruque et al., 2015, Bruque et al., 2016), which is an even more specific line of research.

Likewise, the amount of research in the area has grown substantially lately. Most of this research corresponds to theoretical discussions on the role of $\mathrm{CC}$ in $\mathrm{SCl}$ (Abidi et al., 2014; Jede and Teuteberg, 2015; Pérez-Salazar et al., 2017) but there has also been an increase in empirical research that merits attention by academics and practitioners (Devaraj et al., 2007; Bruque et al. 2015; Bruque et al. 2016). However, results to date regarding CC-CSI relationship are diffuse, not fully understood, and with many 
mechanisms and effects that have only been addressed in part or not at all. Thus, further and fuller attention is required to understand this CC-SCI relationship (Bruque et al., 2015). This improved knowledge may affect the way researchers approach CC-SCI and can be very useful for the design of future research endeavours in the area. Also, company managers may be informed of the potential managerial implications, advantages and risks related to the CC-SCI relationship. A tangible need to develop a better and more focused understanding of the CC-SCI relationship can therefore be stated to exist.

Therefore, the objective of this study is to scrutinize previous research that examines the $\mathrm{CC}-\mathrm{SCl}$ relationship to identify the findings to date, lines of study developed and gaps to advance research in the area. Based on a literature review, this chapter provides an overview of the possible relationships between $\mathrm{CC}$ and $\mathrm{SCl}$ and uses a multidimensional structure to categorize the studies. The study's systemic and integrative approach enables multiple aspects of integration to be addressed, with the focus on integrating processes and activities, technologies and systems, and partners. It is not limited to any particular aspect of integration (e.g., Manufacturing integration, as in Helo et al. (2014), or supply chain collaborative strategies, as in Duan and Liu, (2016)) but, rather, gives a broader view of CC-SCI. This chapter also identifies, from existing literature, gaps and directions for future research.

The aim, therefore, is to contribute to improving knowledge of the $\mathrm{CC}-\mathrm{SCl}$ relationship through a Systematic Literature Review and analysis of papers that address the CC-SCI relationship published in scientific journals.

This chapter has been organized into five sections. After this introduction, the second section describes the methodology. In the third section, the results obtained are presented and discussed. Section four presents the conclusions and, lastly, section five provides a summary of the chapter.

\subsection{METHODOLOGY}

In order to achieve the research objective (Biel and Glock, 2016; Scheidegger et al., 2018) the Systematic Literature Review (SLR) technique has been used (Denyer and Tranfield, 2009). Following the steps established in this technique (Denyer and Tranfield, 2009), the existing literature on the investigated issue has been identified. The literature analysis and synthesis allows to identify the existing findings, research directions and gaps. 
Systematic Literature Review (SLR) is a tried and tested method that examines the bibliographic sources for a specific topic with the aim of arriving at an organized outcome based on current accumulated knowledge of the topic in question (Denyer and Tranfield, 2009). An SLR seeks to classify and analyse contributions to the literature in a specific research area. The most important advantage of this method is that it consists of a number of commonly accepted steps, and so can be easily verified or replicated by other researchers (Denyer and Tranfield, 2009). Therefore, transparency, a commonly accepted structure, commonly accepted steps, and replicability are SLR's greatest strengths compared to a simple literature review.

SLR is considered to be an aid to researchers, as it enables the synthesis of available studies on a particular subject and provides scientific knowledge to underpin practice. In this chapter, SLR has been used to integrate information obtained from a set of individual studies of $\mathrm{CC}-\mathrm{SCl}$ and to identify topics that are lacking in evidence, thus pointing toward areas for future research. By providing a clear and explicit summary of CC-SCI studies, SLR has produced a greater range of relevant results, rather than the conclusions being limited to the findings of a small number of papers. Results from previous studies have been combined to offer the best evidence possible on the topic, while knowledge drawn from existing $\mathrm{CC}-\mathrm{SCl}$ research has identified knowledge gaps.

To conduct an SLR, first it is important to delimit the research area and establish a protocol to identify, select, review and synthesize relevant literature (Seuring and Muller, 2008). This chapter follows the five steps for a SLR proposed by the Denyer and Tranfield (2009) methodology: (i) Formulation of the research question(s); (ii) Identification of studies; (iii) Selection and evaluation of studies; (iv) Analysis and synthesis; and (v) Presentation of results and discussion (see Figure 1.1). It should be noted that SLR has been successfully used in IT (Boell and Cecez-Kecmanovic, 2014; Ashraf et al., 2017) apart from the area of the supply chain (Abidi et al. 2014; Montoya-Torres and OrtizVargas, 2014; Zimmermann et al., 2015). The following gives a brief description of these five steps and indicates how they have been carried out in the specific framework of this research.

\begin{tabular}{|c|c|c|c|c|}
\hline $\begin{array}{l}\text { (i) Formulation } \\
\text { of the research } \\
\text { question(s) }\end{array}$ & $\begin{array}{l}\text { (ii) Identification of } \\
\text { studies }\end{array}$ & $\begin{array}{l}\text { (iii) Selection } \\
\text { and evaluation } \\
\text { of studies }\end{array}$ & $\begin{array}{l}\text { (iv) Analysis } \\
\text { and synthesis }\end{array}$ & $\begin{array}{l}\text { (v) Presentation } \\
\text { of results and } \\
\text { discussion }\end{array}$ \\
\hline
\end{tabular}

Figure 1.1. Research methodology

Source: Based on Denyer and Tranfield (2009) 
(i) Formulation of the research questions

The first step in any SLR is to define the research question, i.e., to identify the question(s) that the research has to answer (Seuring and Muller, 2008, Denyer and Tranfield, 2009; Biel and Glock, 2016; Rajagopal et al., 2017; Scheidegger et al., 2018). The following Research Questions $(R Q)$ have been determined for the purpose of this study:

RQ1. What are the findings to date, the areas of study developed and the research gaps related to Cloud Computing (CC) use in the firm and its effect on Supply Chain Integration $(\mathrm{SCl}) ?$

This general $R Q$ can be divided into three specific ones:

RQ1.1: What is the current state of knowledge of Cloud Computing (CC) use in the firm and its effect on Supply Chain Integration (SCI)?

RQ1.2: What are the main research directions in relation to the adoption of CC for SCI?

RQ1.3: What are the gaps and future research directions that can be identified based upon existing work?

It is important to emphasize that RQ1.1 and RQ1.2 are preliminary questions for all types of review and are used to establish what has already been studied in the CC-SCI field. RQ1.1 and RQ1.2 answers will be the basis for responding to RQ1.3, which will shed light on a possible way forward in the CC-SCI field.

(ii) Identification of studies

This step involves looking for and locating relevant studies to answer the research question(s). In this case, a search was conducted of the main bibliographic databases, including ABI Inform Global, ScienceDirect, Emerald Insight, and Scopus. Since the aim has been to identify papers that address the way that cloud computing is applied to the supply chain to achieve integration, three sets of keywords have been selected, with the criterion that the three sets are represented in the search chain. First, the word "Cloud" has been selected for the set that represents cloud computing. As "Cloud" is a sufficiently acknowledged IT term (Buyya et al., 2009), it has been used directly in searches. Second, the word "Supply Chain" has been selected for the supply chain as a whole. "Supply Chain" is also a sufficiently well-known term for it to be used directly in the searches. Third, the integration set is represented by a series of words that reflect the different possible dimensions/layers of supply chain integration (Rai et al., 2006; FabbeCostes and Jahre, 2008), i.e., flow integration (information flows, physical flows, and financial flows) (Rai et al., 2006), and process, system and partner integration (FabbeCostes and Jahre, 2008). Technology, manufacturing and logistics integration have also 
been considered in this set. Selecting these three sets of keywords enables papers in the intersection area between them to be identified. Filters used in the papers identification process were "TI" and "AB", with "TI" referring to "Title" and "AB" to "Abstract". These terms indicated to the search engine that we wanted to locate the key terms in the title or abstract of database papers, respectively. An initial search was made using the following combinations of terms: TI \& AB (Cloud) AND TI \& AB ("Supply chain") AND TI \& AB ("Collaboration" OR "Flow integration" OR "Information integration" OR "Physical integration" OR "Financial integration" OR "Process integration" OR "Technology integration" OR "System integration" OR "Partner integration" OR "Customer integration" OR "Supplier integration" OR "Manufacturing integration" OR "Logistics integration"). It was determined that the terms should appear in the papers' titles, abstracts or keywords. The literature was obtained from relevant journals in the areas of Operations Management, Operations Research, General Management and Information Technology. There was no restriction to the date of publication. This process identified a total of 598 papers.

(iii) Selection and evaluation of studies

After the first search phase, the abstracts, methodologies, main results and conclusions of the identified papers were closely examined in order to determine whether they were relevant to the research questions. The following inclusion criteria were used for the papers selection: scientific papers; literature reviews and in press papers; written in English; peer-reviewed. Papers should be published in journals with impact indexes (JCR or SJR), which ensures the quality of primary research (Thomé et al., 2016). Also, the following exclusion criteria were applied to select papers consistent with this research: (a) Papers that do not refer to the subject of this research; (b) Duplicated items; (c) Books, theses, dissertations, patents and communications to conferences, and (d) Papers that were not indexed in journals with scientific quality indicators, such as Journal Citation Reports (JCR) (Social Sciences Citation Index (SSCI) and Social Citation Index $(\mathrm{SCI})$ ), and Scimago Journal \& Country Rank (SJR). In the end phase, the papers have been read in depth. This process yielded 77 papers for further in-depth analysis. The processes of search, identification, inclusion and exclusion of papers has been done by two researchers who reached consensus on which papers should be considered in the subsequent stages of the review. This is a good practice in SLRs carried out in the Operations Management area (Thomé et al., 2016). 


\section{(iv) Analysis and synthesis}

In the fourth stage, the studies selected and evaluated in the previous stage were analysed and synthesized. Each study was analysed and synthesized according to thematic content. The key research topic of each study was identified. Studies were then grouped by three mains topic. For each main topic, the research lines were identified and finally the papers were classified into research sublines. So, a classification in three levels has been obtained: (1) Research topic (level 1); (2) Research line (level 2) and (3) Research subline (level 3).

$\mathrm{SCl}$ dimensions recognized in the literature are used as the main classification grouping criteria (Rai et al., 2006; Fabbe-Costes and Jahre, 2008) and are also used as the criteria for the keyword search. Thus, a multidimensional framework developed from the prior literature on Supply Chain Integration (Rai et al., 2006; Fabbe-Costes and Jahre, 2008) has been used to systematically classify the papers. On the one hand, Fabbe-Costes and Jahre (2008) propose three interconnected SCI dimensions or layers: (1) process and activity integration; (2) system integration; (3) partner integration. These dimensions generate the first grouping level in three main research topics:

- The first main topic includes studies in which CC use is analysed in process and activity integration between chain members. On the second level, research lines are identified (manufacturing process integration and logistics integration involving and integrating different chain members). Research sublines are identified on the third level.

- The second main topic includes studies on CC use in technology and system integration with reference to the integrated use of technological tools and systems. Research lines identified on the second level are: intra-organizational technology integration and inter-organizational technology integration. Research sublines are also identified on the third level.

- $\quad$ The third main topic includes studies that analyse the impact of $C C$ on supply chain partner integration. The second level of classification includes internal integration, supplier integration and customer integration. As in the previous topics, research sublines are identified.

Rai et al. (2006), however, categorize SCI according to other integration layers that stand for integration flows in the supply chain. According to these authors, these flows are information, physical, and financial:

- Information flow integration is the extent to which operational, tactical and strategic information is shared between a focal firm and its supply chain partners. 
- Physical flow integration is the extent to which a focal company uses global optimization with supply chain partners to manage the storage and flow of materials and finished products.

- Financial flow integration is defined as the extent to which financial flows between a focal firm and its supply chain partners are driven by workflow events.

Interaction between these dimensions or layers is considered in order to provide a broader view of the impact of $\mathrm{CC}$ on $\mathrm{SCl}$ : the three main research topics (process and activity integration; technology and system integration; and SC partner integration) are interrelated with supply chain flow integration (information, physical, and financial).

Figure 1.2 shows the three classification levels. There are three main research topics on the first level. The lines of research identified for each major topic are shown on the second level. The research sublines are identified for each research line on the third level. Information, physical and financial flow integration in the supply chain is also taken into consideration, as we identify whether these dimensions are considered in each of the analysed papers. The criteria used for the classification were sent to five IT and supply chain researchers, who confirmed criteria consistency. 


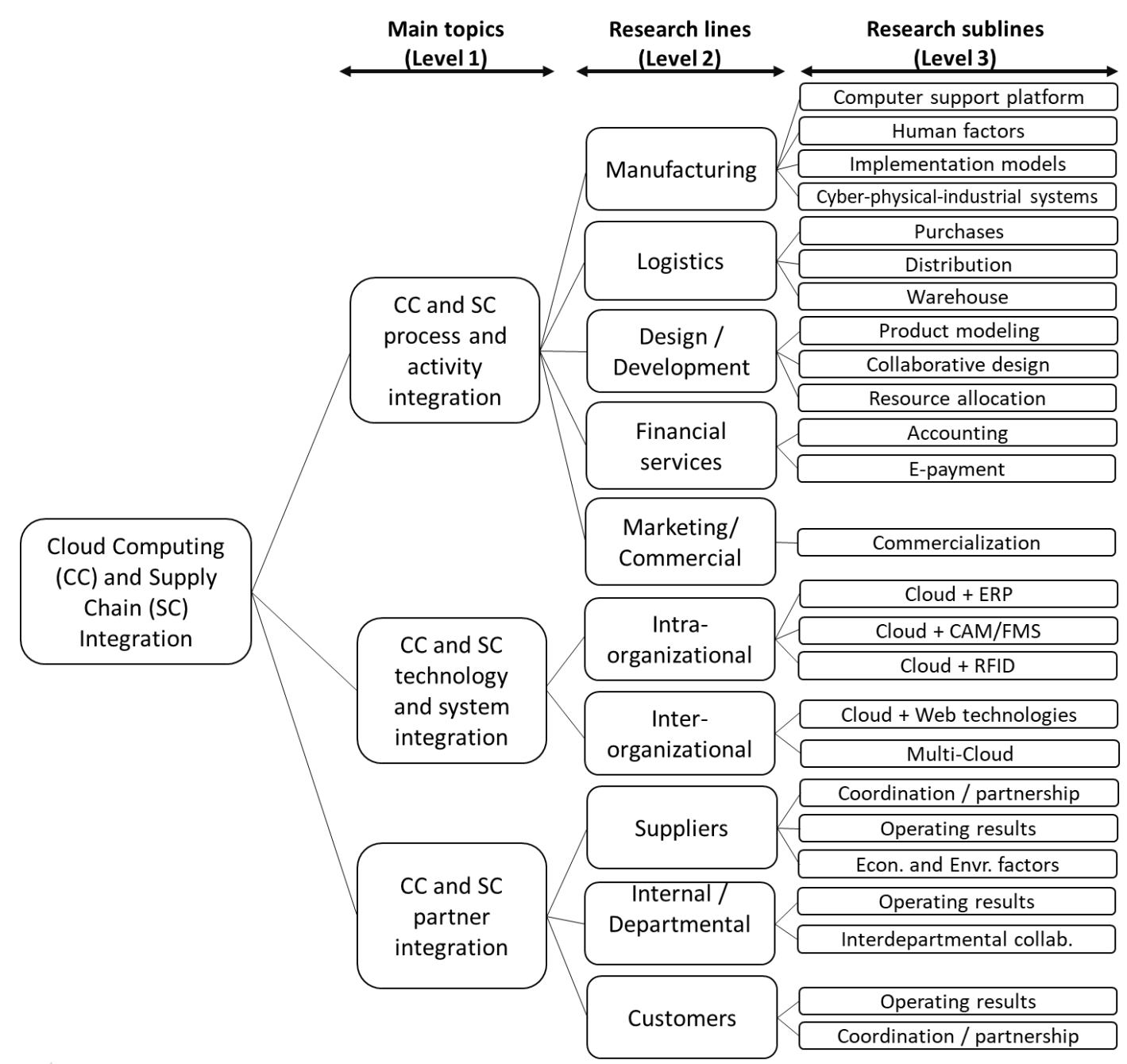

integration of the SC's information, physical and/or financial flows

Figure 1.2. Proposed framework for the literature classification

Source: Own elaboration

The methodology used for the search, selection and evaluation of papers is summarized in Figure 1.3. 


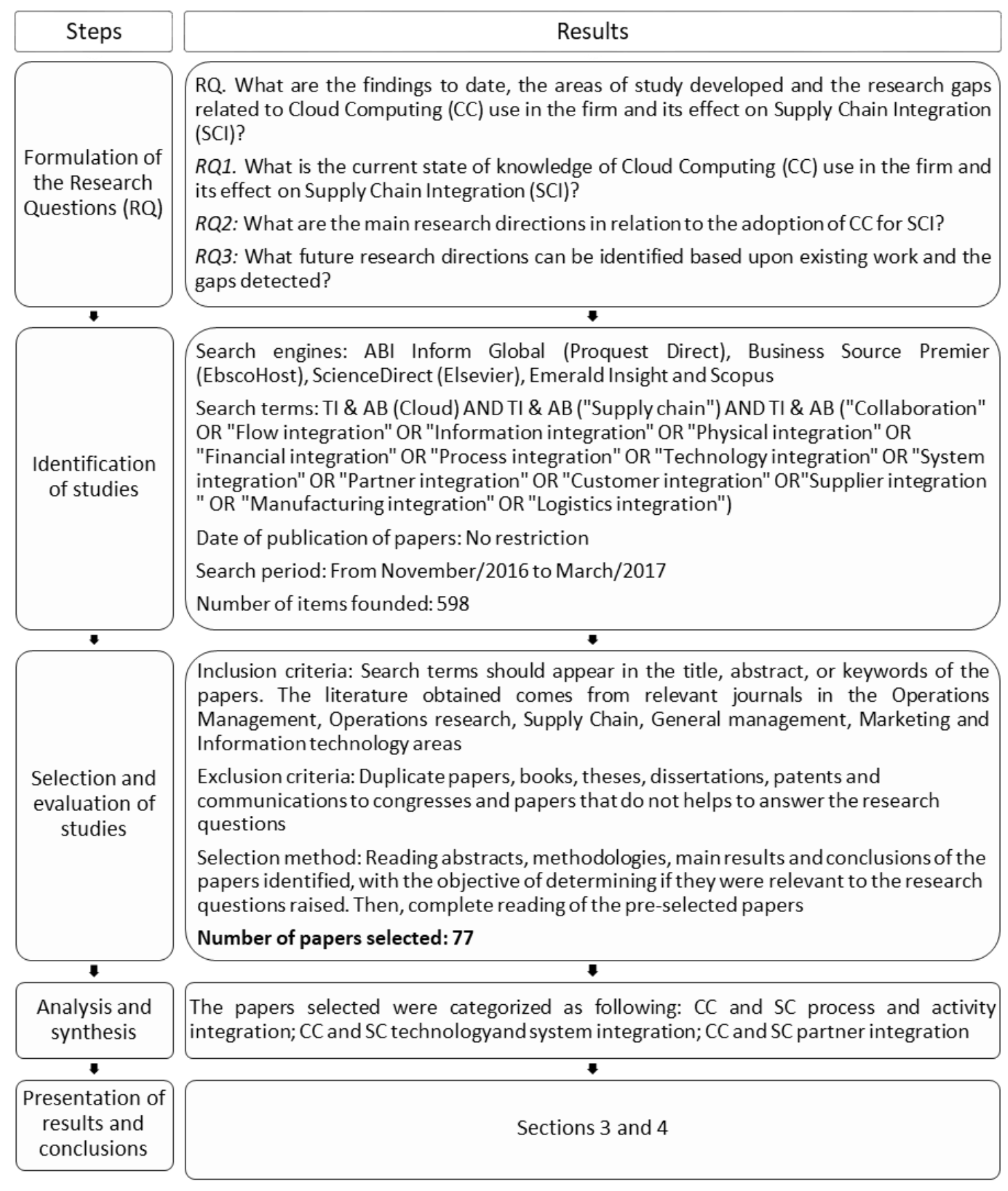

Figure 1.3. Summary of the research methodology Source: Own elaboration

\section{(v) Present the results}

In the following section, the results are discussed by identified research topic/research line/research subline. First, a descriptive analysis is given of the identified papers; next, the first main topic (CC-process and activity integration relationship) is addressed, followed by the second main topic (CC-technology and system integration relationship); finally, the third main topic (CC-Supply Chain partner integration relationship) is analysed. A paper can be in different research topics, lines, and sublines. A classification 
of the possible supply chain flow types (information -INF-, physical -PHY-, or financial FIN-) is presented for each of the research topics, with emphasis on the effect that CC can have on the process. Finally, the research gaps and the future research lines that have been identified are shown.

\subsection{RESULTS AND DISCUSSION}

The analysis of the 77 selected papers allows to identify the current state of knowledge of $\mathrm{CC}$ effect on SCI (answer RQ1) and gaps detected and future research directions (answer RQ3). Studies were grouped by three mains topic. For each main topic, the research directions were identified and finally the papers were classified into research sublines (answer RQ2). These results are shown in detail below.

\subsubsection{DESCRIPTIVE ANALYSIS}

First, studies were analysed chronologically by year of publication. Research interest in the CC-SCI relationship is relatively new in the literature, with studies published in 2010 being the earliest identified. Research interest has grown, especially over the last five years, with the trend continuing to the present day. The highest number of publications was recorded in 2016 and a further 13 papers related to this study's topic of interest had either been published or were "in press" by March 2017.

Table 1.1 lists the journals in which papers dealing with $\mathrm{CC}$ and $\mathrm{SCl}$ have been published. Journals with over $2.6 \%$ of the total analysed (2 or more papers) are highlighted. The fact that papers have been published in journals dealing mainly with Industrial Computing, Supply Chain Management and Operations Management underscores the relevance of the topic and its multidisciplinary nature. $27.3 \%$ of the references (21 papers) were published in only 3 journals: Robotics and ComputerIntegrated Manufacturing, Computers in Industry, and Journal of Manufacturing Systems. 
Table 1.1. Journals in which the papers were published

\begin{tabular}{|c|c|c|c|}
\hline Source & JCR (2016) & Authors & $\%$ \\
\hline $\begin{array}{l}\text { Robotics and Computer-Integrated } \\
\text { Manufacturing }\end{array}$ & 2.846 & $\begin{array}{l}\text { Xu (2012), Valilai and Houshmand } \\
\text { (2013), Wang and Xu (2013), Givehchi } \\
\text { et al. (2016), Cheng et al. (2017), Hao } \\
\text { and Helo (2017), Liu et al. (2017), } \\
\text { Schlechtendahl et al. (2017), Azevedo } \\
\text { et al. (2017), Tao et al. (2017), Wang } \\
\text { et al. (2017) }\end{array}$ & 14.3 \\
\hline Computers in Industry & 2.691 & $\begin{array}{l}\text { Li et al. (2013), Helo et al. (2014), } \\
\text { Mezgár and Rauschecker (2014), Li et } \\
\text { al. (2015a), Babiceanu and Seker } \\
\text { (2016), Lyu et al. (2017) }\end{array}$ & 7.8 \\
\hline Journal of Manufacturing Systems & 2.770 & $\begin{array}{l}\text { Wu et al. (2013), Thekinen and } \\
\text { Panchal (2016), Lee (2017), Lu and Xu } \\
\text { (2017) }\end{array}$ & 5.2 \\
\hline Computers and Industrial Engineering & 2.623 & $\begin{array}{l}\text { Kong et al. (2015), Chen et al. (2016), } \\
\text { Huang et al. (2017) }\end{array}$ & 3.9 \\
\hline Manufacturing Letters & - & $\begin{array}{l}\text { Wang and Wang (2014), Mourtzis et } \\
\text { al. (2016), Yang et al. (2016) }\end{array}$ & 3.9 \\
\hline Computer Networks & 2.516 & Wang et al. (2016), Xia et al. (2016) & 2.6 \\
\hline $\begin{array}{l}\text { International Journal of Production } \\
\text { Economics }\end{array}$ & 3.493 & Harris et al. (2015), Singh et al. (2015) & 2.6 \\
\hline $\begin{array}{l}\text { Journal of Network and Computer } \\
\text { Applications }\end{array}$ & 3.500 & Li et al. (2013), Liu et al. (2014) & 2.6 \\
\hline \multicolumn{3}{|l|}{ Others (less than $2.4 \%$ ) } & 57.1 \\
\hline \multicolumn{3}{|l|}{ Total } & 100 \\
\hline
\end{tabular}

On the other hand, the analysed papers present considerable geographic dispersion, as can be seen in Tables 1.2 and 1.3. Although the majority of papers were written by multicountry authors, there is a large number of papers from China and the United States.

Table 1.2. Publishing countries

\begin{tabular}{|l|c|}
\hline Country & $\%$ \\
\hline Multi-country & 22 \\
\hline China & 17 \\
\hline United States & 15 \\
\hline Taiwan & 6 \\
\hline Australia & 4 \\
\hline India & 4 \\
\hline New Zealand & 4 \\
\hline Greece & 4 \\
\hline $\begin{array}{l}\text { Other countries (less than } 3 \\
\text { papers) }\end{array}$ & $\mathbf{2 6}$ \\
\hline Total & $\mathbf{1 0 0}$ \\
\hline
\end{tabular}

Table 1.3. Publishing continents

\begin{tabular}{|l|c|}
\hline Continent & $\%$ \\
\hline Asia & 33 \\
\hline Europe & 22 \\
\hline Multi-Continent & 20 \\
\hline America & 18 \\
\hline Oceania & 7 \\
\hline Africa & 0 \\
\hline Total & $\mathbf{1 0 0}$ \\
\hline
\end{tabular}

In addition, publications from Asia, Europe and the Americas, as well as multi-continental publications, confirm global interest in the subject. 
Table 1.4 lists the research methods used in the analysed papers, with the development of models/architecture predominating: $26.2 \%$ (22 papers) out of all the papers analysed.

Table 1.4. Methodologies used in the papers analysed

\begin{tabular}{|c|c|c|}
\hline Methodology & Papers & $\%$ \\
\hline Model / architecture development & $\begin{array}{l}\text { Brant and Sundaram (2015), Carrillo et al. } \\
\text { (2014), Chen et al. (2016), Cheng et al. } \\
\text { (2014), Duan and Liu (2016), Abedi (2016), } \\
\text { Akbaripour et al. (2015), Kong et al. (2015), } \\
\text { Lee (2017), Li et al. (2013), Li et al. (2015a), } \\
\text { Lin et al. (2015), Liu et al. (2014), Mo and } \\
\text { Lorchirachoonkul (2011), Mourtzis et al. } \\
\text { (2016), Andreadis et al. (2015), Oliveira et al. } \\
\text { (2013), Singh et al. (2015), Wu et al. (2015), } \\
\text { Xing et al. (2016), Yang et al. (2016), Yue et } \\
\text { al. (2015) }\end{array}$ & 26.2 \\
\hline $\begin{array}{l}\text { Literature review/Elaboration of theoretical } \\
\text { framework }\end{array}$ & $\begin{array}{l}\text { Abedi et al. (2013), Christauskas and } \\
\text { Miseviciene (2012), Golightly et al. (2016), } \\
\text { Harris et al. (2015), Li et al. (2013), Lu and } \\
\text { Xu (2017), Lyu et al. (2017), Pattnayak and } \\
\text { Pradhan (2016), Radke and Tseng (2015), } \\
\text { Azevedo et al. (2017), Tien (2011), } \\
\text { Babiceanu and Seker (2016), Wu et al. } \\
\text { (2013), Xia et al. (2016), Bi and Cochran } \\
\text { (2014) }\end{array}$ & 17.9 \\
\hline Development of Tool / Platform / Computer system & $\begin{array}{l}\text { Chen et al. (2015), Chiu et al. (2013), } \\
\text { Demirkan et al. (2010), Gupta and Jones } \\
\text { (2014), Helo et al. (2014), Ko et al. (2016), Li } \\
\text { et al. (2015b), Mourtzis et al. (2016), Tao et } \\
\text { al. (2011), Valilai and Houshmand (2013), } \\
\text { Wang et al. (2015), Wang et al. (2017), } \\
\text { Wang and Wang (2014), Yan et al. (2014), } \\
\text { Yang and Lin (2016) }\end{array}$ & 17.9 \\
\hline Case study & $\begin{array}{l}\text { Chen et al. (2014), Dehne et al. (2015), } \\
\text { Giriraj and Muthu (2013), Givehchi et al. } \\
\text { (2016), Hao and Helo (2017), Huang et al. } \\
\text { (2017), Leukel et al. (2011), Mezgár and } \\
\text { Rauschecker (2014), Sharma and Shah } \\
\text { (2015), Wang and Xu (2013) }\end{array}$ & 11.9 \\
\hline Simulation & $\begin{array}{l}\text { Cheng et al. (2017), Lee (2017), Liu et al. } \\
\text { (2017), Mehrsai et al. (2013), } \\
\text { Schlechtendahl et al. (2017), Tao et al. } \\
\text { (2017), Thekinen and Panchal (2016), Wang } \\
\text { et al. (2016) }\end{array}$ & 9.5 \\
\hline Hypothesis test & $\begin{array}{l}\text { Bruque et al. (2015), Bruque et al. (2016), Liu } \\
\text { et al. (2016), Schniederjans et al. (2016), } \\
\text { Schniederjans and Hales (2016), } \\
\text { Subramanian et al. (2015), Subramanian } \\
\text { and Abdulrahman (2017) }\end{array}$ & 8.3 \\
\hline \multicolumn{2}{|l|}{ Other (less than 7 items) } & 8.3 \\
\hline \multicolumn{2}{|l|}{ Total } & 100 \\
\hline
\end{tabular}

A significant number of papers adopted other research methodologies, such as literature reviews, the development of computer tools, simulations, hypothesis testing, etc. This shows that this study's topic of interest has been investigated from several different methodological perspectives. 
Table 1.5 shows the classification of the analysed papers into the main research topics (level 1), research lines (level 2) and research sublines (level 3) identified and used in the categorization. Data show that the "processes and activities integration" group stands out as the most studied topic to date, with $51.6 \%$ of the analysed papers. "Technology and system integration" ranks second by volume of published papers, with $25.8 \%$ of the research papers, and finally "SC partner integration", with $22.6 \%$ of analysed papers, is the group that has received the least attention from researchers to date.

Table 1.5. Literature classification according to main research topics

\begin{tabular}{|c|c|c|c|c|}
\hline $\begin{array}{l}\text { Main topic } \\
\text { (Level 1) }\end{array}$ & $\begin{array}{l}\text { Research line } \\
\quad \text { (Level 2) }\end{array}$ & $\begin{array}{l}\text { Research subline } \\
\text { (Level 3) }\end{array}$ & Authors & $\%$ \\
\hline \multirow{13}{*}{$\begin{array}{l}\text { CC and SC's } \\
\text { process and } \\
\text { activity } \\
\text { Integration }\end{array}$} & \multirow{4}{*}{ Manufacturing } & $\begin{array}{l}\text { Computer support } \\
\text { platform }\end{array}$ & $\begin{array}{l}\text { Brant and Sundaram (2015), Chiu et al. } \\
\text { (2013), Givehchi et al. (2016), Lee } \\
\text { (2017), Lu and Xu (2017), Tao et al. } \\
\text { (2017), Wang and Wang (2014) }\end{array}$ & 7.5 \\
\hline & & Human factors & $\begin{array}{l}\text { Golightly et al. (2016), Hao and Helo } \\
\text { (2017), Mourtzis et al. (2016) }\end{array}$ & 3.2 \\
\hline & & $\begin{array}{l}\text { Implementation } \\
\text { models }\end{array}$ & $\begin{array}{l}\text { Abedi (2016), Akbaripour et al. (2015), } \\
\text { Azevedo et al. (2017), Liu et al. (2014), } \\
\text { Liu et al. (2017), Mezgár and } \\
\text { Rauschecker (2014), Paniti (2014), } \\
\text { Thekinen and Panchal (2016), Valilai } \\
\text { and Houshmand (2013), Wang et al. } \\
\text { (2016), Wang and Xu (2013), Wu et al. } \\
\text { (2013), Wu et al. (2015), Xu (2012) }\end{array}$ & 15.1 \\
\hline & & $\begin{array}{l}\text { Industrial Physical } \\
\text { Cyber Systems } \\
\text { (ICPS) }\end{array}$ & $\begin{array}{l}\text { Babiceanu and Seker (2016), Giriraj and } \\
\text { Muthu (2013), Lee (2017), Simmhan et } \\
\text { al. (2013), Wang et al. (2017), Yue et al. } \\
(2015)\end{array}$ & 6.5 \\
\hline & \multirow{3}{*}{ Logistics } & Distribution & $\begin{array}{l}\text { Harris et al. (2015), Kong et al. (2015), Li } \\
\text { et al. (2013), Oliveira et al. (2013), Pan } \\
\text { et al. (2010), Wang et al. (2015) }\end{array}$ & 6.5 \\
\hline & & Purchases & Lee $(2017)$ & 1.1 \\
\hline & & Warehouse & $\begin{array}{l}\text { Gupta and Jones (2014), Yan et al. } \\
(2014)\end{array}$ & 2.2 \\
\hline & \multirow{3}{*}{$\begin{array}{l}\text { Design / } \\
\text { Development }\end{array}$} & Product modeling & Lyu et al. (2017) & 1.1 \\
\hline & & Collaborative design & $\begin{array}{l}\text { Andreadis et al. (2015), Wu et al. (2015), } \\
\text { Xia et al. (2016) }\end{array}$ & 3.2 \\
\hline & & Resource allocation & Thekinen and Panchal (2016) & 1.1 \\
\hline & \multirow{2}{*}{ Financial } & Accounting & Christauskas and Miseviciene (2012) & 1.1 \\
\hline & & E-payment & Yang and Lin (2016) & 1.1 \\
\hline & $\begin{array}{l}\text { Marketing/ } \\
\text { Commercial }\end{array}$ & Commercialization & Dehne et al. (2015), Li et al. (2015b) & 2.2 \\
\hline \multicolumn{4}{|l|}{ SUBTOTAL } & 51.6 \\
\hline \multirow{3}{*}{$\begin{array}{l}\text { CC and SC's } \\
\text { technology } \\
\text { and system } \\
\text { Integration }\end{array}$} & \multirow{3}{*}{$\begin{array}{l}\text { Intra- } \\
\text { organizational }\end{array}$} & Cloud + ERP & $\begin{array}{l}\text { Chen et al. (2015), Helo et al. (2014), } \\
\text { Sharma and Shah (2015) }\end{array}$ & 3.2 \\
\hline & & Cloud + CAM/FMS & $\begin{array}{l}\text { Bi and Cochran (2014), Chen et al. } \\
\text { (2014), Cheng et al. (2017), Mourtzis et } \\
\text { al. (2016), Schlechtendahl et al. (2017), } \\
\text { Tao et al. (2011), Yang et al. (2016) }\end{array}$ & 7.5 \\
\hline & & RFID & $\begin{array}{l}\text { Gupta and Jones (2014), Ko et al. } \\
\text { (2016), Lin et al. (2015), Mo and } \\
\text { Lorchirachoonkul (2011), Pattnayak and } \\
\text { Pradhan (2016) }\end{array}$ & 5.4 \\
\hline
\end{tabular}




\begin{tabular}{|c|c|c|c|c|}
\hline & \multirow[t]{2}{*}{$\begin{array}{l}\text { Inter- } \\
\text { organizational }\end{array}$} & $\begin{array}{l}\text { Cloud }+ \text { Web } \\
\text { technologies }\end{array}$ & $\begin{array}{l}\text { Bruque et al. (2015), Carrillo et al. } \\
\text { (2014), Chen et al. (2016), Li et al. } \\
\text { (2015a), Li et al. (2015b), Singh et al. } \\
\text { (2015) }\end{array}$ & 6.5 \\
\hline & & Multi-Clouds & $\begin{array}{l}\text { Li et al. (2013), Sharma and Shah } \\
\text { (2015), Wang et al. (2015) }\end{array}$ & 3.2 \\
\hline \multicolumn{4}{|l|}{ SUBTOTAL } & 25.8 \\
\hline \multirow{7}{*}{$\begin{array}{l}\text { CC and SC's } \\
\text { partner } \\
\text { Integration }\end{array}$} & \multirow{3}{*}{ Suppliers } & $\begin{array}{l}\text { Coordination / } \\
\text { partnership }\end{array}$ & $\begin{array}{l}\text { Demirkan et al. (2010), Duan and Liu } \\
\text { (2016), Liu et al. (2016), Radke and } \\
\text { Tseng (2015), Schniederjans et al. } \\
\text { (2016), Subramanian and Abdulrahman } \\
\text { (2017) }\end{array}$ & 6.5 \\
\hline & & Operating results & Abedi et al. (2013), Bruque et al. (2016) & 2.2 \\
\hline & & $\begin{array}{l}\text { Economic and } \\
\text { environmental } \\
\text { factors }\end{array}$ & $\begin{array}{l}\text { Schniederjans and Hales (2016), } \\
\text { Subramanian et al. (2015), Xing et al. } \\
\text { (2016) }\end{array}$ & 3.2 \\
\hline & \multirow{2}{*}{$\begin{array}{l}\text { Internal/ } \\
\text { Departmental }\end{array}$} & Operating results & $\begin{array}{l}\text { Abedi et al. (2013), Bruque et al. (2016), } \\
\text { Cheng et al. (2014) }\end{array}$ & 3.2 \\
\hline & & $\begin{array}{l}\text { Interdepartmental } \\
\text { collaboration }\end{array}$ & Duan and Liu (2016), Leukel et al. (2011) & 2.2 \\
\hline & \multirow{2}{*}{ Customers } & Operating results & $\begin{array}{l}\text { Bruque et al. (2016), Wang et al. (2017), } \\
\text { Tien (2011) }\end{array}$ & 3.2 \\
\hline & & $\begin{array}{c}\text { Coordination / } \\
\text { partnership }\end{array}$ & Duan and Liu (2016), Leukel et al. (2011) & 2.2 \\
\hline \multicolumn{4}{|l|}{ SUBTOTAL } & 22.6 \\
\hline \multicolumn{4}{|l|}{ TOTAL } & 100 \\
\hline
\end{tabular}

The "Implementation Models", "Computer support platform" and "Cloud + CAM/FMS" subgroups were the most addressed research sublines in the analysed papers, representing a sum total of $30.1 \%$. These were followed by the "Industrial Physical Cyber Systems (ICPS)", "Distribution", "Cloud + Web technologies" and "Coordination/partnership" subgroups, with $26 \%$ of the analysed publications.

\subsubsection{LITERATURE CLASSIFICATION AND ANALYSIS: MAIN TOPICS AND RESEARCH LINES/SUBLINES}

This section gives literature classification and analysis results. The three main research topics are presented with their research lines and within them, the detected research sublines. Tables for each of the main topics classify papers into research lines and sublines. Tables are presented for each section showing the integration flows detected in the analysed papers. Flows considered (information flow -INF-, physical flow -PHYand financial flow -FIN) are indicated, with which ever SCI dimension is being addressed in the papers marked with an "X". Each paper's contribution to the literature is also shown. Finally, papers that consider information, physical, and financial flow integration are analysed. 


\subsubsection{Research topic one: Cloud computing and supply chain process and activity}

integration

In this research topic, the following research directions have been identified in relation to $\mathrm{CC}$ and SCl: (1) manufacturing integration; (2) logistics integration; design/development integration; (4) financial services integration, and (5) marketing/commercial integration. The following tables (Tables 1.6, 1.7, 1.8, 1.9 and 1.10) show the grouping of the papers into research lines and research sublines.

Table 1.6. Papers related to manufacturing integration research line and its sublines

\begin{tabular}{|c|c|c|c|c|}
\hline \multicolumn{5}{|r|}{ Computer support platform } \\
\hline Authors & INF & $\mathrm{PHY}$ & FIN & Contribution to literature \\
\hline $\begin{array}{l}\text { Brant and } \\
\text { Sundaram } \\
(2015)\end{array}$ & $X$ & & & $\begin{array}{l}\text { Proposal of a computer platform based on CC for the manufacturing } \\
\text { integration (micro metal additives) }\end{array}$ \\
\hline $\begin{array}{l}\text { Chiu et al. } \\
(2013)\end{array}$ & $X$ & $\mathrm{X}$ & & $\begin{array}{l}\text { Development of a platform for services and flows management } \\
\text { (materials and information) }\end{array}$ \\
\hline $\begin{array}{l}\text { Givehchi et } \\
\text { al. (2016) }\end{array}$ & $\mathrm{x}$ & $x$ & & $\begin{array}{l}\text { Implementation of a platform based on Cloud-DPP methodology, in } \\
\text { which it supports the manufacturing flows }\end{array}$ \\
\hline Lee (2017) & $X$ & $\mathrm{X}$ & & $\begin{array}{l}\text { Creation of a Cloud architecture integrated with loT to overcome } \\
\text { mixed flow problems through a centralized control server. }\end{array}$ \\
\hline $\begin{array}{l}\text { Lu and Xu } \\
\text { (2017) }\end{array}$ & $X$ & $\mathrm{X}$ & & $\begin{array}{l}\text { Develop a computer system for a network environment integrated } \\
\text { with Cloud }\end{array}$ \\
\hline $\begin{array}{l}\text { Tao et al. } \\
\text { (2017) }\end{array}$ & $\mathrm{X}$ & $\mathrm{X}$ & & $\begin{array}{l}\text { Creation of a manufacturing service simulation platform (SDMSim) } \\
\text { which includes the services integration and manufacturing tasks. }\end{array}$ \\
\hline $\begin{array}{l}\text { Wang and } \\
\text { Wang } \\
(2014)\end{array}$ & $X$ & $\mathrm{X}$ & & $\begin{array}{l}\text { Introduction of an integration platform for waste-based re- } \\
\text { manufacturing of electrical and electronic equipment (WEEE) and } \\
\text { based on the concept of Cloud manufacturing }\end{array}$ \\
\hline \multicolumn{5}{|r|}{ Human factors } \\
\hline Authors & INF & $\mathrm{PHY}$ & FIN & Contribution to literature \\
\hline $\begin{array}{l}\text { Golightly et } \\
\text { al. (2016) }\end{array}$ & $\mathrm{x}$ & & & $\begin{array}{l}\text { Research on the importance of human factors in the cloud } \\
\text { manufacturing integration }\end{array}$ \\
\hline $\begin{array}{l}\text { Hao and } \\
\text { Helo } \\
(2017)\end{array}$ & $\mathrm{X}$ & $x$ & & $\begin{array}{l}\text { Description of a practical demonstration using loT, Wearable, } \\
\text { Augmented Reality and Cloud Computing to support worker } \\
\text { activities and communication in discrete factories }\end{array}$ \\
\hline $\begin{array}{l}\text { Mourtzis et } \\
\text { al. }(2016)\end{array}$ & $x$ & & & $\begin{array}{l}\text { Creation of a smart factory-inspired social networking framework in } \\
\text { which employees collaborate to address product and production } \\
\text { issues }\end{array}$ \\
\hline \multicolumn{5}{|r|}{ Models implementation } \\
\hline Authors & INF & $\mathrm{PHY}$ & FIN & Contribution to literature \\
\hline $\begin{array}{l}\text { Abedi } \\
(2016)\end{array}$ & $X$ & $\mathrm{x}$ & & $\begin{array}{l}\text { Development of a CC-based building information modeling and } \\
\text { system architecture (CACCBIM) architecture }\end{array}$ \\
\hline $\begin{array}{l}\text { Akbaripour } \\
\text { et al. } \\
(2015)\end{array}$ & $x$ & $\mathrm{X}$ & & $\begin{array}{l}\text { Development of a prospective conceptual model called "The Global } \\
\text { Cloud-Based Supply Chain" that can overcome or mitigate the } \\
\text { problems and risks associated with supply chain processes } \\
\text { worldwide }\end{array}$ \\
\hline $\begin{array}{l}\text { Azevedo et } \\
\text { al. (2017) }\end{array}$ & $\mathrm{x}$ & $x$ & & $\begin{array}{l}\text { Creation of a model based on CC to support the complete life cycle } \\
\text { of the extended manufacturing companies, from the creation to the } \\
\text { phases of operation and dissolution }\end{array}$ \\
\hline $\begin{array}{l}\text { Liu et al. } \\
\text { (2014) }\end{array}$ & $x$ & $x$ & & $\begin{array}{l}\text { Creation of a virtualization and resource sharing model based on } \\
\text { CC to support the integration of complex manufacturing and } \\
\text { underlying resources }\end{array}$ \\
\hline
\end{tabular}




\begin{tabular}{|c|c|c|c|c|}
\hline $\begin{array}{l}\text { Liu et al. } \\
\text { (2017) }\end{array}$ & $\mathrm{x}$ & & & $\begin{array}{l}\text { Creation of a multi-tasking Cloud manufacturing model that } \\
\text { incorporates the workload modeling of the task }\end{array}$ \\
\hline $\begin{array}{l}\text { Mehrsai et } \\
\text { al. (2013) }\end{array}$ & $\mathrm{X}$ & $\mathrm{X}$ & & $\begin{array}{l}\text { Introduction of a Cloud-based framework for input and output } \\
\text { manufacturing to support the production of individualized products } \\
\text { in the turbulent global marketplace }\end{array}$ \\
\hline $\begin{array}{l}\text { Mezgár } \\
\text { and } \\
\text { Rauscheck } \\
\text { er (2014) }\end{array}$ & $\mathrm{X}$ & $\mathrm{x}$ & & $\begin{array}{l}\text { Introduction of a model for the connection of network manufacturing } \\
\text { enterprises and cloud-based IT systems with reference to } \\
\text { interoperability }\end{array}$ \\
\hline $\begin{array}{l}\text { Paniti } \\
(2014)\end{array}$ & $\mathrm{x}$ & $\mathrm{x}$ & & $\begin{array}{l}\text { Creation of a new algorithm to control the tools trajectory on } \\
\text { manufacturing processes }\end{array}$ \\
\hline $\begin{array}{l}\text { Thekinen } \\
\text { and } \\
\text { Panchal } \\
(2016)\end{array}$ & $\mathrm{x}$ & $\mathrm{x}$ & & $\begin{array}{l}\text { Creation of a model to analyse the allocation and availability of } \\
\text { manufacturing resources through Delayed Acceptance (DA), } \\
\text { Superior Trading Cycle (TTC) and Munkres }\end{array}$ \\
\hline $\begin{array}{l}\text { Valilai and } \\
\text { Houshman } \\
\text { d (2013) }\end{array}$ & $\mathrm{x}$ & $\mathrm{X}$ & & $\begin{array}{l}\text { Suggestion of a service-oriented approach from CC for the } \\
\text { integration of product data based on the STEP standard to support } \\
\text { XML data structures }\end{array}$ \\
\hline $\begin{array}{l}\text { Wang et al. } \\
\quad(2016)\end{array}$ & $\mathrm{x}$ & $\mathrm{X}$ & & $\begin{array}{l}\text { Presentation of an intelligent factory model that incorporates } \\
\text { network control, Cloud and industrial monitoring terminals with } \\
\text { intelligent integration (machines, conveyors and products) }\end{array}$ \\
\hline $\begin{array}{l}\text { Wang and } \\
\text { Xu (2013) }\end{array}$ & $\mathrm{X}$ & $\mathrm{X}$ & & $\begin{array}{l}\text { Creation of a service-oriented integrated (Interoperable Cloud } \\
\text { manufacturing system) }\end{array}$ \\
\hline $\begin{array}{l}\text { Wu et al. } \\
(2013)\end{array}$ & $\mathrm{X}$ & $\mathrm{x}$ & & $\begin{array}{l}\text { Review of the state of the research on critical fields for the } \\
\text { enablement of cloud manufacturing }\end{array}$ \\
\hline $\begin{array}{l}\text { Wu et al. } \\
(2015)\end{array}$ & $\mathrm{X}$ & $\mathrm{X}$ & & $\begin{array}{l}\text { Comparison of the existing definitions of Cloud manufacturing to } \\
\text { identify the essential characteristics of each one }\end{array}$ \\
\hline Xu (2012) & $\mathrm{X}$ & $\mathrm{x}$ & & $\begin{array}{l}\text { Suggestion of a model that offers two adoptions types of CC in the } \\
\text { manufacturing sector }\end{array}$ \\
\hline \multicolumn{5}{|c|}{ Industrial Physical Cyber Systems (ICPS) } \\
\hline Authors & INF & PHY & FIN & Contribution to literature \\
\hline $\begin{array}{l}\text { Babiceanu } \\
\text { and Seker } \\
(2016)\end{array}$ & $\mathrm{x}$ & $\mathrm{x}$ & & $\begin{array}{l}\text { Review of the current state of literature for virtualization and cloud- } \\
\text { based services for manufacturing systems and the Big Data } \\
\text { Analytics' use for the planning, control of manufacturing operations }\end{array}$ \\
\hline $\begin{array}{l}\text { Giriraj and } \\
\text { Muthu } \\
\text { (2013) }\end{array}$ & $\mathrm{x}$ & & & $\begin{array}{l}\text { Research on the information flow from the assembly process to the } \\
\text { company offices }\end{array}$ \\
\hline Lee (2017) & $\mathrm{X}$ & $\mathrm{X}$ & & $\begin{array}{l}\text { Suggestion of a new and effective cybernetic-physical system } \\
\text { architecture to support the manufacture of multiple sites and multiple } \\
\text { products }\end{array}$ \\
\hline $\begin{array}{l}\text { Simmhan } \\
\text { et al. } \\
\text { (2013) }\end{array}$ & $\mathrm{X}$ & & & $\begin{array}{l}\text { Creation of a scalable software model for the SmartGrid cyber } \\
\text { system (use Cloud technologies to support the information flows } \\
\text { integration) }\end{array}$ \\
\hline $\begin{array}{l}\text { Wang et al. } \\
\text { (2017) }\end{array}$ & $\mathrm{x}$ & $X$ & & $\begin{array}{l}\text { Review of recent approaches to Cloud manufacturing and Cloud } \\
\text { robotics }\end{array}$ \\
\hline $\begin{array}{l}\text { Yue et al. } \\
(2015)\end{array}$ & $X$ & $X$ & & $\begin{array}{l}\text { Creation of a model to service-oriented to Industrial Cybernetic } \\
\text { Systems (SCFI) }\end{array}$ \\
\hline
\end{tabular}


Table 1.7. Papers related to logistics integration research line and its sublines

\begin{tabular}{|c|c|c|c|c|}
\hline \multicolumn{5}{|r|}{ Distribution } \\
\hline Authors & INF & PHY & FIN & Contribution to literature \\
\hline $\begin{array}{l}\text { Harris et } \\
\text { al. (2015) }\end{array}$ & $\mathrm{x}$ & $\mathrm{x}$ & & $\begin{array}{l}\text { Identification of the possible reasons for a slow CC adoption for } \\
\text { distribution integration and evaluate how recent technological } \\
\text { advances could overcome these barriers }\end{array}$ \\
\hline $\begin{array}{l}\text { Kong et al. } \\
\text { (2015) }\end{array}$ & $x$ & $\mathrm{x}$ & & $\begin{array}{l}\text { Creation of a Cloud-based platform for the logistics center auction } \\
\text { (CALC) and propose of a tools implementation to increase flexibility } \\
\text { and integration for logistics operations }\end{array}$ \\
\hline $\begin{array}{l}\text { Li et al. } \\
(2013)\end{array}$ & $x$ & $x$ & & $\begin{array}{l}\text { Research the resource virtualization and encapsulation services of } \\
\text { a logistics center (technologies of resource expression and } \\
\text { encapsulation services) }\end{array}$ \\
\hline $\begin{array}{l}\text { Oliveira et } \\
\text { al. (2013) }\end{array}$ & $\mathrm{x}$ & $x$ & & $\begin{array}{l}\text { Creation of a smart model to obtain the vehicles position through } \\
\text { the use of mobile devices }\end{array}$ \\
\hline $\begin{array}{l}\text { Pan et al. } \\
(2010)\end{array}$ & $\mathrm{X}$ & & & $\begin{array}{l}\text { Definition of a framework for intelligent } 4 \mathrm{PL} \text { integration, with basic } \\
\text { capabilities to assist in making timely decisions in the logistics } \\
\text { scenarios management }\end{array}$ \\
\hline $\begin{array}{l}\text { Wang et al. } \\
\text { (2015) }\end{array}$ & $\mathrm{x}$ & & & $\begin{array}{l}\text { Analysis of the related concepts and characteristics of Cloud } \\
\text { service in logistics }\end{array}$ \\
\hline \multicolumn{5}{|r|}{ Purchases } \\
\hline Authors & INF & PHY & FIN & Contribution to literature \\
\hline Lee (2017) & & $\mathrm{x}$ & & $\begin{array}{l}\text { Creation of an optimization model based on Genetic Algorithm (GA) } \\
\text { and Cloud support for forwarding customer orders }\end{array}$ \\
\hline \multicolumn{5}{|r|}{ Warehouses } \\
\hline Authors & INF & PHY & FIN & Contribution to literature \\
\hline $\begin{array}{l}\text { Gupta and } \\
\text { Jones } \\
(2014)\end{array}$ & $\mathrm{x}$ & $\mathrm{x}$ & & $\begin{array}{l}\text { Analysis of the feasibility of a Cloud-based warehouse } \\
\text { management system (WMS) that continuously and autonomously } \\
\text { captures RFID tagged inventory and distributes data management } \\
\text { processes }\end{array}$ \\
\hline $\begin{array}{l}\text { Yan et al. } \\
(2014)\end{array}$ & $x$ & $x$ & & $\begin{array}{l}\text { Analysis of the warehouse integration based on Cloud of Things, in } \\
\text { order to provide SC's flexibility and agility }\end{array}$ \\
\hline
\end{tabular}

Table 1.8. Papers related to design/process development integration research/sublines

\begin{tabular}{|c|c|c|c|c|}
\hline \multicolumn{5}{|r|}{ Product modeling } \\
\hline Authors & INF & PHY & FIN & Contribution to literature \\
\hline $\begin{array}{l}\text { Lyu et al. } \\
\text { (2017) }\end{array}$ & $\mathrm{x}$ & & & $\begin{array}{l}\text { Research the recent advances on product modeling, information } \\
\text { technologies (such as CC) and product development processes. }\end{array}$ \\
\hline \multicolumn{5}{|r|}{ Collaborative design } \\
\hline Authors & INF & PHY & FIN & Contribution to literature \\
\hline $\begin{array}{l}\text { Andreadi } \\
\text { s et al. } \\
(2015)\end{array}$ & $\mathrm{X}$ & & & $\begin{array}{l}\text { Analysis of the CC use on the process of mechanical drawing and } \\
\text { design }\end{array}$ \\
\hline $\begin{array}{l}\text { Wu et al. } \\
(2015)\end{array}$ & $\mathrm{x}$ & $\mathrm{x}$ & & $\begin{array}{l}\text { Suggestion of a collaborative design architecture with integrated } \\
\text { manufacturing services, information management and supply chain } \\
\text { integration }\end{array}$ \\
\hline $\begin{array}{c}\text { Xia et al. } \\
(2016)\end{array}$ & $\mathrm{x}$ & & & $\begin{array}{l}\text { Elaboration of a framework for the closed loop design evolution in } \\
\text { order to achieve a continuous improvement of an engineering system }\end{array}$ \\
\hline \multicolumn{5}{|r|}{ Resource allocation } \\
\hline Authors & INF & PHY & FIN & Contribution to literature \\
\hline $\begin{array}{l}\text { Thekinen } \\
\text { and } \\
\text { Panchal } \\
\text { (2016) }\end{array}$ & $\mathrm{x}$ & $\mathrm{x}$ & & $\begin{array}{l}\text { Creation of a model to analyse the design's allocation and availability } \\
\text { and manufacturing resources across the Cloud }\end{array}$ \\
\hline
\end{tabular}


Table 1.9. Papers related to financial processes integration research line and its sublines

\begin{tabular}{|c|c|c|c|l|}
\hline \multicolumn{2}{|c|}{ Accounting } \\
\hline Authors & INF & PHY & FIN & Contribution to literature \\
\hline $\begin{array}{c}\text { Christaus } \\
\text { kas and } \\
\text { Misevicie } \\
\text { ne (2012) }\end{array}$ & $\mathrm{X}$ & & $\mathrm{X}$ & Analysis of CC in small and medium enterprises of Lithuania \\
\hline \multicolumn{1}{|c|}{ Online payment system } \\
\hline $\begin{array}{c}\text { Authors } \\
\text { Lin } \\
\text { (2016) }\end{array}$ & INF & PHY & FIN & Contribution to literature \\
\hline
\end{tabular}

Table 1.10. Papers related to marketing/commercial integration research line and its sublines

\begin{tabular}{|c|c|c|c|l|}
\hline \multicolumn{3}{|c|}{ Commercialization } \\
\hline Authors & INF & PHY & FIN & Contribution to literature \\
\hline $\begin{array}{c}\text { Dehne et } \\
\text { al. (2015) }\end{array}$ & X & & & $\begin{array}{l}\text { Definition of the CR-OLAP concept, an efficient system for complex } \\
\text { queries that need to analyse large data stores }\end{array}$ \\
\hline $\begin{array}{c}\text { Li et al. } \\
\text { (2015b) }\end{array}$ & $X$ & & $\begin{array}{l}\text { Development of an enterprise network integration architecture } \\
\text { oriented to the convergence of data with relative enabling } \\
\text { technologies }\end{array}$ \\
\hline
\end{tabular}

\section{Cloud computing and manufacturing integration}

The literature findings indicate that "manufacturing integration" is the most addressed research line to date. Table 1.6 shows that several authors (e.g. Chiu et al., 2013; Brant and Sundaram, 2015; Lu and Xu, 2017) have proposed CC-based IT platforms for process integration in the manufacturing industry. The proposed platforms serve as a tool to support information and physical flows along the supply chain. The results of these authors' research show that when used in conjunction with platforms or computer systems, CC adoption is a facilitator of the integration of related data, tasks, services or resources. The interrelationship between human factors, CC use and manufacturing integration has also been analysed in the literature (Golightly et al., 2016; Hao and Helo, 2017; Mourtzis et al., 2016). The results shows that CC use supports human factors, which, in turn, generates positive impacts on the flow of information across manufacturing processes. In addition, several authors (e.g., Paniti, 2014; Thekinen and Panchal, 2016; Azevedo et al., 2017) have proposed models or CC implementation architectures for manufacturing process integration. These models help both companies and academics better understand how to implement CC for manufacturing process integration. In general terms, they are based on the assertion that $\mathrm{CC}$ can positively 
impact efficient monitoring by improving coordination, collaboration and communication in manufacturing. Test results of the models show that $\mathrm{CC}$ has a positive effect in several fields, e.g. integrating information between manufacturing companies (Mezgár and Rauschecker, 2014), resource sharing and production scalability (Wang and Xu, 2013; Paniti 2014; Liu et al., 2014). Finally, in relation to Industrial Physical Cyber Systems (ICPS), authors such as Giriraj and Muthu (2013), Simmhan et al. (2013), Yue et al. (2015), Lee (2017) and Wang et al. (2017) have suggested that if these systems are used in conjunction with $\mathrm{CC}$, they can support the manufacture of multiple products at multiple sites by integrating the information and physical flows between them. Real time information flow assurance in the assembly process has been investigated and it has been stated that CC supports the integration of a large number of mixed applications, and a vast amount of data generated by sensors in real time (e.g., Yue et al., 2015).

\section{Cloud computing and logistics integration}

"Logistics integration" is another research line that has received considerable attention from researchers, especially the "distribution integration" research subline (Table 1.7). The frameworks, proposed models and concepts led to a consensus that CC can support information and physical flows. Consequently, communication between supply chain members (such as transport companies, suppliers and customers) may be enabled by CC use (Pan et al., 2010; Li et al., 2013; Oliveira et al., 2013; Harris et al., 2015; Kong et al., 2015; Wang et al., 2015). In addition, as it is an efficient method of storing and processing purchase channel data and expediting the delivery of purchased products (Lee, 2017), CC can be used as a technological tool to support purchase integration through a beneficial effect on purchase forecasting. CC also has a positive effect on warehouse integration, as it integrates both the information flow and the physical flow by providing flexibility and agility, and facilitating resource sharing among participants throughout the supply chain life cycle (Gupta and Jones, 2014; Yan et al., 2014).

\section{Cloud computing and design/development integration}

Limited attention has been given in the literature to the "design/development integration" line compared to manufacturing integration and logistics integration (Table 1.8). The literature findings show that $\mathrm{CC}$ has a positive impact on product modeling (Lyu et al., 2016), collaborative design (Andreadis et al., 2015; Wu et al., 2015, Xia et al., 2016), and resource allocation (Thekinen and Panchal, 2016). Companies have real-time access to customer demand data by virtue of the information flow integration that $\mathrm{CC}$ 
provides (Xia et al., 2016). Thus, they can adapt their production to variations in demand and respond to their customers' real needs (Thekinen and Panchal, 2016; Wu et al., 2015). The papers that address "design/development integration" determine that CC can support the new product design and development process through customer-company integration.

\section{Cloud computing and financial services integration}

Table 1.9 shows that "Financial services integration" is the research line to which the smallest number of studies has been devoted in the "process and activities integration" research topic. However, the limited literature in this area indicates that CC use can improve financial flow integration by optimizing payment processes and real-time cash flow between partners (Yang and Lin, 2016). There is a noticeable increase in the speed of these flows as a result of CC's rapid data analysis and its ability to provide access to multiplatform data with instant information retrieval of payments made, costs and availability of products to customers (Christauskas and Miseviciene, 2012; Yang and Lin, 2016). CC can therefore improve the management of production costs, accounting activities and online payment systems (e-payment) via financial integration (Yang and Lin, 2016).

\section{Cloud computing and marketing/commercial integration}

The "marketing/commercial integration" research line has also received very little attention from researchers (Table 1.10). The few papers found in this line suggest that CC supports commercial integration by supporting purchasing and warehouse datarelated information and physical flows (Dehne et al., 2015; Li et al., 2015b). CC is an efficient tool for storing and processing purchase order data (orders) and can make the exchange of physical resources (products) more flexible and more agile along the entire supply chain (Dehne et al., 2015; Li et al., 2015b).

\section{Research findings in topic one}

Papers classified in this research topic find that CC provides process and activity integration throughout the supply chain (as it improves scalability, flexibility, agility, adaptation to changes, and supply chain planning). CC enables supply chain processes to be integrated at a lower cost, with a shorter deployment time, and with increased response speed while at the same time encourages innovation. Literature shows that CC has a strong impact on supply chain processes and activities, especially on efficiency in 
manufacturing integration and logistics integration. There is some evidence that $\mathrm{CC}$ can also have a positive impact on design/development integration in the supply chain, financial integration, and commercial integration, but the literature has devoted little attention to these fields, which highlights the need for further research in these areas.

Regarding to manufacturing integration in the supply chain, literature offers evidence that CC enhances supply chain flexibility and agility by improving real-time production and assembly processes through information sharing. CC enables rapid scalability of manufacturing resources, and part replenishment and management over the Internet in real time, while also improving manufacturing planning and optimization. Literature also shows that CC use likewise improves logistics integration, allowing supply chain members to communicate with transportation companies, suppliers and customers. CC use can increase logistical capacity by organizing and executing order processes, creating logistic networks, and improving transport management. Research on CC application for some Manufacturing and Logistics sub-lines, such as human resource integration, purchases integration and warehouse integration, needs to be further studied.

CC can also have a positive impact on design/development integration in supply chain, impacting the new product design and development process by supporting customercompany integration and allowing companies to have real-time access to customer demand information. Also, CC use can improve financial flow integration by optimizing payment processes and real-time cash flow between partners. In addition, CC supports commercial integration in the supply chain by supporting informational and physical flows related to purchasing and warehouse data. Model integration related to Products, Collaborative design, Resource allocation, E-payment, Accounting and Commercialization are sub-lines that lack scientific evidence regarding their relationship to $\mathrm{CC}$ use.

1.3.2.2. Research topic two: Cloud computing and supply chain technology and system integration

In this research topic the following research lines have been identified: (1) intraorganizational integration, and (2) inter-organizational integration. The following tables (Tables 1.11 and 1.12) show the grouping of the papers into research lines and research sublines. 
Table 1.11. Papers related to intra-organizational technology/system integration research line and its sublines

\begin{tabular}{|c|c|c|c|c|}
\hline \multicolumn{5}{|r|}{$C C+E R P$} \\
\hline Authors & INF & $\mathrm{PHY}$ & FIN & Contribution to literature \\
\hline $\begin{array}{l}\text { Chen et } \\
\text { al. }(2015)\end{array}$ & $\mathrm{X}$ & $X$ & $\mathrm{X}$ & $\begin{array}{l}\text { Definition of a Cloud ERP platform in which business customers can } \\
\text { select web services and customize a single ERP system to meet their } \\
\text { specific needs }\end{array}$ \\
\hline $\begin{array}{l}\text { Helo et } \\
\text { al. (2014) }\end{array}$ & $\mathrm{X}$ & & & $\begin{array}{l}\text { Creation of a CC-based manufacturing execution system (ERP/MES) } \\
\text { architecture that supports the real-time information flow between } \\
\text { departments and manufacturing processes }\end{array}$ \\
\hline $\begin{array}{l}\text { Sharma } \\
\text { and Shah } \\
(2015)\end{array}$ & $\mathrm{X}$ & & & $\begin{array}{l}\text { Analysis of the role of information technology (IT), ERP and CC } \\
\text { services to optimize the information sharing and improve the SC } \\
\text { productivity in small and medium-sized enterprises (SMEs) }\end{array}$ \\
\hline \multicolumn{5}{|r|}{$C C+C A M / F M S$} \\
\hline Authors & INF & $\mathrm{PHY}$ & FIN & Contribution to literature \\
\hline $\begin{array}{l}\text { Bi and } \\
\text { Cochran } \\
(2014)\end{array}$ & $\mathrm{X}$ & $X$ & & $\begin{array}{l}\text { Analysis of recent literature for Internet of Things (IOT) and their } \\
\text { applications (discuss in particular the Big Data and CC impact on } \\
\text { manufacturing systems) }\end{array}$ \\
\hline $\begin{array}{l}\text { Chen et } \\
\text { al. (2014) }\end{array}$ & $\mathrm{X}$ & $X$ & & $\begin{array}{l}\text { Creation of a new approach to Cloud manufacturing development } \\
\text { based on a four-layer SaaS model }\end{array}$ \\
\hline $\begin{array}{l}\text { Cheng et } \\
\text { al. (2017) }\end{array}$ & $\mathrm{X}$ & $X$ & & $\begin{array}{l}\text { Simulation of an offer-demand concept of manufacturing services in the } \\
\text { CC-based information system }\end{array}$ \\
\hline $\begin{array}{l}\text { Mourtzis } \\
\text { et al. } \\
(2016)\end{array}$ & $\mathrm{X}$ & $X$ & & $\begin{array}{l}\text { Creation of a model that combines enabling techniques such as } \\
\text { Internet of Things (IoT), CC and Big Data for optimization the } \\
\text { manufacturing systems }\end{array}$ \\
\hline $\begin{array}{l}\text { Schlechte } \\
\text { ndahl et } \\
\text { al. (2017) }\end{array}$ & $\mathrm{X}$ & $\mathrm{X}$ & & $\begin{array}{l}\text { Analysis of communication requirements for manufacturing control } \\
\text { system based on CC }\end{array}$ \\
\hline $\begin{array}{l}\text { Tao et al. } \\
(2011)\end{array}$ & $\mathrm{X}$ & $X$ & & $\begin{array}{l}\text { Analysis of four typical Cloud manufacturing service platforms (public, } \\
\text { private, community and hybrid Cloud) }\end{array}$ \\
\hline $\begin{array}{l}\text { Yang et } \\
\text { al. (2016) }\end{array}$ & $\mathrm{X}$ & $X$ & & $\begin{array}{l}\text { Creation of a method of selecting dynamic manufacturing service } \\
\text { through multiple clouds }\end{array}$ \\
\hline \multicolumn{5}{|r|}{$C C+R F I D$} \\
\hline Authors & INF & $\mathrm{PHY}$ & FIN & Contribution to literature \\
\hline $\begin{array}{l}\text { Gupta } \\
\text { and } \\
\text { Jones } \\
(2014)\end{array}$ & $X$ & $X$ & & $\begin{array}{l}\text { Analysis of the feasibility of a cloud-based warehouse management } \\
\text { system (WMS) that continuously and autonomously captures RFID } \\
\text { tagged inventory and distributes data management processes }\end{array}$ \\
\hline $\begin{array}{l}\text { Ko et al. } \\
(2016)\end{array}$ & $X$ & $X$ & & $\begin{array}{l}\text { Development of a cost-effective material tracking and management } \\
\text { system based on an integrated RFID service for automated tracking } \\
\text { with ubiquitous access }\end{array}$ \\
\hline $\begin{array}{l}\text { Lin et al. } \\
(2015)\end{array}$ & $X$ & $X$ & & $\begin{array}{l}\text { Creation of a cloud architecture for the RFID SC system, with a detailed } \\
\text { schema of authentication, transfer of ownership, retrieval of authority } \\
\text { and data sharing }\end{array}$ \\
\hline $\begin{array}{l}\text { Mo and } \\
\text { Lorchirac } \\
\text { hoonkul } \\
(2011)\end{array}$ & $\mathrm{X}$ & $\mathrm{X}$ & & $\begin{array}{l}\text { Creation of two RFID-based solutions to complement the virtualization } \\
\text { model and services in CC. }\end{array}$ \\
\hline $\begin{array}{l}\text { Pattnaya } \\
\text { k and } \\
\text { Pradhan } \\
\text { (2016) }\end{array}$ & $X$ & $X$ & & $\begin{array}{l}\text { Analysis of RFID transparency and the preamble of Cloud-based } \\
\text { service technology used in SC management to minimize business } \\
\text { costs }\end{array}$ \\
\hline
\end{tabular}


Table 1.12. Papers related to inter-organizational technology/system integration research line and its sublines

\begin{tabular}{|c|c|c|c|c|}
\hline \multicolumn{5}{|r|}{$C C+W e b$ Technologies } \\
\hline Authors & INF & $\mathrm{PHY}$ & FIN & Contribution to literature \\
\hline $\begin{array}{l}\text { Bruque et } \\
\text { al. (2015) }\end{array}$ & $\mathrm{X}$ & $\mathrm{X}$ & $\mathrm{X}$ & $\begin{array}{l}\text { Analysis of the two technologies effects, CC and Web } 2.0 \text {, on the } \\
\text { operational performance }\end{array}$ \\
\hline $\begin{array}{l}\text { Carrillo et } \\
\text { al. (2014) }\end{array}$ & $\mathrm{X}$ & $\mathrm{X}$ & & $\begin{array}{l}\text { Description of the improvements made by SCLOUDPY, a web system } \\
\text { for order flow management in SC }\end{array}$ \\
\hline $\begin{array}{l}\text { Chen et } \\
\text { al. (2016) }\end{array}$ & $\mathrm{X}$ & & & $\begin{array}{l}\text { Creation of a QoS (Web Service Composition) method based on CC, } \\
\text { through an optimization process to help users make flexible decisions }\end{array}$ \\
\hline $\begin{array}{l}\text { Li et al. } \\
(2015 a)\end{array}$ & $\mathrm{X}$ & & & $\begin{array}{l}\text { Introduction of the concepts of Data Portal (DP) and Collaboration } \\
\text { Agent }(\mathrm{CA}) \text {, which present a light and little-coupled infrastructure for } \\
\text { the integration of business networks }\end{array}$ \\
\hline $\begin{array}{l}\text { Li et al. } \\
\text { (2015b) }\end{array}$ & $\mathrm{X}$ & $\mathrm{X}$ & & $\begin{array}{l}\text { Creation of an integrated SC system for small businesses in Australia } \\
\text { - a service-oriented solution PHOENIX }\end{array}$ \\
\hline $\begin{array}{l}\text { Singh et } \\
\text { al. (2015) }\end{array}$ & $\mathrm{X}$ & & & $\begin{array}{l}\text { Development of an integrated system that uses CC and Web to } \\
\text { integrate CS members }\end{array}$ \\
\hline \multicolumn{5}{|r|}{ Multi-Clouds } \\
\hline Authors & INF & $\mathrm{PHY}$ & FIN & Contribution to literature \\
\hline $\begin{array}{l}\text { Li et al. } \\
(2013)\end{array}$ & $X$ & & & $\begin{array}{l}\text { Analysis of the development of CC from a technical and commercial } \\
\text { point of view (requirements and challenges of services and multi-cloud } \\
\text { integrations) }\end{array}$ \\
\hline $\begin{array}{l}\text { Sharma } \\
\text { and Shah } \\
(2015)\end{array}$ & $\mathrm{X}$ & $\mathrm{X}$ & & $\begin{array}{l}\text { Analysis of the information technology services role (such as Web } \\
\text { Technologies and CC) to improve the success and productivity of SC }\end{array}$ \\
\hline $\begin{array}{l}\text { Wang et } \\
\text { al. (2015) }\end{array}$ & $\mathrm{X}$ & $X$ & & $\begin{array}{l}\text { Development of a Cloud-based government procurement information } \\
\text { integration platform, including layers of physical resources, virtual } \\
\text { resource control and Cloud services, to solve problems in the } \\
\text { management of government procurement information resources }\end{array}$ \\
\hline
\end{tabular}

\section{Cloud computing and intra-organizational technology/system integration}

The literature findings indicate that "intra-organizational technology integration" is the most addressed research line in topic two. Table 1.11 shows that $\mathrm{CC}$ can be coupled with technologies such as ERP (Helo et al., 2014; Sharma and Shah; 2015; Chen et al., 2015); CAM/FMS (Tao et al., 2011; Bi and Cochran, 2014; Chen et al., 2014; Mourtzis et al., 2016; Yang et al., 2016; Cheng et al., 2017; Schlechtendahl et al., 2017) and RFID (Mo and Lorchirachoonkul, 2011; Gupta and Jones, 2014; Lin et al., 2015; Ko et al., 2016; Pattnayak and Pradhan, 2016). Authors such as Helo et al. (2014) and Sharma and Shah (2015) show that CC takes the form of an overarching management system with a unified user interface for different systems (e.g., ERPs and CRMs). In addition, Bi and Cochran (2014) and Mourtzis et al., (2016) indicate that CC can be combined with enabling techniques such as the Internet of Things (IoT) and Big Data to optimize and integrate supply chain processes. As such, CC integration with existing IT systems can have very positive effects on companies, including improvements to internal supply chain flexibility, deployment and accessibility, and the utilization of shared resources (Mo and Lorchirachoonkul, 2011; Gupta and Jones, 2014;Cheng et al., 2017). So, CC used in 
conjunction with intra-organizational technologies could reduce internal information distortions, increase the rate of resource use and, therefore, increase the efficiency of internal supply chain processes (e.g., Sharma and Shah, 2015; Lin et al. 2015; Pattnayak and Pradhan, 2016).

\section{Cloud computing and inter-organizational technology/system integration}

Table 1.12 shows that "Inter-organizational technology/system integration" is another research line that has received considerable attention from researchers, especially the "CC + Web Technologies" subline (Carrillo et al., 2014; Bruque et al., 2015; Li et al., 2015a; Li et al., 2015b; Singh et al., 2015; Chen et al., 2016). The literature findings also indicate that CC can even be combined with a set of clouds (multi-cloud) (Li et al., 2013; Sharma and Shah, 2015; Wang et al., 2015). This fusion of systems and technologies helps to integrate upstream and downstream technological resources into the supply chain (Singh et al., 2015; Li et al., 2015a). In fact, some authors such as Bruque et al. (2015) and Sharma and Shah (2015) show that supply chain efficiency and competitiveness can be enhanced by integrating technologies (such as Web 2.0) via CC. In addition, CC is also compatible with the integration of a large number of mixed applications, platforms and infrastructures that can have very positive effects on $\mathrm{SCI}(\mathrm{Li}$ et al., 2015a; Wang et al., 2015). As a result, CC use could improve resource sharing with supply chain members, and the dynamism of collaboration systems (Bruque et al. 2015; Li et al., 2015a).

\section{Research findings in topic two}

Papers related to CC use in technology and system integration in supply chain show that integrating CC with existing IT systems in supply chain can improve flexibility, accessibility and shared resources utilization. CC becomes an exhaustive management system improving links between supply chain members, accelerating the use of shared resources, and making work plans available to all the supply chain members in real time. This could result in reductions in information distortions and in the rate of resource use due to task and services integration. $\mathrm{CC}$ is also compatible with the integration of a large number of mixed applications, hardware and a large amount of data generated by sensors and devices in real-time remote manufacturing control systems. This merging of systems and technologies helps to integrate technological resources in the organization's functional areas and also in the supply chain. So, the efficiency and 
competitiveness of the supply chain can be enhanced by integrating technologies and systems.

Literature offers evidence that $\mathrm{CC}$ and supply chain technology and system integration has a positive impact at both the intra-organizational and inter-organizational levels. CC enhance integration of technological resources in the functional areas of the organization and upstream and downstream in the supply chain. At the intra-organizational level, CC can be coupled with technologies such as ERP, CAM/FMS and RFID, which could lead companies to achieve efficiency of internal supply chain processes. The relationship between $\mathrm{CC}, \mathrm{ERP}$ and $\mathrm{SCl}$ is a research sub-line that needs to be further deepened. In inter-organizational level, resource sharing with supply chain members could be supported by integrating $\mathrm{CC}$, web technologies and even a set of clouds (multi-cloud). This technology integration could eventually improve supply chain efficiency and business competitiveness. Research on multi-clouds use and their influence on SCI need to be further deepened.

\subsubsection{Research topic three: Cloud computing and supply chain partner integration}

In this research topic the following research lines have been identified: (1) supplier integration; (2) internal integration, and (3) customer integration. The following tables (Tables 1.13, 1.14, and 1.15) show the grouping of the papers into research lines and research sublines.

Table 1.13. Papers related to supplier integration research line and its sublines

\begin{tabular}{|c|c|c|c|c|}
\hline \multicolumn{5}{|r|}{ Coordination / partnership } \\
\hline Authors & INF & $\mathrm{PHY}$ & FIN & Contribution to literature \\
\hline $\begin{array}{l}\text { Demirkan } \\
\text { et al. } \\
(2010) \\
\end{array}$ & $X$ & & & $\begin{array}{l}\text { Analysis of the performance of a SaaS established under different } \\
\text { coordination strategies between application service providers } \\
\text { (ASP) and application infrastructure providers (AIP) }\end{array}$ \\
\hline $\begin{array}{l}\text { Duan and } \\
\text { Liu (2016) }\end{array}$ & $\mathrm{X}$ & & & $\begin{array}{l}\text { Analysis of collaborative strategies and research applied to SC } \\
\text { based on CC }\end{array}$ \\
\hline $\begin{array}{l}\text { Liu et al. } \\
\text { (2016) }\end{array}$ & $X$ & & & $\begin{array}{l}\text { Analysis of how IT infrastructure capabilities based on the flexibility } \\
\text { and integration of Cloud structures contribute to the agility and, } \\
\text { consequently, to the enterprise performance }\end{array}$ \\
\hline $\begin{array}{l}\text { Radke and } \\
\text { Tseng } \\
(2015)\end{array}$ & $\mathrm{X}$ & & & $\begin{array}{l}\text { Identification of the architectural problems of data and } \\
\text { organizational layers of SC that transcend the vast organizational } \\
\text { boundaries, from the point of view of information sharing }\end{array}$ \\
\hline $\begin{array}{l}\text { Schniederj } \\
\text { ans et al. } \\
(2016)\end{array}$ & $\mathrm{X}$ & & & $\begin{array}{l}\text { Analysis of the CC use impact on collaboration and its final impact } \\
\text { on humanitarian SC agility }\end{array}$ \\
\hline $\begin{array}{l}\text { Subramani } \\
\text { an and } \\
\text { Abdulrahm } \\
\text { an (2017) }\end{array}$ & $X$ & $\mathrm{X}$ & & $\begin{array}{l}\text { Analysis of the logistics cooperative resilience and the CC providers } \\
\text { within a framework of SC risk assessment }\end{array}$ \\
\hline \multicolumn{5}{|r|}{ Operating results } \\
\hline Authors & INF & $\mathrm{PHY}$ & FIN & Contribution to literature \\
\hline
\end{tabular}




\begin{tabular}{|c|c|c|c|l|}
\hline $\begin{array}{c}\text { Abedi et al. } \\
\text { (2013) }\end{array}$ & $X$ & $X$ & & $\begin{array}{l}\text { Research of the CC potential as collaborative construction tool for } \\
\text { the prefabricated SC management }\end{array}$ \\
\hline $\begin{array}{c}\text { Bruque et } \\
\text { al. (2016) }\end{array}$ & $X$ & $X$ & & $\begin{array}{l}\text { Analysis of Community CC effects on the SC's informational and } \\
\text { physical flows integration }\end{array}$ \\
\hline \multicolumn{7}{|c|}{ Economic and environmental factors } \\
\hline Authors & INF & PHY & FIN & Contribution to literature \\
\hline $\begin{array}{c}\text { Schniederj } \\
\text { ans and } \\
\text { Hales } \\
\text { (2016) }\end{array}$ & $X$ & & & $\begin{array}{l}\text { Analysis of how CC can help companies not only maintain proper } \\
\text { SC collaboration, but also balances both economic and } \\
\text { environmental performance }\end{array}$ \\
\hline $\begin{array}{c}\text { Subramani } \\
\text { an et al. } \\
\text { (2015) }\end{array}$ & $X$ & $X$ & & $\begin{array}{l}\text { Development of a conceptual model to empirically examine the } \\
\text { ecological and cost benefits of integration between service } \\
\text { providers in the Cloud }\end{array}$ \\
\hline $\begin{array}{c}\text { Xing et al. } \\
\text { (2016) }\end{array}$ & $X$ & & & $\begin{array}{l}\text { Creation of a Cloud-based model to help the SC stakeholders } \\
\text { address the implications of life-cycle information management and } \\
\text { improve the timeliness of their carbon emissions }\end{array}$ \\
\hline
\end{tabular}

Table 1.14. Papers related to internal integration research line and its sublines

\begin{tabular}{|c|c|c|c|l|}
\hline \multicolumn{3}{|c|}{ Operating results } \\
\hline Authors & INF & PHY & FIN & Contribution to literature \\
\hline $\begin{array}{c}\text { Abedi et al. } \\
\text { (2013) }\end{array}$ & $\mathrm{X}$ & $\mathrm{X}$ & & $\begin{array}{l}\text { Analysis of the CC potential as collaborative tools in construction } \\
\text { for the prefabricated SC management }\end{array}$ \\
\hline $\begin{array}{c}\text { Bruque et } \\
\text { al. (2016) }\end{array}$ & $\mathrm{X}$ & $\mathrm{X}$ & & Analysis of the Community CC effects on the SC's integration flows \\
\hline $\begin{array}{c}\text { Cheng et } \\
\text { al. (2014) }\end{array}$ & $\mathrm{X}$ & & & $\begin{array}{l}\text { Discussion of the feasibility and integration requirements of a } \\
\text { service model for the Cloud SC of small and medium-sized } \\
\text { enterprises (SMEs) }\end{array}$ \\
\hline \multicolumn{2}{|c|}{ Interdepartmental collaboration } \\
\hline Authors & INF & PHY & FIN & Contribution to literature \\
\hline $\begin{array}{c}\text { Duan and } \\
\text { Liu (2016) }\end{array}$ & $\mathrm{X}$ & & & $\begin{array}{l}\text { Analysis of collaborative strategies and research on SC based on } \\
\text { CC }\end{array}$ \\
\hline $\begin{array}{c}\text { Leukel et } \\
\text { al. (2011) }\end{array}$ & $\mathrm{X}$ & & & $\begin{array}{l}\text { Representation of SC systems as a set of service offerings and } \\
\text { customer demand as service requests }\end{array}$ \\
\hline
\end{tabular}

Table 1.15. Papers related to customer integration research line and its sublines

\begin{tabular}{|c|c|c|c|c|}
\hline \multicolumn{5}{|r|}{ Operating results } \\
\hline Authors & INF & PHY & FIN & Contribution to literature \\
\hline $\begin{array}{l}\text { Bruque et } \\
\text { al. (2016) }\end{array}$ & $\mathrm{x}$ & $\mathrm{x}$ & & Analysis of the Community CC effects on SC's integration flows \\
\hline $\begin{array}{l}\text { Wang et al. } \\
\qquad(2017)\end{array}$ & $\mathrm{x}$ & $\mathrm{x}$ & & $\begin{array}{l}\text { Application of the Cloud-based production service concept to form } \\
\text { a scalable and interoperable order model for self-service } \\
\text { restaurants }\end{array}$ \\
\hline $\begin{array}{l}\text { Tien } \\
(2011)\end{array}$ & $\mathrm{x}$ & $x$ & & $\begin{array}{l}\text { Analysis of a simultaneous and real-time management proposal of } \\
\text { the supply and demand chains (supported by CC) in order to } \\
\text { promote massive customization. }\end{array}$ \\
\hline \multicolumn{5}{|r|}{ Coordination / partnership } \\
\hline Authors & INF & $\mathrm{PHY}$ & FIN & Contribution to literature \\
\hline $\begin{array}{l}\text { Duan and } \\
\text { Liu (2016) }\end{array}$ & $\mathrm{x}$ & & & $\begin{array}{l}\text { Analysis of collaborative strategies and research applied to supply } \\
\text { chains based on CC }\end{array}$ \\
\hline $\begin{array}{l}\text { Leukel et } \\
\text { al. (2011) }\end{array}$ & $\mathrm{X}$ & $\mathrm{x}$ & & $\begin{array}{l}\text { Representation of SC systems as a set of service offerings and } \\
\text { customer demand }\end{array}$ \\
\hline
\end{tabular}




\section{Cloud computing and supplier integration}

The literature findings indicate that "supplier integration" is the most addressed research line in the "partner integration" research topic (Table 1.13). CC may have a positive impact on collaboration and coordination with supply chain suppliers (Demirkan et al., 2010; Radke and Tseng, 2015; Duan and Liu, 2016; Liu et al., 2016; Schniederjans et al., 2016; Subramanian and Abdulrahman; 2017) given that CC can contribute to supplier integration as, apart from resource sharing, it also enables the exchange of skills, knowhow and production data. In addition, CC affords the company and suppliers real-time access to production and logistics data and, consequently, greater supply chain visibility and flexibility (Liu et al., 2016). CC use for supplier integration can therefore improve the supply chain's operational, financial and environmental performance (Abedi et al., 2013; Subramanian et al., 2015; Schniederjans and Hales, 2016; Bruque et al., 2016; Xing et al., 2016).

\section{Cloud computing and internal integration}

Table 1.14 shows that another research line that has received considerable attention from researchers is "Internal integration". CC may be a useful tool for improving operating results and firm performance as it can help internal partners to achieve higher integration levels (Abedi et al., 2013; Cheng et al., 2014; Bruque et al., 2016). The reason for this is that CC can increase interdepartmental collaboration and integration (with employees, departments, and internal processes). CC supports not only resource sharing, but also strategies, skills, know-how, and information about internal processes and activities (Leukel et al., 2011; Duan and Liu, 2016).

\section{Cloud computing and customer integration}

The literature findings indicate that "Customer integration" is a research line that has received considerable attention from researchers (Table 1.15). From the perspective of integration between a central company and its customers, CC-supported integration of a company's SC with its customers' could provide better operational results (Tien, 2011; Bruque et al., 2016; Wang et al., 2016). CC use in SCI may eliminate problems in the SC such as the bullwhip effect (a mismatch that can occur between real demand and demand estimates) (Bruque et al., 2016; Wang et al., 2017). In the same line, CC has a positive impact on coordination/partnership as the service provided is better oriented toward meeting consumer needs (Leukel et al. 2011; Duan and Liu, 2016). CC not only enables greater integration between the central company and its customers through data 
storage and analysis, but also contributes to a better understanding of demand (Tien, 2011; Wang et al., 2017).

\section{Research findings in topic three}

From the perspective of supply chain partner integration (suppliers, internal/departmental, customers), $\mathrm{CC}$ is an important factor that facilitates the integration of trading partners and collaboration between them by enabling supply chain members and stakeholders to communicate in real time. CC supports information sharing by supply chain partners using a wide variety of different media and gives users the ability to manage an immense amount of data in a short period of time. Consequently, a substantial increase in the speed of the informational flow between supply chain members could be achieved.

Regarding supplier integration, CC enables resource sharing, allowing suppliers to have real-time access to production and demand data, while the company has access to supply data from their suppliers. As a result, CC could support collaboration and coordination between companies and suppliers, resulting in greater supply chain visibility and flexibility. As far as the integration of internal partners (employees and departments) is concerned, CC use could increase interdepartmental collaboration and integration. By supporting vertical integration, $\mathrm{CC}$ use could improve information sharing on internal processes and activities and, consequently, enhance collaboration and integration both intra-departmental and inter-departmental. Finally, CC can also improve customer integration, contributing to a better understanding of demand and reducing supply chain bullwhip effect. However, research on CC-internal integration (Inter-departmental collaboration) and CC-customer integration (company-customer coordination) needs to be deepened.

\subsubsection{Cloud computing and supply chain flow integration}

Information flow integration is the most researched topic to date. The benefits that CC gives to information flow integration derive from its ability to process, analyse, store and distribute mass data, which allows companies to share information both internally and externally. The literature findings shows that $\mathrm{CC}$ is an effective means of integrating information along the supply chain, improving the information sharing with supply chain partners through a wide variety of media (e. g. Liu et al., 2016). CC enables users to manage an immense amount of data in a short period of time converts into a substantial increase in the speed of information flow compared to other more traditional IT. The 
availability of real-time information provided by CC offers several advantages to information flow integration, such as: real-time access to data; flow optimization and improved IT infrastructure as a platform for communication between chain partners; greater visibility of supply chain data; and increased agility to respond adequately to rapid and unexpected changes (e.g. Carrillo et al., 2014). In this sense, CC has a positive impact on information sharing and that this can ultimately lead to greater supply chain performance (e. g. Bruque et al., 2016).

CC use for physical flow integration has been less investigated than CC use for information flow integration. However, findings in the literature have already highlighted the great benefits that $\mathrm{CC}$ can have in physical flow integration. For example, the CC use is conducive to the integration of physical resource distribution through real-time monitoring of the supply chain. CC facilitates communication about material flow, which is useful for improving inventory management; data on raw materials, production and other processes that can be controlled in real time by virtue of CC's large computing power; and storage and data management acquired with CC use (e.g. Yan et al., 2014). $\mathrm{CC}$ enables effective integration both inside and outside the factory when used in conjunction with control and automation tools, which in turn permits the automatic execution of manufacturing tasks (improving design, efficiency and resource sharing) (e. g. Wu et al., 2013). In this sense, CC use has a positive impact on physical flow integration by reducing inventory levels and associated costs. In addition, CC allows the creation and control of applications that improve physical resource integration and covers the gap between the real world and virtual world (e. g. Jede and Teuteberg, 2015).

Finally, only a very limited number of studies have addressed CC use in financial flow integration. The scant literature on this research line indicates that CC use could improve financial flow integration by optimizing payment processes and real-time cash flow between partners (Jede and Teuteberg, 2015; Bruque et al., 2016). CC's rapid data analysis could accelerate these flows and allows access to multi-platform data with swift information retrieval about payments made, costs and availability of products to customers.

\subsubsection{IDENTIFIED GAPS AND PATHS FOR FURTHER INVESTIGATION}

This systematic literature review has synthesized the previous research to help understand the $\mathrm{CC}-\mathrm{SCl}$ relationship. As seen in the previous section, there are several research lines that have been little explored. We shall now propose lines for future research based on the research gaps that have been detected and considering the main SCI topics. 


\section{Research gaps identified in topic one}

"Manufacturing integration" and "logistics integration" are the two most researched lines in the "CC and process/activity integration" topic. Although there are a considerable number of papers on these research lines, some questions remain unanswered. The literature shows that organizations using $\mathrm{CC}$ can achieve more effective $\mathrm{SCl}$ in manufacturing and logistics contexts (e.g., Li et al., 2013). However, there are very few studies that empirically prove CC's potential to improve Business Performance when applied to manufacturing and logistics integration. In addition, no empirical papers have been identified that examine the characteristics, technical difficulties and costs of CC implementation to improve manufacturing and logistics integration. In other respects, Table 1.7 shows that limited attention has been given to the "purchases" and "warehouse" research sublines, revealing a research gap in these areas.

Limited attention has been paid to the "design/process integration", "financial integration" and "Marketing/commercial integration" research lines in the literature compared to manufacturing integration and logistics integration, (Tables 1.8, 1.9 and 1.10). In particular, very little research has been conducted into the "Product modeling", "Resource allocation", "Accounting", "Online payment system" and "Commercialization" sublines to date. For example, no papers have been identified that examine the relationship of these research sublines with $\mathrm{CC}$ use, $\mathrm{SCl}$ levels and Business Performance. Likewise, no papers have been identified that analyse the CC types and models that might be more efficient at achieving the associated higher integration levels.

\section{Research gaps identified in topic two}

Both "intra-organizational technology/system integration" and "inter-organizational technology/system integration" have received considerable attention from researchers (Tables 1.9 and 1.10). However, some points remain unexplored. The literature shows that CC use may increase information accuracy by reducing IT errors through technology and system automation and integration (e.g., Sharma and Shah, 2015). In addition, CC use could increase Business Performance by mitigating the limiting effect of certain contingent factors on the relationship (i.e., technological complexity and incompatibility) (Jede and Teuteberg, 2015). Notwithstanding, there are very few studies that empirically prove the potential of applying $\mathrm{CC}$ to technology/system integration and any impacts that this relationship (CC-other technologies) might have on the supply chain. In addition, a small number of papers have been identified that help determine the difficulties of 
implementing and integrating some technologies (e.g., the Internet of Things and Big Data) in the CC-SCI field. Finally, no papers have been identified that analyse the opportunities and challenges connected with $\mathrm{CC}-\mathrm{SCl}$ and recent information technologies, such as those of Industry 4.0 (block chain, collaborative robotics, additive manufacturing, wearable technology, drones, and smart glasses, among others).

\section{Research gaps identified in topic three}

"Supplier integration" is the most researched line in the "CC and partner integration" topic. Although the literature shows that $\mathrm{CC}$ can help companies to manage operations with lower costs and improve coordination/collaboration with their partners (e.g. Demirkan et al., 2010) some questions remain unanswered. For example, no studies have been identified that analyse the cloud implementation levels required to encourage the cooperative behaviour of the chain's suppliers. In addition, no studies have been identified that analyse the increased efficiency of supplier integration and its impact on business results after CC implementation. Another point that remains unexplored is a comparison of the cloud types (hybrid, community or public cloud) to support the collaborative relationship with vendors (e.g., Vendor Managed Inventory or VMI strategies). Table 1.13 also shows that limited attention has been given to the "operating results" research subline, revealing a research gap in this area.

In the literature, limited attention has been given to the "internal integration" research line compared to "supplier integration" (Table 1.14). In particular, "interdepartmental collaboration" has been very little researched to date. For example, no papers have been identified comparing the impacts of specific types of cloud (internal or micro-cloud) with traditional IT (such as ERP) on achieving higher levels of internal integration. In addition, no studies have been identified that quantitatively analyse the improvement in internal integration performance (between departments, employees and internal processes) after CC implementation. Lastly, no studies have been identified that define the way that business characteristics (culture, number of departments and employees, management support) might affect the levels of internal integration through CC use.

Finally, "customer integration" is another research line that needs to be further explored by researchers. The literature shows that $C C$ use may enable the effective and efficient integration of businesses with their consumers (e.g., Wang et al., 2017). However, Table 1.15 shows that the number of papers identifying issues related to this research line is not significant. For example, a small number of papers have analysed the CC usecustomer integration relationship and its impact on operational and financial 
performance. No studies have been identified in this line that analyse, for example, the potential impacts of the cloud models (SaaS, laaS and PaaS) on customer integration levels and Business Performance. There are also very few papers that quantitatively investigate the relationships between the customer integration levels generated by cloud use and their impact on product customization levels. Similarly, no studies have been identified that compare the impacts of some types of cloud (e.g., community cloud) on demand integration and on product co-creation. Lastly, no practical studies have been identified that analyse the role played by the "CC-customer integration" relationship in increasing customer satisfaction through personalized production.

\section{Paths for further investigation}

The literature findings show a positive relationship between $\mathrm{CC}$ use and $\mathrm{SCl}$ improvement. However, the research results reveal areas of study that have received little or no attention from previous researchers. Some suggestions for future research are highlighted below.

In general lines, it is suggested that longitudinal studies of CC-SCl should be conducted as a way of measuring and evaluating the medium- and long-term performance of this relationship. As seen in Table 1.4, the growing number of papers that have conducted empirical research to quantify the impact of CC use on SCI levels shows the need for more research to explore this line. Researchers are encouraged to exploit methodological tools such as case studies in combination with quantitative methods to validate and test the theoretical concepts identified in this review. Also, considering that a greater number of developed countries tend to use CC more widely, we encourage researchers to conduct empirical research investigating the adoption of technologies of this type to integrate the supply chains of companies located in developing countries. In addition, new studies could investigate the difficulties or success factors of $\mathrm{CC}$ implementation in SCI or a case analysis (e.g., success vs. failure) of the CC-SCI relationship. Furthermore, if any differences exist between the different CC types (Microcloud, Private Cloud, Hybrid Cloud and Community Cloud) and CC models (laaS, PaaS, SaaS) as a support for SCI, they should be analysed. Lastly, further work is required on financial flows (the least researched integration flow) to find additional evidence and examples of applications.

In relation to research topic one (process and activity integration), further studies could analyse the $\mathrm{CC}-\mathrm{SCI}$ relationship both at the operational level (e.g., flexibility, quality, delivery and service) and regarding the indicators of overall Business Performance (i.e., 
revenues, market share, profit margin, turnover, economic and financial profitability). In particular, new studies should deepen the research into CC use to improve purchasing and warehouse integration. In the same line, researchers could conduct studies to understand the possible implications that $\mathrm{CC}$ use could have on specific types of process (e.g., product modeling, resource allocation, accounting, online payment system and commercialization).

Regarding research topic two (technology and system integration), further studies should be conducted to confirm the impacts of the relationship between CC use and other data integration technologies (e.g., Big Data and the Internet of Things) to support SCI. In addition, research should also be conducted into the impacts of CC use to support very recent technologies (e.g., block chain, collaborative robotics, additive manufacturing) as a way to improve the $\mathrm{SCl}$ levels. New studies should also examine the relationship between CC use and vision technologies (e.g., drones, wearable technology and smart glasses) to improve SCI and optimize Business Performance. Finally, new studies could be conducted to identify challenges related to the implementation, integration, risks and economic viability of enabling technologies (such as digital automation and additive manufacturing) in the $\mathrm{CC}-\mathrm{SCl}$ field.

With regard to research topic three (partner integration), new practical studies could be conducted that analyse challenges in the CC-SCI relationship to improve co-design/coproduction. In addition, new studies should confirm the potential of using the Cloud as a tool to help companies integrate demand (customer relationship) and supply (supplier relationship). Furthermore, researchers could analyse the influence of cloud types (micro-cloud, internal cloud, community cloud, and public cloud) and cloud models (SaaS, laaS, PaaS) on the efficiency of supply chain partner coordination. Finally, the number of investigations that analyse the effects of CC-partner integration on operational and financial results is small (Tables 13 and 15), highlighting the need for more research in this research area.

As seen earlier, there seems to be a consensus in the literature that $\mathrm{CC}$ adoption has a positive effect on $\mathrm{SCl}$. However, theoretical and empirical research should be continued to provide a better understanding of the $\mathrm{CC}-\mathrm{SCI}$ relationship.

\subsection{CONCLUSIONS}

The major findings of this chapter refer to the main relationships that exist in the $\mathrm{CC}-\mathrm{SCI}$ area and give readers an overview of the full potential of CC use in SCI. The study 
findings are intended for both researchers and company managers, and can help them understand what has been studied, trends in the area, and knowledge gaps (areas barely explored or not at all). On the one hand, researchers will be able to orientate their studies toward improving knowledge and bringing to light new uses for $\mathrm{CC}$ to $\mathrm{SCI}$. On the other hand, company managers will be informed of the possible managerial implications, advantages and risks related to the CC-SCI relationship.

Responses to specific Research Questions and the chapter's conclusions based on the results of the systematic literature review are presented below.

RQ1.1: What is the current state of knowledge of CC use in the firm and its effect on SCl?

Broadly-speaking, the literature findings show that $\mathrm{CC}$ is a very effective technological tool for integrating data, as it has a range of impacts when used to improve integration in the supply chain. CC can advance the development of the supply chain through effective supply chain flow integration (information, physical, and financial), which, in turn, supports other types of integration (process, technology and partner). CC has a significant impact on the efficiency of supply chain process and activity integration (manufacturing, logistics, design/development, commercial and financial integration) as it improves scalability, flexibility, agility, adaptation to changes and supply chain planning (e.g., Paniti 2014; Bruque et al., 2015). In addition, the literature shows that integrating CC with existing IT systems can improve system flexibility, deployment and accessibility (e.g., Helo et al., 2014; Schlechttendahl et al., 2017). With respect to supply chain partner integration, $\mathrm{CC}$ is an important factor that facilitates integration and collaboration among business partners (internal, suppliers and customers) as it enables SC members and stakeholders to communicate in real time (e.g., Abedi et al., 2013; Schniederjans et al. 2016).

RQ1.2: What are the main research directions in relation to the adoption of CC for SCI? The grouping of the literature in this study helps to deepen our understanding of the research and extant knowledge of the $\mathrm{CC}-\mathrm{SCl}$ relationship. The study has focused on three fundamental topics (Fabbe-Costes and Jahre, 2008):

(1) Process and activity integration, with reference to research lines: CC use in manufacturing, logistics, design, financial and marketing integration. Within this large area, the sublines that have been researched are: computer support platforms, human factors, implementation models, cyber-physical-industrial systems, purchases, distribution, warehouse, product modeling, collaborative design, resource allocation, account, e-payment, and commercialization; 
(2) Technology and system integration, i.e., the use of CC to integrate other internal technologies in companies as well as those used in processes throughout the SC. The research in this topic addresses the relationships between $\mathrm{CC}$ and other intraorganizational technologies (such as ERP, CAM/FMS, RFID) and interorganizational technologies (such as Web technologies and multi-cloud);

(3) SC partner integration, which analyses research lines on the effects of CC on internal/departmental integration, and supplier and customer integration. The following are examined in this topic: CC use to support SC coordination and interdepartmental collaboration; and factors related to operational, economic and environmental results. The $\mathrm{CC}-\mathrm{SCI}$ relationship has also been analysed from the perspective of flow integration (Rai et al., 2006): physical flow integration, with reference to CC use to manage the storage and flow of materials and finished products between the central company and supply chain partners; information flow integration, where $\mathrm{CC}$ is used to share operational, tactical and strategic information between a focal firm and its supply chain partners; and financial flow integration, with reference to the use of $\mathrm{CC}$ to support financial flows between a focal firm and its supply chain partners.

RQ1.3: What future research directions can be identified based upon existing work and the gaps detected?

New theoretical and empirical studies could analyse the impact of CC use and SCI types (i.e., manufacturing and logistics integrations, internal and external technology integrations, and internal, supplier and customer integrations) on operational and financial performance. In addition, some types of integrations (design/development, financial, commercial, purchasing, and warehouse integrations) have not been explored to any great extent, which highlights the need for more research in these areas. Researchers are encouraged to exploit methodological tools such as case studies and longitudinal analyses to validate and test the theoretical concepts identified in this review. Also, new studies could address the difficulties or success factors of CC implementation in $\mathrm{SCl}$ and the differences that exist between the different $\mathrm{CC}$ types and models as supports for SCI. Finally, researchers could investigate how other IT might enhance the effects of $\mathrm{CC}$ on $\mathrm{SCl}$, as well as the effects of other SC strategies to boost the effects of $\mathrm{CC}$ on $\mathrm{SCl}$. 


\subsubsection{TRENDS AND PROGRESS IN THE FIELD}

The CC-SCI relationship is a relatively new topic in the literature, with studies published in 2010 being the earliest identified. This chapter's findings show that significant progress has been made in the study of the impact of $\mathrm{CC}$ on $\mathrm{SCl}$, with evident growing research interest, especially during the past five years. This trend has continued to the present day, with the highest number of published studies recorded in 2016 (21 papers) and as many as 13 papers on CC-SCI published in the first three months of 2017. Another trend is that papers on the $\mathrm{CC}-\mathrm{SCI}$ relationship have been published in journals dealing mainly with Industrial Computing, Supply Chain Management and Operations Management (21 papers in only 3 journals: Robotics and Computer-Integrated Manufacturing, Computers in Industry, and Journal of Manufacturing Systems). It was also observed that a considerable number of papers were published by multi-country authors, mainly from China and the United States, but also from Asia, Europe and North America. This shows that there is global interest in the $\mathrm{CC}-\mathrm{SCl}$ relationship and a worldwide growth in research. Another trend observed was the use of research methodologies related to developing models/architecture, literature reviews, the development of computer tools, simulations, and hypothesis testing.

The SLR conducted in this chapter indicates that the positive relationship between CC and $\mathrm{SCl}$ in the three major research groups and in all integration dimensions should be acknowledged as progress in the field.

\subsubsection{MANAGERIAL IMPLICATIONS}

Based on evidence from the literature review, additional management insights can be obtained on how the use of $\mathrm{CC}$ might impact $\mathrm{SCI}$. CC is a relatively new technology that is evolving and developing rapidly. It is important for managers to be aware of any possible implications, advantages and risks connected with the implementation of this tool in the company. The main topics, research lines and research sublines have been identified according to the literature to date in which CC may have a greater effect on $\mathrm{SCl}$. Managers should be aware that $\mathrm{CC}$ has enormous potential for supporting process and activity integration; technology and SC system integration; partner integration and information, physical and financial flows throughout the SC. For managers, these conclusions are proof of the great potential that CC has for information sharing among SC members, for interconnecting production and delivery centres, for improving service quality, for reducing costs and for generating greater flexibility and agility in the SC. 
In this way, aware of the effects of the CC-SCI relationship, managers could conduct operational activities more effectively. For example, the use of CC has been shown to increase the speed and flexibility of processes, improve logistical and technological capabilities and impact the efficiency and effectiveness of collective efforts among members of the chain (Oliveira et al., 2013; Bruque et al., 2016; Carrillo et al., 2014). Thus, managers could use the findings in this chapter to better understand the role and types of approaches to the CC-SCI relationship and achieve better Business Performance. In other words, the conclusions of this chapter may affect the way that managers consider and organize their companies' technological resources to achieve better results.

Moreover, the proposed framework could be used by managers to assess the potential effects of CC on their company and this information could serve as an initial support for decision-making on the implementation of such technology. It has been seen that $\mathrm{CC}$ can improve supply chain visibility through effective communication and real-time information sharing among supply chain partners (such as demand and inventory levels). In this way, managers and companies can use the information gathered in this chapter to benchmark potential areas of the supply chain where CC implementation would result in improved SCl.

Finally, global supply chains in developed regions include various subsidiaries in developing regions. According to a BSA Global Cloud Computing Scorecard (2018) report, the top ten countries with policies aimed at boosting the cloud are highly developed, including Germany, Japan and the United States. So, this chapter's findings could serve as a reference to help companies in regions that are at less advanced implementation levels of these technologies, such as the BRICS (Brazil, Russia, India, China and South Africa).

Armed with a deeper understanding of the benefits and challenges of using this technology in the Supply Chain, business managers could use the information in this chapter as a starting point for using CC to enhance the competitiveness of their Supply Chain companies.

\subsubsection{LIMITATIONS}

We fully recognize that our study has some limitations. Readers, future scholars and researchers should also be aware of these limitations and interpret what is presented in this chapter in their context. The SLR technique is reliable and recommended by a large number of scientific papers published in numerous databases (Boell and Cecez- 
Kecmanovic, 2014; Montoya-Torres and Ortiz-Vargas, 2014; Zimmermann et al., 2015; Ashraf et al., 2017). However, it is criticized for several reasons. On the one hand, the criteria used for including papers may have led to the exclusion of other, similarlyimportant papers (for example congress communications). On the other hand, while the authors have conducted a comprehensive literature search of the ABI Inform Global, ScienceDirect, Scopus, and Emerald Insight databases to identify all relevant potential papers, it is likely that some research papers have been omitted (papers present only in other databases). But, SLR depends on available and accessible research studies (both conceptual and empirical) and the researcher's criteria (Denyer and Tranfield, 2009). However, despite these criticisms, if the SLR technique is rigorously applied, it is possible to obtain reasonable knowledge of the research questions (Denyer and Tranfield, 2009). Another limitation of this research that should be highlighted is that the classification of the papers is subjective, as it is based on the researcher's opinions. This is also an inherent limitation of SLR (Correia et al., 2017; Pérez-Salazar et al., 2017). Nonetheless, previous literature theory frameworks have been used to reduce this limitations. In addition, a check was conducted in an attempt to reduce the bias of the proposed classification in which a group of five IT and supply chain researchers verified the adequacy of the classification framework (Rai et al., 2006; Fabbe-Costes and Jahre, 2008).

\subsection{SUMMARY}

- A Systematic Literature Review (SLR) of 77 papers was conducted to identify, select, review and synthesize the relevant literature on Cloud Computing and Supply Chain Integration, and detect extant gaps and future research lines.

- Interest in the CC-SCI topic is growing in different industrial areas and it has been approached from several methodological perspectives by multi-country authors.

- CC has a strong impact on process and activity integration, by enhancing technological resource integration in the organization's functional areas, and upstream and downstream in the supply chain. CC also supports the supply chain flow integration, especially information and physical flows.

- Further research is needed on CC use in some types of integrations (e.g., design/development, financial, commercial, purchasing and warehouse integrations) to provide a better understanding of the $\mathrm{CC}-\mathrm{SCI}$ relationship. 


\section{REFERENCES}

\section{Papers that compose the systematic literature review}

Abedi, M., Fathi, M. S., \& Rawai, N. M. (2013). The Impact of Cloud Computing Technology to Precast Supply Chain Management. International Journal of Construction Engineering and Management, 2 (4A), 13-16.

Abedi, M. (2016). Integrated Collaborative Tools for Precast Supply Chain Management. Scientia Iranica, 232 (2), 429-448.

Akbaripour, H., Houshmand, M., \& Valilai, O.F. (2015). Cloud-Based Global Supply Chain: A Conceptual Model and Multilayer Architecture. Journal of Manufacturing Science and Engineering, 137 (4), 1-6.

Andreadis, G., Fourtounis, G., \& Bouzakis, K. D. (2015). Collaborative design in the era of Cloud Computing. Advances in Engineering Software, 81, 66-72.

Azevedo, A., Faria, J., \& Ferreira, F. (2017). Supporting the entire life-cycle of the extended manufacturing enterprise. Robotics and Computer-Integrated Manufacturing, 43, 2-11.

Babiceanu, R.F., \& Seker, R. (2016). Big Data and virtualization for manufacturing cyber-physical systems: A survey of the current status and future outlook. Computers in Industry, 81, 128-137.

Bi, Z., \& Cochran, D. (2014). Big data analytics with applications. Journal of Management Analytics, 1 (4), 249-265.

Brant, A., \& Sundaram, M. M. (2015). A novel system for Cloud-based micro additive manufacturing of metal structures. Journal of Manufacturing Processes, 20, 478-484.

Bruque, S., Moyano, J., \& Maqueira, J. M. (2015). Use of Cloud technology, Web 2.0 and operational performance: the mediating role of supply chain integration. International Journal of Logistics Management, 26 (3), 426-458.

Bruque, S., Moyano, J., \& Maqueira, J. M. (2016). Supply chain integration through community Cloud: Effects on operational performance. Journal of Purchasing and Supply Management, 22 (2), 141-153.

Carrillo, M., \& Franky, C. (2014). Modelo SCLOUDPY para la gestión de pedidos en la nube. Información Tecnológica, 25 (4), 35-42.

Chen, C.-S., Liang, W.-Y., \& Hsu, H.-Y. (2015), A Cloud Computing platform for ERP applications. Applied Soft Computing, 27, 127-136.

Chen, F., Dou, R., Li, M., \& Wu, H. (2016). A flexible QoS-aware Web service composition method by multiobjective optimization in Cloud manufacturing. Computers and Industrial Engineering, 99, 423-431.

Chen, S. L., Chen, Y. Y., \& Hsu, C. (2014). A new approach to integrate internet-of-things and software-asa-service model for logistic systems: A case study. Sensors, 14 (4), 6144-6164.

Cheng, J. S., Li, F. C., Ou, T.Y., \& Kung C.C. (2014). The strategic research on integrating services model for SMEs cloud supply chain in Taiwan. International Journal of Electronic Business Management, 12 (1), 33-40.

Cheng, Y., Tao, F., Zhao, D., Zhang, L., \& Zuo, Y. (2017). Modeling of manufacturing service supply-demand matching hypernetwork in service-oriented manufacturing systems. Robotics and Computer-Integrated Manufacturing, $45(\mathrm{C}), 59-72$.

Chiu, P. C., Liao, A. Y. H., Liao, C. H., Yango, Y. N. (2013). Cloud-Based Supply Chain Integration Service Platform. Journal of Electronic Science and Technology, 11(2), 201-208.

Christauskas, C., \& Miseviciene, R. (2012). Cloud-computing based accounting for small to medium sized business. Engineering Economics, 23 (1), 14-21.

Dehne, F., Kong, Q., Rau-Chaplin, A., Zaboli, H., \& Zhou, R. (2015). Scalable real-time OLAP on Cloud architectures. Journal of Parallel and Distributed Computing, 79, 31-41.

Demirkan, H, Cheng, H. K., \& Bandyopadhyay, S. (2010). Coordination Strategies in a SaaS Supply Chain. Journal of Management Information Systems, 26 (4), 119-143.

Duan, R., \& Liu, X. (2016). Collaborative strategies and applied research of costume design supply chains based on Cloud Computing. GAK Gummi Fasern Kunststoffe, 69 (13), 28-32.

Giriraj, M., \& Muthu, S. (2013). A Cloud Computing methodology for industrial automation and manufacturing execution system. Journal of Theoretical and Applied Information Technology, 52 (3), 301-307. 
Givehchi, M., Haghighi, A., \& Wang, L. (2016). Cloud-DPP for distributed process planning of mill-turn machining operations. Robotics and Computer-Integrated Manufacturing, 47, 76-84.

Golightly, D., Sharples, S., Patel, H., Ratchev, S., (2016). Manufacturing in the Cloud: a human factors perspective. International Journal of Industrial Ergonomics, 55, 12-21.

Gupta, S., \& Jones, E.C. (2014). Optimizing supply chain distribution using Cloud based autonomous information. International Journal of Supply Chain Management, 3 (4), 79-90.

Hao, Y., \& Helo, P. (2017). The role of wearable devices in meeting the needs of Cloud manufacturing: A case study. Robotics and Computer-Integrated Manufacturing, 45, 168-179.

Harris, I., Wang, Y., \& Wang, H. (2015). ICT in multimodal transport and technological trends: Unleashing potential for the future. International Journal of Production Economics, 159, 88-103.

Helo P., Suorsa, M., Hao, Y., \& Anussornnitisarn, P. (2014). Toward a Cloud-based manufacturing execution system for distributed manufacturing. Computers in Industry, 65 (4), 646-656.

Ko, H. Sang, Azambuja, M., \& Lee, H. F. (2016). Cloud-based Materials Tracking System Prototype Integrated with Radio Frequency Identification Tagging Technology. Automation in Construction, 63, 144-154.

Kong, X. T.R., Fang, J., Luo, H., \& Huang, G. Q. (2015). Cloud-enabled real-time platform for adaptive planning and control in auction logistics center. Computers and Industrial Engineering, 84, 79-90.

Lee, H. (2017). Framework and development of fault detection classification using loT device and Cloud environment. Journal of Manufacturing Systems, 43(2), 257-270.

Leukel, J., Kirn, S., \& Schlegel, T. (2011). Supply chain as a service: A Cloud perspective on supply chain systems. Systems Journal, 5 (1), 16-27.

Li, Q., Luo, H., Xie, P. X, Feng, X. Q., \& Du, R. Y. (2015a). Product whole life-cycle and omni-channels data convergence oriented enterprise networks integration in a sensing environment. Computers in Industry, 70, 23-45.

Li, W., Zhong, Y., Wang, X., \& Cao, Y. (2013). Resource virtualization and service selection in Cloud logistic. Journal of Network and Computer Applications, 36, (6), 1696-1704.

Li, Y., Dai, W., Armstrong, A., Clarke, A., \& Du, M. (2015b). Developing an integrated supply chain system for small businesses consortium in Australia: a service-oriented PHOENIX solution. Int. J. High Performance Computing and Networking, 8 (1), 81-89.

Lin, I.-C., Hsu, H.-H., \& Cheng, C.-Y. (2015). A Cloud-Based Authentication Protocol for RFID Supply Chain Systems. Journal of Network and Systems Management, 23 (4), 1-20.

Liu, N., Li, X., \& Shen, W. (2014). Multi-granularity resource virtualization and sharing strategies in Cloud manufacturing. Journal of Network and Computer Applications, 46, 72-82.

Liu, S., Yang, Y., Qu W.G., \& Liu, Y. (2016). The business value of Cloud Computing: the partnering agility perspective. Industrial Management and Data Systems, 116 (6), 1160-1177.

Liu, Y., Xu, X., Zhang, L., Wang, L., \& Zhong, R. Y. (2016). Workload-based multi-task scheduling in cloud manufacturing. Robotics and Computer-Integrated Manufacturing, 45, 3-20.

Lu, Y., \& Xu, X. (2017). A semantic web-based framework for service composition in a Cloud manufacturing environment. Journal of Manufacturing Systems, 42, 69-81.

Lyu, G., Chu, X., \& Xue, D. (2017). Product modeling from knowledge, distributed computing and lifecycle perspectives: A literature review. Computers in Industry, 84, 1-13.

Mehrsai, A., Karimi, H. R., \& Thoben, K. D. (2013). Integration of Supply Networks for Customization with Modularity in Cloud and Make-To-Upgrade Strategy. Systems Science \& Control Engineering: An Open Access Journal, 1(1), 28-42.

Mmanagement, Comput. Sci. Eng., vol. 15,

Mezgár, I., \& Rauschecker, U. (2014). The challenge of networked enterprises for Cloud Computing interoperability, Computers in Industry. 65 (4), 657-674.

Mo, J.P.T., \& Lorchirachoonkul, W. (2011). Design of RFID Cloud services in a low bandwidth Network Environment. International Journal of Engineering Business Management, 3(1), 38-43.

Mourtzis, D., Doukas, M., \& Milas, N. (2016). A knowledge-based social networking app for collaborative problem-solving in manufacturing. Manufacturing Letters, (10), 1-5.

Oliveira, R.R., Noguez, F. C., Costa, C. A., Barbosa, J. L., \& Prado, M. P. (2013). SWTRACK: an intelligent model for cargo tracking based on off-the-shelf mobile devices. Expert System Application, 40, 2023-2031. 
Pan, T., Zheng, L., \& Yan, G. (2010). Research of Information Framework for Fourth Party Logistics. Journal of Convergence Information Technology, 5 (7), 90-99.

Paniti, I. (2014). Adaptation of Incremental Sheet Forming into Cloud manufacturing. CIRP Journal of Manufacturing Science and Technology, 7 (3), 185-190.

Pattnayak, P., \& Pradhan, J. (2016). Minimizing cost using Cloud Computing with RFID based supply chain management. International Journal of Control Theory and Applications, 9 (20), 9475-9480.

Radke, A.M., \& Tseng, M.M. (2015). Design considerations for building distributed supply chain management systems based on Cloud Computing. Journal of Manufacturing Science and Engineering, 137 (4), 1-7.

Schlechtendahl, J., Kretschmer, Felix, S., Zhiqian, L., Armin, \& Xu, X. (2017). Extended study of network capability for Cloud based control systems. Robotics and Computer-Integrated Manufacturing, 43, 8995.

Schniederjans, D. G., Ozpolat, K., \& Chen, Y. (2016). Humanitarian supply chain use of Cloud Computing. Supply Chain Management: An International Journal, 21 (5), 569-588.

Schniederjans, D. G., \& Hales, D. N. (2016). Cloud Computing and its impact on economic and environmental performance: A transaction cost economics perspective. Decision Support Systems, 86, 73-82.

Sharma, S., \& Shah, B. (2015). Thinking Cloud-enabled adept and agile supply chain for SMEs: A conceptual study. International Journal of Business Information Systems, 19 (3), 342-365.

Simmhan, H. et al. (2013). Cloud-based software platform for big data analytics in smart grid. IEEE Comput. Sci. Eng., 38-47(99), 1-10.

Singh, A., Mishra, N., Ali, S.I., Shukla, N., Shankar, R., 2015. Cloud computing technology: reducing carbon footprint in beef supply chain. International Journal of Production Economics, 164, 462-471.

Subramanian, N., Abdulrahman, M. D., \& Zhou, X. (2015). Reprint of Integration of logistics and Cloud Computing service providers: Cost and green benefits in the Chinese context. Transportation Research, 74, 81-93.

Subramanian, N., \& Abdulrahman, M. D. (2017). Logistics and cloud computing service providers' cooperation: a resilience perspective. Production Planning \& Control, 28 (11-12), 919-928.

Tao, F., Z., L., Venkatesh, V. C., Luo, Y., \& Cheng, Y. (2011). Cloud manufacturing: a computing and serviceoriented manufacturing model. Journal of Engineering Manufacture, 225 (10), 1969-1976.

Tao, F., Cheng, J., Cheng, Y., Gu, S., Zheng, T., \& Yang, H. (2017). SDMSim: A manufacturing service supply-demand matching simulator under Cloud environment. Robotics and Computer-Integrated Manufacturing, 45, 34-46.

Thekinen, J., \& Panchal, J. H. (2016). Resource allocation in Cloud-based design and manufacturing: A mechanism design approach. Journal of Manufacturing Systems, 43 (2), 327-338.

Tien, J.M. (2011). Manufacturing and services: from mass production to mass customization. Journal of Systems Science and Systems Engineering, 20 (2), 129-154.

Valilai, O. F., \& Houshmand, M. (2013). A collaborative and integrated platform to support distributed manufacturing system using a service-oriented approach based on Cloud Computing paradigm. Robotics and Computer-Integrated Manufacturing, 29 (1), 110-127.

Wang, P.Y., Shen, J., Guo, W.Q., Zhang, C., \& Zhang, B. (2015). Cloud-based government procurement information integration platform. Journal of Digital Information Management, 13 (3), 147-155.

Wang, S., Wan, J., Zhang, D., Li, D., \& Zhang, C. (2016). Towards smart factory for industry 4.0: a selforganized multi-agent system with big data based feedback and coordination. Computer Networks, 101, 158-168.

Wang, X. V., \& Xu, X. W. (2013). An interoperable solution for Cloud manufacturing. Robotics and ComputerIntegrated Manufacturing, 29 (4), 232-247.

Wang, X. V., \& Wang, L. (2014). From Cloud manufacturing to Cloud remanufacturing: A Cloud-based approach for WEEE recovery. Manufacturing Letters, 2(4), 91-95.

Wang, X. V., Wang, L., Mohammed, A., \& Givehchi, M. (2017). Ubiquitous manufacturing system based on Cloud: A robotics application. Robotics and Computer-Integrated Manufacturing, 45, 116-125.

Wu, D., Greer, M. J., Rosen, D. W., \& Schaefer, D. (2013). Cloud manufacturing: Strategic vision and stateof-the-art. Journal of Manufacturing Systems, 32 (4). 564- 579.

Wu, D., Rosen, D.W., Wang, L. \& Schaefer, D. (2015). Cloud-based design and manufacturing: a new paradigm in digital manufacturing and design innovation. Computer-Aided Design, 59, 1-14. 
Xia, M., Li, T., Zhang, Y., \& Silva, C. W. (2016). Closed-loop design evolution of engineering system using condition monitoring through internet of things and Cloud Computing. Computer Networks, 101, 5-18.

Xing, K., Qian, W., \& Zaman, A. U. (2016). Development of a Cloud-based platform for footprint assessment in green supply chain management. Journal of Cleaner Production, 139, 191-203.

Xu, X. (2012). From Cloud Computing to Cloud manufacturing. Robotics and Compute-Integrated Manufacturing, 28 (1), 75-86.

Yan, J., Xin, S., Liu, Q., Xu, W., Yang, L., Fan, L., Chen, B., \& Wang, Q. (2014). Intelligent Supply Chain Integration and Management Based on Cloud of Things. International Journal of Distributed Sensor Networks, 10 (3), 1-15.

Yang, J., \& Lin, P. (2016), A mobile payment mechanism with anonymity for Cloud Computing. Journal of Systems and Software, 116, 69-74.

Yang, C., Shen, W., Lin, T., \& Wang, X. (2016). lot-enabled dynamic service selection across multiple manufacturing clouds. Manufacturing Letters, 7, 22-25.

Yue, X., Cai, H., Yan, H., Zou, C., \& Zhou, K. (2015). Cloud-assisted industrial cyber-physical systems: An insight. Microprocessors and Microsystems, 39(8), 1262-1270.

\section{Complementary bibliographical references}

Abidi, H., Leeuw, S., \& Klumpp, M. (2014). Humanitarian supply chain performance management: a systematic literature review. Supply Chain Management, 19 (5-6), 592-608.

Adjei, J. K. (2015). Explaining the role of trust in Cloud Computing services. Digital Policy, Regulation and Governance, 17 (1), 54- 67.

Alshamaila, Y., Papagiannidis, S., \& Li, F. (2013). Cloud Computing adoption by SMEs in the north east of England: a multi-perspective framework. Journal of Enterprise Information Management, 26 (3), 250275.

Ashraf, M. M., Hasan, N., Lewis, U., \& Hasan, M. R. (2017). A Systematic Literature Review of the Application of Information Communication Technology for Visually Impaired People. International Journal of Disability Management, 11, 1-18.

Azevedo, S., Prata, P., \& Fazendeiro, P. (2013). Assessment of supply chain agility in a Cloud Computingbased framework. Scalable Computing: Practice and Experience, 13 (4), 295-301.

Bhoir, H., \& Principal, R. P. (2014). Cloud Computing for Supply Chain Management. International Journal of Innovations in Engineering Research and Technology, 1 (2), 1-9.

Biel, K., \& Glock, C.H. (2016). Systematic literature review of decision support models for energy-efficient production planning. Computers \& Industrial Engineering, 101, 243-259.

Boell, S. K., \& Cecez-Kecmanovic, D. (2014). A hermeneutic approach for conducting literature reviews and literature searches. Communications of the Association for Information Systems, 34 (12), 257- 286.

BSA, The Software Alliance (2018). BSA Global Cloud Computing Scorecard. Powering a Bright Future, BSA, The Software Alliance, Washington. Available at: http://cloudscorecard.bsa.org/2018/; [Consulted on 10 June 2018]

Buyya, R., Broberg, J. \& Goscinski, A. (2011). Cloud Computing: Principles and Paradigms. John Wiley \& Sons. New York: Inc. Wiley Press.

Buyya, R., Yeo, C.H., Venugopal, S., Broberg, J., \& Brandic, I. (2009). Cloud Computing and emerging IT platforms: Vision, hype and reality for delivering computing as the 5th utility. Future Generation Computer Systems, 25 (6), 599-616.

Casey, G., Cegielski, L., Jones-Farmer, A., Wu, Y., \& Hazen, B. T. (2012). Adoption of Cloud Computing technologies in supply chains. The International Journal of Logistics Management, 23 (2), $184-211$.

Chen, H., Daugherty, P. J., \& Roath, A. S. (2009). Defining and operationalizing supply chain process integration. Journal of Business Logistics, 30 (1), 63-84.

Correia, E., Carvalho, H., Azevedo, S.G., \& Govindan, K. (2017). Maturity models in supply chain sustainability: a systematic literature review. Sustainability, 9, 64.

Denyer, D., \& Tranfield, D. (2009). Producing a systematic review. The SAGE handbook of organizational research methods. London: Sage Publications, 671-689. 
Devaraj, S., Krajewski, L., \& Wei, J. C. (2007). Impact of e-business technologies on operational performance: the role of production information in the supply chain. Journal of Operations Management, 25 (6), 1199-1216.

Díaz-Madroñero Boluda, F., Mula, J. M., and Payá, D. P. (2017). A mathematical programming model for integrating production and procurement transport decisions. Applied Mathematical Modelling, 52, 527543.

Doherty, E., Carcary, M., \& Conway, G. (2015). Migrating to the Cloud. Journal of Small Business and Enterprise Development, 22 (3), $512-527$.

Fabbe-Costes, N., \& Jahre, M. (2008). Supply chain integration and performance: a review of the evidence. The International Journal of Logistics Management, 19 (2), 130-154.

Flynn, B. B., Huo, B., \& Zhao, X. (2010). The impact of supply chain integration on performance: a contingency and configuration approach. Journal of Operations Management, 28 (1), 58-71.

Frohlich M., \& Westbrook R. (2001). Arcs of integration: an international study of supply chain strategies. Journal of Operations Management, 19 (2), 185-200.

Harland, C., Zheng, J., Johnson, T., \& Lamming, R. (2004). A conceptual model for researching the creation and operation of supply network. British Journal of Management, 15 (1), 1-21.

Huang, M. C., \& Huang, H. H. (2018). How transaction-specific investments influence firm performance in buyer-supplier relationships: The mediating role of supply chain integration. Asia Pacific Management Review, In Press 1-9. Available on 10.1016/j.apmrv.2018.03.001.

Jede, A., \& Teuteberg, F. (2015). Integrating Cloud Computing in supply chain processes. A comprehensive literature review. Journal of Enterprise Information Management, 28 (6), 72-94.

Kumar, V., Chibuzo, E. N., Garza-Reyes, J. A., Kumari, A., Rocha-Lona, L., \& Lopez-Torres, G. C. (2017). The impact of supply chain integration on performance: Evidence from the UK food sector. Procedia Manufacturing, 11, 814-821.

Lal, P., \& Bharadwaj, S.S. (2015). Understanding the impact of Cloud-based services adoption on organizational flexibility. An exploratory study. Journal of Enterprise Information Management, 29 (4), 566-588.

Littler, D., Leverick, F., \& Bruce, M. (1995). Factors affecting the process of collaborative product development: a study of UK manufacturers of information and communications technology products. Journal of Product Innovation Management, 12 (1), 16-23.

Maqueira, J. M., Bruque, S., \& Minguela-Rata, B. (2017). Environment Determinants in Business Adoption of Cloud Computing. Industrial Management \& Data Systems, 117 (1), 228-246.

Marston, S., Li, Z., Bandyopadhyay, S., Zhang, J., \& Ghalsasi, A. (2011). Cloud Computing - the business perspective, Decision Support Systems. 51 (1), 176-189.

Mell, P., \& Grance, T. (2011). The NIST definition of Cloud Computing. Recommendations of the National Institute of Standards and Technology. National Institute of Standards and Technology, Gaithersburg, MD.

Montoya-Torres, J. R., \& Ortiz-Vargas, D. A. (2014). Collaboration and information sharing in dyadic supply chains: a literature review over the period 2000-2012. Estudios Gerenciales, 30(133), 343-354.

Oliveira, T., Thomas, M., \& Espadanal, M. (2014). Assessing the determinants of Cloud Computing adoption: an analysis of the manufacturing and services sectors. Information and Management, 51 (5), 497-510.

Pérez-Salazar, M. R., Lasserre, A. A. A., Cedillo-Campos, M. G., \& González, J. C. H. (2017). The role of knowledge management in supply chain management: A literature review. Journal of Industrial Engineering and Management, 10 (4), 711-788.

Rai, A., Patnayakuni, R., \& Seth, N. (2006). Firm performance impacts of digitally enabled supply chain integration capabilities. MIS Quarterly, 30 (2), 225-246.

Rajagopal, V., Venkatesan, S.P., \& Goh, M. (2017). Decision-making models for supply chain risk mitigation: A review. Computers \& Industrial Engineering, 113, 646-682.

Ross, P., \& Blumenstein, M. (2013). Cloud Computing: the nexus of strategy and technology. Journal of Business Strategy, 34 (4), 39-47.

Ryan, W. M., \& Loeffler, C. M. (2010). Insights Into Cloud Computing. Intellectual Property \& Technology Law Journal, 22 (11), 22-27.

Scheidegger, A. P. G., Pereira, T. F., de Oliveira, M. L. M., Banerjee, A., \& Montevechi, J. A. B. (2018). An introductory guide for hybrid simulation modelers on the primary simulation methods in industrial 
engineering identified through a systematic review of the literature. Computers \& Industrial Engineering, $124,474-492$.

Schramm, T., Nogueira, S., \& Jones, D. (2011). Cloud Computing and Supply Chain: A Natural Fit for the Future. Logistics Management, 3, 9-11.

Seuring, S., \& Muller, M. (2008). From a literature review to a conceptual framework for sustainable supply chain management. Journal of Cleaner Production, 16 (15), 1699-1710.

Son, I., Lee, D., Lee, J.-N. \& Chang, Y. B. (2014). Market perception on cloud computing initiatives in organizations: an extended resource-based view. Information \& Management, 51 (6), 653-669.

Thomé, A. M. T., Scavarda, L. F., and Scavarda, A. J. (2016). Conducting systematic literature review in operations management. Production Planning \& Control, 27(5), 408-420.

Troyer, C., \& Cooper, R. (1995). Smart moves in supply chain integration. Transportation and Distribution, $36,55-62$.

Vermula, R., \& Zsifkovits, H. (2016). Cloud Computing for Supply Chain Management. BHM, 161 (5), 229 232.

Wang, Y., Wang, Y., \& Yang, Y. (2010). Understanding the determinants of RFID adoption in the manufacturing industry. Technological Forecasting and Social Change, 77 (5), 803-815.

Winans, T. B., \& Brown, J. S. (2009). Moving Information Technology Platforms to the Clouds: Insights Into IT Platform Architecture Transformation. Journal of Service Science, 2 (2), 23-33.

Zimmermann, A., Schmidt, R., Sandkuhl, K., Jugel, D., Moehring, M., \& Wissotzki, M. (2015). Enterprise architecture management for the internet of things. Proceedings of the Digital Enterprise Computing, 139-148. Böblingen, Germany. 


\title{
Chapter 2
}

\section{A Systematic Literature Review of Supply Chain Flexibility and Customer Microsegmentation/ Mass Personalization adoption}

\begin{abstract}
This chapter analyses the current state of research on Supply Chain Flexibility (SCF) and the Customer Microsegmentation/Mass Personalization (CMS/MP) adoption with the objective: to identify the literature findings to date and the research gaps and to provide guidelines for future research in this area. To this end, a systematic review of 64 papers was undertaken to address the use of SCF as a productive response to CMS/MP. Three main research topics have been identified: (1) Personalization levels and flexible processes in Supply Chain, where flexible processes in Supply Chain are analysed as a productive response to high levels of CMS/MP; (2) SCF and CMS/MP enabling technologies, in which technologies to support the CMS/MP implementation and SCF are considered, and (3) Supply Chain collaborative processes for SCF and CMS/MP, where product co-creation and relationships between Supply Chain members is analysed. Each of these three Main Topics have been divided into Research Lines and Research Sublines that allowed identifying a positive relationship between the SCF and the CMS/MP strategies.
\end{abstract}

Keywords: Systematic Literature Review, Supply Chain Management, Supply Chain Flexibility, Customer Microsegmentation, Mass Personalization 


\section{A Systematic Literature Review of Supply Chain Flexibility and Customer Microsegmentation/ Mass Personalization adoption}

\subsection{INTRODUCTION}

In an increasingly globalised technology market, an efficient Supply Chain management is a significant competitive advantage. Focusing on the customer needs and desires is now seen as a prerequisite for business success (Griffiths and Margetts, 2000; Strasser et al., 2011; Oh et al., 2013; He et al., 2016). In this sense, Customer Microsegmentation (CMS) is defined as a set of plans that serve as a reference for business decisionmaking, in order to meet the individual customer requirements (Squire et al., 2006; Tien, 2011; Purohit et al., 2016). The CMS strategy simultaneously considers real-time demand chains (customer knowledge) and supply chain management (goods and services) (Machado and Moraes, 2008; Tien, 2011). A strategy closely related to CMS is the Mass Personalization (MP), where mass production occurs, but allows the product to be altered in the manufacturing process itself to meet the customers' individual needs (Stump and Badurdeen, 2012). Although these strategies are closely linked, CMS is more related to Marketing, while MP is more related to Production (Squire et al., 2006; Hansotia, 2009; Purohit, et al., 2016). For this reason, in this chapter we consider both concepts as closely related under the term Customer Microsegmentation/Mass Personalization (CMS/MP).

Supply Chain Flexibility (SCF) is the ability of a Supply Chain to change its processes, resources, structure and governance mechanisms within a given scope, responding in terms of production volume and product variability to changes in demand (Lummus et al., 2003; Pfeiffer et al., 2013; Oh et al., 2013). The changing environment is making SCF one of the competitive priorities with which many companies must establish management actions (Wadhwa et al., 2007; Huo et al., 2017). A highly developed Supply Chain will be flexible and have standardised processes that can be adapted efficiently to new market situations (Elms and Low, 2013; Barrales-Molina et al., 2015; Rojo et al., 2018).

In reference to the relationship between both concepts (SCF and CMS/MP), a way of responding to unanticipated changes in customer needs, market dynamism and competitors' actions is through the adoption of an SCF strategy (Moon et al., 2012; Oh et al., 2013; Stojanov and Ding, 2015). The SCF allows companies to be able to provide individually designed products and services to each customer (Da Silveira et al., 2001; Urgo et al., 2016). Although there are some indications of a positive relationship between SCF and CMS/MP, greater and more complete attention is required to understand the 
causes and consequences of the SCF-CMS/MP relationship. The better knowledge can affect the way researchers and business managers approach the relationship between SCF and CSM/MP and can be very useful in the design of future research efforts in this area.

After a thorough search of the previous literature, no papers have been identified that made systematic literature reviews of SCF adoption as an operational response to CMS/MP environments. Therefore, the objective of this study is to scrutinize previous research that simultaneously examines SCF-CMS/MP relationship to identify the findings to date, topics, lines and sublines of study developed and gaps to advance research in the SCF-CMS/MP area. A multidimensional structure is used to categorize and analyse the identified papers, the literature findings to date, and the research gaps and guidelines for future research related to the SCF-CMS/MP relationship. To achieve this objective, the chapter has been structured in four sections, preceded by this introduction. The methodology is described in the second section. The results and discussion are outlined in the third section. Finally, in section four, the conclusions and limitations are presented.

\subsection{METHODOLOGY}

Systematic Literature Review is considered an aid to researchers, as it involves synthesizing available studies on a particular subject and provides scientific knowledge to underpin practice (Denyer and Tranfield, 2009). The most important advantage of this method is that it consists of a number of commonly accepted steps, and so can be easily verified or replicated by other researchers (Seuring and Muller, 2008, Denyer and Tranfield, 2009). In this chapter, this methodology has been used to integrate information obtained from a set of papers that simultaneously address the SCF and CMS/MP. From these papers, Main Topics, Research Lines and Research Sublines that are lacking in evidence the simultaneous relationship between SCF and CMS/MP are identified. It is important to note that Systematic Literature Review has been used in the Supply Chain research area (Abidi et al., 2014; Zimmermann et al., 2015) and in the customer relationship field (Mustak et al., 2013; Keränen et al., 2012).

In order to conduct a Systematic Literature Review, it is important to delimit the research area and establish a protocol for identifying, selecting, reviewing and synthesizing the literature (Seuring and Muller, 2008). This chapter follows the following five steps for the systematic literature review (Denyer and Tranfield 2009): (1) Formulation of the Research Questions, (2) Identification of studies, (3) Selection and evaluation of studies, 
(4) Analysis and synthesis, and (5) Presentation of the results. The following is given a brief description of these five steps.

(1) Formulation of the Research Questions

According to Seuring and Muller (2008), the first step in a Systematic Literature Review is to define the Research Question (RQ), i.e., to identify the question(s) that the research has to answer. In this sense, the following $R Q$ has been determined for the purpose of this study:

RQ2. What are the findings to date, the areas of study developed and the research gaps related to SCF-CMS/MP relationship?

This general $R Q$ can be divided into three specific ones:

RQ2.1: What are the main research's topics, lines and sublines of work regarding the joint approach of the SCF and CMS/MP?

RQ2.2: What is currently known about the interaction between SCF and CMS/MP adoption?

RQ2.3: Based on existing literature, what are the gaps and future work lines identified? Therefore, the study objective is located at the intersection area between the SCF concept and the CMS/MP concept. Figure 2.1 shows this area in which the identified papers are located.

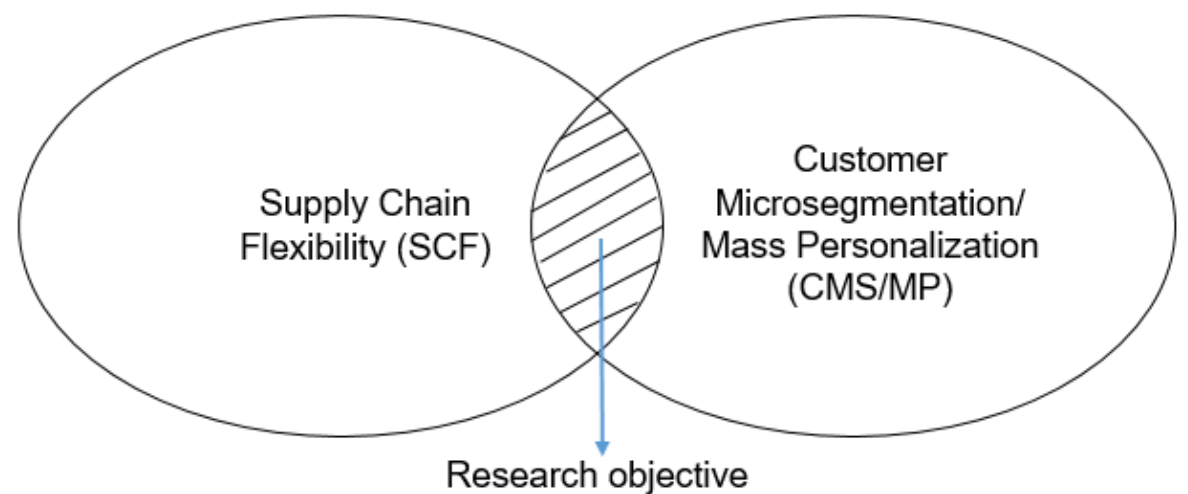

Figure 2.1. Simultaneous relationship between SCF and CMS/MP as research objective

Source: Own elaboration 


\section{(2) Identification of studies}

This step involves looking for and locating relevant studies to answer the Research Question. In this case, a search was conducted of the main bibliographic databases, including $\mathrm{ABI}$ Inform Global, Science Direct, Emerald Insight, Scopus and Web of Science (Mongeon and Paul-Hus, 2016). Keyword selection was based on the concepts of SCF (Lummus et al., 2003), CMS and MP (Squire et al., 2006; Tien, 2011). Filters used in the paper identification process were determined that the terms should appear in the papers' titles, abstracts or keywords. Search keywords have been identified in a brainstorming among researchers. Several pilot tests have been conducted to avoid the appearance of false positives and false negatives, which eliminates errors in the process. Database search was made using the following search string: 'Title' OR 'Abstract' OR 'Keyword' ('Supply Chain' AND 'flexib*) AND 'Title' OR 'Abstract' OR 'Keyword' ('mass customization' OR 'mass personalization' OR 'individual marketing' OR 'one-to-one marketing' OR 'marketing of one' OR 'segment of one' OR 'customer individualization' OR 'customer microsegmentation' OR 'customer hypersegmentation'). This search string has allowed to identify the papers that interrelate SCF and CMS/MP (intersection area, see Figure 2.1).The literature was obtained from relevant journals in the areas of Operations Management, Marketing and Information Technology. There was no restriction to the date of publication and searches were conducted between November 1, 2018 and December 31, 2018. This process identified 589 papers.

(3) Selection and evaluation of studies

After the first search phase, the abstracts, methodologies, main results and conclusions of the identified papers were closely examined in order to determine whether they were relevant to the Research Questions (SCF and CMS/MP relationships). The following inclusion criteria were used for the papers selection: scientific papers; literature reviews and in press papers; written in English; peer-reviewed. Papers should be published in journals with impact indexes (JCR or SJR), which ensures the quality of primary research (Thomé et al., 2016). Also, the following exclusion criteria were applied to select papers consistent with this research: papers that do not refer to the subject of this research; duplicated items; and conference papers, books, theses, dissertations or patents. This process yielded 64 papers for further in-depth analysis. The processes of search, identification, inclusion and exclusion of papers has been done by two researchers who reached consensus on which papers should be considered in the subsequent stages of the review. This is a good practice in SLRs carried out in the Operations Management area, which could reduce the publication bias (Thomé et al., 2016). Figure 2.2 shows the 
PRISMA template of the paper identification/selection process, detailing how papers have been selected based on inclusion and exclusion criteria (Moher et al., 2009).

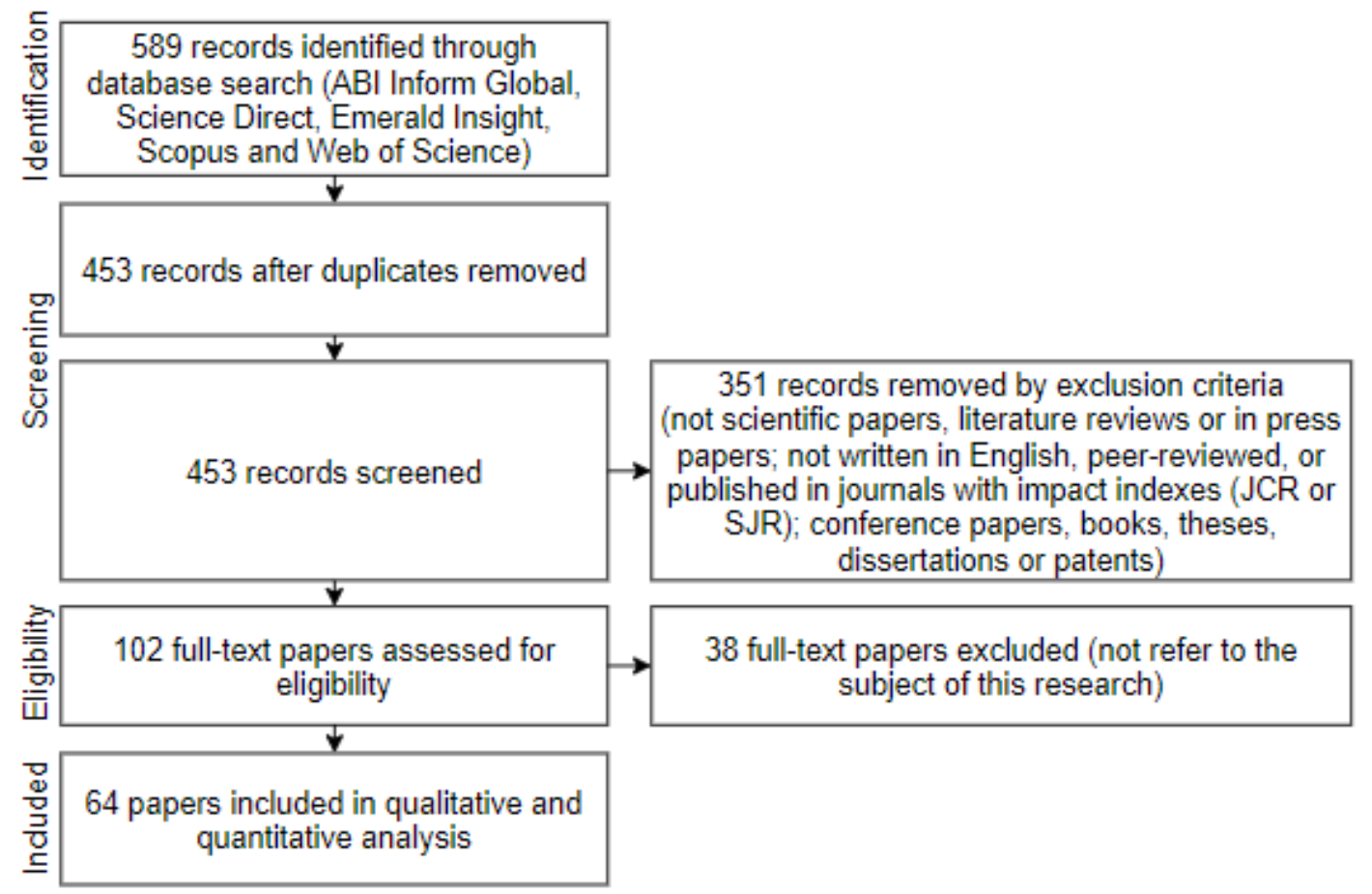

Figure 2.2. Identification and selection of the papers

Source: Own elaboration based on Moher et al. (2009)

(4) Analysis and synthesis

In the fourth step, the 64 papers selected and evaluated in the previous stage were analysed and synthesized. For this, each selected paper has been read in detail. The papers content has been coded, identifying their Main Topic, and the Research Line/subline in which they fit. Other important issues, such as the identification of the methodology used, contribution of each paper, and the industrial area addressed are also evaluated and classified in this stage. A database (Excel) has been created with the papers coding. Researchers have reached consensus on the coding and classification carried out, ensuring the inter-coders reliability (Thomé et al., 2016). This classification process is also a good practice in SLR papers in the Operations Management area (Thomé et al., 2016; Maçaira et al., 2018). Once the 64 papers have been analysed, the main research topic of each selected paper have been defined. These main research topics were partially defined in accordance with the proposals of Da Silveira et al. (2001), which suggested 'Processes and methodologies' and 'Enabling technologies' as dimensions to analyse the MP implementation. In addition, a common pattern of papers analysing 'Collaborative Processes' in the SCF and MP/CMS area has been observed and, for this reason, this main topic has been added to complement what has been 
suggested by Da Silveira et al. (2001). In the process of grouping papers by topic, both the use of previously used classification typologies and the observation of common patterns among the papers analysed are considered good practices in the methods of research analysis and synthesis (Tranfield et al., 2003). These three dimensions, therefore, have given rise to the main research topics related to the simultaneous relationship between SCF and CMS/MP, which are described below.

- Personalization levels and flexible processes in Supply Chain: The first main research topic includes studies in which the production strategies that support the development of flexible processes in Supply Chain as a productive response to the high levels of CMS/MP. Manufacturing systems, reconfigurable production, product configuration (modular production and product's family), and order preparation and delivery are practices related to this research field (Ismail et al., 2007; Al-Zaher et al., 2013; Levandowski et al., 2015).

- Collaborative processes in Supply Chain for SCF and CMS/MP: The second main research topic refers to products co-creation between Supply Chain members for SCF and CM/MP and the relationship with Supply Chain suppliers. In collaborative processes in Supply Chain for SCF and CMS/MP, customer demands are transmitted to a production unit, where a custom-made product is manufactured to meet those demands. In this way, customers act as a co-creators of products (Fogliatto and Da Silveira, 2008; Stojanov and Ding, 2015; Coker and Helo, 2016).

- SCF and CMS/MP enabling technologies: In the third main research topic are included the technologies that support the SCF and CMS/PM implementation. Data integration technologies, vision technologies, automation and robotics, and additive manufacturing enable the development of SCF in factories, as a way to support the CMS/PM implementation (Kaiser et al., 2015; Achillas et al., 2017).

For each main research topic (Level 1), the Research Lines were identified (Level 2) and finally the papers were classified into Research Sublines (Level 3). Thus, a three-level literature classification framework has been defined. It should be noted, as shown in Figure 2.3, that each Research Line and subline contains papers dealing with SCF and CMS/MP from specific perspectives. In this classification framework, each paper was located according to thematic content in the SCF-CMS/MP context. One paper can be classified into one or more groups at the same time. 


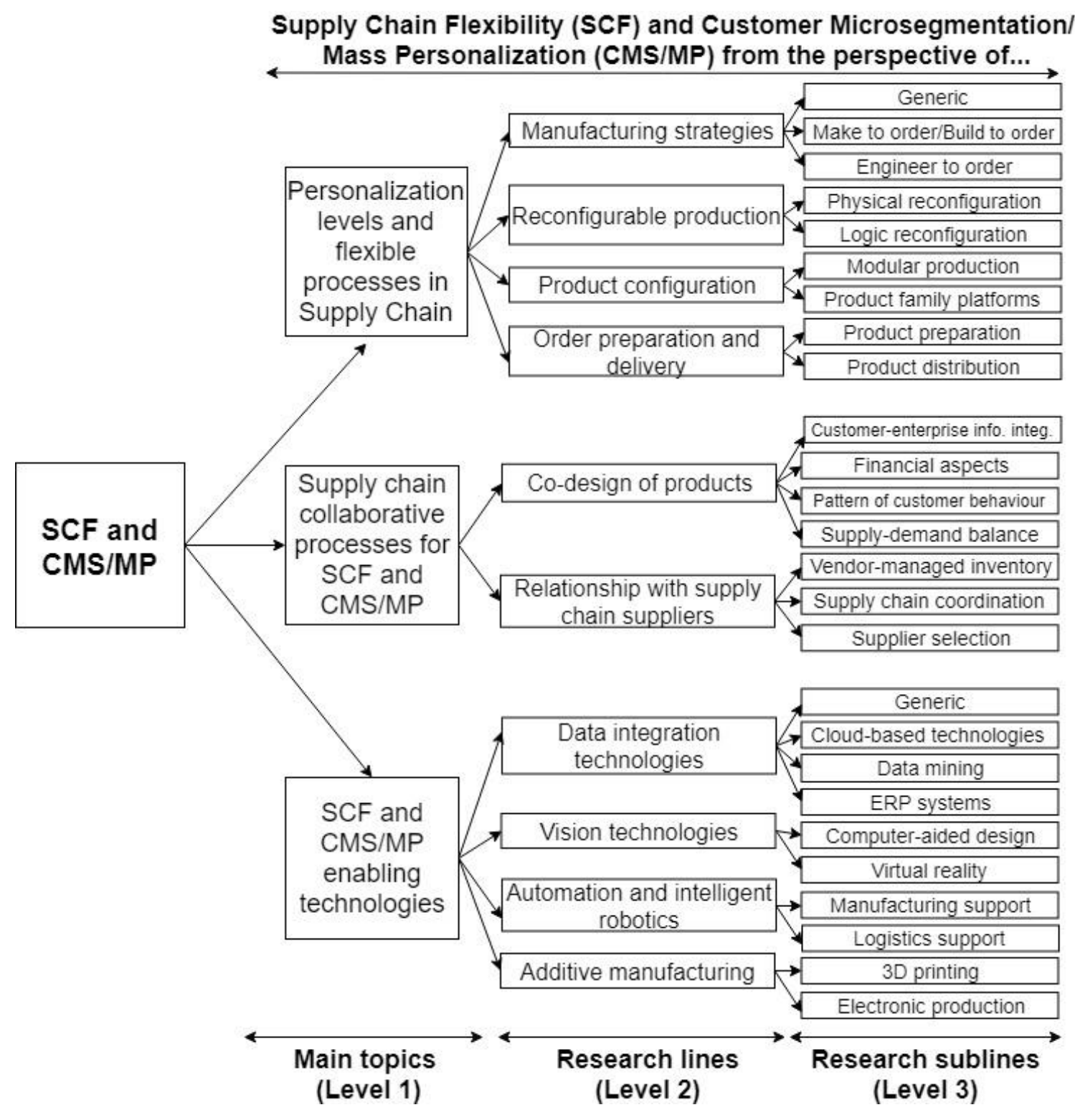

Figure 2.3. Literature classification framework

Source: Own elaboration

(5) Presentation of results

The main key topic of each paper was identified. Studies were then grouped into Main Topic and finally classified into Research Lines and Research Sublines. The methodology used for the search, selection and evaluation of papers is summarized in Figure 2.4. 


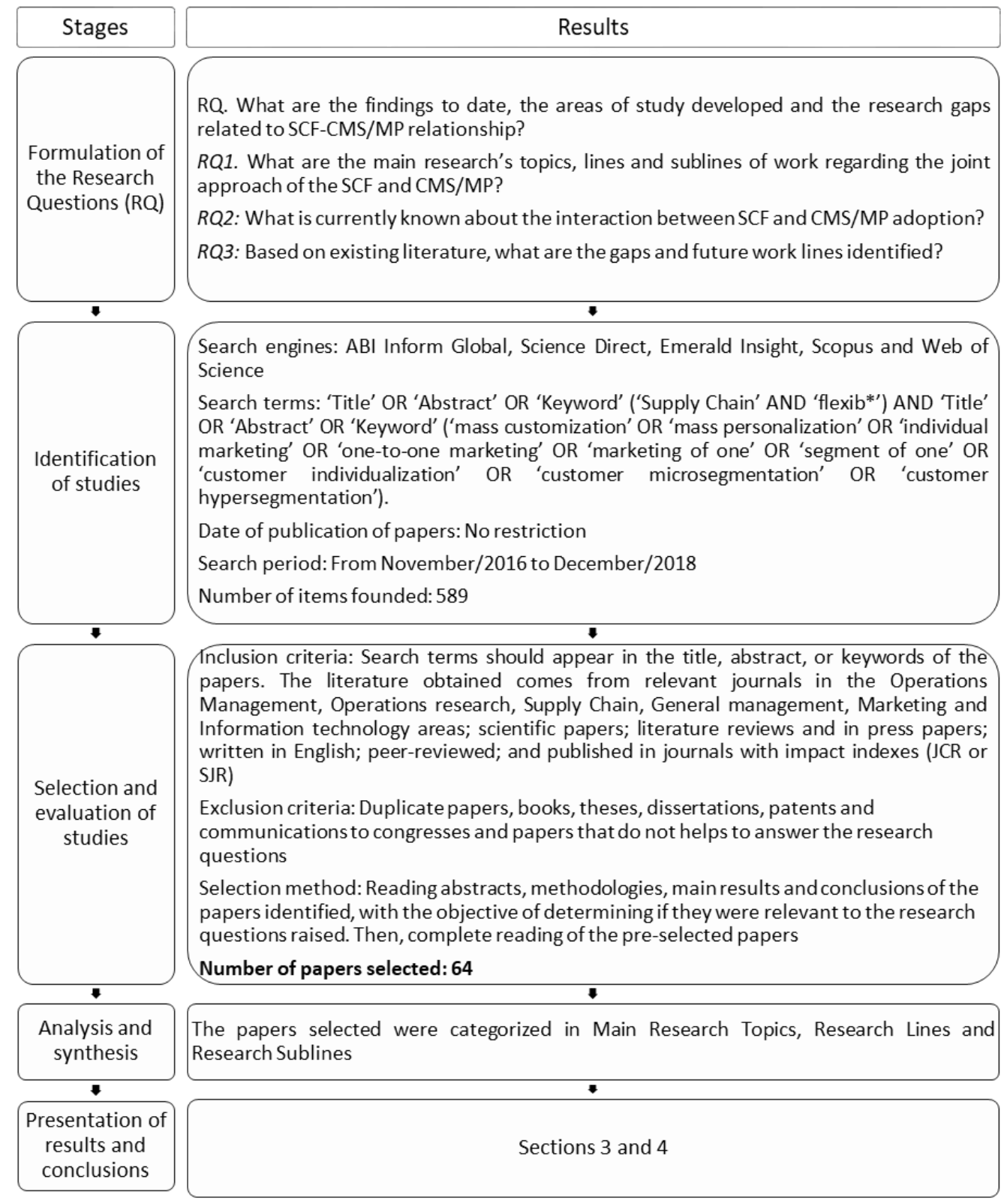

Figure 2.4. Summary of the research methodology Source: Own elaboration

In the following section, the research results are presented and discussed.

\subsection{RESULTS AND DISCUSSION}

First, a descriptive analysis is given of the identified papers; next, the personalization levels and flexible processes in Supply Chain are addressed, followed by the enabling technologies analysis for SCF and CMS/MP; finally, the collaborative processes for SCF and CMS/MP are addressed. 


\subsubsection{DESCRIPTIVE RESULTS}

First, a chronological approximation is used, classifying the selected papers by year of publication (Figure 2.5). The first paper on this research topic were published in 1997 (Fisher, 1997) and 2015 is the year with the highest number of publications (eight papers) to date. From the first localized paper (1997) to the current date (2018) there is an increasing trend in the number of publications analysing simultaneously SCF and CMS/MP (dashed line).

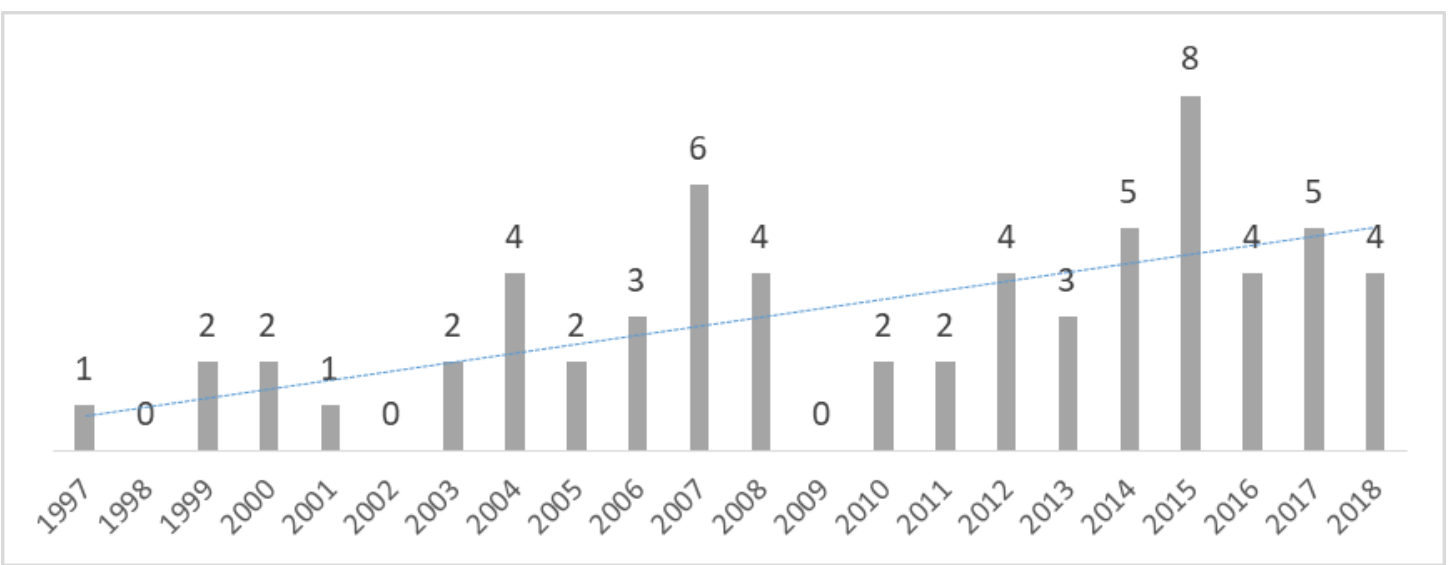

Figure 2.5. Time evolution of research on SCF and CMS/MP Source: Own elaboration

Moreover, Table 2.1 lists the Journals in which papers dealing with the relationship between the SCF and CMS/MP have been published. These journals deal mainly with Operations Management, Marketing, and Computer Science. This emphasizes the multidisciplinary nature and relevance of the subject under investigation. International Journal of Production Research and Production Planning and Control appear as those in which most papers relating simultaneously SCF and CMS/MP have been located. 
Table 2.1. Journals in which the papers analysed were published

\begin{tabular}{|c|c|c|c|}
\hline Reference & Journal & Sum & $\begin{array}{c}\% \\
\text { total }\end{array}$ \\
\hline $\begin{array}{l}\text { Achillas et al. (2017), Chen and } \\
\text { Chen (2008), Hanafy and } \\
\text { Elmaraghy (2015), Tse et al. } \\
\text { (2012), Gualandris et al. } \\
\text { (2013), Vickery et al. (2015) }\end{array}$ & International Journal of Production Research & 6 & $9 \%$ \\
\hline $\begin{array}{l}\text { Comstock et al. (2004), } \\
\text { Coronado et al. (2004), Purohit } \\
\text { et al. (2016), Potter et al. } \\
\text { (2004), } \\
\text { Furst and Schmidt (2001) }\end{array}$ & Production Planning and Control & 5 & $8 \%$ \\
\hline $\begin{array}{l}\text { Dev, Shankar and Dey (2014), } \\
\text { Coker and Helo (2016) }\end{array}$ & Benchmarking: An International Journal & 2 & $3 \%$ \\
\hline $\begin{array}{l}\text { Dev et al. (2014), Yao and Xu } \\
\text { (2018) }\end{array}$ & Computers \& Industrial Engineering & 2 & $3 \%$ \\
\hline $\begin{array}{l}\text { Ismail et al. (2007), Huang et al. } \\
(2007)\end{array}$ & IEEE Transactions on Engineering Management & 2 & $3 \%$ \\
\hline $\begin{array}{l}\text { Jiao et al. (2006), Custodio et } \\
\text { al. (2018) }\end{array}$ & $\begin{array}{l}\text { International Journal of Advanced Manufacturing } \\
\text { Technology }\end{array}$ & 2 & $3 \%$ \\
\hline $\begin{array}{l}\text { Kaiser et al. (2015), Molina et } \\
\text { al. (2005) }\end{array}$ & $\begin{array}{l}\text { International Journal of Computer Integrated } \\
\text { Manufacturing }\end{array}$ & 2 & $3 \%$ \\
\hline $\begin{array}{l}\text { Peng and Yu (2007), Schuh et } \\
\text { al. (2007) }\end{array}$ & $\begin{array}{l}\text { International Journal of Manufacturing Technology } \\
\text { and Management }\end{array}$ & 2 & $3 \%$ \\
\hline $\begin{array}{l}\text { Fogliatto and Da Silveira } \\
\text { (2008), Um et al. (2017) }\end{array}$ & International Journal of Production Economics & 2 & $3 \%$ \\
\hline $\begin{array}{l}\text { Morariu et al. (2015), Stump } \\
\text { and Badurdeen (2012) }\end{array}$ & Journal of Intelligent Manufacturing & 2 & $3 \%$ \\
\hline $\begin{array}{l}\text { Al-Zaher et al. (2013), Nobre et } \\
\text { al. (2008) }\end{array}$ & Journal of Manufacturing Systems & 2 & $3 \%$ \\
\hline $\begin{array}{l}\text { Alsafi and Vyatkin (2010), } \\
\text { Wong et al. (2007) }\end{array}$ & Robotics and Computer-Integrated Manufacturing & 2 & $3 \%$ \\
\hline Marin and Brîndaşu (2015) & Academic Journal of Manufacturing Engineering & 1 & $2 \%$ \\
\hline Urgo et al. (2016) & Computer-Aided Design and Applications & 1 & $2 \%$ \\
\hline Morariu et al. (2016) & Computers in Industry & 1 & $2 \%$ \\
\hline Fung et al. (2004) & Concurrent Engineering Research and Applications & 1 & $2 \%$ \\
\hline Zhong et al. (2017) & Engineering & 1 & $2 \%$ \\
\hline Akkermans et al. (2003) & European Journal of Operational Research & 1 & $2 \%$ \\
\hline Stojanov and Ding (2015) & Fibres and Textiles in Eastern Europe & 1 & $2 \%$ \\
\hline Fisher (1997) & Harvard Business Review & 1 & $2 \%$ \\
\hline Lau et al. (2007) & Industrial Management \& Data Systems & 1 & $2 \%$ \\
\hline Claycomb et al. (2005) & Industrial Marketing Management & 1 & $2 \%$ \\
\hline Lee et al. (1999) & International Journal of Agile Management Systems & 1 & $2 \%$ \\
\hline Costantino et al. (2014) & International Journal of Applied Decision Sciences & 1 & $2 \%$ \\
\hline Strasser et al. (2011) & $\begin{array}{l}\text { International Journal of Computer Aided Engineering } \\
\text { and Technology }\end{array}$ & 1 & $2 \%$ \\
\hline Ho et al. (2008) & $\begin{array}{llll}\text { International Journal of Enterprise Network } \\
\text { Management }\end{array}$ & 1 & $2 \%$ \\
\hline Koo and Tanchoco (1999) & $\begin{array}{l}\text { International Journal of Flexible Automation and } \\
\text { Integrated Manufacturing }\end{array}$ & 1 & $2 \%$ \\
\hline Chen and Tseng (2007) & $\begin{array}{l}\text { International Journal of Flexible Manufacturing } \\
\text { Systems }\end{array}$ & 1 & $2 \%$ \\
\hline Kumar et al. (2015) & $\begin{array}{l}\text { International Journal of Industrial and Systems } \\
\text { Engineering }\end{array}$ & 1 & $2 \%$ \\
\hline Um (2017) & International Journal Of Logistics Management & 1 & $2 \%$ \\
\hline Wurzer and Reiner (2018) & $\begin{array}{l}\text { International Journal Of Operations \& Production } \\
\text { Management }\end{array}$ & 1 & $2 \%$ \\
\hline Engelhardt-Nowitzki (2012) & $\begin{array}{l}\text { International Journal of Physical Distribution \& } \\
\text { Logistics Management }\end{array}$ & 1 & $2 \%$ \\
\hline
\end{tabular}




\begin{tabular}{|c|c|c|c|}
\hline Chung et al. (2018) & Applied Sciences-Basel & 1 & $2 \%$ \\
\hline Squire et al. (2006) & $\begin{array}{l}\text { International Journal of Productivity and Quality } \\
\text { Management }\end{array}$ & 1 & $2 \%$ \\
\hline Kim (2014) & $\begin{array}{l}\text { International Journal of Services and Operations } \\
\text { Management }\end{array}$ & 1 & $2 \%$ \\
\hline Wadhwa and Rao (2000) & International Journal of Technology Management & 1 & $2 \%$ \\
\hline Favi and Germani (2012) & $\begin{array}{l}\text { International Journal on Interactive Design and } \\
\text { Manufacturing }\end{array}$ & 1 & $2 \%$ \\
\hline Frutos and Borenstein (2003) & $\begin{array}{lrrr}\text { Journal of } & \text { Construction } & \text { Engineering } & \text { and } \\
\text { Management } & & & \\
\end{array}$ & 1 & $2 \%$ \\
\hline Levandowski et al. (2015) & Journal of Engineering Design & 1 & $2 \%$ \\
\hline Griffiths and Margetts (2000) & Journal of Materials Processing Technology & 1 & $2 \%$ \\
\hline Kortmann et al. (2014) & Journal Of Operations Management & 1 & $2 \%$ \\
\hline Tien (2011) & $\begin{array}{l}\text { Journal of Systems Science and } \\
\text { Engineering }\end{array}$ & 1 & $2 \%$ \\
\hline Wiengarten et al. (2017) & Operations Management Research & 1 & $2 \%$ \\
\hline Brabazon et al. (2010) & Production and Operations Management & 1 & $2 \%$ \\
\hline Padayachee and Bright (2003) & South African Journal of Industrial Engineering & 1 & $2 \%$ \\
\hline Total & & 64 & $100 \%$ \\
\hline
\end{tabular}

Table 2.2 presents the countries of origin of the main authors of the papers analysed. The results show a considerable geographical dispersion, which emphasizes that researchers from different parts of the world are interested in the SCF-CMS/MP research area. The countries that concentrate the greatest number of main authors of the papers identified are the United Kingdom, China and the United States.

Table 2.2. Countries of origin of the main authors

\begin{tabular}{|c|c|c|c|}
\hline Reference & Country & Sum & $\%$ \\
\hline $\begin{array}{l}\text { Brabazon et al. (2010), Coronado et al. (2004), Griffiths and } \\
\text { Margetts (2000), Ismail et al. (2007), Potter et al. (2004), Squire } \\
\text { et al. (2006), Tse et al. (2012), Um (2017), Um et al. (2017) }\end{array}$ & United Kingdom & 9 & $14 \%$ \\
\hline $\begin{array}{l}\text { Fung et al. (2004), Ho et al. (2008), Lee et al. (1999), Stojanov } \\
\text { and Ding (2015), Yao and Xu (2018), Huang et al. (2007), Lau et } \\
\text { al. (2007) }\end{array}$ & China & 7 & $11 \%$ \\
\hline $\begin{array}{l}\text { Chen and Chen (2008), Claycomb et al. (2005), Stump and } \\
\text { Badurdeen (2012), Tien (2011), Fisher (1997), Vickery et al. } \\
\text { (2015) }\end{array}$ & United States & 6 & $9 \%$ \\
\hline $\begin{array}{l}\text { Dev, Shankar and Dey (2014), Kumar et al. (2015), Purohit et al. } \\
\text { (2016), Wadhwa and Rao (2000), Dev et al., (2014) }\end{array}$ & India & 5 & $8 \%$ \\
\hline $\begin{array}{l}\text { Costantino et al. (2014), Favi and Germani (2012), Urgo et al. } \\
\text { (2016), Gualandris et al. (2013) }\end{array}$ & Italy & 4 & $6 \%$ \\
\hline $\begin{array}{l}\text { Strasser et al. (2011), Engelhardt-Nowitzki (2012), Furst and } \\
\text { Schmidt (2001) }\end{array}$ & Austria & 3 & $5 \%$ \\
\hline $\begin{array}{l}\text { Fogliatto and Da Silveira (2008), Nobre et al. (2008), Custodio et } \\
\text { al. (2018) }\end{array}$ & Brazil & 3 & $5 \%$ \\
\hline $\begin{array}{l}\text { Al-Zaher et al. (2013), Hanafy and Elmaraghy (2015), Peng and } \\
\text { Yu (2007) }\end{array}$ & Canada & 3 & $5 \%$ \\
\hline $\begin{array}{l}\text { Marin and Brîndaşu (2015), Morariu et al. (2016), Morariu et al. } \\
\text { (2015) }\end{array}$ & Romania & 3 & $5 \%$ \\
\hline Chen and Tseng (2007), Jiao et al. (2006), Wong et al. (2007) & Singapore & 3 & $5 \%$ \\
\hline Chung et al. (2018), Kim (2014), Koo and Tanchoco (1999) & South Korea & 3 & $5 \%$ \\
\hline Kaiser et al. (2015), Schuh et al. (2007) & Germany & 2 & $3 \%$ \\
\hline Akkermans et al. (2003), Kortmann et al. (2014) & Holland & 2 & $3 \%$ \\
\hline
\end{tabular}




\begin{tabular}{|c|c|c|c|}
\hline Alsafi and Vyatkin (2010), Zhong et al. (2017) & New Zealand & 2 & $3 \%$ \\
\hline Comstock et al. (2004), Levandowski et al. (2015) & Sweden & 2 & $3 \%$ \\
\hline Frutos and Borenstein (2003) & Argentina & 1 & $2 \%$ \\
\hline Wurzer and Reiner (2018) & Australia & 1 & $2 \%$ \\
\hline Coker and Helo (2016) & Finland & 1 & $2 \%$ \\
\hline Achillas et al. (2017) & Greece & 1 & $2 \%$ \\
\hline Molina et al. (2005) & Mexico & 1 & $2 \%$ \\
\hline Padayachee and Bright (2003) & South Africa & 1 & $2 \%$ \\
\hline Wiengarten et al. (2017) & Spain & 1 & $2 \%$ \\
\hline \multicolumn{2}{|l|}{ TOTAL } & 64 & $100 \%$ \\
\hline
\end{tabular}

Table 2.3 shows the industrial sectors that have been considered in the revised papers. Sixty-seven percent of the papers have a generic approach, i.e. do not specifically target an industrial sector. Although the automotive, fashion and energy sectors have been approached with some profusion, there is a paucity of studies applied to the particularities of specific industrial sectors.

Table 2.3. Industrial sectors analysed

\begin{tabular}{|c|c|c|c|}
\hline Reference & Industrial sector & Sum & $\%$ \\
\hline $\begin{array}{l}\text { Achillas et al. (2017), Akkermans et al. (2003), Alsafi and } \\
\text { Vyatkin (2010), Chen and Chen (2008), Chen and Tseng } \\
\text { (2007), Coker and Helo (2016), Coronado et al. (2004), } \\
\text { Costantino et al. (2014), Chung et al. (2018), Dev, Shankar } \\
\text { and Dey (2014), Dev et al. (2014), Engelhardt-Nowitzki } \\
\text { (2012), Fisher (1997), Furst and Schmidt (2001), } \\
\text { Gualandris et al. (2013), Hanafy and Elmaraghy (2015), } \\
\text { Huang et al. (2007), Ismail et al. (2007), Jiao et al. (2006), } \\
\text { Koo and Tanchoco (1999), Kortmann et al. (2014), Kumar } \\
\text { et al. (2015), Lau et al. (2007), Lee et al. (1999), Marin and } \\
\text { Brîndaşu (2015), Molina et al. (2005), Morariu et al. (2016), } \\
\text { Morariu et al. (2015), Nobre et al. (2008), Peng and Yu } \\
\text { (2007), Potter et al. (2004), Squire et al. (2006), Strasser et } \\
\text { al. (2011), Stump and Badurdeen (2012), Tse et al. (2012), } \\
\text { Urgo et al. (2016), Um (2017), Um et al. (2017), Vickery et } \\
\text { al. (2015), Wiengarten et al. (2017), Wong et al. (2007), } \\
\text { Wurzer and Reiner (2018), Zhong et al. (2017) }\end{array}$ & Generic & 43 & $67 \%$ \\
\hline $\begin{array}{l}\text { Al-Zaher et al. (2013), Brabazon et al. (2010), Griffiths and } \\
\text { Margetts (2000), Kim (2014), Levandowski et al. (2015), } \\
\text { Schuh et al. (2007) }\end{array}$ & Automotive & 6 & $9 \%$ \\
\hline $\begin{array}{l}\text { Fung et al. (2004), Purohit et al. (2016), Stojanov and Ding } \\
(2015), \text { Tien (2011), Yao and Xu (2018) }\end{array}$ & Fashion & 5 & $8 \%$ \\
\hline $\begin{array}{l}\text { Custodio et al. (2018), Fogliatto and Da Silveira (2008), Ho } \\
\text { et al. (2008) }\end{array}$ & Energy & 3 & $5 \%$ \\
\hline Comstock et al. (2004), Wadhwa and Rao (2000) & Technology & 2 & $3 \%$ \\
\hline Frutos and Borenstein (2003) & Building & 1 & $2 \%$ \\
\hline Claycomb et al. (2005) & E-commerce & 1 & $2 \%$ \\
\hline Favi and Germani (2012) & Household Appliances & 1 & $2 \%$ \\
\hline Padayachee and Bright (2003) & Flashlights & 1 & $2 \%$ \\
\hline Kaiser et al. (2015) & Medical products & 1 & $2 \%$ \\
\hline \multicolumn{2}{|l|}{ TOTAL } & 64 & $100 \%$ \\
\hline
\end{tabular}




\subsubsection{LITERATURE CLASSIFICATION AND ANALYSIS: MAIN TOPICS, RESEARCH LINES AND RESEARCH SUBLINES}

Table 2.4 classifies the papers analysed according to the three Main Topics, Research Lines and Research Sublines identified. All Research Lines and Research Sublines simultaneously deal with SCF and CMS/MP from a specific perspective (see Figure 2.3). The data show that the group 'Personalization levels and flexible processes in Supply Chain' stands out as the Main Topic most approached so far. In this Main Topic, the first Research Line focuses on manufacturing systems, referring to the relationship between SCF and CMS/MP from a generic approach, as well as in the make-to-order/build-toorder and engineer-to-order fields. Reconfigurable production is the second Research Line and is focused on the application of physical and logical reconfigurations to Supply Chain processes for SCF and CMS/MP. The third Research Line focuses on product configuration for SCF and CMS/MP from the perspective of modular production and product family platforms. At last, order preparation and delivery strategies is the fourth subgroup in this Main Topic, and refers to the assembly and distribution processes in SCF and CMS/MP.

Table 2.4. Literature classification

\begin{tabular}{|c|c|c|c|c|}
\hline $\begin{array}{c}\begin{array}{c}\text { Main Topic } \\
\text { (Level 1) }\end{array} \\
\end{array}$ & $\begin{array}{c}\text { Research Line } \\
\text { (Level 2) }\end{array}$ & $\begin{array}{c}\text { Research Subline } \\
\text { (Level 3) }\end{array}$ & Reference & $\%$ \\
\hline \multirow{6}{*}{$\begin{array}{l}\text { Personalization } \\
\text { levels and } \\
\text { flexible } \\
\text { processes }\end{array}$} & \multirow{3}{*}{ Manufacturing systems } & Generic & $\begin{array}{l}\text { Comstock et al. (2004), } \\
\text { Coronado et al. (2004), } \\
\text { Kortmann et al. (2014) }\end{array}$ & \multirow{6}{*}{$49 \%$} \\
\hline & & $\begin{array}{l}\text { Make to order/ } \\
\text { Build to order }\end{array}$ & $\begin{array}{l}\text { Brabazon et al. (2010), } \\
\text { Claycomb et al. (2005), } \\
\text { Custodio et al. (2018), } \\
\text { Engelhardt-Nowitzki } \\
(2012)\end{array}$ & \\
\hline & & Engineer to order & $\begin{array}{l}\text { Levandowski et al. } \\
(2015), \text { Wadhwa and } \\
\text { Rao (2000) }\end{array}$ & \\
\hline & \multirow[t]{2}{*}{$\begin{array}{l}\text { Reconfigurable } \\
\text { manufacturing }\end{array}$} & $\begin{array}{l}\text { Physical } \\
\text { reconfiguration }\end{array}$ & $\begin{array}{l}\text { Al-Zaher et al. (2013), } \\
\text { Chen and Chen (2008), } \\
\text { Dev, Shankar and Dey } \\
\text { (2014), Koo and } \\
\text { Tanchoco (1999), } \\
\text { Molina et al. (2005), } \\
\text { Stump and Badurdeen } \\
(2012) \text { Urgo et al. } \\
(2016) \text {, Wong et al. } \\
(2007)\end{array}$ & \\
\hline & & $\begin{array}{l}\text { Logic } \\
\text { reconfiguration }\end{array}$ & $\begin{array}{l}\text { Alsafi and Vyatkin } \\
\text { (2010), Al-Zaher et al. } \\
(2013), \quad \text { Dev et al. } \\
\text { (2014), Stump and } \\
\text { Badurdeen (2012) }\end{array}$ & \\
\hline & Product configuration & $\begin{array}{l}\text { Modular } \\
\text { production }\end{array}$ & $\begin{array}{l}\text { Favi and Germani } \\
\text { (2012), Gualandris et al. } \\
\text { (2013), Ismail et al. } \\
\text { (2007), Purohit et al. }\end{array}$ & \\
\hline
\end{tabular}




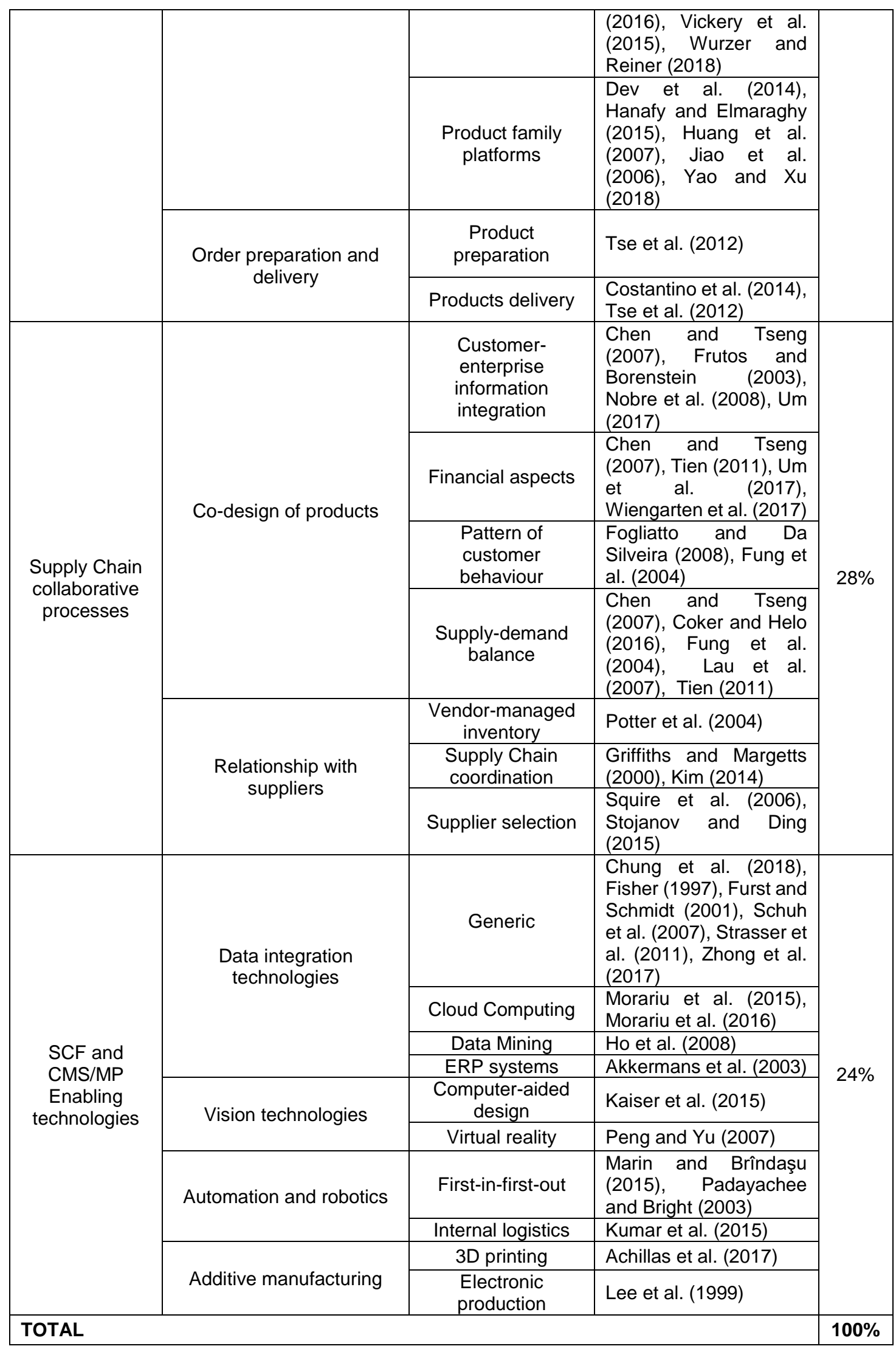

Moreover, 'Collaborative Processes in Supply Chain for SCF and CMS/MP' ranks as the second Main Topic in terms of volume of published papers. In this Main Topic, the first 
Research Line focuses on co-creation of products, focusing on customer-factory interaction, customer behaviour patterns, supply-demand balance and financial aspects. The second Research Line investigates the relationship with partners focusing on supplier-managed inventory strategies, Supply Chain coordination issues, and supplier selection.

Finally, 'SCF and CMS/MP Enabling technologies' is the least researched group to date. Data integration technologies is the first Research Line in this Main Topic and focuses on the use of cloud computing, data mining, ERP systems, and generic information technologies. The second Research Line investigates the vision technologies, focusing on use of computer-aided design and virtual reality. Automation and robotics from the perspective of first-in-first-out strategies and issues related to internal logistics is the third Research Line. At last, the fourth Research Line analyses the additive manufacturing, referring to the use of 3D printing and electronic production.

In the following subsections, are detailed each of the three Main Topics, as well as the Research Lines and Research Sublines described above. In the tables that will be presented below (Tables 2.5, 2,6 and 2.7), each paper is classified according to the Main Topic, Research Lines and Research Sublines that it is located. For each paper, the Research Lines/sublines in which it is located is identified with an "X". It is important to note that a paper may be located in one or more Research Lines/sublines.

\subsubsection{Personalization levels and flexible processes in Supply Chain}

Table 2.5 provides the classification of the papers related to the Main Topic 'Personalization levels and flexible processes in Supply Chain'. The Research Lines/sublines that deal with the SCF-CMS/MP relationship in the first Main Topic are described below. 
Table 2.5. Papers related to personalization levels and flexible processes in Supply Chain

\begin{tabular}{|c|c|c|c|c|c|c|c|c|c|}
\hline & \multicolumn{3}{|c|}{ Manufacturing systems } & \multicolumn{2}{|c|}{$\begin{array}{l}\text { Reconfigurable } \\
\text { manufacturing }\end{array}$} & \multicolumn{2}{|c|}{$\begin{array}{c}\text { Product } \\
\text { configuration }\end{array}$} & \multicolumn{2}{|c|}{$\begin{array}{l}\text { Preparation } \\
\text { and delivery }\end{array}$} \\
\hline Reference & GEN & MTO/BTO & ETO & PR & LR & MP & PFP & PP & PD \\
\hline $\begin{array}{c}\text { Alsafi and } \\
\text { Vyatkin (2010) }\end{array}$ & & & & & $\mathrm{x}$ & & & & \\
\hline $\begin{array}{c}\text { Al-Zaher et al. } \\
(2013)\end{array}$ & & & & $\mathrm{x}$ & $\mathrm{x}$ & & & & \\
\hline $\begin{array}{c}\text { Brabazon et al. } \\
(2010)\end{array}$ & & $x$ & & & & & & & \\
\hline $\begin{array}{l}\text { Chen and Chen } \\
\text { (2008) }\end{array}$ & & & & $\mathrm{x}$ & & & & & \\
\hline $\begin{array}{c}\text { Claycomb et al. } \\
(2005)\end{array}$ & & $x$ & & & & & & & \\
\hline $\begin{array}{c}\text { Comstock et al. } \\
(2004)\end{array}$ & $x$ & & & & & & & & \\
\hline $\begin{array}{l}\text { Coronado et al. } \\
(2004)\end{array}$ & $x$ & & & & & & & & \\
\hline $\begin{array}{c}\text { Costantino et al. } \\
(2014)\end{array}$ & & & & & & & & & $x$ \\
\hline $\begin{array}{c}\text { Custodio et al. } \\
(2018)\end{array}$ & & $\mathrm{X}$ & & & & & & & \\
\hline Dev et al. (2014) & & & & & & & $x$ & & \\
\hline $\begin{array}{l}\text { Dev, Shankar } \\
\text { and Dey (2014) }\end{array}$ & & & & $\mathrm{x}$ & $\mathrm{x}$ & & & & \\
\hline $\begin{array}{c}\text { Engelhardt- } \\
\text { Nowitzki (2012) }\end{array}$ & & $x$ & & & & & & & \\
\hline $\begin{array}{c}\text { Favi and } \\
\text { Germani (2012) }\end{array}$ & & & & & & $\mathrm{x}$ & & & \\
\hline $\begin{array}{c}\text { Gualandris et al. } \\
(2013)\end{array}$ & & & & & & $\mathrm{x}$ & & & \\
\hline $\begin{array}{c}\text { Hanafy and } \\
\text { Elmaraghy } \\
(2015)\end{array}$ & & & & & & & $\mathrm{x}$ & & \\
\hline $\begin{array}{c}\text { Huang et al. } \\
(2007)\end{array}$ & & & & & & & $x$ & & \\
\hline $\begin{array}{l}\text { Ismail et al. } \\
(2007)\end{array}$ & & & & & & $x$ & & & \\
\hline Jiao et al. (2006) & & & & & & & $x$ & & \\
\hline $\begin{array}{c}\text { Koo and } \\
\text { Tanchoco (1999) }\end{array}$ & & & & $\mathrm{x}$ & & & & & \\
\hline $\begin{array}{c}\text { Kortmann et al. } \\
(2014)\end{array}$ & $x$ & & & & & & & & \\
\hline $\begin{array}{l}\text { Levandowski et } \\
\text { al. (2015) }\end{array}$ & & & $x$ & & & & & & \\
\hline $\begin{array}{l}\text { Molina et al. } \\
(2005)\end{array}$ & & & & $\mathrm{x}$ & & & & & \\
\hline $\begin{array}{l}\text { Purohit et al. } \\
(2016)\end{array}$ & & & & & & $\mathrm{x}$ & & & \\
\hline $\begin{array}{l}\text { Stump and } \\
\text { Badurdeen } \\
(2012)\end{array}$ & & & & $x$ & $x$ & & & & \\
\hline Tse et al. (2012) & & & & & & & & $x$ & $x$ \\
\hline $\begin{array}{l}\text { Urgo et al. } \\
\text { (2016) }\end{array}$ & & & & $x$ & & & & & \\
\hline $\begin{array}{c}\text { Vickery et al. } \\
(2015)\end{array}$ & & & & & & $x$ & & & \\
\hline $\begin{array}{c}\text { Wadhwa and } \\
\text { Rao (2000) }\end{array}$ & & & $x$ & & & & & & \\
\hline $\begin{array}{l}\text { Wong et al. } \\
(2007)\end{array}$ & & & & & $\mathrm{x}$ & & & & \\
\hline $\begin{array}{c}\text { Wurzer and } \\
\text { Reiner (2018) }\end{array}$ & & & & & & $\mathrm{x}$ & & & \\
\hline $\begin{array}{c}\text { Yao and Xu } \\
(2018)\end{array}$ & & & & & & & $x$ & & \\
\hline TOTAL & 3 & 4 & 2 & 7 & 5 & 6 & 5 & 1 & 2 \\
\hline \multirow{2}{*}{$\%$} & $9 \%$ & $11 \%$ & $6 \%$ & $20 \%$ & $14 \%$ & $17 \%$ & $14 \%$ & $3 \%$ & $6 \%$ \\
\hline & \multicolumn{3}{|c|}{$26 \%$} & \multicolumn{2}{|c|}{$34 \%$} & \multicolumn{2}{|c|}{$31 \%$} & \multicolumn{2}{|c|}{$9 \%$} \\
\hline
\end{tabular}




\section{Manufacturing systems}

Comstock et al. (2004) and Coronado et al. (2004) analyse the relationship between the order penetration point (the stage of manufacturing at which the customer's order is considered) and the personalization levels. Moving downstream in Supply Chain from the point of order penetration could increase process efficiency and reduce lead times, but CMS/MP levels would also become lower. On the other hand, changes upstream in Supply Chain of the final product assembly process could significantly increase the variety of products (a type of flexibility), but production costs would also be higher (Comstock et al., 2004; Coronado et al., 2004). Moreover, Kortmann et al. (2014) identify that the CMS/MP capability has a positive mediating relationship between SCF and operational efficiency, which represents an important competitive advantage.

In order-based manufacturing environments, such as make-to-order (Claycomb et al., 2005; Custodio et al., 2018), build-to-order (Brabazon et al., 2010; Engelhardt-Nowitzki, 2012) and engineer-to-order (Wadhwa and Rao, 2000; Levandowski et al., 2015), production activity could start only after orders are received. Make-to-order/Build-toorder represents the finished product manufacture once the customer places a sales order, while in Engineer-to-order the customer defines practically all the product characteristics. Make-to-order/ Build-to-order significantly increases the flexibility level in Supply Chain and reduces finished product inventory levels and manufacturing time (Claycomb et al., 2005). This manufacturing strategy can bring significant benefits in terms of reduced lead times and inventory holdings, allowing companies to achieve flexibility in adapting to market volatility (Brabazon et al., 2010; Engelhardt-Nowitzki, 2012; Custodio et al., 2018). In Engineer-to-order, production flexibility is scalable and aspects related to cycle times, production costs, quality and higher CMS/MP levels could be managed along the Supply Chain (Wadhwa and Rao, 2000; Levandowski et al., 2015).

\section{Reconfigurable production}

Reconfigurable production systems can offer a variety of products in short production and with a high flexibility level. In this sense, physical and logical reconfigurations along the Supply Chain can favour manufacturing operations, making it more efficient (e.g. Stump and Badurdeen, 2012; Al-Zaher et al., 2013; Dev, Shankar and Dey, 2014). Through physical reconfiguration, it is possible to reduce machine and tool downtime and improve the decision-making process under uncertain conditions (e.g. choice of equipment and process routes) (e.g. Koo and Tanchoco, 1999; Molina et al., 2005; Chen 
and Chen, 2008; Urgo et al., 2016). Logical reconfiguration allows manufacturing processes to be streamlined without human intervention, which could minimize overall costs through process reconfiguration (Wong et al., 2007; Alsafi and Vyatkin, 2010; Stump and Badurdeen, 2012; Al-Zaher et al., 2013; Dev et al., 2014).

\section{Product configuration}

Through the product configuration, it is possible to group basic elements into a common module, which is used to derive different product variants. Modular production (Ismail et al., 2007; Favi and Germani, 2012; Gualandris et al., 2013; Vickery et al., 2015; Purohit et al., 2016; Wurzer and Reiner, 2018) and product family platforms (Jiao et al., 2006; Huang et al., 2007; Dev et al., 2014, Hanafy and Elmaraghy, 2015; Yao and Xu, 2018) increase the responsiveness of the production system along the Supply Chain and are an effective way to achieve higher levels of SCF and CMS/MP. Modular production stands out as one of the main facilitators of CMS/MP and has positive impacts on SCF (Gualandris et al., 2013), improving production time (Vickery et al., 2015), and reducing processes costs (Ismail et al., 2007; Favi and Germani, 2012; Purohit et al., 2016; Wurzer and Reiner, 2018). Through the use of a common platform for developing/configuring products, the product family platforms allows companies to adapting rapidly and dynamically to demand changes (Huang et al., 2007; Dev et al., 2014; Yao and $\mathrm{Xu}, 2018$ ), reducing time-to-market and delivery times (Jiao et al., 2006; Hanafy and Elmaraghy, 2015).

\section{Order preparation and delivery}

CMS/MP requires not only manufacturing flexibility at a lower cost, but also specific logistics solutions to manage the high level of differentiation. In this sense, activities related to product preparation, such as collection planning and packaging (Tse et al., 2012), and flexible distribution (Costantino et al., 2014) can reduce the negative effects of environmental variability, inefficiencies in transport and act as a support for CMS/MP (Tse et al., 2012; Costantino et al., 2014).

\subsubsection{Supply Chain collaborative processes for SCF and CMS/MP}

Table 2.6 provides the classification of the papers related to Supply Chain collaborative processes for SCF and CSM/MP (second Main Topic). The Research Lines/sublines that deal with the SCF-CMS/MP relationship in this Main Topic are described below. 
Table 2.6. Papers related to Supply Chain collaborative processes for SCF-CMS/MP

\begin{tabular}{|c|c|c|c|c|c|c|c|}
\hline \multirow{2}{*}{ Reference } & \multicolumn{4}{|c|}{ Co-creation of products } & \multicolumn{3}{|c|}{ Relationship with suppliers } \\
\hline & CEI & FA & PCB & SDB & VMI & SCC & SS \\
\hline Chen and Tseng (2007) & $\mathrm{X}$ & $\mathrm{X}$ & & $\mathrm{X}$ & & & \\
\hline $\begin{array}{c}\text { Fogliatto and Da Silveira } \\
(2008)\end{array}$ & & & $\mathrm{X}$ & & & & \\
\hline Frutos and Borenstein (2003) & $\mathrm{X}$ & & & & & & \\
\hline Fung et al. (2004) & & & $\mathrm{X}$ & $\mathrm{X}$ & & & \\
\hline Griffiths and Margetts (2000) & & & & & & $\mathrm{X}$ & \\
\hline $\operatorname{Kim}(2014)$ & & & & & & $\mathrm{X}$ & \\
\hline Lau et al. (2007) & & & & $X$ & & & \\
\hline Nobre et al. (2008) & $\mathrm{X}$ & & & & & & \\
\hline Potter et al. (2004) & & & & & $\mathrm{X}$ & & \\
\hline Squire et al. (2006) & & & & & & & $\mathrm{X}$ \\
\hline Stojanov and Ding (2015) & & & & & & & $\mathrm{X}$ \\
\hline Coker and Helo (2016) & & & & $x$ & & & \\
\hline Tien (2011) & & $\mathrm{X}$ & & $\mathrm{X}$ & & & \\
\hline Um (2017) & $\mathrm{X}$ & & & & & & \\
\hline Um et al. (2017) & & $\mathrm{X}$ & & & & & \\
\hline Wiengarten et al. (2017) & & $\mathrm{X}$ & & & & & \\
\hline TOTAL & 4 & 4 & 2 & 5 & 1 & 2 & 2 \\
\hline \multirow{2}{*}{$\%$} & $20 \%$ & $20 \%$ & $10 \%$ & $25 \%$ & $5 \%$ & $10 \%$ & $10 \%$ \\
\hline & \multicolumn{4}{|c|}{$75 \%$} & \multicolumn{3}{|c|}{$25 \%$} \\
\hline
\end{tabular}

\section{Co-creation of products}

The agile interaction between clients and companies (Frutos and Borenstein, 2003; Chen and Tseng, 2007; Nobre et al., 2008; Um, 2017) and the search for the balance between supply and demand flexibility (Fung et al., 2004; Chen and Tseng, 2007; Lau et al., 2007); Tien, 2011; Coker and Helo, 2016) are determining factors in the co-design of products. On the one hand, the interaction between customers and companies is a factor that can increase the degrees of agility and flexibility in the Supply Chain to manage high levels of complexity (Frutos and Borenstein, 2003; Chen and Tseng, 2007; Nobre et al., 2008). On the other hand, the balance between supply and demand flexibility must be analysed and aligned with flexibility strategies, considering the economic advantage of the CMS/MP processes (Chen and Tseng, 2007; Tien, 2011; Um et al., 2017; Wiengarten et al., 2017) and customer satisfaction (Fung et al., 2004; Fogliatto and Da Silveira, 2008). In fact, some authors link product variety management strategies (such as the product co-creation) to supply chain responsiveness, and relate SCF to cost reduction (Um et al., 2017; Wiengarten et al., 2017) and increased operational performance (Lau et al., 2007) in CMS/MP environments. 


\section{Relationship with partners}

In a Supply Chain where CMS/MP strategies are used, suppliers must also be more flexible to support the production schedule. Supplier management (Potter et al., 2004; Squire et al., 2006; Stojanov and Ding, 2015) and coordination between company and suppliers (Griffiths and Margetts, 2000; Kim, 2014) could lead to greater flexibility in the entire Supply Chain, and in particular in logistics systems. Supplier-managed inventories could reduce delivery times and costs and, consequently, impact CMS/MP positively (Potter et al., 2004). In addition, the coordination between business and suppliers must be faster and more structured to give greater visibility to customer demand throughout the Supply Chain (Griffiths and Margetts, 2000; Kim, 2014).

\subsubsection{SCF and CMS/MP enabling technologies}

Table 2.7 provides the classification of the papers related to SCF and CMS/MP enabling technologies (third Main Topic). The Research Lines/sublines that deal with the SCFCMS/MP relationship in this Main Topic are described below.

Table 2.7. Papers related to SCF and CMS/MP enabling technologies

\begin{tabular}{|c|c|c|c|c|c|c|c|c|c|c|}
\hline \multirow[b]{2}{*}{ Reference } & \multicolumn{4}{|c|}{$\begin{array}{l}\text { Data integration } \\
\text { technologies }\end{array}$} & \multicolumn{2}{|c|}{$\begin{array}{c}\text { Vision } \\
\text { technologies }\end{array}$} & \multicolumn{2}{|c|}{$\begin{array}{c}\text { Automation } \\
\text { and } \\
\text { robotics }\end{array}$} & \multicolumn{2}{|c|}{$\begin{array}{c}\text { Additive } \\
\text { manufacturing }\end{array}$} \\
\hline & $\begin{array}{c}\mathrm{GE} \\
\mathrm{N}\end{array}$ & $\mathrm{CC}$ & DM & ERP & CAD & VR & MS & LS & 3DP & EP \\
\hline $\begin{array}{c}\text { Achillas et al. } \\
(2017)\end{array}$ & & & & & & & & & $x$ & \\
\hline $\begin{array}{l}\text { Akkermans et al. } \\
(2003)\end{array}$ & & & & $X$ & & & & & & \\
\hline Chung et al. (2018) & $X$ & & & & & & & & & \\
\hline Fisher (1997) & $\mathrm{X}$ & & & & & & & & & \\
\hline $\begin{array}{l}\text { Furst and Schmidt } \\
(2001)\end{array}$ & $x$ & & & & & & & & & \\
\hline Ho et al. (2008) & & & $\mathrm{X}$ & & & & & & & \\
\hline Kaiser et al. (2015) & & & & & $X$ & & & & & \\
\hline Kumar et al. (2015) & & & & & & & & $\mathrm{X}$ & & \\
\hline Lee et al. (1999) & & & & & & & & & & $\mathrm{X}$ \\
\hline $\begin{array}{l}\text { Marin and Brîndaşu } \\
(2015)\end{array}$ & & & & & & & $\mathrm{X}$ & & & \\
\hline Morariu et al. (2016) & & $\mathrm{X}$ & & & & & & & & \\
\hline Morariu et al. (2015) & & $\mathrm{X}$ & & & & & & & & \\
\hline $\begin{array}{l}\text { Padayachee and } \\
\text { Bright (2003) }\end{array}$ & & & & & & & $\mathrm{X}$ & & & \\
\hline Peng and Yu (2007) & & & & & & $\mathrm{X}$ & & & & \\
\hline Schuh et al. (2007) & $\mathrm{X}$ & & & & & & & & & \\
\hline $\begin{array}{c}\text { Strasser et al. } \\
(2011)\end{array}$ & $x$ & & & & & & & & & \\
\hline Zhong et al. (2017) & $X$ & & & & & & & & & \\
\hline TOTAL & 6 & 2 & 1 & 1 & 1 & 1 & 2 & 1 & 1 & 1 \\
\hline \multirow{2}{*}{$\%$} & $35 \%$ & $12 \%$ & $6 \%$ & $6 \%$ & $6 \%$ & $6 \%$ & $12 \%$ & $6 \%$ & $6 \%$ & $6 \%$ \\
\hline & \multicolumn{4}{|c|}{$59 \%$} & & & \multicolumn{2}{|c|}{$18 \%$} & \multicolumn{2}{|c|}{$12 \%$} \\
\hline
\end{tabular}




\section{Data integration technologies}

As we can see in Table 2.7, the category called 'Generic' was included for the papers that did not refer to a specific data integration technology. In this line, the data integration technologies use increases the potential for production process flexibility through support for interaction and collaboration between the links in the Supply Chain (Schuh et al., 2007; Strasser et al., 2011). Interest integrated supply chain has been increasing, and researchers have emphasized the importance and effects of integration technologies to achieve higher levels of SCF and CMS/MP (Fisher, 1997; Furst and Schmidt, 2001; Zhong et al., 2017; Chung et al., 2018). Integrated smart factories that share interchangeable processes throughout the Supply Chain enable companies to understand the customers' individual needs and to plan the supply chain operations (Chung et al., 2018).

From a more specific approach, Cloud Computing, Data Mining and ERP technologies play an important role in the information integration within the company and with the chain partners (customers, suppliers and stakeholders). Cloud computing is an important technology that fosters great agility in responding to environmental changes (Morariu et al., 2015; Morariu et al., 2016). Data mining offers greater flexibility to the production process management and is superior to conventional methods of process analysis (Ho et al., 2008). ERP systems offer a positive contribution to CMS/MP (standardization of processes and information) but have some inflexibility with respect to Supply Chain changes (insufficient extended business functionality across organizational boundaries) (Akkermans et al., 2003).

\section{Vision technologies}

One of the limitations of current CMS/MP practices is the inefficient interaction between product developers and production data, which is usually separated from the product model during the product review and evaluation. Tools based on computer-aided design (Kaiser et al., 2015) and virtual reality (Peng and Yu, 2007) are effective in linking production data with product design information. The use of such technologies can incorporate flexibility into the development and production processes of personalized products (Peng and Yu, 2007; Kaiser et al., 2015). 


\section{Automation and robotics}

Automation and Robotics have a significant potential in the flexibility and agility of manufacturing processes (Padayachee and Bright, 2003; Marin and Brîndaşu, 2015) and to support internal logistics (Kumar et al., 2015). Aligned with a production prioritization strategy, industrial automation is a way to minimize the assembly stations' operational complexity (Padayachee and Bright, 2003; Marin and Brîndaşu, 2015). In addition, internal logistics can be facilitated by the use of automated guided vehicles, which reduces loading/unloading and material transfer times between workstations (Kumar et al., 2015).

\section{Additive manufacturing}

The practice based on digital manufacturing, such as additive manufacturing and electronic production (Lee et al., 1999) is one of the more important SCF-CMS/MP facilitators. 3D manufacturing offers new material options, improved processing speeds, and greater production autonomy, enabling the co-creation of personalized products (Achillas et al., 2017). Both 3D print manufacturing and electronic production are flexible alternatives that could result in shorter lead times and lower overall production costs. However, these results are obtained when a low volume CMS/MP is adopted (Achillas et al., 2017).

\subsubsection{Identified gaps and paths for further research}

In the previous subsections, literature related to the SCF-CMS/MP context has been synthesized as a way to identify what is under study in this research area. We shall now propose lines for future research based on the research gaps that have been detected using this search keywords and databases, as defined in the paper's Methodology. Table 2.8 shows the gaps identified from this study and the paths for further research.

'Reconfigurable production' is the most researched Line in the Main Topic "Personalization levels and flexible processes in Supply Chain". Although there is a considerable number of papers on this subject, some research areas remain unexplored. For example, only one identified paper discusses the reconfigurable manufacturing implementation in the SCF-CMS/MP area (Wong et al., 2007). There is a research gap that could analyse how reconfigurable manufacturing could be integrated, for example, with manufacturing strategies, technologies and Supply Chain processes. In the 'Manufacturing Systems' context, it is necessary new researches to support the 
identification of the balance point between the personalization levels and the costs associated with Supply Chain in manufacturing strategies. Moreover, in the 'Product configuration' context, although the modular production development and the use of product family platforms can maximize the efficiency of the production process, some questions need to be looked into. It is necessary more study to deepen the simultaneously relationship between modular production, flexibility levels in Supply Chain, personalization and customer satisfaction. With regard to 'Preparation and delivery of products', the relationship between the assembly processes in the SCFCMS/MP area is a research direction that has received a very little attention. It is necessary to investigate the operational and financial performance of assembly and delivery processes in the SCF and CMS/MP area. 


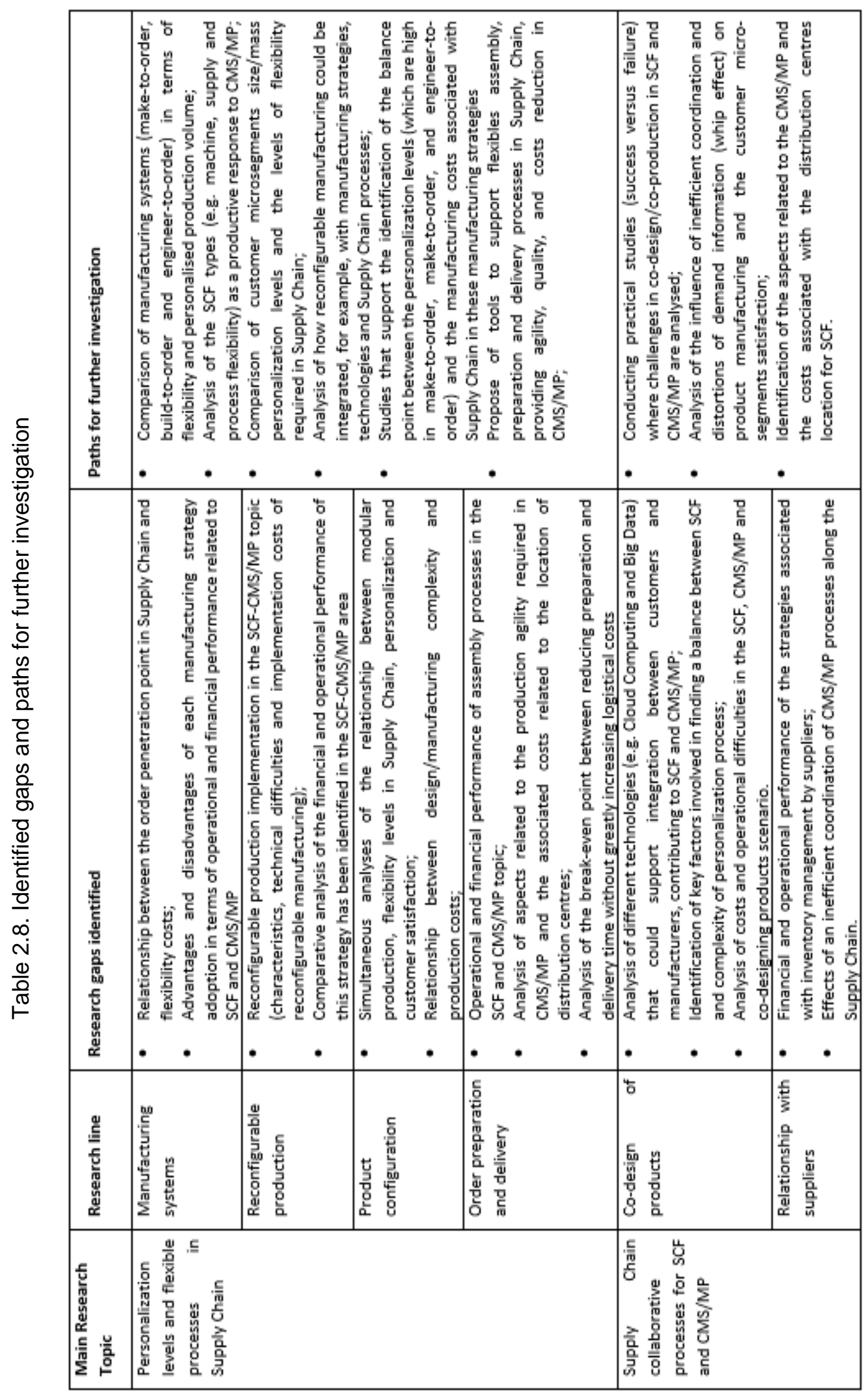




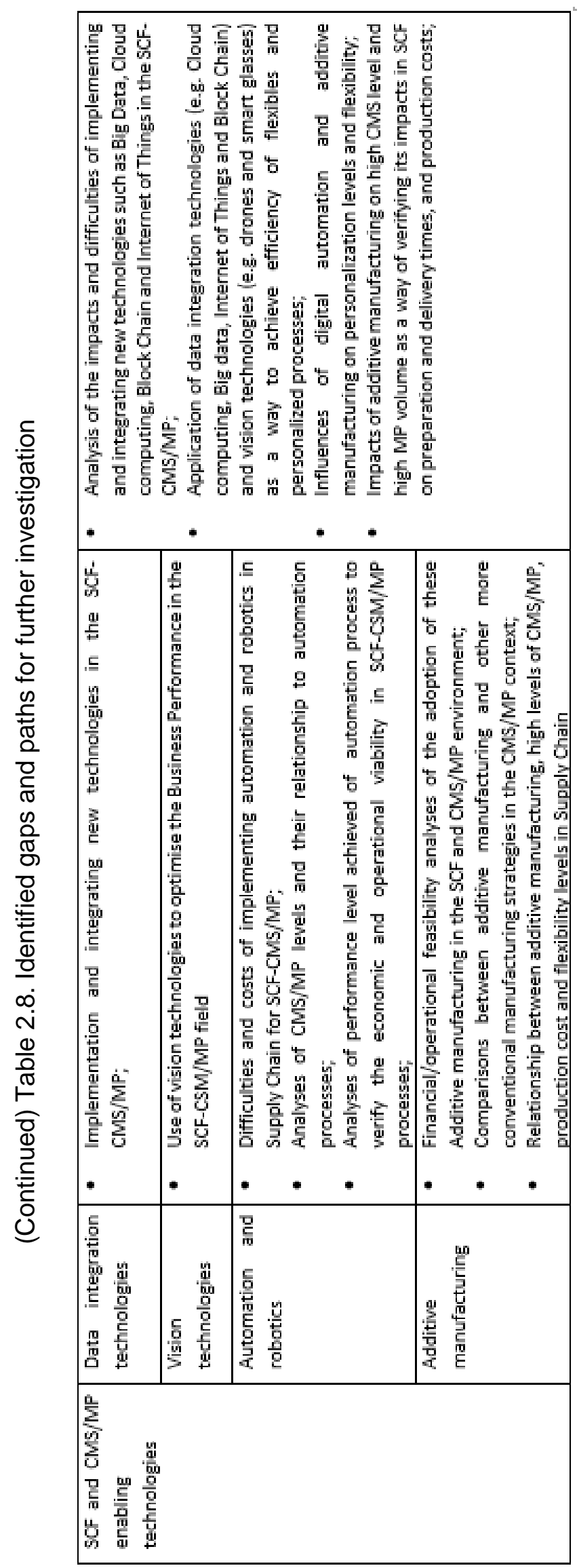


Likewise, in "Supply Chain collaborative processes for SCF and CMS/MP" there is not a significant number of papers identifying issues related to SCF-CMS/MP and products codesign. Tien (2011) states that the personalization level of a co-designed product must be aligned with the company's flexibility strategy. However, there are some Research Lines that are little explored such as the different technologies (e.g. Cloud Computing and Big Data) that could support integration between customers and manufacturers contributing to SCF and CMS/MP; practical studies (success versus failure) of coproduction; and analysis of costs and operational difficulties in co-designing products. In addition, the number of studies investigating the key factors involved in finding a balance between SCF and complexity of personalization processes is also very small. In addition, it is known that many companies prefer to use a supplier-managed raw material inventory strategy. In these situations, suppliers have access to information related to orders and raw material inventory levels and must manage it in such a way that there are no stock breaks. New papers could analyse the financial and operational performance of the strategies associated with inventory management by suppliers, as well as the effects of an inefficient coordination of CMS/MP processes along the Supply Chain (bullwhip effect).

Finally, in 'Data Integration Technologies' is the most researched line of "SCF and CMS/MP enabling technologies", the most papers dealing with this line do not specify the kind of data integration technology adopted. The literature shows that data integration technologies enable companies to advance into a new era of CMS/MP, where flexibility in Supply Chain is an important factor for production. However, some research areas remain unexplored. For example, a very small number of studies have addressed the vision technologies impacts in the SCF-CMS/MP field. Its necessary new studies examining the relationship of other vision technologies (e.g. drones, wearable technology and smart glasses) to optimise the Business Performance in the SCFCSM/MP field. In addition, few studies have analysed the relationship between automation and robotics in the SCF-CMS/MP field. The analysis of difficulties and costs of implementing automation and robotics in Supply Chain for SCF-CMS/MP could be analysed in further researches. Moreover, the relationship between the personalization levels and automation processes to verify the economic and operational viability of these technologies in the CSM/MP processes could also be explored in future research. Likewise, it is known that additive manufacturing is a recent research topic, so this explains the small number of studies focusing on this issue. Only two of the identified papers address the relationship between additive manufacturing in the SCF-CMS/MP environment, emphasizing the strong potential for further research in this area (e. $g$. 
financial/operational feasibility analyses of the adoption of these manufacturing systems for SCF and CMS/MP, and comparisons between additive manufacturing and other more conventional manufacturing strategies in the CMS/MP context).

\subsection{CONCLUSIONS}

In this work, a Systematic Literature Review of 64 papers has been carried out in order to identify the current state of research on SCF and CMS/MP. Responses to the Research Questions and the chapter's conclusions based on the results of the systematic literature review are presented below.

With respect to RQ1, "What are the main research's topics, lines and sublines of work regarding the joint approach of the SCF and CMS/MP?", this work provides a novel classification of the existing literature on SCF and CMS/MP. This classification is done at three levels: Main Topics (Level 1), Research Lines (Level 2) y Research Sublines (Level 3).

Regarding RQ2, "What is currently known about the interaction between SCF and CMS/MP adoption?', regarding 'Personalization levels and flexible processes along the Supply Chain', the customer's order entry point is a key factor in the definition of the CMS/MP level. The higher the customer's order penetrates the value chain, the higher the product personalization level will be. Make-to-order/build-to-order, and engineer-toorder systems are listed as manufacturing strategies with a high level of flexibility to meet the customers' individual needs. Reconfigurable physical and logical productions are designed to change and adjust quickly to the production structure and can thus offer a high flexibility level to respond in a timely manner to the customer requirements changes. Modular products and product family platforms are listed as two types of configuration that provide the standardization level needed for companies to adapt quickly and efficiently to new markets. In terms of the 'Supply Chain collaborative processes', codesigning products allows exploring the balance between supply and demand flexibility, providing a sustained competitive advantage and can have a significant strategic and financial value if properly aligned. The relationship with partners should also be more flexible, faster and structured to give greater visibility to demand, increase business responsiveness and support production programs. From the 'SCF and CMS/MP enabling technologies' perspective, the literature shows that the adoption of data integration technologies can increase collaboration, response to environmental changes, and flexibility in production processes along the Supply Chain. The vision technologies can improve the interaction between product developers and production data and thus 
improve process flexibility and reduce production times. Automation and robotics can significantly increase process flexibility and agility, offering greater mixing and lower production volume, shorter product life cycles, and shorter delivery times. Additive manufacturing is an important facilitator of CMS/MP, offering new material options, improved processing speeds, and greater production autonomy.

Concerning RQ3, "Based on existing literature, what are the gaps and future work lines identified?', the results of this research reveal areas of study that have received little or no attention from previous researchers. On the one hand, there are few empirical studies investigating the factors related to the operational and financial performance of the SCFCMS/MP processes. New papers could compare the manufacturing strategies in terms of flexibility and personalised production volume. Also, further research could analyse the SCF types as a productive response to CMS/MP and the possible relationships between flexibility/personalization levels with customer satisfaction. On the other hand, few studies analyse the potential impacts that some CMS/MP enabling technologies (e.g. Big Data and Internet of Things) could have on the relationship between SCF and CMS/MP. Finally, the Supply Chain collaborative processes and its impact on SCFCMS/MP context has not been explored to any great extent, which highlights the need for more research in this area. Further theoretical and practical studies should be conducted to assess the influence of factors such as coordination, demand flexibility and distribution on FEC-CMS/MP.

Researchers are encouraged to exploit methodological tools such as case studies and longitudinal analyses to validate and test the theoretical concepts identified in this review. Theoretical and empirical research should be continued to provide a better understanding of the SCF-CMS/MP relationship.

\subsubsection{LIMITATIONS}

We fully recognize that our study has some limitations. Researchers should also be aware of these limitations and interpret what is presented in this chapter in their context. Systematic Literature Review is a methodology reliable and recommended by a large number of scientific papers. However, the criteria used for including papers may have led to the exclusion of other, similarly-important papers. Systematic Literature Review depends on available and accessible research studies and the researcher's criteria (Denyer and Tranfield, 2009). Through the SLR method, it is possible to obtain reasonable knowledge of the Research Questions (Denyer and Tranfield, 2009), although some of SLR's good practices in Operations Management have not been carried out, such as forward and backward searches (Thomé et al., 2016). 
Another limitation of this research is that the keyword selection (search strings) as well as the papers classification, are subjective processes, as it is based on the researcher's opinions. This limitation is inherent in Systematics Literature Reviews (Denyer and Tranfield, 2009); whatever methodological models are applied, the subjectivity of classifications is not eliminated. However, an attempt has been made to minimize this issue by grouping the analysed papers into Main Research Topics, Research Lines and Research Sub Lines, which have been based on theoretical contributions to support the proposed multidimensional classification criteria (Da Silveira et al., 2001).

\section{REFERENCES}

\section{Papers that compose the systematic literature review}

Achillas, C., Tzetzis, D., and Raimondo, M.O. (2017). Alternative production strategies based on the comparison of additive and traditional manufacturing technologies. International Journal of Production Research, 55 (12), 3497-3509.

Akkermans, H.A., Bogerd, P., Yucesan, E., and van Wassenhove, L.N. (2003). The impact of ERP on supply chain management: exploratory findings from a European Delphi study. European Journal of Operational Research, 146 (2), 284-301.

Alsafi, Y., and Vyatkin, V. (2010). Ontology-based reconfiguration agent for intelligent mechatronic systems in flexible manufacturing. Robotics and Computer-Integrated Manufacturing, 26 (4), 381-391.

Al-Zaher, A., ElMaraghy, W., and Pasek, Z.J. (2013). RMS design methodology for automotive framing systems BIW. Journal of Manufacturing Systems, 32 (3), 436-448.

Brabazon, P. G., MacCarthy, B., Woodcock, A., and Hawkins, R. W. (2010). Mass Customization in the Automotive Industry: Comparing Interdealer Trading and Reconfiguration Flexibilities in Order Fulfilment. Production and Operations Management, 19 (5), 489-502.

Chen, J., and Chen, F. F. (2008). Adaptive scheduling and tool flow control in flexible job shops. International Journal of Production Research, 46 (15), 4035-4059.

Chen, S., and Tseng, M. M. (2007). Aligning demand and supply flexibility in custom product co-design. International Journal of Flexible Manufacturing Systems, 19 (4), 596-611.

Chung, B.D., Kim, S.I., and Lee, J.S. (2018). Dynamic Supply Chain Design and Operations Plan for Connected Smart Factories with Additive Manufacturing. Applied Sciences, 8 (4), 583.

Claycomb, C., Dröge, C., and Germain, R. (2005). Applied customer knowledge in a manufacturing environment: Flexibility for industrial firms. Industrial Marketing Management, 34 (6), 629-640.

Coker, J., and Helo, P. (2016). Demand-supply balancing in manufacturing operations. Benchmarking: An International Journal, 23 (3), 564-583.

Comstock, M., Johansen, K., and Winroth, M. (2004). From mass production to mass customization: Enabling perspectives from the Swedish mobile telephone industry. Production Planning and Control, 15 (4), 362-372.

Coronado, A.E., Lyons, A.C., Kehoe, D.F., and Coleman, J. (2004). Enabling mass customization: Extending build-to-order concepts to Supply Chains. Production Planning and Control, 15 (4), 398-411.

Costantino, F., Gravio, G.D., and Shaban, A. (2014). Multi-criteria logistics distribution network design for mass customisation. International Journal of Applied Decision Sciences, 7 (2), 151-167.

Custódio, D. T., Vaccaro, G. L. R., Nunes, F. L., Vidor, G., and Chiwiacowsky, L. D. (2018). Variant product configuration of industrial air handling units in a MTO environment. The International Journal of Advanced Manufacturing Technology, 95 (1-4), 1025-1037.

Dev, N.K., Shankar, R., and Dey, P.K. (2014). Reconfiguration of Supply Chain network: An ISM-based roadmap to performance. Benchmarking, 21 (3), 386-411. 
Dev, N.K., Shankar, R., Dey, P.K., and Gunasekaran, A. (2014). Holonic supply chain: a study from familybased manufacturing perspective. Computers \& Industrial Engineering, 78, 1-11.

Engelhardt-Nowitzki, C. (2012). Improving value chain flexibility and adaptability in build-to-order environments. International Journal of Physical Distribution and Logistics Management, 42 (4), 318-337.

Favi, C., and Germani, M. (2012). A method to optimize assembly of industrial product in early design phase: From product architecture to assembly sequence. International Journal on Interactive Design and Manufacturing, 6 (3), 155-169.

Fisher, L.M. (1997). What is the right supply chain for your product?. Harvard Business Review, 75 (2), 105116.

Fogliatto, F. S., and Da Silveira, G.J.C. (2008). Mass customization: A method for market segmentation and choice menu design International. Journal of Production Economics, 111 (2), 606-622.

Frutos, J.D., and Borenstein, D. (2003). Object-oriented model for customer-building company interaction in mass customization environment. Journal of Construction Engineering and Management, 129 (3), $302-$ 313.

Fung, R.Y.K., Chong, S.P.Y. and Wang, Y. (2004). A framework of product styling platform approach: Styling as intangible modules. Concurrent Engineering Research and Applications, 12 (2), 89-103.

Furst, K., and Schmidt, T. (2001). Turbulent markets need flexible supply-chain communication. Production Planning and Control, 12 (5), 525-533.

Griffiths, J, and Margetts, D. (2000). Variation in production schedules - implications for both the company and its suppliers. Journal of Materials Processing Technology, 103 (1), 155-159.

Gualandris, J., and Kalchschmidt, M. (2013). Product and process modularity: improving flexibility and reducing supplier failure risk. International Journal of Production Research, 51 (19), 5757-5770.

Hanafy, M., and Elmaraghy, H. (2015). Developing assembly line layout for delayed product differentiation using phylogenetic networks. International Journal of Production Research, 53 (9), 2633-2651.

Ho, G.T.S., Lau, H.C.W., Lee, C.K.M., and Ip, A.W.H. (2008). Real-time process mining system for Supply Chain network: OLAP-based fuzzy approach. International Journal of Enterprise Network Management, 2 (1), 84-103.

Huang, G. Q., Zang, X. Y., and Lo, V. H.Y. (2007). Integrated Configuration of Platform Products and Supply Chains for Mass Customization: A Game-Theoretic Approach. IEEE Transactions On Engineering Management 54, (1), 156-171.

Ismail, H., Reid, I., Mooney, J., Poolton, J., and Arokiam, I. (2007). How small and medium enterprises effectively participate in the mass customization game. IEEE Transactions on Engineering Management, 54 (1), 86-97.

Jiao, J., Kumar, A., and Lim, C.M. (2006). Flexibility valuation of product family architecture: A real-option approach. International Journal of Advanced Manufacturing Technology, 30 (1), 1-9.

Kaiser, C., Vogt, S., and Tilebein, M. (2015). Virtual development and production framework for textile orthotics, International Journal of Computer Integrated Manufacturing, 30 (7), 680-689.

Kim, B. (2014). Effective Supply Chain strategy to enhance firm's responsiveness: Empirical evidence from the BMW Leipzig plant. International Journal of Services and Operations Management, 18 (1), 21-37.

Koo, P.H., and Tanchoco, J.M.A. (1999). Non-hierarchical shop floor control in single-stage multimachine systems. International Journal of Flexible Automation and Integrated Manufacturing, 7 (1), 19-46.

Kortmann, S., Gelhard, C., Zimmermann, C., and Piller, F.T. (2014). Linking strategic flexibility and operational efficiency: the mediating role of ambidextrous operational capabilities. Journal of Operations Management. 32 (7/8), 475-490.

Kumar, R., Haleem, A., Garg, S.K., and Singh, R.K. (2015). Automated guided vehicle configurations in flexible manufacturing systems: A comparative study. International Journal of Industrial and Systems Engineering, 21 (2), 207-226.

Lau, A. K., Yam, R. C., and Tang, E. P. (2007). Supply chain product co-development, product modularity and product performance: Empirical evidence from Hong Kong manufacturers. Industrial Management and Data Systems, 107 (7), 1036-1065.

Lee, W.B., and Lau, H.C.W. (1999). Factory on demand: the shaping of an agile production network. International Journal of Agile Management Systems 1 (2), 83-87.

Levandowski, C.E., Jiao, J.R., and Johannesson, H. (2015). A two-stage model of adaptable product platform for engineering-to-order configuration design. Journal of Engineering Design, 26 (7), 220-235. 
Marin, R.L., and P. D. Brîndaşu. (2015). A self-organizing approach for mixed-model manufacturing based on autonomous entities Academic Journal of Manufacturing Engineering 13 (2), 60-65.

Molina, A., Rodriguez, C.A., Ahuett, H., Cortés, J.A., Ramírez, M., Jiménez, G., and Martinez, S. (2005). Next-generation manufacturing systems: Key research issues in developing and integrating reconfigurable and intelligent machines. International Journal of Computer Integrated Manufacturing, 18 (7), 525-536.

Morariu, O., Morariu, C., and Borangiu, T. (2016). Shop-floor resource virtualization layer with private cloud support. Journal of Intelligent Manufacturing, 27 (2), 447-462.

Morariu, O., Borangiu, T., and Raileanu, S. (2015). vMES: Virtualization aware manufacturing execution system. Computers in Industry 67, 27-37.

Nobre, F. S., Tobias, A. M., and Walker, D. S. (2008). The pursuit of cognition in manufacturing organizations. Journal of Manufacturing Systems, 27 (4), 145-157.

Padayachee, J., and Bright, G. (2013). The design of reconfigurable assembly stations for high variety and mass customisation manufacturing. South African Journal of Industrial Engineering, 24(3), 43-57.

Peng, Q., and Yu, C. (2007). A visualised manufacturing information system for mass customisation. International Journal of Manufacturing Technology and Management, 11 (3), 278-295.

Potter, A., Breite, R., Naim, M., and Vanharanta, H. (2004). The potential for achieving mass customization in primary production Supply Chains via a unified taxonomy. Production Planning and Control, 15 (4), 472-481.

Purohit, J.K., Mittal, M.L., Mittal, S., and Sharma, M.K. (2016). Interpretive structural modelling-based framework for mass customisation enablers: an Indian footwear case. Production Planning and Control, 27 (9), 774-786.

Schuh, G., Baessler, E., and Meier, J. (2007). An evaluation method for the identification of flexible production technologies for Mass Customisation in the automotive industry. International Journal of Manufacturing Technology and Management, 10 (4), 347-359.

Squire, B., Cousins, P.D., and Brown, S. (2006). Collaborating for customisation: an extended resourcebased view of the firm. International Journal of Productivity and Quality Management, 1 (1), 8-25.

Stojanov, T., and Ding, X. (2015). Supplier selection for mixed-model production: A case study from the apparel industry. Fibres and Textiles in Eastern Europe, 23 (1), 8-12.

Strasser, T., Rooker, M, and Ebenhofer, G. (2011). An IEC 61499 distributed control concept for reconfigurable robots. International Journal of Computer Aided Engineering and Technology, 3 (3), 344359.

Stump, B., and Badurdeen, F. (2012). Integrating lean and other strategies for mass customization manufacturing: A case study. Journal of Intelligent Manufacturing, 23 (1), 109-124.

Tien, J. M. (2011). Manufacturing and services: From mass production to mass customization. Journal of Systems Science and Systems Engineering, 20 (2), 129-154.

Tse, Y.K., Tan, K.H., Ting, S.L., Choy, K.L., Ho, G.T.S., and Chung, S.H. (2012). Improving postponement operation in warehouse: An intelligent pick-and-pack decision-support system. International Journal of Production Research, 50 (24), 7181-7197.

Um, J. (2017). Improving supply chain flexibility and agility through variety management. The International Journal of Logistics Management, 28: 464-487.

Um, J., Lyons, A., Lam, H.K., Cheng, T.C.E., and Dominguez-Pery, C. (2017). Product variety management and supply chain performance: A capability perspective on their relationships and competitiveness implications. International Journal of Production Economics, 187, 15-26.

Urgo, M., Terkaj, W., Cenati, C., Giannini, F., Monti, M., and Pellegrinelli, S. (2016). Zero-point fixture systems as a reconfiguration enabler in flexible manufacturing systems Computer-Aided Design and Applications, 13 (5), 684-692.

Vickery, S.K., Bolumole, Y.A., Castel, M.J., and Calantone, R.J. (2015). The effects of product modularity on launch speed. International Journal of Production Research, 53 (17), 5369-5381.

Wadhwa, S., and Rao, K. S. (2000). Flexibility: an emerging meta-competence for managing high technology. International Journal of Technology Management, 19 (7), 820-845.

Wiengarten, F., Singh, P. J., Fynes, B., and Nazapour, A. (2017). Impact of mass customization on cost and flexibility performances: the role of social capital. Operations Management Research, 10 (3-4), 137-147. 
Wong, M.M., Tan, C.H., Zhang, J.B., Zhuang, L.Q., Zhao, Y.Z., and Luo, M. (2007). On-line reconfiguration to enhance the routing flexibility of complex automated material handling operations. Robotics and Computer-Integrated Manufacturing, 23 (3), 294-304.

Wurzer, T., and Reiner, G. (2018). Evaluating the impact of modular product design on flexibility performance and cost performance with delivery performance as a moderator. International Journal of Operations \& Production Management, 38 (10), 1987-(2008).

Yao, Y., and Xu, Y. (2018). Dynamic decision making in mass customization. Computers \& Industrial Engineering, 120, 129-136.

Zhong, R.Y., Xu, X., Klotz, E., and Newman, S.T. (2017). Intelligent manufacturing in the context of industry 4.0: A review. Engineering, 3 (5), 616-630.

\section{Complementary bibliographical references}

Abidi, H., Leeuw, S., and Klumpp, M. (2014). Humanitarian Supply Chain performance management: a systematic literature review. Supply Chain Management: An International Journal, 19 (5/6), 592-608.

Barrales-Molina, V., Llorens-Montes, F. J., and Gutierrez-Gutierrez, L. J. (2015). Dynamic capabilities, human resources and operating routines: A new product development approach. Industrial Management \& Data Systems, $115(8), 1388-1411$.

Da Silveira, G., Borenstein, D., and Fogliatto, F. S. (2001). Mass customization: Literature review and research directions. International journal of production economics, 72(1), 1-13.

Denyer, D. and Tranfield, D. (2009). Producing a systematic review. In D.A. Buchanan, A. Bryman, The Sage Hand-book of Organizational Research Methods pp. 671-689 Sage Publications Ltd, London.

Elms, D.K, and Low, P. (2013). Global value chains in a changing world. World Trade Organization, Geneva.

Hansotia, B. (2009). Marketing by objectives: Using segmentation based on purchase timing to enhance customer equity. Journal of Direct, Data and Digital Marketing Practice, 10 (4), 336-355.

He, Y., Stecke, K. E., and Smith, M. L. (2016). Robot and machine scheduling with state-dependent part input sequencing in flexible manufacturing systems. International Journal of Production Research, 54 (22), 6736-6746.

Huo, B., Gu, M., and Wang, Z. (2017). Supply chain flexibility concepts, dimensions and outcomes: an organisational capability perspective. International Journal of Production Research, 56 (17), 5883-5903.

Keränen, J., Piirainen, K. A., and Salminen, R. T. (2012). Systematic review on B2B branding: research issues and avenues for future research. Journal of Product and Brand Management, 21 (6), 404-417.

Lummus, R. R., Duclos, L. K., and Vokurka, R. J. (2003). Supply Chain Flexibility: Building a New Model. Global Journal of Flexible Systems Management, 4 (4), 1-13.

Machado, A.G.C. and Moraes, W.F.A. (2008). Mass customization in civil construction. Revista Brasileira de Gestao de Negocios, 10 (29), 347-364.

Maçaira, P.M., Thomé, A.M.T., Oliveira, F.L.C., and Ferrer, A.L.C. (2018). Time series analysis with explanatory variables: a systematic literature review. Environmental Modelling and Software, 107, 199209.

Moher, D., Liberati, A., Tetzlaff, J., and Altman, D. G. (2009). Preferred reporting items for systematic reviews and meta-analyses: the PRISMA statement. Annals of internal medicine, 151 (4), 264-269.

Mongeon, P., and Paul-Hus, A. (2016). The journal coverage of Web of Science and Scopus: a comparative analysis. Scientometrics, 106 (1), 213-228.

Moon, K., Yi, C., and Ngai, E. (2012). An instrument for measuring Supply Chain flexibility for the textile and clothing companies. European Journal of Operational Research, 222 (2), 191-203.

Mustak, M., Jaakkola, E., and Halinen, A. (2013). Customer participation and value creation: a systematic review and research implications. Managing Service Quality, 23 (4), 341-359.

Oh S., Ryu, K., and Jung. M. (2013). Reconfiguration framework of a supply network based on flexibility strategies. Computers and Industrial Engineering, 65 (1), 156-165.

Pfeiffer D., Terlunen, S., Fischer, J., and Hellingrath, B. (2013). Introducing Supply Chain Segmentation Procedures into Flexibility Management. Proceedings of the 24th Annual Conference of the Production and Operations Management Society 1-10. 
Purohit, J.K., Mittal, M.L., Mittal S. et al. (2016). Interpretive structural modelling-based framework for mass customisation enablers: an Indian footwear case. Production Planning and Control, 27 (9), 774-786.

Rojo, A., Stevenson, M., Lloréns-Montes, F. J., and Perez-Arostegui, M. N. (2018). Supply chain flexibility in dynamic environments: The enabling role of operational absorptive capacity and organisational learning. International Journal of Operations \& Production Management, 38 (3), 636-666.

Seuring, S. and Muller, M. (2008). From a literature review to a conceptual framework for sustainable Supply Chain management. Journal of Cleaner Production, 16 (15), 1699-1710.

Squire, B., Cousins, P.D., and Brown, S. (2006). Collaborating for customisation: an extended resourcebased view of the firm. International Journal of Productivity and Quality Management, 1 (1), 8-25.

Simonson, I. (2005). Determinants of Customers Responses to Customized Offers: Conceptual Framework and Research Propositions. Journal of Marketing, 69: 32-47.

Thomé, A. M. T., Scavarda, L. F., and Scavarda, A. J. (2016). Conducting systematic literature review in operations management. Production Planning \& Control, 27(5), 408-420.

Tranfield, D., Denyer, D., and Smart, P. (2003). Towards a methodology for developing evidence-informed management knowledge by means of systematic review. British journal of management, 14 (3), 207-222.

Wadhwa, S., Saxena, A., and Chan, F. T. S. (2007). Framework for flexibility in dynamic supply chain management. International Journal of Production Research, 46 (6), 1373-1404.

Zimmermann, A., and Rossmann, A. (2015). Enterprise Architecture Management for the Internet of Things. Lecture Notes in Informatics. 139-148. 


\section{BLOCK II}

\section{Explicative analyses}




\title{
Chapter 3
}

\section{Lean Production implementation, Cloud- supported Logistics and Supply Chain Integration: Interrelationships and effects on Business Performance}

\begin{abstract}
This chapter analyses the interrelationships between Lean Production implementation, Cloud-supported Logistics use, Supply Chain Integration, and their effects on business performance. A random sample of 260 companies obtained from a population of 1,717 Spanish companies in intermediate positions in their supply chains has been used to test five hypotheses. The data were collected by telephone survey using the CATI computerised system, with a response rate of 15.6 percent (260 valid questionnaires). Structural equation modelling has been used to test the five proposed hypotheses. The findings indicate that Lean Production implementation facilitates Cloud-supported Logistics use and that the latter's use, in turn, facilitates Supply Chain Integration. However, Cloud-supported Logistics use can be seen not to directly influence business performance improvement, although it does so indirectly through the mediating role of Supply Chain Integration.
\end{abstract}

Keywords: Lean Production implementation, Cloud-supported Logistics, Supply Chain integration, Business performance. 

Chain Integration: Interrelationships and effects on Business Performance

\subsection{INTRODUCTION}

In the current economic environment characterised by market globalisation and high levels of competitiveness, Supply Chain Management has been recognised as an extremely important aspect of business strategy to improve competitiveness (Romano, 2003; McCormack, et al., 2008; Oh et al., 2013). Market dynamism also encourages companies to be more efficient in order to produce with quality, lower costs and in the shortest possible time (Moyano-Fuentes, Sacristán-Díaz and Martínez-Jurado, 2012; Barrales-Molina et al., 2015). When companies implement Lean Production, this is the goal that they are pursuing (Moyano-Fuentes, Sacristán-Díaz and Martínez-Jurado, 2012). Also, in the quest for improved Business Performance, Information Technology (IT) has been found to play a major role in Lean Production implementation (Brunn and Medford, 2004) and in supply chain process integration (Bruque et al., 2015). This study, therefore, aims to delve further into the interrelationships between Lean Production, IT (Cloud-supported Logistics) and Supply Chain Integration and their impacts on Business Performance.

Womack et al., (1990) define Lean Production as a systematic approach to the identification and elimination of waste and low or nil value-added activities through continuous improvement. The underlying principles of Lean Production and its effects on Supply Chain Management have been extensively studied in recent decades and there is growing interest among researchers in this area (Shah and Ward, 2003, Cagliano et al., 2006, Moyano-Fuentes, Martínez-Jurado et al., 2012, Uhrin et al., 2017). Supply Chain is made up of unconnected entities that work together through complex processes to deliver products/services.

In this context, Information Technologies (IT) may be able to facilitate production planning, demand and supply planning, accounting and customer service, among others (Ghaffari et al., 2014; Rai et al., 2015). Cloud Computing is an IT-based tool: a set of virtualised and distributed resources that are diffuse and ubiquitous, geographically dispersed, and accessible on demand through web-based technologies (Hayes, 2008; Fingar, 2009; Buyya et al., 2011). More specifically, Cloud-supported Logistics is the application of cloud systems to the area of logistics. In Cloud-supported Logistics, the information that supports the logistics process is no longer located on local systems, but located and run on distributed networks accessible through a web browser (Wang et al., 
2012; Li et al., 2013; Nowicka, 2014). Cloud-supported Logistics offers great computing power and storage capacity, and is a powerful tool for improving logistics services and providing enterprises with greater efficiency than previous IT systems (Li et al., 2013; Oliveira, 2013; Trappey et al., 2016). The literature recognises that Cloud Computing is a technological tool that may not have a direct impact on business results, but does so through other resources and capabilities (Bruque et al., 2015, 2016) and Supply Chain Integration is, precisely, one of these capabilities (Rai et al., 2006; Bruque et al., 2016).

Supply Chain Integration consists of sharing information and activities quickly across the value chain as a way of promoting the cooperative behaviour of the chain's agents (Devaraj et al., 2007). Some papers show that IT such as Cloud Computing may affect the internal aspects of the organisation's productive structure, as well as the interconnections and workings within inter-organisational configurations (MoyanoFuentes, Martínez-Jurado et al., 2012; Vermula and Zsifkovits, 2016; Braojos et al., 2019). More specifically, Cloud-supported Logistics could enable the effective and efficient integration of the businesses and systems with which it interacts (suppliers, consumers, logistics operators) (Li, 2013; Subramanian et al., 2015).

The previous literature has dealt separately with the Lean Production implementation-IT (Bruun and Mefford, 2004; Ward and Zhou, 2006; Riezebos et al., 2009), IT-Supply Chain Integration (Gunasekaran and Ngai, 2004; Li et al., 2009; Prajogo and Olhager, 2012) and Cloud-Supply Chain Integration (Mehrsai, et al., 2013; Bruque et al., 2015, 2016) relationships. However, no papers have been identified that address these variables together and the relationship/s between them and Business Performance. This joint analysis could be relevant, since organisational factors such as Lean Production implementation, and technological factors such as Cloud Computing, could have multiplier effects on Supply Chain Integration and Business Performance. On the one hand, Lean Production is a management system that seeks efficiency and so has a positive impact on Business Performance (van der Vaart et al., 2012; Stump and Badurdeen, 2012). On the other hand, Cloud Computing is an IT that achieves greater efficiency than previous technologies, and its direct effect on logistics activities and on Supply Chain Integration has also been confirmed (Bruque et al., 2015; Trappey et al., 2016). So, companies that use Lean Production may be induced to use Cloud-supported Logistics in order to continue gaining in efficiency. The value of this study lies in the fact that evidence is made available to academics and practitioners that supports the role played by these operationally- and strategically-linked factors and that this combination translates into better Business Performance. 
The objective of this study is, therefore, to analyse the interrelationships between Lean Production implementation, Cloud-supported Logistics use, Supply Chain Integration, and the effects of all three on Business Performance. The intention is to answer the following research questions: (1) what is the relationship between Lean Production implementation and Cloud-supported Logistics, and how does this relationship affect company performance? and (2) what role does Cloud-supported Logistics play in Business Performance when Lean Production and Supply Chain Integration are in place?

To achieve this objective, the chapter has been structured into six sections preceded by this introduction. The second section presents the research background and the third section sets out the research hypotheses. The fourth section describes the methodology used and the fifth section presents the obtained results and their discussion. Finally, section six highlights the conclusions and future research lines.

\subsection{THEORETICAL BACKGROUND}

\subsubsection{LEAN PRODUCTION, IT AND BUSINESS PERFORMANCE}

There have been clear movements towards Lean Production implementation since its first use (Krafcik, 1988; Womack et al., 1990; Womack and Jones, 1996). Lean Production seeks the continuous improvement and elimination of all forms of waste and extends to manufacturing operations, distribution, product development and processing times (Hopp and Spearman, 2004; Holweg, 2007; Stump and Badurdeen, 2012). There is some consensus in the literature that the practices commonly associated with Lean Production implementation are: Just in time, Cellular Manufacturing, Total Productive Maintenance, Total Quality Management, and Human Resources Management (Cagliano et al., 2006; Shah et al., 2008; Moyano et al., 2012). On the one hand, the use of Lean Production practices could increase production efficiency and response to demand variations, reduce production waiting times and eliminate everything that is not strictly needed to produce added value for the organisation (van der Vaart et al., 2012). On the other hand, one of the main challenges that companies face in lean implementations is increased integration with their key suppliers and customers in order for all the activities to be optimised from the final customer's point-of-view (Pérez et al., 2010).

There is a broad consensus in the previous literature on the role that IT plays as a means of generating efficiency and competitive advantages (Wang et al., 2010; Subramanian 
et al., 2015; Jede and Teuteberg, 2015). Some papers show that IT could affect the internal aspects of an organisation's productive structure, as well as the interconnections and workings in inter-organisational configurations (Moyano-Fuentes, Martínez-Jurado et al., 2012; Bruque et al., 2015, 2016). The reason for this is that IT enables companies to better manage information along the entire supply chain (Bruun and Mefford, 2004). Newer technologies such as Cloud Computing offer several advantages over traditional IT models, including faster data transaction speeds, elasticity, flexibility and increased IT performance (Marston et al., 2011; Jede and Teuteberg, 2015; Liu et al., 2016). Cloud Computing can be applied to most business functions, including logistics, through the Internet and the aggregation of distributed computing resources (Oliveira, 2013; Rai et al., 2015; Al-jawazneh, 2016).

The application of Lean Production has enabled many organisations to improve their efficiency (Lamming, 1996; Mason-Jones and Towill, 1999; Shah and Ward, 2007). Similar benefits have been achieved through the application of IT (Ghaffari et al., 2014; Rai et al., 2015; Vermula and Zsifkovits, 2016). With regard to the complementarity between Lean Production implementation and IT use, Ward and Zhou (2006) consider that Lean-IT approaches are mutually exclusive. The source of organisational knowledge needed to implement Lean Production and IT is very different and this may prevent companies from initiating a simultaneous large-scale development process of the two tools (Ward and Zhou, 2006). Nevertheless, other research shows that Lean adoptionIT approaches could be a generator of business efficiency (Herron and Braiden, 2007; Mo, 2009; Riezebos et al., 2009; Pinho and Mendes 2017). According to these studies, IT could be a powerful tool that leads to significant long-term results, especially when complemented by other key resources, such as Lean Production.

\subsubsection{CLOUD COMPUTING, SUPPLY CHAIN INTEGRATION AND BUSINESS PERFORMANCE}

In Cloud Computing, IT resources are not located in companies but in virtualised and distributed systems (Hayes, 2008; Fingar, 2009; Buyya et al., 2011). Cloud Computing provides ubiquitous access through the Internet to a set of highly configurable computing resources that can be easily and widely accessed by multiple clients (Wang et al., 2010; Abdulaziz, 2012; Ghaffari et al., 2014). Three different types of service models can be distinguished in Cloud Computing: Infrastructure as a Service (laaS), Platform as a Service (PaaS) and Software as a Service (SaaS) (Ryan and Loeffler, 2010). laaS involves sharing data or IT infrastructure that can be used as a service; PaaS entails providing a complete platform for application development and deployment; and SaaS 
involves delivering software online as an on-demand service (Bruque et al., 2015). These service models can be organised into four deployment models: Private Cloud, internally in a single organisation; Community Cloud, enabling a group of business partners to share key resources; Public Cloud, deployed by providers who offer their services to the business community; and Hybrid Cloud, which combines public and private models (Mell and Grance, 2011; Bruque et al., 2015).

Cloud Computing offers several advantages over traditional IT models, including increased flexibility, configurability, scalability and reduced IT deployment costs (Tuncay, 2010; Marston et al., 2011; Liu et al., 2016). Cloud Computing advantages may include the use of instant global platforms, as well as the elimination of hardware infrastructure and software licensing (Wu et al., 2013; Jede and Teuteberg, 2015). However, Cloud Computing is not exempt from limitations, such as concerns about data security and privacy, service availability, and low compatibility with existing applications and systems (Oliveira et al., 2014; Doherty et al., 2015; Vermula and Zsifkovits, 2016).

Cloud Computing could affect the internal aspects of an organisation's productive structure, as well as the interconnections and workings in inter-organisational configurations (Vermula and Zsifkovits, 2016). Findings in the literature show that Cloud Computing is being rapidly adopted by companies in their business processes and in all their functional areas, including Supply Chain Integration (Jede and Teuteberg, 2015, Vermula and Zsifkovits, 2016). The previous literature shows that Cloud Computing could be a very effective technological tool for integrating data through effective supply chain flow integration (physical, information and financial) (Bruque et al., 2015, 2016). Authors such as Rai et al., (2012) and Vermula and Zsifkovits (2016) state that Cloud Computing is a good choice of IT and support the creation of a network between companies through the integration of flows and processes. In particular, SaaS-based Cloud Computing encompasses key supply chain management processes more broadly than traditional IT and can be applied more effectively to planning, creation, manufacturing and delivery processes (Dermirkan et al., 2010). Cloud computing also has important implications for coordination strategies in supply chain networks and can reduce development and integration costs (Dermirkan et al., 2010). Specifically, some research shows that Cloud-supported Logistics could reduce errors in the information systems that support companies' logistics activities while automating and integrating logistics data collection tasks (Li et al., 2013; Subramanian et al., 2015). These systems use various innovative technologies such as the Internet of Things, RFID, Artificial Intelligence, Augmented Reality and Virtual Reality, among others (Yan et al., 2014; Zhong et al., 2015; Botta et al., 2016). Cloud-supported Logistics could, therefore, 
achieve better Business Performance (Oliveira, 2013; Vermula and Zsifkovits, 2016; Aljawazneh, 2016).

With respect to the Cloud Computing-Business Performance relationship, some research shows that Cloud Computing could affect the internal aspects of an organisation's productive structure, as well as the interconnections and workings in interorganisational configurations (Rai et al., 2015; Vermula and Zsifkovits, 2016). Specifically, Cloud-supported Logistics could improve business efficiency through the integration of appropriate information on order processing and distribution, as well as help to improve inventory and fleet management (Oliveira, 2013). As a result, this technology could have a strong impact on the efficiency of processes and activities across the supply chain and help companies to achieve better results (Rai et al., 2015). Notwithstanding this, some evidence in the literature indicates that there is no direct relationship between Cloud Computing use and better Business Performance, but that it does so through other resources and capacities (Bruque et al., 2015, 2016).

Finally, the relationship between Supply Chain Integration and Business Performance has been widely analysed in the literature (Giménez et al., 2012). There is some consensus that there may be a positive effect between Supply Chain Integration and the business results, whether operational or financial ( $\mathrm{Li}$ et al, 2009). Both internal and external process integration should be considered if the company is to achieve a full effect on its performance (Stank et al., 2001; Giménez and Ventura, 2005). Integration between Supply Chain partners, both in the initial and final production stages, plays a crucial role in improving Business Performance (Devaraj et al., 2007; Flynn et al., 2010). Based on the same logic, Supply Chain Integration development reduces uncertainty and allows for greater flexibility and responsiveness to supply chain members' needs (Johnston and Wright, 2004; Malhotra and Mackelprang, 2012). More recent studies show that the integration of physical, information and financial flows could lead to synergy benefits achieved through an integrated system that would positively impact Business Performance (Bruque et al., 2015; 2016).

\subsection{HYPOTHESES}

\subsubsection{LEAN PRODUCTION IMPLEMENTATION AND BUSINESS PERFORMANCE}

Lean Production is managed for the purpose of eliminating waste at all supply chain stages and could reduce the system's sources of variability and thus increase efficiency 
and improve operational and financial performance (Lamming, 1996; Rich and Hines, 1997; Mason-Jones and Towill, 1999; Li et al., 2005; Shah and Ward, 2007).

On the one hand, Lean Production implementation could have an effect on operational performance, improving the speed, visibility and transparency of processes by standardising work at company level (Moyano-Fuentes and Sacristán-Díaz, 2012; Moyano-Fuentes et al., 2012). In this way, Lean Production implementation could increase the accuracy of information and decrease the sources of variability, allowing supply chain members to synchronously structure their collaborative process practices while reducing misconceptions and information asymmetries (Moyano et al., 2012). Consequently, Lean Production implementation could mitigate the limiting effect of certain contingent factors on the relationship (e.g., complexity of the chain's physical or operational flows and demand variability, among others) and thus improve business results (Moyano et al., 2012).

On the other hand, Lean Production implementation could have an effect on financial performance by allowing the execution of operations at minimum cost and without any waste (Womack et al., 1990). The inclusion of some Lean Production-related practices (e.g., TQM, JIT and TPM) could drive up financial results due to reductions in per-unit manufacturing costs, resource savings and inventory levels (McKone et al., 2001; Uhrin et al., 2017). So, Lean Production implementation could facilitate the incremental improvement of products in terms of maximum quality, cost savings and responsiveness to customer needs (Mason-Jones and Towill, 1999; Jabbour et al., 2013).

Lean Production implementation could, therefore, have a direct positive effect on Business Performance (operational and financial), acting on the causes of waste and inflexibility, improving production efficiency, eliminating process redundancies and reducing production costs (Hopp and Spearman, 2004; Stump and Badurdeen, 2012). Lean Production implementation in the business environment could therefore be a competitive advantage to an organisation facing high levels of global competition.

The following hypothesis is proposed based on the above arguments:

H1. There is a positive relationship between Lean Production implementation and Business Performance

\subsubsection{LEAN PRODUCTION IMPLEMENTATION AND CLOUD-SUPPORTED LOGISTICS}

Constant technological changes in the business environment provide companies with new capabilities and resources that can be implemented at the organisational level 
(Wang et al., 2010; Oliveira, 2013). The incorporation of IT allows better coordination with partners and can facilitate the development of supply chain capabilities (Wu et al., 2006). New IT has enormous potential to facilitate collaborative planning among supply chain partners through the sharing of information on demand forecasts and production schedules (Chen and Paulraj, 2004).

Moreover, a company that adopts Lean Production aims to increase process efficiency (Rich and Hines, 1997; Shah and Ward, 2007, Ugarte et al., 2016). Although Lean Production can be adopted without using IT, as Toyota did in the 90s (Womack et al., 1990), IT also allows for greater efficiency (Ghaffari et al., 2014; Rai et al., 2015; Vermula and Zsifkovits, 2016). In continuous improvement processes, new and more powerful IT adds new levels of efficiency compared to previous technologies (Marston et al., 2011). Therefore, companies that adopt Lean Production in pursuit of additional efficiency gains would be able to use the most powerful innovative technologies, such as Cloud Computing (Moyano-Fuentes, Martínez-Jurado et al., 2012).

In fact, Mo (2009) considers the need to develop Lean Production and IT projects together as essential, but with Lean as a preliminary stage to IT projects for the obtained results to be successful. Herron and Braiden (2007) state that Lean Production implementation is a standard process for developing, analysing and implementing productivity improvement plans, which are more effective prior to IT implementation. In this sense, the IT implementation should be subsequent to the restructuring of the company's activities that require it, as pursued by Lean Production, in order to achieve greater IT optimisation and a higher return on investment (Herron and Braiden, 2007; Mo, 2009, Pinho and Mendes, 2017).

Some recent studies have found that Cloud Computing applications in the supply chain in general, and in the logistics field in particular, enable physical, information and financial flows to be managed more efficiently (Bruque et al., 2015; 2016). More specifically, Cloud-supported Logistics could reduce errors in the information systems that support companies' logistics activities, while automating and integrating logistics data collection tasks ( $\mathrm{Li}$ et al., 2013; Subramanian et al., 2015). Lean Production implementation could thus boost the use of IT such as Cloud-supported Logistics by minimising the operational complexities of logistics processes, increasing efficiency and speed when responding to demand variations and improving integration with key suppliers and customers (Mo, 2009, Moyano-Fuentes, Martínez-Jurado et al., 2012; Pérez et al., 2010; Pinho and Mendes, 2017). Therefore, Lean Production implementation and IT use (Cloud-supported Logistics use) could be factors that would 
support logistics operations being carried out with maximum stability, which could mean saving on resources and improving information quality.

Taking these arguments together, it can be stated that Lean Production implementation may be the reason why IT use achieves higher efficiency levels. Thus, the following hypothesis can now be formulated:

H2. There is a positive relationship between Lean Production implementation and Cloudsupported Logistics

\subsubsection{CLOUD-SUPPORTED LOGISTICS AND BUSINESS PERFORMANCE}

In the Cloud-supported Logistics context, logistics managers have come to perceive that organisations using this technology can achieve better business results (Al-jawazneh, 2016). Through Cloud-supported Logistics, companies can manage operations with lower transport costs through coordination with partners, which could improve the company's financial results (Vermula and Zsifkovits, 2016). Cloud-supported Logistics improves logistics services and achieves reliable daily planning and operations with less investment, which could also generate better financial results (Li et al., 2013; Oliveira, 2013). In the same vein, Tao et al., (2011) and Subramanian et al., (2015) stress that the consequences of Cloud-supported Logistics are related to reduced delivery times (operational performance) and logistics costs (financial performance). Cloud-supported Logistics could, therefore, provide technological capabilities that facilitate greater management control by increasing coordination and reducing operational and delivery costs and, thereby, improving operational and financial performance ( $\mathrm{Li}$ et al., 2013; Oliveira, 2013; Subramanian et al., 2015).

Cloud-supported Logistics could support collaboration between logistics networks and facilitate the planning and optimisation of processes for location data capture, route analysis and statistical forecasting (Abdulaziz, 2012; Li et al., 2013; Oliveira, 2013; Subramanian et al., 2015). Cloud-supported Logistics could also support planning and time allocation applications and long-distance control systems (Abdulaziz, 2012; Vermula and Zsifkovits, 2016; Al-jawazneh, 2016). Thus, Cloud-supported Logistics could promote flexibility, scalability and speed, and so improve the visibility of the company, its processes and its relationship with logistics partners (Bruque et al., 2015). As a result, Cloud-supported Logistics could positively affect operational results (in terms of flexibility, efficiency, punctuality and delivery accuracy) and financial results (by reducing storage and transport costs). 
In short, Cloud-supported Logistics is changing the way in which companies interact with their internal and external partners (suppliers, consumers and logistics operators) and could be a key tool for improving Business Performance. The following hypothesis can be proposed based on the above arguments:

H3. There is a positive relationship between Cloud-supported Logistics and Business Performance.

\subsubsection{CLOUD-SUPPORTED LOGISTICS AND SUPPLY CHAIN INTEGRATION}

The literature has suggested that effective Supply Chain Management requires greater collaboration and integration between chain members (Berman, 2002; Boon-itt and Wong, 2011). In order to achieve the full potential of Supply Chain Management, it is necessary to integrate the physical, information and financial flows between the chain partners in the supply chain (Troyer and Cooper, 1995; Rai et al., 2006). In fact, the integration and alignment of internal and inter-company processes in the supply chain are important factors in creating value in a business context (Cagliano et al., 2006; Bruque et al., 2015, Diaz-Madroñero et al., 2015).

Supply Chain Integration was created to promote cooperation, interaction and collaboration between supply chain partners (Ellinger et al., 2000; Pagell, 2004; Foerstl et al., 2017). In this sense, IT in general and Cloud Computing in particular could improve Supply Chain Integration through the identification, capture, storage and management of information both inside and outside the company, and provide capabilities to manage physical, information and financial flows (Azevedo et al., 2013; Jede and Teuteberg, 2015; Bruque et al., 2016).

From a logistics integration perspective, Cloud-supported Logistics allows companies to communicate with transport companies, suppliers and customers (Li et al., 2013; Subramanian et al., 2015). Cloud-supported Logistics could therefore have a positive effect on internal integration and between logistics partners (Bruque et al., 2015, 2016). According to Oliveira (2013), Cloud-supported Logistics increases logistics capacity through the integration of appropriate information on order processing, logistics network design and distribution, whilst also helping to improve inventory and fleet management. Oliveira (2013) also indicates that Cloud Computing has been increasingly used in logistics as a way of integrating information on freight forwarding, customs clearance, warehousing, and other value-added services. Cloud computing also fosters logistics integration through the virtualisation of companies and the efficient provision of 
resources to users, giving logistics providers' real-time integration through different channels (Li et al., 2013; Bhoir and Principal, 2014).

So, Cloud-supported Logistics could be an effective way of integrating logistics data throughout the supply chain by providing ubiquitous and reliable real-time information on warehouse management, inventory, order processing and distribution (Wang et al., 2010; Jede and Teuteberg, 2015). Thus, Cloud-supported Logistics could build cooperation and collaboration relationships between suppliers, focal companies and customers and, as a result, would enable and promote Supply Chain Integration.

Taking these arguments together, the following hypothesis can be formulated:

H4. There is a positive relationship between Cloud-supported Logistics and Supply Chain Integration

\subsubsection{SUPPLY CHAIN INTEGRATION AND BUSINESS PERFORMANCE}

Supplier-customer integration has an interaction effect that is more strongly linked to operational performance than if taken in isolation (Romano, 2003; Devaraj et al., 2007). In fact, both internal and external process integration should be considered if companies aspire to achieving a full effect on their performance (Stank et al., 2001; Giménez and Ventura, 2005; Devaraj et al., 2007; Flynn et al., 2010, Diaz-Madroñero et al., 2015).

There is some consensus in previous literature that a positive effect could exist between Supply Chain Integration and Business Performance, whether operational or financial (Paulraj et al., 2006; Li et al., 2009; Shou et al., 2017). One of the main objectives of Supply Chain Integration is to quickly share information between business units through cooperation, interaction and collaboration between chain partners (Pagell, 2004; Fantazy et al., 2009). In fact, the development of Supply Chain Integration reduces uncertainty and allows for greater flexibility in responding to chain members' needs (Malhotra and Mackelprang, 2012). Supply Chain Integration could encourage shared planning and flexible arrangements to counter unexpected situations and thus contribute positively to improved Business Performance (Johnston and Wright, 2004).

Moreover, to achieve a high level of Supply Chain Integration, it is necessary to align physical, information and financial flows (Rai et al., 2006). In this sense, authors such as Bruque et al., $(2015,2016)$ emphasise the importance of physical, information and financial integration flows as a way to improve Business Performance. Once the supply chain flows are integrated, companies can expect benefits in terms of greater flexibility, efficiency and timely production/delivery (Stank et al., 1999; Gunasekaran and Ngai, 2004). Consequently, Business Performance would be improved due to the response to 
changes in demand, improved delivery times, reduced production times, and reduced production/delivery costs (Marinagi et al., 2014).

Based on the above arguments, it can be expected that Supply Chain Integration could have positive effects on Business Performance. Therefore, the following hypothesis is proposed:

H5. There is a positive relationship between Supply Chain Integration and Business Performance.

Figure 3.1 presents the five hypothesised links in a theoretical research model.

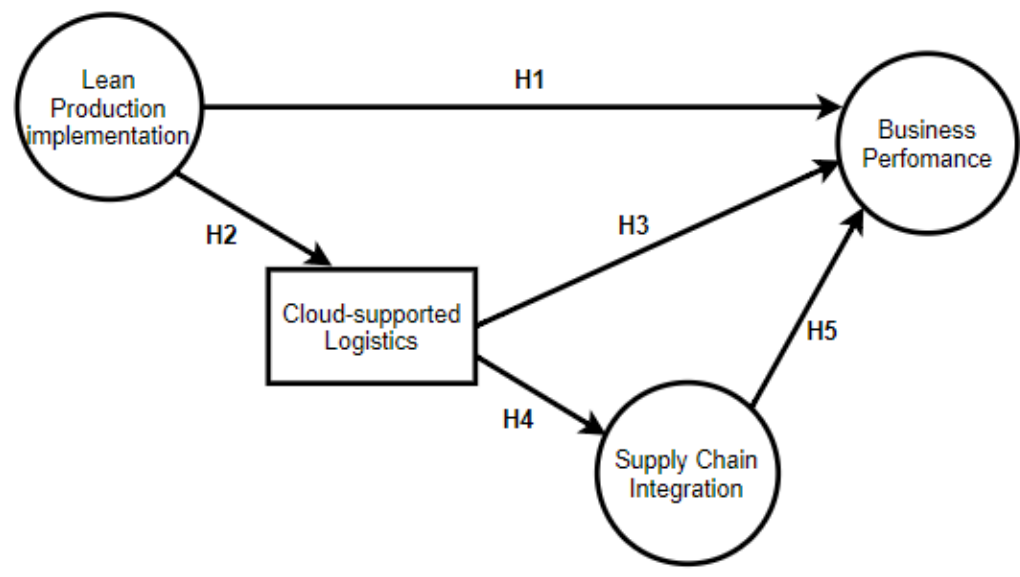

Figure 3.1. Baseline theoretical model

\subsection{METHODOLOGY}

\subsubsection{POPULATION, QUESTIONNAIRE AND DATA GATHERING}

To test the stated hypotheses, the Iberian Balance Sheet Analysis System (SABI) was used to identify a population of 1,717 active Spanish companies with more than 50 employees. These companies occupy an intermediate position in the supply chain, so companies that are very close to the customer or the raw materials have not been considered. The companies were classified by sector according to the National Classification of Economic Activities (CNAE), omitting the sectors of economic activity that were not considered relevant for this analysis (any industries or sectors purely related to extractive activities or to raw materials and their transformation). The selection of the sample units was carried out randomly (simple random sampling) and the fieldwork was conducted from November 13, 2017 to February 5, 2018. The sample eventually comprised 260 companies ( $15.1 \%$ percent of the response rate). 
The questionnaire items were drawn from the literature. As in other studies on similar research topics (Rai et al., 2006; Flynn et al., 2010; Moyano-Fuentes, Martínez-Jurado et al., 2012; Bruque et al., 2015, 2016), a Likert scale questions was used to capture the key research themes. The questionnaire was pre-tested by seven internationally recognised researchers in the specific areas related to this study: Lean Production and Supply Chain Management (4) and IT use and adoption (3). As a result of the preliminary test, several items were reformulated in the questionnaire, which was simplified and modified in line with the researchers' recommendations. Subsequently, a pilot test was carried out in which the authors conducted telephone interviews with 15 companies randomly obtained from the SABI database. The objective of his stage was to check whether respondents were in agreement with the terms used in the questionnaire and understood what was being surveyed. Following this process, the questionnaire was again modified and adapted according to the companies' suggestions and the final version was produced for its use in the subsequent fieldwork stage. The 15 pilot test results were not considered in the subsequent analysis.

Data collection was carried out by telephone survey using a Computer Aided Telephone Interviewing (CATI) method. In this method, interviewers have access to an information system that randomly displays the contact details of potential interviewees. The CATI system allows appointments to be made with interviewees and their responses are saved in real time (Hair et al., 2009). The data were collected by four interviewers who received specific training on the research purpose, objectives and background. In addition, on the first working day, a researcher instructed, supervised and supported interviewers in the company interviewing process. The four members of the interview team worked simultaneously for four hours a day throughout the fieldwork period.

The questionnaire was subdivided into two different areas depending on who the respondent was. The first section was directed at the head of Supply Chain Management, Logistics or Operations Management. This section contained questions related to Lean Production implementation, Supply Chain Integration and Business Performance. The second section was addressed to the IT manager, who answered questions regarding Cloud-supported Logistics. Since there were two different respondents in each company, the survey was considered complete only when the responses were received from both respondents. If this was not the case, i.e., if the questionnaire of one of the two respondents in a company remained unanswered, they were put in an annexed database of 'Incomplete surveys', and the non-responding manager was called again by the interviewers. A web-based questionnaire was also designed for companies that had completed only one section, for companies that 
preferred to answer via web and for some interviewees that stated that they would only be able to answer the questions outside their normal working hours. In this way, respondents who had not yet answered could do so in their spare time, thus completing the remaining fieldwork.

A comparison of firms that were surveyed and those that were not did not reveal evidence of any response bias, since there were no significant differences in sales of companies in the sample and the population. Finally, early responses were compared with those of late respondents and no significant differences were found for any variables included in the study (Armstrong and Overton, 1977; Corsten and Felde, 2005). The sample and population distribution have similar patterns. Thus, by industrial sector (Table 3.1), the sector with the greatest representation in the population is Food products (36.6\%), as it is in the sample $(41.5 \%)$, followed by Chemicals (14.6\% and $15.8 \%$, population and sample, respectively) and Motor vehicles (11.2\% and 12.3\%). In short, the above analyses confirmed that the sample used in the study corresponds to a random pattern and is representative of the population.

Table 3.1. Sample, population distribution and response rate by industry

\begin{tabular}{|l|c|c|c|c|c|}
\hline Sector & \multicolumn{2}{|c|}{$\begin{array}{c}\text { No. of companies in } \\
\text { population }\end{array}$} & $\begin{array}{c}\text { No. of companies in } \\
\text { sample }\end{array}$ & $\begin{array}{c}\text { Response } \\
\text { rate }\end{array}$ \\
\hline Food products & 629 & $36.6 \%$ & 108 & $41.5 \%$ & $17.2 \%$ \\
\hline Tobacco and related products & 7 & $0.4 \%$ & 1 & $0.4 \%$ & $14.6 \%$ \\
\hline Beverages & 89 & $5.2 \%$ & 13 & $5.0 \%$ & $14.6 \%$ \\
\hline Fabrics and textile & 86 & $5.0 \%$ & 11 & $4.2 \%$ & $12.8 \%$ \\
\hline Leather and shoes & 75 & $4.4 \%$ & 8 & $3.1 \%$ & $10.7 \%$ \\
\hline Chemicals & 251 & $14.6 \%$ & 41 & $15.8 \%$ & $16.3 \%$ \\
\hline Pharmaceuticals & 85 & $5.0 \%$ & 15 & $5.8 \%$ & $17.6 \%$ \\
\hline Informatics, electronics and optical & 91 & $5.3 \%$ & 13 & $5.0 \%$ & $14.3 \%$ \\
\hline Electrical machinery and equipment & 97 & $5.7 \%$ & 11 & $4.2 \%$ & $11.3 \%$ \\
\hline Motor vehicles & 192 & $11.2 \%$ & 32 & $12.3 \%$ & $16.7 \%$ \\
\hline Furniture & 115 & $6.7 \%$ & 7 & $2.7 \%$ & $6.1 \%$ \\
\hline Total & $\mathbf{1 7 1 7}$ & $\mathbf{1 0 0} \%$ & $\mathbf{2 6 0}$ & $\mathbf{1 0 0} \%$ & $\mathbf{1 5 . 1} \%$ \\
\hline
\end{tabular}

\subsubsection{VARIABLES}

Cloud-supported Logistics use: this variable has been measured by a direct question, where respondents were asked to assess the degree of Cloud Computing use in logistics operations (see Table 3.2). This question was addressed to the chief IS or IT officer. Respondents answered using a 1-7 Likert scale, with 1 meaning 'not used' and 7 
meaning 'in all cases'. Asking a direct question to capture Cloud technology use level has previously been used in the literature (Bruque et al., 2016).

Lean Production implementation: is a second-order construct composed of two dimensions: cellular manufacturing composed of three items; and Lean practices composed of four items (see Table 3.2). Respondents were asked to evaluate the questionnaire statements relating to the implementation of certain issues linked to Lean Production (Moyano-Fuentes, Martínez-Jurado et al., 2012). In this instance, the questions were addressed to the Supply Chain Management, Logistics or Operations Manager with answers on a 1-7 Likert scale, with 1 indicating "totally disagree" and 7, 'totally agree'. This is in line with the previous use of the same construct (MoyanoFuentes, Martínez-Jurado et al., 2012; Uhrin et al., 2017).

Supply Chain Integration: is a second-order construct composed of three dimensions: Physical flow integration, Information flow integration, and Financial flow integration. Physical flow integration, composed of two items, refers to storage management and material and finished product flow; information flow integration, composed of three items, refers to the exchange of operational, tactical and strategic information between supply chain members; and financial flow integration, composed of two items, is defined as the extent to which supply chain financial flows are driven by workflow events (Rai et al., 2006) (see Table 3.2). In the questionnaire, the questions were addressed to the Supply Chain Management, Logistics or Operations Manager, and a 1-7 Likert scale was used for all items, with 1 indicating 'totally disagree' and 7, 'totally agree' (Rai et al., 2006; Bruque et al., 2015, 2016).

Business Performance: is a second-order construct composed of two dimensions: Operational performance and Financial performance. As it is difficult to compare the performance of firms operating in different industries, we decided to use perceptual measures (Flynn et al., 1995, Bruque et al., 2016). Operational performance (Flynn et al., 2010; Bruque et al., 2015, 2016), composed of five items, refers to the results that the company achieves in flexibility and delivery performance. Financial performance (Flynn et al., 2010; Yu et al., 2013), also composed of five items, consists of the valuecreating capacity of for-profit organisations and refers to growth and return on sales and profits, as well as market share and return on investment (see Table 3.2). Respondents were asked to rate the importance of this set of elements related to their company's performance (Flynn et al., 2010). The questions were addressed to the Supply Chain Management, Logistics or Operations Manager, with answers given on a 1-7 Likert scale, with 1 representing 'totally disagree' and 7 'totally agree' (Flynn et al., 2010; Yu et al., 2013; Bruque et al., 2015, 2016). 
Table 3.2 shows the items that compose each of the above variables. Items marked with an asterisk are those that were eliminated after exploratory factor analysis as they had a standardised factor load of $<0.5$. The final items have been marked in bold (item code) in Table 3.2. Details of the exploratory factor analysis are presented in Section 5 (see Table 3.3). 


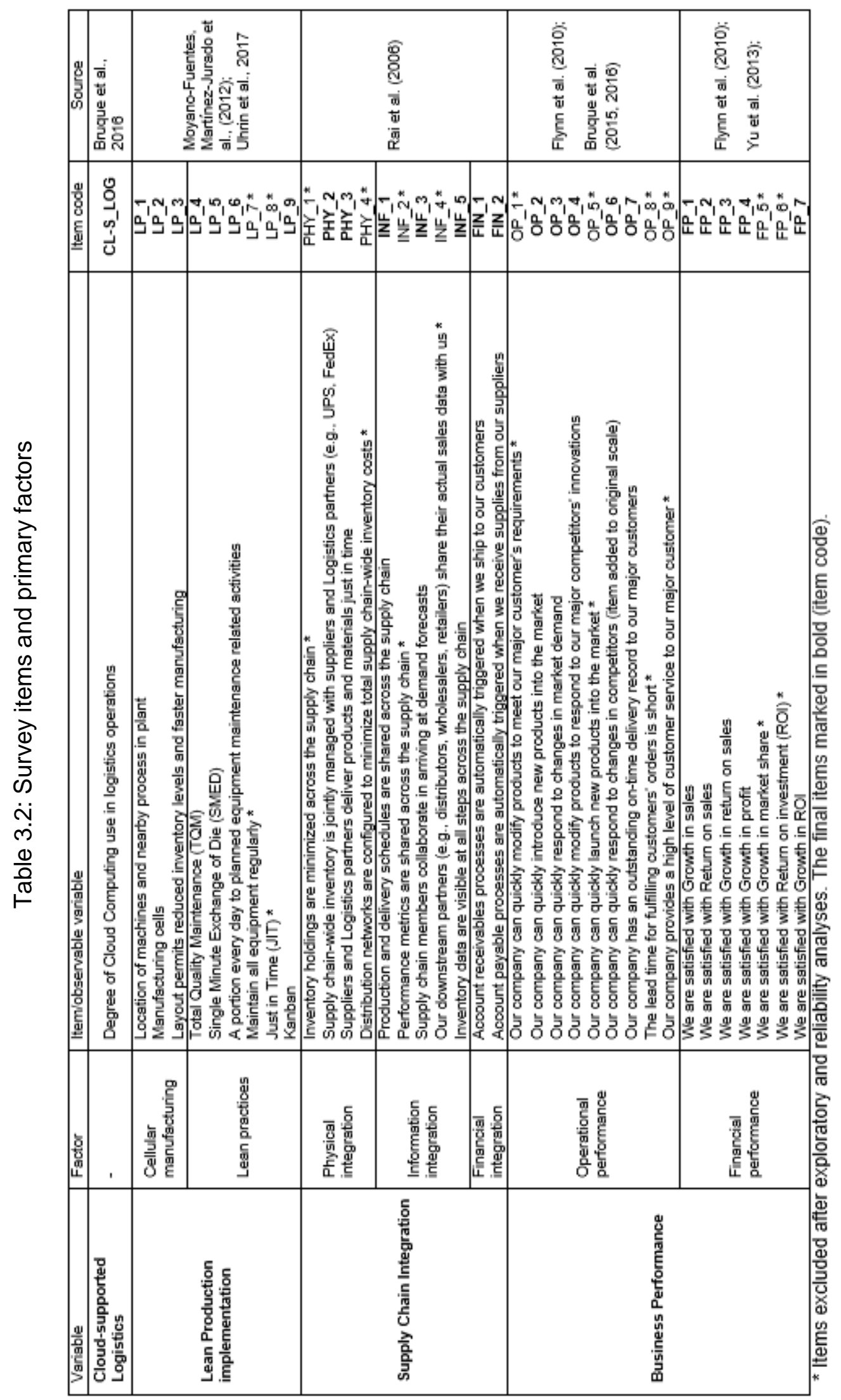




\subsubsection{DATA ANALYSIS: FACTOR ANALYSIS AND STRUCTURAL EQUATION MODEL}

Factor Analysis is a methodology used to confirm scale dimensionality and presents two different modalities: exploratory factor analysis, which enables measurement model identification; and confirmatory factor analysis, which enables evaluation of the final measurement model (Gorsuch 1983; Gerbin et al., 1996). In both analyses, the standardised load values of the scale items should be greater than or equal to 0.5 (Kaplan, 2000).

Structural Equation Modelling is a statistical approach to test hypotheses on relationships between observable and non-observable variables (Satorra, 1993) and has been used quite extensively in the Supply Chain Management field (Bernardes and Zsidisin, 2008; Li et al., 2009; Acar et al., 2017). The objective of SEM is to confirm the relationships proposed in the explanatory model, confronting hypotheses with empirical data (Kaplan, 2000). A Structural Equation Model is divided into two basic parts: the measurement model and the structural model. The first determines how the unobservable construct is measured by means of these indicators, while the second estimates the effects and relations between variables (Hair et al., 2009).

The following steps are suggested for implementing a Structural Equation Model (Kaplan 2000; Kline 2005): (i) Specification, in which the hypothetical relationship between variables, whether latent or observable, is established; (ii) Identification, in which the model parameters are determined; (iii) Parameter estimation, in which parameter values and their measurement errors are determined by exploratory factor analysis (measurement model identification), confirmatory factor analysis (final measurement model evaluation) and variance and/or covariance analysis (structural model parameter estimation) (Gorsuch, 1983; Gerbin et al., 1996); (iv) Fit evaluation, with reference to model data accuracy (parameters used for a model to be considered a fit, at confidence level = 95\%, can be $x^{2} / \mathrm{df}<5$; RMSEA < 0.06; and/or MFI, NFI, NNFI, CFI and IFI close to one) (Satorra, 1993); (v) Model re-specification, in which the researcher should, if necessary, seek methods to improve the model fit (by adding or removing parameters that have been estimated in the original model if there is no good fit in exploratory factor analysis, confirmatory factor analysis or the structural model) (Hair et al., 2009); and (iv) Results interpretation, in which it is concluded whether the hypotheses are accepted or rejected.

The following presents the measurement model, identified and evaluated from the Factor Analysis application; and the structural equation model, to confirm the hypothetical relationships proposed in the explanatory model. 


\subsection{ANALYSIS AND RESULTS}

\subsubsection{MEASUREMENT MODEL}

First, seven internationally renowned researchers in the areas included in this research (Lean Production and Supply Chain Management, and IT Adoption) ensured the content validity of the questionnaire. Then, scale dimensionality was checked with an exploratory factor analysis using SPSS software. Items with a standardised factor load of $<0.5$ were eliminated after the first exploratory factor analysis (Kaplan, 2000) (see Table 3.2). A new exploratory factor analysis was performed in which items with factor loads of below 0.5 were not included. This new analysis indicated that the remaining items fulfilled the requirement (standardised load values $\geq 0.5$ ) (Table 3.3). The scale's reliability was also tested using SPSS software, and it was confirmed that all factors met the requirement (Cronbach's $\alpha>0.6$ ) (Nunnally and Bernstein, 1994; Malhotra, 2004). Divergent validity was checked by comparing Cronbach's a coefficient (Table 3.3) with correlations between scale items (Table 3.4) (Amand and Ward, 2004). This analysis confirmed divergent validity, as the scales' Cronbach's $\alpha$ coefficients were higher in every case than the correlation coefficients with other scales.

Table 3.3. Exploratory factor analysis

\begin{tabular}{|c|c|c|c|c|c|c|}
\hline Variable & Factor & $\begin{array}{l}\text { Item } \\
\text { code }\end{array}$ & $\begin{array}{c}\text { Combrach's } \\
\alpha \\
\end{array}$ & $\begin{array}{l}\text { Standardized } \\
\text { factor loading }\end{array}$ & Barlett test & $\begin{array}{c}\text { \% Explained } \\
\text { variance }\end{array}$ \\
\hline \multirow{7}{*}{$\begin{array}{l}\text { Lean Production } \\
\text { implementation }\end{array}$} & \multirow{3}{*}{$\begin{array}{c}\text { Cellular } \\
\text { manufacturing }\end{array}$} & LP_1 & \multirow{3}{*}{.74} & .845 & \multirow{3}{*}{$\begin{array}{c}X^{2}=178,521 \\
\mathrm{df}=3 \\
\text { sig. }=0.00\end{array}$} & \multirow{3}{*}{$66.224 \%$} \\
\hline & & LP_2 & & .820 & & \\
\hline & & LP_3 & & .775 & & \\
\hline & \multirow{4}{*}{ Lean practices } & LP 4 & \multirow{4}{*}{.75} & .735 & \multirow{4}{*}{$\begin{array}{c}X^{2}=241,074 \\
\mathrm{df}=6 \\
\text { sig. }=.00\end{array}$} & \multirow{4}{*}{$58.054 \%$} \\
\hline & & LP_5 & & .810 & & \\
\hline & & LP_6 & & .794 & & \\
\hline & & LP_9 & & .704 & & \\
\hline \multirow{7}{*}{$\begin{array}{l}\text { Supply Chain } \\
\text { Integration }\end{array}$} & \multirow{2}{*}{$\begin{array}{l}\text { Physical } \\
\text { integration }\end{array}$} & PHY_2 & \multirow{2}{*}{.63} & .857 & \multirow{2}{*}{$\begin{array}{c}X^{2}=64.383 \\
\text { df }=1 \\
\text { sig. }=.00\end{array}$} & \multirow{2}{*}{$73.517 \%$} \\
\hline & & PHY_3 & & .857 & & \\
\hline & \multirow{3}{*}{$\begin{array}{l}\text { Informational } \\
\text { integration }\end{array}$} & INF_1 & \multirow{3}{*}{.67} & .805 & \multirow{3}{*}{$\begin{array}{c}X^{2}=131.516 \\
\text { df }=3 \\
\text { sig. }=.00\end{array}$} & \multirow{3}{*}{$61.351 \%$} \\
\hline & & INF 4 & & .826 & & \\
\hline & & INF_5 & & .714 & & \\
\hline & \multirow{2}{*}{$\begin{array}{l}\text { Financial } \\
\text { integration }\end{array}$} & FIN_1 & \multirow{2}{*}{.79} & .908 & \multirow{2}{*}{$\begin{array}{c}X^{2}=140.040 \\
\text { df }=1 \\
\text { sig. }=.00\end{array}$} & \multirow{2}{*}{$82.384 \%$} \\
\hline & & FIN_2 & & .908 & & \\
\hline \multirow{10}{*}{$\begin{array}{l}\text { Business } \\
\text { Performance }\end{array}$} & \multirow{5}{*}{$\begin{array}{l}\text { Operational } \\
\text { performance }\end{array}$} & OP_2 & \multirow{5}{*}{.84} & .809 & \multirow{5}{*}{$\begin{array}{c}X^{2}=643.518 \\
\mathrm{df}=10 \\
\text { sig. }=.00\end{array}$} & \multirow{5}{*}{$61.979 \%$} \\
\hline & & OP_3 & & .846 & & \\
\hline & & $\mathrm{OP}_{4} 4$ & & .838 & & \\
\hline & & OP 6 & & .704 & & \\
\hline & & $\mathrm{OP} 7$ & & .729 & & \\
\hline & \multirow{5}{*}{$\begin{array}{l}\text { Financial } \\
\text { performance }\end{array}$} & FP 1 & \multirow{5}{*}{.93} & .853 & \multirow{5}{*}{$\begin{array}{c}X^{2}=1175.646 \\
\mathrm{df}=10 \\
\text { sig. }=.00\end{array}$} & \multirow{5}{*}{$78.785 \%$} \\
\hline & & FP_2 & & .916 & & \\
\hline & & FP_3 & & .947 & & \\
\hline & & FP_4 & & .898 & & \\
\hline & & FP 7 & & .818 & & \\
\hline
\end{tabular}




\begin{tabular}{|c|c|c|c|c|c|c|c|c|c|c|c|c|c|c|c|c|c|c|c|c|c|c|c|}
\hline$g \sigma_{1}$ & & & & & & & & & & & & & & & & & & & & & & & - \\
\hline $\begin{array}{l}0 \\
g^{\prime}\end{array}$ & & & & & & & & & & & & & & & & & & & & & & & : \\
\hline $\begin{array}{l}\tilde{a}^{\prime} \\
a^{\prime}\end{array}$ & & & & & & & & & & & & & & & & & & & & & - & & : \\
\hline $\begin{array}{l}a_{1}^{\prime} \\
a^{\prime}\end{array}$ & & & & & & & & & & & & & & & & & & & & & $\begin{array}{l}: \\
q\end{array}$ & & ले \\
\hline$a_{1}$ & & & & & & & & & & & & & & & & & & & - & 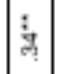 & $\begin{array}{l}\vdots \\
\vdots \\
\text { a }\end{array}$ & & 察 \\
\hline $\begin{array}{l}y_{1}^{\prime} \\
a^{\prime}\end{array}$ & & & & & & & & & & & & & & & & & & & 思 & 畜 & $\frac{\vdots}{4}$ & & 实 \\
\hline '- & & & & & & & & & & & & & & & & & & - & 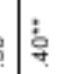 & $\frac{\vdots}{5}$ & 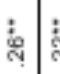 & & :ें \\
\hline$a^{\prime} n$ & & & & & & & & & & & & & & & & & - & 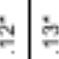 & $: \vdots$ & : & 罚 & & : \\
\hline$g^{\prime}{ }^{\prime}$ & & & & & & & & & & & & & & & & - & : & 9 & $\frac{\vdots}{4}$ & $\frac{\vdots}{\bar{y}}$ & $\begin{array}{l}\vdots \\
\text { वे }\end{array}$ & & बें \\
\hline$a^{\prime}$ & & & & & & & & & & & & & & & - & $\frac{1}{2}$ & $\frac{1}{5}$ & 95 & : & : & $\begin{array}{l}\vdots \\
\text { : }\end{array}$ & & $\dot{q}$ \\
\hline$a^{\prime}{ }^{\prime}$ & & & & & & & & & & & & & & - & 离 & : & $\vdots$ & 9 & $\frac{\vdots}{4}$ & $\frac{\vdots}{\mathrm{N}}$ & $\begin{array}{l}\vdots \\
\$\end{array}$ & & : \\
\hline$\frac{a}{2}-$ & & & & & & & & & & & & & - & 就 & $\frac{1}{\vdots}$ & 落 & $\vdots$ & $\underset{\square}{q}$ & 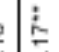 & $\vdots$ & $\begin{array}{l}\vdots \\
\vdots\end{array}$ & & $\dot{\leftrightarrow}_{\mathrm{N}}$ \\
\hline a'r & & & & & & & & & & & & - & $\vdots$ & : & 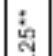 & : & 放 & 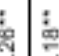 & : & $:$ & : & & : \\
\hline$\Delta^{\prime}{ }^{\prime}$ & & & & & & & & & & & - & $\mid \begin{array}{l}5 \\
\vdots \\
0\end{array}$ & 界 & 离 & 澚 & : & 罚 & 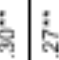 & :ึู & 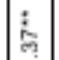 & : & & : \\
\hline$a^{\prime}+$ & & & & & & & & & & - & $\frac{\vdots}{q}$ & $:$ & $\vdots$ & : & : & : & 8 & 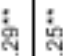 & $:$ & : & : & $\vdots$ & $\stackrel{\vdots}{\sharp}$ \\
\hline$g^{\prime}$ & & & & & & & & & - & $\frac{\vdots}{r}$ & $\frac{\vdots}{\square}$ & 妾 & : & : & : & 商 & : & : & à & : & : & & : \\
\hline ه' & & & & & & & & - & ד̦i & 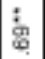 & 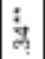 & 站 & 离 & : & : & : & $\frac{\vdots}{4}$ & $\dot{0}$ & 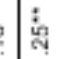 & $\mid$\begin{tabular}{l}
1 \\
\hdashline \\
\hdashline
\end{tabular} & : & & $\dot{d}$ \\
\hline$z^{\prime} N$ & & & & & & & - & {$\left[\begin{array}{l}\vdots \\
\vdots \\
\hdashline \\
\hdashline\end{array}\right.$} & 总 & $\begin{array}{c}\vdots \\
4\end{array}$ & $\therefore$ & $\therefore$ & $\stackrel{\oplus}{\oplus}$ & : & : & $\frac{\vdots}{4}$ & $\begin{array}{ll}\vdots \\
\vdots\end{array}$ & 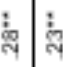 & 4 & 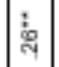 & $\begin{array}{c}\vdots \\
4\end{array}$ & & : \\
\hline$\frac{z_{u}^{\prime}}{u}-$ & & & & & & - & $\vdots$ & $\vdots$ & $\vdots$ & $\vdots$ & $\dot{y}$ & : & 离 & : & 吕 & 新 & 橧 & $\underset{N}{\vdots}$ & 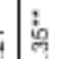 & : & $\vdots$ & & 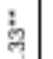 \\
\hline סـإِ & & & & & - & : & $:$ & 畜 & ì & ì & 离 & : & :ุ & : & \. & : & : & : & वู & 罚 & 峦 & & 变 \\
\hline$\underline{\underline{z}}$ & & & & - & 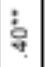 & : & 思 & 离 & 离 & 离 & : & $\frac{\vdots}{\grave{c}}$ & : & 离 & 悹 & : & : & : & 离 & 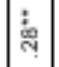 & : & & ¿⿳亠丷厂 \\
\hline$\underline{\underline{\underline{u}}}-$ & & & - & 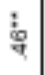 & 章 & : & 永 & 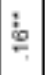 & $\begin{array}{l}\vdots \\
4 \\
\end{array}$ & 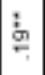 & 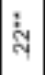 & 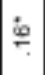 & 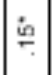 & $\mid$ & : & : & $\frac{1}{7}$ & $\vdots$ & : & : & $\begin{array}{l}\vdots \\
*\end{array}$ & ì & 竞 \\
\hline$\frac{x^{\prime}}{a}$ & & - & : & $\vdots$ & : & : & : & $\therefore$ & $\frac{\vdots}{4}$ & $\vdots$ & : & $\approx$ & : & : & : & $\mid \begin{array}{l}1 \\
\vdots \\
9\end{array}$ & 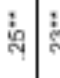 & : & $\frac{1}{\square}$ & : & 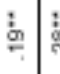 & : & $\begin{array}{lll}3 \\
\vdots\end{array}$ \\
\hline 좀 & - & $\vdots 0$ & 薄 & $\stackrel{1}{=}$ & $\vdots$ & $\begin{array}{l}\vdots \\
\text { ù } \\
\end{array}$ & $\left.\mid \begin{array}{l}\vdots \\
\vdots \\
\hdashline\end{array}\right]$ & $\mid \begin{array}{l}\vdots \\
\vdots \\
0\end{array}$ & 施 & $\stackrel{\dot{m}}{\longrightarrow}$ & {$\left[\begin{array}{l}\vdots \\
\vdots \\
\hdashline\end{array}\right.$} & 8 & $\dot{m}$ & : & 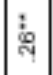 & $\frac{1}{4}$ & : & 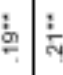 & 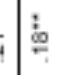 & 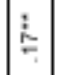 & 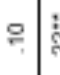 & $\vdots$ & 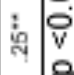 \\
\hline & $\begin{array}{l}N_{1} \\
\frac{x_{2}}{2}\end{array}$ & $\mid \begin{array}{l}m \\
\frac{7}{1} \\
\frac{1}{2}\end{array}$ & 年 & $\begin{array}{l}D_{1}^{\prime} \\
\underline{\underline{\underline{u}}}\end{array}$ & $\mid \begin{array}{l}\infty \\
\vdots \\
\underline{\underline{u}} \\
\underline{\underline{n}}\end{array}$ & 年 & $\mid \begin{array}{l}N_{1} \\
\frac{z^{2}}{2}\end{array}$ & $\begin{array}{l}N_{1} \\
\vdots \\
\vdots\end{array}$ & $\begin{array}{l}m \\
\vdots \\
0\end{array}$ & $\begin{array}{l}\overrightarrow{1} \\
0^{\prime}\end{array}$ & $\mid \begin{array}{l}\infty \\
\vdots \\
\vdots\end{array}$ & a' & $\mid \begin{array}{l}-1 \\
0^{\prime} \\
\end{array}$ & $\mid \begin{array}{l}y_{1} \\
0^{\prime} \\
\end{array}$ & $\mid \begin{array}{l}m \\
0 \\
0 \\
0 \\
\end{array}$ & $\left|\begin{array}{l}+ \\
a_{1}^{\prime} \\
2^{\prime}\end{array}\right|$ & a & ב⿱ & a & $\mid \begin{array}{l}a_{1} \\
a^{\prime}\end{array}$ & ؛ & & "ِ \\
\hline
\end{tabular}


A confirmatory factor analysis was also performed to confirm scale dimensionality and convergent validity using EQS 6.1 software. Two second-order factors were used to measure Lean Production implementation (Moyano-Fuentes, Martínez-Jurado et al., 2012): Cellular manufacturing, composed of the observable variables LP_1, LP_2 and LP_3; and Lean practices, composed of the observable variables LP_4, LP_5, LP_6 and LP_9. Three second-order factors were used to measure Supply Chain Integration (Rai et al., 2006): Physical flow integration, composed of the observable variables PHY_2 and PHY_3; Information flow integration, composed of the observable variables INF_1, INF_3 and INF_5; and Financial flow integration, composed of the observable variables FIN_1 and FIN_2. For Business Performance, two second-order factors were used (Flynn et al., 2010): Operational performance, composed of the observable variables OP_2, OP_3, OP_4, OP_6 and OP_7; and Financial performance, composed of the observable variables FP_1, FP_2, FP_3, FP_4 and FP_7.

Data exploration was performed using standardised estimation (Mardia test) and confirmed the data's multivariate non-normality. This result indicates that the Robust Maximum Probability Method could be applied to the data analysed in this study (Satorra, 1993). Finally, a model was designed with the above 24 items and Cloud-supported Logistics observable variables to check the fit of the confirmatory factor analysis. The obtained results were as follows: scaled, Satorra-Bentler, $x^{2}=496.4920$, with 238 degrees of freedom, $x^{2} / \mathrm{df}=2.086$; Root Mean Square Error of Approximation (RMSEA) $=0.06$; McDonald Fit Index $(\mathrm{MFI})=0.608$; Normal Fit Index $(\mathrm{NFI})=0.787$; Non Normal Fit Index $(\mathrm{NNFI})=0.854$; Comparative Fit Index $(\mathrm{CFI})=0.875$; Incremental Fit Index (IFI) $=0.877$. Thus, final confirmatory factor analysis fit was satisfactory. Table 3.5 shows the standardised factor loads and the $\mathrm{R}^{2}$ for each variable in confirmatory factor analysis. 
Table 3.5. Confirmatory factor analysis

\begin{tabular}{|c|c|c|c|}
\hline Factor & $\begin{array}{c}\text { Factor/Observable } \\
\text { Variable }\end{array}$ & $\begin{array}{c}\text { Standardized factor } \\
\text { loading }\end{array}$ & $\mathbf{R}^{2}$ \\
\hline \multirow{2}{*}{ Lean Production implementation } & Cellular manufacturing & .77 & .59 \\
\hline & Lean practices & .73 & .53 \\
\hline \multirow{3}{*}{ Supply Chain Integration } & Physical integration & .84 & .70 \\
\hline & Informational integration & .85 & .72 \\
\hline & Financial integration & .50 & .25 \\
\hline \multirow{2}{*}{ Business Performance } & Operational performance & .60 & .37 \\
\hline & Financial performance & .59 & .35 \\
\hline \multirow{3}{*}{ Cellular manufacturing } & LP_1 & .76 & .57 \\
\hline & LP 2 & .70 & .49 \\
\hline & LP 3 & .66 & .44 \\
\hline \multirow{4}{*}{ Lean practices } & LP_4 & .62 & .39 \\
\hline & LP_5 & .71 & .50 \\
\hline & LP_6 & .73 & .53 \\
\hline & LP_9 & .60 & .37 \\
\hline \multirow{2}{*}{ Physical integration } & PHY 2 & .70 & .49 \\
\hline & PHY_3 & .68 & .46 \\
\hline \multirow{3}{*}{ Informational integration } & INF_1 & .73 & .53 \\
\hline & INF_3 & .69 & .48 \\
\hline & INF 5 & .53 & .28 \\
\hline \multirow{2}{*}{ Financial integration } & FIN_1 & .71 & .51 \\
\hline & FIN_2 & .91 & .82 \\
\hline \multirow{5}{*}{ Operational performance } & OP_2 & .82 & .67 \\
\hline & $\mathrm{OP} 3$ & .84 & .71 \\
\hline & $\mathrm{OP} \_4$ & .83 & .69 \\
\hline & $\mathrm{OP} 6$ & .52 & .27 \\
\hline & OP_7 & .55 & .30 \\
\hline \multirow{5}{*}{ Financial performance } & $\mathrm{FP} 1$ & .78 & .61 \\
\hline & $\mathrm{FP} 22$ & .93 & .86 \\
\hline & $\mathrm{FP} 33$ & .97 & .94 \\
\hline & $\mathrm{FP} 44$ & .84 & .71 \\
\hline & FP_7 & .73 & .54 \\
\hline
\end{tabular}

Considering that the scale dimensionality confirmation process was successful, the final measurement model of each of the factors included in this study and the theoretical structural model (Figure 3.2) can now be presented. The measurement model (thin lines) shows how each latent variable is measured by observable variables (items). The structural model (thick lines) shows the relationships between the three latent variables (Lean Production implementation, Supply Chain Integration and Business Performance) and a directly observable variable (Cloud-supported Logistics). 


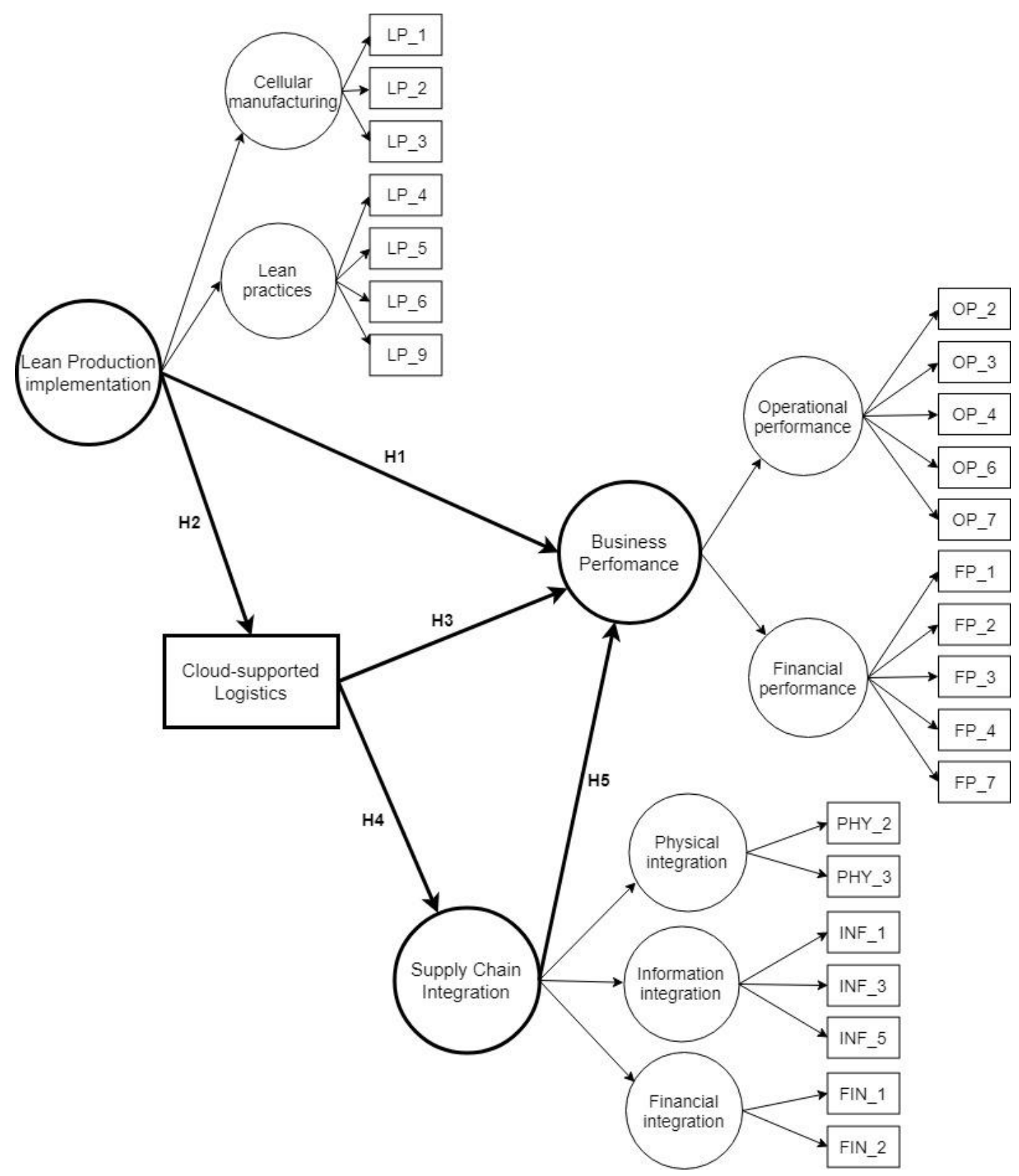

Figure 3.2. Measurement model and theoretical structural model

\subsubsection{STRUCTURAL MODEL AND DISCUSSION OF RESULTS}

The Robust Maximum Likelihood Method was used to develop the structural model using EQS 6.1 software. This is considered the most accurate method for non-standard environments (Satorra, 1993) and has been used to test the five hypotheses. The results show that this model yielded a good overall fit (scaled, Satorra-Bentler, $x^{2}=436.6503$, with 256 degrees of freedom, $x^{2} / \mathrm{df}=1.706 ; \mathrm{RMSEA}=0.05 ; \mathrm{MFI}=0.707 ; \mathrm{NFI}=0.821$; $\mathrm{NNFI}=0.901 ; \mathrm{CFI}=0.915 ; \mathrm{IFI}=0.917)$ (Satorra, 1993). The relationships in $\mathrm{H} 1, \mathrm{H} 2, \mathrm{H} 4$ and $\mathrm{H} 5$ were seen to be significant $(\mathrm{p}<0.05)$, while the relationship in $\mathrm{H} 3$ did not receive 
sufficient support (Figure 3.3). Hypothesis H5 received the highest support with a load of 0.75 ; followed by $\mathrm{H} 1$, which received support with a significant ratio load of 0.42 . $\mathrm{H} 2$ and $\mathrm{H} 4$ also received significant support, but with slightly lower standardised parameters (0.25 and 0.15 , respectively).

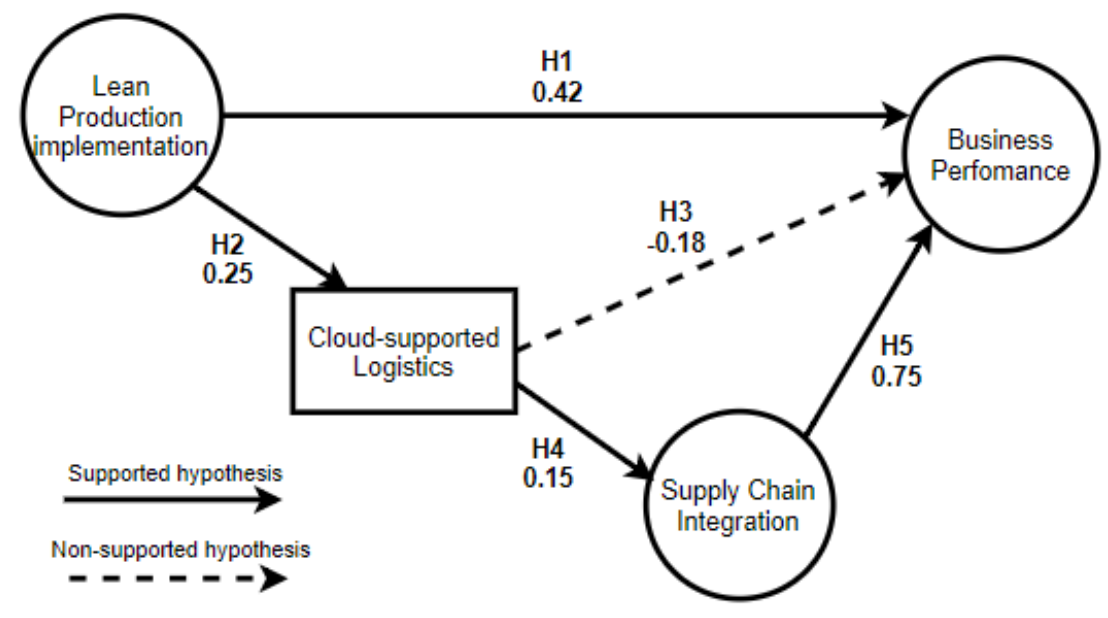

Figure 3.3. Structural model

In the model, $\mathrm{H} 1$ receives sufficient support: Lean Production implementation improves Business Performance. As discussed in the arguments leading to $\mathrm{H} 1$, there are several possible ways for Lean Production implementation to lead to better Business Performance. If a company has adopted Lean Production, an incremental improvement in products, services and operations can be expected. Lean Production implementation could also eliminate process redundancies and maintain continuity of production routines, as well as reduce stocks and production costs.

A direct positive effect of Lean Production implementation on Cloud-supported Logistics $(\mathrm{H} 2)$ has also been identified. As seen before, Lean Production seeks to increase efficiency through minimising the operational complexities of Logistics processes and increasing efficiency and speed to respond to demand variations. Also, Cloud Computing offers several advantages over traditional IT models, such as faster data transaction speeds, elasticity, and flexibility, which is also conducive to increased efficiency. Thus, since Lean Production pursues efficiency and IT such as Cloud Computing achieves higher levels of efficiency than more traditional IT, Lean Production implementation leads organisations to use Cloud Computing in Logistics processes.

This chapter has also analysed the effects of Cloud-supported Logistics on Business Performance $(\mathrm{H} 3)$, but this relationship has not been supported by our analysis. This result supports the idea that Cloud-supported Logistics could not provide direct and tangible operational and financial benefits to the companies at the time of the fieldwork. 
In addition, $\mathrm{H} 4$ receives sufficient support in the analyses described in the previous section: Cloud-supported Logistics improves Supply Chain Integration. As discussed in the arguments leading to $\mathrm{H} 4$, there are several possible ways in which Cloud-supported Logistics can lead to internal and external Supply Chain Integration, e.g., by improving information sharing about inventory management, raw material processes, production and ordering.

Finally, a direct positive effect has also been identified of Supply Chain Integration on Business Performance (H5). As noted in several previous studies in the production and operations management field (e.g., Stank et al., 1999; Pagell, 2004; Flynn et al., 2010), integrating the links that form the supply chain flows can bring many benefits to supply chain partners. If a supply chain has its flows integrated, benefits can be expected in the form of improved ordering and planning, efficient warehouse management, shorter lead times and accurate supplier-customer interaction, among others.

\subsection{CONCLUSIONS AND FUTURE RESEARCH LINES}

Our findings identify a positive relationship between Lean Production and Business Performance and are aligned with the prior literature (e.g., Lamming, 1996; Mason-Jones and Towill, 1999; Li et al., 2005; van der Vaart et al., 2012). These studies also show that Lean Production principles and practices could increase business efficiency by reducing production times and eliminating everything that is not strictly necessary for the production of added value for the organisation. Since the relationship between Lean Production implementation and Business Performance is a known finding, the $\mathrm{H} 1$ results meet our expectations.

On the other hand, our study also shows the positive effect of Lean Production implementation on Cloud-supported Logistics, demonstrating that Lean Production implementation and IT use can have a complementary effect, as previously suggested by other authors (e.g., Mo, 2009; Moyano-Fuentes, Martínez-Jurado et al., 2012; Pinho and Mendes, 2017). This effect would facilitate the extension of Lean practices along the supply chain and would be aligned with recent interest in extending research on Lean Supply Chain Management (Marodin et al., 2017; Tortorella et al., 2018).

This research found that Cloud-supported Logistics is a tool used by companies to improve logistics-related flow management without seeking a direct effect on Business Performance. This finding is consistent with the previous literature, which concluded that Operational performance does not benefit from the application of IT such as Cloud 
Computing directly (Thun, 2010; Bruque et al., 2015, 2016). Moreover, it is aligned with other research that shows that IT by itself does not improve competitive performance except in conjunction with other complementary resources and capabilities (Powell and Dent-Micallef, 1997).

In other respects, our results point to Cloud-supported Logistics having a positive influence on Supply Chain Integration. This is consistent with Bruque et al., (2015, 2016), who found that Cloud Computing implementation is directly and positively related to Supply Chain Integration. The novelty of this study is that the specific use of Cloud Computing for logistical purposes is an effective channel for integrating the supply chain and sharing logistics information. These results, therefore, indicate the importance of analysing Cloud Computing for specific purposes rather than as a broader construct when analysing its business utility.

Our findings indicate that Supply Chain Integration plays a mediating role between Cloud-supported Logistics and Business Performance (operational and financial) and are consistent with the findings of Bruque et al., (2015; 2016), who identified that supply chain flow integration is significantly related to operational performance. The novelty of this study is that, unlike Bruque et al., $(2015,2016)$, our analysis also considers financial performance. Thus, better Business Performance in supply chains can be achieved with technologically integrated physical, information and financial flows. In fact, Cloudsupported Logistics provides logistics integration capabilities and reiterate the need to carefully consider how IT is used in intra/inter-organisational logistics processes.

Moreover, an indirect effect is observed between Cloud-supported Logistics and Business Performance via Supply Chain Integration. This finding is also in line with findings in the previous literature, which show the indirect role between IT use and performance (Powell and Dent-Micallef, 1997; Bruque et al., 2015).

Finally, the results show that Lean production has a strong direct effect on Business Performance (0.42), which means that companies using Lean Production achieve better Business Performance. There is also the strong indirect effect between Cloud-supported Logistics and Business Performance, which is greater than the direct effect of Lean on Business Performance. Due to the mediating effect of Supply Chain Integration between Cloud-supported Logistics and Business Performance, the latter improves much more than if Lean Production is used alone without the use of Cloud-supported Logistics. This is partly due to the effect of Lean on Business Performance and, also, to the very powerful indirect effect of Cloud-supported Logistics on Business Performance via Supply Chain Integration. Although there are findings in the previous literature to the 
effect that Lean Production can lead companies to use IT in order to make efficiency gains, this is the first research to demonstrate that by specifically relying on IT in Cloudsupported Logistics, Lean production has greater direct and indirect impacts on Business Performance. This is the result of the mediating effect of Supply Chain Integration between Cloud-supported Logistics and Business Performance.

\subsubsection{MANAGEMENT IMPLICATIONS}

This chapter not only sheds light on the theoretical relationships between Lean Production implementation, Cloud-supported Logistics, Supply Chain Integration, and Business Performance; there are also other findings and implications that can affect the way that managers perceive and organise these resources in their companies in their quest for better results. Managers need to know that they can use Lean Production and its different practices to directly achieve better performance, both financially and operationally. However, when Lean practices are based on IT in general, and on Cloudsupported Logistics in particular, the effect on Business Performance is multiplied, not by a direct effect derived from Cloud Computing use, but by the integration that Cloudsupported Logistics brings about in the supply chain and its powerful impact on both financial and operational Business Performance. Managers could therefore consider the complementarity between Lean Production implementation and Cloud-supported Logistics as a way to leverage Business Performance.

By adopting Lean Production, which provides the business efficiency that the Cloudsupported Logistics user pursues, companies can achieve efficiency in intra- and interorganisational integration. It is important for supply chain managers to know that Cloud Computing applied to logistics when Lean practices are in place not only helps Supply Chain Integration but has a strong indirect impact on Business Performance. These further efficiency gains would be achieved through cooperation with supply chain members and could thus lead to better operational and financial results.

The findings of this chapter could, therefore, help business managers become aware of how powerful Lean Production, Cloud-supported Logistics and Supply Chain Integration are and of the impacts of these tools on Business Performance.

\subsubsection{LIMITATIONS AND FUTURE RESEARCH LINES}

This study focuses on the industrial sectors that are in an intermediate position in the supply chain and targets companies that frequently interact with upstream and downstream supply members. The implications of the findings are, therefore, both far- 
reaching and robust. However, more research and analysis must be conducted in a variety of industrial and geographical settings to confirm the chapter's findings.

In addition, results have only been obtained from Spanish industry and without focusing on specific industrial sectors. The studies need to be conducted and replicated with company samples from other geographical environments and to specifics industrial sectors to confirm the obtained results. A logical extension of this work would consist of empirically replicating the obtained results in other contexts in which the identified relationships would be tested with larger samples and several informants in each company. It would also be advisable to use a longitudinal methodology in the future for a study of causality in the observed relationships, since the cross-sectional nature of the data does not allow causal inferences to be extracted. It is also necessary to examine the lag between progress being made in the Lean Production implementation level and the time when the company makes advances in Cloud-supported Logistics.

\section{REFERENCES}

Abdulaziz, A. (2012). Cloud Computing for increased business value. International Journal of Business Society Science, 3 (1), 234-239.

Acar, M., Tarim, M., Zaim, H., Zaim, S., and Delen, D. (2017). Knowledge management and ERP: Complementary or contradictory?. International Journal of Information Management, 37 (6), 703-712.

Ahire, S.L., and Devaraj, S. (2001). An empirical comparison of statistical construct validation approaches. IEEE Transactions on Engineering Management, 48 (3), 319-329.

Al-jawazneh, B. (2016). The Prospects of Cloud Computing in Supply Chain Management (A Theoretical Perspective). Journal of Management Research, 8 (4), 145-158.

Amand, G., and Ward, P. (2004). Fit, flexibility and performance in manufacturing: coping with dynamic environments. Production and Operations Management, 13 (4), 369-385.

Armstrong, J.S., and Overton, T.S. (1997). Estimating nonresponse bias in mail surveys. Journal of Marketing Research, 14(3), 396-402.

Azevedo, S., Prata, P., and Fazendeiro, P. (2013). Assessment of supply chain agility in a Cloud Computingbased framework. Scalable Computing: Practice and Experience, 13 (4), 295-301.

Amand, G., and Ward, P. (2004). Fit, flexibility and performance in Manufacturing: Coping with Dynamic Environments. Production and Operations Management, 13 (4), 369-385.

Barrales-Molina, V., Llorens-Montes, F. J., and Gutierrez-Gutierrez, L. J. (2015). Dynamic capabilities, human resources and operating routines: A new product development approach. Industrial Management \& Data Systems, $115(8), 1388-1411$.

Berman, B. (2002). Should your firm adopt a mass customization strategy? Business Horizons, 45 (4), 51 60.

Bernardes, E.S., and Zsidisin, G.A. (2008). An examination of strategic supply management benefits and performance implications. Journal of Purchasing and Supply Management, 14 (2), 209-219.

Bhoir, H., and Principal, R. P. (2014). Cloud Computing for Supply Chain Management. International Journal of Innovations in Engineering Research and Technology, 1 (2), 1-9.

Boon-itt, S., and Wong, C.Y. (2011). The moderating effects of technological and demand uncertainties on the relationship between Supply Chain Integration and customer delivery performance. International Journal of Physical Distribution \& Logistics Management, 41 (3), 253-76. 
Botta, A., de Donato, W., Persico, V., and Pescapé, A. (2016). Integration of Cloud computing and Internet of Things: A survey. Future Generation Computer Systems, 56, 684-700.

Braojos, J., Benitez, J., and Llorens-Montes, F. J. (2019). How do social commerce-IT capabilities influence firm performance? Theory and empirical evidence. Information \& Management, 56 (2), 155-171.

Brunn, P., and Mefford, R.N. (2004). Lean production and the Internet. International Journal of Production Economics, 89 (3), 247-260.

Bruque, S., Moyano, J., and Maqueira, J. M. (2015). Use of Cloud technology, Web 2.0 and operational performance: the mediating role of Supply Chain Integration. International Journal of Logistics Management, 26 (3), 426-458.

Bruque, S., Moyano, J., and Maqueira, J. M. (2016). Supply Chain Integration through community Cloud: Effects on operational performance. Journal of Purchasing and Supply Management, 22 (2), 141-153.

Buyya, R., Broberg, J., and Goscinski, A. (2011). Cloud Computing: Principles and Paradigms. John Wiley \& Sons. New York: Inc. Wiley Press.

Cagliano, R., Caniato, F., and Spina, G. (2006). The linkage between Supply Chain Integration and manufacturing improvement programmes. International Journal of Operations \& Production Management 26, (3), 282-99.

Chen, I., and Paulraj, A. (2004). Towards a theory of supply chain management: the constructs and measurements. Journal of Operations Management, 22 (2), 119-150.

Cook, T., and Campbell, D. (1979). Quasi-experimentation: design and analysis issues for field settings. Boston: Houghton Mifflin.

Corsten, D., and Felde, J. (2005). Exploring the performance effects of key-supplier collaboration. An empirical investigation into Swiss buyer-supplier relationship. International Journal of Physical Distribution \& Logistic Management, 35 (6), 445-461.

DeGroote, S.E., and Marx, T.G. (2013). The impact of IT on supply chain agility and firm performance: an empirical investigation. International Journal of Information Management, 33, 909-916.

Dermirkan, H., Cheng, H.K., and Bandyopadhyay, S. (2010). Coordination strategies in SaaS supply chain. Journal of Management Information Systems, 26 (4), 119-143.

Devaraj, S., Krajewski, L., and Wei, J. C. (2007). Impact of e-business technologies on operational performance: the role of production information in the supply chain. Journal of Operations Management, 25 (6), 1199-1216.

Díaz-Madroñero Boluda, Payá, D. P., and F. Mula, J. M. (2015). A review of tactical optimization models for integrated production and transport routing planning decisions. Computers and Industrial Engineering, $88,518-535$.

Doherty, E., Carcary, M., Conway, G., and Matlay, H. (2015). Migrating to the Cloud-examining the drivers and barriers to adoption of Cloud Computing by Smes in Ireland; an exploratory study. Journal of Small Business and Enterprise Development, 22 (3), 512-527.

Ellinger, A. E., Daugherty, P.J., and Keller, S.B. (2000). The relationship between marketing/Logistics interdepartmental integration and performance in US manufacturing firms: an empirical study. Journal of Business Logistics, 21 (1), 1-21.

Fantazy, K.A., Kumar, V., and Kumar, U. (2009). An empirical study of the relationships among strategy, flexibility and performance in the supply chain context. Supply Chain Management: An International Journal, 14 (3), 177-188.

Fingar, P. (2009). Dot. Cloud. The 21st Century Business Platform. Meghan-Kiffer Press, Tampa, Florida.

Flynn, B.B., Sakakibara, S., and Schroeder, R.G. (1995). Relationship between JIT and TQM: practices and performance. Academy of Management Journal, 38 (5), 1325-1360.

Flynn, B.B., Huo, B., and Zhao, X. (2010). The impact of Supply Chain Integration on performance: a contingency and configuration approach. Journal of Operations Management, 28 (1-2), 58-71.

Foerstl, K., Schleper, M. C., and Henke, M. (2017). Purchasing and supply management: From efficiency to effectiveness in an integrated supply chain. Journal of Purchasing and Supply Management, 23 (4), 223228.

Gerbin D., and Hamilton J. (1996). Viability of Exploratory Factor Analysis as a Precursor to Confirmatory Factor Analysis. Structural Equation Modelling, 3 (1), 62-72. 
Ghaffari, K., Delgosha, S. M., and Abdolvand, N. (2014). Towards Cloud Computing: A swot analysis on its adoption in SMES. International Journal of Information Technology Convergence and Services, 4 (2), 13-20.

Ghobakhloo, M., and Tang, S. H. ((2014)). IT investments and Business Performance improvement: The mediating role of Lean manufacturing implementation. International Journal of Production Research, 52(18), 5367-5384.

Giménez, C., and Ventura, E. (2005). Logistics-production, Logistics-marketing and external integration: their impact on performance. International Journal of Operations \& Production Management, 25 (1), 20 38

Giménez, C.; Van der Vaart, T., and Van Donk, P. (2012). Supply Chain Integration and performance: the moderating effect of supply complexity. International Journal of Operations \& Production Management, 32 (5), 583-610.

Gorsuch, R. (1983). Factor Analysis (2nd ed.), Erlbaum, Hillsdale.

Gunasekaran, A., and Ngai, E. W. T. (2004). Information systems in supply chain integration and management. European Journal of Operational Research, 159 (2), 269-295.

Hair, J.F., Black, W.C., Babin, B.J., and Anderson, R.E. (2009). Multivariate Data Analysis. New Jersey: Prentice Hall.

Hayes, B. (2008). Cloud Computing. Communications of the ACM, 51 (7), 9-11.

Herron, C., and Braiden, P. M. 2017. Defining the foundation of Lean manufacturing in the context of its origins (Japan), in IET International Conference on Agile Manufacturing, 148-157.

Holweg, M. (2007). The genealogy of Lean Production. Journal of Operations Management, 25 (2), 420-37.

Hopp, W.J., Spearman, M.L. (2004). To pull or not to pull: what is the question?. Manufacturing and Service Operations Management 6 (2), 133-48.

Jabbour, C.J.C., de Sousa Jabbour, A.B.L., Govindan, K., Teixeira, A.A., and de Souza Freitas, W.L. (2013). Environmental management and operational performance in automotive companies in Brazil: the role of human resource management and Lean manufacturing. Journal of Cleaner Production, 47, 129-140.

Jede, A., and Teuteberg, F. (2015). Integrating Cloud Computing in supply chain processes. A comprehensive literature review. Journal of Enterprise Information Management, 28 (6), 72-94.

Johnston, D.A., and Wright, L. (2004). The e-business capability of small and medium sized firms in international supply chains. Information Systems and e-Business Management, 2 (2/3), 223-40.

Kaplan, D. (2000). Structural equation modelling: Foundations and extensions. Newbury Park: Sage.

Krafcik, J.F. (1988). Triumph of the Lean Production system. Sloan Management Review, 30 (1), 41-52.

Lamming, R.C. (1996). Squaring Lean supply with supply chain management. International Journal of Operations and Production Management, 16 (2), 183-96.

Li, G., Yang, H., Sun, L., and Sohal, A. S. (2009). The impact of IT implementation on Supply Chain Integration and performance. International Journal of Production Economics, 120 (1), 125-138.

Li, S., Rao, S.S., Ragu-Nathan, T.S., and Ragu-Nathan, B. (2005), Development and validation of a measurement instrument for studying supply chain management practices, Journal of Operations Management 23, (6), 618-41.

Li, W., Zhong, Y., Wang, X., and Cao, Y. (2013). Resource virtualization and service selection in Cloud logistic. Journal of Network and Computer Applications, 36 (6), 1696-1704.

Liu, S., Yang, Y., Qu W.G., and Liu, Y. (2016). The business value of Cloud Computing: the partnering agility perspective. Industrial Management and Data Systems, 116 (6), 1160-1177.

Malhotra, M.K., Mackelprang, and A.W. (2012). Are internal manufacturing and external supply chain flexibilities complementary capabilities? Journal of Operations Management, 30 (3), 180-200.

Malhotra, N.K. (2004). Marketing Research: An Applied Orientation (4th Ed.) Pearson Education, Inc.: New Jersey.

Marinagi, C., Trivellas, P., and Sakas, D. (2014). The impact of Information Technology on the development of Supply Chain Competitive Advantage. Procedia - Social and Behavioral Sciences, 147, 586-591.

Marodin, G.A., Tortorella, G.L., Frank, A.G., and Filho, M. (2017). The moderating effect of lean supply chain management on the impact of lean shop floor practices on quality and inventory. Supply Chain Management: An International Journal, 22 (6), 473-485. 
Marston, S., Li, Z., Bandyopadhyay, S., Zhang, J., and Ghalsasi, A. (2011). Cloud Computing - the business perspective. Decision Support Systems, 51 (1), 176-189.

Mason-Jones, R., and Towill, D.R. (1999). Total cycle time compression and the agile supply chain. International Journal of Production Economics, 62 (1/2), 61-73.

McCormack, K., Ladeira, M.B., and Oliveira, M.P.V. (2008). Supply chain maturity and performance in Brazil. Supply Chain Management: An International Journal, 13 (4), 272-282.

McKone, K.E., Schroeder, R.G., and Cua, K.O. (2001). The impact of total productive maintenance on manufacturing performance. Journal of Operations Management, 19 (1), 39-58.

Mehrsai A., Karimi H. R., and Thoben K. D. (2013). Integration of Supply Networks for Customization with Modularity in Cloud and Make-To-Upgrade Strategy. Systems Science \& Control Engineering, 1 (1), 2842.

Mell, P., and Grance, T. (2011). The NIST definition of Cloud Computing. Recommendations of the National Institute of Standards and Technology. National Institute of Standards and Technology, Gaithersburg, MD.

Miles, R.E., and Snow, C.C. (2007). Organization theory and supply chain management: an evolving research perspective. Journal of Operations Management, 25 (2), 459-463.

Mo, J.P.T. (2009). The role of Lean in the application of information technology to manufacturing. Computers in Industry, 60 (4), 266-276.

Moyano-Fuentes, J., and Sacristán-Díaz, M. (2012). Learning on Lean: a review of thinking and research. International Journal of Operations \& Production Management, 32 (5), 551-582.

Moyano-Fuentes, J., Martínez-Jurado, P.J., Maqueira-Marín, J.M., and Bruque-Cámara, S. (2012). Impact of use of information technology on Lean Production adoption: evidence from the automotive industry. International Journal of Technology Management, 57 (1-3), 132-148.

Moyano-Fuentes, J., Sacristán-Díaz, M., and Martínez-Jurado, P. J, (2012). Cooperation in the supply chain and Lean Production adoption: Evidence from the Spanish automotive industry. International Journal of Operations \& Production Management, 32 (9), 1075-1096.

Nowicka, K. (2014). Smart city Logistics on cloud computing model. Procedia - Social and Behavioral Sciences, 151, 266-281.

Nunnally, J.C., and Bernstein, I.H. (1994). Psychometric Theory, (3rd ed.), McGraw-Hill: New York.

Oh, S., Ryu, K., and Jung, M. (2013). Reconfiguration framework of a supply network based on flexibility strategies. Computers and Industrial Engineering, 65 (1), 156-165.

Oliveira, R.R., Noguez, F. C., Costa, C. A., Barbosa, J. L., and Prado, M. P, (2013). SWTRACK: an intelligent model for cargo tracking based on off-the-shelf mobile devices. Expert System with Applications, 40, 2023-2031.

Oliveira, T., Thomas, M., and Espadanal, M. (2014). Assessing the determinants of Cloud Computing adoption: an analysis of the manufacturing and services sectors. Information and Management, 51 (5), 497-510.

Pagell, M. (2004). Understanding the factors that enable and inhibit the integration of operations, purchasing and Logistics. Journal of Operations Management, 22 (5), 459-487.

Paulraj, A., Chen, I.J., and Flynn, J. (2006). Levels of strategic purchasing: Impact on supply integration and performance. Journal of Purchasing and Supply Management, 12 (3), 107-122.

Pérez, C., de Castro, R., Simons, D., and Gimenez, G. (2010). Development of lean supply chains: a case study of the Catalan pork sector. Supply Chain Management: An International Journal, 15 (1), 55-68.

Pinho, C., and Mendes, L. (2017). IT in Lean-based manufacturing industries: systematic literature review and research issues. International Journal of Production Research, 55, 7524-7540.

Powell, T.C., and Dent-Micallef, A. (1997). Information technology as competitive advantage: the role of human, business and technology resources. Strategic Management Journal, 18 (5), 375-405.

Prajogo, P., and Olhager, J. (2012). Supply chain integration and performance. The effects of long-term relationships, information technology and sharing, and Logistics integration. International Journal of Production Economics, 135, 514-522.

Rai, R, Sahoo, G, and Mehfuz, S. (2015). Exploring the factors influencing the Cloud Computing adoption: a systematic study on Cloud migration. SpringerPlus, 4 (1), 1-12.

Rai, A., Patnayakuni, R., and Seth, N. (2006). Firm performance impacts of digitally enabled Supply Chain Integration capabilities. MIS Quarterly, 30 (2), 225-246. 
Rai, A., Pavlou, P.A., Im, G., and Du, S. (2012); Interfirm IT capability profiles and communications for cocreating relational value: evidence from the Logistics industry. MIS Quarterly 36, (1), 233-262.

Reinartz, W., Haenlein, M., and Henseler, J. (2009). An empirical comparison of the efficacy of covariancebased and variance-based SEM", Working Papers Collection, No. 44, INSEAD, Fontainebleau.

Rich, N., and Hines, P. (1997). Supply-chain management and time-based competition: the role of the supplier association. International Journal of Physical Distribution and Logistics Management, 27 (3), 210-225.

Romano, P. (2003). Coordination and integration mechanisms to manage Logistics processes across supply networks. Journal of Purchasing \& Supply Management, 9 (3), 119-34.

Ryan, W.M., and Loeffler, C.M. (2010). Insights into Cloud Computing. Intellectual Property and Technology Law Journal, 22 (11), 22-27.

Satorra, A. (1993). Multi-sample analysis of moment-structures: asymptotic validity of inferences based on second order moments. In: Haagen, K., Bartholomeusz, A., Deistler, M. (Eds.), Statistical modelling and latent variables. Elsevier, North Holland, Amsterdam.

Shah, R., and Ward, P.T. (2003). Lean manufacturing: context, practice bundles and performance. Journal of Operations Management, 21 (2), 129-49.

Shah, R., and Ward, P.T. (2007). Defining and developing measures of Lean Production. Journal of Operations Management, 25 (4), 785-805.

Shah, R., Chandrasekaran, A., and Linderman, K. (2008). In pursuit of implementation patterns: the context of Lean and Six Sigma. International Journal of Production Research, 46 (23), 6679-99.

Shou, Y., Li, Y., Park, Y., and Kang, M. (2017). Supply chain integration and operational performance: The contingency effects of production systems. Journal of Purchasing and Supply Management, 24 (4), $352-$ 360.

Stank, T.P., Crum, M., and Arango, M. (1999). Benefits of inter-firm co-ordination in food industry supply chains. Journal of Business Logistics, 20 (2), 21-41.

Stank, T.P., Keller, S.B., and Daugherty, P.J. (2001). Supply chain collaboration and logistical service performance. Journal of Business Logistics, 22 (1), 29-48.

Stump, B., and Badurdeen, F. (2012). Integrating Lean and other strategies for mass customization manufacturing: A case study. Journal of Intelligent Manufacturing, 23 (1), 109-124.

Subramanian, N., Abdulrahman, M. D., and Zhou, X. (2015). Reprint of Integration of Logistics and Cloud Computing service providers: Cost and green benefits in the Chinese context. Transportation Research, 74, 81-93.

Tao, F., Z., L., Venkatesh, V. C., Luo, Y., and Cheng, Y. (2011). Cloud manufacturing: a computing and service-oriented manufacturing model. Journal of Engineering Manufacture, 225 (10), 1969-1976.

Thun, J.H. (2010). Angles of integration: an empirical analysis of the alignment of internet based information technology and global supply chain management. Journal of Supply Chain Management, 46 (2), 30-44.

Tortorella, G. L., Giglio, R., and Limón-Romero, J. (2018). Supply chain performance: how lean practices efficiently drive improvements. Journal of Manufacturing Technology Management, 29 (5), 829-845.

Trappey, A. J. C., Trappey, C. V., Chang, S. W. C., and Tun Nien Hsu, W. T. L. (2016). A one-stop logistic services framework supporting global supply chain collaboration. Journal of Systems Science and Systems Engineering, 25(2), 229-253.

Troyer, C., and Cooper, R. (1995). Smart moves in Supply Chain Integration. Transportation and Distribution $36,55-62$.

Tuncay, E. (2010). Effective use of Cloud Computing in education institutions. Procedia- Social and Behavioral Sciences, 2 (2), 938-942.

Ugarte, G. M., Golden, J. S., and Dooley, K. J. (2016). Lean versus green: The impact of lean logistics on greenhouse gas emissions in consumer goods supply chains. Journal of Purchasing and Supply Management, 22 (2), 98-109.

Uhrin, A., Bruque-Cámara, S., and Moyano-Fuentes, J. (2017). Lean Production, workforce development and operational performance. Management Decision, 55 (1), 103-118.

Van der Vaart, T.; Van Donk, P; Giménez, C., and Sierra, V. (2012). Modelling the integration-performance relationship. Collaborative practices, enablers and contextual factors. International Journal of Operations and Production Management, 32 (9), 1043-1074. 
Vermula, R., and Zsifkovits, H. (2016). Cloud Computing for Supply Chain Management. Berg- und Hüttenmännische Monatshefte, 161 (5), 229-232.

Wang, Y., Wang, Y., and Yang, Y. (2010). Understanding the determinants of RFID adoption in the manufacturing industry. Technological Forecasting and Social Change, 77 (5), 803-815.

Wang, X., Li, W.F., Zhong, Y. and Zhao, W. (2012). Research on cloud Logistics-based one-stop service platform for Logistics center. IEEE 16th International Conference on Computer Supported Cooperative Work in Design, 558-563, Wuhan, China.

Ward P, and Zhou H, (2006). Impact of information technology integration and Lean/ just-in-time practices on lead-time performance. Decision Sciences, 37 (2), 177-203.

Womack, J.P., and Jones, D.T. (1996). Lean Thinking, Simon and Schuster, New York, NY.

Womack, J.P., Jones, D.T., and Ross, D. (1990). The Machine That Changed the World, MacMillan, New York, NY.

Wu, D., Greer, M. J., Rosen, D. W., and Schaefer, D. (2013). Cloud manufacturing: Strategic vision and state-of-the-art. Journal of Manufacturing Systems, 32 (4). 564- 579.

Wu, F., Yeniyurt, S., Kim, D., and Cavusgil, S.T. (2006). The impact of information technology on supply chain capabilities and firm performance: a resource based view. Industrial Marketing Management, 35 (4), 493-504.

Yan, J., Xin, S., Liu, Q., Xu, W., Yang, L., Fan, L., Chen, B., and Wang, Q. (2014). Intelligent supply chain integration and management based on cloud of Things. International Journal of Distributed Sensor Networks, (2014), 1-15.

Yu, W., Jacobs, M.A., Salisbury, W.D., and Enns, H. (2013). The effects of Supply Chain Integration on customer satisfaction and financial performance: An organizational learning perspective. International Journal of Production Economics, 146 (1), 346-358.

Zhong, R. Y., Lan, S., Xu, C., Dai, Q., and Huang, G. Q. (2015). Visualization of RFID-Enabled Shopfloor Logistics Big Data in Cloud Manufacturing. The International Journal of Advanced Manufacturing Technology, 84 (1-4), 5-16. 


\title{
Chapter 4
}

\section{Lean Production Implementation, Mass Personalization and Business Performance: How does Supply Chain Flexibility affect their interrelationships?}

\begin{abstract}
This chapter analyses the mediating role of Supply Chain Flexibility in the interrelationships between Lean Production implementation, Mass Personalization and business performance. A random sample of 260 companies obtained from a population of 1,717 Spanish companies that occupy an intermediate position in the supply chain has been used to test the proposed hypothetical framework. Telephone surveys using the CATI computerized system has been used to collect data, obtaining a response rate of 15.6, and a Structural Equation Modelling have been design to test the six proposed hypothesis. Findings indicate that companies initially implement Lean Production to optimize Mass Personalization processes and improve business performance. However, in the presence of Supply Chain Flexibility, Lean Production implementation no longer has a direct impact on Mass Personalization and business performance, but it does have an indirect impact through the flexibility it achieves (shown as a mediator effect). Therefore, companies should implement Lean Production to achieve flexibility and thus optimize the Mass Personalization processes and obtain better performance.
\end{abstract}

Keywords: Lean Production implementation, Supply Chain Flexibility, Mass Personalization, Business Performance 


\section{Lean Production Implementation, Mass Personalization and Business Performance: How does Supply Chain Flexibility affect their interrelationships?}

\subsection{INTRODUCTION}

Supply Chain Management is defined as a set of actions that allows companies to manage, plan and control their operations as a way to facilitate collaboration between supply chain actors (suppliers, producers, distributors and customers) (Frazelle 2001; Waters 2007; Gunasekarana et al. 2008). In order to be more effective and efficient, producing with quality, lower costs and in the shortest possible, companies are adopting management practices in their supply chains as a way to achieve better results (Flynn et al., 2010). In this context, Lean Production, Mass Personalization and Supply Chain Flexibility have an important role to improve supply chain effectiveness and efficiency and, thus, enhance business performance (Shah and Ward, 2003, Cagliano et al., 2006, Da Silveira and Arkader, 2007; Machado and Moraes, 2011; Moyano-Fuentes et al., 2012).

Lean Production can be defined as a socio-technical management system oriented to efficiency, which is used for the identification and elimination of waste-low or nil valueadded activities through continuous improvement (Womack et al., 1990; Shah and Ward, 2003). Lean Production implementation seeks the elimination of all waste forms, extending to manufacturing operations, distribution, product development and processing times (Hopp and Spearman, 2004; Holweg, 2007; Stump and Badurdeen, 2012).

Mass Personalization refers to a company's ability to provide personalized products and services at a price and speed comparable to standard offers for a mass market (Purohit et al., 2016; Wang et al., 2016). In the Mass Personalization context, companies need to respond quickly and effectively to changes in demand, which can be achieved through Supply Chain Flexibility (Lummus et al. 2003; Pfeiffer et al. 2013; Oh et al. 2013). Supply Chain Flexibility is defined as the ability of a Supply Chain to change its processes, resources, structure and governance mechanisms within a given scope, responding in terms of production volume and product variability to changes in demand (Molina et al., 2005). In fact, Supply Chain Flexibility appears as a key competitive factor to meet the requirements demanded by customers and provide variety and delivery speed of personalized products and services (Griffiths and Margetts, 2000; Molina et al., 2005; Zhang et al., 2005; Danese et al., 2013). 
Previous literature has dealt separately with the relationship between Lean Productionbusiness performance, Lean-Supply Chain Flexibility, Lean-Mass Personalization, and Supply Chain Flexibility-Mass Personalization. There is growing interest among researchers in the underlying principles of Lean Production and its effects on business performance, Supply Chain Flexibility and Mass Personalization (Shah and Ward, 2003, Cagliano et al., 2006, Moyano-Fuentes et al., 2012a, Uhrin et al., 2017). Such studies show that Lean Production implementation could improve business performance, increasing production effectiveness and efficiency by reducing the production waiting times, and eliminating everything that is not strictly necessary to produce added value for the organization (van der Vaart et al., 2012). Lean Production could also be a catalyst for organisations to achieve greater levels of Supply Chain Flexibility, since it could improving coordination and integration between company departments and with supply chain partners (Zair, 1992; Chen y Popvich, 2003; Moyano-Fuentes, Martinez-Jurado et al., 2012). There are indications that Lean Production implementation could improve Supply Chain Flexibility by reducing installation time, allowing products to be manufactured to the required quality standard and maintaining the components flow without interruption (Stump and Badurdeen, 2012). Furthermore, certain Lean Production principles could support a productive environment that is able to respond to the large demand variations observed in Mass Personalization (Chen y Popvich, 2003; Stump and Badurdeen, 2012). Nevertheless, some research shows that Lean Production seeks to minimize the system's variability (de Treville and Antonakis, 2006; Shah and Ward, 2007; Moyano-Fuentes, Martinez-Jurado et al., 2012), which goes against the high variability demanded in Supply Chain Flexibility/Mass Personalization environments. There are also a considerable number of studies investigating the relationship between Supply Chain Flexibility and Mass Personalization (Moon et al. 2012; Oh et al. 2013; Stojanov and Ding 2015). These studies indicate that Supply Chain Flexibility could be a way to respond to unforeseen changes in customer needs, market dynamism and competitors' actions in a Mass Personalization context (Da Silveira et al. 2001; Urgo et al. 2016).

However, the interrelationship between Lean Production implementation, Supply Chain Flexibility, Mass Personalization, and their joint impacts on business performance remains unexplored. The better evidence on the role played by Lean Production, Mass Personalization and Supply Chain Flexibility on Business Performance could affect the way researchers and practitioners approach them, becoming more aware of the important role of Supply Chain in competitiveness. Thus, the value of this study is that academics and practitioners may have supporting evidence on the role played by such 
management resources, operationally and strategically linked, and how this combination could be transformed into better business performance.

Therefore, we delve deeper into the interrelationships between Lean Production, Supply Chain Flexibility and Mass Personalization, with the objective of analyse the relationships between these management resources and their joint impacts on business performance. Specifically, it is intended to answer the following Research Question: What role does Lean Production implementation play in Mass Personalization and business performance, in presence of Supply Chain Flexibility?

To achieve this objective, this chapter has been structured into six sections, which are preceded by this introduction. The second section presents the research background and the third section sets out the research hypotheses. The fourth section describes the methodology used and the fifth section presents the results obtained and their discussion. Finally, the sixty section highlights the conclusions and future research lines.

\subsection{THEORETICAL BACKGROUND}

\subsubsection{LEAN PRODUCTION, SUPPLY CHAIN FLEXIBILITY AND BUSINESS PERFORMANCE}

There are clear movements towards Lean Production implementation since its first use (Krafcik, 1988; Womack et al., 1990; Womack and Jones, 1996). It is based on Toyota's Production System and focuses on waste disposal, inventory reduction, improved process performance and human resource embedding (Womack et al., 1991; Stump and Badurdeen, 2012). Lean Production emerges as a management philosophy for manufacturing based on continuous improvement that optimizes resources of the organization, encompassing both internal operations and the relationship between the main supply chain partners (Womack and Jones, 1996; Jayaram et al., 2008; MoyanoFuentes, Martinez-Jurado et al., 2012). It extends to manufacturing operations, distribution, and processing times (Hopp and Spearman, 2004; de Trevilley Antonakis, 2006; Holweg, 2007).

The underlying principles of Lean Production and its effects on Supply Chain Management have been extensively studied in recent decades and there is growing interest among researchers in this area (Womack et al., 1990; Cagliano et al., 2006; Uhrin et al., 2017). There is some consensus in the literature that the practices commonly associated with Lean Production implementation are: Just in time, Cellular Manufacturing, Total Productive Maintenance, Total Quality Management, and Human 
Resources Management (Shah y Ward, 2003; Shah et al., 2008; Moyano-Fuentes and Sacristan-Diaz, 2012).

From the business performance perspective, literature findings indicate that Lean Production implementation could enable organizations to optimize their performance at all organizational levels (Womack et al., 1990; Jayaram et al., 2008). Some research shows that Lean Production seeks to minimize the system's variability sources to increase business efficiency (de Treville and Antonakis, 2006; Shah and Ward, 2007; van der Vaart et al., 2012). It could impact the production efficiency, responding to demand variations, reducing the production waiting times, and eliminating everything that is not strictly necessary to produce added value for the organization (Hopp and Spearman, 2004; Holweg, 2007; Stump and Badurdeen, 2012). The literature also shows that Lean Production implementation is associated with improvements in labour productivity, quality and production time (White et al., 1999, Jabbour et al., 2013; Uhrin et al., 2017).

Furthermore, Supply Chain Flexibility appears as a key competitive factor to adapt to changing environmental requirements (Danese et al., 2013, Rojo et al., 2016). In fact, previous literature show that the changing environment is making Supply Chain Flexibility one of the competitive priorities with which many companies must establish management actions (Elms and Low, 2013; Moon et al. 2012). Although relationships have been established between different types of flexibilities, the extent to which flexibility affects the system's performance has not yet been sufficiently investigated (Gong, 2008). Literature shows that business performance could be related to a company's ability to offer flexibility (Upton, 1995; Gong, 2008; Dev et al., 2014) and that the whole chain performance could be improved if it is built with flexible components (Gong, 2008). Supply Chain Flexibility allows companies to change their processes, resources, structure and management mechanisms, responding quickly to changes in demand in terms of production volume and product variety (Lummus et al., 2003; Sanchez and Pérez, 2005; Purnomo and Sufa, 2015). In this way, companies would be able to respond to individual requests, quickly, without considerable cost and consequently improve their performance (Seebacher and Winkler, 2015). Literature that directly links Lean Production, Supply Chain Flexibility and their impacts on business performance is scarce. Lean Production could be a facilitating agent for Supply Chain Flexibility, supporting the various flexibility types, allowing companies to redesign production systems, change product design for production, and control inventory and service levels (Stump and Badurdeen, 2012). Some authors show that through "Lean Supply Chain", companies could reduce costs, increase flexibility and considerably increase 
improvements in the products to be manufactured (Vonderembse et al., 2006, MoyanoFuentes and Sacristan-Díaz, 2012, Marodin et al., 2017).

\subsubsection{LEAN PRODUCTION, MASS PERSONALIZATION AND BUSINESS PERFORMANCE}

Mass Personalization appears as a recent trend by companies and represents a major competitive advantage (Lau, 1995; Kumar et al., 2015, Marin and Brîndaşu, 2015). It refers to a set of plans that serve as a reference for decision-making, in order to provide individually designed products and services to each client (Frutos and Borenstein, 2003; Machado and Moraes, 2008; Wang, 2009; Machado and Moraes, 2011; Tien, 2011). In fact, some authors show that Mass Personalization denotes the ability to provide rapid transmission of personalized goods and services at low cost and in large scale (Purohit et al., 2016; Wang et al., 2016). Although there may be implementation difficulties (Brabazon et al., 2010; Arroyo-Gutiérrez and Jiménez-Par, 2013), Mass Personalization is becoming popular after the success of its implementation in various companies, such as Dell, BMW and Compaq (Ghiassi and Spera, 2003; Hsu and Wang, 2004; Gunasekaran, 2005; Kim, 2014).

To achieve the expected Mass Personalization levels and improve business performance, companies need to focus on improving process characteristics and product quality (Ho et al., 2008). Literature shows that Mass Personalization strategies allow companies to provide individually designed products and services without large increases in costs (Frutos and Borenstein, 2003; Machado and Moraes, 2008; Wang, 2009; Machado and Moraes, 2011; Tien, 2011). These practices play an important role in the efficiency and profitability of a company, resulting in better operational and financial results (Elking et al., 2017).

The operational and financial success of Mass Personalization depends on low levels of finished product inventory, low production time, and cost management at each production stage (Kakati, 2002; Claycomb et al., 2005), which could be achieved through the Lean Production implementation. However, literature relating Lean Production implementation, Mass Personalization and business results is scarce. Boynton et al. (1993) shows that Lean Production is an important factor for a company wishing to transition to Mass Personalization. There are indications that, in cases of high-level personalization, some Lean Production practices may be difficult to apply (e.g., JIT and load levelling), requiring the integration of other concepts to increase the efficiency of operations (Stump and Badurdeen, 2012). On the other hand, certain Lean Production principles could be implemented on Mass Personalization environments (e.g. continuous 
improvement, waste reduction, teamwork and 5S), increasing production efficiency to respond demand variations (Moyano-Fuentes, Martinez-Jurado et al., 2012; Stump and Badurdeen, 2012; Singh and Teng, 2016).

\subsubsection{SUPPLY CHAIN FLEXIBILITY, MASS PERSONALIZATION AND BUSINESS PERFORMANCE}

Literature shows that there has been a growing interest in Supply Chain Flexibility and Mass Personalization in recent years (Brettel et al., 2016). Supply chains that compete in a market with highly unpredictable consumer demand, such as Mass Personalization environments, may need to be more flexible (Gong, 2008; Moon et al., 2012; Oh et al., 2013; Stojanov y Ding, 2015; Urgo et al., 2016). In fact, there is consensus in the research that Supply Chain Flexibility could represent a potential source of response to individual customer requirements (Griffiths y Margetts, 2000; Vickery et al., 2003; Peng y Yu, 2007).

Regarding to personalization levels and flexible processes, literature shows that the manufacturing systems (Make-to-order/Build-to-order, and Engineer-to-order), reconfigurable production (logic and physical), product configuration (modular production and products family platform), and order products preparation and delivery are practices related to this research field (Ismail et al. 2007; Al-Zaher et al. 2013; Levandowski et al. 2015). Make-to-order/build-to-order, and engineer-to-order systems are listed as manufacturing strategies with a high level of flexibility to meet the customers' individual needs (Claycomb et al. 2005; Purnomo and Sufa 2015; Levandowski et al. 2015). Reconfigurable physical and logical productions are designed to change and adjust quickly to the production structure and can thus offer a high flexibility level to respond in a timely manner to the customer requirements changes (Al-Zaher et al. 2013; Dev et al. 2014). Modular products and product family platforms are listed as two types of configuration that provide the standardization level needed for companies to adapt quickly and efficiently to new markets (Jiao et al. 2006; Zheng et al. 2017). Order preparation and delivery are related to flexible logistics solutions (Tse et al. 2012; Costantino et al. 2014).

With respect to Supply Chain Flexibility, Mass Personalization, and their impacts on business performance, companies could operationally respond to high-demand changes in Mass Personalization environments through Supply Chain Flexibility (Lummus et al., 2003; Martinez and Perez, 2006; Oh et al., 2013). In a flexible supply chain environment, companies would be able to develop sourcing, production and delivery processes in a cost-effective, efficient and rapid manner companies and to respond in terms of volume 
and variety to individual customer requests (Pine, 1993; Zipkin, 2001; Vickery et al., 2003; Moser, 2007; Stump and Badurdeen, 2012; Urgo et al, 2016).

\subsection{HYPOTHESES}

\subsubsection{LEAN PRODUCTION IMPLEMENTATION AND BUSINESS PERFORMANCE}

In order to eliminate waste at all stages of the supply chain and reduce the system's variability sources, Lean Production implementation is an increasingly used tool to improve efficiency and produce added value for organizations (Womack et al., 1990; Mason-Jones and Towill, 1999; van der Vaart et al., 2012). Lean Production implementation could facilitate incremental improvement of products, services, operations, quality and efficiency, eliminating redundancies, improving operational processes and maintaining continuity with previous routines (Jones and Towill, 1999; Li et al. 2005; Moyano-Fuentes, Martinez-Jurado et al., 2012). In fact, the inclusion of Cellular Manufacturing and some Lean Production practices (e.g., TQM, JIT and TPM) could support the combination of maximum stability with minimal planning and assembly effort (Moyano-Fuentes and Sacristan-Diaz, 2012). As a result, companies could perceive reduced manufacturing unit costs and inventory levels, as well as resource savings and improved process quality (McKone et al., 2001; Uhrin et al., 2017; Elking et al., 2017).

Moreover, Lean Production implementation could increase information accuracy and decreasing variability sources, allowing supply chain members to synchronously structure their collaborative process practices (Moyano-Fuentes, Martinez-Jurado et al., 2012). In fact, previous literature shows that operational performance is directly related to the collaboration level between supply chain partners (Jede and Teuteberg, 2015; Bruque et al., 2016). In this sense, Lean Production implementation could improve speed, visibility and transparency of processes by standardizing work the corporate level (Hopp and Spearman, 2004, Moyano-Fuentes and Sacristán-Díaz, 2012). Consequently, it could mitigate the limiting effect on the relationship of certain contingent factors (e.g. complexity of the physical or operational flows of the chain, variability of demand, among others) and thus improve business performance (Moyano-Fuentes, Martinez-Jurado et al., 2012)

Therefore, Lean Production implementation could have a direct positive effect on business performance (operational and financial), which come from increased labour productivity, quality and production time (White et al., 1999; Stump and Badurdeen, 
2012; Elking et al., 2017). As a result, supply chain processes could be faster, more accurate and less costly, due to their widely recognised benefits such as reduced stock, increased efficiency, reduced costs and improved delivery time (Shah y Ward, 2003; Uhrin et al., 2017).

Taking these arguments together, we can affirm that Lean Production implementation could generate better business performance, and we are therefore in a position to state the following hypothesis:

H1: There is a positive relationship between Lean Production implementation and the Business Performance

\subsubsection{LEAN PRODUCTION IMPLEMENTATION AND SUPPLY CHAIN FLEXIBILITY}

As seen above, Lean Production implementation in business environment seeks continuous improvement and disposal of all waste forms (Mason-Jones and Towill, 1999; Stump and Badurdeen, 2012; Jabbour et al., 2013). Certain Lean Production principles could be implemented in flexible supply chain environments (e.g. continuous improvement, waste reduction, teamwork and 5S), increasing production efficiency and responding to variations in demand (Moyano-Fuentes, Martinez-Jurado et al., 2012; Singh and Teng, 2016). Lean Production enables grouping basic elements of product family members into a common module, which would be used to derive different product variants and combine it with different components (Moyano-Fuentes, Martinez-Jurado et al., 2012). In this sense, adopting Lean Production for Supply Chain Flexibility environments could be an appropriate option, as its characteristics would reduce operational complexities and facilitate structural, process, resource and management changes (Uhrin et al., 2017). Since Lean Production could be able to support the components flow without interruptions, it would reduce the production time and allow the flexible manufacturing of products with characteristics and quality standards demanded. In addition, Lean Production could act on the loss and inflexibility causes, improve work pace and production efficiency (Baum et al., 2000; Swafford et al., 2006; Moyano y Sacristán, 2012). Thus, through Lean Production implementation companies could reduce process uncertainties, delivery time and costs (Moyano-Fuentes, MartinezJurado et al., 2012), which would also contribute to higher levels of flexibility.

Previous literature shows that integration and collaboration between supply chain members is essential to achieve better flexibility levels (Potter et al. 2004; Nobre et al. 2008; Stojanov and Ding 2015). Through Lean Production, companies could reduce waiting times and improve the integration of value chain linkages, with the aim of 
eliminating everything that is not strictly necessary to produce added value for the organization (Womack et al., 1990; van der Vaart et al., 2012). In this sense, Lean Production could be a catalyst for organisations to achieve greater levels of flexibility, since it could improving coordination and integration between company departments and with supply chain partners (Zair, 1992; Chen y Popvich, 2003; Moyano-Fuentes, Martinez-Jurado et al., 2012). Thus, Lean Production would support the real-time information sharing related to the various chain flexibility types, allowing companies to redesign production systems, change product design, and control inventory and service levels (Li et al. 2005; Moyano-Fuentes, Martinez-Jurado et al., 2012; Uhrin et al. 2017). Consequently, Lean Production implementation could contribute to a greater effectiveness of Supply Chain Flexibility, refining routines and processes, and thus increasing efficiency to respond to dynamic market changes (Zair, 1992).

Therefore, Lean Production implementation could support the agile and real-time information sharing related to the different types of Supply Chain Flexibility (MoyanoFuentes, Martinez-Jurado et al., 2012), allowing companies to redesign production systems, change product design, and control inventory and service levels (Akkermans et al., 2003; Wang, 2009). Lean Production implementation would reduce process uncertainties, delivery time and costs, which would contribute to increase Supply Chain Flexibility levels (Baum et al. chain, 2000; Swafford et al., 2006; Moyano and Sacristan, 2012).

Based on the above arguments, it can be expected that Lean Production implementation could have positive effect on Supply Chain Flexibility. Therefore, the following hypothesis is proposed:

H2: There is a positive relationship between Lean Production implementation and Supply Chain Flexibility

\subsubsection{LEAN PRODUCTION IMPLEMENTATION AND MASS PERSONALIZATION}

Literature shows that Mass Personalization follows the order-based manufacturing model, and is therefore associated with high system variability and difficulty in forecasting demand (Badurdeen and Liyanage, 2009; Stump and Badurdeen, 2012). Lean Production implementation could be a positive factor in Mass Personalization environments, allowing basic elements of product family members to be grouped into a common module, which would be used to derive different product variants and combine it with different components (Stump and Badurdeen, 2012; Moyano-Fuentes, Martinez- 
Jurado et al., 2012). In this way, Lean Production could act in the demand changes, and diminishing market exit time and delivery time.

By reducing installation times, allowing products to be manufactured to the required quality standard and maintaining the component flow without interruption, Lean Production could support a productive environment that is able to respond to the large demand variations observed in Mass Personalization (Chen y Popvich, 2003; MoyanoFuentes, Martinez-Jurado et al., 2012). In fact, certain Lean Production principles could easily be implemented in Mass Personalization environments (e.g. continuous improvement, waste reduction, teamwork and 5S) increasing the demand response potential in this environments (Stump and Badurdeen, 2012).

Moreover, Mass Personalization requires that companies not only focus on manufacturing operations (process characteristics and product quality), but also on improving process characteristics and product quality (Holweg, 2007; Ho et al., 2008). Lean Production implementation could act as a positive factor in Mass Personalization, since it extends to manufacturing operations, distribution, product development and processing times (Hopp and Spearman, 2004; de Trevilley Antonakis, 2006; Holweg, 2007). In this sense, Lean Production implementation allows supply chain members to synchronously structure their collaborative process practices, reducing misguided uncertainty and information asymmetries (Moyano-Fuentes, Martinez-Jurado et al., 2012; Singh and Teng, 2016). Thus, Lean Production implementation could support all stages of the value chain and thus enable companies to provide personalized goods and services.

In short, Lean Production implementation could facilitate the incremental improvement of Mass Personalization, eliminating redundancies, maintaining the continuity of previous routines and allowing companies to be able to modify and develop personalized products and services. Taking these arguments together and we are therefore in a position to state the following hypothesis:

H3: There is a positive relationship between Lean Production Implementation and Mass Personalization

\subsubsection{SUPPLY CHAIN FLEXIBILITY AND BUSINESS PERFORMANCE}

Due to the high demand variability, the current business environment requires companies to be more flexible in supply chain systems, which appears as a key competitive factor to adapt to changing requirements (Alsafi and Vyatkin, 2010; Danese et al., 2013; Asad et al., 2016). Supply Chain Flexibility allows companies to change their 
processes, structure and management mechanisms as a way of responding in terms of production volume and product variety to changes in demand (Lummus et al., 2003; Sanchez and Pérez, 2005; Pfeiffer et al., 2013; Oh et al., 2013). In this way, Supply Chain Flexibility could significantly reduce manufacturing times in a variable demand environment which, in turn, would be positively related to better business performance (da Silveira and Arkader, 2007; Purnomo and Sufa, 2015, Acar et al., 2017).

In the same line, authors such as Gong (2008) and Dev et al. (2014) show that business performance could be directly related to the ability of the company to offer product flexibility. In fact, increased Supply Chain Flexibility faces uncertainty about the products that will be demanded by customers in a given period without incurring a higher cost penalty (Gerwin, 1993; Upton, 1995; Gong, 2008). Thus, Supply Chain Flexibility could be a factor that minimises overall process costs and, therefore, companies could respond to individual requests quickly without considerable costs (Lummus et al., 2005; Alsafi and Vyatkin, 2010; Seebacher and Winkler, 2015).

Supply Chain Flexibility could, therefore, be a productive response factor through which companies could be more adaptable to situations of uncertainty, acting on supply disruptions and changes in demand (Stevenson and Spring, 2007; Seebacher and Winkler, 2015; Asad et al., 2016). Through Supply Chain Flexibility, companies could develop procurement, production and delivery processes in a cost-effective, efficient and rapid manner (Pine, 1993; Vickery et al., 2003; Urgo et al.2016).

Taking these arguments together, we can affirm that Supply Chain Flexibility could generate better business performance, and we are therefore in a position to state the following hypothesis:

H4: There is a positive relationship between Supply Chain Flexibility and the Business Performance

\subsubsection{SUPPLY CHAIN FLEXIBILITY AND MASS PERSONALIZATION}

Supply chains competing in a market with highly unpredictable consumer demand may need to be more flexible (Gong, 2008; Moon et al., 2012; Urgo et al., 2016). Indeed, there is consensus in research that Supply Chain Flexibility could represent a potential source of response to individual customer requirements (Griffiths and Margetts, 2000; Vickery et al., 2003; Peng and Yu, 2007).

In the Mass Personalization environments, customer requirements are treated as a range of negotiable options rather than a set of fixed inputs (Chen and Tseng, 2007). Through Supply Chain Flexibility, firms could respond effectively to such requirements 
and meet the individual needs of their customers (Lummus et al., 2003; Giachetti et al., 2003; Chu, 201; Stump and Badurdeen, 2012). This is because more flexible supply chains could allow firms to change their processes, resources, structure and management mechanisms (Lummus et al., 2003; Al-Zaher et al., 2013). Thus, companies would be able to vary the output volume, develop new products, and modify the product mix and services (Sanchez and Pérez, 2005; Moon et al., 2012; Oh et al., 2013).

In this same line, Supply Chain Flexibility could be a factor that would minimize cycle times, terms and complexities of production in a variable demand environment (da Silveira and Arkader, 2007; Purnomo and Sufa, 2015). It could be observed, then, an improvement in response capacity and, consequently, companies could effectively use business resources to quickly produce a range of products and services to satisfy individual demand (Zipki, 2001; Squire et al., 2006; Barman and Canizares, 2015).

In short, through Supply Chain Flexibility, firms could offer goods and services with different personalization levels, allowing firms to achieve economies of scale and scope, both of which are necessary to develop Mass Personalization capacity (Stump and Badurdeen, 2012).

Based on the above arguments, the following hypothesis is proposed:

H5: There is a positive relationship between Supply Chain Flexibility and Mass Personalization

\subsubsection{MASS PERSONALIZATION AND BUSINESS PERFORMANCE}

The economic production of custom-made and high-variety goods appears as a challenge facing modern enterprises (Stump and Badurdeen, 2012; Al-Zaher et al., 2013). In response, production systems have evolved from Mass Production techniques to Mass Personalization (Lau, 1995; Kumar et al., 2015, Marin and Brîndaşu, 2015). Previous literature shows that companies such as Dell, BMW or Motorola have been able to improve their performance through Mass Personalization (Ghiassi and Spera, 2003; Selladurai, 2004; Hsu and Wang, 2004; Gunasekaran, 2005; Kim, 2014). These will achieve better economics and operational results by increasing individual customer satisfaction, offering products with desired characteristics, acceptable delivery times, and without drastically increasing production costs.

Mass Personalization is associated with extensive application of customer knowledge to respond to their individual needs and thus offer products and services aligned with their expectations (Kakati, 2002; Claycomb et al., 2005; Hanafy and Elmaraghy, 2015). In this 
context, Mass Personalization could positively affect business performance, both operational and financial, by offering price, quality and speed of delivery at each production stage (da Silveira et al., 2001; Brettel et al., 2016; Purohit et al., 2016). Thus, Mass Personalization could allow companies to provide products and services quickly, individually designed and without large cost increases, which would be related to better business results both operational and financial (Machado and Moraes, 2008; Wang, 2009; Tien, 2011).

Mass Personalization strategies, therefore, allow companies to provide individually designed products and services, playing an important role in in a company's efficiency and profitability, which could result in better operational and financial performance (Frutos and Borenstein, 2003; Machado and Moraes, 2011; Elking et al., 2017).

Based on the above arguments, we are therefore in a position to state the following hypothesis:

H6: There is a positive relationship Mass Personalization and the Business Performance Figure 4.1 shows the five hypothesized links in a theoretical research model.

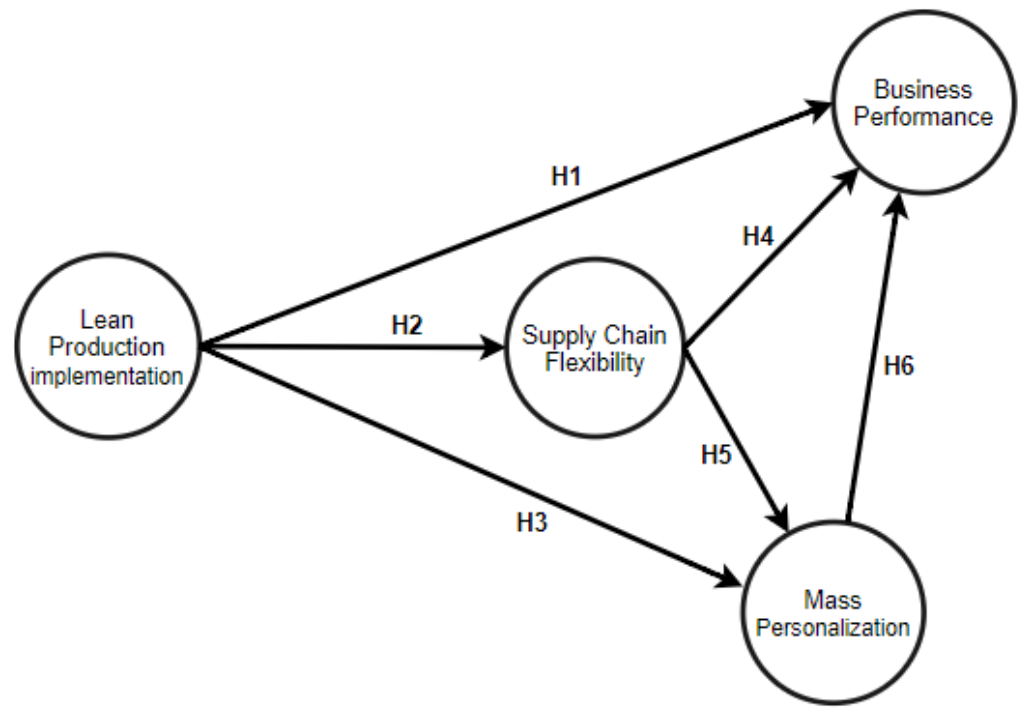

Figure 4.1. Theoretical baseline model

\subsection{METHODOLOGY}

\subsubsection{POPULATION, QUESTIONNAIRE AND DATA GATHERING}

A population of 1,717 companies taken from the Iberian Balance Sheet Analysis System (SABI) has been used to test the research hypotheses. Population has been identified based on the following inclusion criteria: Spanish companies, with more than 50 
employees, and that occupy an intermediate position in supply chain. Companies that occupy a supply chain position very close to customer or raw materials and those industries or sectors purely related to extractive activities or to raw materials and their transformation (according to National Classification of Economic Activities) have not been considered. The fieldwork to select the sample units, conducted from November 13, 2017 to February 5, 2018, has been carried out randomly (simple random sampling), and the sample eventually comprised 260 companies $(15.1 \%$ percent of the response rate).

A questionnaire has been formulated to capture key research themes, and its items have been taken from literature (Flynn et al, 2010, Moon et al., 2012; Moyano-Fuentes, Martínez-Jurado et al., 2012). Six internationally recognized researchers in the specific areas related to this study previously tested the questionnaire used in the interviews: Supply Chain Management (4) and Marketing (2). According to the researchers' recommendations, several items of the questionnaire were reformulated to be better aligned with research objectives and clearer to be understood by companies. In order to identify the understanding level of the questionnaire by companies, a pilot test was subsequently carried out. In this test, the research's authors made telephone interviews with 15 companies obtained randomly from the SABI database. Then, the questionnaire was again modified and adapted according to the companies' suggestions and, thus, the final version was reached for its use in the subsequent stage of the fieldwork. The pilot test results were not considered in the subsequent analysis. The questionnaire contained questions related to Lean Production implementation, Supply Chain Flexibility, Mass Personalization and Business Performance and was aimed at the head of Supply Chain Management, Logistics or Operations Management.

Data gathering was carried out by a telephone survey using a Computer Aided Telephone Interviewing (CATI) method. CATI systems allow interviewers to access an information system that randomly displays the contact details of potential interviewees, arrange appointments with them, and store their responses in real time (Hair et al., 2009). The data were collected by four interviewers, who worked simultaneously for four hours a day throughout the fieldwork period. The team of interviewers received specific training on research background and objectives, and were instructed, supervised, and supported by the research's authors on the first working day. A web-based questionnaire was also designed for companies that had prefer to answer via web and for some interviewees that stated they would only be able to answer the questions outside their normal working hours. Thus, respondents who had not yet answered could do it in their spare time, thus completing the remaining fieldwork. 
To analyse the response bias evidence, a comparison between surveyed and nonsurveyed companies has been made, and the results have not indicated response bias. It has also been verified whether there was any specific characteristic or pattern in the reasons given by the companies to justify the refusal when they were invited to participate in the study. To this end, telephone calls have been made to some of these randomly selected companies and it was found that there were no specific characteristics or patterns. In addition, the responses obtained have been compared with those of late respondents, and no significant differences have been found for any of the variables included in the study. Finally, it has been verified whether the sample and population distribution had similar patterns. Results have confirmed that the sample used in the study corresponds to a random pattern and is representative of the population (Table 4.1).

Table 4.1. Sample, population distribution and response rate by industry

\begin{tabular}{|l|c|c|c|c|c|}
\hline Sector & \multicolumn{2}{|c|}{$\begin{array}{c}\text { No. of companies in } \\
\text { population }\end{array}$} & $\begin{array}{c}\text { No. of companies in } \\
\text { sample }\end{array}$ & $\begin{array}{c}\text { Response } \\
\text { rate }\end{array}$ \\
\hline Food products & 629 & $36.6 \%$ & 108 & $41.5 \%$ & $17.2 \%$ \\
\hline Tobacco and related products & 7 & $0.4 \%$ & 1 & $0.4 \%$ & $14.6 \%$ \\
\hline Beverages & 89 & $5.2 \%$ & 13 & $5.0 \%$ & $14.6 \%$ \\
\hline Fabrics and textile & 86 & $5.0 \%$ & 11 & $4.2 \%$ & $12.8 \%$ \\
\hline Leather and shoes & 75 & $4.4 \%$ & 8 & $3.1 \%$ & $10.7 \%$ \\
\hline Chemicals & 251 & $14.6 \%$ & 41 & $15.8 \%$ & $16.3 \%$ \\
\hline Pharmaceuticals & 85 & $5.0 \%$ & 15 & $5.8 \%$ & $17.6 \%$ \\
\hline Informatics, electronics and optical & 91 & $5.3 \%$ & 13 & $5.0 \%$ & $14.3 \%$ \\
\hline $\begin{array}{l}\text { Electrical machinery } \\
\text { equipment } \text { and }\end{array}$ & 97 & $5.7 \%$ & 11 & $4.2 \%$ & $11.3 \%$ \\
\hline Motor vehicles & 192 & $11.2 \%$ & 32 & $12.3 \%$ & $16.7 \%$ \\
\hline Furniture & 115 & $6.7 \%$ & 7 & $2.7 \%$ & $6.1 \%$ \\
\hline Total & $\mathbf{1 7 1 7}$ & $\mathbf{1 0 0} \%$ & $\mathbf{2 6 0}$ & $\mathbf{1 0 0} \%$ & $\mathbf{1 5 . 1 \%}$ \\
\hline
\end{tabular}

\subsection{VARIABLES}

Lean Production implementation: It is a second-order construct composed by two dimensions: Cellular manufacturing, with three items (LP_1, LP_2, LP_3), refers to the physical distribution and production plant layout; and Lean practices, with four items (LP_4, LP_5, LP_6, LP_9), refers to the implementation of commonly known Lean Production practices (Moyano-Fuentes, Martínez-Jurado et al., 2012) (see Table 4.2). Respondents were asked to evaluate the questionnaire statements in relation to Lean Production implementation using a 1-7 Likert scale (1 means "in total disagreement" and 
7 means "in total agreement"). It is in line with the previous use of the same constructor (Moyano-Fuentes, Martínez-Jurado et al., 2012; Uhrin et al., 2017).

Supply Chain Flexibility: It is a second-order construct composed by four dimensions: Sourcing flexibility, with two items (SCF_4, SCF_5), refers to flexibility in the process of selecting suppliers to meet variations in demand; Operating system flexibility, with four items (SCF_6, SCF_7, SCF_8, SCF_10), refers to the flexibility of volume and production structure adjustment to facilitate processes and introduce new products in the market; Distribution flexibility, with four items (SCF_12, SCF_13, SCF_14, SCF_15), refers to the flexibility to modify warehouse structure and distribution models; and Information system flexibility, with two items (SCF_17, SCF_18), refers to the flexibility of information systems in order to support the supply chain members' needs (Moon et al., 2012) (See Table 4.2). Respondents were asked to evaluate the questionnaire statements in relation to Supply Chain Flexibility using a 1-7 Likert scale (1 means "in total disagreement" and 7 means "in total agreement"). (Moon et al., 2012).

Mass Personalization: It is a first-order construct composed by seven items (MP_1, MP_2, MP_3, MP_4, MP_5, MP_6, MP_7), and refers to the ability to personalize products with speed, low cost, variety and high production volume to adapt to customer requests (See Table 4.2). Respondents were asked to evaluate the questionnaire statements in relation to Mass Personalization using a 1-7 Likert scale (1 means "in total disagreement" and 7 means "in total agreement"). It is in line with the previous use of the same constructor (Huang et al., 2007)

Business Performance: It is a second-order construct composed of two dimensions: Operational performance, with four items (OP_1, OP_2, OP_3, OP_4), refers to the results that the company achieves in flexibility and delivery performance; and Financial performance, with five items (FP_1, FP_2, FP_3, FP_4, FP_7), consists of the valuecreating capacity of for-profit organizations and refers to growth and return on sales and profits (Flynn et al., 2010) (See Table 4.2). Respondents were asked to evaluate the questionnaire statements in relation to Supply Chain Flexibility using a 1-7 Likert scale (1 means "in total disagreement" and 7 means "in total agreement") (Flynn et al., 2010; Yu et al., 2013; Bruque et al., 2015, 2016).

Table 4.2 shows the items that compose each of the previous variables, and items marked with an asterisk have been eliminated after exploratory factorial analysis (standardized factorial load of <.5). Details of the exploratory factorial analysis are presented in Table 4.3. 


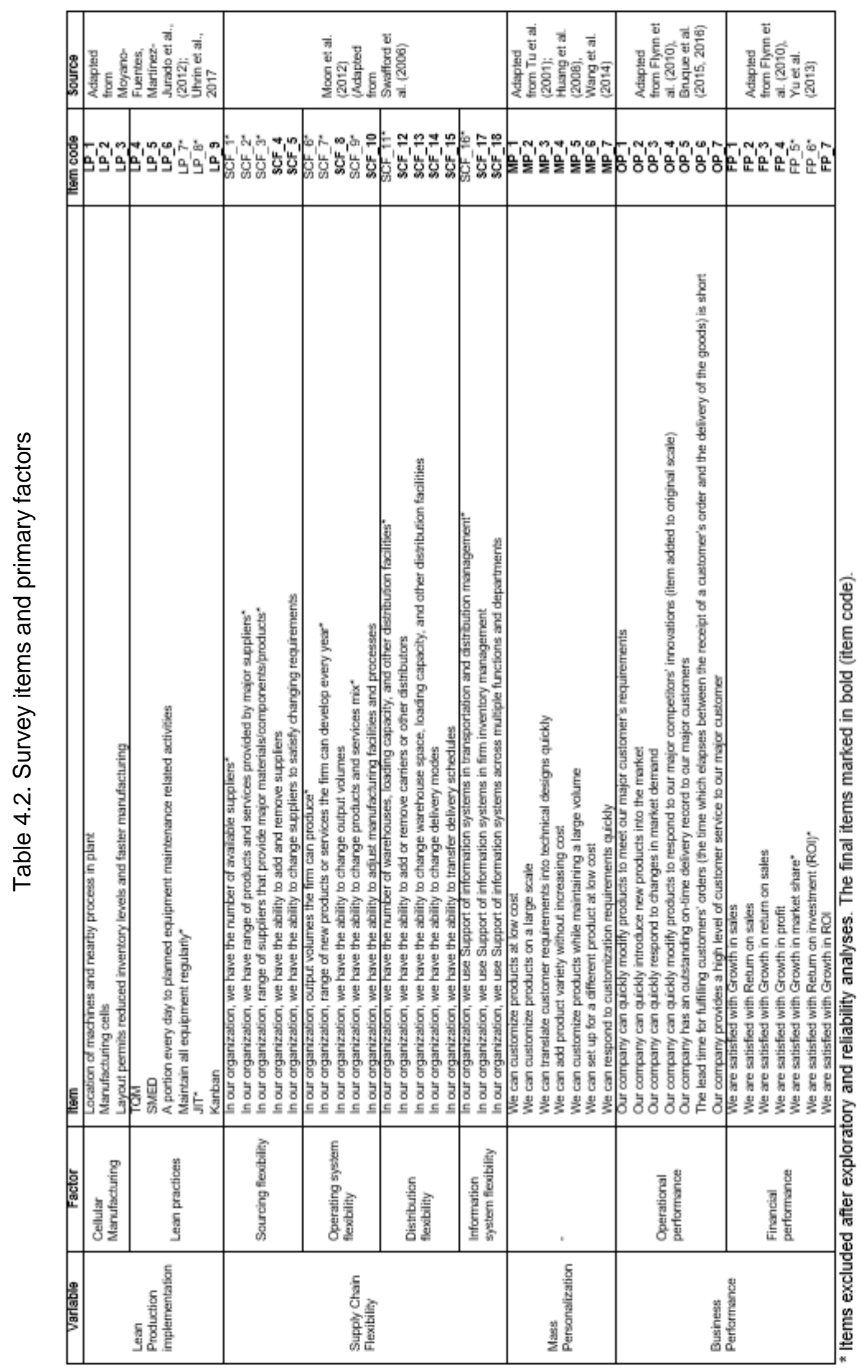




\subsubsection{DATA ANALYSIS: FACTORIAL ANALYSIS AND STRUCTURAL EQUATION MODEL}

Structural Equation Models represent a statistical technique used to confront the hypothetical relationships with empirical data (Kaplan, 2000). This technique confirm the relationships proposed in the explanatory model, in which relationships between observable and non-observable variables are defined (Satorra, 1993). Since Structural Equation Model is widely used in the supply chain management field (Li et al., 2009; Acar et al., 2017), it has been selected to contrast the hypotheses defined in this chapter.

In Structural Equation Model, firstly is necessary to identify and to evaluate the measurement model, and Factorial Analysis is a methodology used for this purpose. Exploratory analysis and confirmatory analysis are the modalities included in Factorial Analysis. The first is used to identify the measurement model, while the second is used to evaluate the final measurement model evaluation and to confirm the convergent validity (Gorsuch 1983; Gerbin et al. 1996). Both exploratory and confirmatory factorial analyses serve to define parameter values and their measurement error, and the criterion used to identify and evaluate the measurement model is that the standardized load values of the scale items should be $\geq .5$ (Kaplan, 2000). Specifically in the confirmatory factorial analysis, it is necessary to carry out a previous step, which data exploration should be performed using the normalized estimation (Mardia test). Such step is necessary to verify the data's multivariate non-normality, which confirm (or not) that Robust Maximum Likelihood Method can be utilised.

Subsequently, a variances and/or covariances analysis is used to identify the effects and relations between the structural model variables (estimation of parameter values and their measurement error) (Hair et al., 2009). It is also necessary to perform a fit evaluation, which the model data accuracy is analysed (parameters used for a model to be considered adjusted, to confidence level $=95 \%$, can be $x^{2} / d f<5$; RMSEA $<.05$; and/or MFI, NFI, NNFI, CFI and IFI close to unity) (Satorra, 1993). If necessary, the model can be re-specified to improve its fit (adding or removing parameters that have been estimated in the original model, if there is no good adjustment in exploratory factorial analysis, confirmatory factorial analysis or structural model) (Hair et al., 2009). After these analyses, the results should be interpreted, in which it is concluded whether the hypotheses are accepted or rejected.

The following is a detailed presentation of this methodological stage, which the measurement and structural are elaborated to confirm the hypothetical relationships proposed in the exploratory model. 


\subsection{ANALYSIS AND RESULTS}

\subsubsection{MEASUREMENT MODEL}

The first step to define the measurement model refers to checking the validity of the questionnaire content. For this purpose, six internationally renowned researchers in the areas included in this research (Lean Production and Supply Chain Management), which have ensured the content validity of used questionnaire. Then, to check the scale's dimensionality, an exploratory factorial analysis has been carried out using the SPSS software. In this analysis, items with a standardized factorial load of $<.5$ have been eliminated (Kaplan, 2000). A new exploratory factor analysis has been performed, indicating that the remaining items fulfilled the requirement (standardized load values $\geq$ .5) (Table 4.3). To check the scale's reliability, the SPSS software has been used to identify the Cronbach's $\alpha$ of the factors that compose the measurement scale. It has been verified that all factors have met the requirement (Cronbach's $\alpha \geq .7$ ) (Bagozzi and $\mathrm{Yi}, 1988)$. To check the divergent validity, a comparison between the Cronbach's $\alpha$ coefficients with the correlations between scale items has been made (Amand and Ward, 2004). The requirement used in this test has been that Cronbach's $\alpha$ coefficients of each scale (Table 4.3) should be higher than the correlation coefficients with other scales (Table 4.4). Such comparison has confirmed the divergent validity. 
Table 4.3. Exploratory factor analysis

\begin{tabular}{|c|c|c|c|c|c|c|}
\hline Variable & Factor & $\begin{array}{l}\text { Item } \\
\text { code }\end{array}$ & $\begin{array}{c}\text { Combrach's } \\
\alpha\end{array}$ & $\begin{array}{l}\text { Standardized } \\
\text { factor loading }\end{array}$ & Barlett test & $\begin{array}{l}\% \text { Explained } \\
\text { variance }\end{array}$ \\
\hline \multirow{7}{*}{$\begin{array}{l}\text { Lean } \\
\text { Production } \\
\text { implementati } \\
\text { on }\end{array}$} & \multirow{3}{*}{$\begin{array}{l}\text { Layout in } \\
\text { production } \\
\text { plant }\end{array}$} & LP_1 & \multirow{3}{*}{.74} & .845 & \multirow{3}{*}{$\begin{array}{c}X^{2}=178.521 \\
d f=3 \\
\text { sig. }=0.00\end{array}$} & \multirow{3}{*}{$66.224 \%$} \\
\hline & & LP_2 & & .820 & & \\
\hline & & LP_3 & & .775 & & \\
\hline & \multirow{4}{*}{ Lean practices } & LP_4 & \multirow{4}{*}{.75} & .735 & \multirow{4}{*}{$\begin{array}{c}X^{2}=241.074 \\
d f=6 \\
\text { sig. }=0.00\end{array}$} & \multirow{4}{*}{$58.084 \%$} \\
\hline & & LP_5 & & .810 & & \\
\hline & & LP_6 & & .794 & & \\
\hline & & LP_9 & & .704 & & \\
\hline \multirow{10}{*}{$\begin{array}{l}\text { Supply } \\
\text { Chain } \\
\text { Flexibility }\end{array}$} & \multirow{2}{*}{$\begin{array}{l}\text { Sourcing } \\
\text { flexibility }\end{array}$} & SCF_4 & \multirow{2}{*}{.80} & .913 & \multirow{2}{*}{$\begin{array}{c}X^{2}=152.685 \\
d f=1 \\
\text { sig. }=.000\end{array}$} & \multirow{2}{*}{$83.441 \%$} \\
\hline & & SCF_5 & & .913 & & \\
\hline & \multirow{2}{*}{$\begin{array}{l}\text { Operating } \\
\text { system } \\
\text { flexibility }\end{array}$} & SCF_8 & \multirow{2}{*}{.67} & .866 & \multirow{2}{*}{$\begin{array}{c}X^{2}=74.431 \\
d f=1 \\
\text { sig. }=.000\end{array}$} & \multirow{2}{*}{$75.051 \%$} \\
\hline & & SCF_10 & & .866 & & \\
\hline & \multirow{4}{*}{$\begin{array}{l}\text { Distribution } \\
\text { flexibility }\end{array}$} & SCF_12 & \multirow{4}{*}{.77} & .689 & \multirow{4}{*}{$\begin{array}{c}X^{2}=292.703 \\
d f=6 \\
\text { sig. }=.000\end{array}$} & \multirow{4}{*}{$59.281 \%$} \\
\hline & & SCF_13 & & .732 & & \\
\hline & & SCF_14 & & .865 & & \\
\hline & & SCF_15 & & .783 & & \\
\hline & \multirow{2}{*}{$\begin{array}{l}\text { Information } \\
\text { system } \\
\text { flexibility }\end{array}$} & SCF_17 & \multirow{2}{*}{.78} & .911 & \multirow{2}{*}{$\begin{array}{c}X^{2}=147.166 \\
d f=1 \\
\text { sig. }=.000\end{array}$} & \multirow{2}{*}{$82.990 \%$} \\
\hline & & SCF_18 & & .911 & & \\
\hline \multirow{7}{*}{ - } & & MP_1 & & 848 & & \\
\hline & & MP_2 & & .836 & & \\
\hline & & MP_3 & & .711 & $\begin{array}{c}x^{2}= \\
=\end{array}$ & \\
\hline & Personalizatio & MP_4 & .93 & 817 & 1404.341 & $70.221 \%$ \\
\hline & & MP_5 & & .893 & 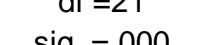 & \\
\hline & & MP_6 & & .873 & & \\
\hline & & MP_7 & & .874 & & \\
\hline & & OP_1 & & .758 & & \\
\hline & & OP_2 & & .798 & & \\
\hline & & OP_3 & & .815 & $X^{2}=916.147$ & \\
\hline & Uperarional & OP_4 & .86 & .809 & $\mathrm{df}=21$ & $55.768 \%$ \\
\hline & & OP_5 & & .577 & sig. $=0.00$ & \\
\hline Business & & OP_6 & & .707 & & \\
\hline Performance & & OP_7 & & .736 & & \\
\hline & & FP_1 & & .853 & & \\
\hline & & FP_2 & & .916 & $\begin{array}{c}X^{2}= \\
0\end{array}$ & \\
\hline & Financial & FP_3 & .93 & .947 & 1175.646 & $78.785 \%$ \\
\hline & & FP_4 & & .898 & sis $=10$ & \\
\hline & & FP_7 & & 818 & sig. $=0.00$ & \\
\hline
\end{tabular}




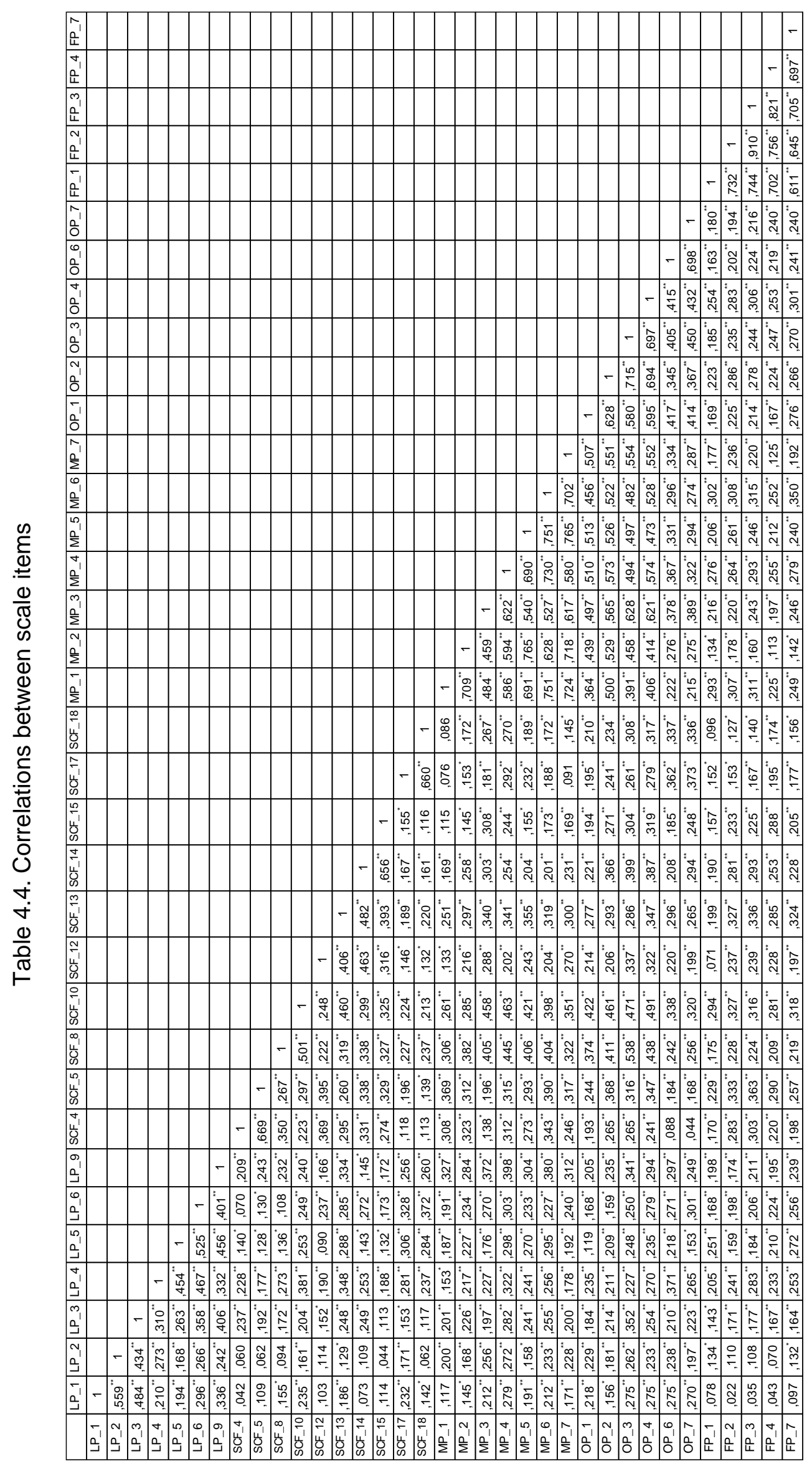


To confirm the scale dimensionality and convergent validity, a confirmatory factorial analysis has been performed using the EQS 6.1 software. Two second-order factors have been used to measure Lean Production implementation (Moyano-Fuentes, Martínez-Jurado et al., 2012): Cellular manufacturing, composed by observable variables LP_1, LP_2, and LP_3; and Lean practices, composed by observable variables LP_4, LP_5, LP_6 and LP_9. Four second-order factors have been used to measure Supply Chain Flexibility (Moon et al., 2012): Sourcing flexibility, composed by observable variables SCF_4 and SCF_5; Operating system flexibility, composed by observable variables SCF_6, SCF_7, SCF_8 and SCF_10; Distribution flexibility, composed by observable variables SCF_12, SCF_13 and SCF_14, SCF_15; and Information system flexibility, composed by observable variables SCF_17 and SCF_18. A first-order factor composed by seven observable variables (MP_1, MP_2, MP_3, MP_4, MP_5, MP_6, and MP_7) have been used to measure Mass Personalization (Tu et al., 2000). For Business Performance, two second-order factors have been used (Flynn et al., 2010): Operational performance, composed by observable variables OP_1, OP_2, OP_3 and OP_4; and Financial performance, composed by observable variables FP_1, FP_2, FP_3, FP_4 and FP_7. A Mardia test (standardized estimation) has been performed to confirm the data's multivariate non-normality. Results of this data exploration indicates that the Robust Maximum Probability Method could be applied to the data analysed in this study (Satorra, 1993). Finally, to check the confirmatory factor analysis adjustment, a model with the above 35 observables variables has been designed. In this analysis, the observable variable OP_5 has not met the requirement (standardized factorial load of $\geq .5$ ) and has therefore been excluded (Kaplan, 2000). A new confirmatory factor analysis has been performed, indicating that the remaining items fulfilled the requirement (standardized load values $\geq .5$ ) (Table 4.5). The results of the model fit analysis have been as follows: scaled, Satorra-Bentler, $x^{2}=1131.7795$, with 543 freedom degrees, $x^{2} / d f=2.084$; Root Mean Square Error of Approximation (RMSEA) = .065; McDonald Fit Index $(\mathrm{MFI})=.322$; Normal Fit Index $(\mathrm{NFI})=.740$; Non Normal Fit Index (NNFI) =.828; Comparative Fit Index $(\mathrm{CFI})=.843$; Incremental Fit Index $(\mathrm{IFI})=.845$. Thus, final confirmatory factor analysis adjustment has been satisfactory. Table 5 shows the standardized factor loads and the $\mathrm{R}^{2}$ for each variable in confirmatory factor analysis. 
Table 4.5. Confirmatory factor analysis

\begin{tabular}{|c|c|c|c|}
\hline Factor & Factor/Observable variable & $\begin{array}{c}\text { Standardized factor } \\
\text { loading }\end{array}$ & $\mathbf{R}^{2}$ \\
\hline \multirow{2}{*}{$\begin{array}{l}\text { Lean Production } \\
\text { implementation }\end{array}$} & Layout in production plant & .70 & .494 \\
\hline & Lean practices & .80 & .638 \\
\hline \multirow{4}{*}{ Supply Chain Flexibility } & Sourcing flexibility & .65 & .423 \\
\hline & Operating system flexibility & .79 & .627 \\
\hline & Distribution flexibility & .79 & .622 \\
\hline & Information system flexibility & .39 & .150 \\
\hline- & Mass Personalization & - & - \\
\hline \multirow{2}{*}{ Business Performance } & Operational performance & .79 & .629 \\
\hline & Financial performance & .44 & .196 \\
\hline \multirow{3}{*}{ Layout in production plant } & LP_1 & .76 & .571 \\
\hline & LP_2 & .70 & .486 \\
\hline & LP_3 & .66 & .439 \\
\hline \multirow{4}{*}{ Lean practices } & LP_4 & .62 & .390 \\
\hline & LP_5 & .71 & .497 \\
\hline & LP_6 & .73 & .531 \\
\hline & LP_9 & .60 & .365 \\
\hline \multirow{2}{*}{ Sourcing flexibility } & SCF_4 & .80 & .643 \\
\hline & SCF_5 & .83 & .696 \\
\hline \multirow{2}{*}{ Operating system flexibility } & SCF_8 & .72 & .517 \\
\hline & SCF_10 & .70 & .485 \\
\hline \multirow[t]{4}{*}{ Distribution flexibility } & SCF_12 & .55 & .308 \\
\hline & SCF_13 & .61 & .372 \\
\hline & SCF_14 & .83 & .694 \\
\hline & SCF_15 & .73 & .533 \\
\hline \multirow{2}{*}{$\begin{array}{l}\text { Information system } \\
\text { flexibility }\end{array}$} & SCF_17 & .84 & .707 \\
\hline & SCF_18 & .78 & .616 \\
\hline \multirow{7}{*}{ Mass Personalization } & MP_1 & .82 & .680 \\
\hline & MP_2 & .82 & .666 \\
\hline & MP_3 & .64 & .412 \\
\hline & MP_4 & .77 & .587 \\
\hline & MP_5 & .89 & .786 \\
\hline & MP_6 & .85 & 723 \\
\hline & MP_7 & .85 & 729 \\
\hline \multirow{6}{*}{ Operational performance } & OP_1 & .73 & .529 \\
\hline & OP_2 & .83 & .683 \\
\hline & OP_3 & .83 & .693 \\
\hline & OP_4 & .83 & .687 \\
\hline & OP_6 & .53 & .279 \\
\hline & OP_7 & .55 & .306 \\
\hline \multirow{5}{*}{ Financial performance } & FP_1 & .78 & .606 \\
\hline & FP_2 & .93 & .863 \\
\hline & FP_3 & .97 & .947 \\
\hline & FP_4 & .84 & .714 \\
\hline & FP_7 & .73 & .535 \\
\hline
\end{tabular}

Figure 4.2 presents the measurement model (thin lines), which shows the dimensions (latent variables) measured by their respective items (observable variables). In addition, the theoretical structural model is presented (thick lines), where the relations between the four constructs are presented (Lean Production implementation, Supply Chain Flexibility, Mass Personalization and Business Performance) 


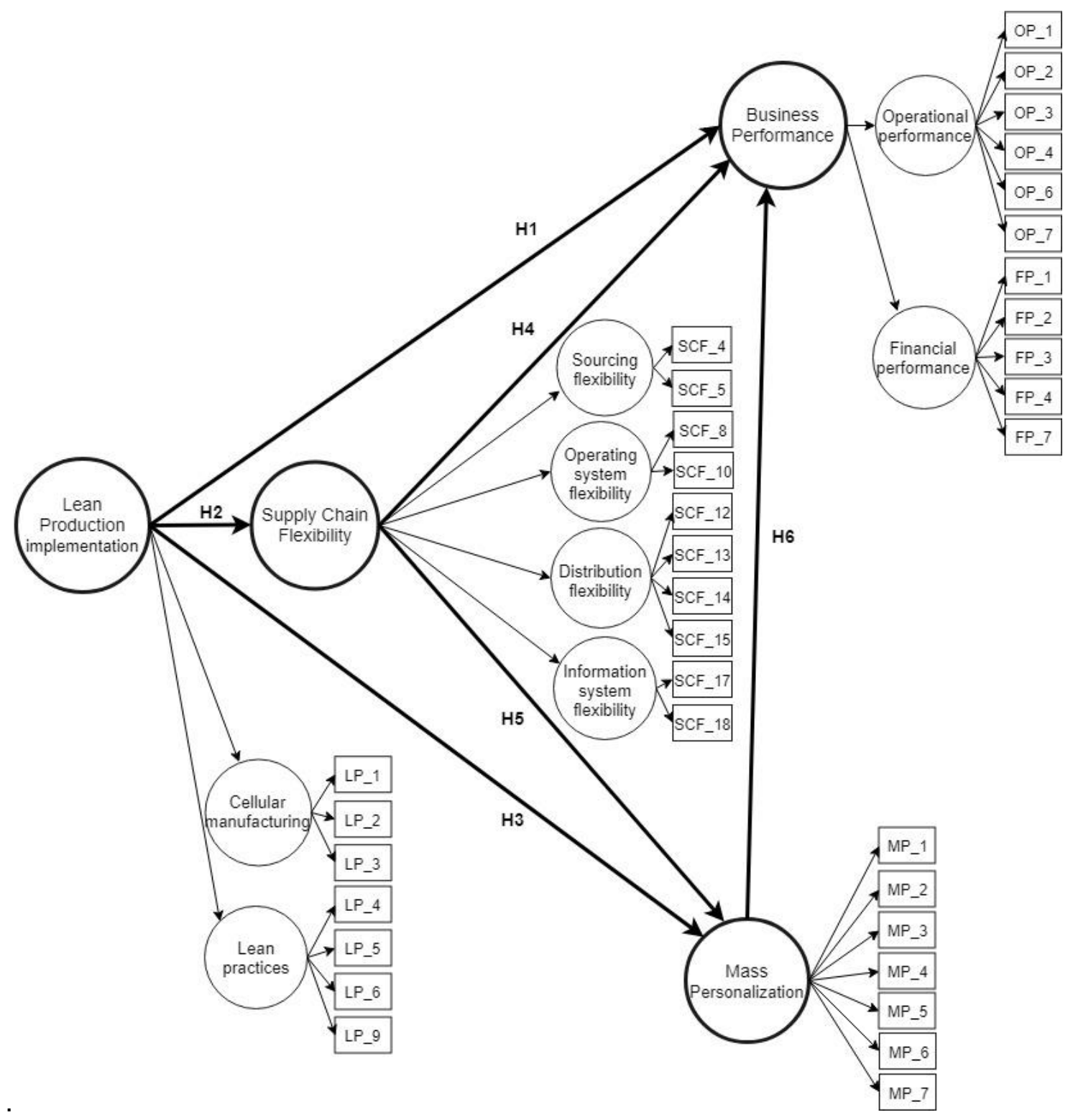

Figure 4.2. Measurement model and theoretical structural model

\subsubsection{STRUCTURAL MODEL}

The Robust Maximum Likelihood Method has been utilised, since it is considered the most accurate method for non-standard environments (Satorra, 1993). EQS 6.1 software has been utilised to develop the structural model and to test the six hypotheses, and the results have been the following: scaled, Satorra-Bentler, $x 2=651.1196$, with 537 freedom degrees, $X^{2} / \mathrm{df}=1.21 ; \mathrm{RMSEA}=.029 ; \mathrm{MFI}=.803 ; \mathrm{NFI}=.850 ; \mathrm{NNFI}=.966 ; \mathrm{CFI}$ $=.970 ; \mathrm{IFI}=.970)$. This indicates that the structural model yielded a good overall fit (Satorra, 1993). The relationships in $\mathrm{H} 2, \mathrm{H} 4, \mathrm{H} 5$ and $\mathrm{H} 6$ have been significant $(\mathrm{p}<0.05)$, while the relationship in $\mathrm{H} 1$ and $\mathrm{H} 3$ did not receive sufficient support (Figure 4.3). $\mathrm{H} 4$ has 
received the highest support with a load of .76; followed by $\mathrm{H} 2$ and $\mathrm{H} 5$, which received support with a significant factorial load of .67 and .56 , respectively. $\mathrm{H} 6$ also received significant support, but with slightly lower standardised parameter (.35).

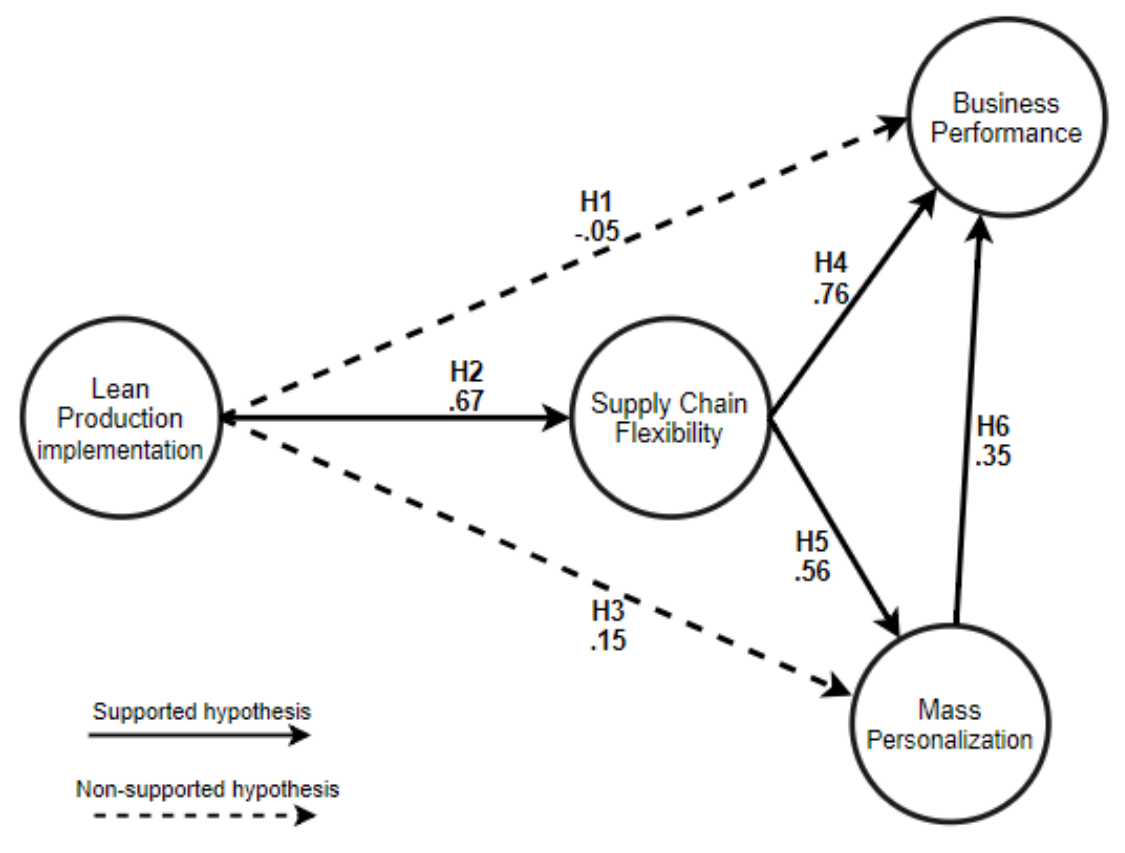

Figure 4.3. Baseline structural model

Figure 4.3 shows the baseline structural model and results. As it can be observed, the relationship between Lean Production implementation and business performance has not been supported by our analysis. This result has been unexpected, since it is not aligned with previous literature that assumes a positive relationship between Lean Production implementation and business performance (e.g. Lamming, 1996; MasonJones and; Li et al. 2005; van der Vaart et al., 2012). Then, in the face of this unexpected result, a new model has been tested (Structural Model 1), removing Supply Chain Flexibility (Figure 4.4). The Structural Model 1 results have been the following: scaled, Satorra-Bentler, $x 2=455.5411$, with 263 freedom degrees, $\mathrm{X} 2 / \mathrm{df}=1.73$; RMSEA = .053; $\mathrm{MFI}=.691 ; \mathrm{NFI}=.851 ; \mathrm{NNFI}=.920 ; \mathrm{CFI}=.930 ; \mathrm{IFI}=.931$. This indicates that the structural model also yielded a good overall fit (Satorra, 1993). 


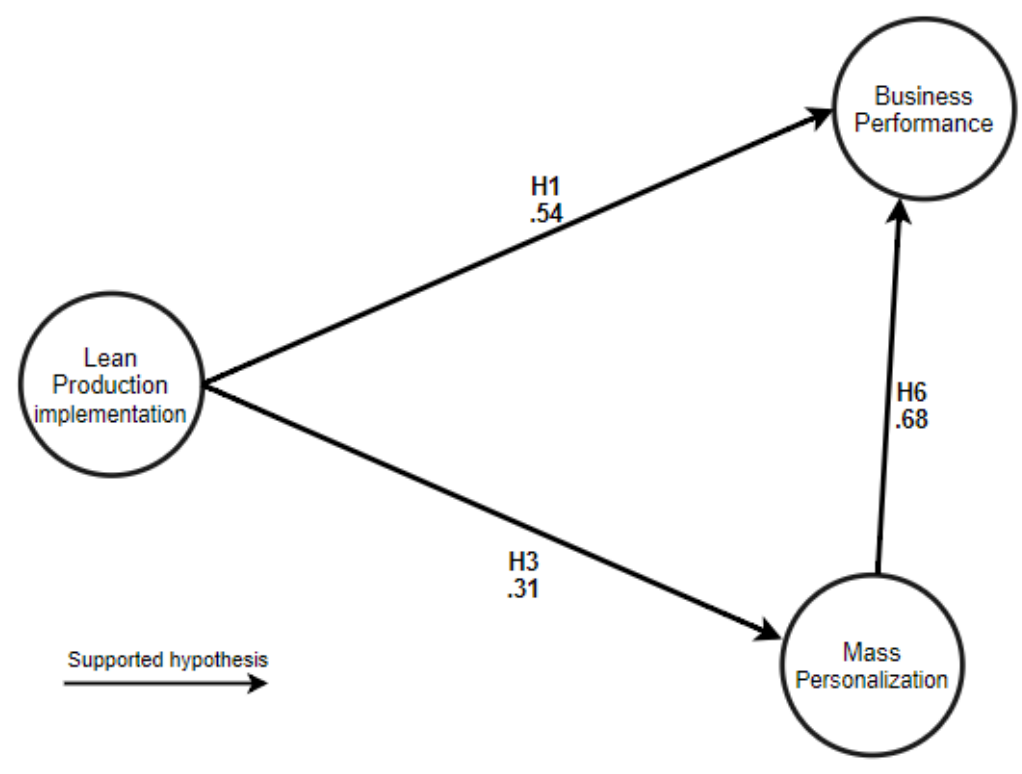

Figure 4.4. Structural model 1

Structural model 1, therefore, shows that removing Supply Chain Flexibility the Lean Production-business performance relationship receives empirical support, as does the Lean Production-Mass Personalization relationship.

Table 6 compares the hypotheses contrasted in Structural Baseline Model and Structural Model 1, highlighting those that have been confirmed (filled in with "Yes"), those that have not been confirmed (filled in with "No") and those that have not been tested in Model 1 ("Not applied"). The fit indicators on Baseline Model and Model 1 show that both fit properly.

Table 4.6. Comparison of Baseline structural model and Structural model 1.

\begin{tabular}{|c|c|c|c|}
\hline \multicolumn{2}{|r|}{ Hypothesis } & $\begin{array}{c}\text { Baseline Model } \\
\text { (With SCF) }\end{array}$ & $\begin{array}{c}\text { Model } 1 \\
\text { (Without SCF) }\end{array}$ \\
\hline $\mathrm{H} 1$ & Lean Production Implementation $\rightarrow$ Business Performance & No & Yes \\
\hline $\mathrm{H} 2$ & Lean Production Implementation $\rightarrow$ Supply Chain Flexibility & Yes & Not applicable \\
\hline $\mathrm{H3}$ & Lean Production Implementation $\rightarrow$ Mass Personalization & No & Yes \\
\hline $\mathrm{H} 4$ & Supply Chain Flexibility $\rightarrow$ Business Performance & Yes & Not applicable \\
\hline $\mathrm{H} 5$ & Supply Chain Flexibility $\rightarrow$ Mass Personalization & Yes & Not applicable \\
\hline $\mathrm{H} 6$ & Mass Personalization $\rightarrow$ Business Performance & Yes & Yes \\
\hline & Fit indicators & $\begin{array}{l}\mathrm{X} 2=651.1196 ; 537 \mathrm{df} ; \\
\mathrm{X} 2 / \mathrm{df}=1.21 ; \mathrm{RMSEA} \\
=.029 ; \mathrm{MFI}=.803 ; \\
\mathrm{NFI}=.850 ; \mathrm{NNFI}= \\
.966 ; \mathrm{CFI}=.970 ; \mathrm{IFI}= \\
.970\end{array}$ & $\begin{array}{l}\mathrm{x} 2=455.5411,263 ; \mathrm{df} ; \\
\mathrm{X} 2 / \mathrm{df}=1.73 ; \mathrm{RMSEA}= \\
.053 ; \mathrm{MFI}=.691 ; \mathrm{NFI}= \\
.851 ; \mathrm{NNFI}=.920 ; \mathrm{CFI} \\
=.930 ; \mathrm{IFI}=.931\end{array}$ \\
\hline
\end{tabular}




\subsection{DISCUSSION, CONCLUSIONS AND FUTURE RESEARCH LINES}

\section{Baseline structural model}

In Baseline structural model we have analysed the relationships between Lean Production, Mass Personalization and business performance, in the presence of Supply Chain Flexibility.

We have analysed the effects of Lean Production implementation on business performance $(\mathrm{H} 1)$, but this relationship has not been supported by our analysis. As seen above, this result has been unexpected, since it is not aligned with previous literature that assumes a positive relationship between Lean Production implementation and business performance (e.g. Lamming, 1996; Mason-Jones and; Li et al. 2005; van der vaart et al., 2012).

It has also been identified that there is a direct positive effect of Lean Production implementation on Supply Chain Flexibility $(\mathrm{H} 2)$. It is in line with previous literature (e.g. Baum et al. chain, 2000; Swafford et al., 2006; Stump and Badurdeen, 2012). Lean Production seeks to increase Supply Chain Flexibility through minimising operational complexities, supporting information sharing, allowing companies to redesign production systems, change product design, and control inventory and service levels. Thus, Lean Production is a catalyst for organisations to achieve greater levels of flexibility. This result is also aligned with Elms and Low (2013), which demonstrates that a supply chain with a high level of development is flexible and has standardized processes (through Lean Production), so that they adapt efficiently to new market situations.

This chapter has also analysed the effects of Lean Production implementation on Mass Personalization $(\mathrm{H} 3)$, but this relationship has not been supported by our analysis. This is in line with the Stump and Badurdeen (2012) findings, which show that some Lean practices (e.g., JIT and load levelling) are difficult to implement in high-level Mass Personalization environments, requiring the integration of other concepts to increase the efficiency of operations.

In addition, $\mathrm{H} 4$ receives sufficient support in the analyses described in the previous section: Supply Chain Flexibility improves business performance. As discussed in the arguments leading to the $\mathrm{H} 4$, there are several possible ways in which more flexible supply chains can lead to better business performance (e.g. making companies more adaptable to situations of uncertainty, acting on supply disruptions and changes in demand). These results are aligned with previous literature (e.g., Pine, 1993; Vickery et al., 2003; Urgo et al. 2016), which demonstrates that, through Supply Chain Flexibility, 
the processes of acquisition, production and delivery are carried out efficiently and quickly, impacting business performance.

It has also been identified that there is a direct positive effect of Supply Chain Flexibility on Mass Personalization (H5). It is in line with several previous studies in the production and operations management field (e.g. Zipki, 2001; da Silveira and Arkader, 2007; Purnomo and Sufa, 2015). Through Supply Chain Flexibility, firms can respond effectively to requirements and meet the individual needs of their customers. Consequently, firms can offer goods and services with different personalization levels, allowing firms to achieve economies of scale and scope, both of which are necessary to develop Mass Personalization capacity.

H6 also receives sufficient support: Mass Personalization implementation improves business performance. As discussed in the arguments leading to $\mathrm{H} 6$, Mass Personalization allows companies to provide individually designed products and services, playing an important role in in a company's efficiency and profitability (Frutos and Borenstein, 2003; Machado and Moraes, 2011; Elking et al., 2017). Through Mass Personalization, companies can provide products and services quickly, individually designed and without large cost increases, which would be related to better both operational and financial performance.

\section{Structural model 1}

In the Structural Equations Model 1 we have analysed the relationships between Lean Production, Mass Personalization and business performance, without Supply Chain Flexibility.

H1 receives sufficient support: Lean Production implementation improves business performance. As discussed in the arguments leading to $\mathrm{H} 1$, there are several possible ways for Lean Production implementation to lead to better business performance. If a company has adopted Lean Production, an incremental improvement in products, services and operations can be expected. Lean Production implementation could also eliminate process redundancies and maintain continuity of production routines, as well as reduce stocks and production costs.

Mass Personalization ( $\mathrm{H} 3$ ), Lean production has a strong direct effect on business performance (.54) and Mass Personalization (.31), which means that companies using Lean achieve better business performance and Mass Personalization levels. Lean production has also a strong direct effect on Supply Chain Flexibility (.67) but, in this situation, the direct relations between Lean Production-business performance and Lean 
Production-Mass Personalization are no longer significant. The results show that there is an even stronger indirect effect between Lean Production implementation and business performance (.67 and .76), as well as between Lean Production implementation and Mass Personalization (.67 and .56).

It has also been identified that there is a direct positive effect of Lean Production Implementation on Mass Personalization (H3). This result could be related to the fact that certain Lean Production principles are easily implemented in Mass Personalization environments (e.g. continuous improvement, waste reduction, teamwork and 5S), which could increases the demand response potential. Lean Production implementation allows supply chain members to synchronously structure their collaborative process practices, eliminating redundancies, maintaining the continuity of previous routines. It could enable companies to be able to modify and develop personalized products and services.

H6 also receives sufficient support: Mass Personalization implementation improves business performance. Mass Personalization is associated with extensive application of customer knowledge to respond to their individual needs. It could enable companies to achieve better performance by increasing individual customer satisfaction, offering products with desired characteristics, acceptable delivery times, and without drastically increasing production costs.

\section{Comparison of Baseline structural model and Structural model 1}

In Baseline structural model it is observed that when Supply Chain Flexibility is present, there is no relationship between Lean Production Implementation and business performance. By removing Supply Chain Flexibility (Structural Model 1), it is verified that there is then a positive relationship between the Lean Production implementation and business performance. Therefore, an indirect impact between Lean Production implementation and business performance is observed, which lead us to conclude that Supply Chain Flexibility exerts a complete mediating relationship between Lean Production implementation and business performance. When Baseline structural model and Structural model 1 are compared, the interpretation arises: companies have initially used Lean Production to achieve better performance, and they have achieved it. However, over time Lean Production has affected Supply Chain Flexibility, increasing it. Moreover, companies being more flexible have achieved greater performance, ceasing Lean Production to have a direct impact on business performance, but indirect through the flexibility it achieves (shown as a mediator effect). 
Similarly, in Baseline structural model it is observed that when Supply Chain Flexibility is present, there is no relationship between Lean Production Implementation and Mass Personalization. By removing Supply Chain Flexibility (Structural Model 1), it is verified that there is then a positive relationship between the Lean Production implementation and Mass Personalization. Therefore, an indirect impact between Lean Production implementation and Mass Personalization is observed, which lead us to conclude that Supply Chain Flexibility also exerts a complete mediating relationship between Lean Production implementation and Mass Personalization. Thus, in presence of Supply Chain Flexibility, Lean Production implementation could not provide direct and tangible benefits to Mass Personalization, but indirectly through the flexibility it achieves (shown as a mediator effect). This is in line with the Stump and Badurdeen (2012) findings, which show that companies would need flexibility as a resource or capacity to reach these personalization levels. A results interpretation might be that Lean Production implementation supports up to certain Mass Personalization levels. However, when a company needs to achieve high Mass Personalization levels, Lean Production by itself does not have enough efficiency to support it, being necessary to integrate other resources and capacities. Thus, Supply Chain Flexibility would add resources and capabilities to supply chain, acting as a mediating factor between Lean Production and high levels of Mass Personalization.

Due the mediating effect of Supply Chain Flexibility, business performance and Mass Personalization grow much more than, if only Lean Production is used without Supply Chain Flexibility. This is due, in one part, to the effect of Lean Production implementation on business performance and Mass Personalization, and, in the other part, to the indirect effect through Supply Chain Flexibility, which is very powerful. Although in the literature, there are previous findings that Lean Production can lead companies to improve their performance and Mass Personalization levels, this chapter demonstrates that by relying on Supply Chain Flexibility, and Lean production achieves a greater impact on business performance and Mass Personalization level.

\subsubsection{MANAGEMENT IMPLICATIONS}

This chapter not only sheds light on the theoretical relationships between Lean Production implementation, Supply Chain Flexibility, Mass Personalization, and Business Performance. Other findings and implications can affect how managers perceive and organize these resources in their companies to achieve higher flexibility and mass personalization levels, as well as better results. Managers need to know that they can use Lean production and its different practices to directly and indirectly achieve 
better financially and operationally performance. When Lean practices are based on Supply Chain Flexibility, then the effect on mass personalization and Business Performance is multiplied. In this way, managers could consider the complementarity between Lean Production implementation and Supply Chain Flexibility as a way to achieve higher levels of Mass Personalization and, ultimately, improve operational and financial performance.

Once the supply chain is flexible, companies can achieve effectiveness in intra- and interorganizational process. Supply chain managers should know that Lean Production, not only helps Supply Chain Flexibility to be even more effective, but also has a strong indirect impact on Mass Personalization and Business Performance. These further gains on efficiency and effective would be achieved through the complementarity between Lean Production and Supply Chain Flexibility could lead companies to achieve better mass personalization levels. Consequently, such companies could effectively satisfy demand variations and, have a better chance of improving their results, both operational and financial.

\subsubsection{LIMITATIONS AND FUTURE RESEARCH LINES}

In order to test the chapter hypothesis, measures have been taken which are considered to be perceptive in nature. Despite the belief that the questionnaires are free of bias, it is impossible to completely rule out this type of apprehension. A practical step forward would be to test the chapter's model with multiple informants, not just by relying on information provided by Supply Chain Management managers. Another limitation is that results have only been obtained from the Spanish industry and without focusing on specifics industrial sectors. Thus, would be necessary to conduct and replicate the studies with samples of companies from different geographical environments, as well as to specific industrial sectors to confirm the results obtained.

It would be advisable to use in the future a longitudinal methodology for the causality study in the observed relationships. It would also be necessary to examine the moderating impacts of Lean Production implementation on the relationship between Supply Chain Flexibility, Mass Personalization and business performance. The relationship between different practices associated with Lean Production, specific flexibility types, different Mass Personalization levels, and their impacts on operational and financial performance should also be studied. 


\section{REFERENCES}

Acar, M., Tarim, M., Zaim, H., Zaim, S., and Delen, D. (2017). Knowledge management and ERP: Complementary or contradictory?. International Journal of Information Management, 37 (6), 703-712.

Alsafi, Y., and Vyatkin, V. (2010). Ontology-based reconfiguration agent for intelligent mechatronic systems in flexible manufacturing. Robotics and Computer-Integrated Manufacturing, 26 (4), 381-391.

Al-Zaher, A., EIMaraghy, W., and Pasek, Z.J. (2013). RMS design methodology for automotive framing systems BIW. Journal of Manufacturing Systems, 32 (3), 436-448.

Amand, G., and Ward, P. (2004). Fit, flexibility and performance in manufacturing: coping with dynamic environments. Production and Operations Management, 13 (4), 369-385.

Bagozzi, R.P. and Yi, Y. (1988). On the evaluation of structural equation models, Journal of Academy of Marketing Science, 16 (2), 74-94.

Barman, S. and Canizares, A.E. (2015). A survey of mass customization in practice. International Journal of Supply Chain Management, 4 (1), 65-72.

Bruque, S., Moyano, J., and Maqueira, J. M. (2016). Supply Chain Integration through community Cloud: Effects on operational performance. Journal of Purchasing and Supply Management, 22 (2), 141-153.

Bruque, S., Moyano, J., and Maqueira, J. M. (2015). Use of Cloud technology, Web 2.0 and operational performance: the mediating role of Supply Chain Integration. International Journal of Logistics Management, 26 (3), 426-458.

Cagliano, R., Caniato, F., and Spina, G. (2006). The linkage between Supply Chain Integration and manufacturing improvement programmes. International Journal of Operations \& Production Management 26, (3), 282-99.

Chen, S., and Tseng, M. M. (2007). Aligning demand and supply flexibility in custom product co-design. International Journal of Flexible Manufacturing Systems, 19 (4), 596-611.

Claycomb, C., Dröge, C., and Germain, R. (2005). Applied customer knowledge in a manufacturing environment: Flexibility for industrial firms. Industrial Marketing Management, 34 (6), 629-640.

Da Silveira, G., Borenstein, D., and Fogliatto, F. S. (2001). Mass customization: Literature review and research directions. International journal of production economics, 72(1), 1-13.

Da Silveira, G.J.C., and Arkader, R. (2007).The direct and mediated relationships between supply chain coordination investments and delivery performance. International Journal of Operations \& Production Management, 27 (2), 140-58.

Danese, P., Manfè, V. and Romano, P. (2018). A Systematic Literature Review on Recent Lean Research: State-of-the-art and Future Directions. International Journal of Management Reviews, 20 (2), 579-605.

Dev, N.K., Shankar, R., Dey, P.K., and Gunasekaran, A. (2014). Holonic supply chain: a study from familybased manufacturing perspective. Computers \& Industrial Engineering, 78, 1-11.

Elms, D.K, and Low, P. (2013). Global value chains in a changing world. World Trade Organization, Geneva.

Flynn, B.B., Huo, B., and Zhao, X. (2010). The impact of Supply Chain Integration on performance: a contingency and configuration approach. Journal of Operations Management, 28 (1-2), 58-71.

Frazelle, E. (2001). Supply Chain Strategy: The Logistics of Supply Chain Management (2nd Ed.). McGrawHill Professional, New York.

Frutos, J.D., and Borenstein, D. (2003). Object-oriented model for customer-building company interaction in mass customization environment. Journal of Construction Engineering and Management, 129 (3), 302 313.

Gerbin D., and Hamilton J. (1996). Viability of Exploratory Factor Analysis as a Precursor to Confirmatory Factor Analysis. Structural Equation Modelling, 3 (1), 62-72.

Gong, Z. (2008). An economic evaluation model of supply chain flexibility. European Journal of Operational Research, 184 (2), 745-758.

Gorsuch, R. (1983). Factor Analysis (2nd ed.), Erlbaum, Hillsdale.

Griffiths, J, and Margetts, D. (2000). Variation in production schedules - implications for both the company and its suppliers. Journal of Materials Processing Technology, 103 (1), 155-159.

Gunasekaran, A., and Ngai, E. W. T. (2004). Information systems in supply chain integration and management. European Journal of Operational Research, 159 (2), 269-295. 
Hair, J.F., Black, W.C., Babin, B.J., and Anderson, R.E. (2009). Multivariate Data Analysis. New Jersey: Prentice Hall.

Hanafy, M., and Elmaraghy, H. (2015). Developing assembly line layout for delayed product differentiation using phylogenetic networks. International Journal of Production Research, 53 (9), 2633-2651.

Ho, G.T.S., Lau, H.C.W., Lee, C.K.M., and Ip, A.W.H. (2008). Real-time process mining system for Supply Chain network: OLAP-based fuzzy approach. International Journal of Enterprise Network Management, 2 (1), 84-103.

Holweg, M. (2007). The genealogy of Lean Production. Journal of Operations Management, 25 (2), 420-37.

Hopp, W.J., Spearman, M.L. (2004). To pull or not to pull: what is the question?. Manufacturing and Service Operations Management 6 (2), 133-48.

Huang, G. Q., Zang, X. Y., and Lo, V. H.Y. (2007). Integrated Configuration of Platform Products and Supply Chains for Mass Customization: A Game-Theoretic Approach. IEEE Transactions On Engineering Management 54, (1), 156-171.

Ismail, H., Reid, I., Mooney, J., Poolton, J., and Arokiam, I. (2007). How small and medium enterprises effectively participate in the mass customization game. IEEE Transactions on Engineering Management, 54 (1), 86-97.

Jabbour, C.J.C., de Sousa Jabbour, A.B.L., Govindan, K., Teixeira, A.A., and de Souza Freitas, W.L. (2013). Environmental management and operational performance in automotive companies in Brazil: the role of human resource management and Lean manufacturing. Journal of Cleaner Production, 47, 129-140.

Jayaram, J., Vickery, S. and Droge, C. (2008). Relationship building, lean strategy and firm performance: an exploratory study in the automotive supplier industry. International Journal of Production Research, 46 (20), 5633-49.

Jede, A., and Teuteberg, F. (2015). Integrating Cloud Computing in supply chain processes. A comprehensive literature review. Journal of Enterprise Information Management, 28 (6), 72-94.

Jiao, J., Kumar, A., and Lim, C.M. (2006). Flexibility valuation of product family architecture: A real-option approach. International Journal of Advanced Manufacturing Technology, 30 (1), 1-9.

Kaplan, D. (2000). Structural equation modelling: Foundations and extensions. Newbury Park: Sage.

Kim, B. (2014). Effective Supply Chain strategy to enhance firm's responsiveness: Empirical evidence from the BMW Leipzig plant. International Journal of Services and Operations Management, 18 (1), 21 -37.

Kumar, R., Haleem, A., Garg, S.K., and Singh, R.K. (2015). Automated guided vehicle configurations in flexible manufacturing systems: A comparative study. International Journal of Industrial and Systems Engineering, 21 (2), 207-226.

Lamming, R.C. (1996). Squaring Lean supply with supply chain management. International Journal of Operations and Production Management, 16 (2), 183-96.

Levandowski, C.E., Jiao, J.R., and Johannesson, H. (2015). A two-stage model of adaptable product platform for engineering-to-order configuration design. Journal of Engineering Design, 26 (7), 220-235.

Li, G., Yang, H., Sun, L., and Sohal, A. S. (2009). The impact of IT implementation on Supply Chain Integration and performance. International Journal of Production Economics, 120 (1), 125-138.

Li, S., Rao, S.S., Ragu-Nathan, T.S., and Ragu-Nathan, B. (2005), Development and validation of a measurement instrument for studying supply chain management practices, Journal of Operations Management 23, (6), 618-41.

Lummus, R. R., Duclos, L. K., and Vokurka, R. J. (2003). Supply Chain Flexibility: Building a New Model. Global Journal of Flexible Systems Management, 4 (4), 1-13.

Machado, A.G.C. and Moraes, W.F.A. (2008). Mass customization in civil construction. Revista Brasileira de Gestao de Negocios, 10 (29), 347-364.

Marin, R.L., and P. D. Brîndaşu. (2015). A self-organizing approach for mixed-model manufacturing based on autonomous entities Academic Journal of Manufacturing Engineering 13 (2), 60-65.

Mason-Jones, R., and Towill, D.R. (1999). Total cycle time compression and the agile supply chain. International Journal of Production Economics, 62 (1/2), 61-73.

McCormack, K., Ladeira, M.B., and Oliveira, M.P.V. (2008). Supply chain maturity and performance in Brazil. Supply Chain Management: An International Journal, 13 (4), 272-282.

McKone, K.E., Schroeder, R.G., and Cua, K.O. (2001). The impact of total productive maintenance on manufacturing performance. Journal of Operations Management, 19 (1), 39-58. 
Molina, A., Rodriguez, C.A., Ahuett, H., Cortés, J.A., Ramírez, M., Jiménez, G., and Martinez, S. (2005). Next-generation manufacturing systems: Key research issues in developing and integrating reconfigurable and intelligent machines. International Journal of Computer Integrated Manufacturing, 18 (7), 525-536.

Moon, K., Yi, C., and Ngai, E. (2012). An instrument for measuring Supply Chain flexibility for the textile and clothing companies. European Journal of Operational Research, 222 (2), 191-203.

Moyano-Fuentes, J., and Sacristán-Díaz, M. (2012). Learning on Lean: a review of thinking and research. International Journal of Operations \& Production Management, 32 (5), 551-582.

Moyano-Fuentes, J., Martínez-Jurado, P.J., Maqueira-Marín, J.M., and Bruque-Cámara, S. (2012). Impact of use of information technology on Lean Production adoption: evidence from the automotive industry. International Journal of Technology Management, 57 (1-3), 132-148.

Moyano-Fuentes, J., Sacristán-Díaz, M., and Martínez-Jurado, P. J, (2012). Cooperation in the supply chain and Lean Production adoption: Evidence from the Spanish automotive industry. International Journal of Operations \& Production Management, 32 (9), 1075-1096.

Nobre, F. S., Tobias, A. M., and Walker, D. S. (2008). The pursuit of cognition in manufacturing organizations. Journal of Manufacturing Systems, 27 (4), 145-157.

Oh S., Ryu, K., and Jung. M. (2013). Reconfiguration framework of a supply network based on flexibility strategies. Computers and Industrial Engineering, 65 (1), 156-165.

Panizzolo, R. (1998). Applying the lessons learned from 27 lean manufacturers: the relevance of relationships management. International Journal of Production Economics, 55 (3), 223-40.

Peng, Q., and Yu, C. (2007). A visualised manufacturing information system for mass customisation. International Journal of Manufacturing Technology and Management, 11 (3), 278-295.

Pfeiffer D., Terlunen, S., Fischer, J., and Hellingrath, B. (2013). Introducing Supply Chain Segmentation Procedures into Flexibility Management. Proceedings of the 24th Annual Conference of the Production and Operations Management Society 1-10.

Potter, A., Breite, R., Naim, M., and Vanharanta, H. (2004). The potential for achieving mass customization in primary production Supply Chains via a unified taxonomy. Production Planning and Control, 15 (4), $472-481$.

Purohit, J.K., Mittal, M.L., Mittal, S., and Sharma, M.K. (2016). Interpretive structural modelling-based framework for mass customisation enablers: an Indian footwear case. Production Planning and Control, 27 (9), 774-786.

Rojo, A., Llorens-Montes, F. J., and Perez-Arostegui, M. N. (2016). The impact of ambidexterity on supply chain flexibility fit. Supply Chain Management: An International Journal, 21 (4), 433-452.

Sánchez, A. M., and Pérez, M. P. (2003). The use of EDI for interorganisational co-operation and coordination in the supply chain. Integrated Manufacturing Systems, 14 (8), 642-651.

Satorra, A. (1993). Multi-sample analysis of moment-structures: asymptotic validity of inferences based on second order moments. In: Haagen, K., Bartholomeusz, A., Deistler, M. (Eds.), Statistical modelling and latent variables. Elsevier, North Holland, Amsterdam.

Seebacher, G. and Winkler, H. (2015). A capability approach to evaluate supply chain flexibility. International Journal of Production Economics, 167, 177-186.

Shah, R., and Ward, P.T. (2003). Lean manufacturing: context, practice bundles and performance. Journal of Operations Management, 21 (2), 129-49.

Shah, R., and Ward, P.T. (2007). Defining and developing measures of Lean Production. Journal of Operations Management, 25 (4), 785-805.

Shah, R., Chandrasekaran, A., and Linderman, K. (2008). In pursuit of implementation patterns: the context of Lean and Six Sigma. International Journal of Production Research, 46 (23), 6679-99.

Singh, A. and Teng, J.T.C. (2016). Enhancing supply chain outcomes through Information Technology and Trust. Computers in Human Behavior, 54, 290-300.

Squire, B., Cousins, P.D., and Brown, S. (2006). Collaborating for customisation: an extended resourcebased view of the firm. International Journal of Productivity and Quality Management, 1 (1), 8-25.

Stojanov, T., and Ding, X. (2015). Supplier selection for mixed-model production: A case study from the apparel industry. Fibres and Textiles in Eastern Europe, 23 (1), 8-12. 
Strasser, T., Rooker, M, and Ebenhofer, G. (2011). An IEC 61499 distributed control concept for reconfigurable robots. International Journal of Computer Aided Engineering and Technology, 3 (3), 344359.

Stump, B., and Badurdeen, F. (2012). Integrating Lean and other strategies for mass customization manufacturing: A case study. Journal of Intelligent Manufacturing, 23 (1), 109-124.

Tien, J. M. (2011). Manufacturing and services: From mass production to mass customization. Journal of Systems Science and Systems Engineering, 20 (2), 129-154.

Uhrin, A., Bruque-Cámara, S., and Moyano-Fuentes, J. (2017). Lean Production, workforce development and operational performance. Management Decision, 55 (1), 103-118.

Urgo, M., Terkaj, W., Cenati, C., Giannini, F., Monti, M., and Pellegrinelli, S. (2016). Zero-point fixture systems as a reconfiguration enabler in flexible manufacturing systems Computer-Aided Design and Applications, 13 (5), 684-692.

Van der Vaart, T.; Van Donk, P; Giménez, C., and Sierra, V. (2012). Modelling the integration-performance relationship. Collaborative practices, enablers and contextual factors. International Journal of Operations and Production Management, 32 (9), 1043-1074.

Vickery, S.K., Jayaram, J., Droge, C. et al. (2003). The effects of an integrative supply chain strategy on customer service and financial performance: an analysis of direct versus indirect relationships. Journal of Operations Management, 21, 523-539.

Vonderembse, M.A., Uppal, M., Huang, S.H. and Dismukes, J.P. (2006). Designing supply chains: towards theory development. International Journal of Production Economics, 100 (2), 223-38.

Wang, H., Mastragostino, R. and Swartz, C.L.E. (2016). Flexibility analysis of process supply chain networks. Computers \& Chemical Engineering, 84, 409-421.

Waters, D. (2007). Global Logistics: New Directions in Supply Chain Management (5a Ed.). Kogan Page Publishers, London.

Womack, J.P., and Jones, D.T. (1996). Lean Thinking, Simon and Schuster, New York, NY.

Womack, J.P., Jones, D.T., and Ross, D. (1990). The Machine That Changed the World, MacMillan, New York, NY.

Yu, W., Jacobs, M.A., Salisbury, W.D., and Enns, H. (2013). The effects of Supply Chain Integration on customer satisfaction and financial performance: An organizational learning perspective. International Journal of Production Economics, 146 (1), 346-358.

Zhang, Q., Vonderembse, M.A. and Lim, J.S. (2005). Logistics Flexibility and its impact on customer satisfaction. International Journal of Logistics Management, 16 (1), 71-95. 


\section{BLOCK III}

Simulation approach 


\title{
Chapter 5
}

\section{Strategic simulation models as a new methodological approach: A decision support tool based on Structural Equations Models and System Dynamics Models}

\begin{abstract}
Hypothesis contrast using statistical models with Structural Equations is a technique widely used in Supply Chain Management research. However, this technique provides a static vision of the observed reality, as a snapshot of that reality at a specific moment in time. In the Supply Chain Management context, dynamic analyses are also necessary to visualize the business behaviour in different scenarios projected in the future. These dynamic analyses can be performed using System Dynamics Models. Strategic simulation emerges for this purpose, as a new path that allows for prospective strategic analysis. This chapter presents a methodological proposal to carry out simulations at a strategic level, using the complementarity between Structural Equation Models and System Dynamics Models. This proposal is illustrated by two applications: first, to the case of Community Cloud use, Supply Chain Integration and their impacts on operational performance; second, to the specific case of Information Technology Integration and Lean/Just-In-Time Practices on Lead-Time Performance.
\end{abstract}

Keywords: Methodological proposal, Decision-making support, Structural equation models, System dynamics models 


\section{Strategic simulation models as a new methodological approach: A decision support tool based on Structural Equations Models and System Dynamics Models}

\subsection{INTRODUCTION}

Supply Chain Management is defined as a set of actions that allow companies to manage, plan and control operations in the entire Supply Chain, through the management of plans that facilitate collaboration, integration and coordination among its stakeholders (suppliers, producers, distributors and customers) (Frazelle, 2001; Waters, 2007; Gunasekarana et al., 2008). Supply Chain Management is essential for companies to improve relationships with customers and suppliers and achieve competitive advantages (Romano, 2003; McCormack et al., 2008).

In the literature, there is a wide evidence of the great interest of academics and researchers in Supply Chain Management and its strategic, tactical and operational aspects, questions that have been researched from various methodological perspectives. These perspectives include literature reviews (Li et al., 2013; Lee, 2017), case studies (Leukel et al., 2011), technical development of architectures and systems (Chiu et al., 2013; Chen et al., 2015) or quantitative analyses (Cagliano et al., 2006; Ward and Zhou, 2006), among others. In this sense, a large number of papers have been identified that investigate the relationships between variables associated with Supply Chain Management through the Structural Equation Models (SEM) use. There are also a large number of papers that use System Dynamics Models (SDM), which allow the behaviour of certain variables to be visualized over time. It is the combination of these last two perspectives the subject of this chapter.

On the one hand, hypothesis testing using SEM is a widely used technique in the Supply Chain Management field (Bruque et al., 2016; Liu et al., 2016; Schniederjans, 2016; Schniederjans and Hales, 2016; Subramanian and Abdulrahman, 2017). However, the statistical models used in this technique provide a static view of the observed reality and measure the relationship between variables or factors at a specific point in time, without offering a time perspective. On the other hand, SDM is a technique widely used to obtain information on how the Supply Chain behaves dynamically and serves as a decision 
support element (Sterman, 2000; Helo, 2000; Campuzano and Mula, 2011). SDM allows the complexity of Supply Chain Management to be managed through their simplification, representing interrelated events that are characterized by their dynamic and random character (Forrester, 1961). From the point of view of the company's strategy, related to the long term, the SDM are of great interest, since they allow the visualization of the behaviour of certain variables of the company in different scenarios projected in a future time.

Therefore, the joint use of SEM and SDM could provide both a fixed picture of the relationships between variables at a given moment in time and the perspective view of these relationships, considering time. In this sense, a complementary use of both techniques would be possible, in order to analyse strategic variables of the company, its relationships and its evolution over time. And although there are a significant number of studies that address the use of SEM (Bruque et al., 2016; Liu et al., 2016; Subramanian and Abdulrahman, 2017) and SDM (Sterman, 2001; Campuzano and Mula, 2010) separately, no papers have been identified that use both techniques in a complementary way.

The objective of this chapter, therefore is to make a methodological proposal for strategic simulation, where these two techniques are linked in a complementary way, which will allow the application of the SDM at the strategic level, using results from the SEM.

To achieve our objective, this chapter is structured in four sections, which begin with this introduction. The second section present a theoretical reference and the third section describes the proposed methodology. In the fourth section, the proposed methodology is illustrated by its application to two supply chain research areas: first, to the case of a specific type of Cloud Computing use, Supply Chain Integration and their impacts on operational performance (Bruque et al., 2016); second, to the specific case of Information Technology Integration and Lean/Just-In-Time Practices on Lead-Time Performance (Ward and Zhou 2006). Finally, in the fifth section, the conclusions, limitations and future lines of research are presented.

\subsection{THEORETICAL REFERENCE}

The novelty of this research focuses on the use of SDM for the prediction of the company's strategic behaviour based on SEM data. Therefore, this section first shows a theoretical reference of SEM methodology, followed by SDM methodology. 


\subsubsection{STRUCTURAL EQUATION MODELS (SEM)}

Structural Equation Models (SEM) represent a statistical approach to test hypotheses about the relationships between observable and non-observable variables (factors, latent variables or constructs) (Satorra, 1993). SEM are multivariate statistical models that combine multiple regression and factor analysis to estimate relationships between multiple variables (Hair et al., 2009). It allows the evaluation of dependency relationships (cause/effect) between variables incorporating the effects of measurement error (Hair et al., 2001). SEM consists of a measurement model, which shows the relationships of the directly observable variables (items) by which latent variables are measured, and a structural model, where the relationship between variables/constructs to be estimated is collected (Satorra, 1993; Kaplan, 2000). The objective of this technique is to confirm the relationships proposed in the explanatory model, confronting hypotheses with empirical data (Kaplan, 2000). A Structural Equation Model is divided into two fundamental parts: the measurement model and the structural model (Satorra, 1993). The first determines how the unobservable construct is measured by means of these indicators, while the second estimates the effects and relations between variables (Hair et al., 2009).

Prior to SEM, measurement scales used in the theoretical model must be validated (Cook and Campbell, 1979). Content validity, scale dimensionality, reliability, and construct validity are the necessary analyses in SEM (Kaplan, 2000; Hair et al., 2009).

Content validation indicates whether the items selected for a scale actually reflect the construct content (Satorra, 1993). A group of expert researchers, who determine the questionnaire capacity to measure all the phenomena that will be evaluated, can evaluate it. The group can eliminate those items that they consider irrelevant, as well as consider new items not previously included in the measurement scales (Hair et al., 2009).

Scale dimensionality implies that a single construct is at the base of the set of items so that the measuring instrument, with its results, represents a single latent variable (Hattie, 1985). Factorial Analysis is a methodology used to verify the scale dimensionality, and presents two different modalities: the exploratory factorial analysis, which allows the measurement model identification; and the confirmatory factorial analysis, which allows the final measurement model evaluation (Gorsuch, 1983; Gerbin et al., 1996). The standardized load values of the scale items should be greater than or equal to .5 (Kaplan, 2000).

Reliability analysis checks the degree to which repeated application of the measuring instrument to the same object or subject produces equal results (Hair et al., 2009). The Cronbach alpha coefficient is a way of evaluating to what extent each element of the 
measuring instrument correlates with the other scale elements (Cronbach, 1951). The use of statistical software such as SPSS allows the identification of Cronbach's $\alpha$, which must be greater than or equal to .7 for the scale to be reliable (Bagozzi and Yi, 1988).

Construct validity analysis guarantees that scores resulting from the questionnaire answers can be considered and used as a valid measure of the phenomenon being studied (Mokkink et al., 2010). Divergent validity can be checked by comparing the Cronbach's a coefficients with the correlations between scale items (Cronbach's $\alpha$ coefficients of each scale should be higher than the correlation coefficients with other scales) (Amand and Ward, 2004). Convergent validity is tested through confirmatory factorial analysis. To do so, it is necessary to carry out a previous step, which data exploration should be performed using the normalized estimation (Mardia test). Such step is necessary to verify the data's multivariate non-normality, which confirm (or not) that Robust Maximum Likelihood Method can be utilised (Satorra, 1993).

There is some variation among the authors regarding the stages of application of SEM. However, the following steps are suggested for the SEM implementation (Kaplan, 2000; Kline, 2005):

(i) Measurement model and structural model specification: In this step, the measurement model is established, where the item or items (directly observable variables) or each construct (latent variable or factor) to be measured, and the error estimate for each observable and latent variable are shown. The structural model is also established, which includes the hypothetical relationship between variables/constructs based on the theory that supports certain hypotheses and that we wish to contrast with real data, generally captured by means of a questionnaire designed for this purpose. An example of a structural model and a measurement model is shown in Figure 5.1. In the structural model (thick line) the relationship between two constructs (Construct $i$ and Construct $J$ ) is shown. The measurement model (thin lines) shows how each latent variable (Dimensions Di1, Di2, Dj1 and Dj2) is measured by observable variables (Items $i 1$, i2, i3, $i 4, i 5, i 6, j 1, j 2, j 3, j 4, j 5$, and $j 6$ ), considering the corresponding measurement error ( Ei1, Ei2, Ei3, Ei4, Ei5, Ei6, Ej1, Ej2, Ej3, Ej4, Ej5, Ej6, ED1, ED2, ED3, ED4 and ED5). 


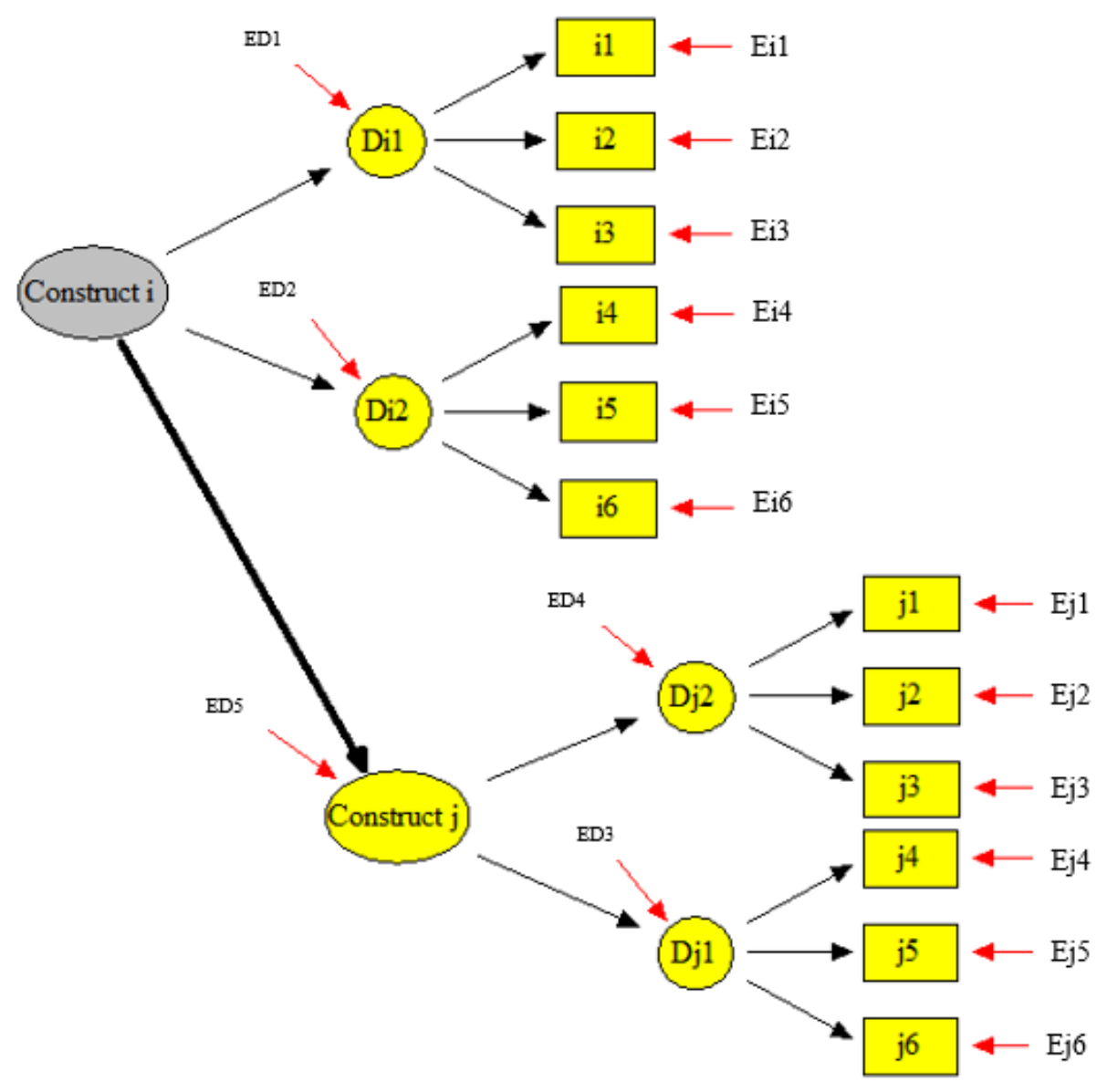

Figure 5.1. Example of measurement and structural models in SEM

(ii) Identification: Once formulated, it is determined whether the measurement model and the structural model are identified by algebraic expressions as a function of the sampling variances and covariances. Each parameter must be correctly identified and derived from the information contained in the variance-covariance matrix.

(iii) Parameter estimation: In this step the values of the unknown parameters are determined, as well as their respective measurement error. When estimating these parameters, both those of the measurement model and those of the structural model are estimated. For its estimation in the measurement model, the Exploratory Factorial Analysis and Confirmatory Factorial Analysis are used. The Exploratory Factorial Analysis allows for the measurement model identification (Gorsuch, 1983; Gerbin et al., 1996) and the Confirmatory Factorial Analysis allows the final measurement model evaluation (Satorra, 1993; Raubenheimer, 2004). For the structural model parameters estimation, the variances and/or covariances analysis is used, whose estimations are made by means of a specific software for SEM (e.g. R and EQS). 
(iv) Evaluation (goodness of fit): once the model parameters have been estimated, the next step is to evaluate the model fit. The most commonly used indicators are RMSEA (root mean square error of approximation) $<.05$ and Chi-square/degrees of freedom $<5$ for a meaningful result (confidence level $=95 \%$ ). Another set of indicators should also be taken into account (e. g. Normal Fit Index or NFI, Non Normal Fit Index or NNFI, Comparative Fit Index or CFI, Incremental Fit Index or IFI, McDonald Fit Index or MFI close to one) (Satorra, 1993; Hair et al., 2009).

(v) Measurement model and/or structural model re-specification: If no good fit in the exploratory factor analysis, confirmatory factor analysis or structural model, the models it must be corrected. The measurement model can be re-specified after the Exploratory Factorial Analysis or Confirmatory Factorial Analysis, eliminating items with a load of less than .5. The structural model is re-specified when it is not well adjusted by making additional theoretical assumptions (Hair et al., 2001) (see Figure 5.1).

(vi) Results interpretation: Finally, the model must be interpreted as a way of defining and discussing whether the hypotheses are accepted or rejected.

It is useful for hypotheses testing that establish relations between variables, and has been used quite extensively in Supply Chain Management field (Li et al., 2009; Acar et al., 2017; Wamba et al., 2017).

\subsubsection{SYSTEM DYNAMICS MODELS (SDM)}

System Dynamics Models (SDM) are proposed to simulate complex systems over time and to understand the structural causes that lead the represented system behaviour (Forrester, 1961). The objective of SDM is to examine the interaction that exists between various functions within a system over time, which makes it possible to understand and improve the components interaction of that system (Campuzano and Mula, 2010). Through SDM, it is possible to identify the cause-effect relationships, response times and feedback effects of a system. Its application has been used in various fields such as Engineering and other disciplines (e.g. Social Sciences, Physical Sciences, Chemistry and Biological Sciences). The following steps are established to build the SDM (Forrester, 1961; Sterman, 2000):

(i) Define the problem or objective: The problem or objective of SDM must be clearly defined. The information related to the problem/objective is reviewed and understood, and the system is described.

(ii) Conceptualisation: The cause-effect relationships between the various variables involved in the system are defined (causal diagram), so that the diagram captures the 
key elements and the relationships between them (Sterman, 2000). In the causal diagram, the system inputs, process, and outputs are shown graphically, and the main variables are connected by means of arrows accompanied by a sign (Figure 5.2). The positive polarity symbol $(+)$ is assigned if the influence of one variable on the other is positive, i.e. the change in the source variable of the arrow will produce a change in the same direction in the target variable. Similarly, the negative polarity symbol (-) is assigned to indicate that the change in the source variable produces a change in the opposite direction on the target variable (Campuzano and Mula, 2010).

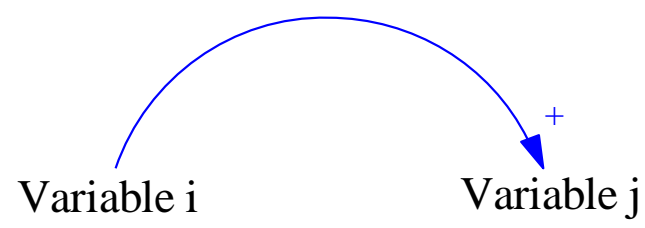

Figure 5.2. Example of a causal diagram in SDM

(iii) Formalisation: The flow diagram (or Forrester diagram) is created. The causal diagram is translated into a terminology that facilitates the writing of equations on the simulation software (Campuzano and Mula, 2010). The variables in SDM can be level variables, flow variables, auxiliary variables or parameters. The level variables are those in which the levels assume the accumulation over time of a certain magnitude. These are the system status variables since the values it takes to determine the situation in which the system finds itself. The flow variables are those that are associated with level variables and collect the actions resulting from the decisions made in the system, determining the level variable variations. The flows explicitly express the variation level per unit time. The flow feeds or reduces the level. To understand the meanings of these variables it is a good metaphor to think of a certain water level in a tank (level variable) and a water inlet valve that supplies it (flow variable). The auxiliary variables and the constant variables (parameters) are those that condition the flow variables behaviour (Campuzano et al., 2010).

Graphically (Figure 5.3), level variables are associated with a rectangle, flow variables with a valve reminder icon, and auxiliary variables and parameters do not have a specific graphical representation, being represented by text with the variable name (Campuzano and Mula, 2010). As in the causal diagram, arrows are used to connect the related variables. 


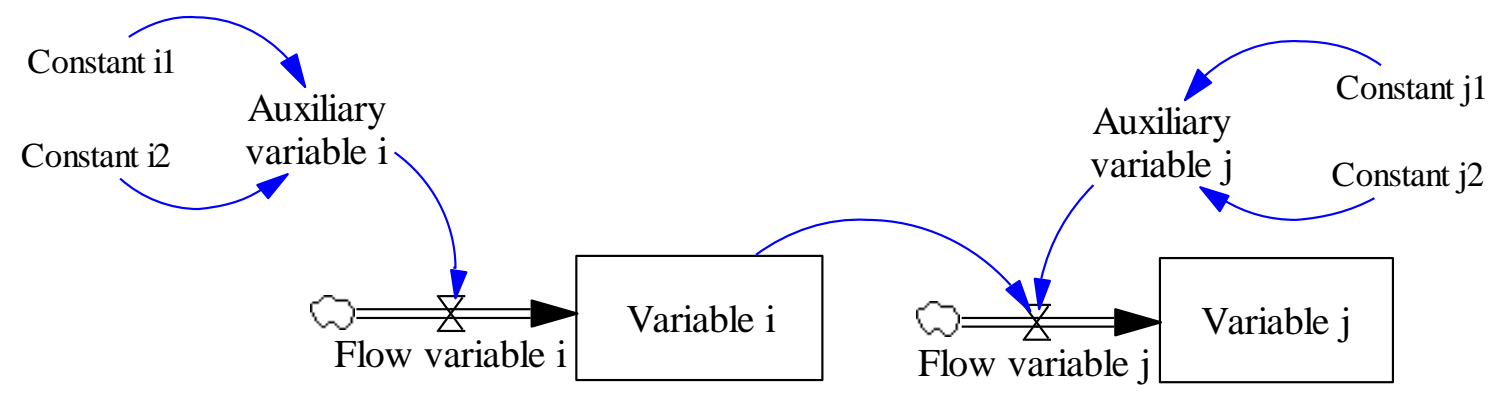

Figure 5.3. Example of a flow diagram in SDM

In addition, the mathematical equations corresponding to the level and flow variables present in the flow diagram must be defined. The auxiliary variables can have an associated equation (if they have parameters associated with them) or a constant value. These equations will help the software used to model the relationships between the variables studied. As an example, the mathematical equations corresponding to Figure 3 would be:

$$
\begin{gathered}
\text { Variable } i=\text { INTEG }(\text { Flow variable } i, 0) \\
\text { Variable } j=\text { INTEG }(\text { Flow variable } j, 0) \\
\text { Flow variable } i=\text { Auxiliary variable } i \\
\text { Flow variable } j=\text { Auxiliary variable } j+\text { Variable } i \\
\text { Auxiliary variable } i=\text { Constant } i 1+\text { Constant } i 2 \\
\text { Auxiliary variable } j=\text { Constant } j 1+\text { Constant } j 2
\end{gathered}
$$

For the example presented above, INTEG is a function of the Vensim® software that represents the Integral of the value in parentheses. The parameters Constant i1, Constant i2, Constant $j 1$ and Constant $j 2$ do not have mathematical equations, as they are constant values. Vensim $\AA$ has a large number of functions, which allows us to analyse the most diverse situations, such as integral, maximum and minimum values, add randomness to the analysis, and time delays. At the end of this Thesis, in the Appendix, a list with the main Vensim ${ }^{\circledR}$ functions and its applications will be provided.

(iv) Performance/evaluation: The model is simulated by means of a specific software, such as Vensim, Ithink, Anylogic, among others. The SDM validity and quality are checked under certain conditions (tests and comparisons) in order to verify the model structure and behaviour. Such tests could be Structure check, Dimensional consistency, Checking Parameters, Extreme conditions, Sensitive test, among others (more in detail in Stage 4) (Sterman, 2000). 
(v) Exploitation: Specific scenarios are defined as a way of analysing the development of the system under consideration in the future. By scenario, we mean each analysis that allows us to obtain one or more graphs of the future evolution of a represented variable, with respect to the value taken by other variables (located on the $\mathrm{X}$-axis and $\mathrm{Y}$-axis). Thus, each scenario allows us to observe the evolution over time of a variable in relation to other variables of the causal or flow model.

The complementarity between Structural Equation Models (SEM) and System Dynamics Models (SDM) has been used to design and perform the strategic simulation model.

\subsection{SEM/SDM METHODOLOGICAL PROPOSAL AT A STRATEGIC LEVEL}

In this section, a methodological proposal using a complementary approach between SEM and SDM is presented. The idea behind the proposal is to allow any researcher who has tested hypotheses with SEM to simulate over time the different relationships between the variables studied. A combined SEM/SDM methodology is a path that allows for prospective strategic analysis, using the complementarity between SEM and SDM by jointly use both methodological approaches: on the one hand, the static one, based on data arising from a given point in time with no future projections (SEM); on the other hand, a future-based projection based on current data, able to provide a vision on how variables may behave in the future (SDM). Generally, SEM establishes structural models of high conceptual level, of strategic level, so the SEM/SDM methodology can be very useful to analyse the temporal evolution of relationships between variables at strategic level.

The SEM/SDM methodology consists of five stages, each of which involves different steps. In Stage 1, the problem/objective to be analysed is clearly defined. In Stage 2, the qualitative data from SEM is used to formulate the SEM/SDM causal diagram. In Stage 3 , the quantitative data from SEM is used to formulate the SEM/SDM flow diagram and mathematical equations. Then, in Stage 4, the SEM/SDM is performed and validity tests are carried out. Finally, in Stage 5, the simulation results from SEM/SDM are analysed. Each of the stages described is detailed below.

\section{Stage 1. Definition of the problem or objective}

In this first stage, the problem or objective to be analysed/achieved through SEM/SDM must be clearly defined. To do this, firstly the data source to be used in the SEM/SDM model is defined (Step 1). These data can be obtained from primary sources (usually 
from surveys, where SEM is used) or secondary sources (from scientific publications with SEM analysis results). Next, the information related to the SEM/SDM problem/objective must be reviewed and understood (Step 2). Here, the variables of interest that will be included in the simulation model are defined, and available data on these variables are verified. Then, the system to be simulated must be described (Step 3) as a manner of contextualising and explaining what is to be analysed. Considering that this methodological proposal seeks to analyse the different relationships between the SEM variables studied over time, some of the simulation objectives could be the following: (a) To know how/how much one or more SEM variables would increase the levels of other variable(s) over time; (b) To analyse the "what if" as a way of verifying how increases in the cause variable loads would affect the effect variables; and (c) To implement or exclude SEM variables and verify how this would affect the system over time.

\section{Stage 2: Conceptualisation}

The objective of this stage is to define the causal diagram of variables that will be analysed in the SEM/SDM. For this purpose, the qualitative data from SEM for the SDM construction would be identified and defined (Step 4). From primary and secondary data sources, the selected data refer to the relationship between the variables to be studied (i.e., the identification of existing relationships between variables and which of them will be included in the study). Next, the SEM cause-effect relationships to be applied in the SDM it is collected (Step 5), as a way to establish how the analysed variables are qualitatively related. To finish this stage, the SEM/SDM causal diagram is created (Step 6 ), in which the cause-effects relationships between the SEM measurement model and/or structural model variables are graphically represented in SDM. Figure 5.4 shows the correspondence between the SEM structural model (see also Figure 1) and the SDM models (see also Figure 5.2). 
SEM

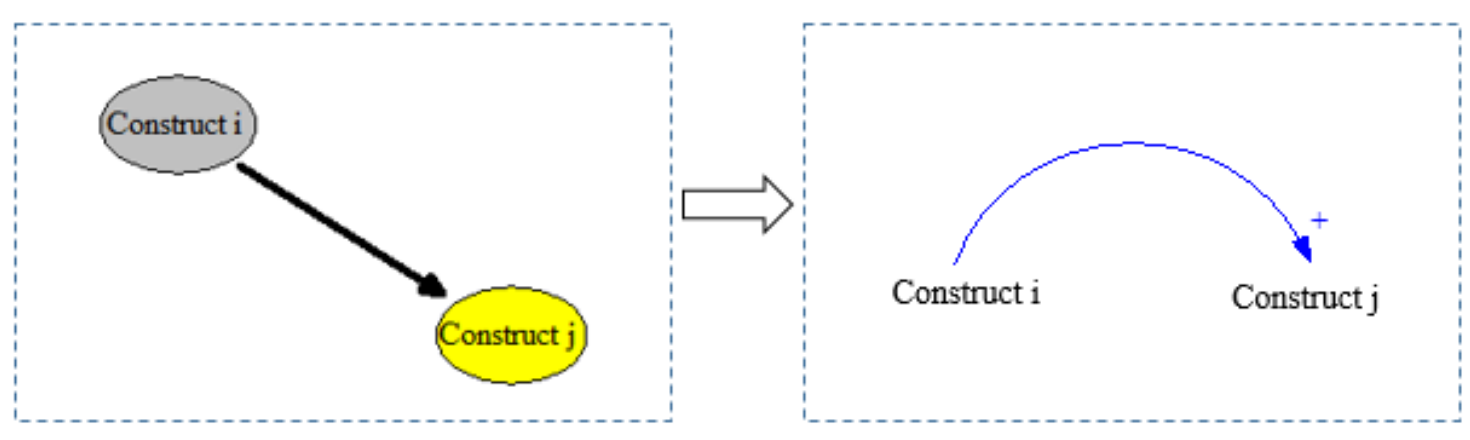

Figure 5.4. SEM structural model convert to SDM causal diagram

At the end of this stage, it is essential to evaluate whether the SEM/SDM causal diagram developed is aligned with the information provided by the SEM. For this, it is necessary to verify if the most important SEM variables are represented in the causal diagram, and if the cause-effect relationship between them is in accordance with the SEM information. If so, we are ready to advance to the next stage. If not, it is necessary to return to the beginning of Stage 2 and repeat steps 4,5 and 6 . This process is important to verify the model's validity.

\section{Stage 3. Formalisation}

The objective of this stage is to define the SEM/SDM quantitative values, the mathematical equations and starting data for the SEM/SDM construction. To do this, firstly (Step 7) the SEM quantitative data is collected. Figure 5.5 specifies how the SEM quantitative data are selected for use in the SDM. For measurement model data, it is possible select information on the factorial loads that the SEM dimensions exert on their items as well as the SEM constructs exert on their dimensions. These loads are represented in Figure 5 by $\alpha 1, \alpha 2, \alpha 3, \alpha 4, \alpha 5, \alpha 6, \alpha 7, \alpha 8, \alpha 9, \alpha 10, \alpha 11$ and $\alpha 12$ (for Dimensions $\rightarrow$ Items) and $\mu 1, \mu 2, \mu 3$ and $\mu 4$ (for Constructs $\rightarrow$ Dimensions). For structural model data, information can be selected from the loads that a construct/variable exert on other construct/variable. This load is represented in Figure 5.5 by $\gamma 1$ (for Construct/variable $\rightarrow$ Construct/variable). 


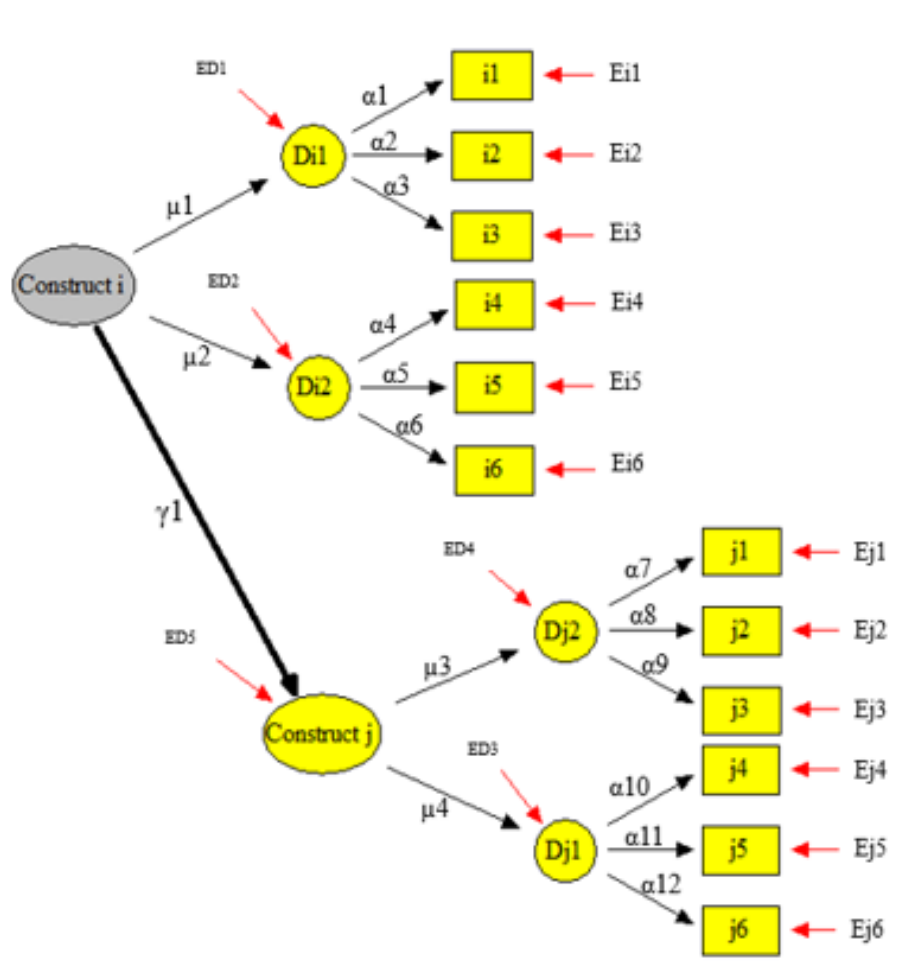

SEM data for SDM analysis
\begin{tabular}{|c|c|c|}
\hline \multicolumn{2}{|c|}{ Measurement model } & $\begin{array}{c}\text { Structural } \\
\text { model }\end{array}$ \\
\hline \begin{tabular}{|c|c|} 
Dimension / \\
tem
\end{tabular} & $\begin{array}{c}\text { Construct } \\
\text { Dimension }\end{array}$ & $\begin{array}{c}\text { Construct } \\
\text { Construct }\end{array}$ \\
\hline$a 1$ & & \\
\hline$a 2$ & & \\
\hline$a 3$ & & \\
\hline$a 4$ & & \\
\hline$a 5$ & & \\
\hline$a 6$ & & \\
\hline$a 7$ & & \\
\hline$a 8$ & & \\
\hline$a 9$ & & \\
\hline$a 10$ & & \\
\hline$a 11$ & & \\
\hline$a 12$ & & \\
\hline & $\mu 1$ & \\
\hline & $\mu 2$ & \\
\hline & $\mu 3$ & \\
\hline & $\mu 4$ & \\
\hline & & $\gamma 1$ \\
\hline
\end{tabular}

Figure 5.5. Identification of the SEM quantitative data to be used in SDM

Next, the SEM/SDM flow diagram is created, which will allow translating the causal diagram information to a specific computer terminology used in the simulations software (Step 8). It is important to note that (i) variables represented in the SEM/SDM causal diagram are not necessarily SDM level variables (they can also be auxiliary variables); (ii) SEM/SDM level variables can correspond to the SEM dimensions or constructs; (iii) SDM auxiliary variables can correspond to the SEM items, dimensions and/or constructs; and (iv) SDM flow variables have no correspondence in the SEM model, as it serves only to "channel" loads of the source variables (cause; independent variables) to the target variables (effect; dependent variables). This will vary according to the research objective.

Figure 5.6 illustrates a generic SEM/SDM flow diagram. Elements observed in the Flow Diagram are described as follows. Construct $i$ and Construct $j$ are the SEM/SDM level variables, representing the SEM constructs. Loads of Construct $i$ is a flow variable that represent a "channel" that connect Dimensions of Construct $i$ to Construct $i$. Similarly, Loads of Construct $j$ is a flow variable that connect Dimensions of Construct $j$ loads to Construct $j$. Dimensions of Construct $i$ and Dimensions of Construct $j$ are auxiliary variables that receive loads of Items of Dimensions $i$ and loads of Items of Dimensions $j$, respectively. Items of Dimensions $i$ and Items of Dimensions $j$ are parameters that represent the loads that SEM items exert on SEM dimensions. 


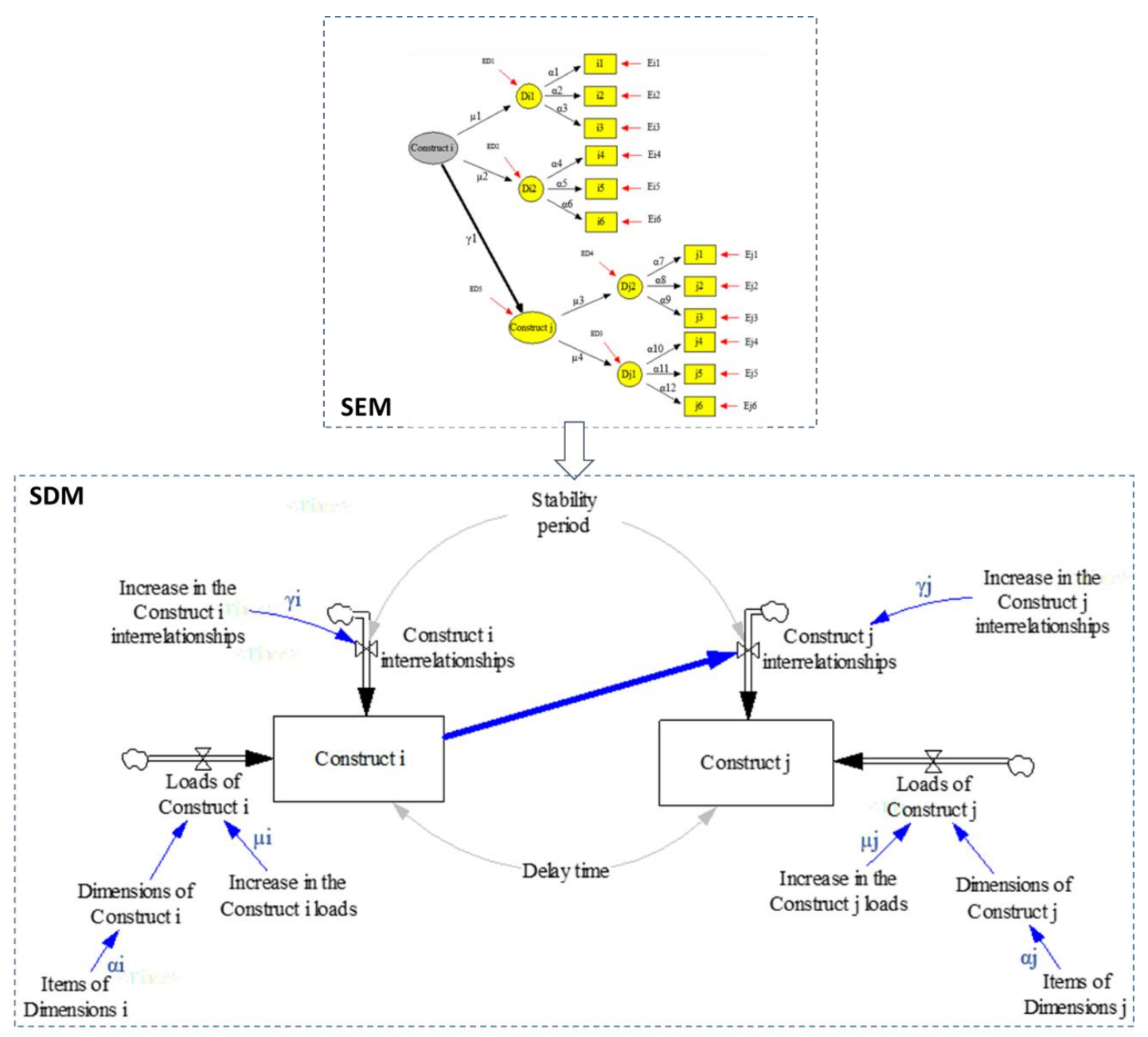

Figure 5.6. Generic SEM/SDM flow diagram

Likewise, the flow variables Construct $i$ interrelationships and Construct $j$ interrelationships have been included in the SEM/SDM to generalize it, making possible to include new variables to the model. For example, if a SEM/SDM user wants to include a new level variable (SEM construct), it is enough to design that variable and connect it with arrows to the Construct $i$ interrelationships or Construct $j$ interrelationships. This procedure will be deeply explained in Section 4, in which the generic SEM/SDM will be applied to specific supply chain cases.

Increase in the Construct $i$ interrelationships and Increase in the Construct $j$ interrelationships are parameters that allow the SEM/SDM user to increase factorial loads in the relationship between SEM/SDM level variables. Similarly, Increase in the Construct $i$ loads and Increase in the Construct $j$ loads are parameters that allow the SEM/SDM user to increase factorial loads in the relationship between SEM/SDM items, dimensions and specific construct. 
Stability period is a parameter that allow the SEM/SDM user increasing or reducing the stability time (time without increasing extra loads). System keeping stable during interval times refers to Stability period, without receiving disruptions of the parameters Increase in the Construct $i$ interrelationships, Increase in the Construct $j$ interrelationships, Increase in the Construct $i$ loads Increase in the Construct $j$ loads. For example, if Stability period is equal to eight, this means that during eight simulation periods the loads coming from these parameters will not act in the system. After these eight periods, the loads return to act in the system during one simulation period and, then, a new period of stability is started equal to eight periods. Therefore, it happens during the whole simulation period. In practical terms, this variable is important because it allows the model users to indicate the time intervals in which they do not want to increase loads to the model. In real life, it would be the time that a company would take to either invest again in the implementation of new variables or increase the level of existing ones. Finally, Delay time is a parameter that defines the loads flow time (time required for the load of a variable to affect another variable associated to the Dimensions of Construct $i$ and Construct $i$, the parameter Delay time represent the required time to the variables loads affect other variables levels.

In the subsequent step (Step 9), the mathematical equations corresponding to the variables present in the SEM/SDM flow diagram must be defined. Table 5.1 shows the SEM/SDM variables and the mathematical equations that define them. The following explanation is focused on variables related to Construct $i$, but the rationale for the variables related to Construct $j$ is the same.

DELAY FIXED, MIN, RANDOM NORMAL, IF THEN ELSE, INTEG, INTEGER and GET XLS CONSTANTS are specific functions of the Vensim ${ }^{\circledR}$ software, and their uses and functionalities are explained in the Appendix at the end of the Thesis. 
Table 5.1. Mathematical equations of SEM/SDM variables

\begin{tabular}{|c|c|c|}
\hline \multicolumn{2}{|c|}{ Variables } & Formula \\
\hline \multirow{2}{*}{ Level } & Construct $i$ & $\begin{array}{l}\text { DELAY FIXED (MIN(RANDOM NORMAL( (Loads of Construct i } \\
+ \text { Construct } i \text { interrelationships)*0.95, (Loads of Construct } i \\
+ \text { Construct } i \text { interrelationships)*1.05, (Loads of Construct it } \\
\text { Construct i interrelationships), } 0.001,3), 1), \text { Delay time, Construct } i \\
\text { interrelationships) }\end{array}$ \\
\hline & Construct $j$ & $\begin{array}{l}\text { DELAY FIXED (MIN(RANDOM NORMAL( (Loads of Construct } j \\
+ \text { Construct } j \text { interrelationships)*0.95, (Loads of Construct } j \\
+ \text { Construct } j \text { interrelationships)*1.05, (Loads of Construct } j+ \\
\text { Construct j interrelationships), } 0.001,3 \text { ), } 1 \text { ), Delay time, Construct } j \\
\text { interrelationships) }\end{array}$ \\
\hline \multirow{4}{*}{ Flow } & $\begin{array}{l}\text { Loads of Construct } \\
\qquad i\end{array}$ & $\begin{array}{l}\text { INTEG }(\text { IF } \\
\text { period)=INTEGER(Time/Stability period), (Dimensions of Construct } \\
i^{*} \text { Increase in the Construct } \text { i loads),0), Dimensions of Construct } \text { i }^{*} \\
\text { Increase in the Construct } \text { i loads) }\end{array}$ \\
\hline & $\begin{array}{l}\text { Loads of Construct } \\
\qquad j\end{array}$ & $\begin{array}{l}\text { INTEG }(\text { IF } \\
\text { period })=\text { INTEGER(Time/Stability period), (Dimensions of Construct } \\
j * \text { Increase in the Construct } j \text { loads),0), Dimensions of Construct } j \text { * } \\
\text { Increase in the Construct j loads) }\end{array}$ \\
\hline & $\begin{array}{l}\text { Construct } i \\
\text { interrelationships }\end{array}$ & $\begin{array}{l}\text { IF THEN ELSE((Time/Stability period)=INTEGER(Time/Stability } \\
\text { period),(RANDOM NORMAL((Increase in the Construct i } \\
\text { interrelationships)*0.95,( Increase in the Construct i } \\
\text { interrelationships)*1.05,( Increase in the Construct } i \\
\text { interrelationships), } 0.001,3)), 0)\end{array}$ \\
\hline & $\begin{array}{l}\text { Construct } j \\
\text { interrelationships }\end{array}$ & $\begin{array}{l}\text { IF THEN ELSE((Time/Stability period)=INTEGER(Time/Stability } \\
\text { period),(RANDOM NORMAL (Construct } i^{*} \text { Increase in the Construct } j \\
\text { interrelationships })^{*} 0.95,\left(\text { Construct } i^{*} \text { Increase in the Construct } j\right. \\
\text { interrelationships })^{*} 1.05,\left(\text { Construct } i^{*} \text { Increase in the Construct } j\right. \\
\text { interrelationships), } 0.01,3)), 0),\end{array}$ \\
\hline \multirow{2}{*}{ Auxiliary } & $\begin{array}{l}\text { Dimensions of } \\
\text { Construct } i\end{array}$ & $\frac{\sum_{i=1}^{n} \text { Items of Dimensions } i}{n}$ \\
\hline & $\begin{array}{l}\text { Dimensions of } \\
\text { Construct } j\end{array}$ & $\frac{\sum_{j=1}^{n} \text { Items of Dimensions } j}{n}$ \\
\hline \multirow{9}{*}{ Parameters } & $\begin{array}{c}\text { Items of } \\
\text { Dimensions } i\end{array}$ & GET XLS CONSTANTS('Data.XIs','Plan1', 'A1') \\
\hline & $\begin{array}{c}\text { Items of } \\
\text { Dimensions } j\end{array}$ & GET XLS CONSTANTS('Data.xIs','Plan1', 'A2') \\
\hline & $\begin{array}{l}\text { Increase in the } \\
\text { Construct i loads }\end{array}$ & GET XLS CONSTANTS('Data.xIs','Plan1', 'A3') \\
\hline & $\begin{array}{l}\text { Increase in the } \\
\text { Construct j loads }\end{array}$ & GET XLS CONSTANTS('Data.xIs','Plan1', 'A4') \\
\hline & $\begin{array}{l}\text { Increase in the } \\
\text { Construct } i \\
\text { interrelationships }\end{array}$ & GET XLS CONSTANTS('Data.xIs', 'Plan1', 'A5') \\
\hline & $\begin{array}{l}\text { Increase in the } \\
\text { Construct } j \\
\text { interrelationships }\end{array}$ & GET XLS CONSTANTS('Data.xIs', 'Plan1', 'A6') \\
\hline & Stability period & GET XLS CONSTANTS('Data.xIs','Plan1','A7') \\
\hline & Delay time & GET XLS CONSTANTS('Data.XIs', 'Plan1', 'A8') \\
\hline & Time & Vensim Settings \\
\hline
\end{tabular}

The level variable Construct $i$ is defined based on Loads of Construct $i$ and Construct $i$ interrelationships. DELAY FIXED function has been included, which allows to indicate a delay time for Loads of Construct $i$ and Construct $i$ interrelationships to affect Construct $i$. For this, we have included the Delay Time parameter in the SEM/SDM. MIN function has been included to stabilize the systems when the maximum level of Construct $i$ is reached (in this case, we have indicated that the maximum value that Construct $i$ can 
reach is 1). RANDOM NORMAL function has been included as a way of allowing the SEM/SDM to use random values that vary between $\pm 5 \%$ of Loads of Construct $i$ and Construct $i$ interrelationships. In this function, it is necessary to indicate a standard deviation (we have indicated the arbitrary value of 0.001 ) and a value for seed (we have indicated the value 3 ). The higher the value of the standard deviation and seed, the higher the variations in factorial loads within the stipulated range $( \pm 5 \%)$. Such function has been included as an attempt to increase the model reality, since the factorial loads contain an associated measurement error, which come from the SEM.

The flow variable Construct $i$ interrelationships is defined from the parameters Increase in the Construct $i$ interrelationships, Stability period and Time. This equation indicates that after the stability time defined by the SEM/SDM user, the model will increase a new load to the Construct $i$. For example, if the Stability period is $\mathrm{T}$, at each $\mathrm{T}$ simulation time the model will apply a new load (with value equal to Increase in the Construct $i$ interrelationships) on Construct $i$. If Stability period is equal to the total simulation period (Stability period = Time), Construct $i$ will not receive loads from Increase in the Construct $i$ interrelationships. It has been necessary to include the INTEGER function so that the division between Time and Stability period is always an integer value. Then, the IF THEN ELSE function has been included, indicating that at each time period equal to the division between the total simulation time and the stability time (Time/Stability period), the model increases a load to Construct $i$ interrelationships. A similar rationale has been used to define the flow variable Loads of Construct. IF THEN ELSE function has been included, indicating that at each time period equal to the division between the total simulation time and the stability time (Time/Stability period), the model increases a load equal to the multiplication product of Dimensions of Construct $i$ loads and Increase in the Constructs i loads.

The auxiliary variable Dimensions of Construct $i$ is defined from Items of Dimensions $i$, which is the average of the items acting on Dimension of construct $i$. The parameter Items of Dimensions $i$ is the average of the items loads that compose Dimension i. These values are constants obtained from the SEM and are associated to an Excel file. The parameters Increase in the Construct $i$ loads and Increase in the Construct $i$ interrelationships are also associated to an Excel file, as well as the construct-construct loads obtained from SEM. Finally, the parameters Stability period and Delay time are also associated to an Excel file, which makes it easier for the model user to change the parameters values in each new scenario. For this, the GET XLS CONSTANTS function has been used, which uses the corresponding parameter value in the Excel file. The 
changes in these parameters values will be used on the SEM/SDM to simulate new scenarios, representing some positive or negative alteration in the model loads.

Then, the SEM/SDM starting data and the time horizon in which the researchers want to simulate the relationship between the variables is defined (Step 10). The following explains a way to define the starting value for the SEM/SDM variables. As in the previous step, the explanation is focused on the variables related to Construct $i$, but the rationale for the variables related to Construct $j$ is the same.

- Items of Dimensions $i$ : In SEM, the relationships between the items and dimensions can be defined and quantified through the Confirmatory Factorial Analysis, the factorial loads of the items that make up a dimension are determined. In this way, the starting data for these parameters is the average of the factorial load that items exerts on Dimension of Construct i.

$$
\text { Items of Dimension } i \text { starting value }=\left(\frac{\sum_{i=1}^{n} \text { items } i \text { load }}{n}\right)
$$

Where:

$$
\begin{aligned}
& \sum_{i=1}^{n} \text { items } \text { i load }=\text { summation of the items } i \text { loads } \\
& n=\text { number of items } i
\end{aligned}
$$

Increase in the Construct $i$ and Increase in the Construct $i$ interrelationships. These values must be defined according to the factorial loads that the SEM/SDM user wants to increase to the model. For the generic model, these values will be zero (no factorial loads apart from those coming from the SEM). When the SEM/SDM user wants to increase a load of 0.1 on certain construct, he/she must add the value 0.1 . These variables will be increased/decreased in the scenario creation stage, as a way to monitor the model behaviour when factorial loads are altered.

- Time, Stability period and Delay time. Time is the variable that represented the time horizon considered (days, weeks, months or years) and must be defined according to the simulation object. For the first simulation, the Stability period value be equal to Time, which allows the model to be analysed only with data from SEM (current scenario). As it will not increase extra loads in this first simulation, the model will not receive any "disruptions" except the loads coming from the SEM data source. Then, Stability period must be equal to the total simulation time, that is, Stability period = Time. The Delay time 
value must be defined according to the simulation object/characteristics. Time, Stability period and Delay time could assume other values in the scenarios to be simulated, as a way of analysing the time related to the results to be achieved.

At the end of this stage, it is essential to evaluate whether the SEM/SDM flow diagram developed is aligned with the information provided by the SEM. For this, it is necessary to check whether the most important SEM variables are represented in the flow diagram, whether the mathematical equations and the starting data are correctly formulated and whether the relationship between the variables is in accordance with the SEM information and the causal diagram (Stage 2). If so, we are ready to advance to the next stage. If not, it is necessary to return to the beginning of Stage 4 and repeat steps 7, 8, 9 and 10 . This process is important to verify the model's validity.

\section{Stage 4. Performance and evaluation}

In this stage, the researchers should check if the SDM is reliable and robust, and if it is coherent with the information coming from SEM. The SEM/SDM model is performed using the starting data (Step 11), in order to generate the base model (current scenario). The SEM/SDM model validity and quality is then checked under certain conditions (Step 12). For this, several tests allow checking the SEM/SDM structure, behaviour and validity. Some of them are the test of extreme conditions, comparison test with similar models, and sensitivity analysis. Table 5.2 shows some of the most commonly used tests to evaluate SDM (Forrester and Senge, 1978; Sterman, 2000; Saysel and Barlas, 2004; Qudrat-Ullah and Seong, 2010). 
Table 5.2. SEM/SDM validate tests

\begin{tabular}{|c|l|}
\hline Method & Test Purpose \\
\hline Limits Adequacy & $\begin{array}{l}\text { Verifies whether important concepts and structures for addressing policy issues are } \\
\text { endogenous to the model }\end{array}$ \\
\hline Structure check & $\begin{array}{l}\text { Analyses whether the model structure is consistent with the system's relevant } \\
\text { descriptive knowledge }\end{array}$ \\
\hline $\begin{array}{c}\text { Dimensional } \\
\text { consistency }\end{array}$ & $\begin{array}{l}\text { Checks whether each equation in the dimensional model corresponds to the real } \\
\text { system }\end{array}$ \\
\hline $\begin{array}{c}\text { Checking } \\
\text { Parameters }\end{array}$ & $\begin{array}{l}\text { Analyses whether the model parameters are consistent with the relevant system } \\
\text { knowledge }\end{array}$ \\
\hline Extreme conditions & $\begin{array}{l}\text { Observes whether the model shows logical behaviour when extreme values are } \\
\text { assigned to the selected parameters }\end{array}$ \\
\hline $\begin{array}{c}\text { Abnormal behavior } \\
\text { tests }\end{array}$ & $\begin{array}{l}\text { The causal relationships of a given construct are deepened. It allows to observe the } \\
\text { importance of structures or variables examining the strange behaviours that can } \\
\text { occur when a relationship is eliminated or modified }\end{array}$ \\
\hline tests & $\begin{array}{l}\text { Analyses the moment in which a certain behaviour is generated in the model, } \\
\text { previously unknown, but that can occur in the real system }\end{array}$ \\
\hline Mroof of Family & $\begin{array}{l}\text { Analyses if the model can generate the same behaviors in other cases similar to } \\
\text { the system for which it was initially built. }\end{array}$ \\
\hline Sensitity test & $\begin{array}{l}\text { Analyses how the model behaves in the face of variations in parameters and } \\
\text { modifications in the initial conditions and in the surrounding conditions. This test } \\
\text { makes it possible to evaluate the performance of the SW in the event of possible } \\
\text { sudden changes in any of its parameters, and a significant number of simulations } \\
\text { are indicated. }\end{array}$ \\
\hline Historial data test & $\begin{array}{l}\text { The results and behavior of the simulation model are compared with the data } \\
\text { obtained from a real situation (for example, historical data of a company) }\end{array}$ \\
\hline Model simplification & $\begin{array}{l}\text { Verify the possibility of simplifying the model, without affecting the results. It can be } \\
\text { used to generate generic models }\end{array}$ \\
\hline
\end{tabular}

After confirmation of the model's validity, we are apt to advance to the next stage. In case the model cannot be validated, it is necessary to return to the beginning of the methodology and review all steps, as a way to identify any error or something to be increased/discarded in the model development process.

\section{Stage 5. Exploitation}

In the last stage of this methodology, it is necessary to specify the SEM/SDM simulation scenarios for which the researchers/managers want to know the results (Step 13) as a way of analysing the development of the system under consideration in the future. As seen above, by scenario we mean each analysis that allows us to obtain one or more graphs of the future evolution of a represented variable, with respect to the value taken by other variables (located on the $\mathrm{X}$-axis and $\mathrm{Y}$-axis). To establish the scenarios, it is interesting to analyse how the multidimensional factors or constructs will evolve according to the values they acquire in their dimensions. Also, know how each of the variables of the causal model evolves in relation to the rest of the model variables. In this stage, the SEM/SDM developed can also serve as a support tool for business decision making. That is to say, it is possible to analyse if and how a defined objective could be reached in a determined time frame (for example, "What to do to increase the level of a determined variable by $10 \%$ in the next 24 months?). With these questions in mind, it is 
possible to consider various analysis scenarios that will depend on the causal and flow model in each case. Through the definition of new decision rules and new values for the simulation variables, researchers and managers must specify those scenarios for which they want to know the results. There is no single way to design such scenarios, as this depends on the research objectives and the researcher's criteria. The next step is to perform the scenarios simulations (Step 14), to then analyse the results obtained and know the future behaviour of the variables studied (Step 15).

Therefore, the proposed methodology is completed. Figure 5.7 presents a summary of the stages. It can be seen that after completing Stages 2, 3 and 4 it is necessary to analyse whether the objectives related to these Stages have been achieved. This verification is necessary to increase reliability and quality for the SEM/SDM developed, to guarantee that it is valid and corresponds to the structure and relationships obtained through SEM. 
Stage 1: Definition of the problem or objective

Stage 2: Conceptualisation

Stage 3: Formalisation

Stage 4: Performance and evaluation

Stage 5: Exploitation

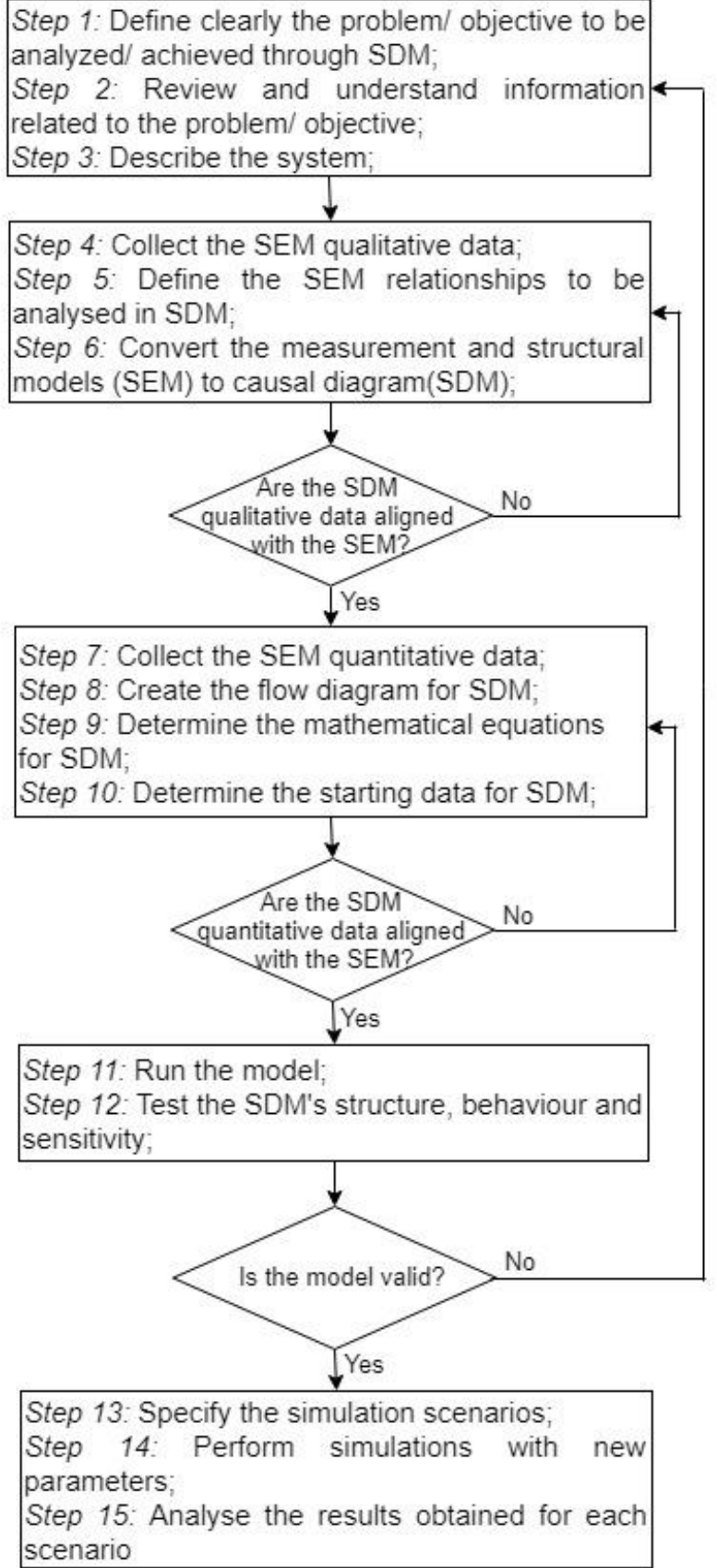

scenario

Figure 5.7. Stages of SEM/SDM methodology

In the following section, the proposed SEM/SDM tool is applied by analysing two cases, using secondary data sources (SEM data from previously published papers). The data source used in these applications have been chosen since they analyse the relationship between important variables related to Supply Chain Management. In addition, they addresses a relatively small number of variables, which can simplify the comprehension of the SEM/SDM application. 


\subsection{APPLYING THE SEM/SDM METHODOLOGY}

\subsubsection{APPLICATION ONE: COMMUNITY CLOUD, SUPPLY CHAIN INTEGRATION AND OPERATIONAL PERFORMANCE}

Community Cloud (CC) is a specific type of Cloud Computing (Ryan and Loeffer, 2010; Mell and Grance, 2011) and can be defined as the cloud infrastructure provided for the exclusive use of a specific community of users who have common concerns, such as mission, security requirements, policy and compliance consideration (Hayes, 2008; Fingar, 2009; Buyya et al., 2011).

Supply Chain Integration (SCI) consists of sharing correct information and activities among the units that form part of the chain, quickly and supported by the IT infrastructure on which the supply chain is built, to encourage the cooperative behaviour of the agents that make up the chain (Devaraj et al., 2007). CC can be used to promote and increase $\mathrm{SCl}$, especially the physical and informational flows that compose it (Bruque et al., 2015). CC improves information sharing in real time on product availability, stock levels, shipment status and production planning (Lancioni et al., 2000; Chen and Paulraj, 2004), improving SCl.

Operational Performance (OP) refer to the results that the company achieves in various operational aspects, such as cost, flexibility and quality. CC can favour flexibility, efficiency, punctuality and precision of deliveries. In addition, CC allows companies to combine and reorganize diverse resources of software and/or hardware in organizations, which affects both internal aspects of the productive structure of the organization itself, as well as the interconnections and functioning of inter-organizational configurations, affecting positively OP (Bruque et al., 2016).

In the following, the five stages of the SEM/SDM methodology are applied. The application to be carried out below is based on the study by Bruque et al. (2016). From a static perspective (SEM), Bruque et al. (2016) establish that there is a positive relationship between Cloud Computing, Supply Chain Integration and Operational Performance.

\section{Stage 1. Definition of the problem or objective}

First, the data source to be used in the SEM/SDM model is defined (Step 1), the paper entitled "Supply chain integration through community Cloud: Effects on operational performance" (Bruque et al., 2016) has been used as a SEM secondary data source to 
this application. In the referred paper, the SEM methodology is used to analyse the effects of Community Cloud (CC) and Supply Chain Integration (SCI) on Operational Performance (OP).

Next, the information related to the SEM/SDM objective must be reviewed and understood (Step 2). In the referred paper, three hypothesis has enunciated and analysed through the SEM methodology. Bruque et al., (2016) state that CC exerts a positive affect $\mathrm{SCl}$ (Hypothesis $\mathrm{H} 1$ ) and demonstrate a positive relationship between $\mathrm{SCl}$ and $\mathrm{OP}$ (Hypothesis $\mathrm{H} 2$ ). The authors also proved that $\mathrm{CC}$ exerts a positive impact on OP (Hypothesis H3).

Likewise, the system to be simulated must be described (Step 3). The results of the SEM analysis that relates $\mathrm{CC}, \mathrm{SCl}$ and $\mathrm{OP}$ have been chosen as the SEM/SDM variables to be used in this application. The referred paper show that the higher the CC use, the higher the $\mathrm{SCl}$ level. It is also observed that the higher $\mathrm{SCl}$ level is related to an improvement in OP. Likewise, the higher CC use is related to an increase in OP.

Therefore, the general objective of the SEM/SDM that will be developed and performed is to analyse the interrelationships of $\mathrm{CC}, \mathrm{SCl}$, and $\mathrm{OP}$ in a time horizon. More specifically, we want to know how a company could increase a factorial load of 0.2 on $\mathrm{SCl}$ and OP levels over 18 months ( 80 weeks) through the variables studied. A "what if" analysis will be performed as a way of verifying how increases in the $\mathrm{CC}$ and $\mathrm{SCl}$ loads would affect OP levels, as well as analyse the impacts of increased CC loads on the improving of SCl levels.

\section{Stage 2: Conceptualisation}

The qualitative data from SEM for the SDM construction would be identified and defined (Step 4). In addition, the SEM cause-effect relationships to be applied in the SDM it is collected (Step 5). The qualitative data and the cause-effect relationships obtained from SEM is presented in Table 5.3.

Table 5.3. The SEM qualitative relationships (Bruque et al., 2016)

\begin{tabular}{|l|c|c|c|}
\hline \multicolumn{2}{|l|}{ Tested Hypothesis } & Relationship & $\begin{array}{c}\text { Will it be used in } \\
\text { the SEM/SDM? }\end{array}$ \\
\hline $\mathrm{H} 1$ & $\mathrm{CC} \rightarrow \mathrm{SCl}$ & Positive and significant & Yes \\
\hline $\mathrm{H} 2$ & $\mathrm{SCl} \rightarrow \mathrm{OP}$ & Positive and significant & Yes \\
\hline $\mathrm{H} 3$ & $\mathrm{CC} \rightarrow \mathrm{OP}$ & Positive and significant & Yes \\
\hline
\end{tabular}


Next, the SEM/SDM causal diagram is created (Step 6), which the cause-effects relationships between the SEM structural model variables are graphically represented (Figure 5.8).

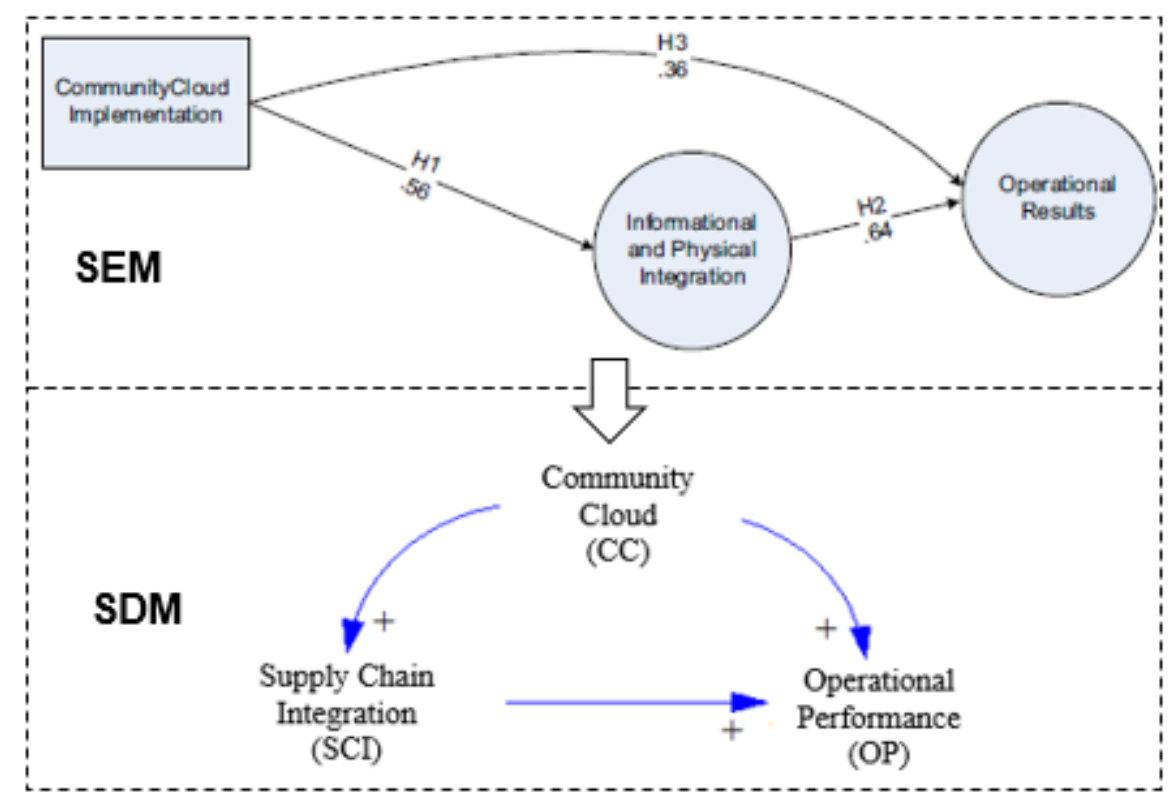

Figure 5.8. Causal diagram of $\mathrm{CC}, \mathrm{SCl}$, and $\mathrm{OP}$

Finally, the causal diagram developed by SEM/SDM has been analysed, confirming that it is aligned with the information provided by SEM. The most important SEM variables are represented in the causal diagram and the cause-effect relationship between them is in accordance with the SEM information.

\section{Stage 3. Formalisation}

The SEM quantitative data is collected (Step 7). Data of the measurement model (items factorial loads) and the structural model (constructs load) have been selected. Figure 5.9 specifies how the SEM quantitative data are selected for use in the SDM. It shows the data referring to the relationships between SEM items and constructs and the factorial load selection to be used in SEM/SDM. 
SEM data for SDM analysis

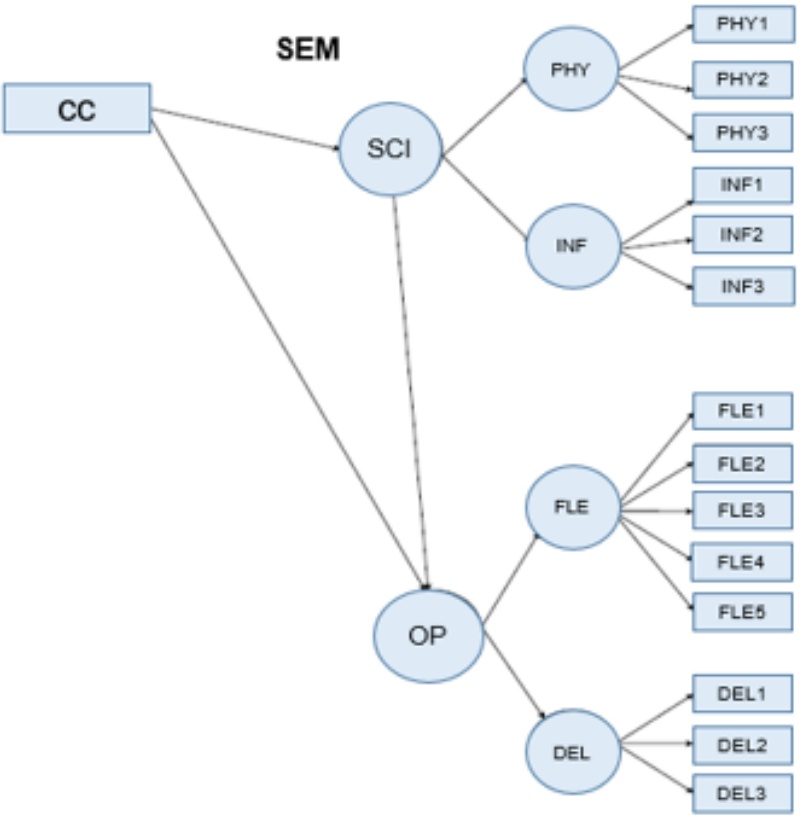

\begin{tabular}{|c|c|c|c|c|}
\hline \multirow[t]{2}{*}{ Construct } & \multicolumn{2}{|c|}{$\begin{array}{l}\text { Construct / } \\
\text { Dimension }\end{array}$} & \multicolumn{2}{|c|}{$\begin{array}{l}\text { Dimension / } \\
\text { Item }\end{array}$} \\
\hline & Dimension & Load & Item & Load \\
\hline \multirow{6}{*}{$\mathrm{SCl}$} & \multirow{3}{*}{ PHY } & \multirow{3}{*}{0.38} & PHY1 & 0.5 \\
\hline & & & PHY2 & 0.5 \\
\hline & & & PHY3 & 0.72 \\
\hline & \multirow{3}{*}{ INF } & \multirow{3}{*}{0.52} & INF1 & 0.65 \\
\hline & & & INF2 & 0.83 \\
\hline & & & INF3 & 0.58 \\
\hline \multirow{8}{*}{ OP } & \multirow{5}{*}{ FLE } & \multirow{5}{*}{0.31} & FLE1 & 0.76 \\
\hline & & & FLE2 & 0.86 \\
\hline & & & FLE3 & 0.76 \\
\hline & & & FLE4 & 0.78 \\
\hline & & & FLE5 & 0.82 \\
\hline & \multirow{3}{*}{ DEL } & \multirow{3}{*}{0.2} & DEL1 & 0.68 \\
\hline & & & DEL2 & 0.81 \\
\hline & & & DEL.3 & 0.73 \\
\hline \multicolumn{2}{|c|}{ Construct $\rightarrow$ Construct } & \multicolumn{2}{|c|}{ Hypothesis } & Load \\
\hline \multirow{2}{*}{\multicolumn{2}{|c|}{$\mathrm{CC} \rightarrow \mathrm{SCl}$}} & \multicolumn{2}{|c|}{ H1 } & 0.56 \\
\hline & & \multirow{2}{*}{\multicolumn{2}{|c|}{$\frac{\mathrm{H} 2}{\mathrm{H} 3}$}} & 0.64 \\
\hline \multicolumn{2}{|c|}{$C C \rightarrow O P$} & & & 0.36 \\
\hline
\end{tabular}

Figure 5.9. Selected SEM data for the SDM

Then, the SEM/SDM flow diagram is created (Step 8). Based on the information collected from the causal diagram and Figure 5.9, the variables (level, flow, auxiliary and parameters) have been defined and the flow diagram has been drawn, as illustrated in Figure 5.10 .

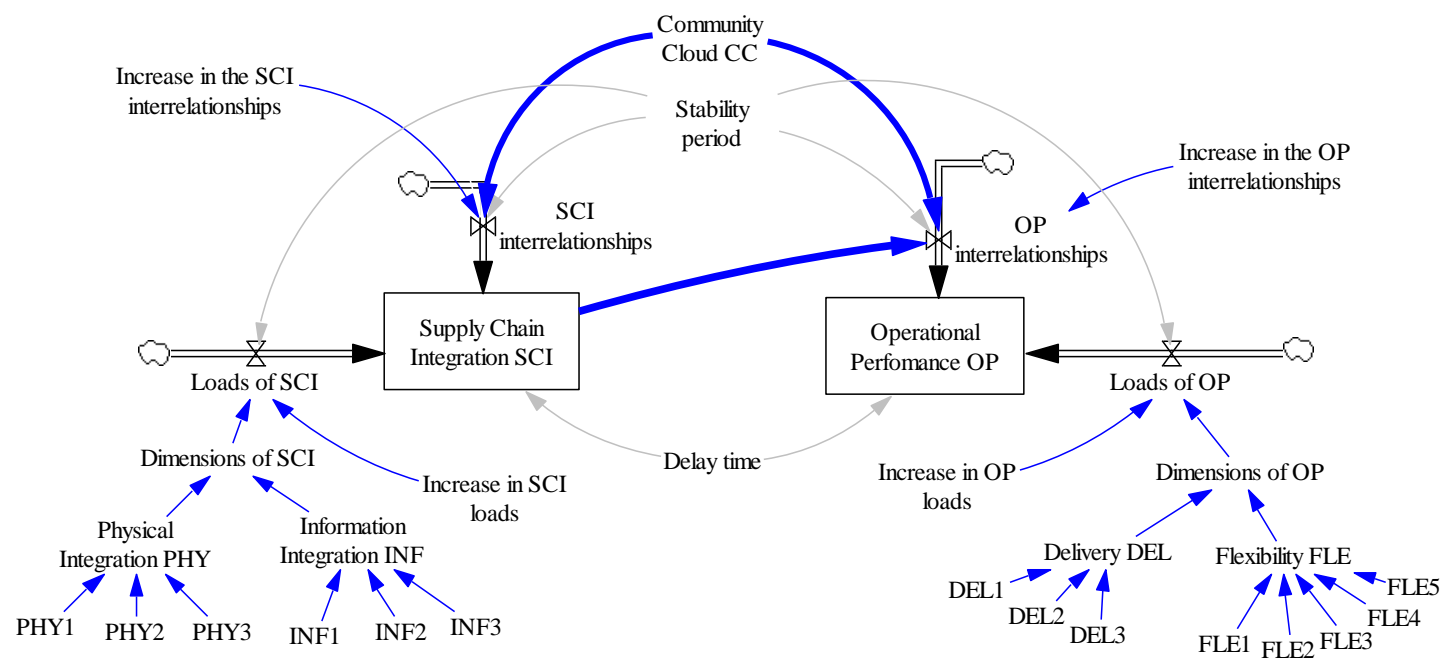

Figure 5.10. Flow diagram of $\mathrm{CC}, \mathrm{SCl}$, and $\mathrm{OP}$

$S C l$ and $O P$ are considered as level variables. The flow variables $S C l$ interrelationships and OP interrelationships are used to "channel" factorial loads from $C C$ to $S C l$, as well as from $C C$ and SCI to OP. Similarly, the flow variables Loads of SCI and Loads of OP 
are used to "channel" the SCI and OP dimensions loads to the correspondent constructs. Dimensions of $S C l$ and Dimensions of $O P$ are auxiliary variables that receive the $P H Y$ and INF and DEL and FLE loads and exert these loads on $S C I$ and $O P$ constructs, respectively. In turn, $P H Y$ and INF and DEL and FLE are auxiliary variables that receive the $S C l$ items load and $O P$ items loads. The parameter $C C$ increases loads on $S C l$ and $\mathrm{OP}$ constructs. The parameters Increase in the $\mathrm{SCl}$ interrelationships and Increase in $\mathrm{OP}$ interrelationships are the loads that affect respectively $\mathrm{SCl}$ and $\mathrm{OP}$. Increase in SCI loads and Increase in SCl loads are parameter that allowing the increase in the Dimensions of $\mathrm{SCl}$ and Dimensions of OP loads that affect $\mathrm{SCl}$ and $\mathrm{OP}$, respectively. The parameters PHY1, PHY2, PHY3, INF1, INF2, INF3 and, DEL1, DEL2, DEL3, FLEX1, FLEX2, FLEX3, FLEX4, FLEX5 are the items loads that affect $S C I$ and $O P$, respectively. Finally, Stability period and Delay time are parameters that allow increasing or reducing the stability time (time without increasing extra loads) and the loads flow time (time required for the constructs loads to affect the constructs levels).

Likewise, the mathematical equations that will compose the flow diagram are formulated (Step VI), as shown in Table 5.4.

Table 5.4. Mathematical equations to $\mathrm{CC}, \mathrm{SCl}$, and $\mathrm{OP}$

\begin{tabular}{|c|c|}
\hline Variable & Formula \\
\hline$S C I$ & $\begin{array}{l}\text { DELAY FIXED (MIN(RANDOM NORMAL ( (Loads of SCI+SCI } \\
\text { interrelationships })^{*} 0.95, \text { (Loads of SCI }+ \text { SCI interrelationships)*1.05, } \\
\text { (Loads of SCI }+S C I \text { interrelationships) }, 0.001,3), 1) \text {, Delay time, } 0.64)\end{array}$ \\
\hline$O P$ & $\begin{array}{l}\text { DELAY FIXED (MIN (RANDOM NORMAL ( (OP interrelationships + Loads of } \\
\text { OP }) * 0.95,(O P \text { interrelationships }+ \text { Loads of OP }) * 1.05, \quad(O P \\
\text { interrelationships }+ \text { Loads of }), 0.001,3), 1), \text { Delay time, } 0.26)\end{array}$ \\
\hline $\begin{array}{l}\text { SCI } \\
\text { interrelationships }\end{array}$ & $\begin{array}{l}\text { IF THEN ELSE }((\text { Time } / \text { Stability period })=I N T E G E R(\text { Time } / \text { Stability } \\
\text { period }),\left(\text { RANDOM NORMAL }\left((\text { Community Cloud CC })^{*} 0.95,(\text { Community }\right.\right. \\
\left.\left.\text { Cloud CC })^{*} 1.05,(\text { Community Cloud CC }), 0.001,3\right)\right){ }^{*} \text { Increase in the SCI } \\
\text { interrelationships }, 0)\end{array}$ \\
\hline $\begin{array}{l}\text { OP } \\
\text { interrelationships }\end{array}$ & 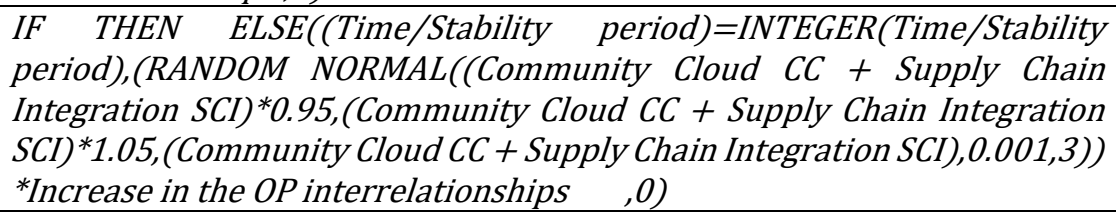 \\
\hline Loads of SCI & $\begin{array}{l}\text { IF } \\
\text { THEN ELSE((Time/Stability period) }=\text { INTEGER(Time/Stability } \\
\text { period),(Dimensions of SCI*Increase in SCI loads),0) }\end{array}$ \\
\hline Loads of $O P$ & $\begin{array}{l}\text { IF THEN ELSE ((Time/Stability period) }=\text { INTEGER(Time/Stability } \\
\text { period),(Dimensions of OP*Increase in OP loads), O) }\end{array}$ \\
\hline Dimensions of SCI & 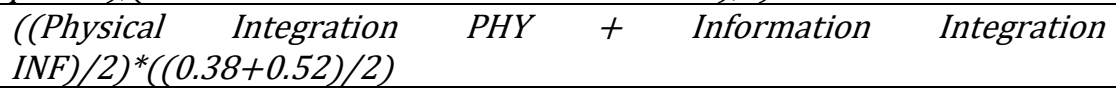 \\
\hline Dimensions of $O P$ & $(($ Delivery DEL + Flexibility FLE $) / 2) *((0.2+0.31) / 2) * 0$ \\
\hline $\begin{array}{l}\text { Physical Integration } \\
\text { PHY }\end{array}$ & $(P H Y 1+P H Y 2+P H Y 3) / 3$ \\
\hline $\begin{array}{l}\text { Information } \\
\text { Integration INF }\end{array}$ & $(I N F 1+I N F 2+I N F 3) / 3$ \\
\hline Flexibility FLE & $(F L E 1+F L E 2+F L E 3+F L E 4+F L E 5) / 5$ \\
\hline Delivery DEL & $(D E L 1+D E L 2+D E L 3) / 3$ \\
\hline
\end{tabular}


SCI has been defined based on SCl interrelationships, Loads of SCI and Delay Time. Similarly, OP has been defined based on OP interrelationships, Loads of OP and Delay Time. The SCl and OP formulas show that, after the time taken for the variables' loads to affect the level of the other variables (Delay time), the cause variables' loads increasing the effect variables' levels. $S C I$ formula shows that the $S C /$ initial level is the factorial load that SCI exert on OP in Time $=0$ (Data from SEM. See Figure 5.9). OP formula shows that the OP initial level is the average of dimensions loads that compose OP constructs Time $=0$ (Data from SEM. See Figure 5.9). SCI interrelationships and OP interrelationships are flow variables defined from the parameters $\mathrm{CC}$, Increase in SCl interrelationships, Increase in OP interrelationships, and Stability period. These equations indicate that after the stability time defined by the model user the SEM/SDM will increase a new load to SCl and OP levels. Loads of SCI and Loads of OP are flow variables defined from the loads average of the Dimensions that compose $S C I$ and $O P$, as well as from Increase in SCI Loads and Increase in OP Loads. The RANDOM NORMAL function has been included as a way of allowing the model to apply random values that vary between $\pm 5 \%$ (so we used the values of 0.95 and 1.05 in that function) of Dimensions loads that compose SCI and OP. Finally, CC, Increase in SCI interrelationships, Increase in OP interrelationships, PHY1, PHY2, PHY3, INF1, INF2, INF3 and DEL1, DEL2, DEL3, FLEX1, FLEX2, FLEX3, FLEX4, FLEX5, are SEM parameters (constant system values), so they have no associated formulas. Their values have been presented in Figure 5.9.

Then, the time horizon of the simulation is defined (Step VII). As in this example we are analysing the impact of $\mathrm{CC}$ on $\mathrm{SCl}$ and $\mathrm{OP}$, an analysis will be performed for the next 18 months ( 80 weeks). It is the average time a company needs to adopt a new Information Technology (McAfee, 2002). Next, the SEM/SDM starting data are determined (Step VII) from the SEM information (Bruque et al., 2016), as detailed below:

- Items of PHY, INF, FLE and DEL: The starting value for the items PHY1, PHY2, PHY3, INF1, INF2, INF3, DEL1, DEL2, DEL3, FLEX1, FLEX2, FLEX3, FLEX4, and FLEX5 are the factorial loads that they exert on PHY and INF dimensions, and on FLE and DEL dimensions. These factorial loads are obtained from SEM Confirmatory Factorial Analysis (see Figure 5.9).

- Increase in SCI loads, Increase in OP loads, Increase in SCl interrelationships and Increase in $O P$ interrelationships: They are the parameters that will allow increasing the Dimensions loads ( $P H Y$ and INF dimensions and FLE and DEL dimensions) on their 
respective constructs $(\mathrm{SCl}$ or $\mathrm{OP})$. The starting data for these variables are defined as the value 0 , and this value can be altered in the scenario formulation stage. For example, if the SEM/SDM user want to increase 0.1 in dimensions loads, Increase in SCI loads and Increase in OP loads value will be 0.1 . These values could be increased/decreased in the scenarios creation stage, as a way to verify the model behaviour when factorial loads are altered.

- Time, Stability period and Delay time. As seen before, the value for Time is 80 weeks. For the first simulation, the Stability period value be equal to Time, which allows the model to be analysed only with data from SEM (current scenario). A Delay Time value equal to two weeks will be adopted, indicating that two simulation periods would be necessary for the cause-variable's loads to affect the effect-variable's levels. Time, Stability period and Delay time can also assume other values in the scenarios that will be simulated, as a way of analysing the time related to the results that will be achieved.

- CC, SCI and OP: the starting values for $\mathrm{CC}$ and $\mathrm{SCl}$ are the factorial loads obtained through the SEM variances and covariances analyses (see construct $\rightarrow$ relationships in Figure 5.9). The starting data for OP is the average of OP items loads in Time $=0$.

-SCI interrelationships, OP interrelationships, Loads of SCI and Loads of OP: These flow variables do not have pre-defined starting values, since their values depend on the SEM/SDM parameters showed in Figure 5.9.

Finally, the flow diagram developed by SEM/SDM has been analysed, confirming that it is aligned with the information provided by SEM. The most important SEM variables are represented in the causal diagram and the cause-effect relationship between them is in accordance with the SEM information. It has also been verified that the mathematical equations and the starting data are correctly formulated and the relationship between variables is in accordance with the SEM information.

\section{Stage 4. Performance and evaluation}

To test the SEM/SDM performance (Step 11) and check its validity and quality (Step 12), the SEM/SDM model is first run using the starting data. This first test presents a positive result, since the model is executed correctly, without unit, development or structural errors. It shows that the SEM/SDM had good results against the Limits Adequacy, Structure check, Dimensional consistency, and Checking Parameters tests (Sterman, 2000). In addition, for this first test, the SEM/SDM model has been performed with only the data obtained from SEM (without adding extra loads to the analysis variables). For this reason, the SEM/SDM should show a stable behaviour (without increasing loads or 
levels) during the whole simulation period. In other words, the variable levels in Time $=80$ should be similar to the variable levels at the beginning of the simulation (Time=0). In the real world, this means that a company would not increase the implementation levels of the items or dimensions that compose the analysed constructs. This shows that the model has performed well against the abnormal behaviour test (Sterman, 2000). The results are shown in Figure 5.11 and confirm the expected stability of the SEM/SDM. SCI and $O P$ have a constant blue line that represents their levels throughout the simulation. In $S C l$, the blue line represents the factorial load it exert on $O P$ and the red line represents the loads it receives from $S C l$ items. In $O P$, the red line represents the factorial load it receives from $S C l$, the blue line represents the factorial load it receives from $C C$, and the green line represent the factorial load it receives from $O P$ items.

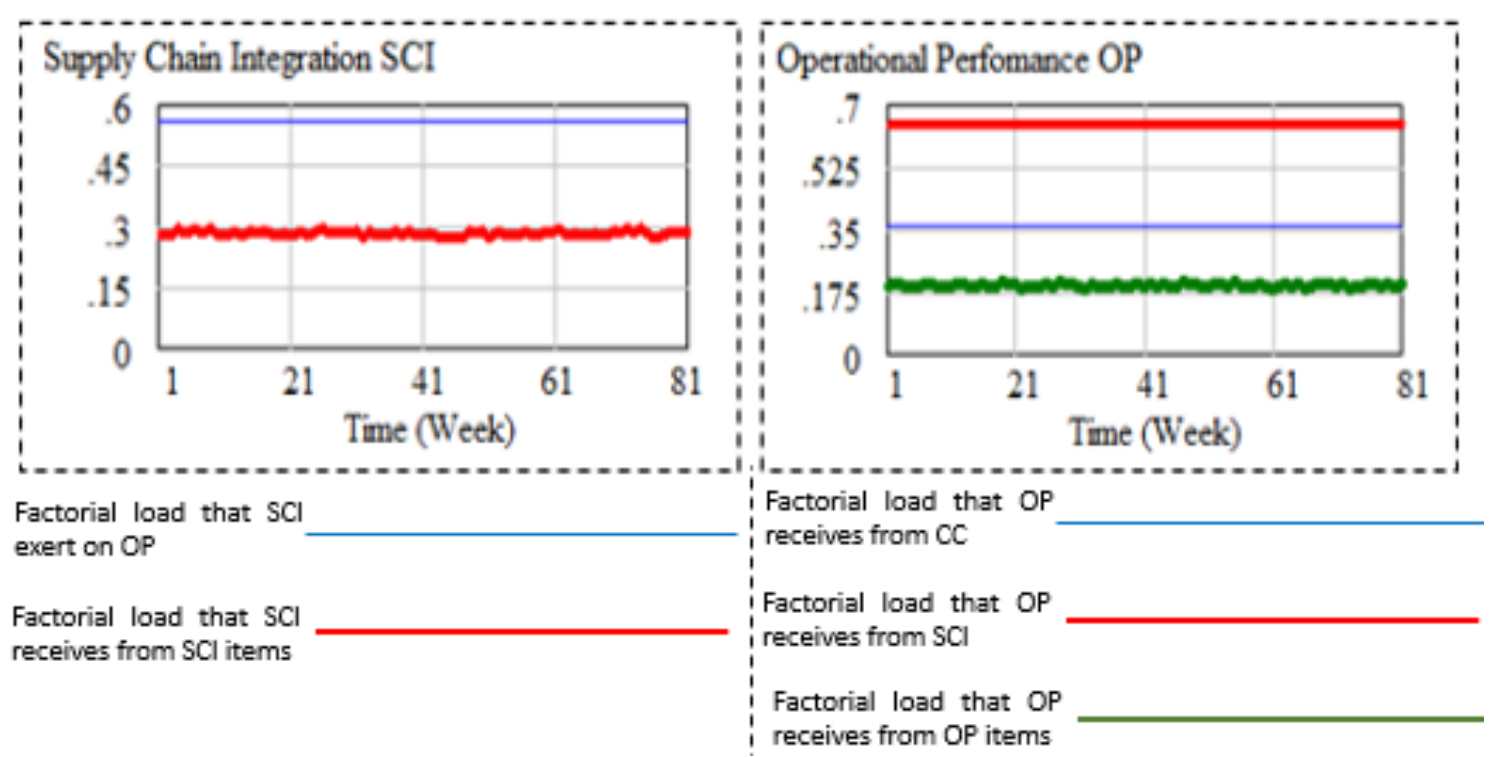

Figure 5.11. SEM/SDM performance for SCI and OP

In addition, extreme conditions test has been performed. In this test, the SEM/SDM robustness is checked through the use of extreme values (very high) for the variable loads. This will allow analysing if the model presents results that correspond to the abrupt variations of the input data. To this end, we have incremented $1000 \%$ in the values of the variables that affect the $S C l$ and $O P$ levels. Figure 5.12 illustrates some of the tests performed, showing that the model is robust even in extreme conditions. 

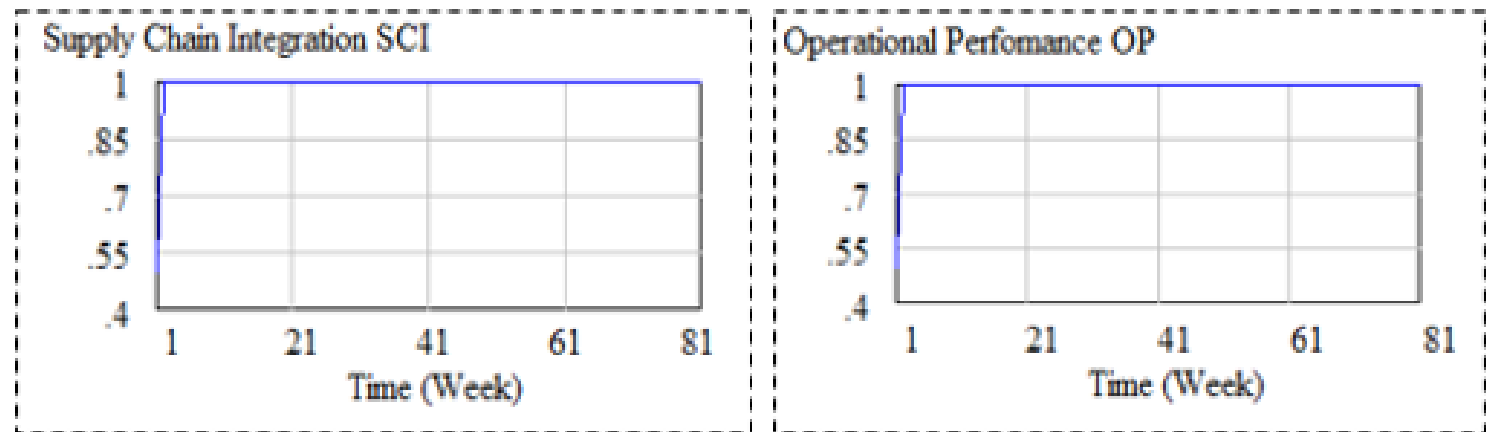

Robust increments on SCI and OP over time

Figure 5.12. Extreme condition test for $\mathrm{SCl}$ and $\mathrm{OP}$

Finally, the SEM/SDM sensitivity test is performed. For this purpose, the Monte Carlo simulation has been used (Figure 5.13). Monte Carlo simulation is a statistical methodology based on a large amount of random sampling to achieve results close to real results, allowing a sufficiently large number of tests to be performed in order to have more accurate results (Bois and Maszle, 1997). Five hundred simulations have been performed for the sensitivity analysis and the values could vary between the minimum and maximum values with a uniform random distribution of the probability. The model sensitivity related to Increase in SCl and SCI relationship (Figure 5.13a), Increase in SCI Loads and SCI (Figure 5.13b), and Increase OP interrelationships and OP (Figure 13c) have been tested. Thus, Figures 5.13a, 5.13b and 5.13c show the Monte Carlo simulations that have been carried out to test the SEM/SDM sensitivity, graphically representing the temporal evolution of a combination of variables during a given period (Bois and Maszle, 1997). That is to say, the possible increases of loads caused by the causal variables on the effect variables ( $Y$ axis) along 80 weeks ( $X$ axis). The red line shows the starting scenario (current) for each combination of causal variables analysed and their impact on the effect variable. The SEM/SDM behaviour throughout the 80 weeks of simulation, represented in Figures 5.13a, 5.13b and 5.13c, shows that the level of the effect variables (SCI in Figure 5.13a, SCI in Figure 5.13b, and OP in Figure 5.13c) are sensitive to variations in causal variable loads (CC level in Figure 5.13a, SCl items in Figure 5.13b and SCI level in Figure 5.13c). That is, variations in the causal variable loads proportionally affect the effect variable levels. Results, therefore, indicate that the SEM/SDM is sensitive to variation in causal variables. 


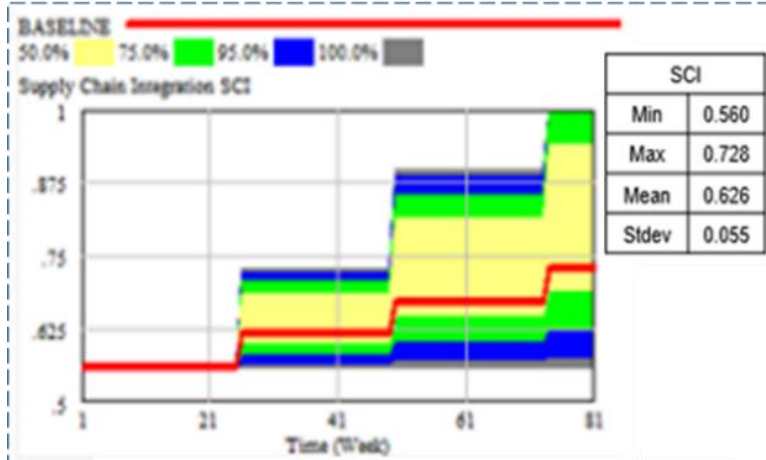

(a) Applying MonteCarlo to $\mathrm{CC}-\mathrm{SCl}$ interrelationship

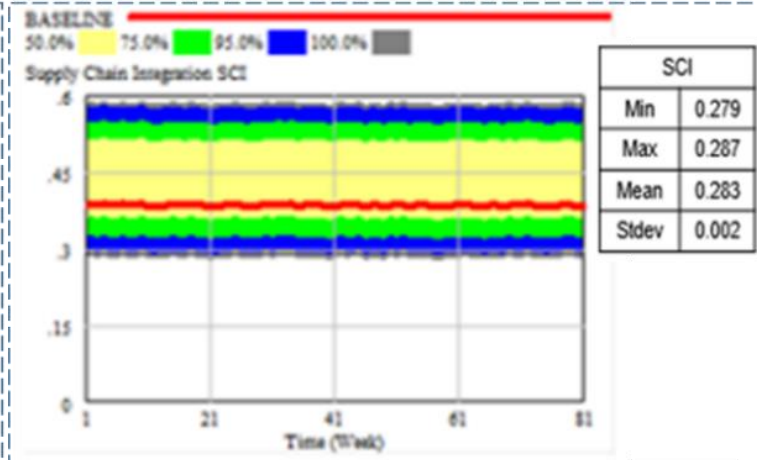

(b) Applying MonteCarlo to $\mathrm{SCl}$ items-SCl interrelationship

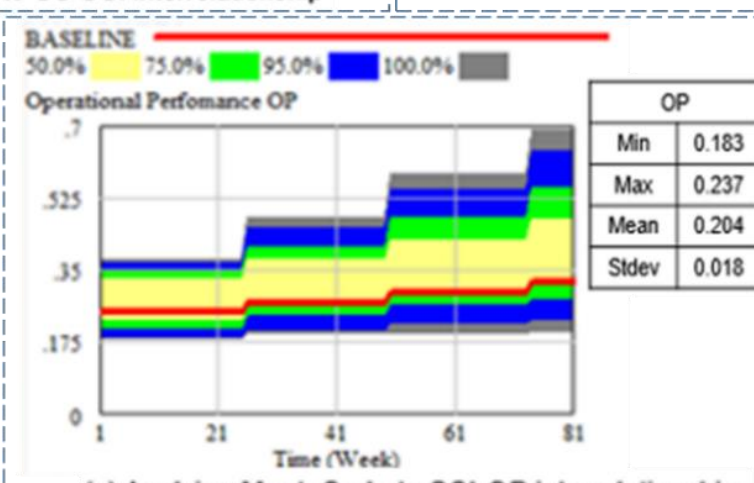

(c) Applying MonteCarlo to SCl-OP interrelationship

Figure 5.13. Sensitive test for SCl and OP

Furthermore, we are going to use Figure 5.13 to explain how the confidence limits represented in the Monte Carlo Simulation graphs should be interpreted. The distribution of the values that the causal variables exert on the effect variable, during any period of time, is shown referring to the confidence limits: the yellow strip represents the confidence limit of $50 \%$, the green one of $75 \%$, the blue one of $95 \%$ and the grey one of $100 \%$. To exemplify, we take as a base the relationship between SCI and OP (Figure 5.13c): the yellow strip shows that there is a $50 \%$ probability that, at the end of the simulation period, $\mathrm{SCl}$ exerts a load that varies between 0.30 and 0.46 on OP. The green strip shows that there is a $75 \%$ probability that $\mathrm{SCl}$ will exert a load that varies between 0.26 and 0.55 over OP at the end of the simulation. Similarly, the blue strip shows that there is a $95 \%$ probability that the load that SCI exerts on OP at the end of the simulation period varies between 0.22 and 0.60 . And, finally, the grey lower and upper limits show that there is a $100 \%$ probability that, at the end of the simulation period, $S C l$ will exert a load on OP that varies between 0.18 and 0.7 .

After checks with favourable results (good results of the SEM/SDM model in terms of structure, behaviour and sensitivity), it can be stated that this model is valid and can be applied for the purpose of this chapter. 


\section{Stage 5. Exploitation}

In the last stage of this methodology, first is necessary to specify the scenarios for which the researchers want to know the results (Step 13) as a way of analysing the development of the system under consideration in the future. As defined in Stage 1, the objective of this simulation is to know how a company could achieve a 0.2 increase in $S C I$ and $O P$ levels over 18 months ( 80 weeks). Five scenarios have been created for this proposal, where we progressively increased by 0.05 the factorial loads of all the SEM/SDM relationships (Table 5.5). That is, in Scenario 1, we have increased by 0.05 in the factorial loads and, in Scenario 2, 0.10. In scenario 3, 0.15 in factorial loads has been increased and, in scenario 4, 0.20. Finally, in scenario 5, 0.25 has been increased in the factorial loads of the model relationships. Next, the scenarios simulations must be performed (Step 14) and the results must be analysed (Step 15).

Table 5.5. Simulations results for $\mathrm{CC}, \mathrm{SCl}$ and $\mathrm{OP}$

\begin{tabular}{|c|c|c|c|c|c|c|c|}
\hline \multirow{2}{*}{} & \multicolumn{7}{|c|}{ Scenarios } \\
\cline { 2 - 8 } & $\begin{array}{c}\text { Current } \\
\text { (SEM data) }\end{array}$ & $\mathbf{1}$ & $\mathbf{2}$ & $\mathbf{3}$ & $\mathbf{4}$ & $\mathbf{5}$ \\
\hline \multirow{4}{*}{ Relationships } & $\begin{array}{c}\text { SCl dimensions } \rightarrow \\
\text { SCl }\end{array}$ & 0 & +.05 & +.10 & +.15 & +.20 & +.25 \\
\cline { 2 - 8 } & $\begin{array}{c}\text { OP dimensions } \\
\rightarrow \text { OP }\end{array}$ & 0 & +.05 & +.10 & +.15 & +.20 & +.25 \\
\cline { 2 - 8 } & $\mathrm{CC} \rightarrow$ SCl & 0 & +.05 & +.10 & +.15 & +.20 & +.25 \\
\cline { 2 - 8 } & SCl $\rightarrow$ OP & 0 & +.05 & +.10 & +.15 & +.20 & +.25 \\
\cline { 2 - 8 } & $\mathrm{CC} \rightarrow$ OP & 0 & +.05 & +.10 & +.15 & +.20 & +.25 \\
\hline \multirow{4}{*}{ Results } & SCl & .64 & .677 & .714 & .751 & .787 & .824 \\
\cline { 2 - 8 } & (SCl increment) & $\mathbf{0}$ & $\mathbf{+ . 0 3 7}$ & $\mathbf{+ . 0 7 4}$ & $\mathbf{+ . 1 1 1}$ & $\mathbf{+ . 1 4 7}$ & $\mathbf{+ . 1 8 4}$ \\
\cline { 2 - 8 } & OP & .26 & .303 & .345 & .388 & .432 & .478 \\
\cline { 2 - 8 } & (OP increment) & $\mathbf{0}$ & $\mathbf{+ . 0 4 3}$ & $\mathbf{+ . 0 8 5}$ & $\mathbf{+ . 1 2 8}$ & $\mathbf{+ . 1 7 2}$ & $\mathbf{+ . 2 1 8}$ \\
\hline
\end{tabular}

Figure 5.14a shows that none of the proposed scenarios has been able to achieve the objective established for SCl. However, Scenario 5 is very close to this objective (which is the 0.2 increase in SCl level). This means that if a company wants to increase the $\mathrm{SCl}$ level by almost 0.2 , it would need to increase the factorial loads of $\mathrm{SCl}$ dimensions and $C C$ variable by 0.25 . Thus, the configurations used in the simulation carried out in Scenario 5 are the most indicated for a company that intends to increase its SCl level by 0.2 at the end of 80 weeks. Likewise, Figure $5.14 \mathrm{~b}$ shows that a company to reach the 0.20 increase in $O P$ level could use the configurations of Scenario 5 . Scenario 4 configurations would also lead to an $O P$ level very close to the initial objective of the simulation. This indicates that an increase of $0.20 \sim 0.25$ in factor loads of $C C, S C I$ dimensions and $O P$ dimensions could lead the company to reach the intended $O P$ level. 


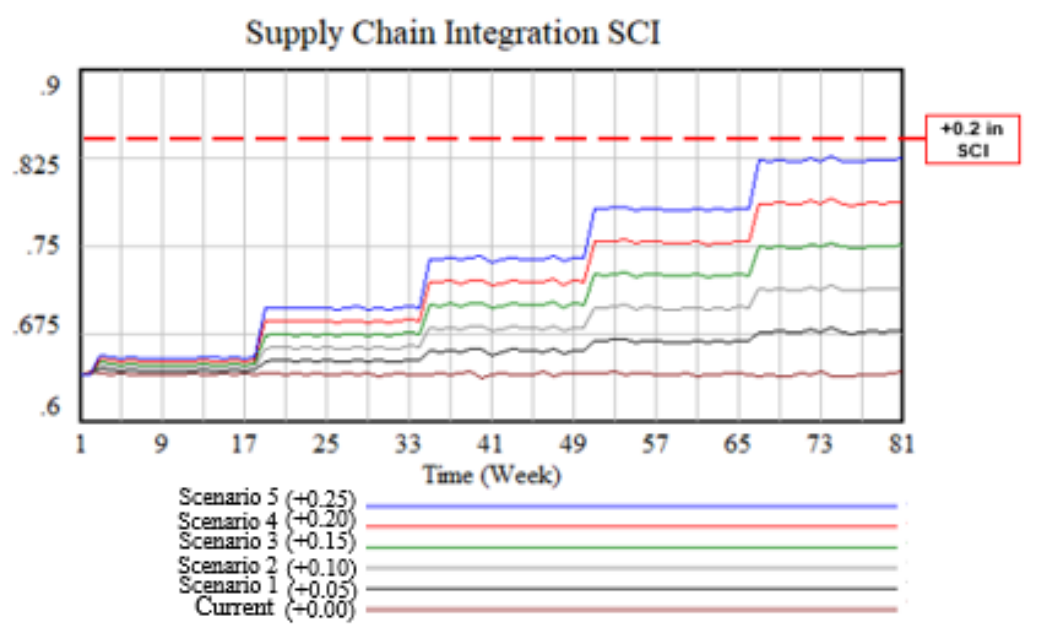

(a) SCl level

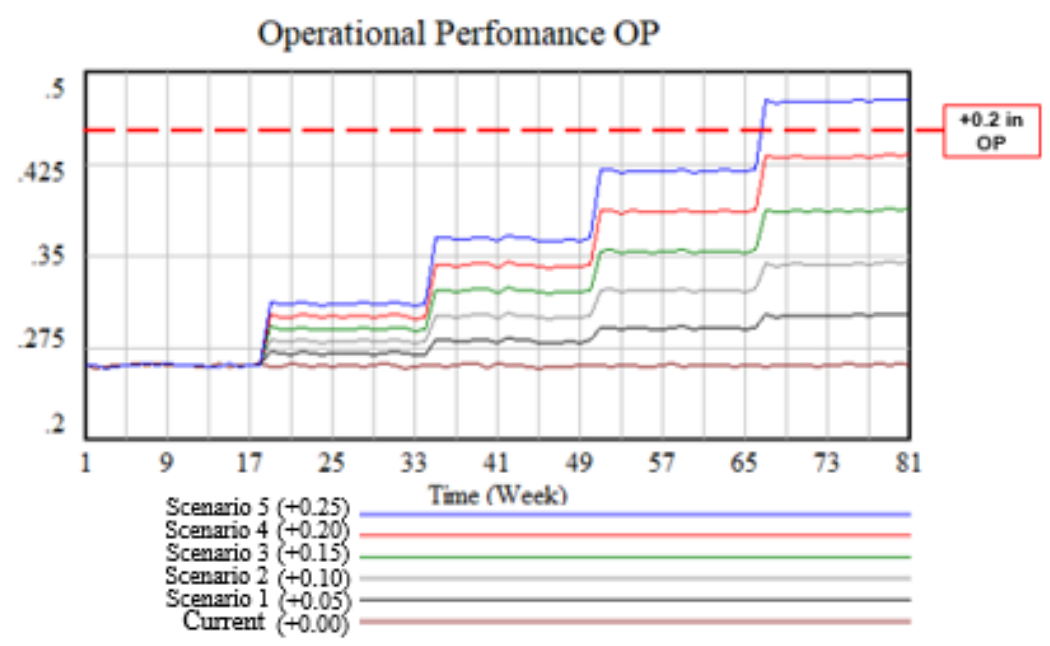

(b) OP level

Figure 5.14. SCl an OP levels over 80 weeks

It is necessary to understand what a 0.2 increase in factor loads of $S C l$ and $O P$ levels represents in practice and how companies could interpret this result to support their decision making. For this point, we suggest the use of the $\mathrm{SCl}$ and $\mathrm{OP}$ measurement scales published in the previous literature, in which the SCI items (Rai et al., 2006) and OP items (Flynn et al., 2010) are shown. Through these measurement scales, companies would be aware of the elements used to measure $\mathrm{SCl}$ and $\mathrm{OP}$, becoming aware of those they already have implemented and those that could be implemented to raise SCI and OP levels in their Supply Chains. Based on Moyano Rai et al. (2006) and Flynn et al. (2010) scales, a fictitious checklist has been made to exemplify how some measurement scales could be used by companies to identify the opportunities of improving they $\mathrm{SCl}$ and $\mathrm{OP}$ levels. From these scale, a company could make a checklist to verify the $\mathrm{SCI}$ and $\mathrm{OP}$ items that have not been implemented and verify the weight 
that each item placed on the SCI and OP constructs. We have checked with a " $V$ " the items that a company would have implemented and with an " $X$ " those that have not (Table 5.6). The fictitious situation represented in Table 5.6 shows that a company could increase its $\mathrm{SCl}$ level through the implementation of PHY2 and INF3, which together weigh $25 \%$ over SCl. Similarly, the company could implement FLE3 and DEL1 to increase $O P$ levels.

Table 5.6. Check list of SCI and OP measurement model

\begin{tabular}{|c|c|c|c|c|c|c|c|}
\hline Construct & Dimensions & Items & & Load & Sum & Weight & Check \\
\hline \multirow{6}{*}{$\mathrm{SCl}$} & \multirow{3}{*}{$\begin{array}{l}\text { Physical flow } \\
\text { integration }\end{array}$} & $\begin{array}{l}\text { Inventory holdings } \quad \text { are } \\
\text { minimized across the supply } \\
\text { chain }\end{array}$ & PHY1 & 0.5 & \multirow{6}{*}{3.78} & $13 \%$ & $\boldsymbol{V}$ \\
\hline & & $\begin{array}{l}\text { Suppliers and logistics } \\
\text { partners deliver products and } \\
\text { materials just-in-time }\end{array}$ & PHY2 & 0.5 & & $13 \%$ & $\boldsymbol{x}$ \\
\hline & & $\begin{array}{l}\text { Distribution networks are } \\
\text { configured to minimize total } \\
\text { supply chain-wide inventory } \\
\text { costs }\end{array}$ & PHY3 & 0.72 & & $19 \%$ & $\boldsymbol{V}$ \\
\hline & \multirow{3}{*}{$\begin{array}{l}\text { Informational } \\
\text { flow } \\
\text { integration }\end{array}$} & $\begin{array}{l}\text { Production and delivery } \\
\text { schedules are shared across } \\
\text { the supply chain }\end{array}$ & INF1 & 0.65 & & $17 \%$ & $\boldsymbol{V}$ \\
\hline & & $\begin{array}{l}\text { Performance metrics are } \\
\text { shared across the supply } \\
\text { chain }\end{array}$ & INF2 & 0.83 & & $22 \%$ & $\boldsymbol{V}$ \\
\hline & & $\begin{array}{l}\text { Supply chain members } \\
\text { collaborate in arriving at } \\
\text { demand forecasts }\end{array}$ & INF3 & 0.58 & & $15 \%$ & $x$ \\
\hline \multirow{8}{*}{ OP } & \multirow{5}{*}{ Flexibility } & $\begin{array}{l}\text { Our company can quickly } \\
\text { modify products to meet our } \\
\text { major } \\
\text { requirements. }\end{array}$ & FLE1 & 0.76 & \multirow{8}{*}{6.2} & $12 \%$ & $\boldsymbol{V}$ \\
\hline & & $\begin{array}{l}\text { Our company can quickly } \\
\text { modify products in response to } \\
\text { the innovations of our main } \\
\text { competitors }\end{array}$ & FLE2 & 0.86 & & $14 \%$ & $\boldsymbol{V}$ \\
\hline & & $\begin{array}{l}\text { Our company can quickly } \\
\text { launch new products into the } \\
\text { market }\end{array}$ & FLE3 & 0.76 & & $12 \%$ & $X$ \\
\hline & & $\begin{array}{l}\text { Our company can quickly } \\
\text { respond to changes in market } \\
\text { demand. }\end{array}$ & FLE4 & 0.78 & & $13 \%$ & $\boldsymbol{V}$ \\
\hline & & $\begin{array}{l}\text { Our company can quickly } \\
\text { respond to changes in } \\
\text { competitors }\end{array}$ & FLE & 0.82 & & $13 \%$ & $\boldsymbol{V}$ \\
\hline & \multirow{3}{*}{ Deliveries } & $\begin{array}{l}\text { Our company has an } \\
\text { outstanding on-time delivery } \\
\text { record to our major customer }\end{array}$ & DEL1 & 0.68 & & $11 \%$ & $X$ \\
\hline & & $\begin{array}{l}\text { The lead time for fulfilling } \\
\text { customer orders is short }\end{array}$ & DEL2 & 0.81 & & $13 \%$ & $V$ \\
\hline & & $\begin{array}{l}\text { Our company provides a high } \\
\text { level of customer service to } \\
\text { our major customer }\end{array}$ & DEL3 & 0.73 & & $12 \%$ & $V$ \\
\hline
\end{tabular}

Furthermore, it is necessary to understand how the company could increase its $C C$ levelwhich represents in practice how the company could interpret the SEM/SDM result to support its decision making and improve its $S C /$ level. For this point, we have suggest 
the use of CC definition (Mell and Grance, 2011). Mell and Grance (2011) have defined $C C$ as the degree of implementation in a company of cloud computing gathering a variety of heterogeneous resources with an operational aim share these resources with other companies we have strong ties to in such a way that these companies usually also provide resources to the network. A company could be analyse in separate bits in the form of phrase extracts, as shown in Table 5.7. Through this definition, which is widely accepted by Cloud Computing scholars, the company will be able to identify the Cloud implementation opportunities and its supply chain flows that could be integrated through such technology. To do so, we have checked with a " $V$ " the items that a company would have implemented and with an "X" those that have not. It is observed that the phrase "...gathering a variety of heterogeneous resources with an operational aim" is the one that has the lowest level of agreement by the company. Thus, the opportunity to increase the Cloud implementation level could be associated with the integration, through Cloud, of a wider range of operational resources related to logistics activities along its Supply Chain. The fictitious situation represented in Table 5.7 shows that a company could improve its CC level in all of the three extracts, especially in the third part of the definition.

Table 5.7. Checklist of CC

\begin{tabular}{|l|l|l|l|l|l|l|l|l|l|l|l|}
\hline & $\mathbf{0}$ & $\mathbf{1}$ & $\mathbf{2}$ & $\mathbf{3}$ & $\mathbf{4}$ & $\mathbf{5}$ & $\mathbf{6}$ & $\mathbf{7}$ & $\mathbf{8}$ & $\mathbf{9}$ & $\mathbf{1 0}$ \\
\hline $\begin{array}{l}\text { "...gathering a variety of heterogeneous } \\
\text { resources with an operational aim" }\end{array}$ & & & $V$ & & & & & & & \\
\hline $\begin{array}{l}\text { "share these resources with other } \\
\text { companies we have strong ties" }\end{array}$ & & & & & & & $V$ & & & & \\
\hline $\begin{array}{l}\text { "in such a way that these companies usually } \\
\text { also provide resources to the network." }\end{array}$ & & & & & & & & $V$ & & \\
\hline
\end{tabular}

\subsubsection{APPLICATION TWO: INFORMATION TECHNOLOGIES INTEGRATION, LEAN} /JUST-IN-TIME AND LEAD-TIME

Currently, there is consensus within the scientific community on the role of Information Technologies as a source of competitive advantage. This is due to the capacity of Information Technologies to process and transmit information needed for more effective decision-making (Liu et al., 2016). Some literature findings emphasize that there is a positive relationship between IT adoption and Supply Chain Management (MoyanoFuentes et al., 2012). It can be related to the fact that the Information Technologies use represents a fundamental role to allow a solid integration of the physical, informational and financial flows along the supply chain (Rai et al., 2006).

Companies are adopting the Information Technologies in their business processes and in all its functional areas, including Supply Chain Management. In this context, the 
widespread use of management philosophies such as Lean Production can be understood. Womack et al. (1990) define Lean Production as a systematic approach to the identification and elimination of waste-low or nil value-added activities through continuous improvement. The underlying principles and practices of Lean Production and its effects on Supply Chain Management have been extensively studied in recent decades and there is growing interest among researchers in this area (Shah and Ward, 2003, Cagliano et al., 2006, Moyano-Fuentes et al., 2012). Just in time is a Lean practice of keeping inventories at the lowest possible level where suppliers deliver just what they need at the right time to complete the production process (Qureshi et al., 2013).

Lead-time can be defined as the time between an order is received from a customer to the time it is delivered to a customer (Treville et al., 2004). Lead-Time can be essential for business success, since its reduction generates rapidity to manufacture the products and achieve an improvement in the service level (Ouyang et al., 2007).

The relationships between these four constructs (Internal IT, External IT, Just in Time and Lead Time) have been analysed in the literature using SEM (Ward and Zhou, 2006). Thus, the application to be carried out below is based on the study by Ward and Zhou (2006), who establish that there is a positive relationship between Internal and External IT, Just in Time and Lead Time.

In the following, the five stages of the SEM/SDM methodology are applied.

\section{Stage 1. Definition of the problem or objective}

First, the data source to be used in the SEM/SDM model is defined (Step 1). In this SEM/SDM application, the paper "Impact of Information Technology Integration and Lean/Just-In-Time Practices on Lead-Time Performance" (Ward and Zhou, 2006) has been used as a secondary source. In the referred paper, the SEM methodology is used to analyse the effects of Information Technology Integration and Lean/Just-In-Time Practices on Lead-Time Performance. The referred paper has been chosen to illustrate the proposed methodology since it analyses the relationship between important variables related to Supply Chain Management. In addition, it addresses a relatively small number of variables, which can simplify the comprehension of the proposed methodology application. It also presents acceptable factorial loads (greater than 0.5) among the measurement model items, which is fundamental for the analysis carried out in this work. Next, the information related to the SEM/SDM problem/objective must be reviewed and understood (Step 2). The authors of the paper used as a secondary data source have enunciated and analysed six hypotheses. From a static perspective (SEM), Ward y Zhou 
(2006) state that Lean/Just-In-Time practices (JIT) exerts a positive impact on LeadTime reduction (LEAD) (Hypothesis $\mathrm{H} 1$ ) and demonstrate a positive relationship between Internal Information Technology Integration (INTERNAL) and External Information Technology Integration (EXTERNAL) (Hypothesis H4) (Table 5.8). The authors also proved that INTERNAL exerts a positive impact on JIT, as well as EXTERNAL also exerts a positive impact on Lean/Just-In-Time practices. Nevertheless, the relationship between INTERNAL and LEAD (Hypothesis H2) and the relationship between EXTERNAL and LEAD (Hypothesis $\mathrm{H} 3$ ) have been rejected by the authors. Then $\mathrm{H} 1, \mathrm{H} 4, \mathrm{H} 5$ and $\mathrm{H} 6$ have been confirmed, while $\mathrm{H} 2$ and $\mathrm{H} 3$ have been rejected.

Likewise, the system to be simulated must be described (Step 3). The results of the SEM analysis that relates INTERNAL, EXTERNAL, JIT, and LEAD (Ward and Zhou, 2006) have been chosen as the SEM/SDM variables to be used in this application. The referred paper show that the higher the INTERNAL level, the higher the EXTERNAL level (and vice versa). It is also observed that the higher both INTERNAL and EXTERNAL, the higher JIT implementation level. Likewise, the higher JIT level is related to a reduction in LEAD level.

In this sense, the objective of the SEM/SDM that will be developed and performed is to analyse the interrelationships of INTERNAL, EXTERNAL, JIT and LEAD in a time horizon. More specifically, we want to know how a company could increase a factorial load of 0.2 on JIT level and reducing $10 \%$ of LEAD over 18 months ( 80 weeks). For this purpose, a "what if" analysis will be performed as a way of verifying how increases in the INTERNAL and EXTERNAL loads would affect JIT levels, as well as analyse the impacts of increased JIT loads on the reduction of LEAD levels.

\section{Stage 2: Conceptualisation}

The qualitative data from SEM for the SDM construction would be identified and defined (Step 4) and the SEM cause-effect relationships to be applied in the SDM it is collected (Step 5). The qualitative relationships obtained from SEM is presented in Table 5.8. It is important to note that $\mathrm{H} 2$ and $\mathrm{H} 3$ will not be included in this SEM/SDM analysis, as the authors have rejected them (as the factor loads between variables are not significant). 
Table 5.8. The SEM qualitative relationships (Ward and Zhou, 2006)

\begin{tabular}{|c|c|c|c|}
\hline \multicolumn{2}{|c|}{ Tested Hypothesis } & Relationship & $\begin{array}{c}\text { Will it be used in } \\
\text { the SEM/SDM? }\end{array}$ \\
\hline $\mathrm{H} 1$ & JIT $\rightarrow \mathrm{LEAD}$ & Positive and significant & Yes \\
\hline $\mathrm{H} 2$ & INTERNAL $\rightarrow$ LEAD & Positive and not significant & No \\
\hline $\mathrm{H} 3$ & EXTERNAL $\rightarrow$ LEAD & Positive and not significant & No \\
\hline $\mathrm{H} 4$ & INTERNAL $\leftrightarrow$ EXTERNAL & Positive and significant & Yes \\
\hline $\mathrm{H} 5$ & INTERNAL $\rightarrow$ JIT & Positive and significant & Yes \\
\hline $\mathrm{H} 6$ & EXTERNAL $\rightarrow$ JIT & Positive and significant & Yes \\
\hline
\end{tabular}

Then, the SEM/SDM causal diagram is created (Step 6). The cause-effects relationships between the SEM structural model variables are graphically represented in Figure 5.15, which the qualitative relationships between INTERNAL, EXTERNAL, JIT and LEAD is showed.

SEM SDM

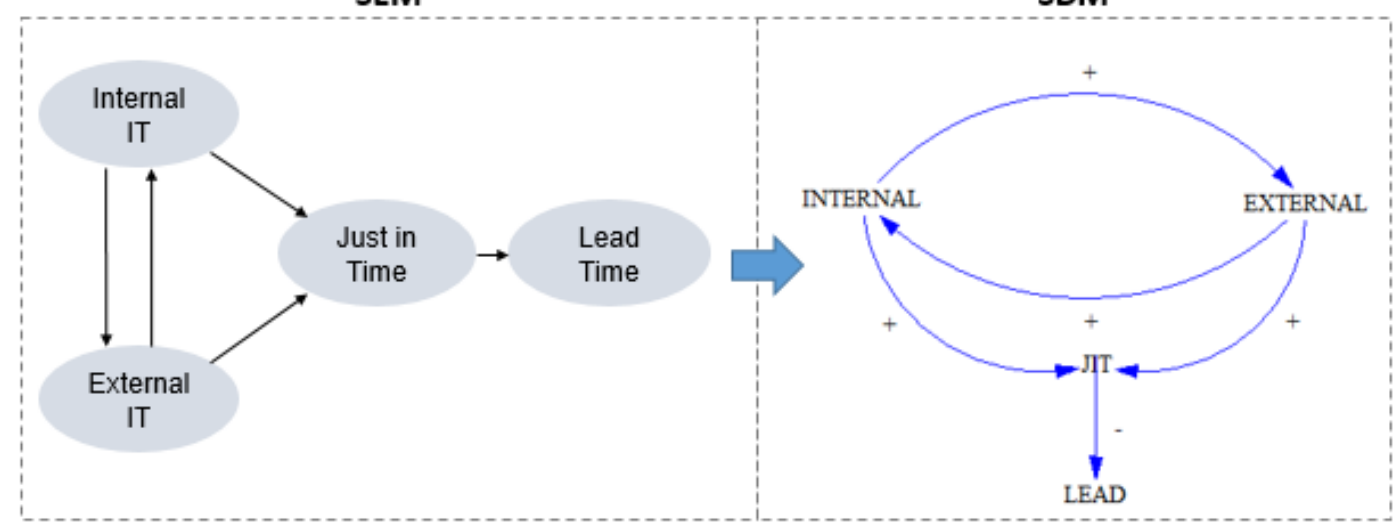

Figure 5.15. Causal diagram of internal and external IT, Lean/JIT, and Lead-time

Finally, the causal diagram developed by SEM/SDM has been analysed, confirming that it is aligned with the information provided by SEM. The most important SEM variables are represented in the causal diagram and the cause-effect relationship between them is in accordance with the SEM information.

\section{Stage 3: Formalisation}

The SEM quantitative data is collected (Step 7). Data of the measurement model (items factorial loads) and the structural model (constructs factorial) have been selected. Figure 5.16 specifies how the SEM quantitative data are selected for use in the SDM. It shows the data referring to the relationships between SEM items and constructs and the factorial load selection to be used in SEM/SDM. 


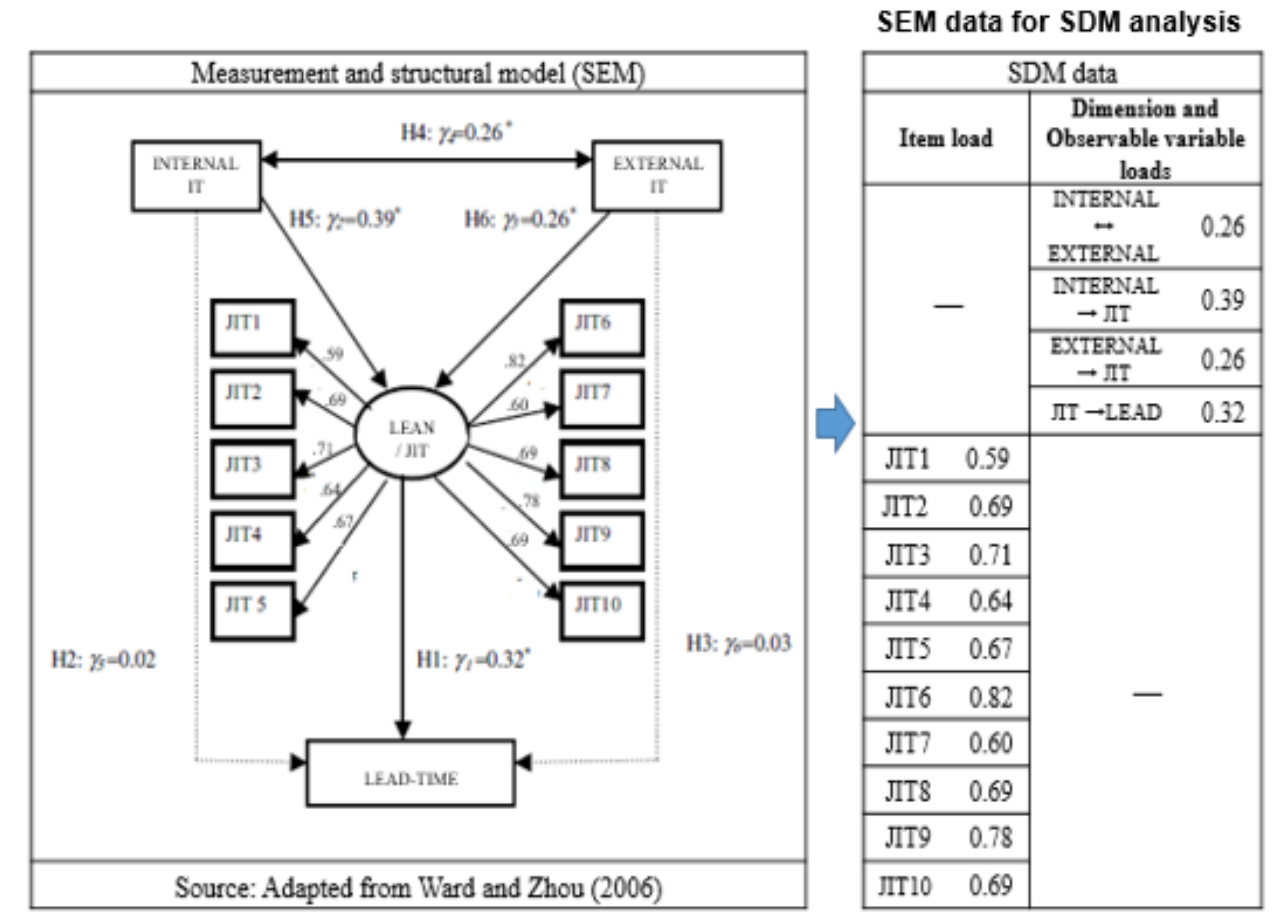

Figure 5.16. Selected SEM data for the SDM

Then, the SEM/SDM flow diagram is created (Step 8). Based on the causal diagram and the data collected in Figure 5.16, the variables (level, flow and parameters) have been defined and the flow diagram has been drawn, as illustrated in Figure 5.17.

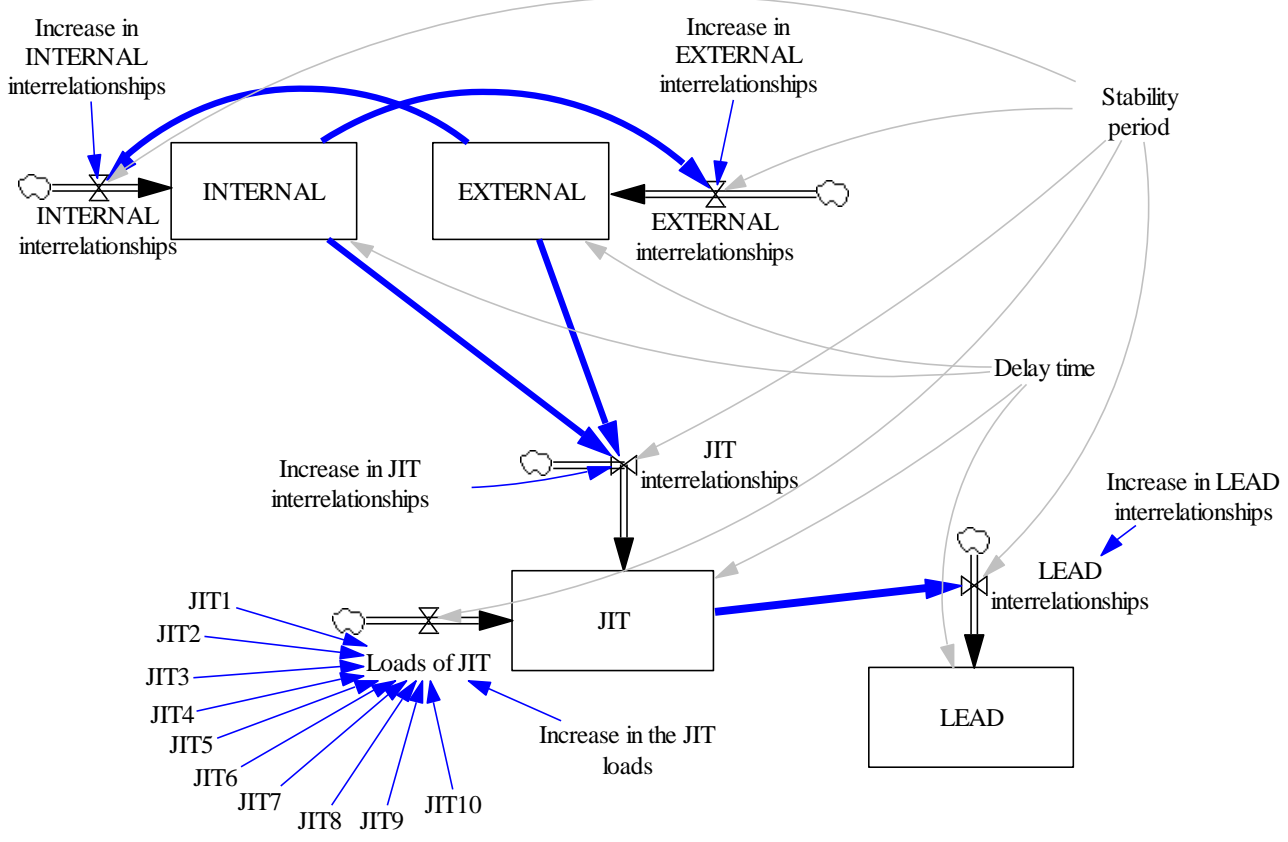

Figure 5.17. Flow diagram of INTERNAL, EXTERNAL, JIT and LEAD 
INTERNAL, EXTERNAL, JIT and LEAD are considered as level variables (structural model variables in SEM). These variables "receive" or "accumulate" the variables loads. The flow variables INTERNAL interrelationships, EXTERNAL interrelationships, JIT interrelationships and $\angle E A D$ interrelationships are used to "channel" the parameters loads to INTERNAL, EXTERNAL, JIT and LEAD. The parameters Increase in INTERNAL interrelationships, Increase in EXTERNAL interrelationships, Increase in JIT interrelationships and Increase in LEAD interrelationships allow the SEM/SDM user to increase factorial loads to INTERNAL, EXTERNAL, JIT and LEAD, respectively. Increase in the JIT loads is a parameter that allowing the SEM/SDM user to increase in JIT items loads in JIT. The parameters JIT1, JIT2, JIT3, JIT4, JIT5, JIT6, JIT7, JIT8, JIT9 and JIT10 are the items loads that affect JIT. Finally, Stability period and Delay time are parameters that allow increasing or reducing the stability time (time without increasing extra loads) and the loads flow time (time required for the constructs loads to affect the constructs levels).Likewise, the mathematical equations that will compose the flow diagram are formulated (Step VI), as shown in Table 5.9.

Table 5.9. Mathematical equations to INTERNAL, EXTERNAL, JIT and LEAD

\begin{tabular}{|c|c|}
\hline Variable & Formula \\
\hline INTERNAL & $\begin{array}{l}\text { DELAY FIXED (MIN(RANDOM NORMAL( (INTERNAL interrelationships)*0.95, } \\
\text { (INTERNAL interrelationships)*1.05, (INTERNAL interrelationships), 0.001, } \\
\text { 3),1), Delay time, 0.39) }\end{array}$ \\
\hline EXTERNAL & $\begin{array}{l}\text { DELAY FIXED (MIN(RANDOM NORMAL( (EXTERNAL interrelationships)*0.95, } \\
\text { (EXTERNAL interrelationships )*1.05, (EXTERNAL interrelationships) , 0.001 , } 3 \\
\text { ),1),Delay time, 0.26) }\end{array}$ \\
\hline$J I T$ & $\begin{array}{l}\text { DELAY FIXED (MIN(RANDOM NORMAL( (Loads of JIT+JIT interrelationships)*0.95 } \\
\text { (Loads of JIT+JIT interrelationships)*1.05, (Loads of JIT+JIT interrelationships), } \\
0.001,3), 2) \text {, Delay time, 0.32) }\end{array}$ \\
\hline$L E A D$ & 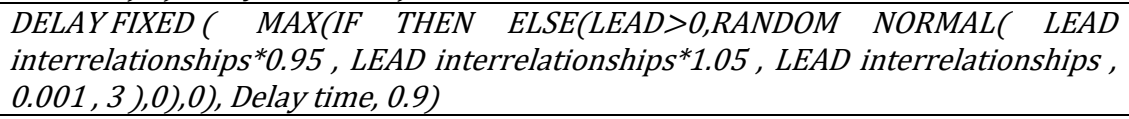 \\
\hline $\begin{array}{l}\text { INTERNAL } \\
\text { interrelationships }\end{array}$ & $\begin{array}{l}\text { IF THEN ELSE((Time/Stability period)=INTEGER(Time/Stability } \\
\text { period),EXTERNAL*Increase in INTERNAL interrelationships }, 0)\end{array}$ \\
\hline $\begin{array}{l}\text { EXTERNAL } \\
\text { interrelationships }\end{array}$ & 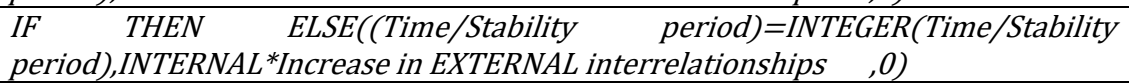 \\
\hline JIT interrelationships & 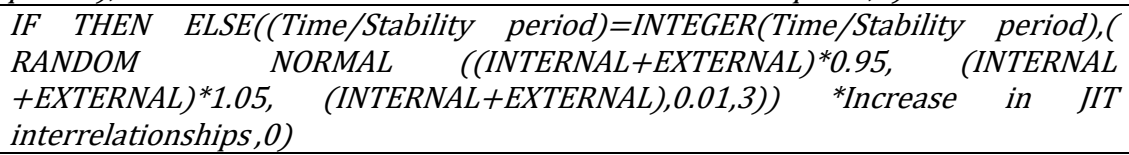 \\
\hline $\begin{array}{l}\text { LEAD } \\
\text { interrelationships }\end{array}$ & $\begin{array}{l}\text { IF THEN ELSE((Time/Stability period)=INTEGER(Time/Stability period), }( \\
\left.\left.\text { RANDOM NORMAL }(-J I T)^{*} 0.95,(-J I T)^{*} 1.05,(-J I T), 0.01,3\right)\right)^{*} \text { Increase in LEAD } \\
\text { interrelationships),0) }\end{array}$ \\
\hline Loads of JIT & $\begin{array}{l}\text { IF THEN ELSE((Time/Stability period)=INTEGER(Time/Stability } \\
\left.\text { period), }\left(\frac{\sum_{i=1}^{n} \text { JIT items load }}{n}\right) * \text { Increase in the JIT loads, } 0\right)\end{array}$ \\
\hline
\end{tabular}

INTERNAL, EXTERNAL, JIT and LEAD have been defined based on INTERNAL interrelationships, EXTERNAL interrelationships, JIT interrelationships and LEAD interrelationships loads, as well as Delay time. The variables formulas show that, after 
the time taken for the variables' loads to affect the level of the other variables (Delay time) the loads are increased to the level variables. The initial value of INTERNAL, EXTERNAL and JIT are the factorial loads of these constructs in Time $=0$. INTERNAL interrelationships, EXTERNAL interrelationships, JIT interrelationships and LEAD interrelationships are flow variables defined from the parameters Increase in INTERNAL interrelationships, Increase in EXTERNAL interrelationships, Increase in JIT interrelationships, Increase in LEAD interrelationships, and Stability period. These equations indicate that after the stability time defined by the model user the SEM/SDM will increase a new load to INTERNAL, EXTERNAL, JIT and LEAD. Loads of JIT is a flow variable defined from the average of the items loads that compose JIT and from Increase in JIT Loads. Finally, Increase in INTERNAL interrelationships, Increase in EXTERNAL interrelationships, Increase in JIT interrelationships, Increase in LEAD interrelationships, Increase in JIT loads, JIT1, JIT2, JIT3, JIT4, JIT5, JIT6, JIT7, JIT8, JIT9 and JIT1O are SEM parameters (constant system values), so they have no associated formulas. Their values have been presented in Figure 5.16.

Then, the time horizon of the simulation is defined (Step VII). As in this example, we are analysing the impact of internal and external IT on JIT practices, an analysis will be performed for the next 18 months ( 80 weeks). It is the average time that a company need to implement a new information technology (McAfee, 2002). Next, the SEM/SDM starting data are determined (Step VII) from the SEM information (Ward and Zhou 2006), as detailed below:

- Items of JIT: the starting value for JIT1, JIT2, JIT3, JIT4, JIT5, JIT6, JIT7, JIT8, JIT9 and JIT1O are the factorial loads that they exert on JIT. These factorial loads are obtained from SEM Confirmatory Factorial Analysis (see Figure 5.16).

- Increase in INTERNAL interrelationships, Increase in EXTERNAL interrelationships, Increase in JIT loads, Increase in JIT interrelationships, and Increase in LEAD interrelationships: The parameter will allow increasing factorial loads on INTERNAL, EXTERNAL, JIT and LEAD. The starting data is defined as the value zero, and this value can be altered in the scenario formulation stage.

- Time, Stability period and Delay time. As seen before, the value for Time is 80 weeks. For the first simulation, the Stability period value be equal to Time, which allows the model to be analysed only with data from SEM (current scenario). A Delay Time value equal to two weeks will be adopted, indicating that two simulation periods would be necessary the cause-variable's loads to affect the effect-variable's levels. Time, Stability 
period and Delay time can assume other values in the scenarios that will be simulated, as a way of analysing the time related to the results that will be achieved.

- INTERNAL, EXTERNAL, JIT: the starting values for these variables are the factorial loads (obtained through variances and covariances analyses) that INTERNAL and EXTERNAL exert on JIT, as well as JIT exerts on LEAD (see Figure 5.16).

-LEAD: The customer lead time (LEAD) of the major product in the surveyed company has decreased between $1 \%$ and $20 \%$ in the past 5 years (Ward and Zhou 2006). Since it is not an exact value, but an interval, we are going to adopt the intermediate lead-time reduction value between $1 \%$ and $20 \%$ (which is $10 \%$ ). In this way, the starting data for LEAD will be 0.9 (in Time=0, Lead=90\%). That means we consider that $10 \%$ of the $100 \%$ of the lead-time has already been reduced before simulation.

-INTERNAL interrelationships, EXTERNAL interrelationships, JIT interrelationships, LEAD interrelationships and Loads of JIT: These flow variables do not have pre-defined starting values, since their values depend on the SEM/SDM parameters showed in Figure 5.16.

Finally, the flow diagram developed by SEM/SDM has been analysed, confirming that it is aligned with the information provided by SEM. The most important SEM variables are represented in the causal diagram and the cause-effect relationship between them is in accordance with the SEM information. It has also been verified that the mathematical equations and the starting data are correctly formulated and the relationship between variables is in accordance with the SEM information.

\section{Stage 4. Performance and evaluation}

To test the SEM/SDM performance (Step 11) and check its validity and quality (Step 12), the SEM/SDM model is first run using the starting data. This first test presents a positive result, since the model is executed correctly, without unit, development or structural errors. It shows that the SEM/SDM had good results against the Limits Adequacy, Structure check, Dimensional consistency, and Checking Parameters tests (Sterman, 2000).

In addition, for this first test, the SEM/SDM model has been performed with only the data obtained from SEM (without adding extra loads to the analysis variables). For this reason, the SEM/SDM should show a stable behaviour (without increasing loads or levels) during the whole simulation period. In other words, the variable levels in Time $=80$ should be similar to the variable levels at the beginning of the simulation (Time $=0)$. In the 
real world, this means that a company would not increase the implementation levels of the items or dimensions that compose the analysed constructs. This shows that the model has performed well against the abnormal behaviour test (Sterman, 2000). The results are shown in Figure 5.18 and confirm the expected stability of the SEM/SDM. INTERNAL, EXTERNAL and $L E A D$ have a constant blue line that represents their levels throughout the simulation. The blue line on INTERNAL represents the loads it receives from EXTERNAL, the blue line on EXTERNAL represents the loads it receives from INTERNAL, and the blue line on LEAD represents the loads it receives from JIT. In JIT, apart from the blue line that represents the loads it receives from $\angle E A D$, the red line represents the loads it receives from the items that compose the JIT construct, since it is the only variable compose by items in the SEM/SDM model.

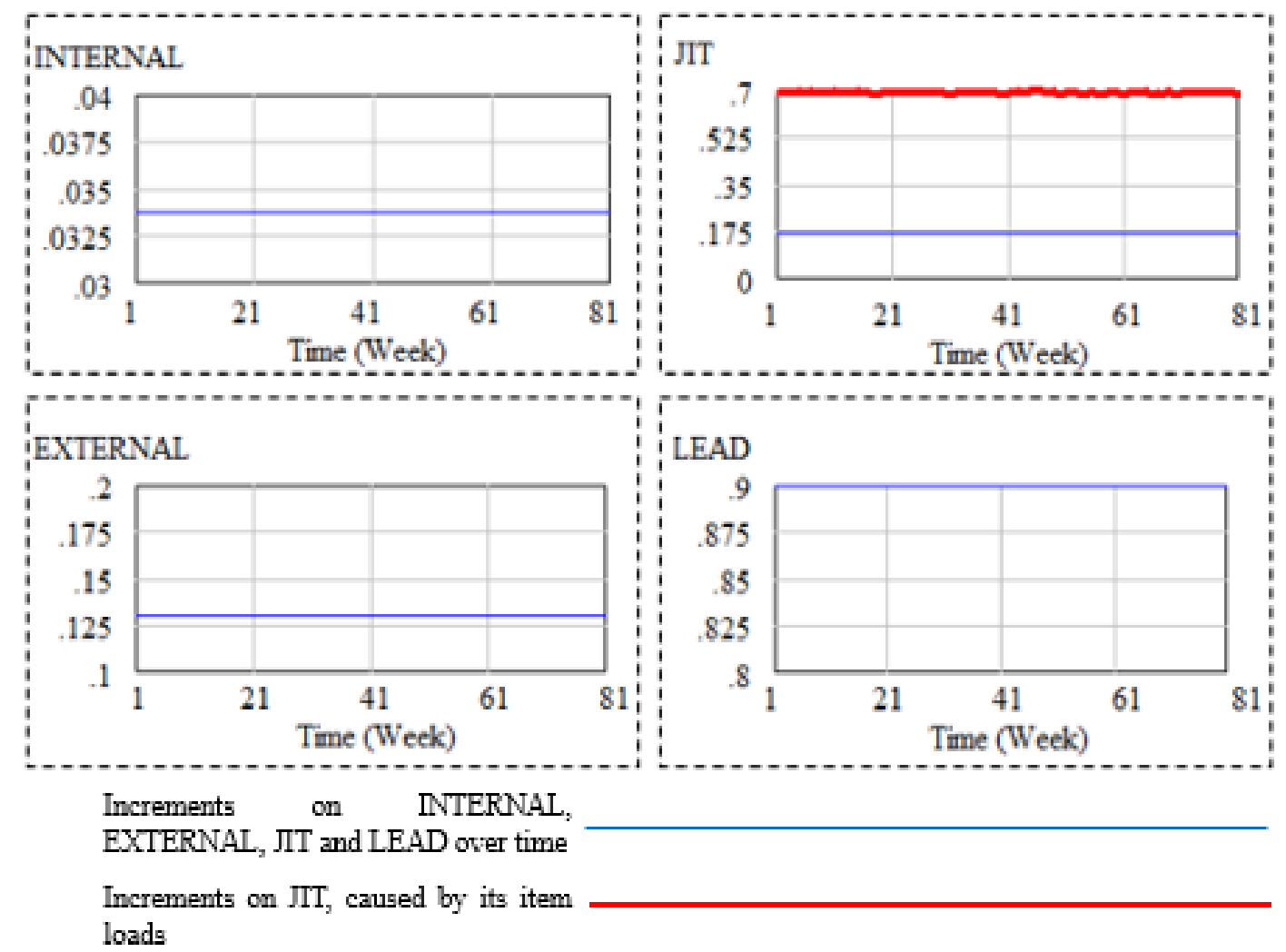

Figure 5.18. Performance of INTERNAL, EXTERNAL, JIT and LEAD

In addition, extreme conditions test has been performed. In this test, the SEM/SDM robustness is checked with extreme values (very high) for the variable loads. This will allow to analyse if the model presents results that correspond to the abrupt variations of the input data. To this end, we have incremented $1000 \%$ in the values of the variables that affect the INTERNAL, EXTERNAL, JIT and LEAD levels. Figure 5.19 illustrates 
some of the tests performed, showing that the model is robust even in extreme conditions.

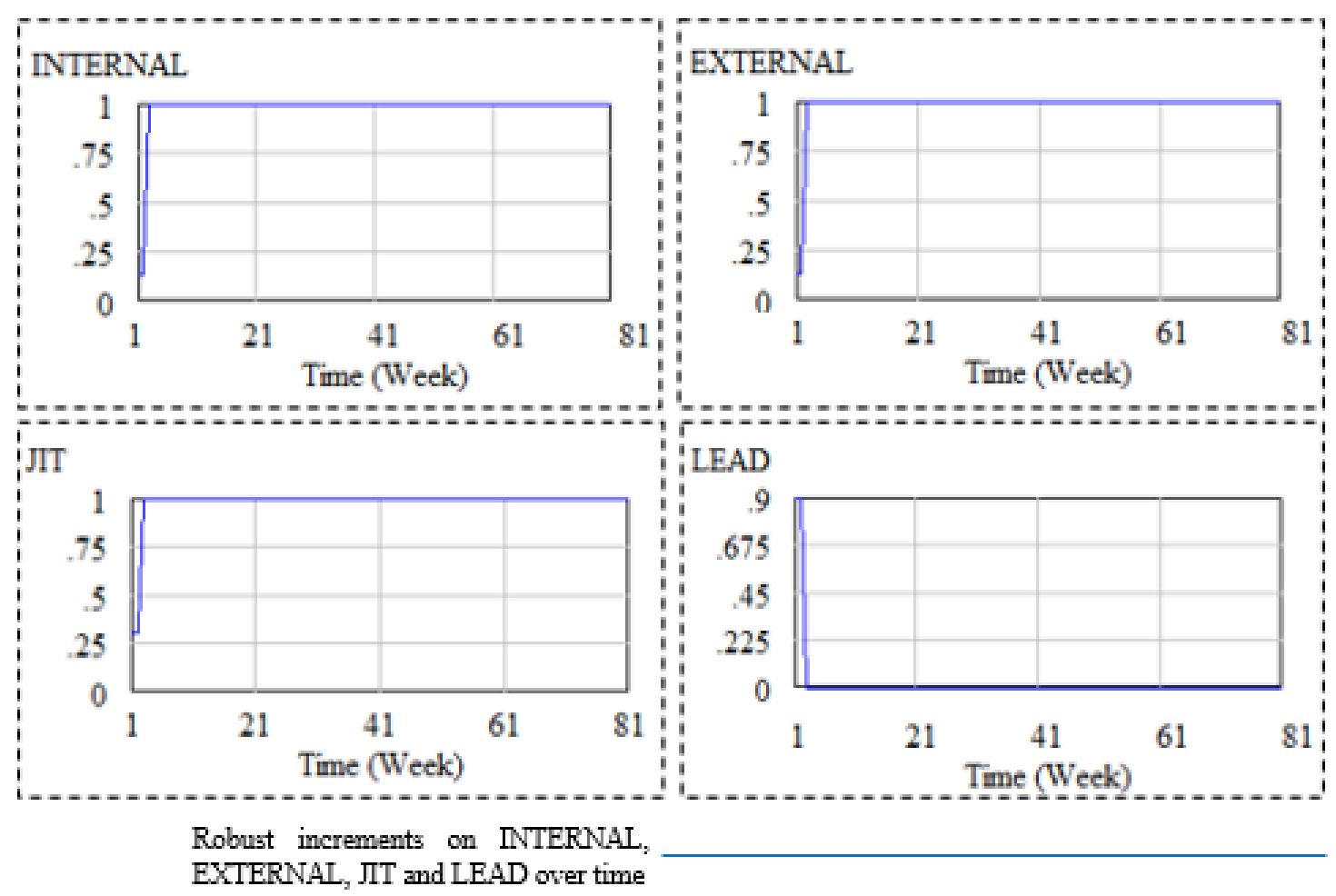

Figure 5.19. Robustness analysis for INTERNAL, EXTERNAL, JIT and LEAD

Finally, the SEM/SDM sensitivity test is performed. For this purpose, the Monte Carlo simulation has been used. The model sensitivity related to Increase in JIT interrelationships and JIT (Figure 5.20a), as well as related to Increase in LEAD interrelationships and LEAD (Figure 5.20b) have been tested. Five hundred simulations have been performed for the sensitivity analysis and the values could vary between the minimum and maximum values with a uniform random distribution of the probability

Thus, Figures 5.20a and 5.20b show the Monte Carlo simulations that have been carried out to test the sensitivity of SEM/SDM (Bois and Maszle, 1997). That is to say, the possible increases of loads caused by the causal variables on the effect variables ( $Y$ axis) along 80 weeks ( $X$ axis). The red line shows the starting scenario (current) for each combination of causal variables analysed and their impact on the effect variable. The SEM/SDM behaviour throughout the 80 weeks of simulation, represented in Figures $5.20 \mathrm{a}$ and $5.20 \mathrm{~b}$, shows that the level of the effect variables (JIT in Figure 5.20a, and LEAD in Figure 5.20b) are sensitive to variations in causal variable loads (INTERNAL and EXTERNAL in Figure 5.20a, and JIT in Figure 5.20b). That is, variations in the causal 
variable loads proportionally affect the effect variable levels. Results, therefore, indicate that the SEM/SDM is sensitive to variation in causal variables.

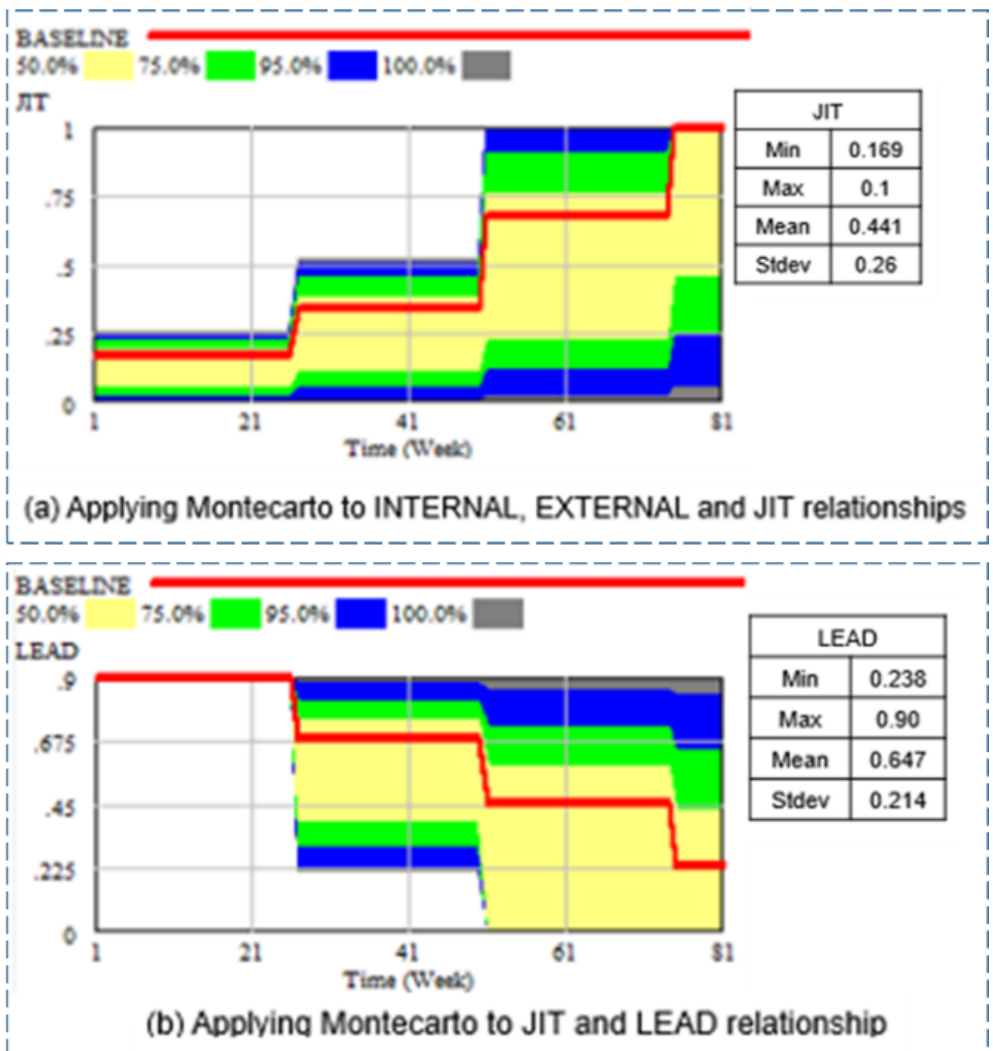

Figure 5.20. Sensitive test to JIT and LEAD

As explained above (see Figure 5.13), the yellow stripe represents the confidence limit of $50 \%$, the green one of $75 \%$, the blue one of $95 \%$ and the grey one of $100 \%$. After checks with favourable results (good results of the SEM/SDM model in terms of structure, behaviour and sensitivity), it can be stated that this model is valid and can be applied for the purpose of this chapter.

\section{Stage 5. Exploitation}

In the last stage of this methodology, first is necessary to specify the scenarios for which the researchers want to know the results (Step 13) as a way of analysing the development of the system under consideration in the future. As defined in Stage 1, the objective of this simulation is to know how a company could achieve a 0.2 increase in JIT and a 0.1 reduction LEAD level over 18 months ( 80 weeks). Five scenarios have been created for this proposal, where we progressively increased by 0.05 the factorial 
loads of all the SEM/SDM relationships (Table 5.10). That is, in Scenario 1, we have increased by 0.05 in the factorial loads and, in Scenario 2, 0.10. In scenario 3, 0.15 in factorial loads has been increased and, in scenario 4, 0.20. Finally, in scenario 5, 0.25 has been increased in the factorial loads of the model relationships. Next, the scenarios simulations must be performed (Step 14) and the results must be analysed (Step 15).

Table 5.10. Simulations results for INTERNAL, EXTERNAL, JIT and LEAD

\begin{tabular}{|c|c|c|c|c|c|c|c|}
\hline \multicolumn{2}{|c|}{} & \multicolumn{7}{c|}{ Scenarios } \\
\cline { 3 - 8 } & & $\begin{array}{c}\text { Current } \\
\text { (SEM data) }\end{array}$ & $\mathbf{1}$ & $\mathbf{2}$ & $\mathbf{3}$ & $\mathbf{4}$ & $\mathbf{5}$ \\
\hline \multirow{3}{*}{ Relationships } & Jit items $\rightarrow$ JIT & 0 & +.05 & +.10 & +.15 & +.20 & +.25 \\
\cline { 2 - 8 } & INTERNAL $\rightarrow$ JIT & 0 & +.05 & +.10 & +.15 & +.20 & +.25 \\
\cline { 2 - 8 } & EXTERNAL $\rightarrow$ JIT & 0 & +.05 & +.10 & +.15 & +.20 & +.25 \\
\cline { 2 - 8 } & JIT $\rightarrow$ LEAD & 0 & +.05 & +.10 & +.15 & +.20 & +.25 \\
\hline \multirow{4}{*}{ Results } & JIT & .32 & .381 & .443 & .505 & .569 & .633 \\
\cline { 2 - 8 } & (JIT increment) & $\mathbf{0}$ & $\mathbf{+ 0 . 0 6}$ & $\mathbf{+ 0 . 1 3}$ & $\mathbf{+ 0 , 1 8}$ & $\mathbf{+ 0 . 2 5}$ & $\mathbf{+ 0 . 3 4}$ \\
\cline { 2 - 8 } & LEAD & .90 & .885 & .869 & .850 & .829 & .807 \\
\cline { 2 - 8 } & (LEAD reduction) & $\mathbf{0}$ & $\mathbf{- . 0 1 5}$ & -.031 & $\mathbf{- . 0 5 0}$ & $\mathbf{- . 0 7 1}$ & -.093 \\
\hline
\end{tabular}

Figure 5.21 a shows that Scenarios 4 and 5 have been able to achieve the objective established for JIT level (which is a 0.2 increase in the JIT level), with the simulation configurations in Scenario 5 leads the company to a JIT level very close to that expected. This means that if a company wants to increase the JIT level by almost 0.2 , it would need to increase the factorial loads of JIT items, as well as of INTERNAL and EXTERNAL variables by in at least 0.15 (Scenario 3). The difference is that if a company increases values over 0.20 or 0.25 in the factorial load of these variables, it could reach its goal in a much shorter time ( 50 weeks). Likewise, Figure $5.21 \mathrm{~b}$ shows that a company to reach the 0.10 reduction in LEAD level could use the configurations of Scenario 5 . This result indicates that an increase of 0.25 in factor loads of INTERNAL, EXTERNAL, JIT, and JIT items could lead the company to reach the intended LEAD level.

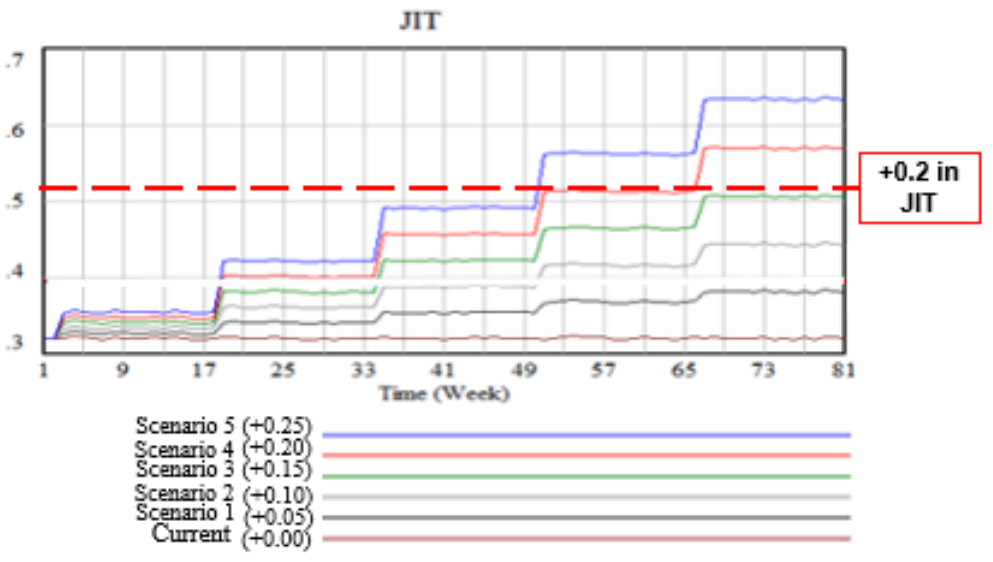

(a) JIT results 


\section{LEAD}

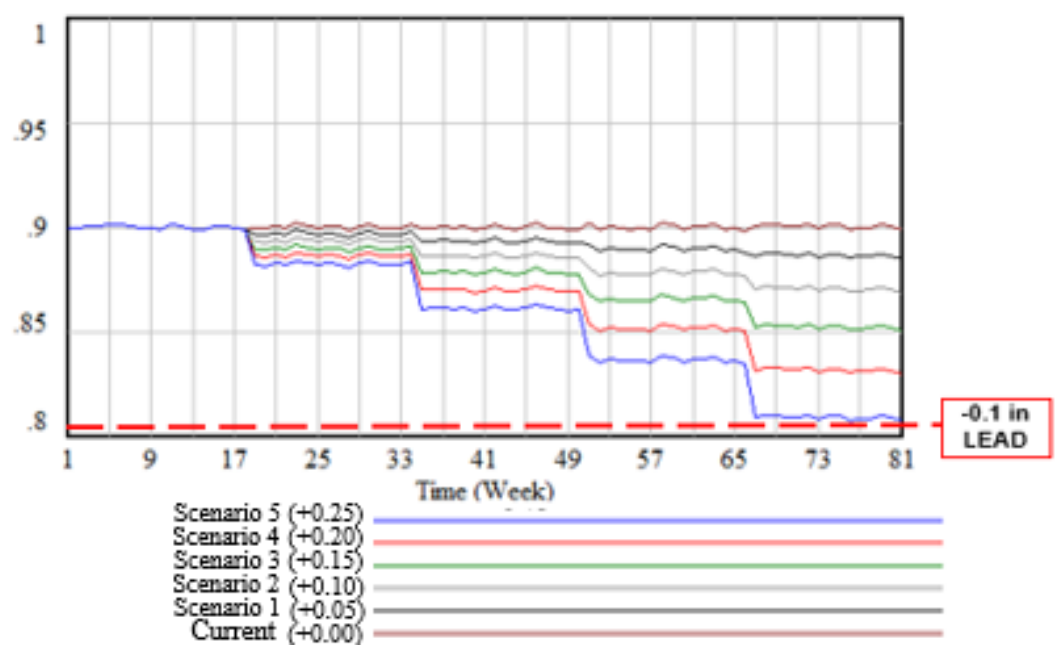

(b) LEAD results

Figure 5.21. JIT and LEAD simulation results over 80 weeks

As seen above, it is necessary to understand what a 0.2 increase in JIT level and 0.1 reduce in $\angle E A D$ represent in practice and how companies could interpret this result to support their decision-making. To do so, we suggest the use of the JIT and LEAD measurement scales (Table 5.11) or items average (Table 5.12) published in the previous literature (Ward and Zhou, 2006). Through these measurement scales, companies could become aware of those practices they already have implemented and those that could be implemented to improve the JIT level and to reduce LEAD in their Supply Chains. Based on the measuremente scale used by Ward and Zhou (2006), a fictitious checklist has been made to exemplify how such measurement scales could be used by companies to identify the opportunities of improving JIT levels and reducing LEAD. We have checked with a " $V$ " the items that a company would have implemented and with an "X" those which have not (Tables 5.11 and 5.12). The fictitious situation represented shows that a company could increase its JIT level through the implementation of JIT2, JIT6 and JIT9, which together weigh 33\% over JIT (Table 5.11). Similarly, the company could implement the technologies Advanced Planning and Scheduling, Invoices and/or Payment, and Direct Material Procurement to improve its $J I T$ and reduce its $L E A D$. 
Table 5.11. Checklist of JIT measurement model

\begin{tabular}{|c|c|c|c|c|c|c|}
\hline Construct & \multicolumn{2}{|l|}{ Items } & Load & Sum & Weight & Check \\
\hline \multirow{10}{*}{ JIT } & Reengineering Production Processes & JIT1 & 0.54 & \multirow{10}{*}{6.15} & $9 \%$ & $V$ \\
\hline & Cycle-Time Reduction & JIT2 & 0.63 & & $10 \%$ & $\boldsymbol{X}$ \\
\hline & Agile Manufacturing Strategies & JIT3 & 0.64 & & $10 \%$ & $\boldsymbol{V}$ \\
\hline & Quick Changeover Techniques & JIT4 & 0.58 & & $9 \%$ & $\boldsymbol{V}$ \\
\hline & Focused-Factory Production Systems & JIT5 & 0.59 & & $10 \%$ & $\boldsymbol{V}$ \\
\hline & JIT/Continuous-Flow Production & JIT6 & 0.71 & & $12 \%$ & $X$ \\
\hline & Cellular Manufacturing & JIT7 & 0.55 & & $9 \%$ & $\boldsymbol{V}$ \\
\hline & Lot-Size Reduction & JIT8 & 0.62 & & $10 \%$ & $\boldsymbol{V}$ \\
\hline & Pull System/Kanban & JIT9 & 0.66 & & $11 \%$ & $X$ \\
\hline & Bottleneck/Constrain Removal & JIT10 & 0.63 & & $10 \%$ & $\boldsymbol{V}$ \\
\hline
\end{tabular}

Table 5.12. Checklist of INTERNAL and EXTERNAL items average

\begin{tabular}{|c|c|c|c|c|c|}
\hline Variable & Items & Means & Sum & Weight & Check \\
\hline \multirow{7}{*}{ INTERNAL } & Advanced MRP & 1.34 & \multirow{7}{*}{8.55} & $16 \%$ & $V$ \\
\hline & Advanced Planning and Scheduling & 1.27 & & $15 \%$ & $\boldsymbol{X}$ \\
\hline & ERP System & 1.18 & & $14 \%$ & $\boldsymbol{V}$ \\
\hline & Computerized Integrated Manufacturing & 1.31 & & $15 \%$ & $\boldsymbol{V}$ \\
\hline & Forecast-Demand Management Software & 1.17 & & $14 \%$ & $\boldsymbol{V}$ \\
\hline & $\begin{array}{l}\text { Manufacturing Execution Systems for Production } \\
\text { Management }\end{array}$ & 1.09 & & $13 \%$ & $\boldsymbol{V}$ \\
\hline & Product Data Management & 1.19 & & $14 \%$ & $\boldsymbol{V}$ \\
\hline \multirow{5}{*}{ EXTERNAL } & Invoices and/or Payment & 1.41 & \multirow{5}{*}{7.3} & $19 \%$ & $X$ \\
\hline & $\begin{array}{l}\text { Collaborative Business Forecasting with } \\
\text { Customers and/or Suppliers }\end{array}$ & 1.46 & & $20 \%$ & $\boldsymbol{V}$ \\
\hline & Direct Material Procurement & 1.49 & & $20 \%$ & $\boldsymbol{X}$ \\
\hline & Customers Enter Orders & 1.52 & & $21 \%$ & $\boldsymbol{V}$ \\
\hline & Customer Service and/or Help Desk & 1.42 & & $19 \%$ & $V$ \\
\hline
\end{tabular}

\subsection{CONCLUSIONS, LIMITATIONS AND FUTURE RESEARCH LINES}

In this chapter it has been proposed a methodology to apply dynamics systems to strategic models, using results from SEM analysis. This methodology has been structured in five stages: (1) clear definition of the problem/objective to be analysed; (2) formulation of the SEM/SDM causal diagram by qualitative data from SEM; (3) formulation of the SEM/SDM flow diagram and mathematical by quantitative data from SEM; (4) perform and validation of the SEM/SDM; and (5) analysis of the SEM/SDM simulation results.

The main contribution of the proposed methodology has been to provide an analysis of static relationships between the variables coming from SEM. As seen above, SEM establishes structural models of high conceptual level, provides a static view of the observed reality, and measures the relationships between strategic variables or factors at a particular point in time. Likewise, SDM allows us to visualize the certain variables behaviour in different scenarios projected in a future time. In this sense, the complementary use of both techniques (SEM and SDM) allows the analysis of strategic variables, its relationships and its evolution over time. Furthermore, this methodology 
can be adapted to the specific conditions of each case, since the input data can be varied according to the SEM model adopted.

The methodological proposal has been illustrated by application to two specific supply chain cases: first, to the case of Community Cloud use, Supply Chain Integration and their impacts on Operational Performance (Bruque et al., 2016); second, to the specific case of Information Technology Integration and Lean/Just-In-Time Practices on LeadTime Performance (Ward and Zhou 2006). The application examples have allowed a dynamic analysis of the relationship between SEM variables over a horizon of 18 months ( 80 weeks), which is the time necessary to implement a new technology (McAfee, 2002). Such applications have shown how the SEM/SDM methodology is able to use the SEM data and turn it into a tool for future analysis of the organization key variables, such as the new technology implementation, Supply Chain Integration, Lean practices, and performance.

One of the most relevant contributions of this chapter arises because of the inclusion of a dynamic effect and analysis to the traditional SEM methodology. The combined use of SEM and SDM introduces flexibility and variability over time in the relationship framework. The joint use of SEM and prospective quantitative analysis such as the one explored here serves as a solution to the traditional criticism directed towards static, cross-sectional methods like structural equations analysis. Therefore, this research is one of the first steps to combine two different methodologies so that it can created a time-dependant scenario drawing upon existing causal relationships in a particular moment of time.

This study can also be a starting point to add a what-if scenario so that managers and researchers can create alternative prospective horizons according to the values that major variables may take over time. This possibility may prove as a great advantage for managers, consultants, technology vendors and other researchers interested in applying sensitive analyses to complex situations in which organizational and technology factors are usually interwoven. A synergetic effect may also arise since the combined use of these two main stream methodologies since their combined use may provide more-thanproportional advantages to a complex, difficult to analyse set of relationships that may vary over time.

An additional advantage of this type of studies consists on calculating the expected time horizon needed to arrive to a particular quantitative target for a particular variable. The methodology proposed here allows to foresee the expected time left to accomplish a particular target and how this term can be modified by modifying the variables that take 
part of the causal set. This is part of the overall sensitivity test that can be also used by researchers, members of the consultancy industry and managers.

In the ground of SDM there are also some advantages provided in this study. One of the most important is the new use given to this methodology by granting a strategic character to the traditional operational use of the method. This is a significant leap since now managers, strategic analysts and consultants can also use this tool to create and justify strategic projections of organizational and technological behaviours. Furthermore, operational and strategic use can both be combined for analysis of a set of significant variables in a given company and/or sector.

Although the proposed methodology has proven to be an effective tool for analysing the behaviour over time of variables and its relationships with other variables, some limitations must be considered. As a new methodology, one of the limitations refers to its comparison, since a relatively small number of tests and applications have been carried out. The fact that the examples proposed correspond to SEM models with direct relations between constructs, dedicated to the proposed methodology understanding, it is also included as a chapter limitation. Therefore, the following future work directions are suggested.

It could be necessary to carry out new tests in more complex SEMs (with mediation and/or moderation relationships). It would be interesting to know whether complex or weak SEMs will necessarily generate complex or weak SDM.

Typically, SEM models do not include feedback loops. SEM model research often uses predominantly linear relationships. Thus, another future research direction could be the analysis of the use of SDM after SEM generation to verify the system's performance if the relationships were non-linear and if potential feedback loops were present in the conceptual model.

Finally, it is also necessary to use the proposed methodology to create simulation models based on primary data sources. This models also can be applied to other research fields (e.g. Human Resources, Marketing, and Finance, among others). Furthermore, an information system/ application could also be developed in order to apply and combine the use of both methodologies in a particular industry or company.

To sum up, the SEM/SDM methodology could be used to carry out analysis of potential scenarios that would help in the decision-making process of companies. Therefore, we invite researchers and practitioners to use the proposed methodology in the feasibility studies to analyse variables implementation in order to achieve of the variables implementation to achieve the companies' strategic objectives of companies. 


\section{REFERENCES}

Batista, J., and Coenders, G. (2000). Modelos de ecuaciones estructurales. La Muralla, Madrid.

Bois, F.Y., and Maszle, D.R. (1997). MCSim: a Monte Carlo simulation program. Journal of Statistics Software, 2, 1-60.

Bruque, S, Moyano, J., and Maqueira, J.M. (2016) Supply chain integration through community Cloud: Effects on operational performance. Journal of Purchasing and Supply Management, 22 (2), 141-153.

Cagliano, R., Caniato, F., and Spina, G. (2006). The linkage between supply chain integration and manufacturing improvement programmes. International Journal of Operations and Production Management, 26 (3), 282-299.

Campuzano, F., and Mula, J. (2011). Supply Chain Simulation: A System Dynamics Approach for Improving Performance. Springer, London.

Campuzano, F., Mula, J., and Peidro, D. (2010). Fuzzy Estimations and System Dynamics for Improving Supply Chains. Fuzzy Sets and Systems, 161,1530-1542.

Campuzano, F., Martínez, E., and Ros, L. (2010) Cadenas de suministro tradicionales y colaborativas: Análisis de su influencia en la gestión de la variabilidad de la demanda. Dyna, 8 (1), 33-40.

Casas, M. (2013) Los modelos de ecuaciones estructurales y su aplicación en el índice europeo de satisfacción al cliente. Universidad San Pablo-CEU, Madrid.

Chen, C.S., Liang, W.Y., and Hsu, H.Y. (2015) A Cloud Computing platform for ERP applications. Applied Soft Computing, 27,127-136.

Chiu, P.C., Liao, A.Y.H., Liao, C.H., and Yango, Y.N. (2013) Cloud-Based Supply Chain Integration Service Platform. Journal of Electronic Science and Technology, 11 (2), 201-208.

Cupani, M. (2012) Análisis de Ecuaciones Estructurales: conceptos, etapas de desarrollo y un ejemplo de aplicación. Tesis, 2 (1), 186-199.

Escobedo, M.T., Hernández, J.A., Estebané, V., Martínez, G. (2016). Modelos de ecuaciones estructurales: características, fases, construcción, aplicación y resultados. Ciencia y Trabajo, 55, 16-22.

Forrester, J.W. (1961). Industrial Dynamics. Pegasus Communications, Waltham.

Frazelle, E. (2001). Supply Chain Strategy: The Logistics of Supply Chain Management (2nd Ed.). McGrawHill Professional, New York.

Gerbin, D., and Hamilton, J. (1996). Viability of Exploratory Factor Analysis as a Precursor to Confirmatory Factor Analysis. Structural Equation Modelling, 3 (1), 62-72.

Gorsuch, R. (1983). Factor Analysis (2nd ed.), Erlbaum, Hillsdale.

Gunasekarana, A., Laib, K., and Chenge, T. (2008). Responsive supply chain: A competitive strategy in a networked economy. Omega, 36 (1), 549-564.

Hair, J., Anderson, R., Tatham, R., and Black, W. (2001) Análisis Multivariante (5ª Ed.). Prentice Hall, Madrid.

Hair, J.F., Black, W.C., Babin, B.J., and Anderson, R.E. (2009). Multivariate Data Analysis. New Jersey: Prentice Hall.

Helo, P.T. (2000). Dynamic Modelling of Surge Effect and Capacity Limitation in Supply Chains. International Journal of Production Research, 38, 4521-4533.

Hu, L., and Bentler, P. (1998). Fit indices in covariance structure modelling: Sensitivity to under parameterized model misspecification. Psychology Methods, 3, 424- 453.

Kaplan, D. (2000). Structural equation modelling: Foundations and extensions. Sage, Newbury Park.

Kerlinger, F., and Lee, H. (2002). Investigación del comportamiento. Métodos de investigación en las ciencias sociales. McGraw-Hill, México.

Kline, R. (2005). Principles and practice of structural equation modelling. Gilford Press, New York.

Lee, H. (2017). Framework and development of fault detection classification using loT device and Cloud environment. Journal of Manufacturing Systems, 43 (2), 257-270.

Leukel, J., Kirn, S., and Schlegel, T. (2011). Supply chain as a service: A Cloud perspective on supply chain systems. Systems Journal, 5 (1), 16-27.

Li, W., Zhong, Y., Wang, X., and Cao, Y. (2013). Resource virtualization and service selection in Cloud logistic. Journal of Network and Computer Applications, 36 (6), 1696-1704. 
Liu, S., Yang, Y., Qu, W.G., and Liu, Y. (2016). The business value of Cloud Computing: the partnering agility perspective. Industrial Management and Data Systems, 116 (6), 1160-1177.

McAfee, A. (2002). The impact of enterprise information technology adoption on operational performance: An empirical investigation. Production and Operations Management, 11 (1), 33-53.

McCormack, K., Ladeira, M.B., and Oliveira, M.P.V. (2008) Supply chain maturity and performance in Brazil. Supply Chain Management. An International Journal, 13 (4), 272-282.

Mejía. M, and Cornejo, C. (2010). Aplicación del modelo de ecuaciones estructurales a la gestión del conocimiento. LACCEI, Arequipa.

Mell, P., and Grance, T. (2011). The NIST definition of Cloud Computing. Recommendations of the National Institute of Standards and Technology. National Institute of Standards and Technology, Gaithersburg, MD.

Moyano-Fuentes, J., Martínez-Jurado, P.J., Maqueira-Marín, J.M., and Bruque-Cámara, S. (2012). El papel de las tecnologías de la información and las comunicaciones (TIC) en la búsqueda de la eficiencia: un análisis desde Lean Production and la integración electrónica de la cadena de suministro. Cuadernos de Economía and Dirección de la Empresa, 15 (3), 105-116.

Ouyang, L.Y., Wu, K.S., and Ho, C.H. (2007). An integrated vendor-buyer inventory model with quality improvement and lead time reduction. European Journal of Operational Research, 108, 349-358.

Pérez-Ríos, J. (1992). Análisis estructural de la empresa, su modelado y silmulación. Revista Internacional de Sistemas, 4 (1-3), 5-30.

Qureshi, M.I., Iftikhar, M., Bhatti, M.N., Shams, T., and Zaman, K. (2013) Critical elements in implementations of just-in-time management: empirical study of cement industry in Pakistan. SpringerPlus, 2 (645), 1-14.

Rai, A., Patnayakuni, R., Seth, N. (2006). Firm performance impacts of digitally enabled supply chain integration capabilities. MIS Quarterly, 30 (2), 225-246.

Raubenheimer, J.E. (2004). An item selection procedure to maximize scale reliability and validity. South African Journal of Psychology, 30 (4), 59-64.

Romano, P. (2003). Co-ordination and integration mechanisms to manage logistics processes across supply markets. Journal of Purchasing and Supply Management, 9 (3), 119-134.

Ruiz, M., Pardo, A., and San Martín, R. (2010). Modelos de ecuaciones estructurales. Papeles del Psicólogo, 31 (1), 34-45.

Satorra, A. (1993). Multi-sample analysis of moment-structures: asymptotic validity of inferences based on second order moments. In: Haagen, K., Bartholomeusz, A., Deistler, M. (Eds.), Statistical modelling and latent variables. Elsevier, North Holland, Amsterdam.

Schniederjans, D.G., and Hales, D.N. (2016). Cloud Computing and its impact on economic and environmental performance: A transaction cost economics perspective. Decision Support Systems, 86, 73-82.

Schniederjans, D.G., Ozpolat, K., and Chen, Y. (2016). Humanitarian supply chain use of Cloud Computing. Supply Chain Management: An International Journal, 21 (5), 569-588.

Shah, R., and Ward, P.T. (2003). Lean manufacturing: context, practice bundles and performance. Journal of Operations Management, 21 (2), 129-149.

Sterman, J. (2000). Business Dynamics: Systems Thinking and Modelling for a Complex World. Irwin/McGraw-Hill.

Subramanian, N., Abdulrahman, M.D., and Zhou, X. (2015). Reprint of Integration of logistics and Cloud Computing service providers: Cost and green benefits in the Chinese context. Transportation Research, 74, 81-93.

Treville, S., Shapiro, R., and Hameri, A.P. (2004). From supply chain to demand chain: The role of lead time reduction in improving demand chain performance. Journal of Operations Management, 21, 613 - 627.

Ward, P., and Zhou, H. (2006). Impact of information technology integration and lean/ just-in-time practices on lead-time performance. Decision Sciences, 37 (2), 177-203.

Waters, D. (2007). Global Logistics: New Directions in Supply Chain Management (5a Ed.). Kogan Page Publishers, London.

Womack, J.P., Jones, D.T., and Ross, D. (1990). The machine that changed the world. Ed. MacMillan/Rawson Associates, Nueva York. 


\title{
Chapter 6
}

\section{A strategic-simulation model for Business Performance: Analysis of factors affecting Supply Chain effectiveness and efficiency}

\begin{abstract}
This chapter analyses, from a dynamic and strategic point of view, how some factors related to the Supply Chain effectiveness and efficiency are interrelated and how they affect Business Performance. Supply Chain Integration, Supply Chain Flexibility and Mass Personalization capacity have been considered as factors related to business effectiveness. Lean Production implementation and Cloud Computing use have been deemed business efficiency-related factors. The interrelation between these factors comes from theoretical models that have been formulated in previous chapters (through hypotheses) and empirically contrasted through Structural Equation Models (SEM). The complementarity SEM and System Dynamics Models (SDM) has been used to design and perform the strategic simulation model. The SEM/SDM developed is applied for helping the strategic decision making process of a Cloud-supported logistics company in the fashion industry to increase its Business Performance. The main contribution of this work is a framework that can be used to model and simulate the impacts of the aforementioned effectiveness and efficiency factors in a real Supply Chain, which will eventually serve as support for strategic decision-making. Therefore, other companies can use the SEM/SDM developed and applied as a reference to improve their Business Performance and to simulate and monitor the future behaviour of a given set of variables.
\end{abstract}

Keywords: Structural Equation Model, System Dynamics Model, Supply Chain Effectiveness, Supply Chain Efficiency, Business Performance 


\section{A strategic-simulation model for Business Performance: Analysis of factors affecting Supply Chain effectiveness and efficiency}

\subsection{INTRODUCTION}

Supply Chain Management is defined as a set of actions that allows companies to manage, plan and control their operations as a way to facilitate collaboration between Supply Chain actors (suppliers, producers, distributors and customers) (Frazelle, 2001; Waters, 2007; Gunasekarana et al., 2008). Supply Chain Management has been recognised as an extremely important aspect of business strategy, as it enables companies to manage their processes in a more efficient and effective way (Flyyn et al., 2010; Moyano-Fuentes et al., 2012). Therefore, Supply Chain Management appears as a key factor for companies to respond efficiently and effectively the very high competitiveness observed in current economic environment (Romano, 2003; Mccormack, et al., 2008).

On the one hand, the dynamism of the markets stimulates companies to be more efficient in order to produce with quality, lower costs and in the shortest possible time, and Lean Production pursues this goal (Moyano-Fuentes, Sacristán-Díaz and Martínez-Jurado, 2012). Womack et al. (1990) define Lean Production as a systematic approach to the identification and elimination of waste-low or nil value-added activities through continuous improvement. Likewise, in the search for improved Business Performance, it has been found that Information Technologies play an important role in in Supply Chain efficiency (Brunn and Medford, 2004; Bruque et al., 2015). As an IT-based tool, Cloud Computing emerges as a set of virtualized and distributed resources that are diffuse and ubiquitous, geographically dispersed, and accessible on demand through web-based technologies (Hayes, 2008; Fingar, 2009; Buyya et al., 2011). More specifically, Cloudsupported Logistics consists of Cloud systems application to Logistics field, where information systems that support logistics process are no longer perfectly located, but are located and run on distributed networks accessible through a web browser (Wang et al., 2012; Li et al., 2013; Nowicka, 2014).

On the other hand, in order to be more effective and responding quickly to changes in demand, companies need to redesign their Supply Chain strategies and adopt management practices in their Supply Chains as a way to achieve better results (Flynn et al., 2010; Strasser et al., 2011). In this context, Supply Chain Integration, Supply Chain Flexibility and Mass Personalization play an important role in the quest to improve Supply 
Chain effective and, ultimately, improve Business. Supply Chain Integration consists of sharing information and activities quickly across the value chain, as a way of promoting the cooperative behaviour of the chain's agents (Devaraj et al., 2007). Supply Chain Flexibility is the ability of a Supply Chain to change its processes, resources, structure and governance mechanisms within a given scope, responding in terms of production volume and product variability to changes in demand (Griffiths and Margetts, 2000; Molina et al., 2005; Rojo et al., 2018). Mass Personalization refers to a company's ability to provide personalized products and services at a price and speed comparable to standard offers for a mass market (Stump and Badurdeen, 2012; Purohit et al., 2016).

Managers in the Supply Chain must take strategic decisions for all participating stakeholders. However, this can be quite a complex task given the large number of relationships between the factors in a Supply Chain and the uncertainties about the results (present and future) that can be obtained from those decisions. In the Supply Chain Management context, there are different methods that help to make better decisions in the present and to estimate the consequences of these decisions in the future. Two of them are the Structural Equations Models (SEM) (Satorra, 1993) and the System Dynamics Models (SDM) (Forrester, 1961). On the one hand, SEM is a widely used technique that provide a static view of the observed reality and measure the relationship between variables or factors at a specific point in time (Liu et al., 2016; Schniederjans and Hales, 2016; Subramanian and Abdulrahman, 2017). On the other hand, SDM is a technique that allows the simplification and visualization of business variables' behaviour in different scenarios projected in a future time (Sterman, 2000; Helo, 2000; Campuzano and Mula, 2010).

The complementarity between SEM and SDM has been used in this work to analyse the above factors related to the Supply Chain effectiveness and efficiency and their relationship with Business Performance. This chapter aims to delve dynamically into the interrelationships of factors related to Supply Chain effectiveness and efficiency and their joint impacts on Business Performance. The static relationships obtained from SEM are used as a starting point for the developed SDM. Therefore, this chapter's findings could result in a tool to support business decision-making, being effective for analysing the behaviour over time of static factors originating from SEM. The theoretical models have been proposed and empirically tested by SEM in Chapters 3 and 4 . These models will be submitted to dynamic simulation through the complementarity between SEM and SDM. Primary data from a Cloud-supported logistics company will also be used as a way to compare the data obtained through SEM/SDM performed with the real data. 
The rest of this chapter is organized as follows: In Section 2, the existing literature on factors related to Supply Chain effectiveness and efficiency and their relationship to Business Performance is briefly revised. In Section 3, the research methodology based on SEM and SDM is presented and applied. In Section 4, the SEM/SDM model is applied as a strategic decision-making tool to analyse the interrelationship between effectiveness and efficiency factors. In addition, the SEM/SDM is used to support decision-making for the specific case of a Cloud-supported logistics company. Finally, in Section 5 conclusions and perspectives for further research are presented.

\subsection{THEORETICAL BACKGROUND}

\subsubsection{SUPPLY CHAIN EFFECTIVENESS FACTORS AND BUSINESS PERFORMANCE}

Previous literature shows that Supply Chain Integration, Supply Chain Flexibility and Mass Personalization are factors that play an important role in Supply Chain effectiveness (Flynn et al., 2010; Strasser et al., 2011).

There is agreement that there may be a positive effect between Supply Chain Integration (SCl) and the Business Performance, whether operational or financial ( $\mathrm{Li}$ et al, 2009; Giménez et al., 2012). Literature also shows that both internal and external process integration should be considered if the company is to achieve a full effect on its performance (Stank et al., 2001; Giménez and Ventura, 2005; Devaraj et al., 2007; Flynn et al., 2010). In fact, the development of SCI reduces the uncertainty and allows for a greater flexibility and responsiveness to the Supply Chain members' needs (Johnston and Wright, 2004; Malhotra and Mackelprang, 2012). Recent studies show that flows integration (physical, information, and financial) could lead to synergy benefits achieved through an integrated system, which would affect Business Performance (Bruque et al. 2015; 2016).

Likewise, previous literature show that Supply Chain Flexibility (SCF) is one of the competitive priorities with which many companies must establish management actions (Elms and Low, 2013; Moon et al. 2012). SCF allows companies to change their processes, resources, structure and management mechanisms, responding quickly to changes in demand in terms of production volume and product variety (Lummus et al., 2003). Literature also shows that Business Performance could be related to a company's ability to offer flexibility (Dev et al., 2014). In fact, companies would be able to respond to individual requests, quickly, without considerable cost and consequently improve their 
performance (Stump and Badurdeen, 2012). However, although relationships have been established between different types of flexibilities, the extent to which flexibility affects the system's performance has not yet been sufficiently investigated.

Mass Personalization (MP) appears as a relatively recent trend by companies and represents a major competitive advantage (Lau, 1995; Kumar et al., 2015, Marin and Brîndaşu, 2015). Several authors show that MP denotes the ability to provide rapid transmission of personalized goods and services at low cost and in large scale (Frutos and Borenstein, 2003; Machado and Moraes, 2008; Purohit et al., 2016). To achieve the expected MP levels and improve business efficiency and performance, companies need to focus on improving process characteristics and product quality (Ho et al., 2008).

\subsubsection{SUPPLY CHAIN EFFICIENCY FACTORS AND BUSINESS PERFORMANCE}

Previous literature has analysed the relationship between some factors related to increased business efficiency. Organizational factors, such as Lean Production implementation, and technological factors, such as Cloud-supported Logistics, could be related to overall business efficiency and performance.

Lean Production implementation (LPI) and its effects on Business Performance have been extensively studied in recent decades (Womack et al., 1990; Womack and Jones, 1996; Cagliano et al., 2006). Literature shows that the practices commonly associated with Lean Production implementation are: Just in time, Cellular Manufacturing, Total Productive Maintenance, Total Quality Management, and Human Resources Management (Shah et al., 2008; Moyano et al., 2012). Literature also shows that LPI extend to manufacturing operations, distribution, product development and processing times (Holweg, 2007; Stump and Badurdeen, 2012), seeking continuous improvement and elimination of all waste forms. In fact, LPI could increase production efficiency and response to demand variations, and eliminating everything that is not strictly necessary to produce benefit for the organization (Pérez et al., 2010; van der Vaart et al., 2012).

The direct and indirect effects of Cloud Computing on Business Performance has been also studied (Bruque et al., 2015; Trappey et al., 2016). Cloud Computing enables ubiquitous, convenient, on-demand network access to a shared pool of configurable computing resources that can be rapidly provisioned and released with minimal management effort or service provider interaction (Mell and Grance, 2011). Literature shows that Cloud Computing is a good IT alternative and achieves greater efficiency than previous technologies (Rai et al., 2012; Vermula and Zsifkovits, 2016). However, some literature evidence indicates that there is no direct relationship between Cloud 
Computing use and better Business Performance, but does through other resources and capabilities (Bruque et al., 2015, 2016).

More specifically, Cloud-supported Logistics (CSL) is the application of Cloud Computing to Logistics. Some research shows that CSL could reduce errors in the information systems that support companies' logistics activities, while automating and integrating logistics data collection tasks (Li et al., 2013; Subramanian et al., 2015). In fact, CSL could affect the internal logistics aspects of the organization's productive structure, as well as the interconnections and functioning within inter-organizational configurations (Rai et al., 2015; Vermula and Zsifkovits, 2016). CSL could improve business efficiency through the integration of appropriate information on order processing and distribution, as well as helping to improve inventory and fleet management (Dermirkan et al., 2010; Oliveira, 2013). As a result, CLS could have a strong impact on coordination strategies in Supply Chain, helping companies to be more efficient (Dermirkan et al., 2010; Rai et al., 2015).

\subsection{METHODOLOGY}

Hypothesis have been tested through Structural Equations Models (SEM) a technique widely used in Supply Chain Management research. However, this technique provides a static vision of the observed reality, as a snapshot of that reality at a specific moment in time. In the Supply Chain Management context, dynamic analyses are also necessary to visualize the business behaviour in different scenarios projected into the future. These dynamic analyses can be performed using System Dynamics Models (SDM). In this context, a combined SEM/SDM methodology is a path that allows for prospective strategic analysis, using the complementarity between SEM and SDM by jointly use both methodological approaches, the static one, based on data arising from a given point in time with no future projections (SEM) and a future-based projection based on current data, able to provide a vision on how variables may behave in the future (SDM). This combined SEM/SDM methodology allow researchers who have tested hypotheses with SEM to create simulations over time on the different relationships between the variables being studied. Generally, SEM establishes structural models of high conceptual level, of strategic level, so SEM/SDM methodology can be very useful to analyse the temporal evolution of relationships between variables at strategic level since it will provide to researchers and managers information about the current valid relationships between a given set of variables and most important a foreseen behaviour path projected into the 
future. Thus, researchers and managers may create time-frames that model a particular business process or problem and bring forward potential solutions.

SEM/SDM methodology is made up of five stages (Figure 6.1). In Stage 1, the problem/objective to be analysed by SEM/SDM is clearly defined. In Stage 2, the qualitative data from SEM are collected and the SEM/SDM causal diagram is formulated. In stage 3, the quantitative data from SEM are collected and the SEM/SDM flow diagram is formulated, then, in Stage 4, the SEM/SDM is performed and validated. Finally, in Stage 5, the SEM/SDM simulation results are generated and analysed.

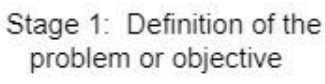
problem or objective

Stage 2: Conceptualisation

Stage 3: Formalisation

Stage 4: Performance and evaluation

Stage 5: Exploitation

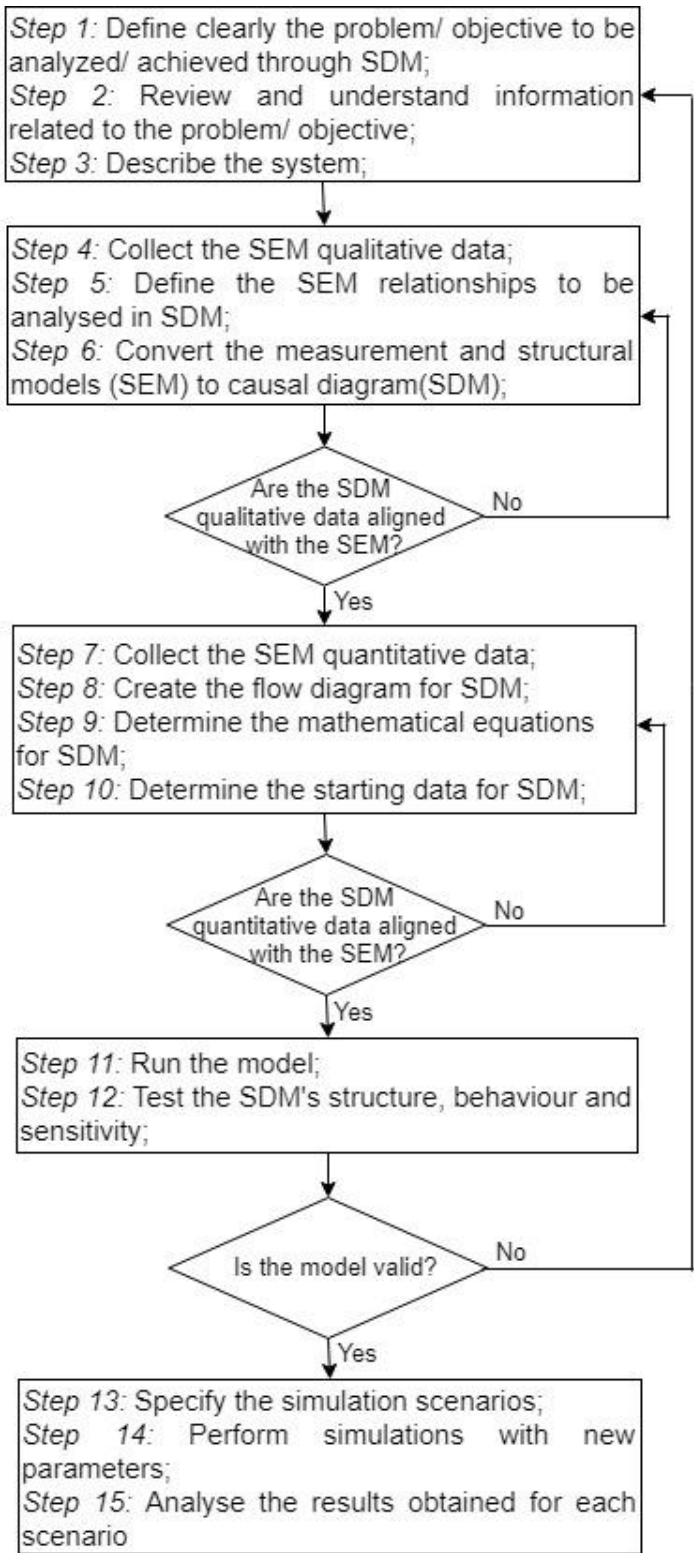

scenario

Figure 6.1. SEM/SDM methodology (Chapter 5) 
The five-stage SEM/SDM methodology is applied to investigate the dynamic interrelationships between factors related to the Supply Chain effectiveness and efficiency and their relationship to Business Performance. The application of SEM/SDM methodology is detailed below.

\section{Stage 1. Definition of the SEM/SDM objective}

First, the data source to be used in the SEM/SDM model is defined (Step 1). Two primary data sources will be used jointly in this simulation. On the one hand, qualitative and quantitative relationships obtained from two Structural Equation Models (SEM1 in Chapter 4 and SEM2 in Chapter 5) will be used to develop and validate the simulation model. On the other hand, the data obtained through an interview with a Cloud-supported logistics company, fictitiously named CSLC for reasons of confidentiality, will be used to define the scenarios that will be analysed. Qualitative and quantitative information was obtained through the interviews in the company. This qualitative information will be key to define all the model parameters in the SDM methodology Therefore, the relationships obtained from SEM1 and SEM2 will be applied to the SEM/SDM model, which will serve as a strategic decision making tool for CSLC. More details about CSLC will be presented in Section 4.

Next, the information related to the SEM/SDM objective must be reviewed and understood (Step 2). The primary data refer to two models of Structural Equations (SEM1 and SEM2) that have been carried out previously (Chapters 4 and 5). On the one hand, SEM1 results shows that Lean production and its different practices to achieve better performance, both financially and operationally (Figure 6.2). When Lean practices are based on Cloud-supported Logistics, then the effect on Business Performance is multiplied. By having Lean Production adopted, which provides business efficiency that the Cloud-supported Logistics user pursues, companies can achieve efficiency in intraand inter-organizational integration. Therefore, Cloud-supported Logistics in the presence of Lean practices, not only helps Supply Chain Integration, but also has a strong indirect impact on Business Performance. 


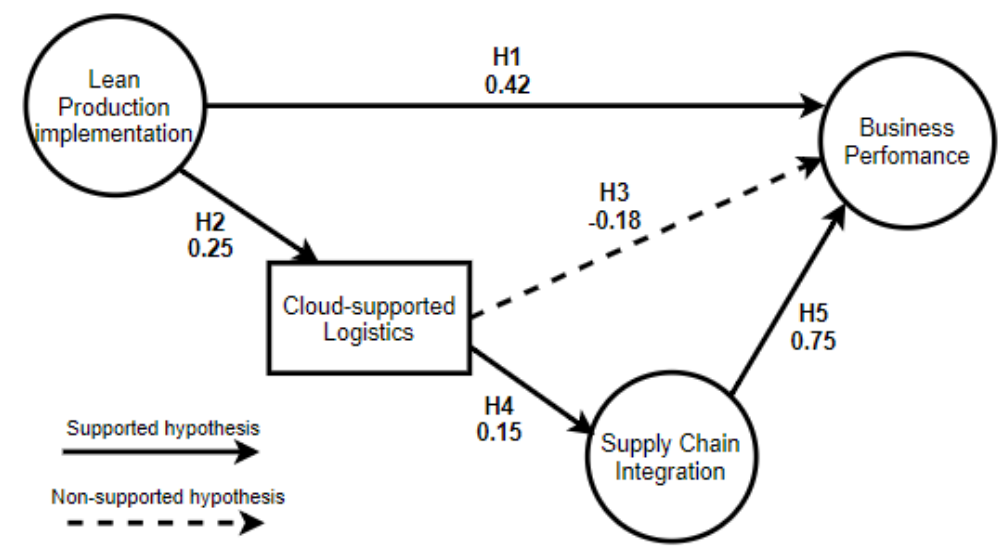

Figure 6.2. SEM1 results (Chapter 4)

On the other hand, SEM2 results show that when Lean practices are based on Supply Chain Flexibility, the effect on Mass Personalization and Business Performance is multiplied (Figure 6.3). The complementarity between Lean Production implementation and Supply Chain Flexibility is a way to achieve higher levels of Mass Personalization and, ultimately, improve operational and financial performance. Lean Production, therefore, not only helps Supply Chain Flexibility to be even more effective, but also has a strong indirect impact on Mass Personalization and Business Performance.

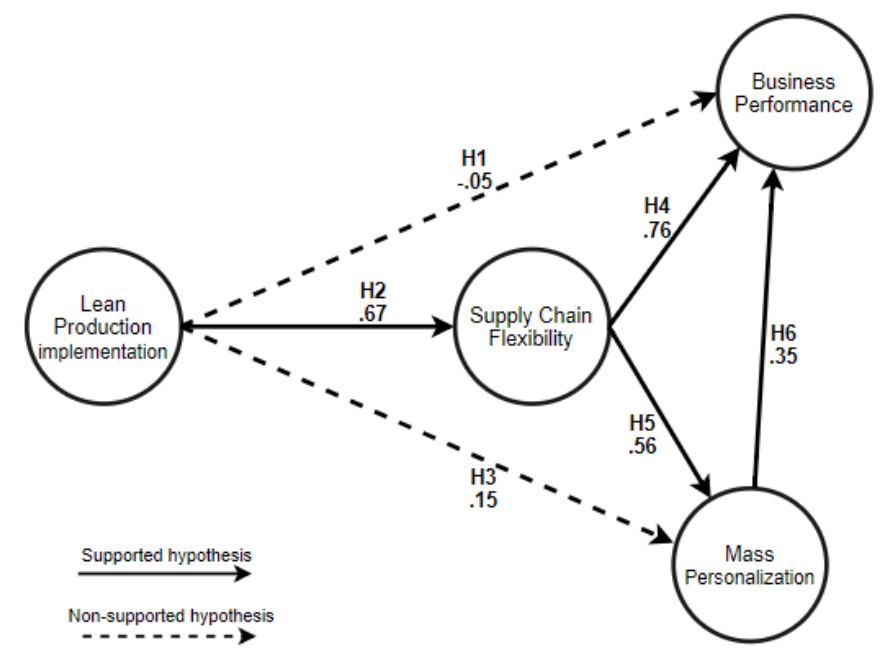

Figure 6.3. SEM2 results (Chapter 5)

Likewise, the system to be simulated must be described (Step 3). On the one hand, the SEM 1 results show that LPI exerts a positive effect on BP (SEM1_H1) and demonstrate a positive relationship between LPI and CSL (SEM1_H2). Positive relationships between CSL and SCI (SEM1_H4), as well as between SCI and BP (SEM1_H5) have also been confirmed (see Figure 6.2). Nevertheless, the relationship between CSL and BP 
(SEM1_H3) have been rejected (see Figure 6.2). On the other hand, the SEM 2 results indicate a positive relationship between LPI and SCF (SEM2_H2), as well as between SCF and BP (SEM2_H4) (see Figure 6.3). Positive relationships between SCF and MP (SEM2_H5), as well as between MP and BP (SEM2_H6) have also been demonstrated. However, the relationship between LPI and BP (SEM2_H1) and the relationship between LPI and MP (SEM2_H3) have been rejected (see Figure 6.3). A visual representation of the model conceptualisation will be presented in the next stage.

Based on the above, the behaviour of the interrelations between variables present in SEM1 and SEM2 variables interrelationships in different scenarios projected in a future time will be analysed. Therefore, the objetive of this SEM/SDM model is to provide a temporal analysis of static relationships between Supply Chain effectiveness and efficiency factors coming from SEM. Therefore, we would like to analyze the interrelationships over time between Lean Production implementation, Cloud-supported Logistics, Supply Chain Integration, Supply Chain Flexibility and Mass Personalization. We also aim to analyse the impact that the combination of these factors on Business Performance over the simulation period. Once the SEM/SDM is developed and validated, we will apply it as a strategic decision making tool for the specific case of CSLC from the company's own data.

\section{Stage 2. Conceptualisation}

In this stage, the causal diagram for SEM/SDM is constructed. The qualitative data from SEM for the SDM construction would be identified and defined (Step 4). Results of eleven hypothesis (five in SEM1 and six in SEM2) tested through the SEM methodology have been used to define the cause-effect relationships to be analysed in the SEM/SDM. In SEM1, the interrelationships between Lean Production implementation (LPI), Cloudsupported Logistics use (CSL), Supply Chain Integration (SCI), and their effects on Business Performance (BP) have been analysed. In SEM2, the mediating role of Supply Chain Flexibility (SCF) in the interrelationships between Lean Production Implementation (LPI), Mass Personalization (MP) and Business Performance (BP) has been analysed.

Next, the SEM cause-effect relationships to be applied in the SDM is collected (Step 5). Qualitative data and the cause-effect relationships obtained from SEM are presented in Table 6.1, which show that just statistically significant relationships between the variables of SEM1 and SEM2 will be used in the SEM/SDM model. 
Table 6.1. Relationships of SEM 1 and SEM 2

\begin{tabular}{|c|c|c|c|c|}
\hline \multicolumn{2}{|c|}{ Tested Hypothesis } & \multicolumn{2}{c|}{ Cause-effect relationships } & $\begin{array}{c}\text { Will it be used in the } \\
\text { SEM/SDM model? }\end{array}$ \\
\hline \multirow{4}{*}{ SEM 1 } & SEM1_H1 & LPI $\rightarrow$ BP & Positive and significant & Yes \\
\cline { 2 - 5 } & SEM1_H2 & LPI $\rightarrow$ CSL & Positive and significant & Yes \\
\cline { 2 - 5 } & SEM1_H3 & CSL $\rightarrow$ BP & Negative and non- significant & No \\
\cline { 2 - 5 } & SEM1_H4 & CSL $\rightarrow$ SCl & Positive and significant & Yes \\
\cline { 2 - 5 } & SEM1_H5 & SCI $\rightarrow$ BP & Positive and significant & Yes \\
\hline \multirow{5}{*}{ SEM 2} & SEM2_H1 & LPI $\rightarrow$ BP & Negative and non- significant & No \\
\cline { 2 - 5 } & SEM2_H2 & LPI $\rightarrow$ SCF & Positive and significant & Yes \\
\cline { 2 - 5 } & SEM2_H3 & LPI $\rightarrow$ MP & Positive and non- significant & No \\
\cline { 2 - 5 } & SEM2_H4 & SCF $\rightarrow$ BP & Positive and significant & Yes \\
\cline { 2 - 5 } & SEM2_H5 & SCF $\rightarrow$ MP & Positive and significant & Yes \\
\cline { 2 - 5 } & SEM2_H6 & MP $\rightarrow$ BP & Positive and significant & Yes \\
\hline
\end{tabular}

Based on the above, we are able to design the SEM/SDM cause-effect diagram (Step 6). In Figure 6.4, the relationships between the SEM structural model variables are visually represented, with the interrelationships between factors that affect the Supply Chain's effectiveness and efficiency, as well as their relationship with Business Performance.

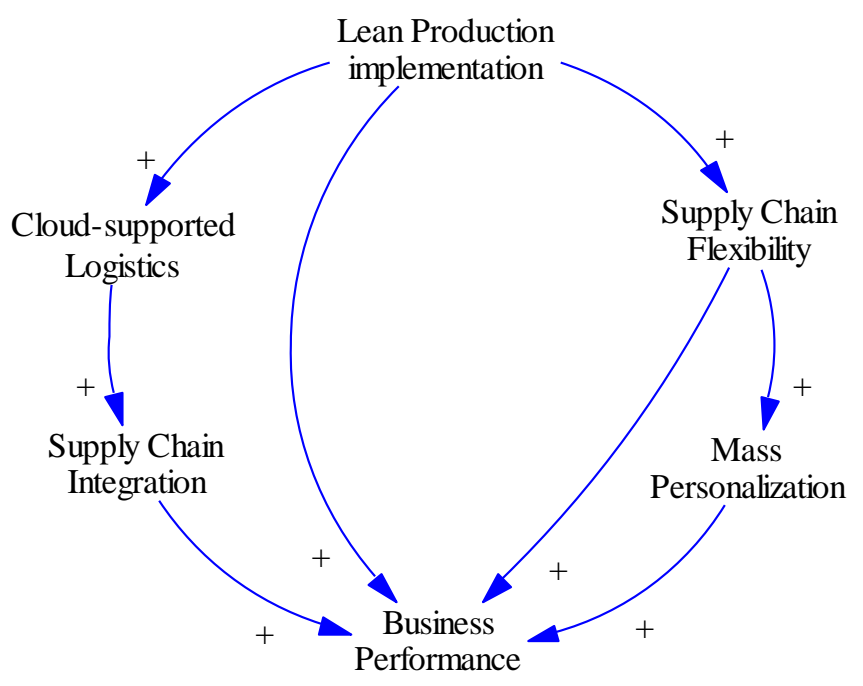

Figure 6.4. Causal diagram to Supply Chain effectiveness and efficiency, and their relationship to Business Performance

Finally, the causal diagram developed by SEM/SDM has been analysed, confirming that it is aligned with the information provided by SEM. Most relevant SEM variables are represented in the causal diagram and the cause-effect relationship between them is in accordance with the SEM information. 


\section{Stage 3: Formalisation}

In this stage, the flow diagram for the SEM/SDM is built up. First, the SEM quantitative data is collected from secondary sources (Step 7). Data of the measurement model (items factorial loads) and the structural model (factorial load between constructs) have been selected. This information is specified on Chapters 3 and 4 , which represents the data referring to the relationships between SEM items and constructs, as well as the factorial load selection to be used in SEM/SDM. Then, the SEM/SDM flow diagram is created (Step 8). Based on the information collected from the causal diagram, the variables (level, flow, auxiliary and parameters) have been defined and the flow diagram has been drawn, as it is shown in Figure 6.5. 


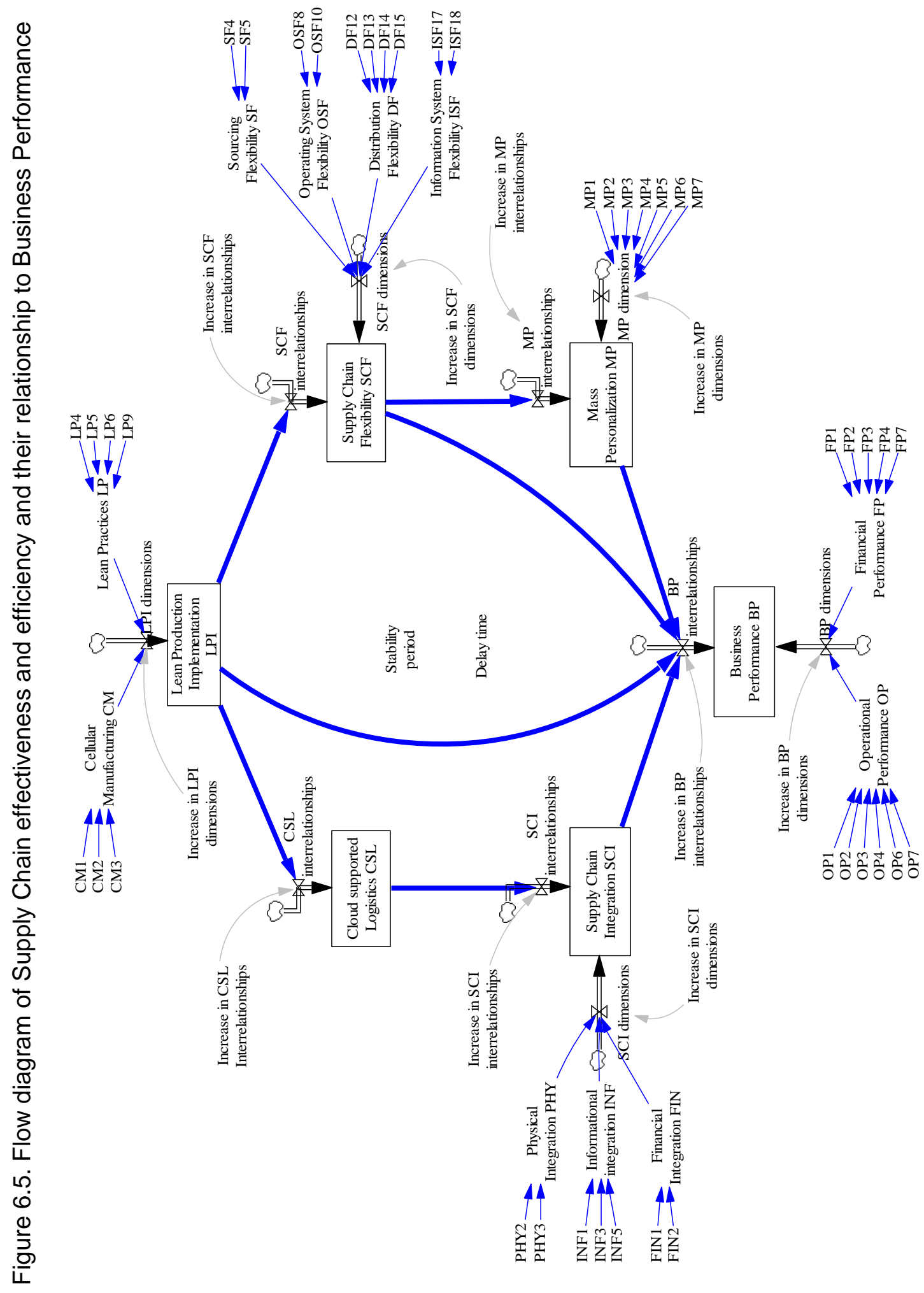


LPI, CSL, SCI, SCF, MP, and BP are considered as level variables. The flow variables $\mathrm{SCl}$ interrelationships, SCl interrelationships, SCF interrelationships, MP interrelationships and $B P$ interrelationships are used to "channel" factorial loads between the levels variables $(\mathrm{LP} \rightarrow C C, L P \rightarrow S C F, L P \rightarrow B F, C C \rightarrow S C l, S C l \rightarrow B P, S C F \rightarrow M P$, $S C F \rightarrow B P$, and $M P \rightarrow B P$ ). Similarly, the flow variables $L P I$ dimensions, $S C l$ dimensions, SCF dimensions, MP dimension, and BP dimensions are used to "channel" dimensions loads to the correspondent level variable. Cellular Manufacturing CM, Lean Practices $L P$, Physical Integration PHY, Information Integration INF, Financial Integration FIN, Sourcing Flexibility SF, Operation System Flexibility OSF, Distribution Flexibility DF, Information System Flexibility ISF, Operational Performance $O P$ and Financial Performance $F P$ are auxiliary variables that receive the items loads. The parameters CM1, CM2, CM3, LP4, LP5, LP6, LP9, PHY2, PHY3, INF1, INF3, INF5, FIN1, FIN2, SF4, SF5, OSF8, OSF10, DF12, DF13, DF14, DF15, ISF17, IFS18, DEL1, MP1, MP2, MP3, MP4, MP5, MP6, MP7, OP1, OP2, OP3, OP4, OP6, OP7, FP1, FP2, FP3, FP4 and FP7 represent the items factorial loads. The parameters Increase in the CSL interrelationships, Increase in the SCl interrelationships, Increase in the SCF interrelationships, Increase in the MP interrelationships, and Increase in BP interrelationships are parameters that allowing the increase extra loads to the level variables interrelationships. Increase in LPI dimensions, Increase in SCl dimensions, Increase in SCF dimensions, Increase in MP dimensions and Increase in BP dimensions are parameters that allowing the increase extra loads to a specific level variable. Finally, Stability Period and Delay Time are parameters that allow increasing or reducing the stability time (time without increasing extra loads) and the loads flow time (time required for the constructs loads to affect the constructs levels). These time variables are related to all level variables and flows in the model. However, arrows connecting these variables have been hidden to make the SEM/SDM cleaner.

Likewise, the mathematical equations that will compose the flow diagram are formulated (Step VI), as shown in Table 6.2. 
Table 6.2. Mathematical equations to the SEM/SDM variables

\begin{tabular}{|c|c|c|}
\hline & Variable & Formula \\
\hline \multirow{6}{*}{ LEVEL } & Lean Production implementation LPI & $\begin{array}{l}\text { DELAY FIXED ( MIN (LPI dimensions, 1), Delay } \\
\text { Time, 0.3) }\end{array}$ \\
\hline & Cloud supported Logistics CSL & $\begin{array}{l}\text { DELAY FIXED ( MIN (CSL interrelationships, 1), } \\
\text { Delay Time, 0.15) }\end{array}$ \\
\hline & Supply Chain Integration SCI & $\begin{array}{l}\text { DELAY FIXED ( MIN (SCI dimensions + SCI } \\
\text { interrelationships, 1), Delay Time, 0.75) }\end{array}$ \\
\hline & Supply Chain Flexibility SCF & $\begin{array}{l}\text { DELAY FIXED ( MIN (SCF dimensions + SCF } \\
\text { interrelationships, 1), Delay Time, 0.76) }\end{array}$ \\
\hline & Mass Personalization MP & $\begin{array}{l}\text { DELAY FIXED ( MIN (MP dimension + MP } \\
\text { interrelationships, 1), Delay Time, 0.75) }\end{array}$ \\
\hline & Business Performance BP & $\begin{array}{l}\text { DELAY FIXED ( MIN ( (BP dimensions + BP } \\
\text { interrelationship, 1), Delay Time, 0.75) }\end{array}$ \\
\hline \multirow{10}{*}{ FLOW } & CSL interrelationships & $\begin{array}{l}\text { IF THEN ELSE ((Time/Stability Period)= } \\
\text { INTEGER(Time/Stability } \quad \text { Period), }((\text { Lean } \\
\text { Production Implementation LPI })^{*} \text { Increase in CSL } \\
\text { Interrelationships), 0) }\end{array}$ \\
\hline & SCI interrelationships & $\begin{array}{l}\text { IF THEN ELSE((Time/Stability Period)= } \\
\text { INTEGER(Time/Stability } \quad \text { Period),(Cloud } \\
\text { supported Logistics CSL)*Increase in SCI } \\
\text { interrelationships ,0) }\end{array}$ \\
\hline & SCF interrelationships & 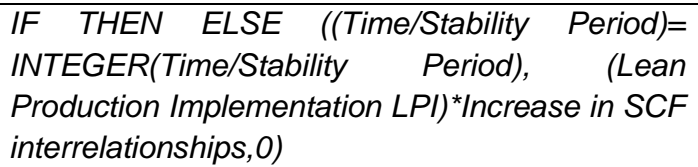 \\
\hline & MP interrelationships & $\begin{array}{l}\text { IF THEN ELSE ((Time/Stability Period)= } \\
\text { INTEGER(Time/Stability Period), (Supply Chain } \\
\text { Flexibility SCF) *Increase in } M P \\
\text { interrelationships,0) }\end{array}$ \\
\hline & BP interrelationships & 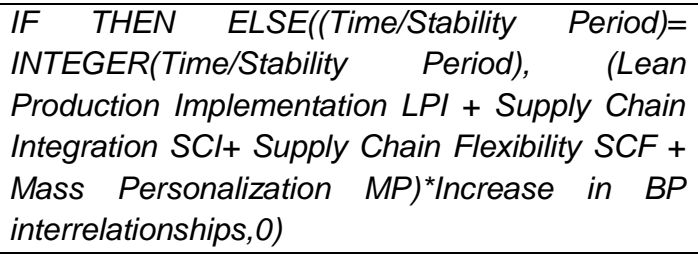 \\
\hline & LPI dimensions & $\begin{array}{l}\text { IF THEN ELSE ((Time/Stability Period)= } \\
\text { INTEGER(Time/Stability Period), }(((\text { Cellular } \\
\text { Manufacturing CM + Lean Practices LP }) / 2)+ \\
\text { Increase in LPI dimensions),0) }\end{array}$ \\
\hline & SCl dimensions & $\begin{array}{l}\text { IF THEN ELSE ((Time/Stability Period)= } \\
\text { INTEGER(Time/Stability Period), (((Financial } \\
\text { Integration FIN + Informational Integration INF + } \\
\text { Physical Integration PHY)/3)*Increase in SCI } \\
\text { dimensions),0) }\end{array}$ \\
\hline & SCF dimensions & $\begin{array}{l}\text { IF THEN ELSE ((Time/Stability Period)= } \\
\text { INTEGER(Time/Stability Period),(((Distribution } \\
\text { Flexibility DF + Information System Flexibility ISF } \\
+ \text { Operating System Flexibility OSF + Sourcing } \\
\text { Flexibility SF)/4)*Increase in SCF dimensions),0) }\end{array}$ \\
\hline & MP dimension & $\begin{array}{l}\text { IF THEN ELSE ((Time/Stability Period })= \\
\text { INTEGER(Time/Stability Period }),(((M P 1+M P 2+ \\
M P 3+M P 4+M P 5+M P 6+M P 7) / 7)^{\star} \text { Increase in } \\
M P \text { dimensions }), 0)\end{array}$ \\
\hline & BP dimensions & $\begin{array}{l}\text { IF } \quad \text { THEN } \quad \text { ELSE((Time/Stability } \\
\text { Period)=INTEGER(Time/Stability } \\
\text { Period),(((Operational Performance OP }\end{array}$ \\
\hline
\end{tabular}




\begin{tabular}{|c|c|c|}
\hline & & $\begin{array}{l}\text { +Financial Performance FP)/2)*Increase in } B P \\
\text { dimensions),0) }\end{array}$ \\
\hline \multirow{11}{*}{$A \cup X I L I A R Y$} & Cellular manufacturing $\mathrm{CM}$ & $((C M 1+C M 2+C M 3) / 3)^{*} 0.7$ \\
\hline & Lean Practices $L P$ & $((L P 4+L P 5+L P 6+L P 9) / 4)^{*} 0.8$ \\
\hline & Physical integration $\mathrm{PHY}$ & $((P H Y 2+P H Y 3) / 2)^{*} 0.84$ \\
\hline & Information integration INF & $((I N F 1+I N F 3+I N F 5) / 3)^{*} 0.85$ \\
\hline & Financial integration FIN & $((F I N 1+F I N 2) / 2) * 0.5$ \\
\hline & Sourcing flexibility SF & $((S F 4+S F 5) / 2)^{*} 0.65$ \\
\hline & Operation system flexibility OSF & $((O S F 8+O S F 10) / 2) * 0.79$ \\
\hline & Distribution flexibility DF & $((D F 12+D F 13+D F 14+D F 15) / 4)^{*} 0.79$ \\
\hline & Information System Flexibility ISF & $((I S F 17+I S F 18) / 2)^{*} 0.39$ \\
\hline & Operational Performance OP & $((O P 1+O P 2+O P 3+O P 4+O P 6+O P 7) / 6)^{*} 0.79$ \\
\hline & Financial Performance FP & $((F P 1+F P 2+F P 3+F P 4+F P 7) / 5)^{*} 0.44$ \\
\hline
\end{tabular}

$L P I, C S L, S C I, S C F, M P$ and $B P$ have been defined based on the level variables dimensions and/or on the level variables interrelationships, as well as on Delay Time. The level variables formulas show that, after Delay Time, the cause variables' loads increase the effect variables' levels. The level variables formulas also show the initial level for these variables, which are the factorial load that the cause variable exert on the effect variable (Data from SEM. See Chapters 3 and 4). For example, the initial value for $\mathrm{SCl}$ is 0.75 , and it means that $\mathrm{SCl}$ exert a load of 0.75 on OP in Time = zero. However, as BP is not a cause level variable, its initial value is the average of dimensions loads that compose BP construct in Time = zero (Data from SEM. See Chapters 3 and 4). Furthermore, a DELAY FIXED function has been included, which indicates a delay time for the cause variables loads affecting the effect variables levels. To do so, the Delay Time parameter in the SEM/SDM has been included. The Vensim function named MIN has been included to stabilize the systems when the maximum level of a level variable is reached (in this case, the maximum value that a variable level can reach is 1 ).

CSL interrelationships, SCI interrelationships, SCF interrelationships, MP interrelationships, and $B P$ interrelationships are flow variables defined from the parameters Increase in CSL interrelationships, Increase in SCI interrelationships, Increase in SCF interrelationships, Increase in MP interrelationships, Increase in BP interrelationships and Stability Period. These equations indicate that after the stability time defined by the model user the SEM/SDM will increase a new load to the level variables. $\mathrm{LPI}$ dimensions, SCI dimensions, SCF dimensions, MP dimension, and BP dimensions are flow variables defined from dimensions loads. These variables also depend of the parameters Increase in LPI dimensions, Increase in SCl dimensions, Increase in SCF dimensions, Increase in MP dimension and Increase in BP dimensions. The IF THEN ELSE function has been included, indicating that at each time period equal to the division between the total simulation time and the stability time (Time/Stability Period), the model increases a load to the variables interrelationships. 
Finally, the auxiliary variables Cellular Manufacturing CM, Lean Practices $L P$, Physical Integration PHY, Information Integration INF, Financial Integration FIN, Sourcing Flexibility SF, Operation System Flexibility OSF, Distribution Flexibility DF, Information System Flexibility ISF, Operational Performance OP and Financial Performance FP are calculated by the average loads of items that compose each dimension.

Then, the time horizon of the simulation is defined (Step VII). The company studied wishes to know the impacts of the model's variables implementation in the next twenty four months, which is the simulation time that will be adopted. Next, the SEM/SDM starting data are determined (Step VII) from the SEM information, as detailed below:

- CM1, CM2, CM3, LP4, LP5, LP6, LP9, PHY2, PHY3, INF1, INF3, INF5, FIN1, FIN2, SF4, SF5, OSF8, OSF10, DF12, DF13, DF14, DF15, ISF17, IFS18, DEL1, MP1, MP2, MP3, MP4, MP5, MP6, MP7, OP1, OP2, OP3, OP4, OP6, OP7, FP1, FP2, FP3, FP4, and FP7: The starting data for these parameters are the factorial loads obtained from SEM Confirmatory Factorial Analysis (see Chapters 3 and 4).

- Increase in CSL interrelationships, Increase in SCI interrelationships, Increase in SCF interrelationships, Increase in MP interrelationships, Increase in BP interrelationships, Increase in LPI dimensions, Increase in SCl dimensions, Increase in SCF dimensions, Increase in MP dimension and Increase in BP dimensions: The starting data for these parameters are defined as the value 0 , and this value can be altered in the scenario formulation stage. For example, if the SEM/SDM user want to increase 0.1 in the SCI dimensions loads, Increase in SCl dimensions will be 0.1 . These values could be increased/decreased in the scenarios creation stage, as a way to verify the model behaviour when factorial loads are altered.

- Time, Stability Period and Delay Time. As seen before, the value for Time is 24 months. For the first simulation, the Stability Period value be equal to Time, which allows the model to be analysed only with data from SEM (current scenario). A Delay Time value equal to one month will be adopted, indicating that one simulation period would be necessary for the cause-variable's loads to affect the effect-variable's levels. Time, Stability Period and Delay Time can also assume other values in the scenarios that will be simulated, as a way of analysing the time related to the results that will be achieved. - LPI, CSL, SCI, SCF, MP and BP: The starting values for these level variables are the factorial loads obtained through the SEM variances or covariances analyses (see construct $\rightarrow$ construct relationships in Figure 6.11). The starting data for OP is the average of OP items loads in Time=zero. 
- LPI dimensions, CSL interrelationships, SCI dimensions, SCI interrelationships, SCF dimensions, SCF interrelationships, MP dimension, MP interrelationships, BP dimensions and $B P$ interrelationships: These flow variables do not have pre-defined starting values, since they depend of the SEM/SDM parameters values.

Finally, the flow diagram developed by SEM/SDM has been analysed, confirming that it is aligned with the information provided by SEM. The most important SEM variables are represented in the causal diagram and the cause-effect relationship between them is in accordance with the SEM information. It has also been verified that the mathematical equations and the starting data are correctly formulated and the relationship between variables is in accordance with the SEM information.

\section{Stage 4: Performance and evaluation}

The SEM/SDM is performed (Step 11) and the SEM/SDM validity and quality is checked (Step 12), The SEM/SDM simulation has been carried out using the Vensim ${ }^{\circledR}$ software. The initial configuration parameters have been established as follows: Start time: zero; End time: 24; and Time unit: months. This first simulation has been performed with just with the data obtained from SEM (without adding extra loads to the analysis variables). For this reason, the SEM/SDM should show a stable behaviour (without increasing loads or levels) during the whole simulation period. In other words, the variable levels in Time $=24$ should be similar to the variable levels at the beginning of the simulation (Time $=0$ ). In the real world, this means that a company would not increase the implementation levels of the items or dimensions that compose the analysed constructs. This shows that the model has performed well against the abnormal behaviour test (Sterman, 2000). The results are shown in Figure 6.6 and confirm the expected stability of the SEM/SDM. The blue line represent the level variables relationships over time. This first performance have generated the baseline model (Figure 6.5), which present a positive result, since the model is executed correctly, without errors of unit, development or structure (Forrester, 1961; Sterman, 2000). It shows that the SEM/SDM had good results against the Limits Adequacy, Structure check, Dimensional consistency, and Checking Parameters tests (Sterman, 2000). 


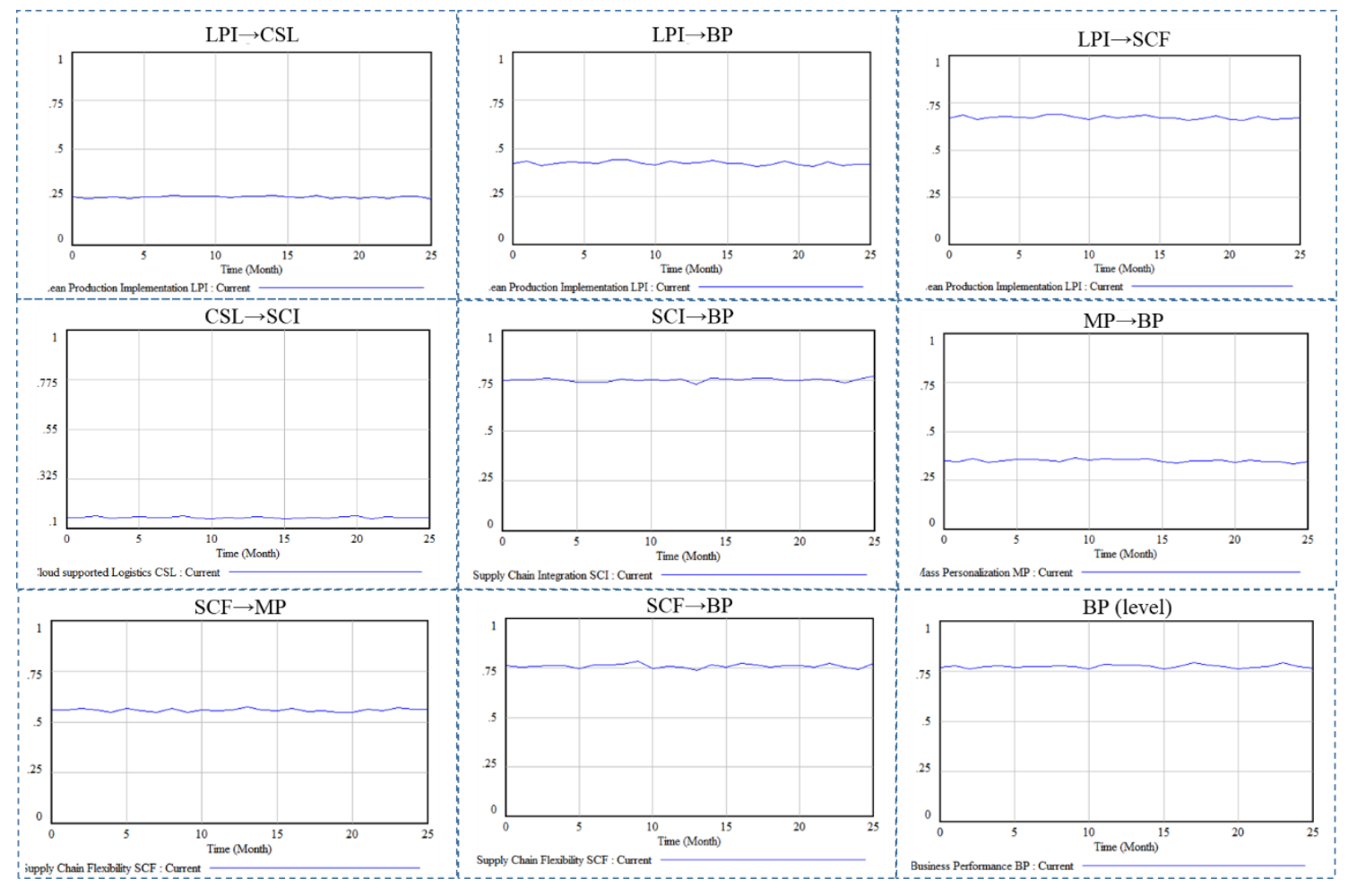

Note: $L P I \rightarrow C L S=$ Impact of Lean Production Implementation (LPI) on Cloud-supported Logistics (CSL); $L P I \rightarrow B P=$ Impact of Lean Production Implementation (LPI) on Business Performance (BP); $L P I \rightarrow S C F=$ Impact of Lean Production Implementation (LPI) on Supply Chain Flexibility (SCF); CSL $\rightarrow S C I=I m p a c t$ of Cloud-supported Logistics (CSL) on Supply Chain Integration (SCl); $S C l \rightarrow B P=I m p a c t$ of Supply Chain Integration (SCI) on Business Performance (BP); $M P \rightarrow B P=$ Impact of Mass Personalization (MP) on Business Performance (BP); SCF $\rightarrow M P=$ Impact of on Supply Chain Flexibility (SCF) on Mass Personalization (MP); $S C F \rightarrow B P=$ Impact of on Supply Chain Flexibility (SCF) on Business Performance $(B P) ; B P($ level) = Impact of BP Dimensions on Business Performance (BP) level;

Figure 6.6. SEM/SDM run for the level variables interrelationships

In addition, the extreme conditions test was performed. In this test, the SEM/SDM robustness is checked with extreme values (very high) for variable loads. This test will check if the model presents results that responds to abrupt variations of the input data. To run this test, the following values were increased by a 1,000\%: Increase in CSL interrelationships, Increase in SCl interrelationships, Increase in SCF interrelationships, Increase in MP interrelationships, Increase in BP interrelationships, Increase in LPI dimensions, Increase in SCI dimensions, Increase in SCF dimensions, Increase in MP dimension, and Increase in BP dimensions. Figure 6.7 shows some of the tests performed (LPI, SCI and BP), confirming that the SEM/SDM is robust even in extreme conditions. Although not represented graphically in Figure 6.7, the other level variables (CSL, SCF, and MP) have also presented robustness in the extreme condition tests. 


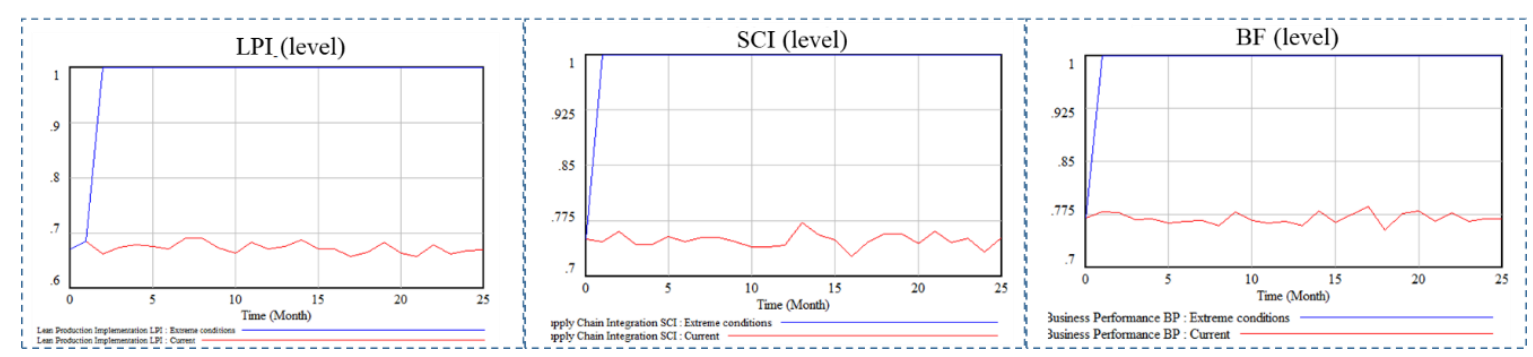

Note: LPI (level): Level of Lean Production Implementation; SCI (Level) = Level of Supply Chain Integration; BP (level) = Level of Business Performance

Figure 6.7. Extreme condition test for the SEM/SDM variables

Finally, the SEM/SDM sensitivity test is performed. For this purpose, the Monte Carlo simulation has been performed using the Vensim ${ }^{\circledR}$ software. Monte Carlo simulation is a statistical methodology based on a large amount of random sampling to achieve results close to real results, allowing a sufficiently large number of tests to be performed in order to have more accurate results (Bois and Maszle, 1997). To do so, five hundred simulations have been performed through Monte Carlo simulation to test sensitivity analysis and the values could vary between the minimum and maximum values with a uniform random distribution. Figure 6.8 shows the Monte Carlo simulations that have been carried out to test the sensitivity of SEM/SDM, graphically representing the temporal evolution of a combination of variables during a given period. That is to say, the possible load increases caused by the causal variables on the effect variables ( $Y$ axis) during 24 months ( $X$ axis). The red line shows the starting scenario (current) for each combination of causal variables analysed and their impact on the effect variable. The SEM/SDM behaviour throughout the 24 months of simulation, represented in the graphs below, shows that the effect variable levels are sensitive to variations in causal variable loads. That is, variations in the causal variable loads proportionally affect the effect variable levels. Therefore, results indicate that the SEM/SDM is sensitive to variation in causal variables. 

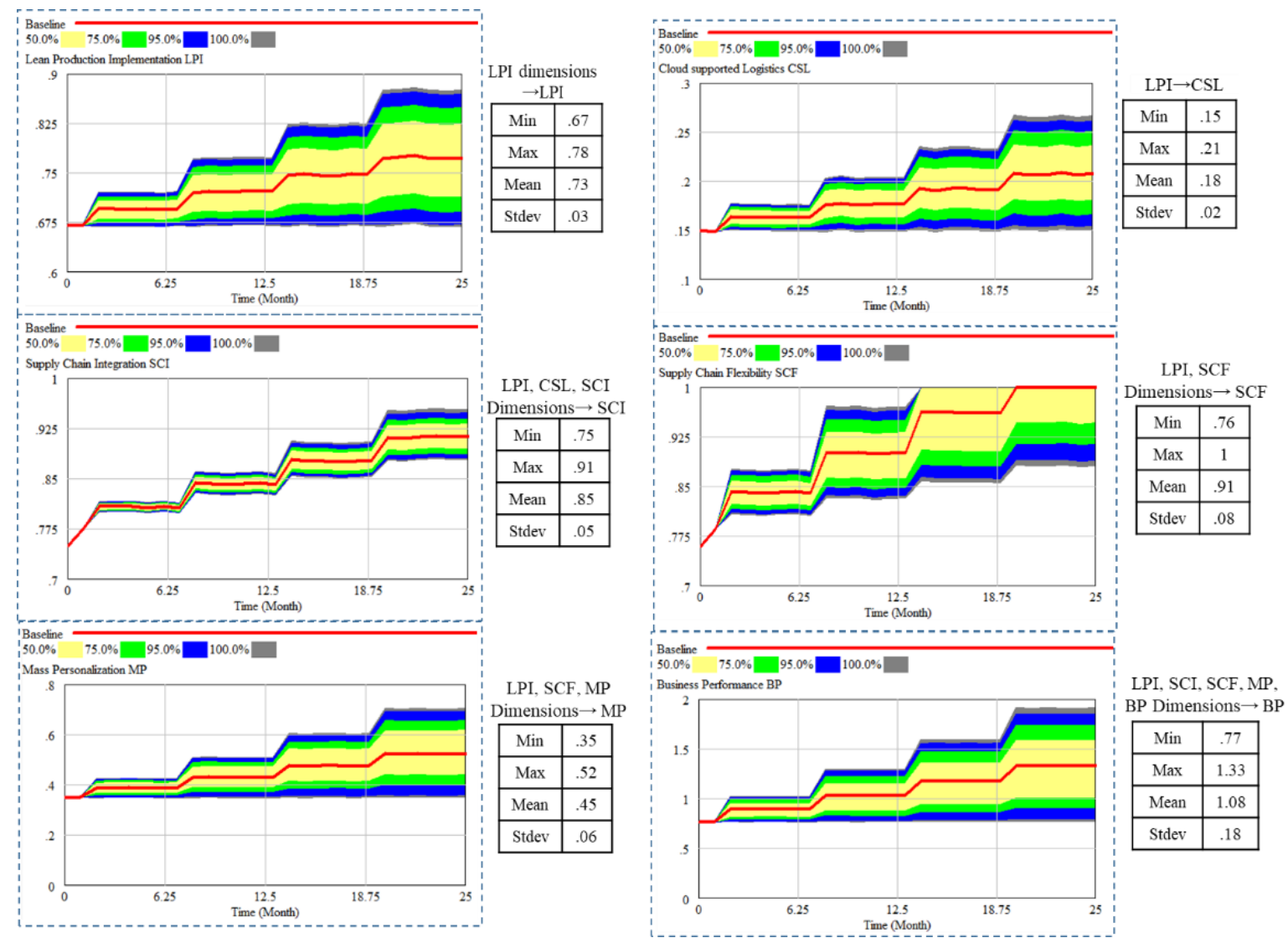

Note: $L P I$ Dimension $\rightarrow L P I=$ Impact of Lean Production Implementation (Dimensions) on Lean Production Implementation (Level); $L P I \rightarrow C S L=$ Impact of Lean Production Implementation (Level) on Cloud-supported Logistics (Level), LPI, CSL, SCI Dimensions $\rightarrow S C I$ (Level) = Impact of Lean Production Implementation (Level), Cloud-supported Logistics (Level) and Supply Chain Integration (Dimensions) on Supply Chain Integration (Level); LPI, SCF Dimensions $\rightarrow$ SCF = Impact of Lean Production Implementation (Level) and Supply Chain Flexibility (Dimensions) on Supply Chain Flexibility (Level); LPI, SCF, MP Dimensions $\rightarrow$ MP = Impact of Lean Production Implementation (Level), Supply Chain Flexibility (Level) and Mass Personalization (Dimensions) on Mass Personalization (Level); LPI, SCI, SCF, MP, BP dimensions $\rightarrow B P$ = Impact of Lean Production Implementation (Level), Supply Chain Integration (Level), Supply Chain Flexibility (Level), Mass Personalization (Level) and Business Performance (Dimensions) on Business Performance (Level)

Figure 6.8. Sensitive test for the SEM/SDM variables

To avoid repetitions and excessive explanations in the following graphs (Figures 10, 12, $13,14,15,16,17$ and 18 ), we are going to use Figure 8 to explain how the confidence limits represented in the Monte Carlo Simulation graphs should be interpreted. The distribution of the values that the causal variables exert on the effect variable, during any period of time, is shown referring to the confidence limits: the yellow strip represents the confidence limit of $50 \%$, the green one of $75 \%$, the blue one of $95 \%$ and the grey one of $100 \%$. To exemplify, we take as a base the relationship between LPI (dimensions) and LPI (level): the yellow strip shows that there is a $50 \%$ probability that, at the end of the simulation period, LPI (dimensions) exerts a load that varies between 0.73 and 0.82 on LPI (level). The green strip shows that there is a $75 \%$ probability that LPI (dimensions) 
will exert a load that varies between 0.70 and 0.84 on LPI (level) at the end of the simulation. Similarly, the blue strip shows that there is a $95 \%$ probability that the load that LPI (dimension) exerts on LPI (level) at the end of the simulation period varies between 0.68 and 0.86 . And, finally, the grey lower and upper limits show that there is a $100 \%$ probability of, at the end of the simulation period, LPI (dimension) exerts a load on LPI (level) 0.67 and 0.88. After checking with favourable results (good results of the SEM/SDM model in terms of structure, behaviour and sensitivity), it can be stated that this model is valid and can be applied for the purpose of this chapter.

\section{Stage 5: Explotation}

This stage is presented in the following section and is subdivided into two parts. First, the general application of SEM/SDM for business decision making is presented. Then, the SEM/SDM developed for the particular case of the company CSLC, a startup specialized in offering logistic services Cloud-suported, is used.

\subsection{SEM/SDM APPLICATION}

\subsubsection{GENERIC APPLICATION}

In order to demonstrate the SEM/SDM possibilities and the cause-effect behavior among the factors analyzed in this study, two generic situations have been presented for its application.

In the first one, we have analyzed how the increase in item loads could impact the construct level during the simulation period. This first analysis is performed with data from the SEM analysis of SEM1 and SEM 2 models (see chapters 4 and 5). To do so, we have created the situation in which a company seeks to increase its LPI level by 0.10 . Six scenarios have benn run. In the scenario that has been named "Current", we have simulated the data arising from the SEM model, where the factorial loads that each item exerts on the LPI level have been used. As expected, the system balance is observed in this scenario, since it is considered that the company has not implemented or increased any of the Lean practices in the next two years. The other five scenarios have been simulated from there, where a 0.04 has been progressively added up on the factorial loads of the items that compose LPI. That is to say, in scenario 1 there has been an increase of 0.04 on the loads of the LPI items. In scenario 2, there has been an increase of 0.08 . So, successively, until scenario 5 , where there has been an increase of 0.2 on the loads of the LPI items. Figure 6.9 shows the effect of the item loads that compose 
LPI (LPI Dimensions) on their level (LPI Level). In the $X$ axis it is located in time and in the $Y$ axis it is located in increment of the LPI level for each scenario. The increased loads in scenarios 1, 2, 3 and 4 have not been sufficient to reach the objective of increasing a load of 0.10 to the LPI level. Moreover, it can be observed that in order for a company to increase the LPI level by 0.10 (dashed green line), it is necessary to increase the LPI item loads by 0.2 (load that has been increased in scenario 5, represented by the blue line). It is also observed that the 0.10 increase achieved in scenario 5 occurs after 19 months. Therefore, scenario 5 (increase of 0.2 on the items loads that make up LPI) is the only one that would allow the company to reach its objective (increase its LPI level by 0.1 ).

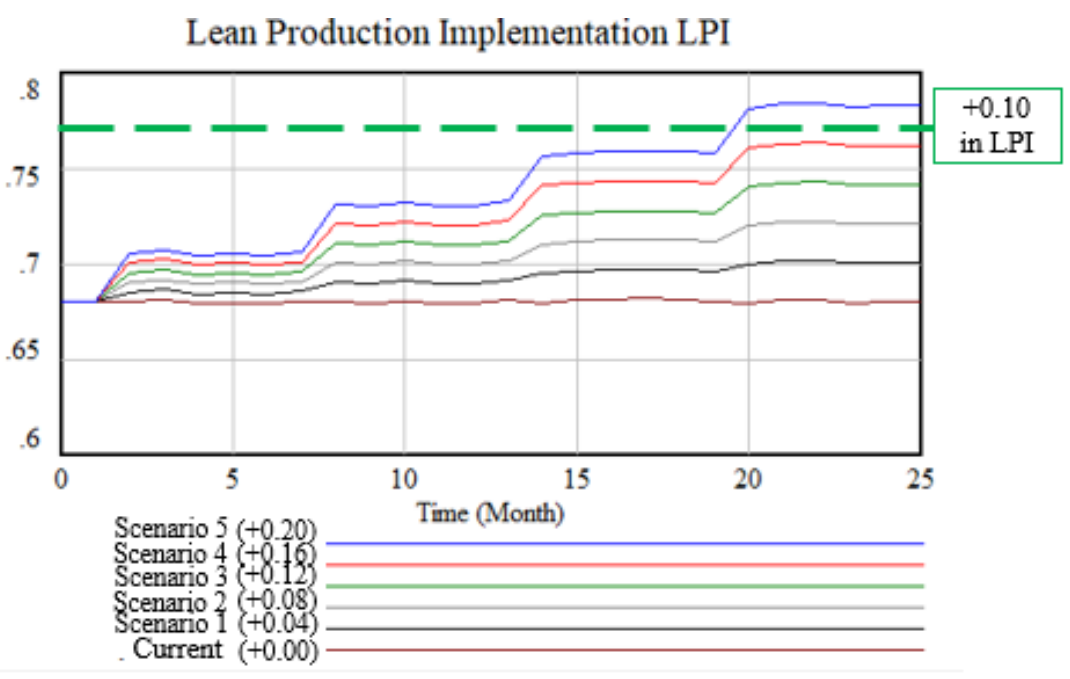

Figure 6.9. Impact of LPI dimensios on LPI over 24 months

It is necessary to understand what a 0.2 increase in LPI dimensions (scenario 5) represents in practice and how companies could interpret this result to support their decision making. For this point, we suggest the use of the LPI measurement scales published in the previous literature, in which the most used Lean practices are listed. Through these measurement scales, companies would be aware of the most commonly used Lean practices, becoming aware of those they already have implemented and those that could be implemented to raise Lean levels in their Supply Chains. Based on Moyano et al. (2012) scale, a fictitious checklist has been made to exemplify how a measurement scale could be used by companies to identify the LP implementation opportunities. From this scale, a company could make a checklist to verify the LPI items that have not been implemented and verify the weight that each item placed on the LPI construct. We have checked with a " $V$ " the items that a company would have 
implemented and with an "X" those that have not (Table 6.3). The fictitious situation represented in Table 6.3 shows that a company could increase its LPI level through the implementation of LPI2 and LPI9, which are those Lean practices that are still not implemented. If the company had to choose one of the two Lean practices, it would be recommended that it opt for LPI2, which has a greater weight than LPI9 on the LPI level. That is, LPI2 has a weight of $15 \%$ on LPI, while LPI9 has a weight of $13 \%$ on LPI. Furthermore, if the company had the conditions and the need to implement both LPI2 and LPI9, it could reach an increase in the LPI level of $28 \%$ (the sum of the LPI2 and LPI9 weights).

48Table 6.3. Checklist of LPI measurement model

\begin{tabular}{|c|c|c|c|c|c|}
\hline Items & & Load & Sum & Weight & Check \\
\hline $\begin{array}{l}\text { We have placed in the plant the machines associated to a certain } \\
\text { process so that they are next to each other }\end{array}$ & LPI1 & .76 & \multirow{7}{*}{4.78} & $16 \%$ & $\boldsymbol{V}$ \\
\hline $\begin{array}{l}\text { We have organized our plant into manufacturing cells (grouping of } \\
\text { workers and machines that perform various specialized operations) }\end{array}$ & LPI2 & .70 & & $15 \%$ & $X$ \\
\hline $\begin{array}{l}\text { In-plant distribution allows operation with a reduced level of } \\
\text { inventories and rapid manufacturing }\end{array}$ & LPI3 & .66 & & $14 \%$ & $\boldsymbol{V}$ \\
\hline We use Total Quality Management & LPI4 & .62 & & $13 \%$ & $\boldsymbol{V}$ \\
\hline We dedicate time each day to plan maintenance-related activities & LPI5 & .71 & & $15 \%$ & $\boldsymbol{V}$ \\
\hline $\begin{array}{l}\text { We carry out regular maintenance on all our equipment, involving the } \\
\text { workers }\end{array}$ & LPI6 & .73 & & $15 \%$ & $\boldsymbol{V}$ \\
\hline We have reduced equipment setup times in our plant (SMED) & LPI9 & .60 & & $13 \%$ & $X$ \\
\hline
\end{tabular}

In the second application, we have analyzed how increasing the level of one construct could affect the level of another construct during the simulation period. To do so, we have also used the Monte Carlo simulation, which 500 simulations have been performed, to analyse how the increase of the LPI level would be related to the CSL level (Figure 6.10). Thus, Figure 6.10 shows the effect of LPI on CSL. Time is located on the $X$ axis. CSL is located on the $Y$ axis. The red line shows the starting scenario (current). The areas of the graph highlighted in yellow, green, blue and grey show the probabilities of CSL level increase caused by LPI. As explained above, yellow represents probability values close to $50 \%$ and green represents probability values close to $75 \%$. Likewise, blue represents probability values close to $95 \%$, while grey represents a probability value close to $100 \%$. Thus, it is more probable that the CLS level at the end of 24 months will vary between 0.15 and 0.18 , which are the lower and upper limits of grey colour. This represents a probable increase of up to 0.03 over the CSL level caused by LPI at the end of the 24 months. 


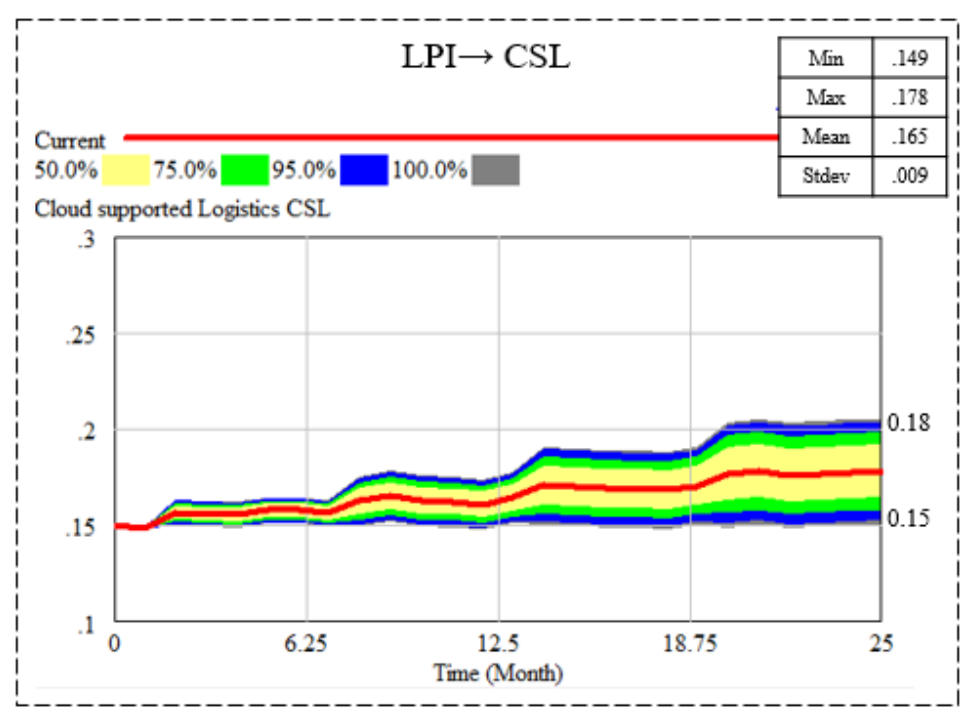

Note: $L P I \rightarrow C S L=$ Impact of Lean Production Implementation (Level) on Cloud-supported Logistics (Level);

Figure 6.10. Impact of LPI on CSL over 24 months

As in the previous application, a company could use the measurement scale (Table 6.3) to verify its possibilities to increase its LPI level by 0.1 . In other words, Table 3 allows the company to verify that items are not implemented and thus study the feasibility of their implementation.

As has been shown, SEM/SDM represents a support tool for business decision making, allowing companies to analyse in a general way the individual or joint impact of cause variables on effect variables throughout the simulation period. In the application above, the SEM/SDM tool has been used to relate LPI dimensions, LPI level and CSL level, but other analyses such as this one can be applied to compare any combination between the model variables.

\subsubsection{SPECIFIC APPLICATION: THE CSLC CASE}

CSLC (fictitious name for confidential reasons), a start-up set up in 2015 in Oporto (Portugal), that currently has more than 70 employees, is dedicated to managing the Supply Chain of its customers and offering them logistics services supported by Cloud Information Technology. CSLC's portfolio of companies has more than 40 brands in the fashion industry - mainly international ones - that are active in different geographies. CSLC is at the centre of a dynamic ecosystem, integrating its clients, end users, suppliers and partners, especially in the fashion and accessories market. As its customers focus on product development, sales and marketing, CSLC is responsible for managing the entire Supply Chain of its partners, supporting the sales channel and 
distributing the products sold to more than 80 countries. CSLC offers a cloud-based collaborative platform that connects the whole chain in one point of access with end-toend visibility, which allows its customers to control and optimize their Supply Chain. Through the integrated platform, CSLC's customers can manage their suppliers, end customers, sales channels, operations, distribution and tracking. Figure 6.11 shows the services offered by CSLC. It can be observed that CSLC enables its customers to get full access to physical and informational flows throughout their Supply Chains, from raw material supplier to product delivery to the end customer. Besides the physical and informational integration of its customers' Supply Chain, CSLC is in charge of the storage processes and stock management, Pick and Pack services and product distribution to the final customer. CSLC is responsible for the vendor management, integrating through its platform the information of raw material suppliers and products with its customers. In addition, CSLC controls the storage process and stock as well as Pick and Pack management. To do so, it has two warehouses/distribution centres, located in Holland and Portugal. Regarding Pick and Pack services, CSLC customizes the clients' products according to the final customers' orders. CSLC is also responsible for the final product distribution and tracking, which is sent to several countries. For this, CSLC has partners such as UPS, FedEx, DHL and DPD.

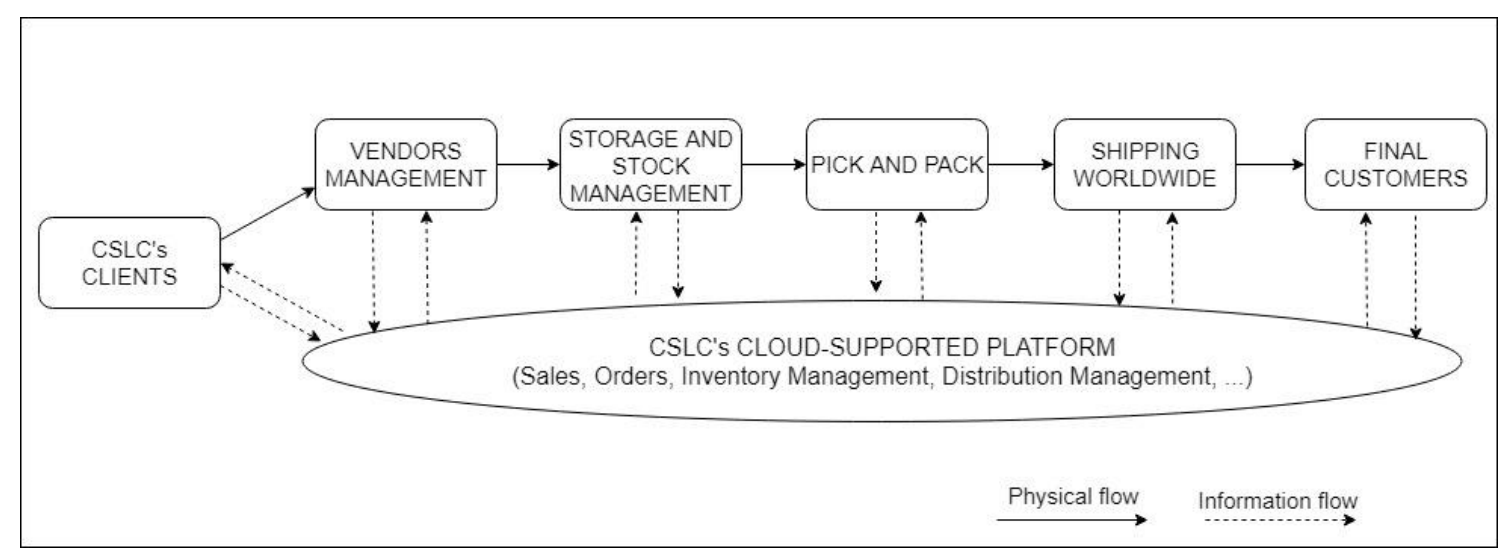

Figure 6.11. CSLC services

In 2016, one year after its inauguration, CSLC already presented very positive results: 150,000 products carried through 2,000 shipments to more than 60 countries. The company finished 2017 with an annual turnover of 650,000 euros and expects to end 2018 with values of 1.5 million euros, sending products to 80 countries and with a forecast growth in the order of $400 \%$. CSLC's success has awakened the interest of several investors who, in 2018, have invested 2.5 million euros in the company. With 
high capital injection, CSLC has to make important strategic decisions to strengthen its results in the coming years.

Considering this situation, it is crucial that CSLC make appropriate decisions to establish strategies that will help the company to increase its effectiveness and efficiency, reflected in its Business Performance. Therefore, the SEM/SMD use as a decision support tool can be relevant for CSLC, emphasizing the possible overtime impacts of the most representative factors on its effectiveness and efficiency. Using the SEM/SDM developed in the previous sections, different scenarios were analysed drawing upon the company's proposals.

First, an interview was conducted with the co-founder and Head of Product Management of CSLC. Through this interview, we asked him about the level of adoption and use of the variables related to effectiveness and efficiency used in this study. The questionnaire used was the same one used to collect data from SEM1 and SEM2. For each statement, the respondent had to evaluate between 1 and 10 the level at which the company has adopted the items of the questionnaire. In addition, he had to indicate these levels in three different times: (a) "How was the company doing in the year 2016?" (b) "How is the company performing currently (year 2018)?" and (c) "How does the company intend to be in the year 2020? The questionnaire used and the respondent answers are listed in the appendix at the end of the thesis.

Once the CSLC data has been collected, the SEM/SDM validation process has been initiated. The SEM/SDM data obtained with secondary data from previous SEM analyses (SEM1 and SEM 2 from Chapters 4 and 5) has been compared with the CSLC's real data. To do so, the CSLC's data (Business Performance in 2016 and 2018) have been compared with the SEM/SDM simulations results (Figure 6.12). On the one hand, the company stressed that in 2016 it had a Business Performance level equal to 0.35 and that in 2018 it has reached the level of 0.47 (dashed black line). On the other hand, a Monte Carlo simulation has been carried out using 500 simulations with the SEM/SDM developed from SEM1 and SEM2 data, and using the same starting data for Business Performance (0.35) that CSLC had in 2016. The average value for Business Performance obtained using the SEM/SDM model (from SEM1 and SEM2 data) was 0.44 at the end of the 24 months. This value is very close to the real value indicated by CSLC (Business Performance equal to 0.47 at the end of 24 months). A conditioned behaviour has been observed with a final value of the Business Performance very close to the company's real performance (difference of approximately $5 \%$ ). Furthermore, the SEM/SDM model developed has also been tested in Section 3 through various methods that have reinforced its validity (Sterman, 2000). We therefore consider that the 
SEM/SDM developed from SEM1 and SEM2 is valid and applicable for the specific case of CSLC.

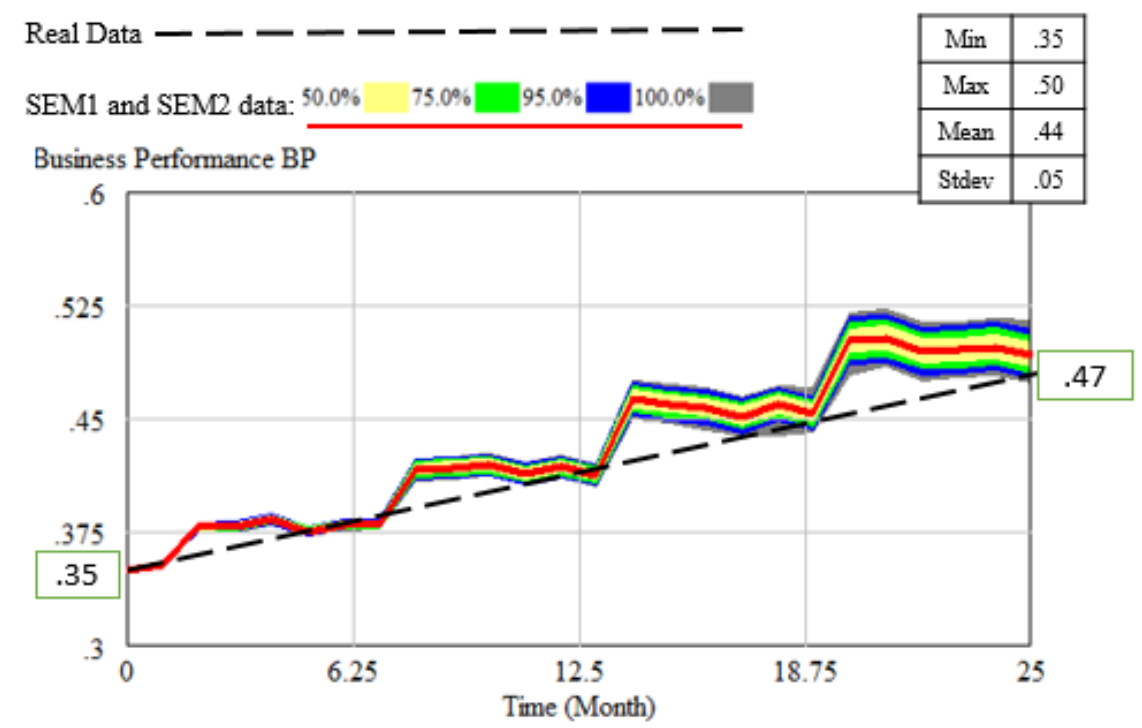

Figure 6.12. SEM/SDM validation with CSLC data

Once the SEM/SDM model is validated, some situations were run that could help the company in its decision making. The SEM/SDM model that has been developed (Section 3) and validated (Figure 6.12) from SEM1 and SEM2 (Chapters 4 and 5) is used for the specific case of CSLC. To do so, we use the company's 2018 and 2020 data (the 2016 data are no longer used, because it has only been used previously to validate SEM/SDM). First of all, the company data for 2018 and 2020 is compared (Table 4). This comparison is made to understand how much the company expects to increase in the next two years (from 2018 to 2020) its level variables (CLS, SCF, SCI, MP and BP). Drawing upon these responses, the cause variable value in 2018 has been calculated, which is the average of the item values in 2018. In order to calculate the "Expected increase to cause variables in 2020" for CSLC, the average of the expected values for the items in 2020 has been substracted from their current value (2018). For example, for the specific case of the SCF level variable (see 6.Table 4): in 2020 the company would like to have an SCF level of 0.72 , and in 2018 it would have an SCF level of 0.56. Then, the expected increase value (the last column in Table 4) is +0.16 (obtained through the subtration of 0.72 by 0.56 ). From this point on, the developed and validated SEM/SDM will help CSLC to define "what to do" to increase these +0.16 over the SCF level. The value of 0.25 has been included as random starting data for LPI, chosen by the authors, since the company does not have this variable implemented. 


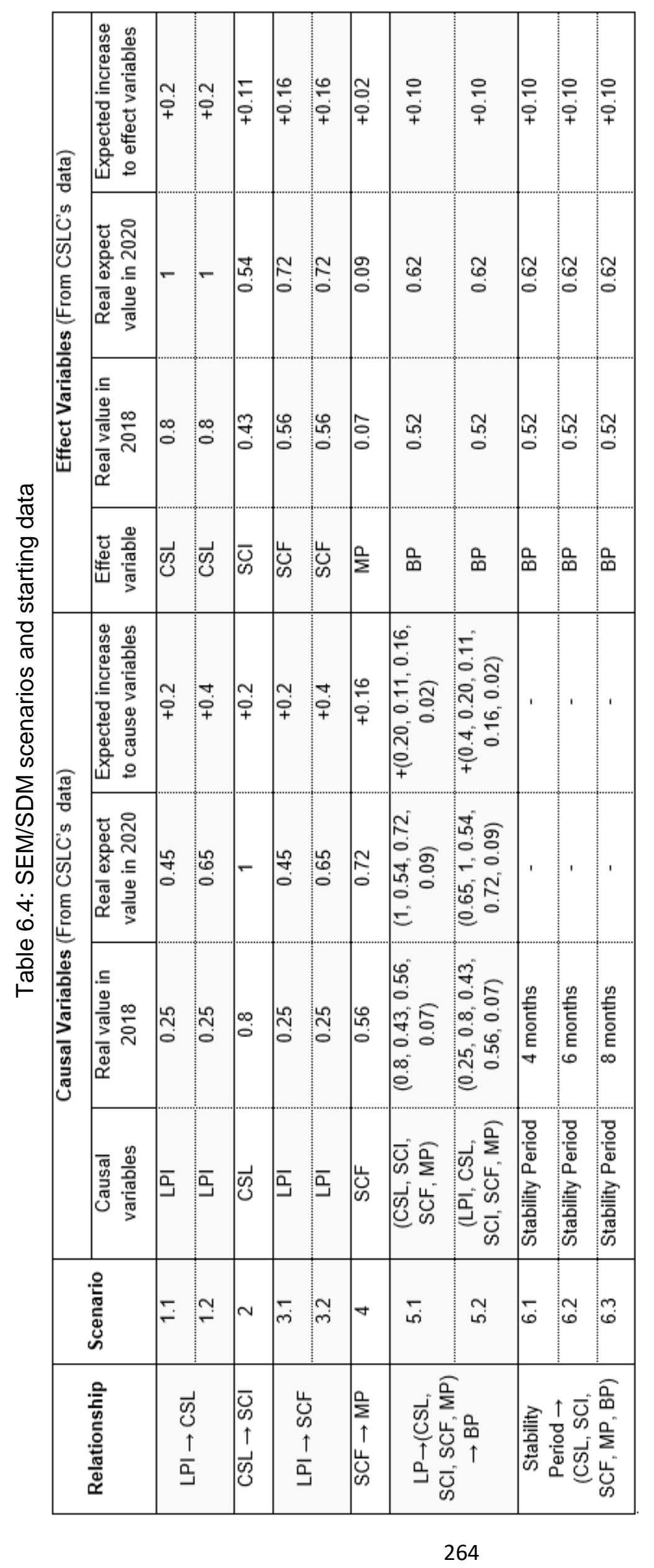


Thus, the SEM/SDM developed and validated from SEM1 and SEM2 (Chapters 4 and 5 ) is now a decision making tool, and it will serve to indicate what CSLC has to do to achieve the desired levels of its study variables. To do so, we have propose scenarios 1, 2, 3, 4 and 5, which will show some possibilities of increasing the cause variables (LPI, CSL, SCI, SCF and MP) over the CSLC effect variables. The following scenarios compare the factors related to the CSLC's effectiveness and efficiency and their posible impacts on CSLC performance. Thus, we have simulated the CSLC's hypothetical scenarios, as a way of analysing the cause-effect relations between the variables studied over a 24-month time horizon. For each scenario, a Monte Carlo technique was used with 500 simulations. The reference value for all of them (red line) has been the increase that CSLC expects to carry out in the causal variables in the next two years (Table 6.4). Except for starting data for LPI (which is not implemented in CSLC), the starting data for the causal variables have been obtained through the CSLC respondent, who evaluated on a scale of 1 to 10 the level of agreement with each scale afirmation.

In scenarios 1.1 and 1.2, the effects that the LPI would exert on CSL at the end of the simulation period have been simulated. It is observed in Figure 6.13 that, if CSLC had LPI with a level of 0.2 at the end of the 24 months (scenario 1.1), its CSL implementation level could be increased by up to 0.06 . On the other hand, if the company is interested in implementing LPI in 0.4 in the next 24 months (scenario 1.2), its CSL level could reach the outcome of 0.13 . Therefore scenario 1.2 yields better results than scenario 1.1 . However, in neither scenario would the company reach the desired level of CSL (dashed green line), which is an increase of 0.2 (Table 6.4). In this case, the company should study the feasibility of further increasing the level of LPI (causal variable) as a way to reach the expected CSL level in 2020 (effect variable).

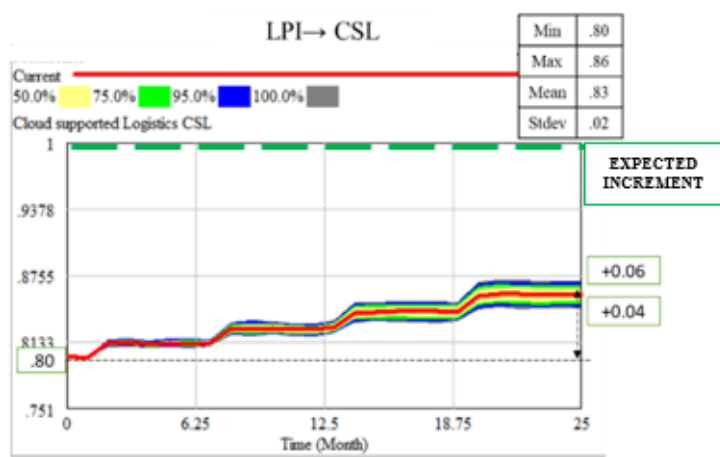

(a) Increasing 0.2 in LPI level

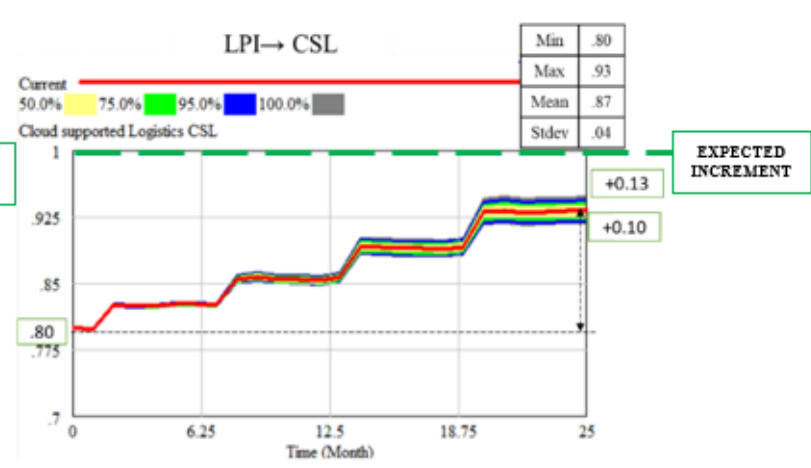

(b) Increasing 0.4 in LPI level

Note: $L P I \rightarrow C S L=$ Impact of Lean Production Implementation (Level) on Cloud-supported Logistics (Level);

Figure 6.13. Scenarios $1.1(\mathrm{a})$ and $1.2(\mathrm{~b})$ 
In Scenario 2 (Figure 6.14), the possible increase that CSL could cause on the SCI level was analysed at the end of two years. Through the simulation carried out, it is observed that an increase of 0.2 in the CSL level could generate an increase of up to 0.17 on the SCI level. The results show that the CSL level (causal variable) incremented is sufficient for the company to reach the expected SCI level (effect variable). Moreover, the results show that the SCl level would be reached between 13 and 14 months after the beginning of the CSL implementation.

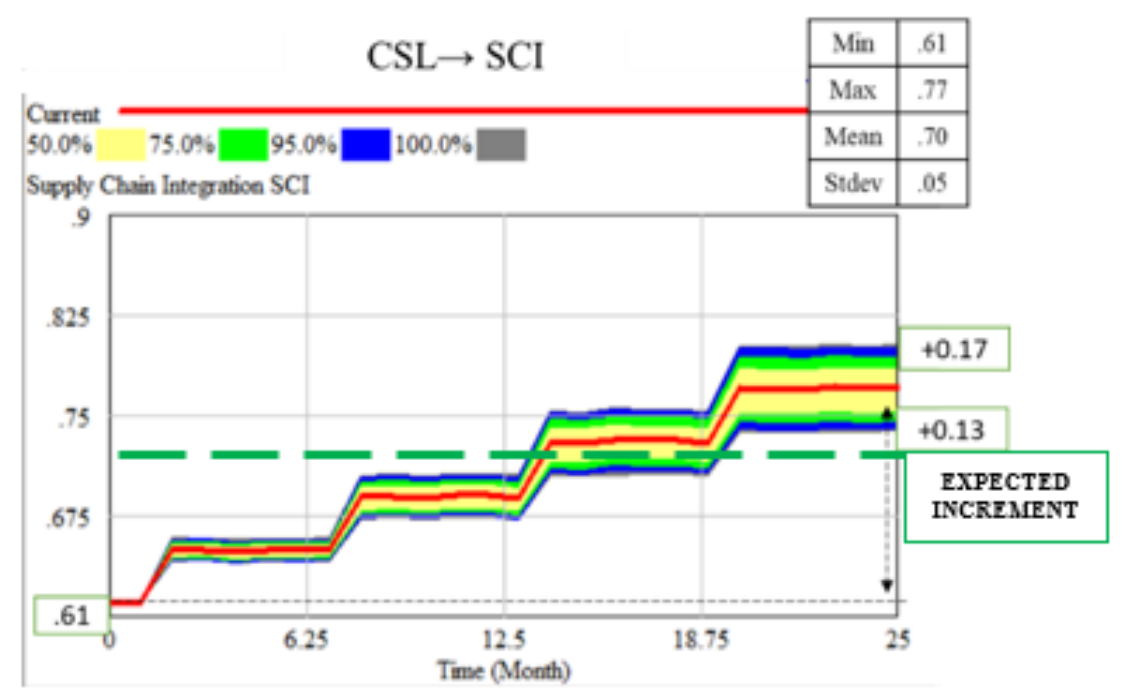

Note: $\mathrm{CSL} \rightarrow \mathrm{SCl}=$ Impact of Cloud-supported Logistics (Level) on Supply Chain Integration (Level)

Figure 6.14. Scenario 2

It is necessary to understand how the company could increase its CLS level (Scenario 2), which represents in practice how the company could interpret the SEM/SDM result to support its decision making and improve its SCI level. For this point, we have suggest the use of Cloud Computing definition (Mell and Grance, 2011). Mell and Grance (2011) have defined $C C$ as the degree of implementation in a company of cloud computing gathering a variety of heterogeneous resources with an operational aim share these resources with other companies we have strong ties to in such a way that these companies usually also provide resources to the network. The company has been analysed in separate bits in the form of phrase extracts, as shown in Table 6.5. CSLC checked with a "V" the level of agreement with the phrases extracts that make up the Cloud Computing definition. Through this definition, which is widely accepted by Cloud Computing scholars, the company will be able to identify the Cloud implementation opportunities and its supply chain flows that could be integrated through such technology. It is observed that the phrase "...gathering a variety of heterogeneous 
resources with an operational aim" is the one that has the lowest level of agreement by the company. Thus, the opportunity to increase the Cloud implementation level could be associated with the integration, through Cloud, of a wider range of operational resources related to logistics activities along its Supply Chain.

Table 6.5. Checklist of Cloud Computing (based on Mell and Grance definition)

\begin{tabular}{|l|l|l|l|l|l|l|l|l|l|l|l|}
\hline & $\mathbf{0}$ & $\mathbf{1}$ & $\mathbf{2}$ & $\mathbf{3}$ & $\mathbf{4}$ & $\mathbf{5}$ & $\mathbf{6}$ & $\mathbf{7}$ & $\mathbf{8}$ & $\mathbf{9}$ & $\mathbf{1 0}$ \\
\hline $\begin{array}{l}\text { "...gathering a variety of heterogeneous } \\
\text { resources with an operational aim" }\end{array}$ & & & & & & $V$ & & & & \\
\hline $\begin{array}{l}\text { "share these resources with other companies } \\
\text { we have strong ties" }\end{array}$ & & & & & & & & & & $V$ & \\
\hline $\begin{array}{l}\text { "In such a way that these companies usually } \\
\text { also provide resources to the network." }\end{array}$ & & & & & & & & & $V$ & \\
\hline
\end{tabular}

The following two scenarios are dedicated to analyze the potential impacts of LPI on the SCF level (Figure 6.15). In Scenario 3.1, we have added a load of 0.2 on the LPI level. It is observed that this increase could result in a gain in the SCF level by up to 0.24 . In Scenario 3.2, we have increased the LPI load by 0.4 and, as a result, the SFC level could be increased by up to 0.32 at the end of the simulation (better scenario). The results show that the LPI level (causal variable) incremented is sufficient for the company to reach the expected SCF level (effect variable). Furthermore, the results show that the SCF level could be reached approximately 8 months after the beginning of the LPI implementation. These positive results encourage the company to analyze in more detail the feasibility of implementing Lean Production in its logistics processes, since until now, Lean Production is still not implemented.

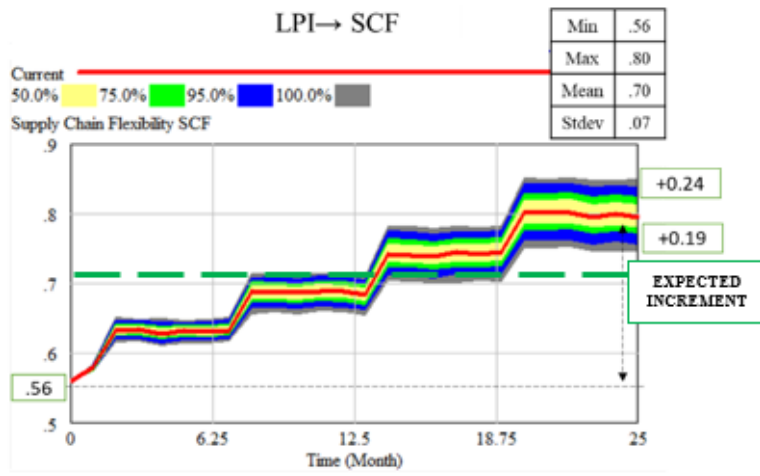

(a) Increasing 0.2 in LPI level

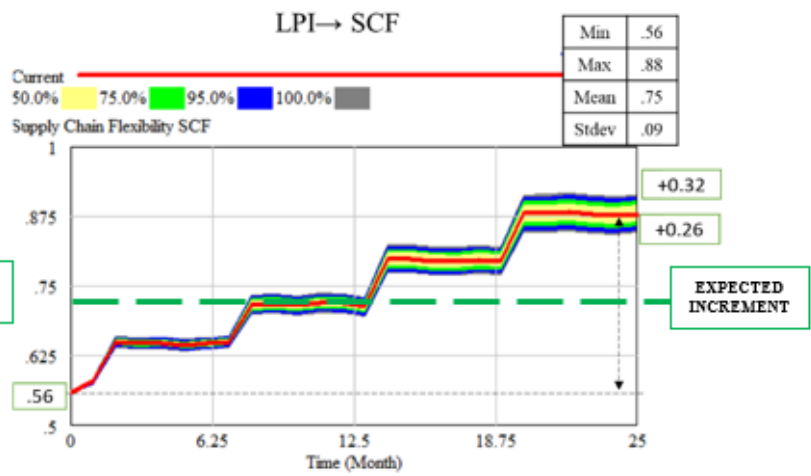

(b) Increasing 0.4 in LPI level

Note: $L P I \rightarrow$ SCF = Impact of Lean Production Implementation (Level) on Supply Chain Flexibiltiy (Level)

Figure 6.15. Scenarios 3.1 (a) and 3.2 (b) 
It is necessary to understand what a increase of 0.2 or 0.4 in LPI dimensions represents in practice and how CSLC could interprets the SEM/SDM results to support its decision making. For this point, we suggest the use of the LPI measurement scales published in the previous literature Moyano et al. (2012), in which the most used Lean practices are listed. Through this measurement scale, CSLC could make a checklist to verify the LPI items that have not been implemented and verify the weight that each item placed on the LPI construct. CSLS have checked with a " $V$ " the items that it would have implemented and with an " $X$ " those that have not (Table 6.6). In fact, the results presented in Table 4 show that the company does not have any of the Lean practices implemented to date, so CSLC managers may choose those practices that are best suited and most easily implemented in their business.

Table 6.6. Checklist of LPI measurement model

\begin{tabular}{|c|c|c|c|c|c|}
\hline \multirow{2}{*}{\multicolumn{2}{|c|}{ Items }} & \multicolumn{3}{|c|}{ SEM2 } & \multirow{3}{*}{$\begin{array}{c}\begin{array}{c}\text { CSLC } \\
\text { Check }\end{array} \\
x\end{array}$} \\
\hline & & Load & Sum & Weight & \\
\hline $\begin{array}{l}\text { We have placed in the plant the machines associated to a certain } \\
\text { process so that they are next to each other }\end{array}$ & LPI1 & .76 & \multirow{7}{*}{4,78} & $16 \%$ & \\
\hline $\begin{array}{l}\text { We have organized our plant into manufacturing cells (grouping of } \\
\text { workers and machines that perform various specialized operations) }\end{array}$ & LPI2 & .70 & & $15 \%$ & $\boldsymbol{X}$ \\
\hline $\begin{array}{l}\text { In-plant distribution allows operation with a reduced level of } \\
\text { inventories and rapid manufacturing }\end{array}$ & LPI3 & .66 & & $14 \%$ & $\boldsymbol{X}$ \\
\hline We use Total Quality Management & LPI4 & .62 & & $13 \%$ & $X$ \\
\hline We dedicate time each day to plan maintenance-related activities & LPI5 & .71 & & $15 \%$ & $X$ \\
\hline $\begin{array}{l}\text { We carry out regular maintenance on all our equipment, involving the } \\
\text { workers }\end{array}$ & LPI6 & .73 & & $15 \%$ & $\boldsymbol{X}$ \\
\hline We have reduced equipment setup times in our plant (SMED) & LPI9 & .60 & & $13 \%$ & $X$ \\
\hline
\end{tabular}

In Scenario 4, the influence of SCF on MP has been analysed during the 24 simulation months. A load increased of 0.16 on SCF level was included in the model (CSLC target for 2020) and we have observed how this increase could affect the MP level (Figure 6.16). The results show that, after 24 simulation months, MP could have its level increased by up to 0.11 , which is well above the minimum planned by CSLC. Thus, the results show that the company would have no problems reaching the desired MP level for the next 24 months. In fact, this level would be reached two months after the start of the SCF implementation. 


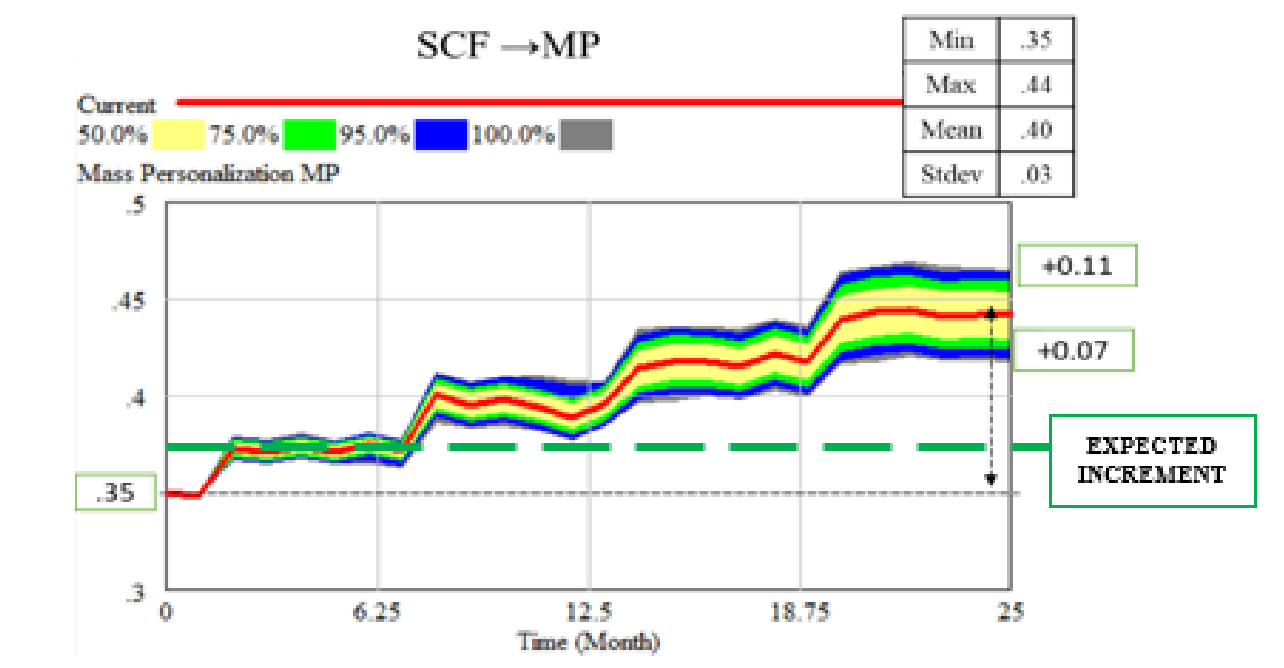

Note: SCF $\rightarrow M P=$ Impact of Supply Chain FLexibility (Level) on Mass Personalization (Level)

Figure 6.16: Scenario 4

As has been done in the previous scenarios, a checklist has been carried out by the company with the SCF scale (Flyyn et al., 2010) as a way of verifying those items that were already implemented and those that could be implemented in the next two years (Table 6.7). Since the MP level (effect variable) would very easily be reached through SCF (causal variable), the company believes that it is not necessary to increase the SCF level in order to reach higher MP levels.

Table 6.7. Checklist of SCF measurement model

\begin{tabular}{|c|c|c|c|c|c|}
\hline \multirow{2}{*}{\multicolumn{2}{|c|}{ SCF Items }} & \multicolumn{3}{|c|}{ SEM2 } & \multirow{3}{*}{$\begin{array}{c}\text { CSLC } \\
\text { Check }\end{array}$} \\
\hline & & Load & Sum & Weight & \\
\hline We have the ability to add and remove suppliers & SCF_4 & .913 & \multirow{10}{*}{8.45} & $11 \%$ & \\
\hline $\begin{array}{l}\text { We have the ability to change suppliers to satisfy changing } \\
\text { requirements }\end{array}$ & SCF_5 & .913 & & $11 \%$ & $\boldsymbol{X}$ \\
\hline We have the ability to change output volumes & SCF_8 & .866 & & $10 \%$ & $\boldsymbol{V}$ \\
\hline $\begin{array}{l}\text { We have the ability to adjust manufacturing facilities and } \\
\text { processes }\end{array}$ & SCF_10 & .866 & & $10 \%$ & $\boldsymbol{X}$ \\
\hline We have the ability to add or remove carriers or other distributors & SCF_12 & 689 & & $8 \%$ & $\boldsymbol{V}$ \\
\hline $\begin{array}{l}\text { We have the ability to change warehouse space, loading capacity, } \\
\text { and other distribution facilities }\end{array}$ & SCF_13 & .732 & & $9 \%$ & $\boldsymbol{V}$ \\
\hline We have the ability to change delivery modes & SCF_14 & .865 & & $10 \%$ & $\boldsymbol{V}$ \\
\hline We have the ability to transfer delivery schedules & SCF_15 & .783 & & $9 \%$ & $\boldsymbol{V}$ \\
\hline $\begin{array}{l}\text { Weise Support of information systems in firm inventory } \\
\text { management }\end{array}$ & SCF_17 & .911 & & $11 \%$ & $\boldsymbol{V}$ \\
\hline $\begin{array}{l}\text { We use Support of information systems across multiple functions } \\
\text { and departments }\end{array}$ & SCF_18 & .911 & & $11 \%$ & $\boldsymbol{V}$ \\
\hline
\end{tabular}


Once the individual relationships between study variables have been analyzed, the following scenario simulates the combined relationship of all study variables (Figure 6.17). First (Scenario 5.1), we observe the level that CSLC could achieve in its results from the starting data indicated for CSL, SCI, SCF and MP. In this situation, it is observed that these variables together could increase the BP level by up to 0.09 . On the other hand, in the case that LPI is also implemented (Scenario 5.2), it is observed that the BP would be even higher, reaching an increase of up to 0.13 at the end of 2020 . Therefore, it can be stated that Scenario 5.2 (which includes LPI) provides better results that scenario 5.1 (without LPI). On the one hand, it is observed that if the company does not have LPI implemented (causal variable), the combined action of CSL, SCI, SCF, and MP (causal variables) could be insufficient to reach the BP level (effect variable) planed by the company at the end of the 24 months (an increase of 0.10 in BP). On the other hand, if the company has LPI implemented (causal variable), the combined action of CSL, SCI, SCF, and MP (causal variables) would be sufficient to achieve a 0.10 increase in the BP level (effect variable) desired by the company.

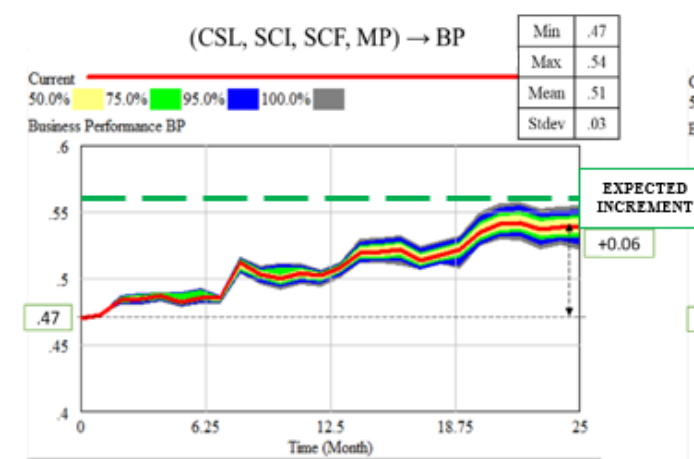

(a) Increase in BP without LPI

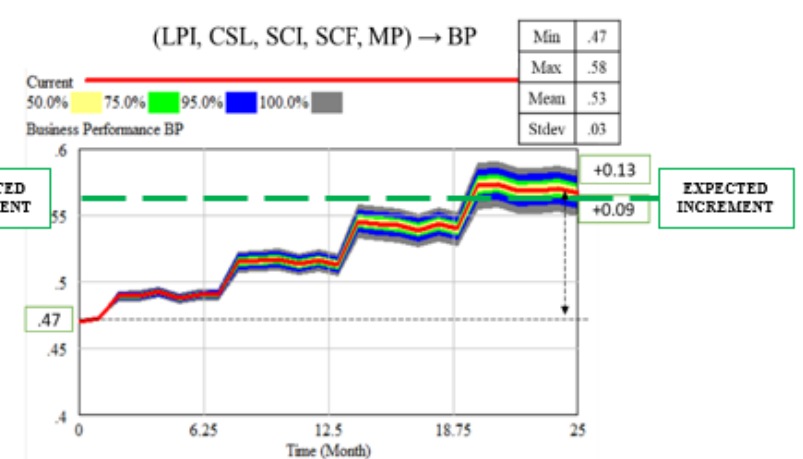

(b) Increase in BP with LPI

Note: (CSL, SCI, SCF, MP) $\rightarrow B P=$ Impact of Cloud-supported Logistics (Level), Supply Chain Integration (Level), Supply Chain Flexibility (Level) and Mass Personalization (Level) on Business Performance; (LPI, CSL, SCI, SCF, MP) $\rightarrow B P=$ Impact of Lean Production Implementation (Level), Cloud-supported Logistics (Level), Supply Chain Integration (Level), Supply Chain Flexibility (Level) and Mass Personalization (Level) on Business Performance; (Level);

Figure 6.17. Scenarios 5.1 (a) and 5.2 (b)

Finally, it has been analysed how the variations in the stability period could affect the BP level at the end of the two simulation years (Figure 6.18). It is observed that if the Stability Period is four months (Scenario 6.1), BP could be increased by up to 0.18 . Furthermore, if the Stability Period is six months (Scenario 6.2), a load of 0.13 could be increased to the level of BP. In addition, if CSLC decides to adopt a Stability Period equal to eight 
months (Scenario 6.3), an increase of BP of up to 0.07 could be observed. The results show that if the company adopts a Stability Period (time in which it does not invest in the implementation of causal variable levels) equal to eight months, the BP level expected for 2020 (increase of 0.1 ) would not be reached. On the other hand, if the company adopts the Stability Period equal to six months, the expected level for BP at the end of the 24 months would be reached. And, finally, if the company has the capacity and possibilities to invest every four months in the implementation of causal variable levels (i.e., Stability Period equal to 4 months), the 0.10 increase in the BP level could be reached after 14 months from the beginning of the causal variables implementation.

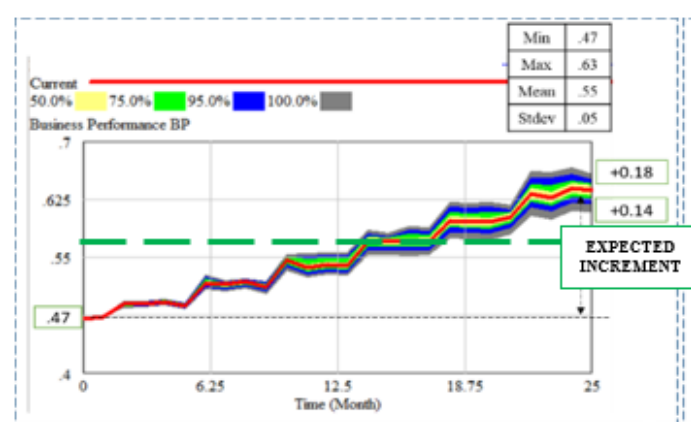

(a) Stability period $=4$ months

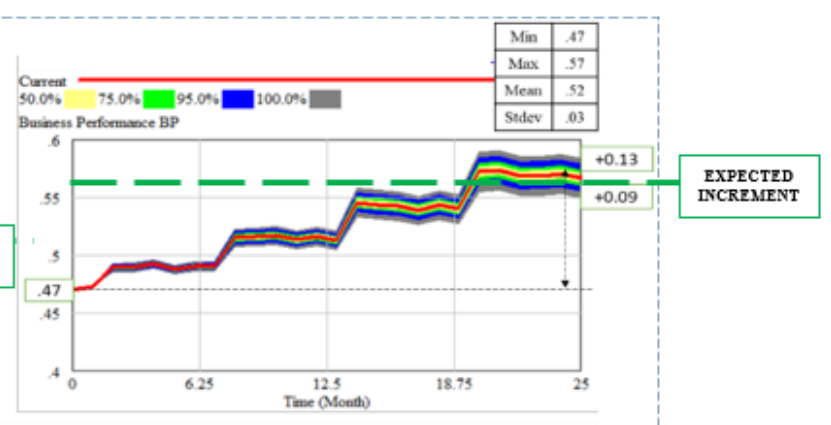

(b) Stability period $=6$ months

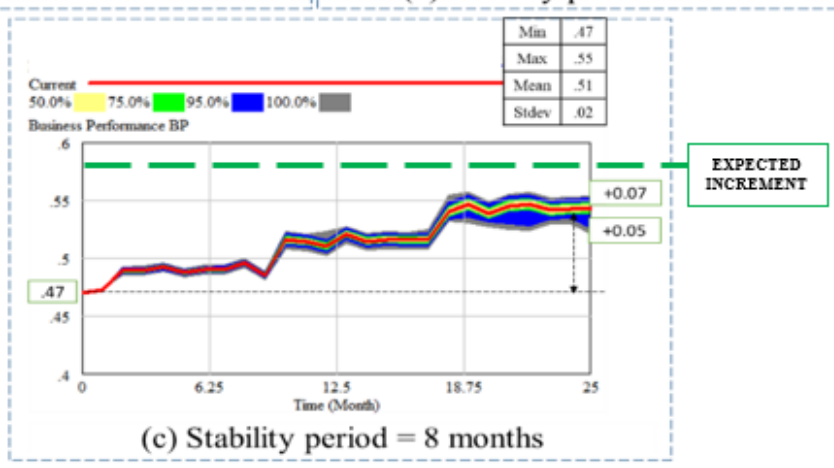

Impact of Lean Production Implementation (Level), Cloud-supported Logistics (Level), Supply Chain Integration (Level), Supply Chain Flexibility (Level) and Mass Personalization (Level) on Business Performance; (Level) with Stability Period equal to four months (a), six months (b) and eight months (c).

Figure 6.18. Scenarios 6.1(a), $6.2(\mathrm{~b})$, and $6.3(\mathrm{c})$

To sum up, it has been observed that the increases that CSLC intends to carry out until 2020 would lead to the following results:

- Through the 0.2 increase in CSL loads, SCI level would increase from 0.61 (2018) to 0.78 (2020), representing an increase of up to 0.17 . Both increases in the CSL level are not sufficient for the company to reach the expected SCI level by 2020. Likewise, if CSLC increases 0.16 on SCF, MP level could go from 0.35 (2018) to 0.46 (2020), which 
represents an increase of 0.11 in MP. The increase in the SCF level is sufficient for the company to reach the desired MP level within 2 months of the simulation beginning.

-If CSLC decides to implement LPI, its results would be boosted. In the first case, its SCF level would go from 0.56 (2016) and would reach up to 0.80 (in that case CSLC would implement 0.2 on the LPI loads) or up to 0.88 (in that case CSLC would implement 0.4 on the LPI loads). In addition, its BP could be increased from 0.06 (if LPI is not implemented) to 0.13 (if LPI has a load of 0.4 at the end of the simulation). In both cases, LPI would be a key factor in improving the desired levels for SCF and BP.

- The last observation includes LPI, CSL, SCI, SCF and MP as implemented variables meanwhile the stability period varies. It is observed that if CSLC has the capacity to increase its variables' load every 4 months (Stability Period $=4$ months), its BP at the end of 24 months would reach a level of 0.65 (increase up to 0.18). Likewise, if CSLC chooses Stability Period equal to 6 months, it could increase the BP level up to 0.60 (increase up to 0.13). Finally, if the Stability Period is equal to 8 months, CSLC would reach a BP level of up to 0.54 , which represents an increase of 0.07 at the end of the two simulation years. Therefore, results are better, and more than proportional, with shorter stability periods.

\subsection{CONCLUSIONS AND FUTURE DIRECTIONS}

This chapter has modelled some strategic factors that affect the Supply Chain effectiveness and efficiency and their impacts on Business Performance. For this purpose, a five-stage SEM/SDM methodology has been applied to design, validate and perform a System Dynamic Model (SDM) using results stemming from the Structural Equation Modelling (SEM). The SEM/SDM developed has been applied to simulate some efficiency-related factors (Lean Production Implementation and Cloud-supported Logistics) and effectiveness-related factors (Supply Chain Integration, Supply Chain Flexibility and Mass Personalization). The interrelationship between these factors and their impact on Business Performance has been simulated over a 24-month time horizon.

The SEM/SDM combined methodology here developed has also been applied as a decision support tool to the specific case of the company named CSLC. The application has allowed a dynamic analysis of the relationship between the above-mentioned factors related to Supply Chain effectiveness and efficiency. From the data collected through an interview with the CSLC co-founder, a series of scenarios have been created in which it has been analysed how such effectiveness and efficiency factors could affect CSLC's 
Business Performance. Based on a comparison of CSLC's real data (2016 and 2018 data) with the simulation results, the SEM/SDM developed has been validated. Then, the SEM/SDM developed and validated has then been applied to obtain projections showing the possible impacts of the variables studied on CSLC results over the aforementioned 24-month time horizon.

The SEM/SDM application to the CSLC case has shown that thanks to the model developed, it is feasible to use the SEM data and turn it into a tool for future analysis of organizational key variables, such as the new technology implementation, Supply Chain Integration, Lean practices, and performance.

Simulations run in this study are just a small portion of the simulations that can be carried out using the methodology proposed in this study. The number of simulations and their structure depends on the number of variables chosen by the researchers or by the company managers. Structure and complexity of the model will be dependant therefore on the simulation objectives and on the variability of the environment and the organization that should be modelled. Thus, this is not a closed research, but a methodological model that could be expanded and/or adapted to this or to other simulation environments for this or other industries, types of technologies and organizational questions.

One of the most relevant advantages of this model is that, by using this methodology, researchers and company managers are able to include the dynamic factor in their research framework. It is commonly argued among researchers and practitioners that research in Business Administration and Technology Management usually fails in considering the dynamic effects in the theoretical and conceptual models. Thus, many of the current and prior research is based on cross-sectional analyses that are valid for a particular moment of time but does not cover dynamic and time-based evolution patterns of the variables being considered.

This study tries to cover this gap existing between the static, cross-sectional studies that make up most of the research done in the area, and the desire of the academic and managerial community in expanding the rather prevalent cross-sectional analysis. This research is a new endeavour that drawing upon a combined methodology, enables companies and researchers to take into consideration the dynamic nature of the environments in which organizational issues are usually embedded.

However, some limitations must be considered in this research. The simulated factors are limited to those that have been previously studied in the two SEMs used. Overall, decision making related to strategic Supply Chain factors is also based on other 
evaluation criteria such as implementation costs, available technologies and trained human resources. In addition, the SEM used as a reference in this study is focused on industrial sectors that hold an intermediate position in the Supply Chain. The SEM/SDM model we have been developed and tested has been applied to the fashion industry, but it could be applied to other industries, as its generality could be adapted to the Supply Chains of other industrial sectors. Such an application to other industrial sectors (e.g. automotive, textile, agricultural and furniture sectors) could be useful to analyse the impacts over time of the study variables (Lean Production, SCI, SCF, and MP) on performance of these industries. Therefore, more research and analysis can be conducted in a variety of industrial and geographical settings in order to generalize the application of the developed SEM/SDM.

During this work, several future research lines have been identified: (1) integrate other aspects or factors that may impact the Supply Chain effectiveness and efficiency; (2) integrate new criteria that could hinder factor the factors implementation, such as financial criteria, inability of human and technological resources and lack of support from senior management; (3) contemplate a more exhaustive evaluation of the factors studied, their combinations, temporal variations, and integration with operational factors; (4) carry out financial viability analysis of the implementation of the factors studied, as a way to better control the company costs; (5) develop a software platform for SEM/SDM simulation able to simulate the evolution of a given business system drawing upon static date gathered from structural equations. This software could also be used to develop theoretical simulations comparisons with real-time evolution of actual data and variables. Thus, researchers and managers could obtain feedback from data comparison and suggest corrective and developmental actions and (6) a comparative analysis could be done by contrasting the findings of this study and its applications to the application of balanced score-card techniques since the evolution foreseen by the proposed methodology can be constantly checked and confronted with actual data arising from balanced score-card tools.

\section{REFERENCES}

Bois, F.Y., and Maszle, D.R. (1997). MCSim: a Monte Carlo simulation program. Journal of Statistics Software, 2, 1-60.

Brunn, P., and Mefford, R.N. (2004). Lean production and the Internet. International Journal of Production Economics, 89 (3), 247-260.

Bruque, S, Moyano, J., and Maqueira, J.M. (2016) Supply chain integration through community Cloud: Effects on operational performance. Journal of Purchasing and Supply Management, 22 (2), 141-153. 
Bruque, S., Moyano, J., and Maqueira, J. M. (2015). Use of Cloud technology, Web 2.0 and operational performance: the mediating role of Supply Chain Integration. International Journal of Logistics Management, 26 (3), 426-458.

Buyya, R., Broberg, J., and Goscinski, A. (2011). Cloud Computing: Principles and Paradigms. John Wiley \& Sons. New York: Inc. Wiley Press.

Cagliano, R., Caniato, F., and Spina, G. (2006). The linkage between Supply Chain Integration and manufacturing improvement programmes. International Journal of Operations \& Production Management 26, (3), 282-99.

Campuzano, F., Mula, J., and Peidro, D. (2010). Fuzzy Estimations and System Dynamics for Improving Supply Chains. Fuzzy Sets and Systems, 161, 1530-1542.

Dermirkan, H., Cheng, H.K., and Bandyopadhyay, S. (2010). Coordination strategies in SaaS supply chain. Journal of Management Information Systems, 26 (4), 119-143.

Dev, N.K., Shankar, R., Dey, P.K., and Gunasekaran, A. (2014). Holonic supply chain: a study from familybased manufacturing perspective. Computers \& Industrial Engineering, 78, 1-11.

Devaraj, S., Krajewski, L., and Wei, J. C. (2007). Impact of e-business technologies on operational performance: the role of production information in the supply chain. Journal of Operations Management, 25 (6), 1199-1216.

Elms, D.K, and Low, P. (2013). Global value chains in a changing world. World Trade Organization, Geneva.

Fingar, P. (2009). Dot. Cloud. The 21st Century Business Platform. Meghan-Kiffer Press, Tampa, Florida.

Flynn, B.B., Huo, B., and Zhao, X. (2010). The impact of Supply Chain Integration on performance: a contingency and configuration approach. Journal of Operations Management, 28 (1-2), 58-71.

Forrester, J.W. (1961). Industrial Dynamics. Pegasus Communications, Waltham.

Frazelle, E. (2001). Supply Chain Strategy: The Logistics of Supply Chain Management (2nd Ed.). McGrawHill Professional, New York.

Frutos, J.D., and Borenstein, D. (2003). Object-oriented model for customer-building company interaction in mass customization environment. Journal of Construction Engineering and Management, 129 (3), 302313.

Giménez, C., and Ventura, E. (2005). Logistics-production, Logistics-marketing and external integration: their impact on performance. International Journal of Operations \& Production Management, 25 (1), 20 38

Giménez, C.; Van der Vaart, T., and Van Donk, P. (2012). Supply Chain Integration and performance: the moderating effect of supply complexity. International Journal of Operations \& Production Management, 32 (5), 583-610.

Griffiths, J, and Margetts, D. (2000). Variation in production schedules - implications for both the company and its suppliers. Journal of Materials Processing Technology, 103 (1), 155-159.

Gunasekarana, A., Laib, K., and Chenge, T. (2008). Responsive supply chain: A competitive strategy in a networked economy. Omega, 36 (1), 549-564.

Hayes, B. (2008). Cloud Computing. Communications of the ACM, 51 (7), 9-11.

Helo, P.T. (2000). Dynamic Modelling of Surge Effect and Capacity Limitation in Supply Chains. International Journal of Production Research, 38, 4521-4533.

Ho, G.T.S., Lau, H.C.W., Lee, C.K.M., and Ip, A.W.H. (2008). Real-time process mining system for Supply Chain network: OLAP-based fuzzy approach. International Journal of Enterprise Network Management, 2 (1), 84-103.

Holweg, M. (2007). The genealogy of Lean Production. Journal of Operations Management, 25 (2), 420-37.

Johnston, D.A., and Wright, L. (2004). The e-business capability of small and medium sized firms in international supply chains. Information Systems and e-Business Management, 2 (2/3), 223-40.

Kumar, R., Haleem, A., Garg, S.K., and Singh, R.K. (2015). Automated guided vehicle configurations in flexible manufacturing systems: A comparative study. International Journal of Industrial and Systems Engineering, 21 (2), 207-226.

Li, G., Yang, H., Sun, L., and Sohal, A. S. (2009). The impact of IT implementation on Supply Chain Integration and performance. International Journal of Production Economics, 120 (1), 125-138.

Li, W., Zhong, Y., Wang, X., and Cao, Y. (2013). Resource virtualization and service selection in Cloud logistic. Journal of Network and Computer Applications, 36 (6), 1696-1704. 
Liu, S., Yang, Y., Qu, W.G., and Liu, Y. (2016). The business value of Cloud Computing: the partnering agility perspective. Industrial Management and Data Systems, 116 (6), 1160-1177.

Lummus, R. R., Duclos, L. K., and Vokurka, R. J. (2003). Supply Chain Flexibility: Building a New Model. Global Journal of Flexible Systems Management, 4 (4), 1-13.

Machado, A.G.C. and Moraes, W.F.A. (2008). Mass customization in civil construction. Revista Brasileira de Gestao de Negocios, 10 (29), 347-364.

Malhotra, M.K., Mackelprang, and A.W. (2012). Are internal manufacturing and external supply chain flexibilities complementary capabilities? Journal of Operations Management, 30 (3), 180-200.

Marin, R.L., and P. D. Brîndaşu. (2015). A self-organizing approach for mixed-model manufacturing based on autonomous entities Academic Journal of Manufacturing Engineering 13 (2), 60-65.

McCormack, K., Ladeira, M.B., and Oliveira, M.P.V. (2008) Supply chain maturity and performance in Brazil. Supply Chain Management. An International Journal, 13 (4), 272-282.

Mell, P., and Grance, T. (2011). The NIST definition of Cloud Computing. Recommendations of the National Institute of Standards and Technology. National Institute of Standards and Technology, Gaithersburg, MD.

Molina, A., Rodriguez, C.A., Ahuett, H., Cortés, J.A., Ramírez, M., Jiménez, G., and Martinez, S. (2005). Next-generation manufacturing systems: Key research issues in developing and integrating reconfigurable and intelligent machines. International Journal of Computer Integrated Manufacturing, 18 (7), 525-536.

Moon, K., Yi, C., and Ngai, E. (2012). An instrument for measuring Supply Chain flexibility for the textile and clothing companies. European Journal of Operational Research, 222 (2), 191-203.

Moyano-Fuentes, J., Martínez-Jurado, P.J., Maqueira-Marín, J.M., and Bruque-Cámara, S. (2012). El papel de las tecnologías de la información and las comunicaciones (TIC) en la búsqueda de la eficiencia: un análisis desde Lean Production and la integración electrónica de la cadena de suministro. Cuadernos de Economía and Dirección de la Empresa, 15 (3), 105-116.

Moyano-Fuentes, J., Sacristán-Díaz, M., and Martínez-Jurado, P. J, (2012). Cooperation in the supply chain and Lean Production adoption: Evidence from the Spanish automotive industry. International Journal of Operations \& Production Management, 32 (9), 1075-1096.

Nowicka, K. (2014). Smart city Logistics on cloud computing model. Procedia - Social and Behavioral Sciences, 151, 266-281.

Oliveira, R.R., Noguez, F. C., Costa, C. A., Barbosa, J. L., and Prado, M. P, (2013). SWTRACK: an intelligent model for cargo tracking based on off-the-shelf mobile devices. Expert System with Applications, 40, 2023-2031.

Pérez, C., de Castro, R., Simons, D., and Gimenez, G. (2010). Development of lean supply chains: a case study of the Catalan pork sector. Supply Chain Management: An International Journal, 15 (1), 55-68.

Purohit, J.K., Mittal, M.L., Mittal, S., and Sharma, M.K. (2016). Interpretive structural modelling-based framework for mass customisation enablers: an Indian footwear case. Production Planning and Control, 27 (9), 774-786.

Rai, A., Pavlou, P.A., Im, G., and Du, S. (2012); Interfirm IT capability profiles and communications for cocreating relational value: evidence from the Logistics industry. MIS Quarterly 36, (1), 233-262.

Rai, R, Sahoo, G, and Mehfuz, S. (2015). Exploring the factors influencing the Cloud Computing adoption: a systematic study on Cloud migration. SpringerPlus, 4 (1), 1-12.

Rojo, A., Stevenson, M., Lloréns-Montes, F. J., and Perez-Arostegui, M. N. (2018). Supply chain flexibility in dynamic environments: The enabling role of operational absorptive capacity and organisational learning. International Journal of Operations \& Production Management, 38 (3), 636-666.

Romano, P. (2003). Co-ordination and integration mechanisms to manage logistics processes across supply markets. Journal of Purchasing and Supply Management, 9 (3), 119-134.

Satorra, A. (1993). Multi-sample analysis of moment-structures: asymptotic validity of inferences based on second order moments. In: Haagen, K., Bartholomeusz, A., Deistler, M. (Eds.), Statistical modelling and latent variables. Elsevier, North Holland, Amsterdam.

Schniederjans, D.G., and Hales, D.N. (2016). Cloud Computing and its impact on economic and environmental performance: A transaction cost economics perspective. Decision Support Systems, 86, 73-82.

Shah, R., Chandrasekaran, A., and Linderman, K. (2008). In pursuit of implementation patterns: the context of Lean and Six Sigma. International Journal of Production Research, 46 (23), 6679-99. 
Stank, T.P., Keller, S.B., and Daugherty, P.J. (2001). Supply chain collaboration and logistical service performance. Journal of Business Logistics, 22 (1), 29-48.

Sterman, J. (2000). Business Dynamics: Systems Thinking and Modelling for a Complex World. Irwin/McGraw-Hill.

Strasser, T., Rooker, M, and Ebenhofer, G. (2011). An IEC 61499 distributed control concept for reconfigurable robots. International Journal of Computer Aided Engineering and Technology, 3 (3), 344359.

Stump, B., and Badurdeen, F. (2012). Integrating Lean and other strategies for mass customization manufacturing: A case study. Journal of Intelligent Manufacturing, 23 (1), 109-124.

Subramanian, N., Abdulrahman, M. D., and Zhou, X. (2015). Reprint of Integration of Logistics and Cloud Computing service providers: Cost and green benefits in the Chinese context. Transportation Research, 74, 81-93.

Trappey, A. J. C., Trappey, C. V., Chang, S. W. C., and Tun Nien Hsu, W. T. L. (2016). A one-stop logistic services framework supporting global supply chain collaboration. Journal of Systems Science and Systems Engineering, 25(2), 229-253.

Van der Vaart, T.; Van Donk, P; Giménez, C., and Sierra, V. (2012). Modelling the integration-performance relationship. Collaborative practices, enablers and contextual factors. International Journal of Operations and Production Management, 32 (9), 1043-1074.

Vermula, R., and Zsifkovits, H. (2016). Cloud Computing for Supply Chain Management. Berg- und Hüttenmännische Monatshefte, 161 (5), 229-232.

Wang, X., Li, W.F., Zhong, Y. and Zhao, W. (2012). Research on cloud Logistics-based one-stop service platform for Logistics center. IEEE 16th International Conference on Computer Supported Cooperative Work in Design, 558-563, Wuhan, China.

Waters, D. (2007). Global Logistics: New Directions in Supply Chain Management (5a Ed.). Kogan Page Publishers, London.

Womack, J.P., and Jones, D.T. (1996). Lean Thinking, Simon and Schuster, New York, NY.

Womack, J.P., Jones, D.T., and Ross, D. (1990). The Machine That Changed the World, MacMillan, New York, NY. 
Chapter 7

General Conclusions 


\section{General Conclusions}

\subsection{INTRODUCTION}

This chapter contains the conclusions reached after the completion of the doctoral thesis project. Based on the findings of the previous chapters, the main conclusions, responses to specifics Research Questions, future research lines, managerial implications, and research limitations are presented below.

\subsection{CONCLUSIONS}

In chapter 1, the current state of research into Cloud Computing (CC) and Supply Chain Integration (SCI) have been analysed, with the objective to identify the findings to date, the areas of study developed and research gaps to provide guidance for future research. For this, a Systematic Literature Review have been conducted, with 77 papers addressing the $\mathrm{CC}-\mathrm{SCl}$ relationship identified for analysis. Based on chapter 1 findings, we are ready to answer the RQ1: What are the findings to date, the areas of study developed and the research gaps related to Cloud Computing use in the firm and its effect on Supply Chain Integration? Chapter 1 provide evidence of a positive relationship between the $\mathrm{CC}$ adoption and $\mathrm{SCI}$. CC is a very effective technological tool for integrating data, as it has a range of impacts when used to improve integration in the supply chain. CC can advance the development of the supply chain through effective supply chain flow integration (information, physical, and financial), which, in turn, supports other types of integration (process, technology and partner). CC has a significant impact on the efficiency of supply chain process and activity integration (manufacturing, logistics, design/development, commercial and financial integration) as it improves scalability, flexibility, agility, and adaptation to changes and supply chain planning. In addition, the literature shows that integrating $\mathrm{CC}$ with existing IT systems can improve system flexibility, deployment and accessibility. Furthermore, CC is an important factor that facilitates integration and collaboration among business partners (internal, suppliers and customers) as it enables SC members and stakeholders to communicate in real time. However, there is a research gap on theoretical and empirical studies that analyse the impact of CC use and SCI types (i.e., manufacturing and logistics integrations, internal and external technology integrations, and internal, supplier and customer integrations) on operational and financial performance. In addition, some types of integrations (design/development, financial, commercial, purchasing, and warehouse integrations) 
have not been explored to any great extent, which highlights the need for more research in these areas.

In chapter 2, the current state of research on Supply Chain Flexibility (SCF) and the Customer Microsegmentation/Mass Personalization (CMS/MP) adoption have been analysed, with the objective: to identify the literature findings to date and the research gaps and to provide guidelines for future research in this area. To this end, a systematic review of 64 papers was undertaken to address the use of SCF as a productive response to CMS/MP. Based on chapter 2 findings, we are ready to answer the RQ3: What are the findings to date, the areas of study developed and the research gaps related to Supply Chain Flexibility-Customer Microsegmentation/Mass Personalization relationship? Chapter 2 findings have allowed identifying a positive relationship between the SCF and the CMS/MP strategies. Three main research topics in the Supply Chain Flexibility-Customer Microsegmentation/Mass Personalization area have been identified: (1) Personalization levels and flexible processes in Supply Chain, (2) SCF and CMS/MP enabling technologies, and (3) Supply Chain collaborative processes for SCF and CMS/MP. Regarding 'Personalization levels and flexible processes along the Supply Chain', the customer's order entry point is a key factor in the definition of the CMS/MP level. The higher the customer's order penetrates the value chain, the higher the product personalization level will be. In terms of the 'Supply Chain collaborative processes', codesigning products allows exploring the balance between supply and demand flexibility, providing a sustained competitive advantage and can have a significant strategic and financial value if properly aligned. From the 'SCF and CMS/MP enabling technologies' perspective, the adoption of technologies can increase collaboration, response to environmental changes, and flexibility in production processes along the Supply Chain. Chapter 2 findings also reveal areas of study that have received little or no attention from previous researchers: there are few empirical studies investigating the factors related to the operational and financial performance of the SCF-CMS/MP processes; few studies analyse the potential impacts that some CMS/MP enabling technologies (e.g. Big Data and Internet of Things) could have on the relationship between SCF and CMS/MP; the Supply Chain collaborative processes and its impact on SCF-CMS/MP context has not been explored to any great extent, which highlights the need for more research in this area.

In chapter 3, the interrelationships between Lean Production implementation, Cloudsupported Logistics use, Supply Chain Integration, and their effects on business performance have been analysed. A random sample of 260 companies obtained from a population of 1,717 Spanish companies in intermediate positions in their supply chains 
has been used to test five hypotheses. The data were collected by telephone survey using the CATI computerised system, with a response rate of 15.6 percent (260 valid questionnaires). Structural equation modelling has been used to test the five proposed hypotheses. Based on chapter 3 findings, we are ready to answer the RQ2: Would be Lean Production Implementation, Cloud-supported Logistics and Supply Chain Integration approaches effective enablers of Business Performance environments? Lean Production implementation facilitates Cloud-supported Logistics use and that the latter's use, in turn, facilitates Supply Chain Integration. However, Cloud-supported Logistics use can be seen not to directly influence business performance improvement, although it does so indirectly through the mediating role of Supply Chain Integration. Chapter 3 findings show that Lean production has a strong direct effect on business performance, which means that companies using Lean Production achieve better Business Performance. There is also the strong indirect effect between Cloud-supported Logistics and Business Performance, which is greater than the direct effect of Lean on Business Performance. Due to the mediating effect of Supply Chain Integration between Cloudsupported Logistics and Business Performance, the latter improves much more than if Lean Production is used alone without the use of Cloud-supported Logistics. This is partly due to the effect of Lean on business performance and, also, to the very powerful indirect effect of Cloud-supported Logistics on business performance via Supply Chain Integration. Although there are findings in the previous literature to the effect that Lean Production can lead companies to use IT in order to make efficiency gains, this chapter demonstrates that by specifically relying on IT in Cloud-supported Logistics, Lean production has greater direct and indirect impacts on Business Performance. This is the result of the mediating effect of Supply Chain Integration between Cloud-supported Logistics and business performance.

In chapter 4 , the mediating role of Supply Chain Flexibility in the interrelationships between Lean Production implementation, Mass Personalization and business performance have been analysed. A random sample of 260 companies obtained from a population of 1,717 Spanish companies that occupy an intermediate position in the supply chain has been used to test the proposed hypothetical framework. Telephone surveys using the CATI computerized system has been used to collect data, obtaining a response rate of 15.6, and a Structural Equation Modelling have been design to test the six proposed hypothesis. Based on chapter 4 findings, we are ready to answer the RQ4: Would be Lean Production, Supply chain Flexibility, and Mass Personalization approaches effective enablers of Business Performance? Chapter 4 findings indicate that companies initially implement Lean Production to optimize Mass Personalization 
processes and improve Business Performance. However, in the presence of Supply Chain Flexibility, Lean Production implementation no longer has a direct impact on Mass Personalization and Business Performance, but it does have an indirect impact through the flexibility it achieves (shown as a mediator effect). Therefore, companies should implement Lean Production to achieve flexibility and thus optimize the Mass Personalization processes and obtain better performance. Chapter 4 findings show that Lean production has a strong direct effect on Business Performance and on Mass Personalization, which means that companies using Lean achieve better Business Performance and Mass Personalization levels. Lean production has also a strong direct effect on Supply Chain Flexibility but, in this situation, the direct relations between Lean Production-Business Performance and Lean Production-Mass Personalization are no longer significant. The results show that there is an even stronger indirect effect between Lean Production implementation and Business Performance, as well as between Lean Production implementation and Mass Personalization. Due the mediating effect of Supply Chain Flexibility, Business Performance and Mass Personalization grow much more than, if only Lean Production is used without Supply Chain Flexibility. This is due, in one part, to the effect of Lean Production implementation on Business Performance and Mass Personalization, and, in the other part, to the indirect effect through Supply Chain Flexibility, which is very powerful. Although in the literature, there are previous findings that Lean Production can lead companies to improve their performance and Mass Personalization levels, this chapter demonstrates that by relying on Supply Chain Flexibility, and Lean production achieves a greater impact on Business Performance and Mass Personalization level.

In chapter 5, a methodological proposal to carry out simulations at a strategic level, using the complementarity between Structural Equation Models (SEM) and System Dynamics Models is presented (SDM). The methodological proposal named "SEM/SDM model" emerges as a new path that allows for prospective strategic analysis. It has been illustrated by two applications: first, to the case of Community Cloud use, Supply Chain Integration and their impacts on operational performance; second, to the specific case of Information Technology Integration and Lean/Just-In-Time Practices on Lead-Time Performance. In chapter 6, the SEM/SDM methodology proposed in chapter 5 has been used. From a dynamic and strategic point of view, it has been analysed how some factors related to the Supply Chain effectiveness and efficiency are interrelated and how they affect Business Performance. Supply Chain Integration, Supply Chain Flexibility and Mass Personalization capacity have been considered as factors related to business effectiveness. Lean Production implementation and Cloud Computing use have been 
deemed business efficiency-related factors. The interrelation between these factors comes from theoretical models that have been formulated in chapters 3 and 4 (through hypotheses) and empirically contrasted through Structural Equation Models (SEM). The main contribution of chapter 6 has been a framework that can be used to model and simulate the impacts of the aforementioned effectiveness and efficiency factors in a real Supply Chain, which will eventually serve as support for strategic decision-making.

Based on chapters 5 and 6 findings, we are ready to answer the RQ5: Would be the combined action of Lean Production Implementation, Cloud-supported Logistics, Supply Chain Integration, Supply Chain Flexibility, and Mass Personalization effective enablers of Business Performance? The SEM/SDM developed and validated has been applied for helping the strategic decision making process of a Cloud-supported logistics company in the fashion industry to increase its Business Performance. The specific case of the Cloud-supported logistics company has been simulated, which the combined relationship of Lean Production Implementation, Cloud-supported Logistics, Supply Chain Integration, Supply chain Flexibility, and Mass Personalization has been analised. On the one hand, it has been observed that if the company does not have Lean Production implemented (causal variable), the combined action of Cloud-supported Logistics, Supply Chain Integration, Supply chain Flexibility, and Mass Personalization (causal variables) could be insufficient to reach the Business Performance level (effect variable) planed by the company at the end of the 24 months (an increase of 0.10 in Business Performance). On the other hand, if the company has Lean Production implemented (causal variable), the combined action of Cloud-supported Logistics, Supply Chain Integration, Supply chain Flexibility, and Mass Personalization (causal variables) would be sufficient to achieve a 0.10 increase in the Business Performance level (effect variable) desired by the company. Therefore, it can be stated that the combination of Cloud-supported Logistics, Supply Chain Integration, Supply chain Flexibility, and Mass Personalization increase Business Performance, but better results are achieve when such variables are combined with Lean Production.

\subsection{MANAGERIAL IMPLICATIONS}

Based on evidence from the descriptive analyses carried out in Block 1 (chapters 1 and 2), additional management insights can be obtained on how the use of $\mathrm{CC}$ might impact $\mathrm{SCl}$, as well as the relationship between SCF and CMS/MP. On the one hand, managers should be aware that $\mathrm{CC}$ has enormous potential for supporting process and activity integration; technology and SC system integration; partner integration and information, 
physical and financial flows throughout the SC. For managers, these conclusions are proof of the great potential that CC has for information sharing among SC members, for interconnecting production and delivery centres, for improving service quality, for reducing costs and for generating greater flexibility and agility in the SC. On the other hand, managers are aware of the potential implications related to SCF and CMS/MP. SCF allows companies to be able to provide individually designed products and services to each customer. Through a deeper understanding of the opportunities and challenges related to flexibles processes, supply chain collaboration and enabling technologies in the SCF-CMS/MP area, company managers could use these findings as a starting point to learn about the possibilities of improvement in their companies' flexible processes, as a way to fill the gaps between what the markets require and what the company offers. Aware of the effects of the $\mathrm{CC}-\mathrm{SCl}$ relationship, as well as SCF-CMS/MP relationship, managers could to better understand the role and types of approaches to the CC-SCI relationship and SCF-CMS/MP and achieve competitive advantage. Thus, the conclusions of Block I could serve as an initial support for decision-making on the implementation of such strategies/technologies and could affect the way managers observe, organize and manage their production processes to achieve better results.

Furthermore, the evidence from the exploratory analyses carried out in Block 2 (chapters 3 and 4) also provide important management insights about the relationships between Lean Production implementation, Cloud-supported Logistics, Supply Chain Integration, Supply Chain Flexibility, Mass Personalization and Business Performance; Managers need to know that they can use Lean Production and its different practices to directly achieve better performance, both financially and operationally. On the one hand, by adopting Lean Production, which provides the business efficiency that the Cloudsupported Logistics user pursues, companies can achieve efficiency in intra- and interorganisational integration. These further efficiency gains would be achieved through cooperation with supply chain members and could thus lead to better operational and financial results. Managers could therefore consider the complementarity between Lean Production implementation and Cloud-supported Logistics as a way to increment Supply Chain Integration and leverage Business Performance. On the other hand, when Lean practices are based on Supply Chain Flexibility, the effect on mass personalization and Business Performance is multiplied. Supply chain managers should know that Lean Production, not only helps Supply Chain Flexibility to be even more effective, but also has a strong indirect impact on Mass Personalization and Business Performance. These further gains on efficiency and effective would be achieved through the complementarity between Lean Production and Supply Chain Flexibility could lead companies to achieve 
better mass personalization levels. Managers could consider the complementarity between Lean Production implementation and Supply Chain Flexibility as a way to achieve higher levels of Mass Personalization and, ultimately, improve operational and financial performance. Managers need to know that they can use Lean production and its different practices to directly and indirectly achieve better financially and operationally performance. These findings and implications could, therefore, help business managers become aware of how powerful Lean Production, Cloud-supported Logistics, Supply Chain Integration, Supply Chain Flexibility and Mass Personalization, and affect how managers perceive and organize these resources in their companies to achieve higher Business Performance.

Finally, based on evidence from the simulation approach carried out in Block 3 (chapters 5 and 6) additional management insights can be obtained on the inclusion of a dynamic effect and analysis to the traditional SEM methodology. The proposed tool can be a starting point to add a what-if scenario so that managers can create alternative prospective horizons according to the values that major variables may take over time. This possibility may prove as a great advantage for managers interested in applying sensitive analyses to complex situations in which organizational and technology factors are usually interwoven. It is a significant leap since now managers can also use this tool to create and justify strategic projections of organizational and technological behaviours. Furthermore, operational and strategic use can both be combined for analysis of a set of significant variables in a given company and/or sector. The application of the SEM/SDM tool has shown that thanks to the model developed, it is feasible to use the SEM data and turn it into a tool for future analysis of organizational key variables, such as the new technology implementation, Lean practices, Supply Chain Integration, Supply Chain Flexibility, Mass Personalization and Business Performance. The SEM/SDM model is not a closed tool, but a methodological model that could be expanded and/or adapted to this or to other simulation environments for this or other industries, types of technologies and organizational questions. So, company managers are able to include the dynamic factor in their companies' framework.

This research is a new endeavour that drawing upon a combined methodology, enables companies and researchers to take into consideration the dynamic nature of the environments in which organizational issues are usually embedded. 


\subsection{RESEARCH LIMITATIONS}

We fully recognize that our study has some limitations. Readers, researchers and companies managers should also be aware of these limitations and interpret what is presented in this doctoral thesis in their context.

First, the Systematic Literature Review (SLR) used on descriptive analyses (Block I, composed by chapters 1 and 2) is reliable technique and is recommended by a large number of scientific papers. However, it is criticized for several reasons. On the one hand, the criteria used for including papers may have led to the exclusion of other, similarly-important papers (for example congress communications). On the other hand, while the authors have conducted a comprehensive literature search of the ABI Inform Global, ScienceDirect, Scopus, Emerald Insight and Web of Science databases to identify all relevant potential papers, it is likely that some research papers have been omitted (papers present only in other databases). However, despite these criticisms, if the SLR technique is rigorously applied, it is possible to obtain reasonable knowledge of the research questions (Denyer and Tranfield, 2009). Another limitation of these chapters findings is that should be highlighted is that the classification of the papers is subjective, as it is based on the researcher's opinions. This is also an inherent limitation of SLR (Correia et al., 2017; Pérez-Salazar et al., 2017). Nonetheless, previous literature theory frameworks have been used to reduce this limitations.

Second, the database used on exploratory analyses (Block II, composed by chapters 3 and 4 ) is focused on the industrial sectors that are in an intermediate position in the supply chain and targets companies that frequently interact with upstream and downstream supply members. The implications of the findings are, therefore, both farreaching and robust. In addition, results have only been obtained from Spanish industrial sectors. The studies need to be conducted and replicated with company samples from other geographical environments to confirm the obtained results. In addition, in order to test the chapter hypothesis, measures have been taken which are considered to be perceptive in nature. Despite the belief that the questionnaires are free of bias, it is impossible to completely rule out this type of apprehension. A practical step forward would be to test the research's model with multiple informants, not just by relying on information provided by Supply Chain Management managers.

Finally, with regard to Block III (composed by chapter 5 and chapter 6), although the proposed methodology has proven to be an effective tool for analysing the behaviour over time of variables and its relationships with other variables, some limitations must be considered. As a new methodology, one of the limitations refers to its comparison, since 
a relatively small number of tests and applications have been carried out. The simulated factors are limited to those that have been previously studied in the two SEMs used. Overall, decision making related to strategic Supply Chain factors is also based on other evaluation criteria such as implementation costs, available technologies and trained human resources. In addition, the SEM used as a reference in this study is focused on industrial sectors that hold an intermediate position in the Supply Chain. Therefore, more research, analysis and tests would be conducted in a variety of industrial and geographical settings in order to generalize the application of the developed SEM/SDM.

\subsection{FUTURE WORK}

During this work, several future research lines have been identified, as described below.

Regarding the research findings of Block 1, researchers are encouraged to developed longitudinal studies of CC-SCI and SCF-CMP/MP relationship. Such studies should be conducted as a way of measuring and evaluating the medium- and long-term performance of these relationship. As seen in chapter 1 and chapter 2, the growing number of papers that have conducted empirical research to $\mathrm{CC}-\mathrm{SCl}$ relationship, as well as to SCF-CMS/MP, shows the need for more research to explore these lines. Researchers are also encouraged to exploit methodological tools such as case studies in combination with quantitative methods to validate and test the theoretical concepts identified in chapters 1 an 2. On the one hand, new studies could investigate the difficulties or success factors of CC implementation in SCl or a case analysis (e.g., success vs. failure) of the CC-SCI relationship. Furthermore, if any differences exist between the different CC types (Micro-cloud, Private Cloud, Hybrid Cloud and Community Cloud) and CC models (laaS, PaaS, SaaS) as a support for SCl, they should be analysed. Lastly, further work is required on financial flows (the least researched integration flow) to find additional evidence and examples of applications. On the other hand, new studies related to SCF-CMS/MP could compare the manufacturing strategies in terms of flexibility and personalised production volume. Also, further research could analyse the SCF types as a productive response to CMS/MP and the possible relationships between flexibility/personalization levels with customer satisfaction. New studies could also analyse the potential impacts that some CMS/MP enabling technologies (e.g. Big Data and Internet of Things) on the relationship between SCF and CMS/MP. Finally, further theoretical and practical studies should be conducted to assess the influence of factors such as coordination, demand flexibility and distribution on SCFCMS/MP. 
With regard to the research carried out in Block 2, more research and analysis must be conducted in a variety of industrial and geographical settings to confirm the chapters' findings. The studies need to be conducted and replicated with company samples from other geographical environments to confirm the obtained results. A logical extension of this work would consist of empirically replicating the obtained results in other contexts in which the identified relationships would be tested with larger samples and several informants in each company. It would be advisable to use a longitudinal methodology in the future for a study of causality in the observed relationships, since the cross-sectional nature of the data does not allow causal inferences to be extracted. On the one hand, it is necessary to examine the lag between progress being made in the Lean Production implementation level and the time when the company makes advances in Cloudsupported Logistics (chapter 3 findings). On the other hand, the relationship between different practices associated with Lean Production, specific flexibility types, different Mass Personalization levels, and their impacts on operational and financial performance should be studied (chapter 4 findings).

Finally, regarding to Block III findings (chapter 5 and chapter 6), several future research lines have been identified. It could be necessary to carry out new tests of the SEM/SDM methodology in more complex SEMs (with mediation and/or moderation relationships). An information system/ application could also be developed in order to apply and combine the use of both methodologies in a particular industry or company. It would also be interesting integrate in the SEM/SDM model other aspects or factors that may impact the Supply Chain effectiveness and efficiency. In addition, new criteria that could hinder factor the factors implementation, such as financial criteria, inability of human and technological resources and lack of support from senior management could be analysed by SEM/SDM in the future. Furthermore, it would be interesting develop a software platform for SEM/SDM simulation able to simulate the evolution of a given business system drawing upon static date gathered from structural equations. This software could also be used to develop theoretical simulations comparisons with realtime evolution of actual data and variables. Finally, a comparative analysis could be done by contrasting the findings of SEM/SDM model and its applications to the application of balanced score-card techniques since the evolution foreseen by the proposed methodology can be constantly checked and confronted with actual data arising from balanced score-card tools.

The results of this doctoral thesis are useful inferences regarding the implications of the variables studied, and will serve as a basis for further studies on this research topic. 
Therefore, future researches could analyse the results of the unstudied interrelationships. 
General References 


\section{GENERAL REFERENCES}

Abdulaziz, A. (2012). Cloud Computing for increased business value. International Journal of Business Society Science, $3(1), 234-239$.

Abedi, M. (2016). Integrated Collaborative Tools for Precast Supply Chain Management. Scientia Iranica, 232 (2), 429 448.

Abedi, M., Fathi, M. S., \& Rawai, N. M. (2013). The Impact of Cloud Computing Technology to Precast Supply Chain Management. International Journal of Construction Engineering and Management, 2 (4A), 13-16.

Abidi, H., Leeuw, S., \& Klumpp, M. (2014). Humanitarian supply chain performance management: a systematic literature review. Supply Chain Management, 19 (5-6), 592-608.

Acar, M., Tarim, M., Zaim, H., Zaim, S., and Delen, D. (2017). Knowledge management and ERP: Complementary or contradictory?. International Journal of Information Management, 37 (6), 703-712.

Achillas, C., Tzetzis, D., and Raimondo, M.O. (2017). Alternative production strategies based on the comparison of additive and traditional manufacturing technologies. International Journal of Production Research, 55 (12), 3497-3509.

Adjei, J. K. (2015). Explaining the role of trust in Cloud Computing services. Digital Policy, Regulation and Governance, 17 (1), 54- 67.

Ahire, S.L., and Devaraj, S. (2001). An empirical comparison of statistical construct validation approaches. IEEE Transactions on Engineering Management, 48 (3), 319-329.

Akbaripour, H., Houshmand, M., \& Valilai, O.F. (2015). Cloud-Based Global Supply Chain: A Conceptual Model and Multilayer Architecture. Journal of Manufacturing Science and Engineering, 137 (4), 1-6.

Akkermans, H.A., Bogerd, P., Yucesan, E., and van Wassenhove, L.N. (2003). The impact of ERP on supply chain management: exploratory findings from a European Delphi study. European Journal of Operational Research, 146 (2), 284-301.

Al-jawazneh, B. (2016). The Prospects of Cloud Computing in Supply Chain Management (A Theoretical Perspective). Journal of Management Research, 8 (4), 145-158.

Alsafi, Y., and Vyatkin, V. (2010). Ontology-based reconfiguration agent for intelligent mechatronic systems in flexible manufacturing. Robotics and Computer-Integrated Manufacturing, 26 (4), 381-391.

Alshamaila, Y., Papagiannidis, S., \& Li, F. (2013). Cloud Computing adoption by SMEs in the north east of England: a multi-perspective framework. Journal of Enterprise Information Management, 26 (3), 250-275.

Al-Zaher, A., EIMaraghy, W., and Pasek, Z.J. (2013). RMS design methodology for automotive framing systems BIW. Journal of Manufacturing Systems, 32 (3), 436-448.

Amand, G., and Ward, P. (2004). Fit, flexibility and performance in manufacturing: coping with dynamic environments. Production and Operations Management, 13 (4), 369-385.

Andreadis, G., Fourtounis, G., \& Bouzakis, K. D. (2015). Collaborative design in the era of Cloud Computing. Advances in Engineering Software, 81, 66-72.

Armstrong, J.S., and Overton, T.S. (1997). Estimating nonresponse bias in mail surveys. Journal of Marketing Research, 14(3), 396-402.

Ashraf, M. M., Hasan, N., Lewis, U., \& Hasan, M. R. (2017). A Systematic Literature Review of the Application of Information Communication Technology for Visually Impaired People. International Journal of Disability Management, 11, 1-18.

Azevedo, A., Faria, J., \& Ferreira, F. (2017). Supporting the entire life-cycle of the extended manufacturing enterprise. Robotics and Computer-Integrated Manufacturing, 43, 2-11.

Azevedo, S., Prata, P., \& Fazendeiro, P. (2013). Assessment of supply chain agility in a Cloud Computing-based framework. Scalable Computing: Practice and Experience, 13 (4), 295-301.

Babiceanu, R.F., \& Seker, R. (2016). Big Data and virtualization for manufacturing cyber-physical systems: A survey of the current status and future outlook. Computers in Industry, 81, 128-137.

Bagozzi, R.P. and Yi, Y. (1988). On the evaluation of structural equation models, Journal of Academy of Marketing Science, 16 (2), 74-94.

Barman, S. and Canizares, A.E. (2015). A survey of mass customization in practice. International Journal of Supply Chain Management, 4 (1), 65-72.

Barrales-Molina, V., Llorens-Montes, F. J., and Gutierrez-Gutierrez, L. J. (2015). Dynamic capabilities, human resources and operating routines: A new product development approach. Industrial Management \& Data Systems, 115 (8), 1388-1411.

Batista, J., and Coenders, G. (2000). Modelos de ecuaciones estructurales. La Muralla, Madrid.

Berman, B. (2002). Should your firm adopt a mass customization strategy? Business Horizons, 45 (4), 51-60.

Bernardes, E.S., and Zsidisin, G.A. (2008). An examination of strategic supply management benefits and performance implications. Journal of Purchasing and Supply Management, 14 (2), 209-219. 
Bhoir, H., \& Principal, R. P. (2014). Cloud Computing for Supply Chain Management. International Journal of Innovations in Engineering Research and Technology, 1 (2), 1-9.

Bi, Z., \& Cochran, D. (2014). Big data analytics with applications. Journal of Management Analytics, 1 (4), 249-265.

Biel, K., \& Glock, C.H. (2016). Systematic literature review of decision support models for energy-efficient production planning. Computers \& Industrial Engineering, 101, 243-259.

Boell, S. K., \& Cecez-Kecmanovic, D. (2014). A hermeneutic approach for conducting literature reviews and literature searches. Communications of the Association for Information Systems, 34 (12), 257- 286.

Bois, F.Y., and Maszle, D.R. (1997). MCSim: a Monte Carlo simulation program. Journal of Statistics Software, 2, 1-60.

Boon-itt, S., and Wong, C.Y. (2011). The moderating effects of technological and demand uncertainties on the relationship between Supply Chain Integration and customer delivery performance. International Journal of Physical Distribution \& Logistics Management, 41 (3), 253-76.

Botta, A., de Donato, W., Persico, V., and Pescapé, A. (2016). Integration of Cloud computing and Internet of Things: A survey. Future Generation Computer Systems, 56, 684-700.

Brabazon, P. G., MacCarthy, B., Woodcock, A., and Hawkins, R. W. (2010). Mass Customization in the Automotive Industry: Comparing Interdealer Trading and Reconfiguration Flexibilities in Order Fulfilment. Production and Operations Management, 19 (5), 489-502.

Braojos, J., Benitez, J., and Llorens-Montes, F. J. (2019). How do social commerce-IT capabilities influence firm performance? Theory and empirical evidence. Information \& Management, 56 (2), 155-171.

Brant, A., \& Sundaram, M. M. (2015). A novel system for Cloud-based micro additive manufacturing of metal structures. Journal of Manufacturing Processes, 20, 478-484.

Brunn, P., and Mefford, R.N. (2004). Lean production and the Internet. International Journal of Production Economics, 89 (3), 247-260

Bruque, S., Moyano, J., \& Maqueira, J. M. (2015). Use of Cloud technology, Web 2.0 and operational performance: the mediating role of supply chain integration. International Journal of Logistics Management, 26 (3), 426-458.

Bruque, S., Moyano, J., \& Maqueira, J. M. (2016). Supply chain integration through community Cloud: Effects on operational performance. Journal of Purchasing and Supply Management, 22 (2), 141-153.

BSA, The Software Alliance (2018). BSA Global Cloud Computing Scorecard. Powering a Bright Future, BSA, The Software Alliance, Washington. Available at: http://cloudscorecard.bsa.org/2018/; [Consulted on 10 June 2018]

Buyya, R., Broberg, J. \& Goscinski, A. (2011). Cloud Computing: Principles and Paradigms. John Wiley \& Sons. New York: Inc. Wiley Press.

Buyya, R., Yeo, C.H., Venugopal, S., Broberg, J., \& Brandic, I. (2009). Cloud Computing and emerging IT platforms: Vision, hype and reality for delivering computing as the 5th utility. Future Generation Computer Systems, 25 (6), 599 616.

Cagliano, R., Caniato, F., and Spina, G. (2006). The linkage between Supply Chain Integration and manufacturing improvement programmes. International Journal of Operations \& Production Management, 26 (3), 282-99.

Campuzano, F., and Mula, J. (2011). Supply Chain Simulation: A System Dynamics Approach for Improving Performance. Springer, London.

Campuzano, F., Martínez, E., and Ros, L. (2010) Cadenas de suministro tradicionales y colaborativas: Análisis de su influencia en la gestión de la variabilidad de la demanda. Dyna, 8 (1), 33-40.

Campuzano, F., Mula, J., and Peidro, D. (2010). Fuzzy Estimations and System Dynamics for Improving Supply Chains. Fuzzy Sets and Systems, 161,1530-1542.

Carrillo, M., \& Franky, C. (2014). Modelo SCLOUDPY para la gestión de pedidos en la nube. Información Tecnológica, 25 (4), 35-42.

Casas, M. (2013) Los modelos de ecuaciones estructurales y su aplicación en el índice europeo de satisfacción al cliente. Universidad San Pablo-CEU, Madrid.

Casey, G., Cegielski, L., Jones-Farmer, A., Wu, Y., \& Hazen, B. T. (2012). Adoption of Cloud Computing technologies in supply chains. The International Journal of Logistics Management, 23 (2), $184-211$.

Chen, C.-S., Liang, W.-Y., \& Hsu, H.-Y. (2015), A Cloud Computing platform for ERP applications. Applied Soft Computing, 27, 127-136.

Chen, F., Dou, R., Li, M., \& Wu, H. (2016). A flexible QoS-aware Web service composition method by multi-objective optimization in Cloud manufacturing. Computers and Industrial Engineering, 99, 423-431.

Chen, H., Daugherty, P. J., \& Roath, A. S. (2009). Defining and operationalizing supply chain process integration. Journal of Business Logistics, 30 (1), 63-84.

Chen, I., and Paulraj, A. (2004). Towards a theory of supply chain management: the constructs and measurements. Journal of Operations Management, 22 (2), 119-150.

Chen, J., and Chen, F. F. (2008). Adaptive scheduling and tool flow control in flexible job shops. International Journal of Production Research, 46 (15), 4035-4059. 
Chen, S. L., Chen, Y. Y., \& Hsu, C. (2014). A new approach to integrate internet-of-things and software-as-a-service model for logistic systems: A case study. Sensors, 14 (4), 6144-6164.

Chen, S., and Tseng, M. M. (2007). Aligning demand and supply flexibility in custom product co-design. International Journal of Flexible Manufacturing Systems, 19 (4), 596-611.

Cheng, J. S., Li, F. C., Ou, T.Y., \& Kung C.C. (2014). The strategic research on integrating services model for SMEs cloud supply chain in Taiwan. International Journal of Electronic Business Management, 12 (1), 33-40.

Cheng, Y., Tao, F., Zhao, D., Zhang, L., \& Zuo, Y. (2017). Modeling of manufacturing service supply-demand matching hypernetwork in service-oriented manufacturing systems. Robotics and Computer-Integrated Manufacturing, 45 (C), 59-72.

Chiu, P. C., Liao, A. Y. H., Liao, C. H., Yango, Y. N. (2013). Cloud-Based Supply Chain Integration Service Platform. Journal of Electronic Science and Technology, 11(2), 201-208.

Christauskas, C., \& Miseviciene, R. (2012). Cloud-computing based accounting for small to medium sized business. Engineering Economics, 23 (1), 14-21.

Chung, B.D., Kim, S.I., and Lee, J.S. (2018). Dynamic Supply Chain Design and Operations Plan for Connected Smart Factories with Additive Manufacturing. Applied Sciences, 8 (4), 583.

Claycomb, C., Dröge, C., and Germain, R. (2005). Applied customer knowledge in a manufacturing environment: Flexibility for industrial firms. Industrial Marketing Management, 34 (6), 629-640.

Coker, J., and Helo, P. (2016). Demand-supply balancing in manufacturing operations. Benchmarking: An International Journal, 23 (3), 564-583.

Comstock, M., Johansen, K., and Winroth, M. (2004). From mass production to mass customization: Enabling perspectives from the Swedish mobile telephone industry. Production Planning and Control, 15 (4), 362-372.

Cook, T., and Campbell, D. (1979). Quasi-experimentation: design and analysis issues for field settings. Boston: Houghton Mifflin.

Coronado, A.E., Lyons, A.C., Kehoe, D.F., and Coleman, J. (2004). Enabling mass customization: Extending build-toorder concepts to Supply Chains. Production Planning and Control, 15 (4), 398-411.

Correia, E., Carvalho, H., Azevedo, S.G., \& Govindan, K. (2017). Maturity models in supply chain sustainability: a systematic literature review. Sustainability, 9, 64.

Corsten, D., and Felde, J. (2005). Exploring the performance effects of key-supplier collaboration. An empirical investigation into Swiss buyer-supplier relationship. International Journal of Physical Distribution \& Logistic Management, 35 (6), 445-461.

Costantino, F., Gravio, G.D., and Shaban, A. (2014). Multi-criteria logistics distribution network design for mass customisation. International Journal of Applied Decision Sciences, 7 (2), 151-167.

Cupani, M. (2012) Análisis de Ecuaciones Estructurales: conceptos, etapas de desarrollo y un ejemplo de aplicación. Tesis, 2 (1), 186-199.

Custódio, D. T., Vaccaro, G. L. R., Nunes, F. L., Vidor, G., and Chiwiacowsky, L. D. (2018). Variant product configuration of industrial air handling units in a MTO environment. The International Journal of Advanced Manufacturing Technology, 95 (1-4), 1025-1037.

Da Silveira, G., Borenstein, D., and Fogliatto, F. S. (2001). Mass customization: Literature review and research directions.

Da Silveira, G.J.C., and Arkader, R. (2007). The direct and mediated relationships between supply chain coordination investments and delivery performance. International Journal of Operations \& Production Management, 27 (2), 14058.

Danese, P., Manfè, V. and Romano, P. (2018). A Systematic Literature Review on Recent Lean Research: State-of-theart and Future Directions. International Journal of Management Reviews, 20 (2), 579-605.

DeGroote, S.E., and Marx, T.G. (2013). The impact of IT on supply chain agility and firm performance: an empirical investigation. International Journal of Information Management, 33, 909-916.

Dehne, F., Kong, Q., Rau-Chaplin, A., Zaboli, H., \& Zhou, R. (2015). Scalable real-time OLAP on Cloud architectures. Journal of Parallel and Distributed Computing, 79, 31-41.

Demirkan, H, Cheng, H. K., \& Bandyopadhyay, S. (2010). Coordination Strategies in a SaaS Supply Chain. Journal of Management Information Systems, 26 (4), 119-143.

Denyer, D. and Tranfield, D. (2009). Producing a systematic review. In D.A. Buchanan, A. Bryman, The Sage Hand-book of Organizational Research Methods pp. 671-689 Sage Publications Ltd, London.

Dermirkan, H., Cheng, H.K., and Bandyopadhyay, S. (2010). Coordination strategies in SaaS supply chain. Journal of Management Information Systems, 26 (4), 119-143.

Dev, N.K., Shankar, R., and Dey, P.K. (2014). Reconfiguration of Supply Chain network: An ISM-based roadmap to performance. Benchmarking, 21 (3), 386-411.

Dev, N.K., Shankar, R., Dey, P.K., and Gunasekaran, A. (2014). Holonic supply chain: a study from family-based manufacturing perspective. Computers \& Industrial Engineering, 78, 1-11. 
Devaraj, S., Krajewski, L., \& Wei, J. C. (2007). Impact of e-business technologies on operational performance: the role of production information in the supply chain. Journal of Operations Management, 25 (6), 1199-1216.

Díaz-Madroñero Boluda, F., Mula, J. M., and Payá, D. P. (2017). A mathematical programming model for integrating production and procurement transport decisions. Applied Mathematical Modelling, 52, 52754.

Díaz-Madroñero Boluda, Payá, D. P., and F. Mula, J. M. (2015). A review of tactical optimization models for integrated production and transport routing planning decisions. Computers and Industrial Engineering, 88, 518-535.

Doherty, E., Carcary, M., \& Conway, G. (2015). Migrating to the Cloud. Journal of Small Business and Enterprise Development, $22(3), 512-527$.

Doherty, E., Carcary, M., Conway, G., and Matlay, H. (2015). Migrating to the Cloud-examining the drivers and barriers to adoption of Cloud Computing by Smes in Ireland; an exploratory study. Journal of Small Business and Enterprise Development, 22 (3), 512-527.

Duan, R., \& Liu, X. (2016). Collaborative strategies and applied research of costume design supply chains based on Cloud Computing. GAK Gummi Fasern Kunststoffe, 69 (13), 28-32.

Ellinger, A. E., Daugherty, P.J., and Keller, S.B. (2000). The relationship between marketing/Logistics interdepartmental integration and performance in US manufacturing firms: an empirical study. Journal of Business Logistics, 21 (1), 121.

Elms, D.K, and Low, P. (2013). Global value chains in a changing world. World Trade Organization, Geneva.

Engelhardt-Nowitzki, C. (2012). Improving value chain flexibility and adaptability in build-to-order environments. International Journal of Physical Distribution and Logistics Management, 42 (4), 318-337.

Escobedo, M.T., Hernández, J.A., Estebané, V., Martínez, G. (2016). Modelos de ecuaciones estructurales: características, fases, construcción, aplicación y resultados. Ciencia y Trabajo, 55, 16-22.

Fabbe-Costes, N., \& Jahre, M. (2008). Supply chain integration and performance: a review of the evidence. The International Journal of Logistics Management, 19 (2), 130-154.

Fantazy, K.A., Kumar, V., and Kumar, U. (2009). An empirical study of the relationships among strategy, flexibility and performance in the supply chain context. Supply Chain Management: An International Journal, 14 (3), 177-188.

Favi, C., and Germani, M. (2012). A method to optimize assembly of industrial product in early design phase: From product architecture to assembly sequence. International Journal on Interactive Design and Manufacturing, 6 (3), 155-169.

Fingar, P. (2009). Dot. Cloud. The 21st Century Business Platform. Meghan-Kiffer Press, Tampa, Florida.

Fisher, L.M. (1997). What is the right supply chain for your product?. Harvard Business Review, 75 (2), 105-116.

Flynn, B. B., Huo, B., \& Zhao, X. (2010). The impact of supply chain integration on performance: a contingency and configuration approach. Journal of Operations Management, 28 (1), 58-71.

Flynn, B.B., Sakakibara, S., and Schroeder, R.G. (1995). Relationship between JIT and TQM: practices and performance. Academy of Management Journal, 38 (5), 1325-1360.

Foerstl, K., Schleper, M. C., and Henke, M. (2017). Purchasing and supply management: From efficiency to effectiveness in an integrated supply chain. Journal of Purchasing and Supply Management, 23 (4), 223-228.

Fogliatto, F. S., and Da Silveira, G.J.C. (2008). Mass customization: A method for market segmentation and choice menu design International. Journal of Production Economics, 111 (2), 606-622.

Forrester, J.W. (1961). Industrial Dynamics. Pegasus Communications, Waltham.

Frazelle, E. (2001) Supply Chain Strategy: The Logistics of Supply Chain Management (2nd Ed.). McGraw-Hill Professional, New York.

Frohlich M., \& Westbrook R. (2001). Arcs of integration: an international study of supply chain strategies. Journal of Operations Management, 19 (2), 185-200.

Frutos, J.D., and Borenstein, D. (2003). Object-oriented model for customer-building company interaction in mass customization environment. Journal of Construction Engineering and Management, 129 (3), 302-313.

Fung, R.Y.K., Chong, S.P.Y. and Wang, Y. (2004). A framework of product styling platform approach: Styling as intangible modules. Concurrent Engineering Research and Applications, 12 (2), 89-103.

Furst, K., and Schmidt, T. (2001). Turbulent markets need flexible supply-chain communication. Production Planning and Control, 12 (5), 525-533.

Gerbin D., and Hamilton J. (1996). Viability of Exploratory Factor Analysis as a Precursor to Confirmatory Factor Analysis. Structural Equation Modelling, 3 (1), 62-72.

Ghaffari, K., Delgosha, S. M., and Abdolvand, N. (2014). Towards Cloud Computing: A swot analysis on its adoption in SMES. International Journal of Information Technology Convergence and Services, 4 (2), 13-20.

Ghobakhloo, M., and Tang, S. H. ((2014)). IT investments and Business Performance improvement: The mediating role of Lean manufacturing implementation. International Journal of Production Research, 52(18), 5367-5384. 
Giménez, C., and Ventura, E. (2005). Logistics-production, Logistics-marketing and external integration: their impact on performance. International Journal of Operations \& Production Management, 25 (1), 20-38

Giménez, C.; Van der Vaart, T., and Van Donk, P. (2012). Supply Chain Integration and performance: the moderating effect of supply complexity. International Journal of Operations \& Production Management, 32 (5), 583-610.

Giriraj, M., \& Muthu, S. (2013). A Cloud Computing methodology for industrial automation and manufacturing execution system. Journal of Theoretical and Applied Information Technology, 52 (3), 301-307.

Givehchi, M., Haghighi, A., \& Wang, L. (2016). Cloud-DPP for distributed process planning of mill-turn machining operations. Robotics and Computer-Integrated Manufacturing, 47, 76-84.

Golightly, D., Sharples, S., Patel, H., Ratchev, S., (2016). Manufacturing in the Cloud: a human factors perspective. International Journal of Industrial Ergonomics, 55, 12-21.

Gong, Z. (2008). An economic evaluation model of supply chain flexibility. European Journal of Operational Research, $184(2), 745-758$.

Gorsuch, R. (1983). Factor Analysis (2nd ed.), Erlbaum, Hillsdale.

Griffiths, J, and Margetts, D. (2000). Variation in production schedules - implications for both the company and its suppliers. Journal of Materials Processing Technology, 103 (1), 155-159.

Gualandris, J., and Kalchschmidt, M. (2013). Product and process modularity: improving flexibility and reducing supplier failure risk. International Journal of Production Research, 51 (19), 5757-5770.

Gunasekaran, A., and Ngai, E. W. T. (2004). Information systems in supply chain integration and management. European Journal of Operational Research, 159 (2), 269-295.

Gunasekarana A., Laib K., and Chenge T. (2008). Responsive supply chain: A competitive strategy in a networked economy. Omega, 36(1), 549-564.

Gupta, S., \& Jones, E.C. (2014). Optimizing supply chain distribution using Cloud based autonomous information. International Journal of Supply Chain Management, 3 (4), 79-90.

Hair, J., Anderson, R., Tatham, R., and Black, W. (2001) Análisis Multivariante (5ª Ed.). Prentice Hall, Madrid.

Hair, J.F., Black, W.C., Babin, B.J., and Anderson, R.E. (2009). Multivariate Data Analysis. New Jersey: Prentice Hall.

Hanafy, M., and Elmaraghy, H. (2015). Developing assembly line layout for delayed product differentiation using phylogenetic networks. International Journal of Production Research, 53 (9), 2633-2651.

Hansotia, B. (2009). Marketing by objectives: Using segmentation based on purchase timing to enhance customer equity. Journal of Direct, Data and Digital Marketing Practice, 10 (4), 336-355.

Hao, Y., \& Helo, P. (2017). The role of wearable devices in meeting the needs of Cloud manufacturing: A case study. Robotics and Computer-Integrated Manufacturing, 45, 168-179.

Harland, C., Zheng, J., Johnson, T., \& Lamming, R. (2004). A conceptual model for researching the creation and operation of supply network. British Journal of Management, 15 (1), 1-21.

Harris, I., Wang, Y., \& Wang, H. (2015). ICT in multimodal transport and technological trends: Unleashing potential for the future. International Journal of Production Economics, 159, 88-103.

Hayes, B. (2008). Cloud Computing. Communications of the ACM, 51 (7), 9-11.

He, Y., Stecke, K. E., and Smith, M. L. (2016). Robot and machine scheduling with state-dependent part input sequencing in flexible manufacturing systems. International Journal of Production Research, 54 (22), 6736-6746.

Helo P., Suorsa, M., Hao, Y., \& Anussornnitisarn, P. (2014). Toward a Cloud-based manufacturing execution system for distributed manufacturing. Computers in Industry, 65 (4), 646-656.

Helo, P.T. (2000). Dynamic Modelling of Surge Effect and Capacity Limitation in Supply Chains. International Journal of Production Research, 38, 4521-4533.

Herron, C., and Braiden, P. M. 2017. Defining the foundation of Lean manufacturing in the context of its origins (Japan), in IET International Conference on Agile Manufacturing, 148-157.

Ho, G.T.S., Lau, H.C.W., Lee, C.K.M., and Ip, A.W.H. (2008). Real-time process mining system for Supply Chain network: OLAP-based fuzzy approach. International Journal of Enterprise Network Management, 2 (1), 84-103.

Holweg, M. (2007). The genealogy of Lean Production. Journal of Operations Management, 25 (2), $420-37$.

Hopp, W.J., Spearman, M.L. (2004). To pull or not to pull: what is the question? Manufacturing and Service Operations Management $6(2), 133-48$.

Hu, L., and Bentler, P. (1998). Fit indices in covariance structure modelling: Sensitivity to under parameterized model misspecification. Psychology Methods, 3, 424- 453.

Huang, G. Q., Zang, X. Y., and Lo, V. H.Y. (2007). Integrated Configuration of Platform Products and Supply Chains for Mass Customization: A Game-Theoretic Approach. IEEE Transactions On Engineering Management 54, (1), 156171.

Huang, M. C., \& Huang, H. H. (2018). How transaction-specific investments influence firm performance in buyer-supplier relationships: The mediating role of supply chain integration. Asia Pacific Management Review, In Press 1-9. Available on 10.1016/j.apmrv.2018.03.001. 
Huo, B., Gu, M., and Wang, Z. (2017). Supply chain flexibility concepts, dimensions and outcomes: an organisational capability perspective. International Journal of Production Research, 56 (17), 5883-5903.

Ismail, H., Reid, I., Mooney, J., Poolton, J., and Arokiam, I. (2007). How small and medium enterprises effectively participate in the mass customization game. IEEE Transactions on Engineering Management, 54 (1), 86-97.

Jabbour, C.J.C., de Sousa Jabbour, A.B.L., Govindan, K., Teixeira, A.A., and de Souza Freitas, W.L. (2013). Environmental management and operational performance in automotive companies in Brazil: the role of human resource management and Lean manufacturing. Journal of Cleaner Production, 47, 129-140.

Jayaram, J., Vickery, S. and Droge, C. (2008). Relationship building, lean strategy and firm performance: an exploratory study in the automotive supplier industry. International Journal of Production Research, 46 (20), 5633-49.

Jede, A., \& Teuteberg, F. (2015). Integrating Cloud Computing in supply chain processes. A comprehensive literature review. Journal of Enterprise Information Management, 28 (6), 72-94.

Jiao, J., Kumar, A., and Lim, C.M. (2006). Flexibility valuation of product family architecture: A real-option approach. International Journal of Advanced Manufacturing Technology, 30 (1), 1-9.

Johnston, D.A., and Wright, L. (2004). The e-business capability of small and medium sized firms in international supply chains. Information Systems and e-Business Management, 2 (2/3), 223-40.

Kaiser, C., Vogt, S., and Tilebein, M. (2015). Virtual development and production framework for textile orthotics, International Journal of Computer Integrated Manufacturing, 30 (7), 680-689.

Kaplan, D. (2000). Structural equation modelling: Foundations and extensions. Newbury Park: Sage.

Keränen, J., Piirainen, K. A., and Salminen, R. T. (2012). Systematic review on B2B branding: research issues and avenues for future research. Journal of Product and Brand Management, 21 (6), 404-417.

Kerlinger, F., and Lee, H. (2002). Investigación del comportamiento. Métodos de investigación en las ciencias sociales. McGraw-Hill, México.

Kim, B. (2014). Effective Supply Chain strategy to enhance firm's responsiveness: Empirical evidence from the BMW Leipzig plant. International Journal of Services and Operations Management, 18 (1), 21-37.

Kline, R. (2005). Principles and practice of structural equation modelling. Gilford Press, New York.

Ko, H. Sang, Azambuja, M., \& Lee, H. F. (2016). Cloud-based Materials Tracking System Prototype Integrated with Radio Frequency Identification Tagging Technology. Automation in Construction, 63, 144-154.

Kong, X. T.R., Fang, J., Luo, H., \& Huang, G. Q. (2015). Cloud-enabled real-time platform for adaptive planning and control in auction logistics center. Computers and Industrial Engineering, 84, 79-90.

Koo, P.H., and Tanchoco, J.M.A. (1999). Non-hierarchical shop floor control in single-stage multimachine systems. International Journal of Flexible Automation and Integrated Manufacturing, 7 (1), 19-46.

Kortmann, S., Gelhard, C., Zimmermann, C., and Piller, F.T. (2014). Linking strategic flexibility and operational efficiency: the mediating role of ambidextrous operational capabilities. Journal of Operations Management. 32 (7/8), 475-490.

Krafcik, J.F. (1988). Triumph of the Lean Production system. Sloan Management Review, 30 (1), 41-52.

Kumar, R., Haleem, A., Garg, S.K., and Singh, R.K. (2015). Automated guided vehicle configurations in flexible manufacturing systems: A comparative study. International Journal of Industrial and Systems Engineering, 21 (2), 207-226.

Kumar, V., Chibuzo, E. N., Garza-Reyes, J. A., Kumari, A., Rocha-Lona, L., \& Lopez-Torres, G. C. (2017). The impact of supply chain integration on performance: Evidence from the UK food sector. Procedia Manufacturing, 11, 814-821.

Lal, P., \& Bharadwaj, S.S. (2015). Understanding the impact of Cloud-based services adoption on organizational flexibility. An exploratory study. Journal of Enterprise Information Management, 29 (4), 566-588.

Lamming, R.C. (1996). Squaring Lean supply with supply chain management. International Journal of Operations and Production Management, 16 (2), 183-96.

Lau, A. K., Yam, R. C., and Tang, E. P. (2007). Supply chain product co-development, product modularity and product performance: Empirical evidence from Hong Kong manufacturers. Industrial Management and Data Systems, 107 (7), 1036-1065.

Lee, H. (2017). Framework and development of fault detection classification using loT device and Cloud environment. Journal of Manufacturing Systems, 43(2), 257-270.

Lee, W.B., and Lau, H.C.W. (1999). Factory on demand: the shaping of an agile production network. International Journal of Agile Management Systems 1 (2), 83-87.

Leukel, J., Kirn, S., \& Schlegel, T. (2011). Supply chain as a service: A Cloud perspective on supply chain systems. Systems Journal, 5 (1), 16-27.

Levandowski, C.E., Jiao, J.R., and Johannesson, H. (2015). A two-stage model of adaptable product platform for engineering-to-order configuration design. Journal of Engineering Design, 26 (7), 220-235.

Li, G., Yang, H., Sun, L., and Sohal, A. S. (2009). The impact of IT implementation on Supply Chain Integration and performance. International Journal of Production Economics, 120 (1), 125-138. 
Li, Q., Luo, H., Xie, P. X, Feng, X. Q., \& Du, R. Y. (2015a). Product whole life-cycle and omni-channels data convergence oriented enterprise networks integration in a sensing environment. Computers in Industry, 70, 23-45.

Li, S., Rao, S.S., Ragu-Nathan, T.S., and Ragu-Nathan, B. (2005), Development and validation of a measurement instrument for studying supply chain management practices, Journal of Operations Management 23, (6), 618-41.

Li, W., Zhong, Y., Wang, X., \& Cao, Y. (2013). Resource virtualization and service selection in Cloud logistic. Journal of Network and Computer Applications, 36, (6), 1696-1704.

Li, Y., Dai, W., Armstrong, A., Clarke, A., \& Du, M. (2015b). Developing an integrated supply chain system for small businesses consortium in Australia: a service-oriented PHOENIX solution. Int. J. High Performance Computing and Networking, 8 (1), 81-89.

Lin, I.-C., Hsu, H.-H., \& Cheng, C.-Y. (2015). A Cloud-Based Authentication Protocol for RFID Supply Chain Systems. Journal of Network and Systems Management, 23 (4), 1-20.

Littler, D., Leverick, F., \& Bruce, M. (1995). Factors affecting the process of collaborative product development: a study of UK manufacturers of information and communications technology products. Journal of Product Innovation Management, $12(1), 16-23$.

Liu, N., Li, X., \& Shen, W. (2014). Multi-granularity resource virtualization and sharing strategies in Cloud manufacturing. Journal of Network and Computer Applications, 46, 72-82.

Liu, S., Yang, Y., Qu W.G., \& Liu, Y. (2016). The business value of Cloud Computing: the partnering agility perspective. Industrial Management and Data Systems, 116 (6), 1160-1177.

Liu, Y., Xu, X., Zhang, L., Wang, L., \& Zhong, R. Y. (2016). Workload-based multi-task scheduling in cloud manufacturing. Robotics and Computer-Integrated Manufacturing, 45, 3-20.

Lu, Y., \& Xu, X. (2017). A semantic web-based framework for service composition in a Cloud manufacturing environment. Journal of Manufacturing Systems, 42, 69-81.

Lummus, R. R., Duclos, L. K., and Vokurka, R. J. (2003). Supply Chain Flexibility: Building a New Model. Global Journal of Flexible Systems Management, 4 (4), 1-13.

Lyu, G., Chu, X., \& Xue, D. (2017). Product modeling from knowledge, distributed computing and lifecycle perspectives: A literature review. Computers in Industry, 84, 1-13.

Maçaira, P.M., Thomé, A.M.T., Oliveira, F.L.C., and Ferrer, A.L.C. (2018). Time series analysis with explanatory variables: a systematic literature review. Environmental Modelling and Software, 107, 199-209.

Machado, A.G.C. and Moraes, W.F.A. (2008). Mass customization in civil construction. Revista Brasileira de Gestao de Negocios, 10 (29), 347-364.

Malhotra, M.K., Mackelprang, and A.W. (2012). Are internal manufacturing and external supply chain flexibilities complementary capabilities? Journal of Operations Management, 30 (3), 180-200.

Malhotra, N.K. (2004). Marketing Research: An Applied Orientation (4th Ed.) Pearson Education, Inc.: New Jersey.

Maqueira, J. M., Bruque, S., \& Minguela-Rata, B. (2017). Environment Determinants in Business Adoption of Cloud Computing. Industrial Management \& Data Systems, 117 (1), 228-246.

Marin, R.L., and P. D. Brîndaşu. (2015). A self-organizing approach for mixed-model manufacturing based on autonomous entities Academic Journal of Manufacturing Engineering 13 (2), 60-65.

Marinagi, C., Trivellas, P., and Sakas, D. (2014). The impact of Information Technology on the development of Supply Chain Competitive Advantage. Procedia - Social and Behavioral Sciences, 147, 586-591.

Marodin, G.A., Tortorella, G.L., Frank, A.G., and Filho, M. (2017). The moderating effect of lean supply chain management on the impact of lean shop floor practices on quality and inventory. Supply Chain Management: An International Journal, 22 (6), 473-485.

Marston, S., Li, Z., Bandyopadhyay, S., Zhang, J., \& Ghalsasi, A. (2011). Cloud Computing - the business perspective, Decision Support Systems. 51 (1), 176-189.

Mason-Jones, R., and Towill, D.R. (1999). Total cycle time compression and the agile supply chain. International Journal of Production Economics, 62 (1/2), 61-73.

McAfee, A. (2002). The impact of enterprise information technology adoption on operational performance: An empirical investigation. Production and Operations Management, 11 (1), 33-53.

McCormack, K., Ladeira, M.B., and Oliveira, M.P.V. (2008) Supply chain maturity and performance in Brazil. Supply Chain Management. An International Journal, 13 (4), 272-282.

McKone, K.E., Schroeder, R.G., and Cua, K.O. (2001). The impact of total productive maintenance on manufacturing performance. Journal of Operations Management, 19 (1), 39-58.

Mehrsai A., Karimi H. R., and Thoben K. D. (2013). Integration of Supply Networks for Customization with Modularity in Cloud and Make-To-Upgrade Strategy. Systems Science \& Control Engineering, 1 (1), 28-42.

Mejía. M, and Cornejo, C. (2010). Aplicación del modelo de ecuaciones estructurales a la gestión del conocimiento. LACCEI, Arequipa.

Mell, P., \& Grance, T. (2011). The NIST definition of Cloud Computing. Recommendations of the National Institute of Standards and Technology. National Institute of Standards and Technology, Gaithersburg, MD. 
Mell, P., and Grance, T. (2011). The NIST definition of Cloud Computing. Recommendations of the National Institute of

Mezgár, I., \& Rauschecker, U. (2014). The challenge of networked enterprises for Cloud Computing interoperability, Computers in Industry. 65 (4), 657-674.

Miles, R.E., and Snow, C.C. (2007). Organization theory and supply chain management: an evolving research perspective. Journal of Operations Management, 25 (2), 459-463.

Mmanagement, Comput. Sci. Eng., vol. 15,

Mo, J.P.T. (2009). The role of Lean in the application of information technology to manufacturing. Computers in Industry, 60 (4), 266-276.

Mo, J.P.T., \& Lorchirachoonkul, W. (2011). Design of RFID Cloud services in a low bandwidth Network Environment. International Journal of Engineering Business Management, 3(1), 38-43.

Moher, D., Liberati, A., Tetzlaff, J., and Altman, D. G. (2009). Preferred reporting items for systematic reviews and metaanalyses: the PRISMA statement. Annals of internal medicine, 151 (4), 264-269.

Molina, A., Rodriguez, C.A., Ahuett, H., Cortés, J.A., Ramírez, M., Jiménez, G. and Martinez, S. (2005). Next-generation manufacturing systems: Key research issues in developing and integrating reconfigurable and intelligent machines. International Journal of Computer Integrated Manufacturing, 18 (7), 525-536.

Mongeon, P., and Paul-Hus, A. (2016). The journal coverage of Web of Science and Scopus: a comparative analysis. Scientometrics, 106 (1), 213-228.

Montoya-Torres, J. R., \& Ortiz-Vargas, D. A. (2014). Collaboration and information sharing in dyadic supply chains: a literature review over the period 2000-2012. Estudios Gerenciales, 30(133), 343-354.

Moon, K., C. Yi, and Ngai, E. (2012). An instrument for measuring Supply Chain flexibility for the textile and clothing companies. European Journal of Operational Research, 222 (2), 191-203.

Morariu, O., Borangiu, T., and Raileanu, S. (2015). vMES: Virtualization aware manufacturing execution system. Computers in Industry 67, 27-37.

Morariu, O., Morariu, C., and Borangiu, T. (2016). Shop-floor resource virtualization layer with private cloud support. Journal of Intelligent Manufacturing, 27 (2), 447-462.

Mourtzis, D., Doukas, M., \& Milas, N. (2016). A knowledge-based social networking app for collaborative problem-solving in manufacturing. Manufacturing Letters, (10), 1-5.

Moyano-Fuentes, J., and Sacristán-Díaz, M. (2012). Learning on Lean: a review of thinking and research. International Journal of Operations \& Production Management, 32 (5), 551-582.

Moyano-Fuentes, J., Martínez-Jurado, P.J., Maqueira-Marín, J.M., and Bruque-Cámara, S. (2012). Impact of use of information technology on Lean Production adoption: evidence from the automotive industry. International Journal of Technology Management, 57 (1-3), 132-148.

Moyano-Fuentes, J., Martínez-Jurado, P.J., Maqueira-Marín, J.M., and Bruque-Cámara, S. (2012). El papel de las tecnologías de la información and las comunicaciones (TIC) en la búsqueda de la eficiencia: un análisis desde Lean Production and la integración electrónica de la cadena de suministro. Cuadernos de Economía and Dirección de la Empresa, 15 (3), 105-116.

Moyano-Fuentes, J., Sacristán-Díaz, M., and Martínez-Jurado, P. J. (2012). Cooperation in the supply chain and Lean Production adoption: Evidence from the Spanish automotive industry. International Journal of Operations \& Production Management, 32 (9), 1075-1096.

Mustak, M., Jaakkola, E., and Halinen, A. (2013). Customer participation and value creation: a systematic review and research implications. Managing Service Quality, 23 (4), 341-359.

Nobre, F. S., Tobias, A. M., and Walker, D. S. (2008). The pursuit of cognition in manufacturing organizations. Journal of Manufacturing Systems, 27 (4), 145-157.

Nowicka, K. (2014). Smart city Logistics on cloud computing model. Procedia - Social and Behavioral Sciences, 151, 266-281.

Nunnally, J.C., and Bernstein, I.H. (1994). Psychometric Theory, (3rd ed.), McGraw-Hill: New York.

Oh S., Ryu, K., and Jung. M. (2013). Reconfiguration framework of a supply network based on flexibility strategies. Computers and Industrial Engineering, 65 (1), 156-165.

Oliveira, R.R., Noguez, F. C., Costa, C. A., Barbosa, J. L., \& Prado, M. P. (2013). SWTRACK: an intelligent model for cargo tracking based on off-the-shelf mobile devices. Expert System Application, 40, 2023-2031.

Oliveira, T., Thomas, M., \& Espadanal, M. (2014). Assessing the determinants of Cloud Computing adoption: an analysis of the manufacturing and services sectors. Information and Management, 51 (5), 497-510.

Ouyang, L.Y., Wu, K.S., and Ho, C.H. (2007). An integrated vendor-buyer inventory model with quality improvement and lead time reduction. European Journal of Operational Research, 108, 349-358.

Padayachee, J., and Bright, G. (2013). The design of reconfigurable assembly stations for high variety and mass customisation manufacturing. South African Journal of Industrial Engineering, 24(3), 43-57.

Pagell, M. (2004). Understanding the factors that enable and inhibit the integration of operations, purchasing and Logistics. Journal of Operations Management, 22 (5), 459-487. 
Pan, T., Zheng, L., \& Yan, G. (2010). Research of Information Framework for Fourth Party Logistics. Journal of Convergence Information Technology, 5 (7), 90-99.

Paniti, I. (2014). Adaptation of Incremental Sheet Forming into Cloud manufacturing. CIRP Journal of Manufacturing Science and Technology, 7 (3), 185-190.

Panizzolo, R. (1998). Applying the lessons learned from 27 lean manufacturers: the relevance of relationships management. International Journal of Production Economics, 55 (3), 223-40.

Pattnayak, P., \& Pradhan, J. (2016). Minimizing cost using Cloud Computing with RFID based supply chain management. International Journal of Control Theory and Applications, 9 (20), 9475-9480.

Paulraj, A., Chen, I.J., and Flynn, J. (2006). Levels of strategic purchasing: Impact on supply integration and performance. Journal of Purchasing and Supply Management, 12 (3), 107-122.

Peng, Q., and Yu, C. (2007). A visualised manufacturing information system for mass customisation. International Journal of Manufacturing Technology and Management, 11 (3), 278-295.

Pérez, C., de Castro, R., Simons, D., and Gimenez, G. (2010). Development of lean supply chains: a case study of the Catalan pork sector. Supply Chain Management: An International Journal, 15 (1), 55-68.

Pérez-Ríos, J. (1992). Análisis estructural de la empresa, su modelado y silmulación. Revista Internacional de Sistemas, $4(1-3), 5-30$

Pérez-Salazar, M. R., Lasserre, A. A. A., Cedillo-Campos, M. G., \& González, J. C. H. (2017). The role of knowledge management in supply chain management: A literature review. Journal of Industrial Engineering and Management, 10 (4), 711-788.

Pfeiffer D., Terlunen, S., Fischer, J., and Hellingrath, B. (2013). Introducing Supply Chain Segmentation Procedures into Flexibility Management. Proceedings of the 24th Annual Conference of the Production and Operations Management Society 1-10.

Pinho, C., and Mendes, L. (2017). IT in Lean-based manufacturing industries: systematic literature review and research issues. International Journal of Production Research, 55, 7524-7540.

Potter, A., Breite, R., Naim, M., and Vanharanta, H. (2004). The potential for achieving mass customization in primary production Supply Chains via a unified taxonomy. Production Planning and Control, 15 (4), 472-481.

Powell, T.C., and Dent-Micallef, A. (1997). Information technology as competitive advantage: the role of human, business and technology resources. Strategic Management Journal, 18 (5), 375-405.

Prajogo, P., and Olhager, J. (2012). Supply chain integration and performance. The effects of long-term relationships, information technology and sharing, and Logistics integration. International Journal of Production Economics, 135, 514-522.

Purohit, J.K., Mittal, M.L., Mittal S. et al. (2016). Interpretive structural modelling-based framework for mass customisation enablers: an Indian footwear case. Production Planning and Control, 27 (9), 774-786.

Qureshi, M.I., Iftikhar, M., Bhatti, M.N., Shams, T., and Zaman, K. (2013) Critical elements in implementations of just-intime management: empirical study of cement industry in Pakistan. SpringerPlus, 2 (645), 1-14.

Radke, A.M., \& Tseng, M.M. (2015). Design considerations for building distributed supply chain management systems based on Cloud Computing. Journal of Manufacturing Science and Engineering, 137 (4), 1-7.

Rai, A., Patnayakuni, R., \& Seth, N. (2006). Firm performance impacts of digitally enabled supply chain integration capabilities. MIS Quarterly, 30 (2), 225-246.

Rai, A., Pavlou, P.A., Im, G., and Du, S. (2012); Interfirm IT capability profiles and communications for cocreating relational value: evidence from the Logistics industry. MIS Quarterly 36, (1), 233-262.

Rai, R, Sahoo, G, and Mehfuz, S. (2015). Exploring the factors influencing the Cloud Computing adoption: a systematic study on Cloud migration. SpringerPlus, 4 (1), 1-12.

Rajagopal, V., Venkatesan, S.P., \& Goh, M. (2017). Decision-making models for supply chain risk mitigation: A review. Computers \& Industrial Engineering, 113, 646-682.

Raubenheimer, J.E. (2004). An item selection procedure to maximize scale reliability and validity. South African Journal of Psychology, 30 (4), 59-64.

Reinartz, W., Haenlein, M., and Henseler, J. (2009). An empirical comparison of the efficacy of covariance-based and variance-based SEM", Working Papers Collection, No. 44, INSEAD, Fontainebleau.

Rich, N., and Hines, P. (1997). Supply-chain management and time-based competition: the role of the supplier association. International Journal of Physical Distribution and Logistics Management, 27 (3), 210-225.

Rojo, A., Llorens-Montes, F. J., and Perez-Arostegui, M. N. (2016). The impact of ambidexterity on supply chain flexibility fit. Supply Chain Management: An International Journal, 21 (4), 433-452.

Rojo, A., Stevenson, M., Lloréns-Montes, F. J., and Perez-Arostegui, M. N. (2018). Supply chain flexibility in dynamic environments: The enabling role of operational absorptive capacity and organisational learning. International Journal of Operations \& Production Management, 38 (3), 636-666.

Romano, P. (2003). Co-ordination and integration mechanisms to manage logistics processes across supply markets. Journal of Purchasing and Supply Management, 9 (3), 119-134. 
Ross, P., \& Blumenstein, M. (2013). Cloud Computing: the nexus of strategy and technology. Journal of Business Strategy, 34 (4), 39-47.

Ruiz, M., Pardo, A., and San Martín, R. (2010). Modelos de ecuaciones estructurales. Papeles del Psicólogo, 31 (1), $34-$ 45.

Ryan, W. M., \& Loeffler, C. M. (2010). Insights Into Cloud Computing. Intellectual Property \& Technology Law Journal, 22 (11), 22-27.

Sánchez, A. M., and Pérez, M. P. (2003). The use of EDI for interorganisational co-operation and co-ordination in the supply chain. Integrated Manufacturing Systems, 14 (8), 642-651.

Satorra, A. (1993). Multi-sample analysis of moment-structures: asymptotic validity of inferences based on second order moments. In: Haagen, K., Bartholomeusz, A., Deistler, M. (Eds.), Statistical modelling and latent variables. Elsevier, North Holland, Amsterdam.

Scheidegger, A. P. G., Pereira, T. F., de Oliveira, M. L. M., Banerjee, A., \& Montevechi, J. A. B. (2018). An introductory guide for hybrid simulation modelers on the primary simulation methods in industrial engineering identified through a systematic review of the literature. Computers \& Industrial Engineering, 124, 474-492.

Schlechtendahl, J., Kretschmer, Felix, S., Zhiqian, L., Armin, \& Xu, X. (2017). Extended study of network capability for Cloud based control systems. Robotics and Computer-Integrated Manufacturing, 43, 89-95.

Schniederjans, D. G., \& Hales, D. N. (2016). Cloud Computing and its impact on economic and environmental performance: A transaction cost economics perspective. Decision Support Systems, 86, 73-82.

Schniederjans, D. G., Ozpolat, K., \& Chen, Y. (2016). Humanitarian supply chain use of Cloud Computing. Supply Chain Management: An International Journal, 21 (5), 569-588.

Schramm, T., Nogueira, S., \& Jones, D. (2011). Cloud Computing and Supply Chain: A Natural Fit for the Future. Logistics Management, 3, 9-11.

Schuh, G., Baessler, E., and Meier, J. (2007). An evaluation method for the identification of flexible production technologies for Mass Customisation in the automotive industry. International Journal of Manufacturing Technology and Management, 10 (4), 347-359.

Seebacher, G. and Winkler, H. (2015). A capability approach to evaluate supply chain flexibility. International Journal of Production Economics, 167, 177-186.

Seuring, S. and Muller, M. (2008). From a literature review to a conceptual framework for sustainable Supply Chain management. Journal of Cleaner Production, 16 (15), 1699-1710.

Shah, R., and Ward, P.T. (2003). Lean manufacturing: context, practice bundles and performance. Journal of Operations Management, 21 (2), 129-49.

Shah, R., and Ward, P.T. (2007). Defining and developing measures of Lean Production. Journal of Operations Management, 25 (4), 785-805.

Shah, R., Chandrasekaran, A., and Linderman, K. (2008). In pursuit of implementation patterns: the context of Lean and Six Sigma. International Journal of Production Research, 46 (23), 6679-99.

Sharma, S., \& Shah, B. (2015). Thinking Cloud-enabled adept and agile supply chain for SMEs: A conceptual study. International Journal of Business Information Systems, 19 (3), 342-365.

Shou, Y., Li, Y., Park, Y., and Kang, M. (2017). Supply chain integration and operational performance: The contingency effects of production systems. Journal of Purchasing and Supply Management, 24 (4), 352-360.

Simmhan, H. et al. (2013). Cloud-based software platform for big data analytics in smart grid. IEEE Comput. Sci. Eng., 38-47(99), 1-10.

Simonson, I. (2005). Determinants of Customers Responses to Customized Offers: Conceptual Framework and Research Propositions. Journal of Marketing, 69: 32-47.

Singh, A. and Teng, J.T.C. (2016). Enhancing supply chain outcomes through Information Technology and Trust. Computers in Human Behavior, 54, 290-300.

Singh, A., Mishra, N., Ali, S.I., Shukla, N., Shankar, R., 2015. Cloud computing technology: reducing carbon footprint in beef supply chain. International Journal of Production Economics, 164, 462-471.

Son, I., Lee, D., Lee, J.-N. \& Chang, Y. B. (2014). Market perception on cloud computing initiatives in organizations: an extended resource-based view. Information \& Management, 51 (6), 653-669.

Squire, B., Cousins, P.D., and Brown, S. (2006). Collaborating for customisation: an extended resource-based view of the firm. International Journal of Productivity and Quality Management, 1 (1), 8-25.

Stank, T.P., Crum, M., and Arango, M. (1999). Benefits of inter-firm co-ordination in food industry supply chains. Journal of Business Logistics, 20 (2), 21-41.

Stank, T.P., Keller, S.B., and Daugherty, P.J. (2001). Supply chain collaboration and logistical service performance. Journal of Business Logistics, 22 (1), 29-48.

Sterman, J. (2000). Business Dynamics: Systems Thinking and Modelling for a Complex World. Irwin/McGraw-Hill.

Stojanov, T., and Ding, X. (2015). Supplier selection for mixed-model production: A case study from the apparel industry. Fibres and Textiles in Eastern Europe, 23 (1), 8-12. 
Strasser, T., Rooker, M, and Ebenhofer, G. (2011). An IEC 61499 distributed control concept for reconfigurable robots. International Journal of Computer Aided Engineering and Technology, 3 (3), 344-359.

Stump, B., and Badurdeen, F. (2012). Integrating Lean and other strategies for mass customization manufacturing: A case study. Journal of Intelligent Manufacturing, 23 (1), 109-124.

Subramanian, N., \& Abdulrahman, M. D. (2017). Logistics and cloud computing service providers' cooperation: a resilience perspective. Production Planning \& Control, 28 (11-12), 919-928.

Subramanian, N., Abdulrahman, M. D., \& Zhou, X. (2015). Reprint of Integration of logistics and Cloud Computing service providers: Cost and green benefits in the Chinese context. Transportation Research, 74, 81-93.

Tao, F., Cheng, J., Cheng, Y., Gu, S., Zheng, T., \& Yang, H. (2017). SDMSim: A manufacturing service supply-demand matching simulator under Cloud environment. Robotics and Computer-Integrated Manufacturing, 45, 34-46.

Tao, F., Z., L., Venkatesh, V. C., Luo, Y., \& Cheng, Y. (2011). Cloud manufacturing: a computing and service-oriented manufacturing model. Journal of Engineering Manufacture, 225 (10), 1969-1976.

Thekinen, J., \& Panchal, J. H. (2016). Resource allocation in Cloud-based design and manufacturing: A mechanism design approach. Journal of Manufacturing Systems, 43 (2), 327-338.

Thomé, A. M. T., Scavarda, L. F., and Scavarda, A. J. (2016). Conducting systematic literature review in operations management. Production Planning \& Control, 27(5), 408-420.

Thun, J.H. (2010). Angles of integration: an empirical analysis of the alignment of internet based information technology and global supply chain management. Journal of Supply Chain Management, 46 (2), 30-44.

Tien, J. M. (2011). Manufacturing and services: From mass production to mass customization. Journal of Systems Science and Systems Engineering, 20 (2), 129-154.

Tortorella, G. L., Giglio, R., and Limón-Romero, J. (2018). Supply chain performance: how lean practices efficiently drive improvements. Journal of Manufacturing Technology Management, 29 (5), 829-845.

Tranfield, D., Denyer, D., and Smart, P. (2003). Towards a methodology for developing evidence-informed management knowledge by means of systematic review. British journal of management, 14 (3), 207-222.

Trappey, A. J. C., Trappey, C. V., Chang, S. W. C., and Tun Nien Hsu, W. T. L. (2016). A one-stop logistic services framework supporting global supply chain collaboration. Journal of Systems Science and Systems Engineering, 25(2), 229-253.

Treville, S., Shapiro, R., and Hameri, A.P. (2004). From supply chain to demand chain: The role of lead time reduction in improving demand chain performance. Journal of Operations Management, 21, 613 - 627.

Troyer, C., \& Cooper, R. (1995). Smart moves in supply chain integration. Transportation and Distribution, 36, 55-62.

Tse, Y.K., Tan, K.H., Ting, S.L., Choy, K.L., Ho, G.T.S., and Chung, S.H. (2012). Improving postponement operation in warehouse: An intelligent pick-and-pack decision-support system. International Journal of Production Research, 50 (24), 7181-7197.

Tuncay, E. (2010). Effective use of Cloud Computing in education institutions. Procedia- Social and Behavioral Sciences, 2 (2), 938-942.

Ugarte, G. M., Golden, J. S., and Dooley, K. J. (2016). Lean versus green: The impact of lean logistics on greenhouse gas emissions in consumer goods supply chains. Journal of Purchasing and Supply Management, 22 (2), 98-109.

Uhrin, A., Bruque-Cámara, S., and Moyano-Fuentes, J. (2017). Lean Production, workforce development and operational performance. Management Decision, 55 (1), 103-118.

Um, J. (2017). Improving supply chain flexibility and agility through variety management. The International Journal of Logistics Management, 28: 464-487.

Um, J., Lyons, A., Lam, H.K., Cheng, T.C.E., and Dominguez-Pery, C. (2017). Product variety management and supply chain performance: A capability perspective on their relationships and competitiveness implications. International Journal of Production Economics, 187, 15-26.

Urgo, M., Terkaj, W., Cenati, C., Giannini, F., Monti, M., and Pellegrinelli, S. (2016). Zero-point fixture systems as a reconfiguration enabler in flexible manufacturing systems Computer-Aided Design and Applications, 13 (5), 684-692.

Valilai, O. F., \& Houshmand, M. (2013). A collaborative and integrated platform to support distributed manufacturing system using a service-oriented approach based on Cloud Computing paradigm. Robotics and Computer-Integrated Manufacturing, 29 (1), 110-127.

Van der Vaart, T., Van Donk, P., Giménez, C., and Sierra, V. (2012). Modelling the integration-performance relationship. Collaborative practices, enablers and contextual factors. International Journal of Operations and Production Management, 32 (9), 1043-1074.

Vermula, R., \& Zsifkovits, H. (2016). Cloud Computing for Supply Chain Management. BHM, 161 (5), 229-232.

Vickery, S.K., Bolumole, Y.A., Castel, M.J., and Calantone, R.J. (2015). The effects of product modularity on launch speed. International Journal of Production Research, 53 (17), 5369-5381.

Vickery, S.K., Jayaram, J., Droge, C. et al. (2003). The effects of an integrative supply chain strategy on customer service and financial performance: an analysis of direct versus indirect relationships. Journal of Operations Management, 21, 523-539. 
Vonderembse, M.A., Uppal, M., Huang, S.H. and Dismukes, J.P. (2006). Designing supply chains: towards theory development. International Journal of Production Economics, 100 (2), 223-38.

Wadhwa, S., and Rao, K. S. (2000). Flexibility: an emerging meta-competence for managing high technology. International Journal of Technology Management, 19 (7), 820-845.

Wadhwa, S., Saxena, A., and Chan, F. T. S. (2007). Framework for flexibility in dynamic supply chain management. International Journal of Production Research, 46 (6), 1373-1404.

Wang, H., Mastragostino, R. and Swartz, C.L.E. (2016). Flexibility analysis of process supply chain networks. Computers \& Chemical Engineering, 84, 409-421.

Wang, P.Y., Shen, J., Guo, W.Q., Zhang, C., \& Zhang, B. (2015). Cloud-based government procurement information integration platform. Journal of Digital Information Management, 13 (3), 147-155.

Wang, S., Wan, J., Zhang, D., Li, D., \& Zhang, C. (2016). Towards smart factory for industry 4.0: a self-organized multiagent system with big data based feedback and coordination. Computer Networks, 101, 158-168.

Wang, X. V., \& Wang, L. (2014). From Cloud manufacturing to Cloud remanufacturing: A Cloud-based approach for WEEE recovery. Manufacturing Letters, 2(4), 91-95.

Wang, X. V., \& Xu, X. W. (2013). An interoperable solution for Cloud manufacturing. Robotics and Computer-Integrated Manufacturing, 29 (4), 232-247.

Wang, X. V., Wang, L., Mohammed, A., \& Givehchi, M. (2017). Ubiquitous manufacturing system based on Cloud: A robotics application. Robotics and Computer-Integrated Manufacturing, 45, 116-125.

Wang, X., Li, W.F., Zhong, Y. and Zhao, W. (2012). Research on cloud Logistics-based one-stop service platform for Logistics center. IEEE 16th International Conference on Computer Supported Cooperative Work in Design, 558-563, Wuhan, China.

Wang, Y., Wang, Y., \& Yang, Y. (2010). Understanding the determinants of RFID adoption in the manufacturing industry. Technological Forecasting and Social Change, 77 (5), 803-815.

Ward, P., and Zhou, H. (2006). Impact of information technology integration and Lean/ just-in-time practices on lead-time performance. Decision Sciences, 37 (2), 177-203.

Waters, D. (2007). Global Logistics: New Directions in Supply Chain Management (5a Ed.). Kogan Page Publishers, London.

Wiengarten, F., Singh, P. J., Fynes, B., and Nazapour, A. (2017). Impact of mass customization on cost and flexibility performances: the role of social capital. Operations Management Research, 10 (3-4), 137-147.

Winans, T. B., \& Brown, J. S. (2009). Moving Information Technology Platforms to the Clouds: Insights Into IT Platform Architecture Transformation. Journal of Service Science, 2 (2), 23-33.

Womack, J.P., and Jones, D.T. (1996). Lean Thinking, Simon and Schuster, New York, NY.

Womack, J.P., Jones, D.T., and Ross, D. (1990). The Machine That Changed the World, MacMillan, New York, NY.

Wong, M.M., Tan, C.H., Zhang, J.B., Zhuang, L.Q., Zhao, Y.Z., and Luo, M. (2007). On-line reconfiguration to enhance the routing flexibility of complex automated material handling operations. Robotics and Computer-Integrated Manufacturing, 23 (3), 294-304.

Wu, D., Greer, M. J., Rosen, D. W., \& Schaefer, D. (2013). Cloud manufacturing: Strategic vision and state-of-the-art. Journal of Manufacturing Systems, 32 (4). 564- 579.

Wu, D., Rosen, D.W., Wang, L. \& Schaefer, D. (2015). Cloud-based design and manufacturing: a new paradigm in digital manufacturing and design innovation. Computer-Aided Design, 59, 1-14.

Wu, F., Yeniyurt, S., Kim, D., and Cavusgil, S.T. (2006). The impact of information technology on supply chain capabilities and firm performance: a resource based view. Industrial Marketing Management, 35 (4), 493-504.

Wurzer, T., and Reiner, G. (2018). Evaluating the impact of modular product design on flexibility performance and cost performance with delivery performance as a moderator. International Journal of Operations \& Production Management, 38 (10), 1987-(2008).

Xia, M., Li, T., Zhang, Y., \& Silva, C. W. (2016). Closed-loop design evolution of engineering system using condition monitoring through internet of things and Cloud Computing. Computer Networks, 101, 5-18.

Xing, K., Qian, W., \& Zaman, A. U. (2016). Development of a Cloud-based platform for footprint assessment in green supply chain management. Journal of Cleaner Production, 139, 191-203.

Xu, X. (2012). From Cloud Computing to Cloud manufacturing. Robotics and Compute-Integrated Manufacturing, 28 (1), 75-86.

Yan, J., Xin, S., Liu, Q., Xu, W., Yang, L., Fan, L., Chen, B., \& Wang, Q. (2014). Intelligent Supply Chain Integration and Management Based on Cloud of Things. International Journal of Distributed Sensor Networks, 10 (3), 1-15.

Yang, C., Shen, W., Lin, T., \& Wang, X. (2016). lot-enabled dynamic service selection across multiple manufacturing clouds. Manufacturing Letters, 7, 22-25.

Yang, J., \& Lin, P. (2016), A mobile payment mechanism with anonymity for Cloud Computing. Journal of Systems and Software, 116, 69-74. 
Yao, Y., and Xu, Y. (2018). Dynamic decision making in mass customization. Computers \& Industrial Engineering, 120, 129-136.

Yu, W., Jacobs, M.A., Salisbury, W.D., and Enns, H. (2013). The effects of Supply Chain Integration on customer satisfaction and financial performance: An organizational learning perspective. International Journal of Production Economics, 146 (1), 346-358.

Yue, X., Cai, H., Yan, H., Zou, C., \& Zhou, K. (2015). Cloud-assisted industrial cyber-physical systems: An insight. Microprocessors and Microsystems, 39(8), 1262-1270.

Zhang, Q., Vonderembse, M.A. and Lim, J.S. (2005). Logistics Flexibility and its impact on customer satisfaction. International Journal of Logistics Management, 16 (1), 71-95.

Zhong, R. Y., Lan, S., Xu, C., Dai, Q., and Huang, G. Q. (2015). Visualization of RFID-Enabled Shopfloor Logistics Big Data in Cloud Manufacturing. The International Journal of Advanced Manufacturing Technology, 84 (1-4), 5-16.

Zhong, R.Y., Xu, X., Klotz, E., and Newman, S.T. (2017). Intelligent manufacturing in the context of industry 4.0: A review. Engineering, 3 (5), 616-630.

Zimmermann, A., Schmidt, R., Sandkuhl, K., Jugel, D., Moehring, M., \& Wissotzki, M. (2015). Enterprise architecture management for the internet of things. Proceedings of the Digital Enterprise Computing, 139-148. Böblingen, Germany. 


\section{Appendix}




\section{APPENDIX}

\section{I: CSLC interview data}

Please rate the following statements and indicate your agreement level on a scale from

1 to 10 , where: $1=$ Minimum level; $10=$ Maximum level. Use 0 for Not applicable.

Appendix I. CSLC interview data

\begin{tabular}{|c|c|c|c|c|}
\hline & & 2016 & 2018 & 2020 \\
\hline- & Degree of Cloud Computing use in logistics operations & 5 & 8 & 10 \\
\hline \multicolumn{5}{|c|}{ SUPPLY CHAIN INTEGRATION } \\
\hline Physical & $\begin{array}{l}\text { Supply Chain-wide inventory is jointly managed with suppliers and Logistics partners (e.g., } \\
\text { UPS, FedEx) }\end{array}$ & 0 & 7 & 9 \\
\hline \multirow{3}{*}{ Information } & Production and delivery schedules are shared across the Supply Chain & 4 & 6 & 7 \\
\hline & Supply Chain members collaborate in arriving at demand forecasts & 4 & 7 & 8 \\
\hline & Inventory data are visible at all steps across the Supply Chain & 4 & 7 & 9 \\
\hline \multicolumn{5}{|c|}{ SUPPLY CHAIN FLEXIBILITY } \\
\hline \multirow{2}{*}{ Sourcing } & We have the ability to add and remove suppliers & 6 & 8 & 10 \\
\hline & We have the ability to change suppliers to satisfy changing requirements & 0 & 0 & 0 \\
\hline \multirow[t]{2}{*}{$\begin{array}{l}\text { Operating } \\
\text { system }\end{array}$} & We have the ability to change output volumes & 8 & 8 & 8 \\
\hline & We have the ability to adjust manufacturing facilities and processes & 0 & 0 & 0 \\
\hline \multirow[b]{2}{*}{ Distribution } & We have the ability to add or remove carriers or other distributors & 5 & 8 & 10 \\
\hline & $\begin{array}{l}\text { We have the ability to change warehouse space, loading capacity, and other distribution } \\
\text { facilities }\end{array}$ & 3 & 6 & 9 \\
\hline \multirow{7}{*}{-} & We can customize products at low cost & 0 & 0 & 0 \\
\hline & We can customize products on a large scale & 0 & 0 & 0 \\
\hline & We can translate customer requirements into technical designs quickly & 4 & 7 & 9 \\
\hline & We can add product variety without increasing cost & 0 & 0 & 0 \\
\hline & We can customize products while maintaining a large volume & 0 & 0 & 0 \\
\hline & We can set up for a different product at low cost & 0 & 0 & 0 \\
\hline & We can respond to customization requirements quickly & 0 & 0 & 0 \\
\hline
\end{tabular}




\begin{tabular}{|c|c|c|c|c|}
\hline \multirow{6}{*}{ Operational } & We can quickly modify products to meet our major customer's requirements & 4 & 6 & 8 \\
\hline & We can quickly introduce new products into the market & 0 & 0 & 0 \\
\hline & We can quickly respond to changes in market demand & 4 & 6 & 8 \\
\hline & We can quickly modify products to respond to our major competitors' innovations & 0 & 0 & 0 \\
\hline & $\begin{array}{l}\text { The lead time for fulfilling customers' orders (the time which elapses between the receipt of a } \\
\text { customer's order and the delivery of the goods) is short }\end{array}$ & 6 & 8 & 10 \\
\hline & We can provide a high level of customer service to our major customer & 7 & 9 & 10 \\
\hline \multirow{5}{*}{ Financial } & We are satisfied with Growth in sales & 8 & 8 & 8 \\
\hline & We are satisfied with Return on sales & 5 & 7 & 9 \\
\hline & We are satisfied with Growth in return on sales & 5 & 8 & 9 \\
\hline & We are satisfied with Growth in profit & 0 & 0 & 0 \\
\hline & We are satisfied with Growth in ROI & 0 & 0 & 0 \\
\hline \multicolumn{5}{|c|}{ LEAN PRODUCTION IMPLEMENTATION } \\
\hline \multirow{3}{*}{$\begin{array}{l}\text { Cellular } \\
\text { Manufacturing }\end{array}$} & $\begin{array}{l}\text { We have placed in the plant the machines associated to a certain process so that they are next } \\
\text { to each other }\end{array}$ & 0 & 0 & 0 \\
\hline & $\begin{array}{l}\text { We have organized our plant into manufacturing cells (grouping of workers and machines that } \\
\text { perform various specialized operations) }\end{array}$ & 0 & 0 & 0 \\
\hline & $\begin{array}{l}\text { In-plant distribution allows operation with a reduced level of inventories and rapid } \\
\text { manufacturing }\end{array}$ & 0 & 0 & 0 \\
\hline \multirow{4}{*}{$\begin{array}{l}\text { Lean } \\
\text { Practices }\end{array}$} & We use Total Quality Management & 0 & 0 & 0 \\
\hline & We dedicate time each day to plan maintenance-related activities & 0 & 0 & 0 \\
\hline & We carry out regular maintenance on all our equipment, involving the workers & 0 & 0 & 0 \\
\hline & We have reduced equipment setup times in our plant (SMED) & 0 & 0 & 0 \\
\hline
\end{tabular}

